Utah State University

DigitalCommons@USU

$\mathrm{Be}$

Bee Lab

6-24-1909

\title{
A Monographic Revision of the Coleoptera Belonging to the Tenebrionide Tribe Eleodiini Inhabiting the United States, Lower California, and Adjacent Islands
}

Frank E. Blaisdell Sr.

Follow this and additional works at: https://digitalcommons.usu.edu/bee_lab_be

Part of the Entomology Commons

\section{Recommended Citation}

Blaisdell, Frank E. Sr., "A Monographic Revision of the Coleoptera Belonging to the Tenebrionide Tribe Eleodiini Inhabiting the United States, Lower California, and Adjacent Islands" (1909). Be. Paper 219.

https://digitalcommons.usu.edu/bee_lab_be/219

This Bulletin is brought to you for free and open access by the Bee Lab at DigitalCommons@USU. It has been accepted for inclusion in Be by an authorized administrator of DigitalCommons@USU. For more information, please contact digitalcommons@usu.edu.

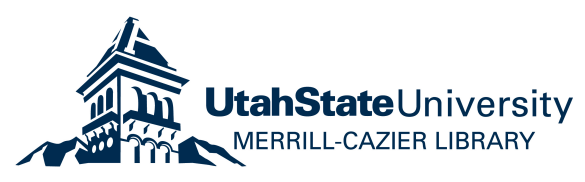


SMITHSONIAN INSTITUTION

UNITED STATES NATIONAL MUSEUM

Bulletin 63

A MONOGRAPHIC REVISION OF THE COLEOPTERA BELONGING TO THE TENEBRIONIDE TRIBE ELEODIINI INHABITING THE UNITED STATES, LOWER CALIFORNIA, AND ADJACENT ISLANDS

FRANK E. BLAISDELL, SR.

Of San Francisco, California

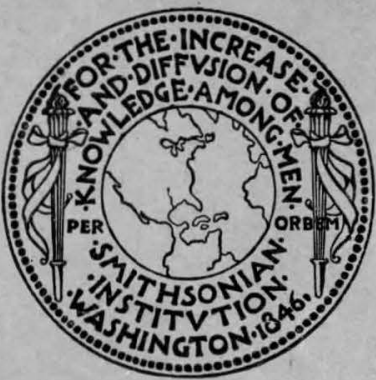

WASHINGTON

GOVERNMENT PRINTING OFFICE 


\section{Bulletin 63}

A MONOGRAPHIC REVISION OF THE COLEOPTERA BELONGING TO THE TENEBRIONIDE TRIBE ELEODIINI INHABITING THE UNITED STATES, LOWER CALIFORNIA, AND ADJACENT ISLANDS

FRANK E. BLAISDELL, SR. Of San Francisco, California

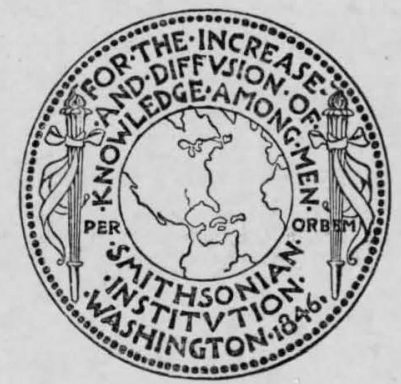

WASHINGTON

GOVERNMENT PRINTING OFFICE 1909 
BULLETIN OF THE UNITED STATES NATIONAL MUSEUM. Issued June 24, 1909.

II 


\section{ADVERTISEMENT.}

The scientific publications of the National Museum consist of two series-the Bulletin and the Proceedings.

The Bulletin, publication of which was begun in 1875 , is a series of more or less extensive works intended to illustrate the collections of the U. S. National Museum and, with the exception noted below, is issued separately. These bulletins are monographic in scope and are devoted principally to the discussion of large zoological and botanical groups, faunas and floras, bibliographies of eminent naturalists, reports of expeditions, etc. They are usually of octavo size, although a quarto form, known as the Special Bulletin, has been adopted in a few instances in which a larger page was deemed indispensable.

This work forms No. 63 of the Bulletin series.

Since 1902 the volumes of the series known as "Contributions from the National Herbarium, " and containing papers relating to the botanical collections of the Museum, have been published as bulletins.

The Proceedings, the first volume of which was issued in 1878, are intended as a medium of publication of brief original papers based on the collections of the National Museum, and setting forth newly acquired facts in biology, anthropology, and geology derived therefrom, or containing descriptions of new forms and revisions of limited groups. A volume is issued annually, or oftener, for distribution to libraries and scientific establishments, and in view of the importance of the more prompt dissemination of new facts a limited edition of each paper is printed in pamphlet form in advance.

\section{RichaRd RathBUN,}

Assistant Secretary, Smithsonian Institution, In Charge of the United States National Museum.

Washington, U. S. A., May 15, 1909. 


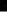




\section{PREFACE.}

In 1901 when work was first seriously begun on the Eleodiini, a bibliography was prepared. The great conflagration in San Francisco that followed the earthquake of 1906 destroyed the California Academy of Sciences with its library, so that when the present monograph was about completed there were no library facilities at hand, nor was it possible for me to review the literature elsewhere. The manuscript was therefore submitted for publication without a final review. Accordingly Mr. E. A. Schwarz, the eminent coleopterist at the U. S. National Museum, most kindly undertook the task for me, and to him I extend my most sincere thanks for the correction of the bibliography, for many suggestions, and for rearranging certain parts of the work.

In the text I have applied the term "heterotype" to the individuals that form the extremes of a specific or a varietal series. The heterotypes therefore, represent the extreme modifications in size, form, sculpturing, and color. The individuals connecting the extremes of a series constitute the intermediates or "mesotypes." Frequently individuals of one species are observed to simulate those of another species in form and sculpturing; an individual of this character has been called an "amphitype." A unique, when serving as a type, is spoken of as a "monotype." When more than one or a series of individuals serve as a basis for a specific or varietal description, they are referred to as "polytypes;" if a male and female serve they are "sexitypes;" otherwise they are "co-types."

Furthermore, in order to systematically deal with the many minor degrees of divergencies exhibited by individuals that are presumably the progeny of parents specifically or racially identical, I have deemed it conservative and scientific to recognize incipient races and incipient subraces. In accordance with that view I have used the name forma to make it possible to relatively define aggregations of individuals possessing some particular or salient characteristic; it is believed that these divergent characters have arisen through local or general climatic or environmental conditions acting upon the progeny of parents specifically or racially identical. 
In other words, the several formæ enumerated under Fleodes dentipes may arise from eggs deposited by a single typical female, under the influence of climatic, geographical, or environmental conditions capable of producing such divergencies.

A Latin name has been used to express the salient characteristic of any given forma, and these characteristics may be similar for each species or variety. A species or variety may have smooth and rough, short and elongate, small and large, caudate or ecaudate forms, consquently a repetition of Latin names is called for.

These terms are absolutely synonymous with the specific or varietal terms and must not be perpetuated as distinct grades, but simply used as an aid in recording data, and as a compromise between unscientific lumping and splitting, or the difference between 47 and 400 species.

Logically the present treatment ought not to seriously collide with the rules of the International Code governing nomenclature.

Frank E. Blaisdell, Sr. 


\section{TABLE OF CONTENTS.}

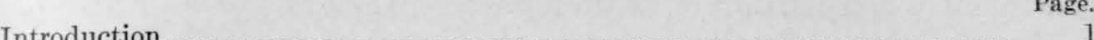

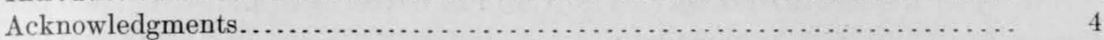

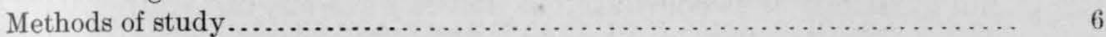

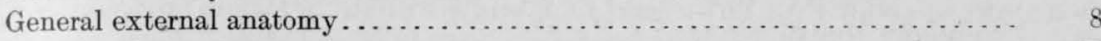

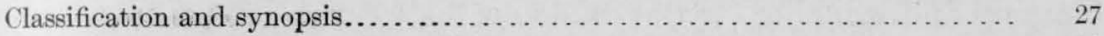

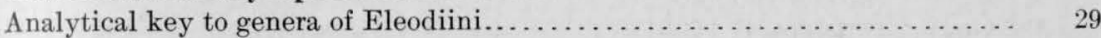

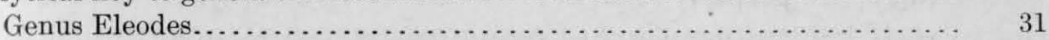

Analytical key to subgenera of Eleodes. . . . . . . . . . . . . . . . . . 33

Synopsis of general subgeneric characters................... $\quad 35$

Subgenus Melaneleodes............................. 36

Group I.-Carbonaria section. ................... 41

Eleodes debilis............................... 41

Eleodes carbonaria................................. 45

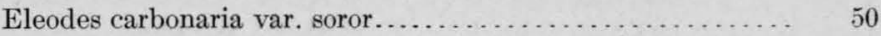

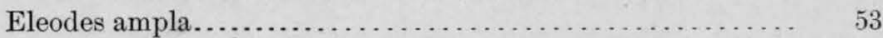

Eleodes ampla var. dolosa. . . . . . . . . . . . . . . 57

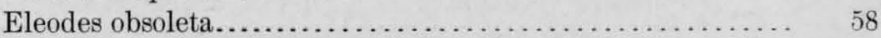

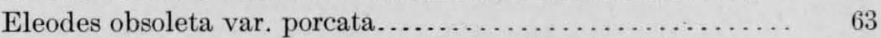

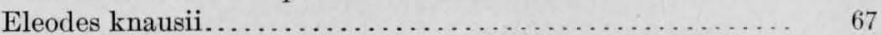

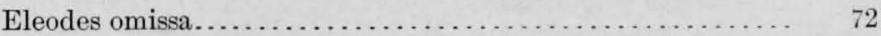

Eleodes omissa var. pygmæa...................... 77

Eleodes omissa var. peninsularis.................. 79

Group I.-Quadricollis section..................... 81

Eleodes quadricollis............................... 81

Eleodes quadricollis var. anthracina................ 87

Eleodes quadricollis var. lustrans................... 89

Eleodes cuneaticollis.......................... 91

Eleodes humeralis.. ............................... 95

Eleodes rileyi................................ 100

Group II.-Tricostata section. . . . . . . . . . . . . . . . . . . . 104

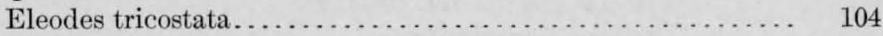

Eleodes pedinoides.......................... 109

Eleodes pedinoides var. neomexicana .............. 113

Subgenus Litheleodes...................................... 114

Analytical key to species of Litheleodes ...................... $\quad 116$

Eleodes arcuata................................ 116

Eleodes extricata................................ 121

Eleodes extricata var. arizonensis.................. 125

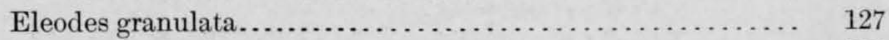

Eleodes letcheri.................................. 133

Eleodes letcheri var. vandykei..................... 136

Subgenus Tricheleodes...................................... 138 
Subgenus Tricheleodes-Continued.

Analytical key to species of Tricheleodes.

Page.

Eleodes hirsuta.

Eleodes pilosa.

Subgenus Pseudeleodes.

Analytical key to species of Promus . mas.

Eleodes insularis............................... 156

Eleodes subnitens............................... 161

Eleodes goryi.................................... . 164

Eleodes striolata.............................. 168

Eleodes fusiformis.............................. 172

Eleodes opaca...................................... 175

Subgenus Heteropromus. . . . . . . . . . . . . . . . . . . . . . . 179

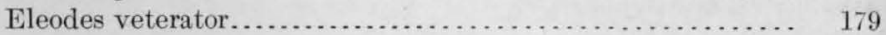

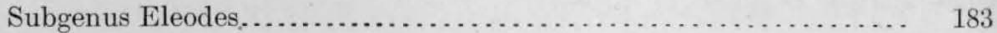

Analytical key to groups of subgenus Eleodes................. 184

Group Obscura................................... 184

Analytical key to species of Obscura group................ 185

Eleodes obscura................................... 187

Eleodes obscura var. dispersa ..................... 190, 191

Eleodes obscura (typical variety)................... 190, 193

Eleodes obscura var. sulcipennis.................. 190, 194

Eleodes arata............................... 194

Eleodes acuta................................... 195

Eleodes suturalis.................................. 199

Eleodes suturalis (typical variety) ................... 202

Eleodes suturalis var, texana....................... 202

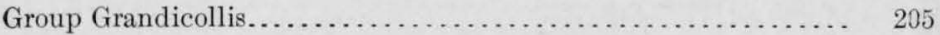

Eleodes grandicollis............................... 207

Group Dentipes, section A........................... 211

Analytical key to species of Dentipes group................. 212

Eleodes sponsa................................... 213

Eleodes hispilabris................................ 217

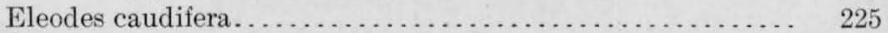

Eleodes longipilosa................................. 230

Group Dentipes, section B.......................... 234

Analytical key to species of Dentipes group............... . 234

Eleodes gracilis . . . . . . . . . . . . . . . . . . . . . . . 237

Eleodes gracilis var. distans...................... 242

Eleodes subcylindrica.......................... 246

Eleodes subpinguis................................ 247

Eleodes dentipes................................. 251

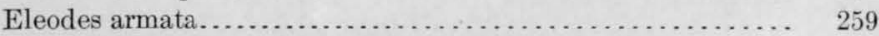

Eleodes armata var. impotens..................... 263

Eleodes militaris........................... 267

Eleodes militaris var. femorata................... 272

Eleodes acuticauda............................... 276

Eleodes acuticauda var. laticollis.................... 280

Eleodes eschscholtzi ............................ 285

Eleodes eschscholtzi var. lucæ....................... 289

Eleodes tenuipes............................. 294

Eleodes wickhami.............................. 297 
Group Dentipes, section B-Continued.

Page.

Eleodes ventricosa............................ 300

Subgenus Blapylis .

Synopsis of genital characters. . . . . . . . . . . . . . . . . . . . .

Analytical key to species of subgenus Blapylis ................. 311

Eleodes tibialis............................. 313

Eleodes snowii..................................... 317

Eleodes lecontei.................................. 321

Eleodes tenebrosa............................. 325

Eleodes tenebrosa var. nana...................... 328

Eleodes inculta . . . . . . . . . . . . . . . . . . . . . . 329

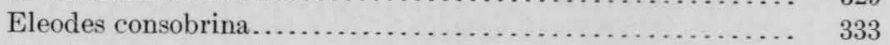

Eleodes scabripennis. . . . . . . . . . . . . . . . . . . . 338

Eleodes blanchardii............................. 339

Eleodes fuchsii................................. 343

Eleodes neotomæ............................ 347

Eleodes hornii. ............................... 350

Eleodes parvicollis...................................... 354

Eleodes parvicollis var. planata................... 359

Eleodes parvicollis var. producta..................... 362

Eleodes parvicollis var. constricta.................. 365

Eleodes hoppingii............................ 368

Eleodes clavicornis............................. 371

Eleodes scabrosa.............................. 375

Eleodes cordata............................... 379

Eleodes cordata var. rotundipennis............... 384

Eleodes pimelioides............................ 384

Eleodes pimelioides var. brunnipes................. 386

Eleodes caseyi............................... 388

Subgenus Metablapylis............................... 391

Analytical key to species of subgenus Metablapylis.............. . $\quad 393$

Eleodes nigrina.......................... 393

Eleodes nigrina var. perlonga.................... 398

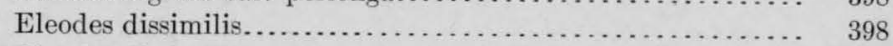

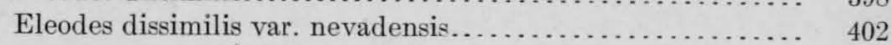

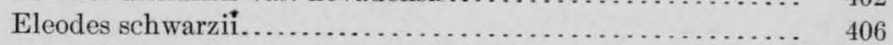

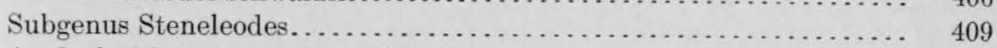

Analytical key to species of Steneleodes................... 411

Eleodes gigantea............................. 412

Eleodes gigantea var. gentilis....................... 416

Eleodes gigantea var. estriata..................... 421

Eleodes longicollis...................................... 425

Eleodes innocens................................. 429

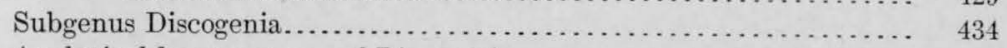

Analytical key to groups of Discogenia...................... . 434

Analytical key to species of Discogenia, Group A. . . . . . . . . . . . . 435

Analytical key to species of Discogenia, Group B............... 435

Eleodes marginata.............................. 436

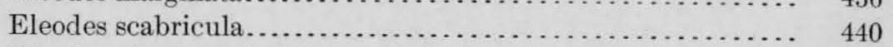

Eleodes planipennis................................. 445

Unrecognized species..................................... 450

Eleodes vicina.............................. 450

Eleodes nitida................................ 450

Eleodes reflexicollis............................... 450 
Unrecognized species-Continued. Page.

Genus Embaphion..................................... 450

Analytical key to species of genus Embaphion.................... "453

Embaphion depressum......................... 453

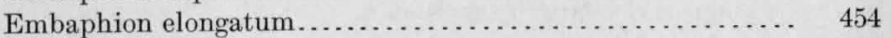

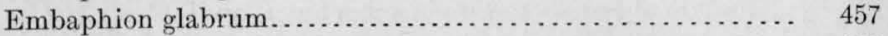

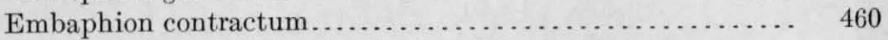

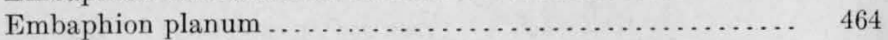

Embaphion contusum............................ 467

Embaphion contusum var. laminatum............. 472

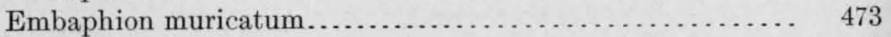

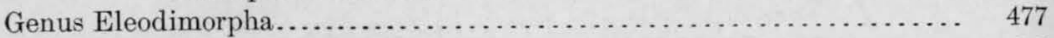

Eleodimorpha bolcan......................... 479

Genus Trogloderus...................................... 483

Analytical key to species of genus Trogloderus..................... 486

Trogloderus costatus......................... 486

Trogloderus tuberculatus....................... 490

Species not recognized ...................................... 493

Eleodes vicina................................ 493

Eleodes nitidus............................. 493

Eleodes reflexicollis.............................. 494

Early stages of the Eleodiini............................... 495

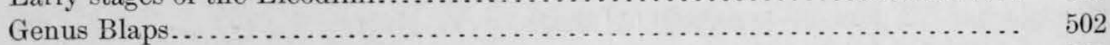

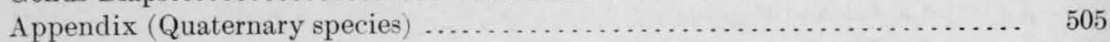

Eleodes elongata................................ 506

Eleodes behrii............................... 506

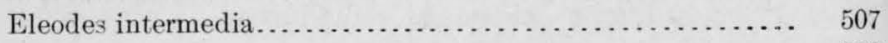

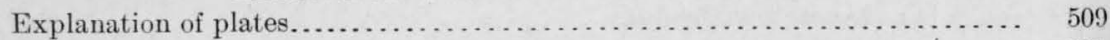

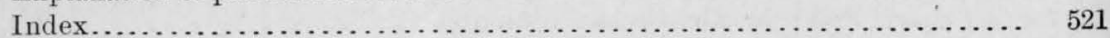




\section{LIST OF ILLUSTRATIONS.}

TEXT FIGURES,

Page.

Genealogical diagram of the subgenus Melaneleodes................. 39

Genealogical diagram of the subgenus Promus.................... 156

Genealogical diagram of the Obscura group, subgenus Eleodes........... 186

Genealogical diagram of the Dentipes group, section A, subgenus Eleodes.... 212

Genealogical diagram of the Dentipes group, section B, subgenus Eleodes.... 236

Genealogical diagram of the subgenus Blapylis. . . . . . . . . . . . . . 309

Genealogical diagram of the subgenus Steneleodes.................. 411

Genealogical diagram of the genus Embaphion . . . . . . . . . . . . . . 452

PLATES.

Facing page.

1. Genital characters of the Eleodiini....................... 524

2. Genital characters of the Eleodiini.............................. 524

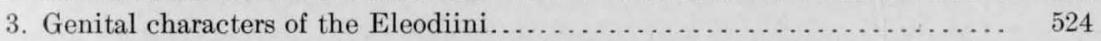

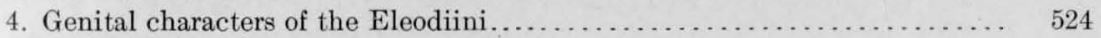

5 . Genital characters of the Eleodiini........................ 524

6. Comparative and genital characters of the Eleodiini and related tribes.... 524

7. Topography of the genital segments of the Eleodiini .............. 524

8. Anatomy of the Eleodiini................................... 524

9. Homology of the genital segments of the Eleodiini. . . . . . . . . . . . . 524

10. Pronota of the Eleodiini . . . . . . . . . . . . . . . . . . . . . . . . 524

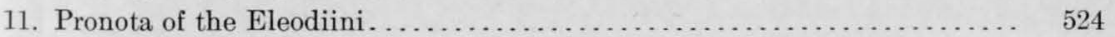

12. Pronota of the Eleodiini. . . . . . . . . . . . . . . . . . . . . . . . . . 524

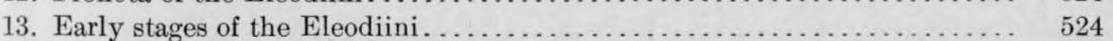




\title{
A MONOGRAPHIC REVISION OF THE COLEOPTERA BELONGING TO THE TENEBRIONIDE TRIBE ELEODIINI INHABITING THE UNITED STATES, LOWER CALIFORNIA, AND ADJACENT ISLANDS.
}

\author{
By Frank E. Blatsdell, Sr., \\ of San Francisco, California.
}

\section{INTRODUCTION.}

Since the publication of the Revision of the Tenebrionidæ ${ }^{a}$ no attempt has been made to treat the Eleodiini in a revisional wav. Material has been constantly accumulating in collections, until it has become a very perplexing problem to refer it in all instances to species already named, or to correlate the numerous variations so evident in many species.

At first I had intended to simply deal with the species of the genus Eleodes, but little by little I was induced to include all of the genera constituting the tribe as limited by previous authorities.

My method has been radically different from any heretofore pursued in the United States and it has been a laborious one. In the following pages I have set forth the results of my investigations and deductions which have been carried on during past five years. About one thousand specimens have been dissected during this time and over five thousand studied superficially.

I became convinced from the results previously arrived at by other writers on the family that all methods resorted to had been inadequate for the proper understanding of species that are so polymorphous and present such a community of habitus.

I decided to carry on a study along the lines of primary sexual characters, and if possible to investigate the mouth-parts and then to correlate the data obtained with characters already known.

${ }^{a}$ Amer. Phil. Soc., XIV.

59780-Bull. $63-09-1$ 
The first part of my task was perfectly feasible; but not so with the mouth-parts, on account of the necessity of mutilating the specimens.

The first species were named by Thomas Say in the year 1823 . He placed them in the genus Blaps.

Eschscholtz a few years later ${ }^{a}$ erected the genus Eleodes, describing several species.

Mannerheim still later ${ }^{b}$ described a few species, redescribing some of Eschscholtz's species with references to the original descriptions.

Then followed the period between the years 1858 and 1865 , the most active in the making known of new species, during which Dr. John L. LeConte described more species than any previous author. Later a number of his species were suppressed by Dr. George Horn, who from 1874 to 1891 occasionally described new species.

Many of the species suppressed by Doctor Horn have been restored to specific standing in the present paper. Doctor Horn was too conservative and his knowledge of the species was based upon characters that were too superficial.

Thomas L. Casey described Eleodes arcuatus in 1884; nine others in $1890,{ }^{\circ}$ and three more in the sixth volume of the annals of the same society.

In 1902 I described Eleodes interrupta from an anomalous specimen of $E$. omissa; in $1895 \mathrm{E}$. impotens, a race of armata, and $E$. confinis, the latter no doubt being an incipient race of $E$. dentipes.

LeConte's E. seriata proved to be identical with Goryi, described by Solier from Mexico.

Lacordaire ${ }^{d}$ explains the generic term Xysta as follows:

Le menton *** est composé de trois parties; une mediane de forme variable; et deux latérales en forme d'ailes, placées sur un plan plus interne, tranchantes latéralement, et d'autant plus larges que la première est moins développée. E'est sur la forme de cet organe qui Eschscholtz s'était basé pour diviser le genre en deux. Il donnait le nem de Xysta aux espèces qui ont la partie médiane très-développée et arrondie en avant, et réservait celui d'Eleodes à celles où son bord antérieur est rétréci et plus ou moins triangulaire, mais il y a entre ces deux formes des passages qui leur enlèvent la faible valeur qu'elles pourraient avoir.

In a footnote he says:

Eschscholtz en indique quatre espèces [gravida, angulata, rotundicollis, sulcata] [belonging to Xysta] du Mexique, mais il $\mathbf{y}$ en a beaucoup d'autres, la tricostata par exemple, * * * Chez la plupart de ces espèces, les ailes latérales du menton étant petites, paraissent au premier coup-d'œil, ne plus exister, mais, avec un peu d'attention on les découvre sans peine.

a Zool. Atlas, 1829-1833, I-V.

${ }^{b}$ Bull. Moscow, 1843.

${ }^{c}$ Annals N. Y. Acad. Sci., V.

¿Genera, p. 149. 
Kirby a describes Pimelia alternata, which is now a synonym of Eleodes tricostata Say. After the description he says: "Mr. Say says of his Pimetia (Edrotes) rotunda that it was the first of that genus found on the New Continent; that above described (alternata) furnishes therefore a valuable addition to the American insect fauna."

A brief reference to European literature shows that formerly the name Pimetia had a wide application, sufficient to include even such remotely related forms as Edrotes and Eleodes.

Pimetia is a Fabrician genus now including a considerable number of European species about the Mediterranean, also Northern Africa and Western Asia.

It may be interesting to the student to compare Eschscholtz's ${ }^{b}$ synoptic characters of the four genera, Blaps, Eleodes, Xystus, and Nycterinus, which are as follows:

Blaps.-Tibiæ anticæ apice bispinosæ. Antennæ articulo tertio sequenti duplo longiore, ultimo acuminato, tribus anticedentibus subglobosis. Labium apice latius, planum. Elytra carina laterali. Mas segmento basali abdominis scopifero.

Eleodes.-Antennæ articulo ultimo transverso, duobus antecedentibus, rotundis compressis, tertio sequenti duplo longiore. Labium apice angustius triangulare. Clypeus indistinctus, antice leviter emarginatus.

Xystus.-Antennæ articulo nltimo transverso, duobus antecedentibus, rotundis compressis, tertio sequenti duplo longiore. Labium transversum, medio dilatatum, apice rotundatum. Clypeus indistinctus, emarginatus.

Nycterinus.-Antennæ articulo ultimo transverso, tribus antecedentibus compressis, tertio sequenti parum longiore. Labium apice latius.

In the synopsis Tagona precedes Blaps, and Prosodes between Blaps and Eleodes, Nycterinus between Xystus and Amphidora. The characters used are very variable. I have not had an opportunity to study Nycterinus. I have a species from Northern Chile that I believe belongs to, or quite close to, this genus.

Gemminger and Harold ${ }^{\circ}$ give two species of Tagona as inhabiting Russia Meridionale and Turcomania; Prosodes, Oriental Europe and Western Asia; Nycterinus, twelve species, mostly Chilean, and Blaps as very numerous in Europe, Asia, and Africa.

I hope this work may be the forerunner of others upon the Tenebrionidæ, and have therefore taken the opportunity to place before the American student many suggestions that would be out of place in an ordinary revision. I sincerely trust that my colleagues will continue to aid me in the future as they have done in the past.

a Fanua Boreali-Americana, IV, 1837, p. 232.

${ }^{b}$ Zool. Atlas, III, 1829.

$c$ Catalogus Col., VII. 
It is a great pleasure to acknowledge the generous loan and gift of material, as follows:

The United States National Museum in Washington made the loan of 1,914 specimens, which were transmitted to me through the kind intercession of Dr. L. O. Howard. This material was of invaluable aid and of great interest, as it contained material from the collections of the following well-known entomologists: H. G. Hubbard, E. A. Schwarz, C. V. Riley, H. Soltau, E. J. Oslar, D. W. Coquillett, H. K. Morrison, M. L. Linell, J. B. Smith, J. D. Mitchell, H. S. Barber, C. F. Baker, and A. S. Fuller.

Mr. Charles Fuchs and Dr. E. C. Van Dyke put all of their material at my disposal.

I am especially indebted to my friend, Henry C. Fall, for the comparison of material with authentic types in the collection of the Museum of Comparative Zoology in Cambridge, Massachusetts, and for the loan of species not well represented from other sources.

To Mr. Frederick Blanchard, of Tyngsboro, Massachusetts, I extend my sincere thanks for his painstaking care in the comparison of many consignments of specimens from my collection with the LeConte types in the collection of the Museum of Comparative Zoology in Cambridge. His valuable notes and short descriptions aided me greatly, and without which I could not have written so authoritatively. At his request Mr. Samuel Henshaw, curator at the museum in Cambridge, very kindly transmitted to me one of LeConte's specimens of Eleodes gentilis.

At my request Mr. Charles Liebeck, of Philadelphia, looked up the literature on Blaps and made notes on specimens in the collection of the Academy of Science in that city.

Prof. H. F. Wickham, at the sacrifice of his own limited time, most kindly looked up literature upon the tribe now under consideration, and those references that could not be obtained upon this coast he copied and forwarded to me, namely, the original descriptions of Mannerheim. I must also thank him for the loan of material, especially for specimens taken in Texas, Nevada, and New Mexico.

I am indebted to Mr. Ralph Hopping for the examination of the material in his collection, especially that from Tulare County, California. I had the privilege of studying a collection taken at Fort Tejon by Messrs. Hopping and Fuchs.

Prof. J. J. Rivers presented me with a series of Eleodes taken at Ocean Park, Los Angeles County.

Dr. C. F. Clark most kindly contributed a collection of Eleodes taken in Napa County, California. 
Mr. Warren Knaus very kindly aided me by the loan and gift of most interesting material collected in Kansas, New Mexico, and Colorado.

The late Beverly Letcher permitted me to study a series of specimens that had been collected along the Colorado River in Arizona.

Lieut. Col. Thos. L. Casey donated several of his species and other specimens. Eleodes riteyi was of particular interest.

The California Academy of Sciences, of San Francisco, placed its material at my service. The collection was of more than ordinary interest on account of material from Lower California.

Mr. Fordyce Grinnell gave me a series of specimens taken in Kern County, California.

I received from Mr. Edward Ehrhorn a small collection from the mountains at Monte Bello, near Mountain View, Santa Clara County, California.

My friend and colleague, Dr. William Lee Moore, and his son Edgar, collected a large series at Verdi, Nevada, and sent the same to me.

My mother, Mrs. Anna G. Blaisdell, gathered an immense series at San Diego, California, and transmitted most of them alive for special studies.

Mr. Albert Koebele very generously gave me a series of specimens taken about Nogales, Arizona, and also permitted me to study those in his collection.

Mr. F. W. Nunenmacher also supplied me bountifully with specimens from about Nogales.

Dr. A. Fényes very kindly sent me material for examination and study.

Prof. F. II. Snow, of the University of Kansas, permitted me to study and identify numerous specimens collected by himself in Arizona and elsewhere.

Dr. R. H. Wolcott, of the University of Nebraska, transmitted to me the entire collection of Eleodes of that institution for study, and also a collection of Mexican species.

I most sincerely thank Mr. Charles O. Waterhouse, of the British Museum, Cromwell Road, London, for a series of Blaps, which he very kindly loaned in response to my request.

Miss Julia Wright, of Palo Alto, California, allowed me to study the native species in her collection, also a collection of Blaps obtained by her while abroad.

I also looked over the collection in the entomological department of Stanford University, through the courtesy of Prof. Vernon Kellogg.

It is my duty and pleasure to thank all who have so promptly aided me, and especially my intimate associates, Dr. Edwin C. Van 
Dyke, Charles Fuchs, and the late Beverly Letcher for their encouragement and advice. Without this material and moral aid the present work could not possibly have been as complete as it is.

\section{METHODS OF STUDY.}

All comparative measurements have been made from outlines drawn by aid of a binocular microscope with either a $\frac{1}{4}, 1,2$, or 3 inch objective and a camera lucida. The legs were measured directly with a finely divided metric ruler, under a hand lense.

Fresh specimens were hardened in alcohol or a two per cent solution of formalin; dried specimens were quickly relaxed in hot water.

To determine the relative length of the antennæ- the parts being relaxed-the head is either retracted or extended so that the apical margin of the pronotum corresponds to the posterior margin of the tempora. (See line C, Plate 8, fig. 1.) The antenna is then thrown back over the disc of the pronotum so that it falls a little within the basal angles. If it does not reach beyond the apical threefourths of the pronotal disc, it is said to be short; if it reaches to the basal margin it is moderate in length; if beyond the basal margin it is long. Qualifying terms are used to express nearness to these points.

This method is arbitrary, but sufficiently correct for all practical purposes, if care be taken to have the head in the proper position.

In determining the relative width and length of the head a tracing is made, care being taken to have the surface plane parallel to the focal plane of the microscope. The drawing is then treated as in fig. 1, Plate 8. A line is drawn transversely, just touching the posterior margins of the eyes and called the post-marginal ocular line, fig. $1 b$, Plate 8 . A second line is drawn from a point on the postmarginal line midway between the eyes to the middle of the anterior margin of the epistoma, and termed the interlocular line (fig. 1a, Plate 8 ). Line $b$ practically divides the head into equal halves, near enough for our purpose. If the distance across the widest or most prominent part of the eyes is twice the length of line $a$, the head is said to be moderate in width; if less, the head is long, and if greater it is wide or broad. The proper qualifying terms being used to express nearness to or extremes of these relative dimensions. For example, the head may be said to be longer than wide, somewhat longer, or distinctly longer than wide. The head is subquadrate, and if line $a$ be one-half the total length, and if the width be twice line $a$, the head is as wide as long. The labrum can not be included in the measurement as it is not fixed.

For the removal of the genital segments the parts must be soft and flexible. In cabinet specimens hot water swells the soft parts, 
so that they approximate their fresh condition. The specimen, when ready, is grasped between the thumb and index finger of the left hand, dorsum to the palm, then with a lance-pointed dissecting needle depress the last two ventral segments, pass the needle internal to the sternite of the seventh segment and forward along the inner surface of the sixth and fifth abdominal segments, cutting first to the right, then to the left, detaching the integumentary attachment along the pleural region; when this is done, with a curved or hooked pointed needle pull out the viscera. Place them on the stage of a dissecting microscope and carefully remove the ensheathing sclerites and membranes from the genital organs; the latter should now be washed in 60 per cent alcohol, then placed into another bath of 60 per cent alcohol to which a little glycerine has been added to prevent too rapid drying while being studied. Remove and wipe with a camel's hair brush, and mount on a white bristol-board slide for the microscope, a minute drop of glue being used for the purpose.

Study the dorsal surface first and be sure to orient the specimen so that the surface is parallel to the focal plane; when finished wet slightly and remove from the slide, wash in water to remove the glue, throw into the alcohol and glycerine, remove and wipe and mount as before, but in a reversed position, and study the ventro-lateral surfaces. When this is done remove as before, wash in alcohol, and mount on a small piece of cardboard and place on the pin beneath the insect for future study.

Parts to observe about the female organs:

Dorsal surface.-General form, pubescence, relation of the valves to each other, apices, cercopoda, dorsal plates, and superior pudendal membrane.

Ventrolateral surfaces.-General surface contour, pubescence, basal prominences, submarginal grooves, position of the fossa and cercopoda, genital fissure, and inferior pudendal membrane.

Parts to observe about the male organs:

Dorsal surface.-General surface contour and form of the edeagophore and its basale and apicale, presence or absence of a membranous area or groove.

Ventral surface.-General form and condition of the membrane, alæ; clavæ, form and relation to the edeagus; degree of inflexion of the sides of the basale. In the male the sternite of the seventh segment must be removed separately and studied in conjunction with the edeagophore. It is of value in classification. Prepare and mount as the other organs.

In order to study the relation of the sclerites of the retractile segments and reproductive organs, clear with liquor potassi.

The study of the tarsi should be most carefully done. I have used a bull's-eye condenser for concentrating the light, and while holding 
the specimen in the light in the most convenient position I have examined the tarsi with a hand lens, for the small species using the compound microscope. The first three joints of the anterior and those of the middle tarsi should be most carefully examined under different angles of illumination. Many specimens have the hairs or spinules rubbed off; if possible use perfect specimens.

A study of the mouth-parts, while exceedingly desirable for the purpose of correlation with the genital parts, is not possible without dissection and mutilation of the specimens. In many instances, nevertheless, this has been done, especially when the material warranted it.

Caution.-The student must bear in mind not to accept measurements representing length, breadth, and thickness in a literal sense, but only as indicative of relative proportions.

GENERAL EXTERNAL ANATOMY.

The following results have been obtained chiefly from a study of Eleodes dentipes.

Form variable. Integuments usually strongly chitinized.

Head (Plate 8, fig. 1) quadrate, nearly encircled by a rather broad impression, which is strongly marked behind the gular peduncle and buccal fissures, less so behind the tempora, sometimes feebly indicated across the dorsum. By this impression the epicranial wall is divided into two regions, the occipital and fronto-buccal. The epicranial sutures are mostly obsolete.

The occipital region is globular and condylar, and the surface more or less finely granulato-punctate; the foramen usually vertically oval, superior margin bisinuate, sinuations separated by a median subtriangular process, inferior margin broadly sinuate and straight between the gular sutures. The superior and visible portion of this region forms the vertex.

Fronto-buccal region moderately depressed, surface lines converging to meet about a length of the region in advance. Frons more or less transverse, never strongly convex; limited laterally by the eyes and the more or less prominent and arcuate preocular frontal ridges, which thicken and descend in front of the eyes to their inferior fourth, articulating with the genæ below. The inflexed and externoanterior surface of the frontal ridges are excavated, forming the antennal fossæ, the anterior margins of which bear a narrow oblongoval mandibular condyle, just behind the lateral frontal suture. The anterior frontal margin is deeply emarginate, middle three-fifths of the emargination straight, sides prominent anteriorly forming the frontal angles, the internal margins of which are straight and anteriorly divergent, forming an obtuse angle with the middle of the 
emargination, the latter receiving the base and obliquely truncate basal angles of the epistoma, forming the more or less evident frontal suture, the latter sometimes apparently sinuate at middle.

Epistoma transverse, surface more or less plane to feebly convex; base embraced by the anterior margin of the frons (see Plate 8, fig. 1); sides straight and convergent anteriorly, continuing the sides of the frons and forming therewith the fronto-epistomal border; anterior margin more or less sinuate, angles rather narrowly rounded.

Tempora small, and not in the least prominent, sloping from the posterior margins of the eyes, and feebly convex, passing evenly into the frons above and the genæ beneath and limited posteriorly by the transverse impression.

Gena not prominent laterally, surfaces feebly convex, limited internally by the gular sutures. Each anterior margin is irregular, presenting for examination two angles-a superior or frontal, and an inferior or mental; three emarginations - a superior, mandibular, and buccal; two processes-the mandibular and buccal. (Plate 8, fig. 15.)

The superior or frontal angle joins the inferior margin of the antennal fossa in front of the inferior fourth of the eye, and separated from the mandibular process which lies below it by a very short and somewhat oblique, shallow apical or superior emargination, the ventral margin of which is more or less beveled; the mandibular process is short and obtuse, and when the superior emargination is obsolete, scarcely recognizable as a distinct part near the superior angle; the mandibular emargination is a small but well marked reëntrant margin between the mandibular process above and buccal process below, its curvature is somewhat oblique superiorly where it forms the ventral edge of the mandibular process; the buccal process is anteriorly prominent, subacute, but not produced, forming the abrupt and external boundary of the deep and evenly rounded buccal emargination, which terminates internally at the mental angle of the gular peduncle. That part of the anterior margin bounded above by the apical angle and the buceal process below is the mandibular portion, while that part between the buccal process above or externally and the mental angle of the gular peduncle ventrally and internally is the buccal portion. The second joint of the maxillary palpus rests in the mandibular emargination when extended against the side of the head. The mandibular portion is opposed to the base of the mandible, and the buccal portion at the internal margin of the emargination gives attachment to the cardo of the maxilla and forms the posterior boundary of the buccal fissure.

The buccal process on its internal surface has a small glenoid cavity by which it articulates with the small globular and somewhat prominent condyle of the mandible. 
The buccal process is moderately produced in Eleodes blanchardii and strongly so in Eleodimorpha bolcan. (See Plate 8, fig. 24.)

Eyes narrowly subreniform, transverse, and slightly oblique, superior margins rounded, the inferior slightly subtruncate against the genæ ventro-anteriorly, rounded somewhat behind this point and continuously so with the arcuate posterior margin; the anterior margin is broadly and evenly emarginate, adapted to the deflexed frontal ridge, and briefly so to the superior genial angle. Surface finely faceted and not setigerous.

Gular region, besides being punctato-granulate, is finely and irregularly or transversely regulose. The gular sutures are widely separated inferiorly at the sides of the occipital foramen, and somewhat arcuately converging anteriorly to become nearly contiguous at a point, whose distance behind the base of the mentum is equal to the width of the gular peduncle, and continuing forward for a short distance to become divergent, passing to the mental angles of the peduncle, bounding laterally the small triangular submentum, whose base is usually a little longer than one of its sides.

The transverse cephalic groove is strongly impressed across the apex of the submentum, becoming less so outwardly just behind the posterior boundary of the buccal fissures.

Gular peduncle short and slightly deflexed, formed by the submentum, whose base forms a free margin, to which is attached the mentum.

Gula.-Between the gular sutures posteriorly is the subtriangular gula, whose base forms the straight inferior boundary of the occipital foramen.

Labrum more or less transverse, sinuate at middle, sinus rounded, lobes rounded and continuously so with the sides; surface feebly convex, punctate, setæ longer latero-anteriorly, and decurved; the anterior margin each side of the central sinuation, just beneath clothed with dense transverse tufts of golden pubescence (labral tufts), which are directed downward, inward, and slightly forward.

Mentum variable, internally giving attachment to the labium; apex of middle lobe free. (See descriptions of species.)

Antennce variable in length. The outer three or four joints are always more or less feebly compressed and slightly dilated; second joint always short, frequently wider than long, and subannular; the third always long, from three to five times as long as the second and usually about as long as the fourth and fifth taken together; the fourth and fifth may be equal in length, or the former a little the longer; fifth, sixth, and seventh usually about equal in length and size and obconical in form; eighth more or less triangular; eighth, ninth and tenth usually more or less transverse; eleventh oval and obliquely truncate at tip. The first joint is moderately arcuate, and 
distinctly constricted beyond the condyle. Joints eight to eleven, inclusive, more or less densely and finely pubescent, with tactile setæ. All the joints are irregularly punctate, and from each puncture arises a seta; setæ longer on the apical moiety of each.

Right mandible (Eleodes dentipes, Plate 8, fig. 12) short, robust, triangular, a little decurved at tip, the latter feebly emarginate.

Superior surface feebly convex, divided by a feeble arcuate ridge into an apical or incisive surface occupying about the anterior third, and a basal or molar surface occupying the basal two-thirds. Incisive surface with a series of short parallel ridges near and at right angles to the internal margin.

External surface with outline quite strongly arcuate, most so in apical half, which becomes apparently transverse; divided by a longitudinal ridge-like prominence into two parts, a superior and an inferior, both feebly concave and finely scabro-punctate. Surface at apex not concave.

Ventral surface (Plate 8, fig. 10) deeply and arcuately excavated; lacinia prominent, rounded and free anteriorly, finely pubescent.

Internal surface (Plate 8, fig. 2) deeply concave within the incisive third; lacinia prominent before the well-developed and transversely oval molar, behind which is a membranous lobe; the latter is pubescent, and the hairs longer than on the lacinia. Molar with a fine elevated margin, the inclosed surface area feebly and irregularly excavated.

Left mandible (E. dentipes) more strongly decurved apically and more deeply excavated within; incisor margin slightly emarginate; external surface at tip more strongly beveled from the emarginate edge. As a whole it is less strongly arcuate and a little longer than the right.

Maxilla (E. dentipes, Plate 8, fig. 11).-The palpi are comparatively large and four-jointed. The basal joint small, quite strongly and outwardly bent at middle; second joint elongate, obconical and nearly twice as long as the third, the latter also obconical and slightly arcuate at base; fourth broadly triangular, not equilateral, the inner margin the shortest, the external and apical subequal.

Lacinia ending in a chitinous claw-like point; external surface concave with margins arcuately dilated at middle, adapted to the internal surface of the galea. The internal surface just basad to the claw-like extremity is densely set with rather long incurving cilialike setr, elsewhere the surface is shining and very glabrous.

Galea of one joint, subtriangular (variable in the different species); external surface evenly convex and glabrous, limited apically by a dense and evenly transverse row of rather short spinules, immediately beyond which the apex is densely set with rather long, incurving spinule-like cilia. 
Cardo subparabolic in outline. Conical eminence at base of palpus quite evident. Palpus and palpiger punctate and setose; cardo more finely so.

Labium (E. dentipes, Plate 8, figs. 3 and 15).- Transverse, body or palpiger subquadrate, with what are apparently the chitinized paraglossæ expanded laterally and connate with the sides above the insertion of the palpi.

The ventral surface of the palpiger is transversely prominent ventrally between the palpi, and gradually declivous posteriorly to base; rounded laterally basad to the palpi, apicad passing into the concave and expanded paraglossæ, which are directed outward and forward, and rounded at apex. The basal joints of the palpi glide over the concave surface of the paraglossæ.

The apical margin of the palpiger is not noticeably membranous, but rapidly and obliquely beveled from the prominent interpalpal surface, at its oral margin giving attachment each side of a brief central interval, to a thick transverse tuft of rather stout but soft golden cilia, which curve upward and forward. The corresponding oral margins of the paraglossæ are also frimbriate with similar cilia, which increase somewhat in length from within outward, longest at apex and gradually diminishing to some extent externally, as they are traced backward and inward along the floor of the mouth. The cilia on the paraglossie are directed inward and forward as shown in fig. 3, Plate 8.

Labial palpi (Plate 8, fig. 3) rather small and three-jointed, inserted into the sides of the palpiger ventrad to the paraglosæ. Joints one and two subequal, the first narrower and obconical, the second slightly stouter and of similar form, the third a little longer, scarcely triangular (subpyriform), feebly flattened and constricted at base within. (Compare figs. 3, 5, and 6, Plate 8.)

Ligula (E. dentipes, Plate 8, fig. 13).-The internal surface of the labium is membranous and marked by a median groove that ends posteriorly at an oval but small eminence; anteriorly just within the apical margin on each side of the median groove is a rounded convexity; they lie within a triangular area bounded anteriorly by the cilia of the apical margin, and laterally by two converging rows of cilia, which pass inward and backward from the apices of the paraglossæ to terminate at the oval eminence. Externally to the rows of cilia the surface declines to the external margins of the paraglossæ, and scattered over which are a number of rather short hairs. Upon the oval membranous eminence at the apex of the triangle is a small arcuate row of very small setæ; these are at the proximal end.

Prothorax.-Inlet bounded above by the apical margin of the pronotum, below by the apical margin of the prosternum. Laterally within the apical angles is a small triangular area, which may be 
termed the apical triangle. It is bounded above by the apical pronotal margin, within by the margin of the inlet, and below by a feebly marked ridge that passes downward from the apex. The outlet is circular and its plane is quite strongly oblique, while that of the inlet is quite vertical. The dorsum is nearly twice as long as the sternum. Ventrally along the margin of the outlet the surface is rather widely impressed from side to side and behind the acetabula. The impression is interrupted at the middle by the prosternal mucro.

Propleurce (prothoracic episterna and epimera) with parts not defined from each other nor from the inflexed sides of the pronotum; limited internally before the acetabula by the prosternal suture; posteriorly no sutures are visible. Surface more or less prominent from the external margin of each acetabulum.

Prosternum with the coxæ more or less protuberant ventrally. Anterior margin broadly sinuate in circular arc, beaded, and usually narrowly deflexed. Prosternal sutures distinct before the acetabula, straight, impressed and subfoveate in basal half. Each suture extends from the external acetabular margin to lateral margin of the prothoracic inlet, where it bounds the inner side of the apical triangle.

Mesothorax. Condyle annular. The dorsal part of the condyle is formed by the transverse and somewhat triangular scutellum, the apex entering between the elytral bases to appear visible as a small, glabrous, and impunctate triangular plate, marked off from the scutellar body by a strong surface deflexion, which is in line with a similar deflexion across each elytral base, the condylar portion being on a lower plane than that which enters the elytral disk. The condylar portion is minutely punctato-scabrous and finely pubescent, its basal margin is feebly and broadly emarginate, with the angles projecting a little beyond the episternal border, and at which point the two plates are not closely articulated, being separated laterally from the episterna by the articular processes of the elytra.

Mesosternum.- - It presents for examination two parts - a condylar and an acetabular portion.

The condylar portion is directed horizontally forward, and arcuate from side to side, forming apparently, when viewed from below in reference to the greatest transverse diameter of the inlet, the middle two-fourths ventrally of the condylar wall. The anterior or free margin is beaded and feebly arcuate anteriorly. From the middle of the margin there extends backward a short glabrous carina, which is slightly dilated where it is continuous with the marginal bead; surface punctato-scabrous and finely pubescent.

The acetabular portion is more or less declivous posteriorly from the horizontal condylar part, the middle third posteriorly entering between the mesacetabula forming the intercoxal salient of the mesosternum, where it may become briefly horizontal, and its apical 
margin truncate, feebly arcuate or sinuate even in individuals of the same species, widely separating the mesocoxæ and terminating at the transverse mid-acetabular line; each lateral third of the posterior border of the mesosternum is arcuately reëntrant, forming the anterior moiety of each mesacetabular cavity, and terminating in the externoposterior angle, which is rather broad and transversely truncate, forming the anterior boundary of the mesacetabular recess (see Acetabula); the surface is more or less concave at middle between the convex and prominent acetabular margins.

The sides of the mesosternum are limited by the mesosternal sutures; these are straight and extend obliquely forward and inward from the external angle of the mesacetabular recess, to the condylar margin, at a point whose distance from the mid-line is about equal to the length of the condylar portion in the mid-line before the prominent intercoxal part. The sutures join the mesosternum and episterna only.

Mesosternal episterna.-Each episternum is triangular and with its surface on the same general plane; anteriorly forming the condylar margin between that formed by the mesosternum below and the mesonotum above; internally uniting with the mesosternum; apical angle received between the epimeron and mesosternum at the angle of the mesacetabular recess; externally and dorsally connate with the epipleural margin and base of the elytron external to its articular process.

The surface is divided into two areas by a gentle arcuate line or ridge which extends transversely from about the middle of the mesosternal suture to the inferior humeral angle. This line may be called the episternal line.

The area anterior to the episternal line is the condylar portion; its surface is finely punctulo-scabrous and pubescent, and subdivided into two unequal portions by a submanginal line, which, beginning at the antero-internal angle runs outward nearly parallel to the marginal bead, thence gently diverging, to arcuately pass to the middle of the superior margin of the condylar area.

Mesosternal epimera.-Each epimeron is rhomboidal, with its inferior border bounding the mesacetabular recess externally; scarcely twice as wide as long, obliquely placed between the mesosternal episternum in front and the metasternal episternum behind, and if its posterior margin be prolonged as a line it will touch the internal angle of the metacoxa of the same side.

The superior margins of the mesosternal episterna and epiməra are inflexed beneath the inferior epipleural margins of the elytra, at the line of inflexion where they pass under, the surface is grooved and beveled to receive and hold the elytral margins; the inflexed portions are continuous with less strongly chitinized dorsal and undifferentiated sclerites, which with similarly inflexed parts of the metasternal 
episterna, form between them the boundaries of a rather large fossa, in the deep and somewhat anterior wall of which is situated the mesothoracic stigma. This stigmatic fossa is situated immediately within the mesosternal epimera under cover of the elytra.

Metasternum short, the median part or body is subquadrate, somewhat equal in length to the abdominal intercoxal process, anteriorly entering between the mesacetabula quite equally with the mesosternal salient and forming with it the intersternal suture; the latter is either straight or arcuate, according to whether the intercoxal processes are truncate or more or less rounded-a variable condition even within specific limits; posteriorly the border is transverse, not in the least entering between the metacetabula.

The sides of the body are produced laterally, much narrowed between the mesacetabula in front and the metacetabula behind to expand somewhat triangularly more externally against the episterna, as the alæ. The anterior borders of the alæ, laterad to the intercoxal process, are arcuately reëntrant to form the posterior moieties of the mesacetabula; the posterior borders of the alæ are less strongly and arcuately reëntrant to form the anterior boundaries of the metracetabula. The basal borders of the alæ are very feebly reëntrant and rounded to fit the feebly arcuate edges of the episterna, forming the metasternal sutures, each extending from the external angle of the mesacetabular recess in front to the external angle of the metacetabulum behind. The anterior basal angle of the metasternal ala is shut off from the externo-posterior angle of the mesosternum by the mesosternal epimeron at the external angle of the mesacetabular recess; the posterior basal angle of the ala is prevented from meeting the first abdominal segment by the interposed episternum at the external metacetabular angle.

Metasternal episternum.-Elongately subrhomboidal, slightly widening at middle, thence feebly narrowing to the posterior border, about three times longer than wide and about three and a half times longer than the mesosternal epimeron; base obliquely truncate and connate with the posterior edge of the mesosternal epimeron, forming the mesepimeral suture; internal border feebly arcuate and connate with the base of the metasternal ala ; the external margin is straight and adapted to the inferior epipleural margin. The posterior edge internally is somewhat inflexed at the external angle of the metacetabulum, externally giving attachment to the small subacutely digitiform metasternal epimeron, which is feebly and inwardly arcuate, resting in a small depression on the surface of the first abdominal segment at the externo-anterior angle, and bounding the metacetabulum at its external angle.

The metathoracio stigma is situated immediately opposite to the posterior extremity of the metasternal episternum and under cover 
of the elytra; unlike the mesothoracic stigma it is surrounded by the soft cuticle; it is large and deeply impressed and the rima stigmatis is antero-posteriorly directed; that of the mesothoracic stigma is directed antero-internally.

The dorsum of the mesothorax is more or less chitinized laterally, less so at middle behind the scutellum. Invisible without removal of the elytra.

The dorsum of the metathorax is membranous except laterally where the episternum extends inward for a short distance beneath the epipleura.

The proacetabula are quite circular, except at the internal margin where the intercoxal prosternal process dilates slightly and impinges upon them.

The mesacetabula are quite circular if the recess for the trochantine be not included, with that it is slightly transverse. The anterior margin of the acetabular recess is more or less angulate from the truncate externo-posterior angle of the mesosternum; the posterior margin is continuously arcuate with that of the acetabulum proper.

The metacetabula are slightly more transverse, but slightly and obtusely angulate anteriorly where the posterior angles of the metasternal alæ form their boundary.

The procoxa are globose.

The mesocoxce are really slightly transverse, but subdivided by an antero-posterior impression into the rounded coxa proper and the outer and smaller division,- the trochantine which occupies the acetabular recess. The coxa proper is quite broadly and outwardly impressed from the articular eavity to the trochantine.

The metacoxe are more transverse, ovate and not divided by an antero-posterior impression; the surface of each is broadly and strongly grooved external to the articular cavity.

The trochanters are small and ovate, scarcely forming a half of the width of the basal extremity of a femur, and but a little longer than wide.

The crural characters are given under the different specific headings. For a study of the relative lengths of the different segments see diagram, fig. 4, Plate 8 .

The grooves on the inferior surfaces of the femora I have denominated as the tibial grooves; because they are adapted to and receive the tibiæ in extreme flexion.

Likewise the grooves observed on the external surfaces of the tibiæ I call the tarsal grooves. These tarsal grooves are not always present in the different species; when present they extend from the more or less open articular cavities on the tibial apices, to become evanescent at varying distances from the same. These tarsal grooves receive the tarsi in hyperextension. 
The tarsi are grooved beneath by the plantar grooves.

Each tarsal joint is more or less obconical and grooved beneath. The sides of the groove are set with a row of marginal spinules, the apical margin also bears a row of apical spinules. At the apex where the apical meet the marginal row, the spinules are usually longer and more conspicuous as acute tufts; these are the apico-marginal tufts. (See Plate 8, fig. 22b.)

The first two joints of the anterior tarsi are frequently thickened and somewhat produced at apex beneath (Plate 8, fig. 9a), obliterating the groove. When the apex is thickened beneath it nearly always bears a tuft of yellowish pubescence, especially in the males of many species, and sometimes in the female a tuft of spinules.

In the males of the subgenus Blapylis it is normal to observe on the first and second joints of the mesotarsi similar tufts on the tips beneath. This is also observed in some species of Promus.

The ultimate joint of each tarsus at apex has the margin above feebly bilobed; beneath the margin is produced into an interungual process, which varies considerably in shape but is probably of no value in the separation of species. (See Plate 6, fig. 18.)

The ungues are slender and acute, moderately arcuate, and slightly subangulate at base beneath. (Plate 6, fig. 19.)

Abdomen.-Ventrally there are only five visible segments, while dorsally there are six.

Morphologically the first visible ventral segment is the second; the study of the retractile segments requires that this be recognized as such.

The first segment dorsally in the mid-line is as long as the second; laterally it gradually narrows so that it points at the bases of the metasternal epimera.

Ventrally the first segment is greatly reduced, and although undifferentiated it forms a part of the metacetabular walls, reaching the sides of the abdomen to appear as a small and short sclerite, connate with the externo-anterior angle of the second segment (first visible), dorsad to the base of the metasternal epimeron, and at the point where the evident dorsal membranous first segment reaches the abdominal margin.

There are six pairs of abdominal stigmata, and in the male are located on each side as follows:

The first stigma is situated about $\frac{1}{3} \mathrm{~mm}$. above the posterior margin of the metathoracic stigma.

The second is about $0.8 \mathrm{~mm}$. above the lateral edge of the second ventral (first visible) segment and on a line drawn transversely across the posterior margins of the metacetabula.

$$
\text { 59780-Bull. } 63-09-2
$$


The third is $0.6 \mathrm{~mm}$. above the basal angle of the third ventral (second visible) segment.

The fourth immediately above and close to the inner membranous edge and basal angle of fourth ventral (third visible) segment.

The fifth is in the same position relative to the fifth ventral (fourth visible) segment, and only partly visible without traction on the sixth tergite or a voluntary extension of the same by the insect.

The sixth is in the same position relative to the sixth ventral (fifth visible) segment as the fourth, but entirely invisible without traction on the sixth tergite. It is distinctly smaller than the other stigmata and is overlapped by the lateral fold or edge of the sixth tergite and also by the apical fold of the fifth. At this point the

The tergite of the sixth segment (Plate 7 , figs. $2 p$ and $4 p$ ) is the other segments.

The first three pairs of stigmata are the largest, the fourth and fifth are slightly smaller.

The tergite of the sixth segment (Plate 7, figs. $2 p$ and $4 p$ ) is moderately chitinized and flexible, evenly and arcuately rounded at apex, the margin set with short setæ and sparsely so over the dorsal surface apically.

The sternite is strongly and firmly chitinized and constitutes the so-called fifth visible ventral segment.

Retractile segments.-Four in number and homologous to those of Hydrophilus piceus as figured by Packard. ${ }^{a}$

Seventh segment.-The tergite and sternite are chitinized and very flexible. The tergite is short, broadly, and not strongly arcuate at apex, most strongly chitinized laterally and quite membranous at middle; margin frimbriate with short setæ and the dorsal surface sparsely pubescent. (Plate 7, figs. $2 r$ and $4 r$.)

The lateral angles at base articulate with the lateral and basal angles of the sternite and in both sclerites these angles are more strongly chitinous than the other parts of the same sclerite. This articulation is stronger in the male.

The sternite is different in the sexes. (See figs. 2 and 5, Plate 2, and figs. $1 e$ and $3 o$, Plate 7.) In the male it is bilobed and described in detail for each species in the body of this work; in the female it is broadly arcuate at apex, in the male deeply emarginate between the lobes.

In both sexes each lateral moiety is made up of a triangular chitinous plate, which at the external and internal basal angles are more or less produced. In the male the internal and more or less anteriorly produced angles are separate and not connate-so as to permit of the abduction and adduction of the lobes which no doubt

a Text-Book Ent., p. 181. 
act as guides to and steady the edeagophore under certain conditions; in the female the interval between these triangular sclerites is continuously membranous and feebly chitinized, so that movement between the lateral moieties is impossible, and the internal basal processes are connate. (Plate 7, fig. $3 o^{\prime}$.) The external basal processes articulate with the tergite of the same segment as described above.

The eighth segment is membranous in both sexes.

The tenth segment is aborted in the female as usual, the tergite fusing with the ninth tergite to constitute the supra-anal plate. (Plate 7, fig. 4q.) In the male the tergite of the tenth segment forms the supra-anal plate; the subanal or sternal wall is membranous in both sexes, possibly somewhat chitinous in the male.

The supra-anal plate is more strongly chitinous laterally and more membranous at middle (Plate 7 , figs. $2 q$ and $4 q$ ) and is in relation laterally with the paranal plates or sclerites.

In the male these paranal sclerites are much smaller and less triangular than in the female, and articulate with a chitinous rod on each side; these rods converge anteriorly so as to form a $\mathrm{Y}$-shaped support and a mechanism for the extension and retraction of the edeagophore; they are wholly internal and give attachment to muscles and ligaments.

The paranal plates in the female are irregularly subquadrate, occupying the lateral wall below the supra-anal plate. Each paranal sclerite may be said to present for examination four borders: a superior, posterior, inferior, and an anterior; four angles: the anteroinferior and postero-inferior being the most important.

The superior border is connected to the sides of the supra-anal plate by membrane, apparently forming an articulation at its anterosuperior angle with the antero-external angle of the anal plate; the posterior border is connected by articulating membrane to the basal margin of the ventral plate or valve; the inferior border gives attachment to the membrane of the ventral wall, and the anterior border giving attachment to the membrane of the eighth segment.

The antero-ventral angle is short and apparently gives attachment to muscles and ligaments which steady the plate against the valve.

The postero-ventral angle is produced into the process of the paranal plate to articulate with the strongly chitinized basal margin of the ventro-lateral plate of the valve, of the same side and upon which the valve plays during abduction and adduction. (Plate 3, fig. 4a.)

The above description of the retractile segments has been founded upon those of Eleodes cordata, as illustrated in Plate 7. The seg- 
ments were studied both as opaque objects and cleared with liquor potassi.

The sclerites of these segments vary a great deal in the different tribes and even in the genera of the Tenebrionidx and are of taxonomic value.

The development of these segments depends a great deal upon the habits of the insect and the manner of oviposition required by the species. In Microschatia inoqualis they are developed to a wonderful degree and are capable of extrusion to the distance of nearly an inch.

The different species of the present tribe exhibit considerable variation in this respect and which might be of aid in the classification of species; but on account of the great amount of work and material required and the time already devoted to this paper, I have not been able to study them nor deemed it wise to further delay the publication of work already done and therefore leave that investigation for a future thesis.

The male intromittent apparatus.-This consists of a carrier, the Edeagophore, and the intromittent organ proper, the Edeagus, and its clava.

Edeagophore, usually more or less flax-seed-shaped, somewhat arched, and consisting of two segments or lobes: a basal segment or body, the basale; an apical segment or apicale.

The apparatus has been described in detail for each species.

The basale is variable in length, half-cylindrical in form, chitinous above and laterally, membranous beneath, decurved at base into a process which gives attachment to muscles and ligaments by which it is attached to and operated upon by the extrusor mechanism described above; dorsally it is convex to a varying degree and often depressed, the sides are more or less inflexed beneath for the attachment of the ventral membrane-strongly so in Embaphion and Eleodes planipennis; the apex is more or less emarginate and adapted to the base of the apicale to which it is attached by articulating membrane. (See Plate 7, fig. 2; Plate 2, figs. 1 and 8; Plate 9, figs. 3 to 9.)

The apicale is always triangular, rarely subpyriform, more or less depressed and usually subacute at apex, sometimes obtuse; the base is more or less lobed and received into the emargination at the apex of the basale; the dorsal surface is more or less convex, frequently membranous at middle, but in the higher forms entirely chitinous; ventral surface is more or less membranous, but chiefly occupied by the edeagus and its protecting clavæ, the inflexed and chitinous sides constitute the alæ which occupy the greater part of the surface; in one genus the alæ support subalæ. (Eleodimorpha, Plate 7, fig. 8.)

The alce are inflexed to a varying degree, strongly so when the ventral surface of the apicale is concave, as in Eleodes cordata 
(Plate 7, fig. 1) and E. dentipes (Plate 9, fig. 6) ; convex ventrally in Embaphion (Plate 7, fig. $7 y$ ) and Eleodes planipennis (Plate 9, fig. 7); in Eleodes scabricula the inferior surface of the apicale is concave apicad to the alæ, which are suddenly prominent. In the different species the alæ are continued basad to a varying degree, becoming more and more membranous. (See figs. 6, 7, and 9, Plate 9.)

The Edeagus (Plate 9, fig. 11a) is usually flattened, sublinguiform in shape and subacute at apex; the ventral surface is narrowly prominent in the median line and more or less concave laterally where it is in contact with the clavæ in repose; the median ridge, divides toward apex to become bilabiate, between which is probably the orifice of the vas deferens. At base the structure is more chitinous and there is a small median process for articulating with the clavæ. The dorsal surface is feebly convex and more or less membranous and marked by a median groove; opposite the attachment of the clave ventrally the surface membrane is reflected upon the internal wall of the apicale, forming the fornix edeagi. In fig. 12 of Plate 9 the orifice of the detached vas deferens can be seen entering the edeagus from the basale just beneath the fornix.

At the base the sides of the edeagus are strongly chitinized and produced into two long processes (Plate 9, figs. 11 $a$ and 12) which extend cephalad within the interior of the basale, giving attachment to muscles.

The clave are usually quite spiculiform (Plate 2, figs. 1 and 8), sometimes sublaminately spiculiform (see figs. 6, $11 d$ and 12, Plate 9) and in Embaphion truncate at tip and concave beneath; in Eleodimorpha they are rather liguliform (see figs. 7 and 8, Plate 7 ).

In repose when the edeagus is retracted they lie parallel to the median line and more or less contiguous; with the edeagus protruded they are at right angles to the axis of the edeagophore.

Each clava may be said to have a base and an apex, a dorsal and a ventral surface, and internal or posterior surface and an external or anterior margin.

The base is obliquely truncate at the posterior or internal surface and articulated to the ventral surface of the edeagus at base; the internal or posterior surface or edge is much thicker than the anterior or external, and triangular in basal half, and thence gradually becoming more ventral as it attains the apex, where it is feebly convex, the basal portion is quite plane; apex subacute to rounded or rather obliquely truncate; the external or anterior edge is usually thin, feebly arcuate and slightly notched near the apex; the dorsal surface more or less convex and the ventral rather concave. (E. dentipes, Plate 9, figs. $11 d$ and 12.)

In repose the clavæ may conceal the edeagus, except at apex, where they slightly diverge, when they are ventral as in Eleodes; or 
the median ventral surface of the edeagus, may be visible between them when they are lateral as in Embaphion, and ventrad but not contiguous as in Eleodimorpha.

The female genital segment (Plate 7, figs. 3 and 4).-Viewed from above it has an outline varying somewhat according to the sulogenus: triangular in Blapylis, quadrate in Melaneleodes, trapezoidal in Eleodes and subparabolic in Steneleodes.

The dorsal surface varies but is usually more or less plane to subogival; ventrally convex - strongly so at base and gradually less so apically.

The segment consists of two chitinous valves concealing and protecting the pudenda between them. The valves are movable on a lateral plane, in abduction exposing the genital orifice and its surrounding pudendal membrane.

Each valve (valvula) consists of a body (corpus valvula) and an apex (apex valvula).

The body is always chitinous; the apex usually membranous and distinctly define from the body, sometimes completely chitinous and not differentiated.

The superior wall of each valve is formed by the dorsal plate (Zamina dorsalis) which is variable in form; its surface usually more or less plane, but may be quite strongly concave. Each plate presents an external, internal, and apical border; at the junction of the external and apical borders an angle is formed, which may be distinct or more or less obsolete.

The internal borders of the dorsal plates are not usually contiguous but distant at base, converging posteriorly, and between which is the more or less exposed superior pudendal membrane. The apical margin is generally defined from the surface of the apex; in some species it is not. The external border is generally more or less explanate, and beneath which is situated the submarginal groove (sulcus submarginalis).

The lateral and ventral walls of a valve are formed by a continuous plate, the Zamina ventro-lateratis, which is connate above with the dorsal plate. It presents for examination a surface and an internal border. The surface is strongly convex at base, frequently prominent laterally, forming the basal prominences, much less convex apically and generally more or less impressed before the apex, with which it is directly continuous.

The internal margins of the ventro-lateral plates of the two valves are not usually contiguous throughout their entire length in the midventral line, but separated by the more or less fusiform genital fissure (fissura genitatis). When this fissure is basad to the middle it is spoken of as being subbasal; when at the middle it is median, and 
when apicad to the middle it is subapical. The fissure when present is closed by the inferior pudendal membrane.

The basal margins of the ventro-lateral plates are strongly chitinized and together form a loose articulation at their basal angles, basad to the genital fissure.

The basal margin of each ventro-lateral plate articulates about its middle with the process of the paranal plate, and is connected by articulating membrane with the posterior margin of the same plate (Plate 3, fig. $4 a$ ) ; dorsally the dorsal plates do not articulate with each other, but on the contrary are widely separated and connected only by membrane.

The apex of each valve is separated by a fossa into two lobes, an external and an internal. The external lobe is only developed in the subgenus Melaneleodes; in all others of our fauna it is obsolete. The internal lobe is always developed and only atrophic in Melaneleodes.

The fossa gives attachment and lodgment to the always short cercopod.

Each valve is more or less finely pubescent about the apex, the dorsal plate is most noticeably pubescent in the subgenus Promus.

The cercopoda are variable in form and size, usually mammilliform, frequently compressed, punctiform in Discogenia and obsolete in Heteropromus. Usually penicillate.

The pubescence on the apex is usually longer than elsewhere, and the internal lobe is often somewhat penicillate.

The valvular body is never very strongly punctate, most noticeably so on the external moiety of the dorsal plate in Promus. The punctures are rather strong in some species of Steneteodes, and the superior pudendal membrane is broadly exposed.

From the sides of the vulva the lateral pudendal membrane is reflected upon the internal surface of the valve and there becomes the valvular membrane (Plate 7 , figs. $3 v$ and $4 v$ ), apically, directly continuous with that of the internal surface of the apex.

The angle of reflection between the lateral pudendal membrane and valvular membrane is the fornix valvulce. In some species the lateral pudendal membrane passes backward directly upon the internal surface of the valve without forming an angle of reflection.

Function.- The edeagophore is the agent by which the reproductive organs are brought into apposition. The apicale by its subacute apex is capable of more or less forcibly separating the tergal and sternal sclerites of the sixth and seventh somites and protects the essential organ from injury.

With the protrusion of the edeagus and its approximation to the genital fissure, the simultaneous abduction of the clavæ forcibly abducts the valvulæ and blocks their closure. 
Homology.-The examination of the male reproductive organs of Hydrophilus triangularis (Plate 9, figs. 1 and 2) suggests the homology between the reproductive organs in the Eleodiini, and also between the former and those of the latter.

In Hydrophilus the edeagophore consists of a basale (Plate 9, fig. $1 d$ ) and two apical valves. The basale is impressed along the median line dorsally and is more or less membranous at that point, and it therefore appears to have been developed by the partial coalescence of two lateral sclerites, termed by Packard the outer lobes; the two apical lobes he terms the inner lobes (Plate 9, fig. $1 a$ ), they are valvular in character and capable of free abduction and adduction; between them is the edeagus.

I consider the outer lobes homologous with the basale, and the inner lobes with the apicale in the Eleodiini.

If fig. 1 of Plate 9 be compared with fig. 12, Plate 2, a similar structural condition of the valves in the two sexes and in very widely separated series will be observed. It is evident that in Hydrophitus there has been less sexual differentiation than in the Eleodiini, and also if the male characters of the latter be considered.

The female genital segment of Hydrophitus (Plate 9, fig. 10) presents a complicated arrangement of sclerites which are noticeably divergent from anything observed in the Eleodiini, and must be considered as a more primitive condition, in this agreeing with the male characters.

It has been made known by Nussbaum that unpaired parts like the edeagus, etc., have been developed from paired ectodermal outgrowths which have fused together, and in all probability there is analogy between these outgrowths in the Insecta and those observed in the Vertebrate Series; if this be so, then there must at some period have been an indifferent stage in the development of these organs, and a time of beginning sexual differentiation.

It appears to me that the apical lobes of Hydrophitus and the apicale of the Eleodiini are homologous with the genital segment of the female. In Hydrophitus there are the two valves capable of free abduction and adduction with the edeagus between and protected by them; in the female of the Eleodiini the two valves are as capable of free movement as in the above and enclose and protect the sexual orifice.

In the female the valves articulate with large paranal plates; in the male the valves or apicale articulate with the outer lobes or basale. and the paranal plates are small and articulate with a $\mathrm{Y}$-shaped chitinous structure that is internal, the basal process of the basale articulating with the arms of the $\mathrm{Y}$ by ligaments. 
It appears to me that the outer lobes (Plate 9, fig. $1 d$ ) which unite to form the basale are the modified greater part, at least, of the paranal plates.

There must be a definite law governing the deposition of chitin; it can not be diffusely deposited-at random, as it were-but it must be first laid down at certain points, called the centers of chitinization, and from these centers spread, or have inherent limitations; different centers coalescing to form larger sclerites or one continuous whole, as in the prothorax. A simple sclerite would then be one formed by the secretion of chitin about a single center; a compound sclerite from two or more centers. The small but symmetrically arranged sclerites observed in the cuticle of larvæ may be cited as simple sclerites.

It might be assumed that the paranal plate in the female is compound; in the male these centers have become shifted, to form the small paranal plate, and the other to become the lateral sclerite of the basale.

The origin of the several sclerites in the female genital segment of Hydrophilus may be accounted for in this way - they have not coalesced and have been shifted according to the laws governing adaptation to function; during divergence and differentiation under changed conditions of environment these several sclerites fuse - of course it is possible for some to be suppressed, others hypertrophied or even revived-and in this manner produce the apparently simple chitinous valves of the Eleodiini. These suggestions are to indicate a line of investigation in the coleopteral series.

An examination of the edeagophore of Blaps (Plate 9, figs. 3 and 4) will be instructive. It will be seen that the apicale is divided longitudinally by a well-marked membranous impressed groove and that the apex is bifid; the basale is also marked by a similar medium groove. These characters indicate a structural condition somewhat intermediate between the Eleodiini and a more primitive state as suggested by Hydrophilus.

If it be imagined that the apicale of Blaps was completely divided along the groove, and the alæ not strongly inflexed, the edeagus and its pallium would bear the same relation to the valves as does the edeagus to the valves in Hydrophitus. There is greater specialization in the Eleodizini than in Hydrophitus or Blaps.

In Eleodes and other members of the Eleodiini the apicale is frequently marked dorsally by a membranous area or groove, and less frequently the basale has an impressed median line. Many species do not normally have this groove and such I consider to be the more highly differentiated, although occasionally it occurs on the apicale even in them, and is then to be considered as an instance of ataval reversion. 
It is to be noted that Escherich, in his paper on the internal male organs of beetles, notes that those of the Carabidæ illustrate the simplest, most primitive condition. Packard figures Blaps as intermediate between the Carabidx and Hydrophilus. ${ }^{a}$

Sculpturing.-From simple punctures the sculpturing passes through the different degrees of modification to distinct murication or tuberculation, or as in a few species to distinct hairiness with comparatively simple punctures.

From a careful study of the sculpturing under high power in the species of the Eleodiini, I have observed the following:

A simple puncture is a more or less rounded depression, variable in size and depth, and bounded by a more or less distinct, although fine wall or margin; from the floor of this depression arises a minute hair or seta, which scarcely passes beyond the mouth of the puncture. The surface with such a punctuation is smooth.

Any modification will affect the puncture in one of two ways: Either by a hypertrophy of its margin or by an increased growth or hypertrophy of the hair-like process. In the first instance the hair may remain small or atrophic; in the second the hair-like process is alone affected. Some punctures may become completely aborted.

The hair-like process arising from the hypodermis may develop into a soft, flexible hair, or by a slightly increased chitinization of its cuticle into a bristle or seta, and by still greater increased chitinization, with or without hypertrophy, into a spinule or spine.

In the muricate type of sculpturing the anterior lip of a puncture is thickened and more or less produced into a blunt or acute point; from the sides of this prominence the margins gradually diminish so that the posterior boundary of the puncture will be but slightly modified; the thickened edge is directed upward and backward, chiefly the latter; the hair or seta may be aborted, remain small, or become more chitinous to become a seta, and be carried upward by the hypertrophied margin to project from the posterior surface of the more prominent anterior margin of the puncture.

When the margin of the puncture is equal and much thickened a tubercle is formed, which varies in size from a granule to a well marked and rounded eminence; the puncture may be entirely closed or obliterated, or may still be evident as a minute pore-like depression with a correspondingly small hair or seta projecting from it, and from some point, usually the posterior wall of the tubercle. There are all the intermediate degrees of variation to be observed.

The punctures may remain simple and the hair become long and flexible.

If the anterior lip of the puncture becomes minutely muricate the sculpturing is more or less asperate.

a Text-Book Ent., p. 494, fig. 465, $A, B$, and $C$. 
On the femora the proximal margin of a puncture is transversely raised so that the seta arising from it is more or less appressed to the surface and directed toward the apex of the femur.

On the tibiæ the murications are more erect, the walls of the punctures being more equally raised. The hypodermal process is usually much thickened to become a spinule or spine - the latter may be very short and stout, and with the produced margins of the puncture from which it arises, very tightly fitted to it, so that both appear as a single element.

The rugulose condition or reticulations frequently observed on the elytral surface is most usually due to the rapid evaporation of the body fluids during and immediately after the casting of the pupal skin, while the integuments are undergoing chitinization. It is the result of shrinking of the cuticular wall.

Often depressions arise in the exoskeletal wall from muscular exertion on the part of the insect while the body surface is yet soft. The contracting muscle dimples in the integument at the point of its attachment; the movements being kept up while the body walls are hardening, the depressions finally become permanent. Such unilateral or bilateral impressions are frequently observed on the pronota of the Eleodiini. Eleodes impressicollis of Bohemann, a synonym of $E$. clavicornis is an instance of this kind-merely a specimen with two thoracic foveæ.

TABULATED MODIFICATIONS OF A PUNCTURE.

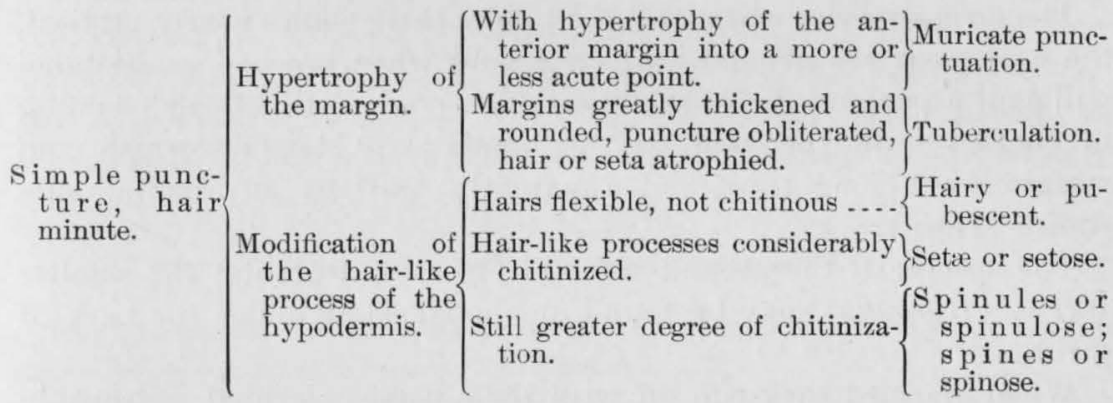

CLASSIFICATION AND SYNOPSIS.

Family TENEBRIONIDA.

Tribe Fi, FiODIINI.

This tribe contains insects of greater size than any other of the heteromerous subfamily Tenebrioninæ.

The body is oblong to ovate, rarely oval, apterous; head prominent, slightly narrowed behind the eyes; epistoma covering the base of the mandibles at the sides; labrum prominent; mentum small, inserted 
upon a gular peduncle; maxillæ exposed; ligula partly concealed; maxillary palpi with the last joint securiform, not very large; eyes transverse, reniform, tolerably finely granulated; antennæ 11-jointed; elytra embracing widely the planks of the abdomen, epipleuræ narrow to moderately wide, middle coxæ with large trochantine, side pieces attaining the coxal cavities; metasternum very short, episterna narrow, epimera quite distinct; hind coxæ widely separated; intercoxal process of abdomen rectangular; third and fourth ventral segments not prolonged behind at the margin.

Legs long; anterior femora frequently toothed; tibial spurs distinct; tarsi channelled beneath; first, second, and third joints of the anterior tarsi are at times thickened beneath, more or less obliterating the groove, setose beneath.

All are black or dark brownish, rarely reddish along the suture; variously though never very roughly sculptured; a few species are pubescent.

The third and fourth ventral abdominal segments are more or less broadly sinuate at apex, the angles appearing somewhat prominent, but not noticeably prolonged.

The tribal comparative genital characters are reserved for a future and special study.

Habits.-Our species are terrestrial and cursorial, apparently strictly nocturnal, or are about in the early morning or late in the day. On warm cloudy days I have seen Eleodes grandicollis and E. acuticauda walking about.

The larger species when disturbed place their bodies nearly vertical, the head near the ground, tail erect, and when touched or irritated will emit a pungent dark oleaginous offensive secretion, which coming in contact with the skin of the hands will stain brownish and remain for a long time, and apparently fixed by an alkaline substance (Horn).

The species of the present tribe rarely ascend plants; the smaller species (Blapylis) may be found on the stems or under the bark of shrubs.

When alarmed they run off with their bodies elevated. Probably it is this habit which has suggested the name "circus bugs," often applied to them in the West (Wickham). In California they are often spoken of as "stink bugs," "beetle bugs," and " tumble bugs." The latter term is applied no doubt on account of their frequently tumbling over when excited; also, pinacate bugs (V. Kellogg). They are a characteristic feature of the arid regions west of the Mississippi River.

Longevity.- Some of the larger and more resisting species evidently live to be several years of age; especially in the warmer regions of 
California (Horn). I have kept several Eleodes dentipes in captivity for over four years. Doctor Horn states that specimens have been kept pinned two months without food or water. Eleodes clavicornis dies quickly in confinement and apparently lives but one season.

Food.-All are vegetable feeders, apparently preferring dried vegetation and fungi, although eating green plants.

Enemies.-Quadrupeds like skunks will feed upon them; chickens devour them readily, as well as ground owls; butcher birds impale them on thorns.

Economics.-As far as I have been able to determine they are neither injurious nor beneficial, unless the larvæ are in some way troublesome, but as they appear to prefer decaying vegetation to the living I doubt that they can be considered objectionable.

Origin and diffusion.-It is impossible for me at this time to express any opinion upon the origin and diffusion of the species making up the tribe Eleodiini; but I believe the species to a great extent had their origin in Mexico, or in adjoining desert regions, and that diffusion has been chiefly northward and westward.

I know of no fossil remains of species referable to the tribe, and a few that were supposedly so were from a very recent deposit and identical with species now existing. (See Appendix.)

It remains for the study of the Mexican fauna to aid us. The South American Nycterinus will be referred to elsewhere.

Distribution.-Abundant both in species and individuals throughout the region west of the Mississippi River, from the northern boundary line of the United States, southward into Lower California and Mexico to South America, where they are replaced by Nycterinus. They also inhabit the islands adjacent to the western coast of the territory above named.

\section{ANALYTICAL KEY TO GENERA OF ELEODIINI.}

Our genera are five in number, one having been introduced from Europe. Outer joints of antennæ broader (Eleodiini)

Outer joints of antennæ not broader;'8-10 moniliform, suddenly shorter than the preceding joint (Blaptini) Blaps.

1. Sides of the epistoma not dilated, margin straight or sinuate, converging anteriorly Trogloderus.

Sides moderately dilated, margin arcuate

2. Epipleuræ attaining the humeral angles

Epipleuræ very narrow, not attaining the humeral angles_____Embaphion.

3. Epipleuræ broader at base, more or less gradually narrowing to apex.

Epipleuræ occupying only a part of the inflexed portion of the elytra ; buccal processes of the genæ not produced. Eleodes.

Epipleuræ occupying the whole of the inflexed portion of the elytra; buccal processes of the genæ acutely produced Eleodimorpha. 
The genera can also be defined by the male genital characters as follows:

Sternite (fig. 6, Plate 6) with lobes fully and strongly connate; clavæ dorsal to the edeagus, connate forming a pallium (similis, mucronata) (Blaptini)

Blaps.

Sternite distinctly bilobed, lobes connected by a membrane that at most is but feebly chitinized, lobes capable of abduction (Eleodiini).

Clave ventrad to the edeagus.

Clavæ spiculiform, notched at side of the tips; alæ more or less strongly inflexed, not prominent ventrally, plane or somewhat concave, never strongly convex (Plate 7 , fig. 1) Eleodes.

Clavæ flattened (liguliform), of equal width throughout, tip obtuse and rounded; alæ short, not strongly inflexed, giving attachment to subalæ (Plate 7 , fig. 8)

Eleodimorpha.

Clavæ laterad to the edeagus, truncate at tip, more or less concave beneath; alæ moderately and evenly inflexed, rather prominent ventrally (Plate 7, fig. 7)

Embaphion.

Trogloderus has the lobes of the sternite united by membrane and capable of abduction. Unfortunately the clavæ could not be studied without destruction of the fragile material at hand.

Genealogy.-The antecedents of the present tribe are not suggested to my mind by the data at hand.

The male sexual characters are the most distinctly differentiated for the generic subdivision of the tribe. The above synoptic table indicates these relationships just as forcibly as a diagram could do where there are so few elements involved.

The genera are related, first, by the bilobed sternite, the lobes being capable of abduction; second, by the relation of the clavæ to the edeagus; third, by divergence having taken place along the line of degree of development in the alæ.

In Eleodimorpha the subalæ have been differentiated as distinct sclerites from the alæ.

In Eleodes and Embaphion the extrusion of the edeagus with simultaneous abduction of the clavæ, is brought about by muscular action-certain extrusor muscles; the return of these structures is accomplished by the inherent elasticity of the alæ, the latter being the continuously produced and inflexed sides of the apicale.

It is logical to suppose that accompanying the differentiation of the subalæ as distinct exoskeletal elements that there has been a corresponding muscular differentiation; for when the continuity of the alæ underwent solution, they in all probability were no longer capable to functionate by their own inherent resiliency-of course, it is possible for the continuity of the elements to be restored by becoming connate at a sutural line; but this would evidently still be a weak point and correspondingly diminish the functional activity of the part. 
In all probability there has been a compensatory development of retractor muscles to overcome this loss of power.

\section{Genus ELEODES Eschscholtz.}

Mentum variable in form, more or less trilobed, the middle lobe larger and more convex; lateral lobes frequently inflexed and more or less concealed. Last joint of labial palpi triangular, narrower than the maxillary, which are broadly triangular or securiform.

Head not deeply inserted, suture between epistoma and front frequently distinct; epistoma truncate or feebly emarginate, sides straight or sinuate and converging anteriorly. Eyes narrow, subreniform. Antennæ eleven jointed, the last three or four usually notably compressed, last joint frequently though not always smaller than the preceding.

Prothorax variable in form, usually applied against the bases of the elytra. Scutellum always present, distinct and equilateral.

Elytra of variable form and sculpture, in many species prolonged into a cauda behind; epipleuræ always distinct, broader at base and always visible at the humeral angles, gradually narrowing to apex.

Legs moderately long, but somewhat variable in this respect; femora never strongly clavate, profemora most so, the mesofemora slightly, the profemora frequently armed in one or both sexes with a tooth of variable form, rarely all the femora armed; tarsi usually channelled and setose beneath, first and second joints of the protarsi frequently slightly thickened beneath and often the first two or three joints are clothed with a tuft of silken hairs, or dilated and densely covered with a spongy pubescence beneath. Spurs of the meso- and metatibiæ well developed, moderately slender, narrowing from base to apex, acute, the internal more or less longer than the external. Varying more or less in the different species.

The above characters are those applicable to the whole genus; characters peculiar to certain groups will be given as of subgeneric value.

The genus Eleodes is one of the largest of the Tenebrionidx and contains many more species than all of the other genera of the present tribe put together (United States). It is also the most polymorphous and has been the most difficult to subdivide of any in our fauna. The study of the genitalia has greatly reduced this difficulty, but extreme variations in many individuals of each species will yet be a source of great perplexity.

The most salient extreme characters observed in the genus may now be reviewed:

Color.-Black, sometimes reddish along the elytral suture as in acuta, obsoleta, and hispilabris; rarely fusco-piceous as in longicollis 
and insularis, probably from immaturity, or from aging in the cabinet; in one instance the elytra are described as castaneous ( $s u b$ cylindrica Casey) ; this unusual coloration is undoubtedly due to immaturity. Dead specimens from long exposure to climatic inclemency become fuscous and even castaneous. In a limited number of species the legs are dark brown throughout, as in bminnipes Casey.

Form.-Notably large and elongate as in the males of gigantea, oblong as in tricostata, elongately oblong as in acuta and texana, oval in veterator, inflated as in ventricosa and depressed in tibiatis.

Size.-Largest in acuta, texana, and grandicollis; smallest in clavicornis.

Surface.-Glabrous and shining, as in dentipes, gigantea, and omissa; opaque as in tricostata and opaca.

Sculpturing.-While usually simple it becomes tuberculate in granosa and gramulata; rugoso-muricate in cordata and muricate to a varying degree in many.

Pubescence.-Body clothed with long flying hairs as in longipilosa, pitosa, and hirsuta, or confined to the elytra as in letcheri; hairs short, recumbent and abundant in veterator and opaca.

Characters that vary within specific limits.-These are the factors which make the limitations of species extremely difficult. Each species may have its extreme large (gigantism) and small (nanism) forms; its smooth and rough forms, elongate and robust forms, while the sculpturing varies from comparatively smooth to rough independently of size or form. This can be accounted for by environment to a great extent and to certain inherent factors.

With robustness there is a relative shortening of the appendages and also of their segments, as for instance the joints of the antennæ from the fourth to the seventh or eighth tend toward equality of length, while in the elongate forms there is a more or less inequality of length evident, the joints decreasing in length more or less from the fourth to the eighth, these joints being comparatively and relatively longer as a part of the general habitus.

These remarks apply most emphatically to the tarsi and their joints as well; the antennæ and legs as a whole exhibit this variation of length; the head varies in size and relative length and breadth even in any particular form.

So it can be seen why in this particular genus (and this fact is worthy of broader application) that the relative length of parts of any appendage can not always be given as evidence of specific distinctness. These conclusions have been arrived at after a long and tedious recourse to micrometrical treatment of hundreds of specimens.

In many specimens, especially in the subgenus Eleodes, there is to be observed a more or less evident smooth median pronotal line 
that may extend from the apical to the basal margins; this line is most pronounced as a rule in $E$. acuticauda var. laticollis, where it often becomes a distinctly impressed line; usually it is only observable as a line in surface luster. The significance of this character is obscure.

Another very interesting character is that observed in the hind tibiæ of the males of certain species of the subgenus Eleodes. The metatibiæ are slightly arcuate and narrow in basal half, rather abruptly dilated and straight in apical half. In the literature I find this character mentioned by Doctor Horn as one of the male characters of $E$. wickhami. This is not a staple nor a specific character, but is observed as peculiar to the male of certain species, but not in all forms of those species; it is seen in the caudate forms of E. eschscholtai and luca, in armata and in the elongate form of dentipes; other males of the same species have the metatibiæ perfectly straight, some have them arcuate in basal half but not abruptly dilated apically.

Individuals of many species exhibit what must be considered as a normal tibial arcuation, which must be distinguished from a common fortuitous arcuateness; the latter usually appears exaggerated and is generally a part of a general abnormal habitus, and it frequently accompanies unusual shortness of the legs.

ANALYTICAL KEY TO SUBGENERA OF ELEODES.

The genus Eleodes may be subdivided by clearly defined female genital characters into the following subgenera:

Internal lobe of the valvular apex well developed, membranous, although frequently chitinous; external lobe obsolete; appendage directed backward and outward

External apical lobe well developed, always membranous; internal lobe feebly developed; appendage directed backward and inward______Melaneleodes.

1. Superior pudendal membrane not broadly exposed $-2$ Superior pudendal membrane broadly or fully exposed; body and apical lobe of-valve fully chitinized; appendage minute______teneleodes.

2. Appendages present, apical lobe defined from body of the valve____________3 Appendages obsolete; apical lobe not defined from body of the valve.

Heteropromus.

3. Appendages moderate in size, subconical to semiellipsoidal and flattened; inferior margins of the valves not contiguous throughout their entire length but separated by a fusiform genital fissure

Appendages minute and punctiform; inferior margins of the valves contiguous throughout; genital fissure closed_______-________Discogenia.

4. Apical lobe subacute, triangular, membranous or more or less semichitinized 
Apical lobe rounded at apex, depressed, well chitinized, more or less concave beneath, convex above______ Metablapylis.

5. Dorsal plate variable in form, not broadened externally, finely, very sparsely punctate, more or less feebly and very sparsely pubescent____________6

Dorsal plate broadened externally, margin strongly arcuate, rather coarsely punctate and sparsely clothed with rather long flying hairs on outer moiety Promus.

6. Submarginal groove not visible from above; surface of dorsal plate at most but feebly concave, generally plane

Submarginal groove dorsal or visible at some point from above; surface of dorsal plate more or less deeply concave

Eleodes.

7. Superior outline of genital segment quadrate, triangulo-parabolic to parabolic $--8$

Superior outline more or less triangular.

Outline triangular; dorsal plate oblong-triangular, external border at most but slightly arcuate, internal border not strongly arcuate at base

Blapylis.

Outline subequilaterally triangular; external border of dorsal plate arcuate, angle obsolete; superior membrane reaching to middle of dorsal plate Tricheleodes.

8. Superior outline of genital segment quadrate to triangulo-parabolic; superior membrane variable in length; dorsal plate oval-oblong, internal border reflexed and impunctate; external border more or less arcuate, angle evident; apex small and membranous; appendage large, more or less semielliptical to subconical, depressed Litheleodes.

Superior outline parabolic, short; dorsal plate subovate, extending upon the apical lobe beyond the appendage, sides not reflexed; appendage short, projecting from beneath the outer border of the apical margin of dorsal plate; genital fissure subapical

Pseudeleodes.

The student must bear in mind in resorting to the use of the above table that care must be taken to familiarize himself with the general structure of the genital segment.

Besides the distinct generic differences there are in each subgenus specific characters which can only be worked out positively with large series, and, while of scientific interest, would not be of practical importance in the separation of species.

The male genital characters may be summarized as follows:

Apicale of the edeagophore broadly triangular, depressed on dorsum and more or less broadly membranous centrally; apex Steneleodes. more or less rounded Metablapylis.

Apicale triangular and slightly elongate, convex dorsally; apex more or less produced and subacute.

Dorsum with an evident median, more or less membranous
groove $\left\{\begin{array}{l}\text { Melaneleodes } \\ \text { Eleodes. } \\ \text { Litheleodes. } \\ \text { Promus. }\end{array}\right.$

Dorsum without median groove, except in tibialis Blapylis. 
SYNOPSIS OF GENERAL SUBGENERIC CHARACTERS.

Anterior femora at least, armed in both sexes (except in caudifera and longipilosa where the teeth are abortive) Eleodes. Anterior femora armed only in the male or mutic.

Anterior tibial spurs dissimilar in the sexes; femora mutic_Melaneleodzs. Anterior tibial spurs similar in the sexes.

Tarsi similar in the sexes, or nearly so.

Middle lobe of the mentum large, lateral lobes rudimentary, invisible without dissection; anterior tarsi with first joint more or less slightly thickened at tip beneath; anterior femora armed or sinuate Discogenia.

Middle lobe of the mentum small; anterior tarsi comparatively simple beneath, groove entire.

Lateral lobes of the mentum fully exposed; sculpturing comparatively simple; femora mutic. Metablapylis.

Lateral lobes moderately exposed; species opaque to shining; elytra tuberculate; anterior femora not sinuate, mutic.

Pseudeleodes.

Anterior tarsi dissimilar in the sexes.

Species pubescent throughout.

Hairs long and flying; femora mutic; anterior tarsi with first joint scarcely produced ventro-apically, ventro-apical spinules noticeably produced in the female, not so in the male; plantar grooves distinct

Tricheleodes.

Hairs short, yellowish and recumbent; form oval, opaque, subdepressed Heteropromus.

Species not usually pubescent, rarely so.

Form elongate, usually large; first joint of the anterior tarsi slightly thickened at tip beneath, bearing a small transverse tuft of yellowish or brownish modified spinules which interrupt the groove in the male; simple in the female.

Steneleodes.

Form ovate or fusiform; the first one or two joints of anterior tarsi in the male more or less thickened and sometimes flattened beneath, densely clothed with fine pubescence; tarsi simple and unmodified in the female; anterior femora armed or mutic. Promus.

Form short ovate, moderate in size to small, robust (elongate and depressed in tibialis); anterior tarsi of the male with first two or three joints feebly thickened at tip beneath and clothed with dense silken or brownish pubescent tufts, obliterating the groove; joints simple with grooves entire in female; femora mutic. Blapylis.

Form ovate, moderate in size, less robust; first joint of the anterior tarsi more or less thickened and slightly more prominent ventrally than the others, pubescent tuft variable, most evident in extricata; in the male first joint with a minute tuft of silken pubescence at tip beneath__Litheleodes. 


\section{Subgenus MELANELEODES, new.}

Anterior spurs of the anterior tibiæ dissimiliar in the sexes, and more or less curved. Longer and slightly thicker than the posterior in the male; notably longer, much broader and stouter and most strongly curved in the female.

In the males of humeralis and rileyi the anterior spurs are much more strongly developed than in the same sex of the other species of the subgenus.

The anterior femora are mutic and the first joint of the anterior tarsi is more or less thickened and feebly produced at tip beneath in both sexes. The male generally has a minute pencil of yellowish or brownish modified spinules on the produced tip; this is surrounded by a few closely placed, ordinary piceous spinules; in the female the produced tip bears only a few ordinary spinules.

Subgeneric genital characters-Male.-Apicale of the edeagophore triangular, distinctly longer than wide, more or less convex above, with a more or less well marked semimembranous median groove; apex more or less acute and rather attenuated; base more or less lobed at middle.

The membrane closing the interlobar sinus of the sternite is always more or less sparsely setose across the bottom of the sinus. This character is rarely observed in any other subgenus.

Female.-Genital segment quadrate to trapezoidal. Each valve has the dorsal plate oblong and more or less distinctly explanate externally. The external tobe of apex is strongly developed, the internal small and rudimentary. The appendage is mammilliform, rarely visible from above, and directed backward and inwards.

Superior pudendal membrane is longitudinally rugulose, reaching apically to the base of the internal apical lobe.

The greater development of the external lobe of the apex is the most distinctive subgeneric character and is not observed in any other division of the genus Eleodes.

I can not at present devise a scheme by which the genital characters can be used in the diagnosis of species; they apparently vary sufficiently to obscure the few constant specific characters.

Variations.-The individuals constituting the specific aggregations of the present subgenus are particularly prone to pronotal variations. This apparent instability is due to the degree to which the pronotal sides are arcuately deflexed, and a certain amount to the degree to which the extreme margin is carried downward and more or less inflexed against the propleuræ as it were. The actual marginal curve is quite constant in each species making up Group I. 
Morphologically the pronotum is widest at the middle in both sexes; but in the female there is a stronger lateral declivity, with a varying amount of lateral compression behind the middle to make the sides appear more or less straight from middle to base; conversely, there is less deflexion anterior to the middle so that individuals of the same species and sex may be more or less strongly arcuate before the middle. In humeralis there is less deflexion than in any other species of Melaneleodes, the marginal bead being nearly always visible in the typical form when the pronotum is viewed vertically from above.

The degree to which the angles are deflexed also gives a varying aspect to the pronotum. By a careful study of the different species in this respect the student will observe that really the pronotum is broadly, evenly, and rather strongly arcuate in the anterior twothirds and thence to base more or less feebly sinuate.

The above remarks apply to what I call a normal subgeneric variability.

Certain fortuitous deviations do occur which are not always easy to explain. The unique specimen described by me a number of years ago as interrupta is a case in point where environment has given evidence of lusus naturee.

The legs vary considerably in regard to length and stoutness of the different segments; sometimes these variations depend upon certain inherent traits of ancestral or developmental origin, constituting an abnormal condition in the relative proportions of the appendages and body. These evasive factors may affect any appendage or somitic part, and a student must bear these data in mind when dealing with the diagnosis of species or referring specimens to their place in the schema taxonomioum.

On account of this variability within specific limits, I have given attention to the general relative proportions of parts under each species. I have been induced to do this from the extraordinary large series of specimens at hand.

Distribution.-The species of Melaneleodes inhabit the following States and countries: Texas, New Mexico, Arizona, Colorado, Nebraska, Kansas, Oklahoma, Montana, South Dakota, California, Lower California, Washington, Oregon, Idaho, Nevada, Utah, Indian Territory, British America (Medicine Hat, Riley) (?), Mexico (see humeralis and quadricollis), Iowa, Wyoming.

Distributed through 19 States out of the 23 west of the Mississippi River. I have no record of specimens from Missouri, Arkansas, Minnesota, and Louisiana. I expect to hear of their occurrence in one or more of those regions. 
Diagram showing distribution.

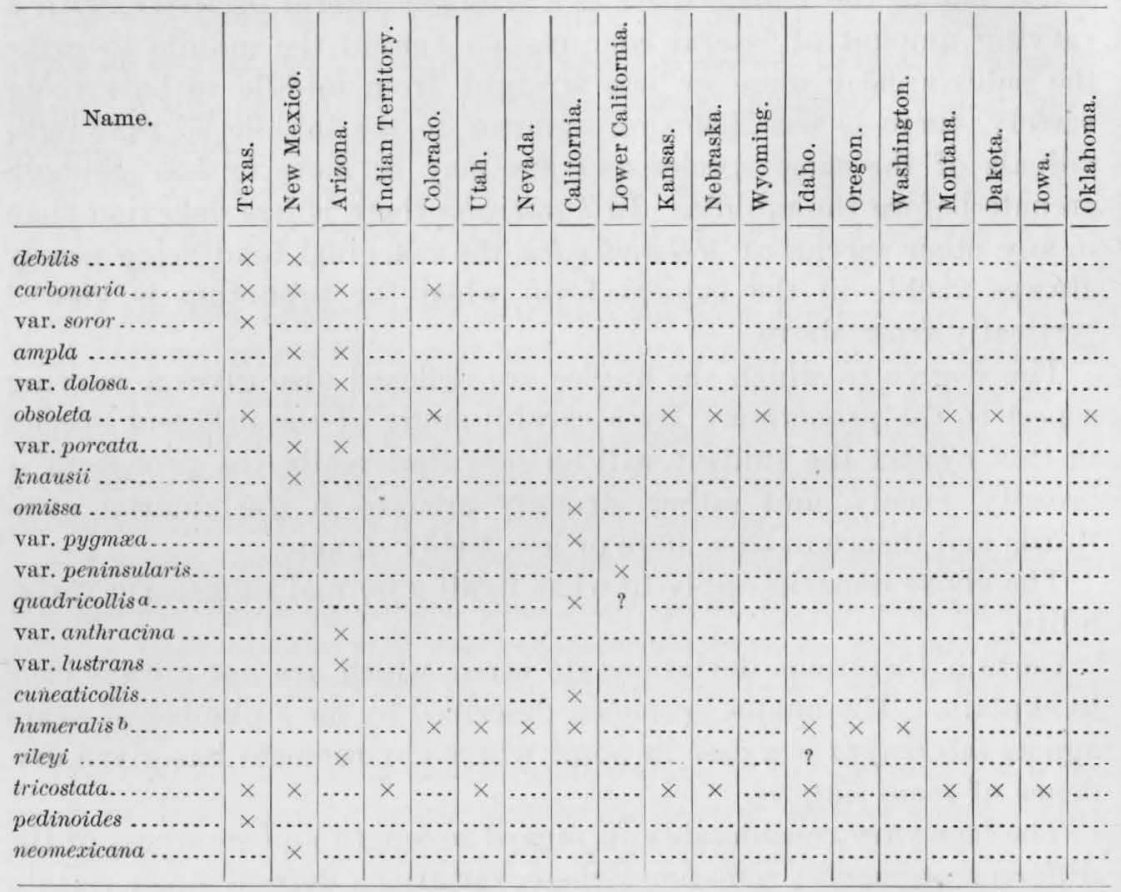

${ }^{a}$ Quadricollis.-Sonora, Mexico. In the Biologia Cent. America (Vol. IV, Pt. 1, p. 80) the author writes that he had seen specimens from Mexico. They probably belonged to a race or a elosely related species. I have not seen an authentic example from Lower California. A specimen so given by Dr. George Horn-and examined by me-is probably a closely related species (Proc. Cal. Acad. Sciences, 2d ser., IV, Pt. 1, p. 350). The specimen was anatomically defective and has since been destroyed.

${ }^{b}$ Humeralis.-Mexico ? In the Biologia (reference as above) the author writes: "There is an example of this species in Mr. F. Bates's collection labeled as from Mexico; possibly some mistake about the locality." I agree with this.

Dr. George Horn, in the Proc. Cal. Acad. Sciences, 2 d ser., IV, Pt. 1, p. 350, gives this species as occurring at Sierra Laguna, San Francisquito, La Chuparosa, and San José del Cabo, Lower California. I have studied these specimens in the collection of the academy and find them not humeralis at all. (See tibialis.)

Genealogy.-In the accompanying diagram I have presented my present views regarding the descent and relationships of the species and races of the subgenus Melaneleodes.

From the subgeneric trunk divergence occurred along the lines of Groups I and II.

In Group I the principal divergence is manifest in the calcarine development as set forth for the Carbonaria and Quadricollis sections.

In the Quadricollis section the calcarine modification is most strongly perpetuated, the specific differentiation resulting in the modification of surface sculpturing, cuneaticollis being intermediate between quadricollis and humeralis, but retaining greater affinity with 
the former; antennal modification resulted in racial divergence in quadricollis, while greater calcarine development characterized the humeralis ramus.

In the Carbonaria section crural development seems to have taken place, not affecting the main carbonaria stem where surface sculpturing has undergone modification along two lines, the smooth and the asperate as indicated in the synopsis of the species.

Group I appears to be very plastic and reactive to modifying forces; Group II less so. In Group I there is evidence of greater specific and racial differentiations.

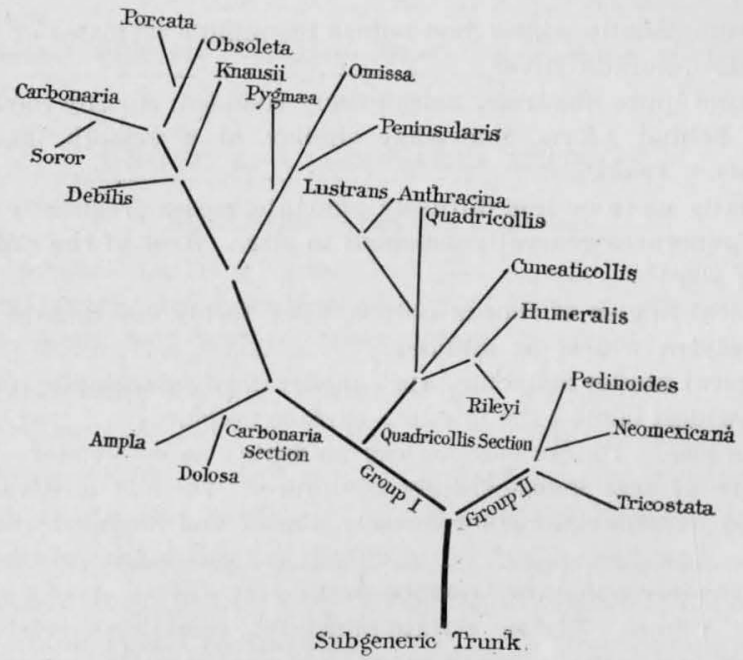

Fig. 1. Genfalogical digram of the subgents melanelodes.

The species of the present subgenus may be divided into two groups as follows:

Elytra elongate oval, convex, comparatively narrow, feebly emarginate at base, humeral angles not rectangular; thorax not conspicuously broadened at base, angles obtuse, not overlapping humeral angles of elytra, more or less arcuately declivous at the sides, marginal bead rarely entirely visible when viewed vertically from above Group I.

Elytra broad, flattened, truncate at base, humeral angles rectangular; thorax conspicuously broadened at base, angles rectangular, overlapping the humeral angles of the elytra; pronotum but slightly arcuately declivous at the sides, marginal bead distinctly visible from above Group II.

\section{Group I may again be conveniently divided into two sections:}

Anterior spur of anterior tibiæ more or less gradually narrowed from base to apex in both sexes Carbonaria Section.

Anterior spur of anterior tibiæ more or less decidedly thickened in both sexes; gradually narrowing from base to apex in the male; much thickened and subparallel, narrowed more or less gradually beyond the middle third or basal half, subacute or obtusely rounded when worn Quadricollis Section. 
GROUP I. CARBONARIA SECTION.

Legs moderate in length

Legs long; elytra rather more pointed behind_

1. Surface smooth, shining, punctures simple

Surface more strongly sculptured, punctures more or less muricate

2. Smaller species

Larger species

3. Elytra with distinct and rather distant series of moderately sized punctures, with a single interstitial series of irregularly spaced, fine punctures (form similar to extricata)

debilis.

4. Elytra with distinct series of rather coarse punctures, punctuation never diffuse.

Pronotum usially widest just before the middle (females at least). East of the Colorado River.

carbonaria.

Pronotum quite quadrate, sides evenly rounded, equally narrowed before and behind (form somewhat similar to a smooth, finely punctate goryi). Texas _______._. soror.

Elytra usually more or less diffusely punctate, series frequently more or less evident, punctures generally subequal in size. West of the Colorado River.

Larger size:

Apical angles of thorax obtuse, apex feebly emarginate or truncate; elytra widest at middle omissa.

Apical angles subacute, apex moderately emarginate; elytra usually widest behind the middle; surface polished______var. peninsularis.

Smaller size. Thorax more or less quadrate; males.slender_-var. pygmoxa.

5. Elytra more or less subasperately sculptured; surface moderately shining, punctures irregularly, rather densely placed and submuricate, rarely substriate knausii.

Elytra muricately punctate; surface dull.

Rather robust. Elytra striato-punctate; sometimes estriate and dif-

fusely punctate; intervals more or less moderately convex _-_obsoleta.

More elongate. Elytra sulcate, intervals strongly convex

6. Surface more or less opaque throughout; pronotum broader_________ampla. Surface more or less shining, pronotum quadrate and polished_-_-var. dolosa.

GROUP I.-QUADRTCOLLIS SECTION.

Anterior spur of the anterior tibiæ, moderately produced in both sexes_-_-_1 Anterior spur of the anterior tibix, strongly produced in both sexes (less in the male)

1. Elytra striato-punctate to diffusely punctate.

Antennæe moderate in length; surface more or less shining; epistoma coarsely and confluently punctate quadricollis.

Antennæ long. Epistoma more finely and not confluently punctate. Larger species; surface dull_____________ar. anthracina.

Smaller species; surface polished and shining_______var. Tustrans.

Elytra with punctures irregularly distributed, without serial arrangement, but producing a strongly rugulose appearance by mutual semicoalescence cuneaticollis.

2. Elongate species_________ 3

Shorter, more robust species_____n 
3. Elytra opaque, densely muricately punctate (Washington) ; frequently granulato-muricately (Nevada and California) or tuberculo-muricately (Colorado) punctured humeralis.

4. Elytra shining, subasparately punctate, punctures rather sparse, often with a feeble lineal arrangement. rileyi.

GROUP II.

Elytra costate 1

Elytra not in the least costate

1. Elytra with alternate interspaces more elevated, at times all quite evenly so; surface opaque

tricostata.

2. Elytra glabrous and shining, with regular striæ of moderately large punctures, interstices equally and very feebly convex; pronotum with basal depressions pedinoides.

Elytra opaque, diffusely punctate; basal depressions of pronotum obsolete -var. neomexicana.

\section{GROUP I.-CARBONARIA SECTION.}

\section{ELEODES DEBILIS LeConte.}

Eleodes debilis.-LeConte, Proc. Nat. Sci. Acad. Phila., 1858, p. 185.Horn, Trans. Amer. Philos. Soc., XIV, 1870, p. 3008.-CaseY, Annals N. Y. Acad. Sci., V, Nov., 1890, p. 396.

Ovate, moderately robust, glabrous and shining.

Head twice as wide as long, feebly convex, rather coarsely punctate, punctures very sparse on the vertex, denser on the epistoma; surface more or less impressed laterally and along the frontal suture. $A n$ tennce moderate, reaching to the base of the prothorax, subequal in the sexes, outer four joints very feebly compressed, scarcely dilated, third joint about equal to the next two taken together, fourth hardly longer than the fifth, the latter, sixth and seventh subequal, eighth feebly triangular, ninth and tenth suborbicular, scarcely transverse, eleventh ovate.

Pronotum subquadrate, widest at the middle, about one-fifth to one-third wider than long; disc rather strongly and evenly convex from side to side, feebly so antero-posteriorly and more or less declivous at the apical angles, finely and sparsely punctulate, rather more strongly so laterally; apex feebly and evenly emarginate, usually obsoletely margined; sides converging a little anteriorly, rather evenly and moderately arcuate in apical two-thirds, thence to base obliquely straight or feebly sinuate, finely margined; base rather broadly rounded and finely margined, about a third wider than the apex; apical angles subacute; basal angles obtuse.

Propleuræ smooth, sparsely and more or less obsoletely punctulate, slightly rugulose.

Elytra oval, widest at the middle, about a third longer than wide; base broadly and very feebly emarginate, scarcely wider than the 
contiguous base of the prothorax; humeri more or less acute; sides evenly arcuate, apex obtusely and narrowly rounded; disc evenly and moderately convex, laterally more strongly rounded, evenly and quite strongly arcuately declivous posteriorly, punctate, punctures slightly separated, moderate sized and arranged in rather distant series; intervals flat with a single series of irregularly spaced and usually fine punctures, both series becoming more or less confused at the sides and apex.

Epipleurce moderate in width, superior margin feebly sinuate beneath the humeri, very gradually narrowing to apex; surface glabrous and more or less finely and sparsely punctulate.

Sterna more or less glabrous, irregularly and more or less densely punctate, rugulose.

Parapleurce rather coarsely and somewhat densely punctate.

Abdomen shining and glabrous, sparsely, and finely punctulate, more or less rugulose.

Legs moderate. Anterior femora mutic in the sexes; anterior tibial spurs slightly dissimilar; first joint of the anterior tarsi produced at tip beneath and feebly dissimilar in the sexes.

Male.-Slightly robust. Thorax quite quadrate; abdomen subhorizontal, first two segments more or less broadly impressed at middle, intercoxal process slightly concave; anterior tibial spurs comparatively small and slender, the anterior one scarcely widened. First joint of the anterior tarsi with a minute pencil of brownish modified spinules surrounded by dark spinules on produced tip beneath.

Female.-Moderately robust. Thorax slightly transverse. Abdomen horizontal and rather strongly convex. Anterior tibial spurs a little larger and longer, the anterior spur slightly widened but gradually narrowed from base to apex. First joint of the anterior tarsi with dark spinules on the produced tip beneath.

Measurements.--Males: Length, 12-13 mm.; width, $5.5 \mathrm{~mm}$. Females: Length, 12.8-14.8 mm.; width, 6-6.5 mm.

Genital characters, male.-Edeagophore elongate oval, acutely pointed at the apical extremity and slightly arched.

Basate oblong, evenly convex, sides slightly arcuate.

A picale triangular, rather evenly convex above, with a narrow median membranous groove at the middle third; sides feebly arcuate at base, thence broadly and more or less strongly sinuate to apex, the latter appearing attenuated; base strongly and moderately narrowly arcuate at middle, laterally broadly sinuate.

Sternite rather short and transversely parabolic. Each lobe with the external border evenly arcuate to apex, the latter narrowly rounded; internal border oblique; surface feebly convex, shining. 
very sparsely punctate and setose apically, setæ moderately short. Sinus triangular, membrane slightly setose at bottom.

Female.-Genital segment quadrate, valves reflexed at the sides, setose, glabrous and shining.

Valvula (Plate 4, fig. 26).--Dorsal plate oblong, explanate externally and slightly deflexed, internally reflexed and impunctate in apical half; surface convex externally, very sparsely punctate, punctures denser on convexity, each with a long seta; external margin straight; angle rectangular and prominent, sometimes feebly rounded, with a few moderately long setæ; apical margin squarely truncate to moderately and arcuately produced in outer half, more or less sinuate over the appendage; internal margin more or less arcuate. Apex short, triangular and acute, set with a few moderately long setæ.

Appendage (cercopod) short and moderate in size, conical or feebly depressed, bearing moderately long setæ.

Basal prominences not evident.

Superior pudendal membrane feebly and distinctly longitudinally rugulose, reaching to about the middle of the dorsal plate.

Ventrolateral surface moderately convex, scarcely concave before the apex; submarginal groove broad and shallow beneath the explanate external border of dorsal plate; surface finely punctate and setose, setæ minute. The internal borders of the valvulæ are contiguous in basal sixth; genital fissure fusiform and moderately wide, with the inferior pudendal membrane visible in basal half.

Habitat.-New Mexico (Santa Fé, C. V. Riley) ; Arizona (Sulphur Spring Valley, Hubbard and Schwarz); Texas (Alpine, elevation 4,400-6,000 feet, H. F. Wickham).

Number of specimens studied, 3 males, 6 females.

Type in the LeConte collection.

Type-locality.-New Mexico; collected by Mr. Fendler.

Salient type-characters.-Thorax subquadrate, slightly narrowed anteriorly; sides broadly rounded; apical angles acute, the basal obtuse; base broadly rounded. Elytra oval and convex, strongly declivous posteriorly, not acuminate at apex; base broadly emarginate; humeri acute; disc quite strongly striato-punctate, intervals with a single series of fine punctules (LeConte).

Diagnostic characters.-In size and shape debitis resembles a smooth extricata, from which it differs in having the anterior femora unarmed in both sexes, and by the distinct and rather distant series of moderate punctures, with a single interstitial series of irregularly spaced fine punctures.

The punctuation in debilis somewhat resembles that observed in carbonaria, from which it can be separated by its smaller size and female genital characters; the latter also separates it from all other members of the subgenus. 
A specimen before me has been compared with the LeConte type and pronounced typical by Mr. F. Blanchard.

This species has been considered as identical with carbonaria, and I agree with Col. Thomas Casey ${ }^{a}$ in considering it a distinct species.

The genital characters are somewhat aberrant to the present subgenus, but on account of the greater development of the external lobe of the valvular apex, I have placed it here; the apical margin of the dorsal plate is quite squarely truncate and the appendage more strongly exposed. In all specimens examined the female genital characters were constant.

On account of the homogeneous structure exhibited by the small series before me, I am unable to indicate with any feeling of certainty, its relationships and descent. A large series illustrating the lines of variation is necessary for this purpose. I might tentatively suggest that debilis may tend toward the subgenus Promus. I would about as soon accept this postulate as to consider it identical with carbonaria.

The mentum ${ }^{b}$ is moderate in size, and more or less triangulotrapezoidal in outline; surface rather coarsely and somewhat densely punctate, laterally with rather broad, shallow, and subfoveate impressions, with a median longitudinal subcariniform convexity; each puncture bears a short inconspicuous seta.

The prosternum between the coxæ is rather prominent ventrally, convex to nearly horizontal and mucronate behind. The mucro is variable in size, sometimes pointed and at others broad and obtusely rounded.

The mesosternum is more or less arcuately oblique and concave.

The intercoxal process of the first ${ }^{c}$ abdominal segment is slightly transverse and equal in length to the post-coxal portion. The metasternal salient is about two-sevenths narrower than the abdominal process.

In the male the second abdominal segment is equal in length to the post-coxal part of the first and about a third of its length longer than the third segment, the latter being about a fourth of its own length longer than the fourth segment.

In the female the second segment is noticeably longer, being about a fourth of its own length longer than the post-coxal part of the first. The fourth is about half as long as the second, while the third is about a fourth of its own length longer than the fourth.

The profemora are somewhat tumid externally, the tibial grooves are well developed, concave, and glabrous, margins subcariniform, converging and meeting at basal third.

${ }^{a}$ VII. Coleopterological Notices, II, Oct. 6, 1890, p. 396.

$b$ The mentum refers to the middle lobe unless otherwise stated.

$c$ In all descriptive remarks only the visible segments are considered. 
The meso- and metafemora are each subequal in width, the former is scarcely compressed, the latter distinctly so. The tibial grooves have their margins feebly subcariniform and gradually converging to become contiguous and evanescent at basal thirds.

The protibiæ are feebly compressed; all the tibiæ are without tarsal grooves, and muricately sculptured.

The tarsi are moderate in length and comparatively slender. The protarsi are about a fourth of their length shorter than a mesotarsus; first four joints subequal in width; the second, third, and fourth are about as long as wide, the fourth slightly smaller than the third; the fifth is about as long as the preceding three taken together; the first is longer than wide, and rapidly narrowing to the base.

The mesotarsi are about a fifth of their length shorter than a metatarsus. First four joints are subequal in width, gradually and slightly diminishing in length from the second to the fourth. Joints one and five are each separately subequal to the combined lengths of the second and third.

The metatarsi are about two-fifths of their length shorter than their metatibiæ. The fourth joint is about equal to the combined lengths of the second and third; the first is a little longer than the same, and the second is just a little longer than the third.

The comparative tarsal measurements were made on the female.

\section{ELEODES CARBONARIA (Say).}

Blaps carbonaria SAY, Journ. Acad. Nat. Sci. Phila., III, 1823, p. 260.

Eleodes carbonaria LeConte, Complete Writings of Thomas Say, II, 1859, p. 125 ; Proc. Acad. Nat. Sci. Phila., 1851, p. 181.-Honn, Trans. Amer. Phil. Soc., XIV, 1870, p. 308.-Champion, Biol: Centr.-Amer., IV, Pt. 1, 1884, p. 308.-Casey, Annals N. Y. Acad. Sci., V, Nov., 1890, p. 395.

Eleodes soror LeConte, Proc. Acad. Nat. Sci. Phila., 1858, p. 185.

Eleodes immunis LeConte, Proc. Acad. Nat. Sci. Phila., 1858, p. 186.Honn, Trans. Amer. Phil. Soc., XIV, 1870, p. 308.

Oblong-ovate, moderately elongate, smooth, more or less shining, estriate, elytral punctures arranged in series.

Head twice as wide as long, more or less convex, rather densely and irregularly punctate, punctures denser anteriorly, sparser about vertex, surface more or less impressed along the frontal suture and laterally. Antenne moderately long, reaching to or very slightly beyond the base of the prothorax, subequal in the sexes, outer four joints feebly compressed, just perceptibly dilated, third joint about equal to the next two taken together, fourth just noticeably longer than the fifth, the latter, sixth and seventh subequal, eighth triangular and as wide as long; ninth and tenth more or less feebly transversely oval; eleventh ovate.

Pronotum subquadrate, widest at or a little in advance of the middle, and about one-fifth to one-third wider than long; disc evenly 
and moderately convex, more or less arcuately declivous laterally and at the apical angles, finely and sparsely punctulate, punctures slightly denser and coarser along the margins laterally; apex slightly emarginate or truncate, finely or more or less obsoletely margined; sides evenly and more or less moderately arcuate from base to apex, or more strongly arcuate in the anterior two-thirds, and thence to base oblique and convergent, or very feebly arcuate, sometimes obsoletely sinuate, finely beaded; base feebly arcuate, finely to more or less obsoletely margined, and one-fifth to one-fourth wider than the apex; apical angles distinct, scarcely at all rounded; basal angles obtuse.

Propleurce finely and very sparsely submuricately punctate and more or less distinctly rugulose.

Elytra oval, widest at the middle, less than twice as long as wide; base slightly emarginate, more or less feebly sinuate laterally, a little wider than or equal to the contiguous base of the prothorax; humeri subacute or feebly obtuse; sides evenly arcuate, apex obtuse; dise moderately convex on the dorsum, at times slightly depressed, laterally quite strongly and evenly rounded, evenly and arcuately declivous posteriorly, serially punctate, strial punctures usually rather large and somewhat deeply impressed, at times rather small and not impressed, the individual punctures are usually more distant from each other than their own diameters; intervals flat, frequently feebly convex, with a single series of very small, distantly and irregularly spaced punctures; laterally the interstitial punctures become larger, and both series more or less irregular and somewhat confused.

Epipleure gradually narrowing from base to apex, superior margin feebly sinuate beneath the humeri; surface finely to obsoletely or distinctly and sparsely punctate.

Sterna shining to subopaque, finely and rather densely punctate, at times rugulose.

Parapleura rather coarsely and quite densely punctate.

Abdomen more or less glabrous, finely and sparsely punctulate, first segment more strongly sculptured; surface obsoletely to distinctly rugulose.

Legs moderate. Anterior femora mutic in the sexes; anterior tibial spurs and tarsi slightly dissimilar in the sexes.

Male.-Body comparatively slender. Elytra rather gradually narrowed and evenly arcuato-obliquely declivous posteriorly. Abdomen slightly oblique, very moderately convex, first two segments more or less impressed at the middle. Anterior spurs of the anterior tibiæ slightly the stouter, almost twice as long as the posterior and gradually narrowing from base to apex, both comparatively slender and acute. Tarsi distinctly longer than in the female, the anterior with first joint bearing a minute pencil of brownish modified spinules, surrounded by ordinary piceous spinules on the thickened tip beneath. 
Female.-Body quite robust. Elytra rather broadly oval, rounded and more or less arcuately and vertically declivous posteriorly. Abdomen horizontal, evenly and rather strongly convex. Anterior spurs of the anterior tibiæ distinctly the stouter, more gradually narrowing from base to apex and about a third longer than the posterior. First joint of the anterior tarsi transversely clothed with ordinary spinules on thickened tip beneath.

The material before me and referred to the present species is quite variable and presents a number of incipient races, of which three may be recognized to aid in the placing of specimens:

Forma glabra.- Smooth and shining. Elytral punctures fine and not impressed, with a tendency to some irregularity on the disc, intervals flat.

Forma typica.-Elytra with rows of rather large, impressed and distinctly defined punctures, intervals flat.

Forma interstitialis.-Elytra with very strongly impressed punctures, intervals feebly convex.

The above forms or incipient races are connected by an abundance of mesotypes and when properly arranged make an instructive morphological series.

Measurements.-Males: Length, 15.8-18 mm.; width, 5.5-6.5 mm. Females: Length, 17-20.5 mm.; width, 7.8-9 mm.

Genital characters, male.-Edeagophore rather elongate, fusiform, somewhat strongly arched and well chitinized.

Basale oblong, rather strongly convex and more or less gibbous basally; sides evenly and rather moderately arcuate.

A picale triangular and feebly elongate; surface evenly convex, with a median longitudinal groove extending from near the apex to near the base, membranous in apical half, linear towards base; sides broadly and very feebly sinuate at middle third, apex subacute; base broadly and arcuately lobed at middle, very feebly sinuate laterally.

Sternite parabolic in outline and slightly transverse. Each lobe with the external border more or less evenly arcuate, apex more or less evenly rounded, angle feebly evident at times; internal border short; surface rather evenly convex and glabrous, quite coarsely and densely punctate apically, more sparsely so towards base, setose, setæ moderate in length, longer about apex, and not very dense.

Sinus short, with the membrane very sparsely setose at bottom.

Female.-Genital segment quadrato-trapezoidal, somewhat depressed and setose.

Valvula (Plate 3, fig. 16).-Dorsal plate oblong, sometimes slightly widened at base, frequently deflexed apically, gradually explanate externally from basal third to apical margin with which it is directly continuous; surface plane, finely to rather coarsely and sparsely punctate, setose, setæ rather short; external border feebly sinuous to 
scarcely arcuate; apical margin not defined from the external apical lobe.

Apex with the outer lobe well developed, the latter three-fourths as wide as the dorsal plate, rather broadly rounded and slightly semimembranous at tip; internal lobe small and membranous; both lobes set with long flying setæ.

Appendage short and more or less conical, sometimes slightly visible from above, directed backwards and slightly inwards. Fossa moderate and fringed with moderately long hairs.

Basal prominences moderate.

Superior pudendal membrane longitudinally rugulose and reaching to the side of the internal lobe of the apex.

Ventrolateral surface rather short, not strongly convex, but more or less gradually sloping to the apex, not usually transversely impressed but sometimes more or less so just behind the narrow transverse basal convexity; submarginal groove well defined beneath the explanate external border of the dorsal plate, not markedly bending inwards at apex to fossa; surfaces finely and sparsely punctate, setose, setæ very short, at apex short and flying. Internal margins of the valvulæ contiguous for a very short distance both at base and apex; genital fissure broadly fusiform, with basal half closed by the inferior pudendal membrane.

Remarls on female genital characters.-Forma glabra has the genital segment quadrate in outline and more thickly setose at apex, with the basal convexities more strongly developed. Forma interstitialis has the dorsal plate more strongly and coarsely punctate.

Mabitat.-Forma typica.-Texas (Alpine, June, elevation 1,4006,000 feet, H. F. Wickham; Uvalde, elevation 930 feet; Granjino, May; Marfa, elevation 4,600-4,800 feet, July, Wickham); New Mexico (Albuquerque, March, Wickham; Santa Fe Canyon, August, elevation, 7,000 feet, F. H. Snow); Arizona (Fort Grant; Oak Creek Canyon, Snow) ; Colorado (La Junta, Garland, Pleasant Valley, on the Arkansas River, Snow; Wickham's List).

Forma glabra.-Texas; New Mexico (Highrolls, May and August; Cloudcroft, June, Warren Knaus); Colorado (Garland, June; Salida); Arizona (Chiricahua Mountains, May; Sulphur Springs Valley, June).

Forma interstitialis.-Texas (El Paso, July, elevation 3,700-3,800 feet, Wickham) ; New Mexico (Deming, July, Hubbard and Schwarz; Luna; Albuquerque, March) ; Arizona (San Simon, July; Sulphur Spring Valley, May; Tucson, April; Chiricahua Mountains, May, Hubbard and Schwarz).

Number of specimens studied, 100.

Type destroyed. 
Type-locality as given by Thomas Say: "Region of the Arkansas River and near the Rocky Mountains."

Salient type-characters.-Thorax subquadrate; sides regularly arcuate; apex very slightly emarginate; base nearly rectilinear, a little arcuate each side near the angles, the latter obtuse. Elytra without impressed strix; six regular series of punctures, which are more distant from each other than the length of their diameters; interstitial lines with a few remote, acute, minute punctures; sides rounded and irregularly punctured (Say).

Diagnostic characters.-Easily recognized from the other members of the subgenus by the smooth polished surface, the elytra being sculptured with rather distantly placed series of coarse punctures; the intervals are flat, with a single series of small distantly spaced punctures. At times the punctures of both series may be equal in size, and the species is then with some difficulty separated from omissa (see p. 72 and forma glabra); typically the intervals are flat, but often become feebly convex and approach porcata (see p. 63 and forma interstitialis). The extreme heterotypical specimens are apt to have a subasperate punctuation.

Immunis LeConte appears to be a true synonym, probably more closely related to var. soror. (See p. 50.)

The mentum is moderate in size, triangulo-trapezoidal to parabolotriangular in outline; surface rather broadly foveate laterally with a median longitudinal ridge, sometimes feebly sculptured, more or less strongly punctate and not noticeably bearded.

The prosternum is variable; frequently continuously rounded between the coxæ and behind, but not with the precoxal portion, not mucronate; often almost horizontally produced, at other times convex between the coxæ and with a more or less strongly developed mucro behind.

The mesosternum at times is quite vertically declivous, at others oblique and more or less feebly concave.

The metasternal process is as wide as the abdominal salient is long.

The abdominal intercoxal process (male) is slightly transverse, a little wider than the metasternal salient, and equal to the postcoxal portion; the latter is also equal in length to the second segment; the third segment is one-third of its length longer than the fourth.

In the female the abdominal process is quadrate, and about a fifth of its width wider than the metasternal salient, and equal in length to the second segment; the latter is about twice as long as the fourth; the third segment is equal in length to the post-coxal part of the first.

59780-Bull. $63-09-4$ 
The profemora (male) are clavate, gradually tumid externally and subcylindrical in section; less so in the female and frequently somewhat compressed. The tibial grooves are more or less well defined by subcariniform margins which become contiguous and evanescent at basal fourth; the floors of the grooves are usually concave, glabrous or sometimes minutely subasperate.

In both sexes the mesofemora are subtumid at middle, with the grooves rather narrow and limited by subasperulate margins, which are more or less evanescent before becoming contiguous at basal third.

The sexes have the metafemora usually just noticeably widening from base to apex; grooves as on the mesofemora.

The protibia are frequently subarcuate, feebly compressed. All the tibiæ are without tarsal grooves and more or less muricate; the articular cavities are closed.

The tarsi are moderate in length and stoutness. The protarsi are about a half of their length shorter than a mesotarsus. Joints two, three, and four are subequal, and combined subequal to the fifth; the first is longer than wide.

The mesotarsi are subequal to (male) or a seventh of their length shorter than (female) a metatarsus. Joints one and five subequal in length, either one is subequal to the combined lengths of the third and fourth; joints two to four subequal in width and length, or just feebly diminishing in length in the order named.

The metatarsi are about a third of their length shorter than a metatibia. The third joint is slightly shorter than the second, both combined about equal in length to the fourth; first joint equal to the combined lengths of joints two, three, and four of a mesotarsus.

\section{ELEODES CARBONARIA var. SOROR LeConte.}

Form as in carbonaria, smooth and more or less feebly shining, sides of the pronotum apparently evenly arcuate; elytral punctures usually moderately small.

Head twice as wide as long, more or less moderately convex, somewhat coarsely, irregularly, and sparsely punctate, punctures slightly denser on the epistoma; surface usually impressed laterally. $A n$ tenna moderate in length, reaching to the base of the prothorax, subequal in the sexes, outer three joints scarcely compressed or dilated, third joint about equal to the next two taken together, the fourth very slightly longer than the fifth, the latter, sixth, and seventh subequal, eighth subtriangular, and slightly shorter than the seventh, ninth and tenth suborbicular, eleventh subovate.

Pronotum quadrate, widest at the middle, where it is one-eighth to one-sixth wider than long, slightly narrowed before and behind; disc moderately convex, quite strongly and arcuately declivous along 
the lateral margins, finely and sparsely punctulate; apex subtruncate and more or less obsoletely margined; sides evenly, broadly and moderately arcuate from base to apex when viewed vertically from above, more strongly so in the anterior three-fourths when viewed obliquely from the side and obsoletely sinuate before the basal angles, margin finely beaded; base broadly arcuate, quite finely margined, and about one-fourth to one-third wider than the apex; apical angles more or less subacute; basal angles obtuse.

Propleurce smooth, finely and sparsely punctulate, more or less sparsely rugulose.

Elytra oval, widest at the middle, rather strongly emarginate at the base and equal to or a little wider than the contiguous base of the prothorax; humeri acute and slightly prominent anteriorly; sides evenly arcuate, apex obtuse and rather narrowly rounded; disc moderately convex on the dorsum, strongly and evenly rounded laterally, evenly and rather strongly arcuately declivous posteriorly, punctate, punctures moderate in size and arranged in moderately distant, scarcely impressed series; intervals more or less irregularly and sparsely punctulate, especially along the suture, laterally the series usually remain distinct.

Epipleurce rather wider than in carbonaria, and gradually narrowing from base to apex; superior margin feebly and broadly sinuate beneath the humeri; surface smooth, sparsely and irregularly punctulate.

Sterna shining, irregularly punctate and more or less rugulose.

Parapleurce irregularly and more or less closely punctate.

Abdomen shining, evenly and sparsely punctate, usually obsoletely rugulose; intercoxal process more strongly sculptured.

Legs moderate as in carbonaria. Anterior femora mutic in the sexes; anterior tibial spurs comparatively small and slightly dissimilar in the sexes, the anterior spur but slightly longer than the posterior. Anterior tarsi with the first joint feebly thickened at tip beneath and slightly dissimilar in the sexes.

Male.-Body moderately slender, elongate-subovate. Elytra gradually narrowing, arcuately and somewhat obliquely declivous posteriorly. Abdomen slightly oblique, moderately convex, more or less broadly impressed at middle of the first two segments, intercoxal process distinctly concave. Anterior spur of the anterior tibiæ gradually narrowing from base to apex. First joint of the anterior tarsi with a small pencil of modified spinules surrounded by ordinary spinules on the thickened tip beneath.

Female.-Body moderately robust. Elytra rather broadly oval, arcuately and somewhat vertically declivous posteriorly. Abdomen horizontal and somewhat strongly convex. Anterior spur of the anterior tibiæ slightly thickened, acute, and gradually narrowing 
from base to apex. First joint of the anterior tarsi set with ordinary spinules on tip beneath.

Measurements.-Males: Length, $16.5 \mathrm{~mm}$; width, $6.5 \mathrm{~mm}$. Females: Length, 18.3-19 mm.; width, 8-8.5 mm.

Genital characters.-Male characters as in carbonaria.

Female.-As in carbonaria, except that the dorsal plate of each valve is narrower, with the sides more parallel and less explanate externally; the outer lobe of the apex is less broadly rounded.

Habitat.-Texas (Eagle Pass and San Antonio, LeConte; Brownsville, Wickham.)

Number of specimens studied, 8.

Type, a female in the LeConte collection.

Type-locality.-Eagle Pass, Texas.

Salient type-characters.-Thorax quadrate, slightly narrowed anteriorly and posteriorly; sides broadly rounded; anterior angles acute, the posterior obtuse. Elytra strongly striato-punctate, intervals sparsely punctate (LeConte).

Diagnostic characters.-On account of the form of the prothorax it somewhat resembles a smooth goryi, and LeConte differentiated it from that species as follows: "The thorax is more quadrate and not more narrowed towards the apex than towards the base; the elytra are more deeply emarginate at base, and transversely much less convex, and those of the female are much less dilated; the punctures are more regular and never have the appearance of foveæ."

All the specimens that I have received have either been labeled goryi or unidentified, and it is undoubtedly confused with that species in collections generally. In all cases of doubt the subgeneric and genital characters must be carefully studied.

The scuplturing of soror is quite like that of a typical carbonaria, except that the serial punctures on the dorsum of the elytra are smaller, although as large or slightly larger and more distinctly defined laterally, the surface is feebly duller, the pronotum more quadrate on account of the strongly deflexed sides of the disc and consequently less strongly rounded when viewed from above, and usually not more narrowed toward the apex than the base, but this character may be variable.

The actual form of the pronotal margin in both sexes is like that of a male carbonaria, widest at the middle and not noticeably more strongly arcuate in the anterior moiety, as in the female of carbonaria.

From the members of the quadricollis section of the present subgenus it is to be known by the form of the anterior spurs of the anterior tibiæ.

I am indebted to Professor Wickham for the specimens in my collection. 
LeConte separated the species described by him as immunis from soror as follows: "Of the same form as soror, but the thorax is more narrowed behind, almost as in E. quadricollis; the punctures of the rows of the elytra are sometimes placed in distinct grooves, while in other specimens the surface is even." (See carbonaria.)

Mr. Blanchard has pronounced my specimens undoubtedly the same as LeConte's type from Eagle Pass, Texas. He also writes that the type and a male from "Texas" have the elytra and under side shining, and two other females from "Texas" are dull.

The mental, sternal, abdominal, and crural characters are as in carbonaria, except that the meso- and metafemora appear to be slightly more slender. The protarsi appear to be subequal in length in the sexes, and the mesotarsi appear relatively slightly shorter.

ELEODES AMPLA, new species.

Subfusiform to fusiform-ovate, subopaque, and smooth.

Head twice as wide as long, more or less moderately convex between the eyes, rather broadly flattened anteriorly, usually feebly impressed laterally, sometimes across base of the epistoma; frontal suture distinct and frequently bisinuate; evenly and sparsely punctate, punctures coarser on the epistoma and finer on the vertex. Antennæ reaching a little beyond the base of the prothorax, very feebly compressed in outer four joints, scarcely dilated, third joint scarcely as long as the next two combined; the fourth, fifth, sixth, and seventh subequal in length; eighth triangular and as long as wide; ninth suborbicular; tenth slightly transversely oval; eleventh oval to ovate, and generally distinctly obliquely truncate at tip.

Pronotum widest at or a little in advance of the middle, about onefourth wider than long; moderately and evenly convex from side to side, feebly so antero-posteriorly, more or less arcuately declivous laterally along the sides; finely and sparsely or almost obsoletely punctulate; apex slightly and evenly emarginate, more or less obsoletely beaded; sides almost evenly arcuate from base to apex when viewed vertically from above, more strongly so in the anterior threefourths, and obsoletely sinuate at basal fourth when viewed obliquely from the side, finely beaded; base quite broadly rounded and more or less feebly sinuate at middle, finely beaded, and about a fourth to a third wider than the apex; apical angles subacute; basal angles obtuse.

Propleurce rather smooth, finely and sparsely punctulate, usually distinctly rugulose.

Elytra oval, less than one-half to about a third longer than wide; base more or less emarginate, frequently sinuate laterally, scarcely to a little wider than the contiguous prothoracic base; humeri subacute, scarcely prominent anteriorly; sides evenly arcuate, apex obtuse and 
rather narrowly rounded; disc more or less moderately convex, sometimes slightly flattened on the dorsum, more strongly and rather evenly rounded laterally, arcuately declivous posteriorly, punctate; the strial punctures are rather small to moderate in size and somewhat closely placed in moderately distant series, usually not at all, but sometimes moderately impressed; intervals flat, rarely slightly convex, and with a single series of rather widely spaced, very fine punctures which at times become slightly irregular, especially laterally and about apex.

Epipleurce moderate in width, gradually narrowing from base to apex, superior margin very broadly and slightly sinuate beneath the humeri; surface smooth, obsoletely to finely and sparsely punctulate.

Sterna more or less shining, strongly punctate, and rugulose.

Parapleurce rather densely, finely, and subscabrously punctate.

$A b d o m e n$ usually shining, sparsely and quite regularly punctulate, more or less rugulose; intercoxal process and fifth segment more strongly sculptured.

Legs long, comparatively moderately stout. Anterior femora mutic and the anterior tibial spurs moderately long, slightly dissimilar in the sexes. Anterior tarsi with the first joint feebly thickened at tip beneath.

Male.-Body moderately slender and more or less fusiform, antennæe reaching a short distance beyond the base of the prothorax. Elytra quite gradually narrowed in posterior fourth, areuately and obliquely declivous. Abdomen distinctly oblique, moderately convex, first two segments more or less impressed at middle, process concave. Anterior spur of anterior tibiæ about a third longer and a little stouter than the posterior, and narrowing moderately from base to apex. First joint of the anterior tarsi with the minute pencil of modified spinules on tip beneath scarcely evident and surrounded by the ordinary spinules.

Female.-Robust. Antennæ reaching just beyond the base of the prothorax. Elytra broadly oval, somewhat gradually narrowed and arcuately declivous posteriorly. Abdomen horizontal and rather strongly convex. Anterior spurs of the anterior tibiæ about a half longer than the posterior and feebly broadened, with sides rather slowly but evenly narrowing to apex, the latter acute. Anterior tarsi with ordinary spinules on the thickened tip beneath, the latter transverse and narrow.

Measurements.-Males: Length, 19-23 mm.; width, 6.5-8.5 mm. Females: Length, 23-25 mm.; width, 6.2-9.5 mm.

Genital characters, male.-Edeagophore elongate, flaxseed-shaped (flattened, oblong-ovate) and more or less arched.

Basale oblong; surface strongly convex towards base; sides feebly arcuate. 
A picale triangular and slightly longer than wide; surface evenly convex, with a narrow median groove in apical half; sides broadly sinuate at the middle, apex gradually narrowed and subacute; base broadly lobed and feebly sinuate laterally.

Sternite transversely parabolic in outline. Each lobe subtriangular with the external border evenly and broadly arcuate, apex rounded but not narrowly; internal border rather short; surface evenly convex, glabrous at basal third, sparsely punctate and setose apically, setæ moderate but longer at apical border. Membrane sparsely setose across the bottom of the sinus.

Female.-Genital segment subquadrate, sometimes slightly deflexed at apex, setose.

Valvula (Plate 4, fig. 27).-Dorsal plate oblong, moderately explanate externally; sides subparallel, and slightly sinous; surface nearly plane, slightly longitudinally concave, glabrous and impunctate in basal third, elsewhere coarsely, sparsely, and irregularly punctate, setose, setæ rather long and reclining; apical margin on external lobe strongly arcuate in outer three-fourths, internally sinuate. Both apical lobes set with long hairs; external lobe large, the internal very small.

Appendage submammilliform and searcely projecting beyond the fossa, hardly visible from above. Fossa rather large.

Basal prominences scarcely evident.

Superior pudendal membrane longitudinally rugulose and reaching about to the base of the internal lobe.

Ventrolateral surface rather strongly convex at base, scarcely to feebly transversely concave before the apex; submarginal groove broad extending beneath the apex to the margin of the fossa. Internal margins of the valves contiguous at basal eighth; fissure broadly fusiform and closed in basal half by the inferior pudendal membrane.

Habitat.-Arizona (Oracle, July 15, Hubbard and Schwarz; Pinal Mountains, collection, University of Nebraska; Santa Rita Mountains, elevation 5,000-8,000 feet, July, F. H. Snow); New Mexico (Santa Fé Canyon, August, elevation 7,000 feet, F. H. Snow); Texas (Brownsville, June, F. H. Snow).

Number of specimens studied, 13.

Type in my own collection.

Type-locality.-Pinal Mountains, Arizona.

Salient type-characters.-Subopaque. Prothorax widest at (male) or in advance (female) of the middle. Elytra noticeably narrowing at apieal fourth in both sexes; striato-punctate, striæ not impressed, strial punctures rather small, the series rather distant, interstitial punctures very fine. Legs long. 
Diagnostic characters.-In collections the females of the present species are usually associated with subnitens, while the males are placed with quadricollis or carbonaria.

On account of its large size and dull integuments ampla has to be carefully differentiated from subnitens, from which it differs in the sides of the pronotum, being more strongly rounded and widest at or in advance of the middle, by the less prominent apical angles, and the subgeneric characters.

Ampla bears no resemblance to a typical carbonaria; the dull luster, fine and unimpressed elytral punctuation readily separates it from the latter species, and besides the males are quite fusiform in outline and the legs are distinctly, longer, characters never observed in carbonaria. A male from Santa Fé canyon, New Mexico, has the strial punctures of the elytra moderately large and slightly impressed, but the form is elongate and fusiform.

From quadricollis it differs by the anterior spurs of the anterior tibiæ of the females, being much narrower and evidently narrowed from base to apex, and by the long legs.

Specimens from about Brownsville, Texas, are more shining than those observed from elsewhere.

For characters separating it from its race dolosa, see below.

In fact, ampla is the largest species in the present section of the subgenus.

The mentum is very moderate for so large a species and varies quite a little in form-triangulo-trapezoidal to trapezoido-parabolic; the surface is moderately strongly punctate, and the setæ are very small, laterally with shallow foveate impressions, rather broadly and longitudinally convex at the middle.

The prosternum is variable, usually feebly convex between the coxæ, rounded behind and very feebly mucronate at middle, or with a moderate mucro; sometimes horizontally produced, compressed, and obliquely truncate.

Mesosternum more or less declivous and feebly concave.

The metasternal process is about as wide as the abdominal salient is long.

The abdominal intercoxal process is slightly transverse (male) or subquadrate (female), and about a fifth of its width wider than the metasternal process, and subequal in length to that of the post-coxal part of the same segment, the latter being quite equal to the second (male), the second segment a little longer (female) than the former. The third segment is about a third longer than the fourth.

The profemora are feebly tumid to rather strongly so (male), less strongly and as variable in the female, in both sexes usually more or less slightly compressed, or subcylindrical, in transverse section in certain specimens (males); tibial grooves not strongly limited by the 
moderate subcariniform margins that converge, become contiguous, and then evanescent at basal fourth. The grooves are not notably concave.

The mesofemora are moderately compressed, subfusiformly and not strongly tumid (male), or gradually wider to near apex in outer half (female); grooves not usually well defined, margins rather feeble.

The metafemora are feebly widened outwardly with sides subparallel; grooves less defined, margins more or less asperulate and evanescent near the middle.

The protibiæ are scarcely compressed; all the tibiæ are without tarsal grooves.

The tarsi are moderately long and comparatively stout.

The protarsi in the male are about a third longer than in the female.

In the male the protarsi are about a fifth of their length shorter than a mesotarsus. Joints subequal in width, two, three, and four subequal in length and width, the fifth scarcely as long as the three preceding taken together; the first not as long as the two following combined. In the female the joints are relatively and proportionally the same.

The mesotarsi (male) are a little shorter than a metatarsus. Joints one and five subequal in length; two and three are subequal in length, the fourth a little shorter.

A metatarsus (male) is about a fourth of its length shorter than its metatibia. Joint one, three times as long as the third, the fourth quite equal to the combined lengths of the second and third, the latter two are subequal in length. In the female the joints are proportionally the same.

ELEODES AMPLA var. DOLOSA, new.

Elongate-ovate, more or less shining, pronotum polished.

Head with the frontal suture obsolete or more or less well marked.

Pronotum quadrate, widest at the middle in both sexes, and a little wider $\left(\frac{1}{12}\right)$ than long; diso polished and shining, very finely and sparsely punctulate, punctures a little denser laterally; sides rather evenly and not strongly arcuate from apex to base, obsoletely sinuate at the basal fourth; base more or less finely and obsoletely beaded and about a fourth wider than the apex.

Elytra with the disc striato-punctate, strial punctures feebly impressed, each puncture moderate in size and separated by about their own diameters; interstitial punctures small, distantly spaced, both series more or less irregular at the periphery.

Legs long. Anterior tibial spurs moderately short. Otherwise as in ampla. 
Male.-Body moderately narrow, elongate-ovate. Elytra moderately narrowed in posterior fourth. Otherwise as in ampla.

Female.-Moderately robust. Elytra less gradually narrowed in the posterior fourth. Otherwise as in ampla.

Measurements.-Males: Length, 18-21 mm.; width, 7-7.5 mm. Females: Length, $21 \mathrm{~mm}$; width, $9 \mathrm{~mm}$.

Genital characters, male.-Edeagophore scarcely at all arched.

Basale elongate and suboval.

A picale elongately triangular; surface extremely sparcely and finely punctulate.

Sternite somewhat transverse. Each lobe triangulo-quadrate, with the external border broadly and feebly sinuate at basal three-fourths, thence arcuate to apex, the latter more or less rounded; internal border short and oblique. Otherwise as in ampla.

Female.-Genital segment quadrate.

Valvula.-Dorsal plate scarcely concave.

Appendage very small.

Ventrolateral surface quite broadly concave before the apex. Otherwise as in ampla.

Habitat.-Arizona (along the Colorado River, Beverly Letcher).

Number of specimens studied, 7 .

Sexitypes in my own collection.

Type-locality.-Western Arizona.

Salient type-characters.-More or less shining, elongate-ovate. Pronotum quadrate, polished, widest at the middle. Elytra striatopunctate, strial punctures not impressed (male) or feebly impressed and coarser (female). Legs long.

Diagnostic characters. - In surface lustre and sculpturing resembles carbonaria; by its larger and more elongate form and long legs it is most closely related to ampla.

$\mathrm{Mr}$. Blanchard writes me that it is not to be referred to any species in the LeConte collection. It has heretofore been referred to carbonaria, but the long legs will quickly separate it from that species.

A specimen in Mr. Blanchard's collection has the sides of the pronotum more strongly arcuate.

The mental, sternal, abdominal, and crural characters are practically the same as in ampla. The anterior tarsi are apparently less elongate in the male, and in both sexes for that matter; in the female joints two, three, and four are comparatively a little smaller.

\section{ELEODES OBSOLETA (Say).}

Blaps obsoleta SAY, Journ. Acad. Nat. Sci. Phila., III, 1823, p. 261.LeConte, Complete Writings of Thomas Say, II, 1859, p. 153.

Eleodes obsoleta Horn, Trans. Amer. Phil. Soc., XIV, 1870, p. 308.

Eleodes obsoleta rar. porcata CASEY, Ann. New York Acad. Sci., V, Nov.. 1890, p. 396. 
Oblong-ovate, slightly elongate, black, feebly shining to subopaque; elytra striate and slightly scabrous, frequently reddish along the suture.

Head twice as wide as long, moderately convex, frontal suture usually distinct, more or less feebly impressed laterally, rather finely and not very densely punctate, punctures slightly sparser on the vertex. Antenna moderate and subequal in the sexes, about reaching to the base of the prothorax, outer four joints feebly compressed, slightly and gradually dilated, third joint equal in length to the next two taken together, fourth just perceptibly longer than the fifth, the latter, sixth and seventh subequal, eighth slightly triangular, ninth and tenth irregularly orbicular in outline, eleventh oval and very slightly longer than wide.

Pronotum widest at or slightly in advance of the middle, subquadrate one-fourth to one-third wider than long; disc moderately and quite evenly convex, more or less declivous at the sides, finely, usually irregularly but quite evenly punctate; apex feebly and evenly emarginate to subtruncate, finely to obsoletely beaded; sides nearly evenly arcuate from base to apex when viewed vertically from above, or more strongly so in the anterior three-fourths, thence oblique and more or less feebly sinuate to base, finely beaded; base more or less evenly and slightly rounded, finely margined and about a third wider than the apex; apical angles distinct and subacute; basal angles usually obtuse.

Propleura finely, more or less irregularly and submuricately punctate, rugulose.

Elytra oval, less than twice as long as wide, usually widest at about the middle; base feebly emarginate, scarcely to slightly wider than the contiguous prothoracic base; humeri subobtuse, scarcely at all prominent anteriorly; sides evenly arcuate, apex obtusely rounded; disc rather evenly convex, slightly flattened on the dorsum, laterally more strongly and rather evenly rounded, arcuately declivous posteriorly; striate, rarely estriate or smooth, striæ impressed and rather coarsely, uniseriately punctate near the suture to more irregularly so externally; intervals flat to moderately convex, sparsely and irregularly punctate, punctures more or less feebly scabrous; striæ less defined and punctures more irregular and denser laterally.

Epipleurce moderate in width, gradually narrowed from base to apex, superior margin beneath the humeri very feebly and broadly sinuate; surface finely and muricately punctate.

Sterna finely to obsoletely punctate.

Parapleurce rather densely and finely punctate.

Abdomen more or less polished, finely, sparsely punctulate, and more or less rugulose; intercoxal process more strongly sculptured. 
Legs rather slender and moderate in length; anterior femora mutic in the sexes; anterior tibial spurs dissimilar; anterior tarsi feebly dissimilar in the sexes, first joint slightly thickened at tip beneath.

Male.-Elongate, elytra rather gradually narrowed posteriorly, quite evenly and arcuately declivous behind. Abdomen moderately oblique, not strongly convex, more or less feebly impressed at middle on first two segments; intercoxal process somewhat concave. Anterior spurs of the anterior tibiæ about twice as long as the posterior, slightly curved, just feebly widened and gradually narrowed from base to apex, the latter acute. First joint of the anterior tarsi with the minute tuft of modified spinules scarcely evident, ordinary spinules present on the thickened tip beneath.

Female.-Robust. Elytra somewhat broadly oval, and slightly narrowed posteriorly, usually arcuately and rather vertically declivous behind; abdomen horizontal and strongly convex. Anterior spurs of the anterior tibiæ usually about a third to a half longer than the posterior, moderately curved and rather gradually narrowed from base to apex, noticeably widened. First joint of the anterior tarsi with ordinary spinules on the thickened tip beneath.

Four forms may be recognized:

Forma glabra.-Elytra estriate and more or less smoothly sculptured.

Forma typica.-Elytra striato-punctate, intervals slightly convex, subasperate.

Forma annectans.-Elytra rather strongly striato-punctate, intervals strongly convex; sculpturing subasperate.

Forma punctata.-Elytra estriate, irregularly and more or less muricately punctate.

Measurements.-Male: Length, 12.5-16 mm., width, 5-7 mm. Female: Length, 14.5-18 mm.; width, 6.5-7.5 mm.

Genital characters, male.-Edeagophore (Plate 3, fig. 1) flax-seedshaped (flattened oblong-ovate), scarcely arched.

Basale oblong-oval, glabrous, moderately convex; sides more or less feebly arcuate.

Apicale slightly elongate and triangular; surface in basal moiety evenly convex, in apical half a median longitudinal membranous groove; sides moderately arcuate in basal half, sinuate at middle, hence feebly or scarcely arcuate to apex, the latter acute but not acuminate; base broadly lobed at middle two-fourths, broadly and feebly sinuate laterally.

Sternite (Plate 3, fig. 2) parabolic in outline. Each lobe with the external border more or less evenly arcuate from base to apex, frequently slightly sinuate in basal half; apex evenly rounded, angle usually not evident; internal border more or less oblique and feebly sinuous; surface rather sparsely punctate in apical moiety, setose, 
setæ not dense and moderate in length, longer on apical border. Membrane very sparsely setose across the bottom of the sinus.

Female.-Genital segment (Plate 3, fig. 3) quadrate, somewhat depressed and setose.

Valvula.-Dorsal plate oblong, explanate externally from base to apex, glabrous; surface more or less plane, never excavated, sometimes with the apical portion slightly deflexed, sparsely punctate, setæ moderate in length, longer apically; external margin feebly sinuate towards base, feebly arcuate towards apex, the latter with the external lobe strongly developed, three-fourths as wide as the dorsal plate and broadly rounded; internal border straight to feebly sinuous, the inner lobe of apex minute and separated from the external by a small sinuation; apex set with long flying setæ.

A ppendage minutely mammilliform, usually invisible from above; fossa fringed with fine and rather long hairs.

Basal prominences not conspicuous.

Superior pudendal membrane longitudinally rugulose, reaching to the base of the internal apical lobe.

Ventrolateral surface (Plate 3, fig. 4) with the basal swollen portion quite short, more or less broadly and transversely concave before the apex; surface glabrous, sparsely punctate and minutely setose; submarginal groove broad and shallow beneath the expanded sides, curving inward beneath the external lobe to the base of the internal lobe. Internal margins of the valves not contiguous at apex; genital fissure broadly fusiform, and nearly closed by the longitudinally rugulose inferior pudendal membrane.

Habitat.-Forma glabra.-Arizona (Williams, Barber, and Schwarz) ; Colorado (Arboles, C. F. Baker).

Forma typica.-Texas (Mobeetee, H. S. Barber); Nebraska (Grant, July, C. V. Riley; Pine Ridge, Sand Hills, Sioux City, collection University of Nebraska); Kansas (F. H. Snow) ; Colorado (Golden, E. J. Oslar; Colorado Springs, June, elevation 6,000-7,000 feet, H. F. Wickham; Sterling, collection University of Nebraska; Platte Canyon, October, Greeley, H. Soltau; La Junta, Durango, South Park, San Luis Valley, Pueblo, West Cliff, Canyon City, Denver; Wickham's List) ; Wyoming (Cheyenne, C. V. Riley and H. F. Wickham) ; Oklahoma (Fort Supply, October, H. S. Barber) ; Montana (Assiniboine, Hubbard and Schwarz; Moose Jaw, August, A. N. Caudell; Helena); South Dakota (Badlands, Pine Ridge, September, L. Stejneger; Hot Springs, collection University of Nebraska). 8).

Forma annectans.-Colorado (Gulnare, Las Animas County, July

Forma punctata.-New Mexico (Coolidge, Wickham); Colorado (Edith; Denver, collection of E. C. Van Dyke). 
Number of specimens studied, 200.

Type destroyed.

Type-locality.-Say received his specimens from the "Arid plains of Arkansas and Missouri, in the vicinity of the Rocky Mts."

Salient type-characters.-Body oblong-subovate, elytra with impressed striæ, which are slightly scabrous with minute elevated points and impressed punctures; interstitial lines also punctured; sutural margin obsoletely reddish brown (Say).

Diagnostic characters. - This common species is to be recognized from the other members of the group by its duller integuments and striato-punctate elytra. In the typical form the elytra are feebly scabrous at the central part of the disc and more strongly so at the periphery; the striæ are very obvious; in some specimens the striæ are obsolete or feebly evident and the sculpturing slightly more scabrous (forma punctata), while in some there is a more or less disappearance of the asperate punctuation so that they are quite smooth and feebly shining and the striæ are feebly marked (forma glabra); this form appears to be rare, as I have only seen four samples, and has no doubt heretofore been referred to quadricollis.

The small and slightly more robust form, reddish along the elytral suture, is to be considered the typical form. Say's measurements are one-half to three-fifths of an inch in length. This form in Colorado and elsewhere has very convex elytral intervals and is here spoken of as forma annectans, and is the homologue of porcata.

The var. porcata is a larger and much more elongate form with strongly convex elytral intervals. (See p. 63.)

The mentum is moderate in size and varies in form from triangulotrepezoidal to trapezoido-parabolic; the surface is moderately punctate, setæ minute, convex at middle, and more or less foveate laterally.

The prosternum is rather short before the coxre and protuberant ventrally with the coxæ, usually rounded antero-posteriorly between the same; in the small forms not mucronate, but in a few specimens there was a very slight mucro. In the larger individuals and in the punctate form the mucro becomes evident, but I have never seen it well developed.

The mesosternum is at times feebly convex, never strongly concave, more or less oblique, but at times it is rather vertically declivous.

The metasternal process is about as wide as the abdominal salient is long (male) or slightly narrower (female).

The abdominal process is quadrate (male) or slightly transverse (female) and about a fourth of its width wider than the metasternal salient, equal in length to the post-coxal part of the first segment, the latter being equal in length to the second (male); the second is a little longer in the female, where it is a half longer than the third; 
in the male the third is a little longer than the fourth, and in the female a little less than twice as long as the fourth.

The metasternum laterally between the coxæ is as long as the width of a mesotibia at apical third.

The femoral and tibial characters are practically as in ampla, except that the legs are much shorter.

The tarsi are moderate in length and rather slender.

The protarsi in the male are a little stouter than in the female; the difference in length is less marked, those of the male being just a little longer.

The protarsi are about a third (male) or a little less (female) of their length shorter than a mesotarsus. Joints two, three, and four are subequal in size, each about as wide as long and together searcely as long as the fifth; the first is a little longer than wide.

The mesotarsi are about a third (male) or a sixth (female) shorter than a metatarsus. Joints two to four diminish just a little in length in the order named; the fifth is about equal to the combined length of the second and third, and subequal to the first.

The metatarsi are about a fourth of their length shorter than a metatibia. Joint three is just noticeably a little shorter than the second, and the two together are subequal in length to the fourth, the latter subequal with the first.

\section{ELEODES OBSOLETA var. PORCATA Casey.}

Oblong-ovate, moderately elongate, black, elytra sulcate.

Head twice as wide as long, frons slightly flattened to feebly convex, faintly impressed laterally, frontal suture usually finely impressed; surface somewhat densely punctate, more coarsely so on the epistoma and finely and sparsely on the vertex; antennce moderate in length and stoutness, outer four joints very slightly compressed, more or less feebly dilated, third joint about equal to the next two taken together, the fourth slightly longer than the fifth, the latter, sixth, and seventh subequal, eighth feebly triangular, ninth and tenth circular in outline, eleventh oval to ovate and very slightly longer than wide.

Pronotum subquadrate, one-fourth to one-third wider than long, widest in advance of the middle as viewed vertically from above, at the middle when viewed obliquely from the side; disc gabrous and shining or feebly alutaceous, moderately and evenly convex, more or less arcuately declivous laterally, finely and rather sparsely punctate, the punctures becoming a little coarser, but not very dense laterally; apex slightly emarginate in circular arc, finely or obsoletely margined; sides quite evenly and moderately arcuate in anterior twothirds, thence less arcuate and oblique to base as viewed vertically 
from above, or more strongly arcuate at the middle, thence oblique and moderately convergent, feebly sinuate to base as viewed obliquely from the side, finely beaded; base quite evenly and feebly rounded, finely to somewhat obsoletely margined and about one-fifth wider than the apex; apical angles distinct, not acute, frequently narrowly rounded; basal angles obtuse, sometimes more or less rounded.

Propleurce finely, sparsely to rather densely submuricately punctate and more or less rugulose.

Elytra oval, usually widest at about the middle, less than twice as long as wide; base broadly and feebly emarginate, as wide as or slightly wider than the contiguous prothoracic base; humeri more or less feebly prominent; sides evenly arcuate, apex not very narrowly rounded; disc quite evenly convex, occasionally slightly flattened on the dorsum, laterally rather evenly and strongly rounded, arcuately declivous posteriorly, deeply sulcate, the sulci finely, uniseriately to irregularly and muricately punctate; intervals about equal in width to the sulci, very convex, usually strongly defined, finely, sparsely, and irregularly punctate; inflexed sides feebly sulcate, intervals feebly convex, irregularly and rather more densely punctate.

Epipleurce moderate in width and gradually narrowing from base to apex, superior margin feebly and broadly sinuate beneath the humeri; surface finely, more or less sparsely, submuricately punctate.

Sterna more or less finely, densely, submuricately punctate and rugulose.

Parapleurce finely and rather densely punctate.

Abdomen somewhat shining, sparsely to more or less densely punctate, especially on the first and last segments, more or less rugulose.

Legs moderate, comparatively rather longer than in obsoleta. Anterior femora mutic in the sexes. Anterior tibial spurs dissimilar. Anterior tarsi dissimilar in the sexes, first joint slightly thickened at tip beneath, with a small tuft of spinules.

Male.-Body somewhat slender. Elytra rather gradually narrowed posteriorly, evenly arcuately and somewhat obliquely declivous at apex. Abdomen slightly oblique, moderately convex and more or less broadly flattened at middle on first two segments, intercoxal process more or less concave. Anterior spurs of the anterior tibiæ about a half longer than the posterior, distinctly wider and gradually narrowing from base to apex. Anterior tarsi longer than in the female, first joint with a minute and inconspicuous tuft of modified spinules, surrounded by ordinary spinules on the thickened tip beneath.

Female.-Body robust. Elytra rather broadly oval, rather rapidly narrowed, arcuately and vertically declivous posteriorly. Abdomen horizontal and strongly convex. Anterior spurs of the anterior tibiæ about a third longer than the posterior, distinctly broadened, 
gradually but less rapidly narrowing from base to apex. First joint of the anterior tarsi with tuft of ordinary spinules at tip beneath.

Measurements.-Males: Length, $12-18 \mathrm{~mm}$.; width, 6-7 mm. Females: Length, $18.5-21 \mathrm{~mm}$; width, $7.5-9.5 \mathrm{~mm}$.

Genital characters, male.-Edeagophore flaxseed-shaped (flattened oblong-ovate), slightly elongate and not usually arched.

Basale oblong, glabrous, evenly convex; sides more or less parallel. A picale triangular, slightly elongate, apical region more or less deflexed; surface glabrous, rather strongly convex at middle, with a long median membranous groove reaching nearly to the base, groove linear in basal third; sides broadly sinuate at middle third, slightly arcuate toward base; apex acute and rather gradually narrowed; base very broadly lobed at middle and very feebly sinuate laterally.

Sternite slightly transverse. Each lobe with the external border feebly arcuate and oblique, becoming arcuate at apex, the latter broadly rounded or feebly subtruncate, angle scarcely evident; internal border nearly straight; surface rather sparsely punctate in apical two-thirds, setose, setæ moderately long on apical border, shorter toward base. Membrane sparsely setose across the bottom of the sinus, which is narrow and triangular.

Female.-Genital segment quadrate and setose.

Valvula (Plate 3, fig. 14).-Dorsal plate somewhat broadly oblong, moderately explanate externally and at apex, frequently with a marked antero-posterior convexity; surface plane, sparsely punctate along the internal moiety and at apex, setæ not long; external and internal borders more or less straight and quite parallel; apex with the external lobe broadly rounded and apparently semi-chitinous, the internal lobe small and membranous as usual and separated from the external by a small sinuation at junction of the first and second inner fourths of the apical margin of the dorsal plate. External lobe set with long flying setæ, a few on the internal lobe.

Appendage small, inferior, and more or less compresso-mammilliform. Fossa rather large and fringed with setæ.

Basal prominences not conspicuous.

Superior pudendal membrane as in obsoleta.

Ventrolateral surface feebly convex toward base, broadly and shallowly concave before the apex, glabrous, finely and very sparsely punctate, setæ minute, denser at apex; submarginal groove shallow and not well defined at the apex, not reaching the internal lobe. Internal margins of the valves contiguous at basal sixth. Genital fissure quite broadly fusiform. Inferior pudendal membrane regulose and largely visible.

It is to be noted that the sides of the dorsal plates are not as strongly explanate as in obsoleta.

59780-Bull. $63-09-5$ 
Habitat.-Arizona (Fort Apache, Casey; Galiuro Mountains, May ; Fort Grant, July; Chiricahua Mountains, May, Hubbard and Schwarz; Williams, July; Ash Fork, June; Flagstaff, July, Barber and Schwarz; Kearn's District, Navajo Indian Reservation, April A. W. Barber; Peach Springs, Walnut, Winslow, July; Seligman, July, H. F. Wickham; Prescott, H. C. Fall) ; New Mexico (Pecos, July).

Number of specimens studied, 85 .

Type is in Col. Thomas Casey's collection.

Type-locality.-Fort Apache, Ariz.

Salient type-characters.-Prothorax with the disc evenly convex, finely, sparsely punctate, the punctures becoming rather coarse laterally but not very dense; apex feebly emarginate; sides more strongly arcuate before the middle, thence moderately convergent and gradually feebly sinuate to the basal angles, which are very obtuse but not distinctly rounded; base feebly and evenly arcuate. Elytra with the dise very deeply sulcate, the sulci finely, rather sparsely and muricately punctate, the intervals equal in width to the sulci, very convex, finely and sparsely punctate (Casey).

Diagnostic characters.-The strongly sulcate elytra separates this race from all others of the group. The individuals are unusually larger and more elongate than obsoleta.

Well developed specimens appear quite distinct from obsoleta, but they mark a heterotypical variation which is connected to the typical form of obsoleta by an abundance of mesotypes of all sizes and sculpturing, so that it can only be considered as a good variety. Some individuals are nearly as large as ampla, notably a series from Fort Grant, Arizona, collected by Hubbard and Schwarz. I have authentic examples before me kindly contributed to Mr. Charles Fuchs and myself by Colonel Casey.

The mentum is moderate and varies in form from trapezoidal to trapeżoido-parabolic; surface is rather strongly punctate, setæ small, moderately convex and more or less strongly foveate laterally and narrowly impressed along the apical margin, the latter being frequently deflexed.

In Casey's types the prosternal process is prolonged and prominent. In the series before me it is very variable-from a small mucro to well developed, or compressed and subtruncate behind.

The mesosternum varies relatively with the foregoing, concave to convex, slightly oblique to vertically declivous.

The intercoxal process of the first abdominal segment is subquadrate (male) or slightly transverse (female), and about a third of its width wider than the metasternal salient.

The metasternum laterally between the coxæ is as long as the width of a mesotibia at apex. 
The post-coxal part of the first segment is equal in lengtin to the process, equal in length to the second segment in the male, and the third segment in the female.

In the male the third segment is a third of its length longer than the fourth; in the female the second is twice as long as the fourth.

The legs are usually quite strongly sculptured. The profemora and the metafemora are as in carbonaria. The mesofemora are usually, gradually and feebly widened from base to apex.

The protibiæ are subcylindrical in transverse section. All the tibiæ are without tarsal grooves and the articular cavities are closed.

The tarsi are moderate in length, comparatively a little stouter than in obsoleta.

A protarsus in the male is about a sixth of its length longer than in the female, and subequal in stoutness in the two sexes.

The relative proportions of the tarsi to each other, and the constituent joints of each one to each other is practically the same as in obsoleta.

\section{ELEODES KNAUSII, new species.}

Oblong-ovate to ovate, more or less shining, estriate and moderately convex.

Head twice as wide as long, feebly convex, frontal suture feebly marked, frons very slightly impressed laterally, somewhat coarsely, irregularly and more or less densely punctate, especially on the epistoma. Antenna moderate in length, outer four joints feebly compressed, distal three slightly dilated, third about as long as the next two taken together, fourth scarcely longer than the fifth, the latter, sixth and seventh subequal in size and about as wide as long, eighth shorter and apparently a little wider than long, ninth subtriangular and slightly transverse, tenth transversely oval, eleventh ovate.

Pronotum subquadrate, widest just in advance of the middle when viewed vertically from above, at the middle when viewed obliquely from the side, and about a third wider than long; disc evenly and moderately convex, rather arcuately declivous at the sides and apical angles, quite finely, irregularly and somewhat sparsely punctate, punctures slightly denser at the sides; apex more or less feebly emarginate in circular arc, finely and more or less obsoletely beaded; sides moderately arcuate in anterior three-fourths, thence obliquely convergent to base as viewed vertically from above, or more strongly arcuate anteriorly, thence convergent and more or less sinuate to base when viewed obliquely from the side, finely beaded; base feebly arcuate, sometimes feebly sinuate at the middle, finely and more or less obsoletely beaded, one-fifth to one-third wider than the apex; apical angles distinct, not at all prominent anteriorly, sometimes very feebly and narrowly rounded; basal angles obtuse. 
Propleura obsoletely to finely, sparsely submuricately punctulate and rugulose.

E7ytra oval, distinctly less than twice as long as wide, widest at the middle; base more or less emarginate, usually feebly sinuate each side of the middle, and generally slightly wider than the contiguous prothoracic base; humeri more or less exposed and obtuse; sides evenly arcuate, apex obtuse and rather narrowly rounded; disc moderately convex on the dorsum, quite evenly and strongly rounded at the sides, arcuately declivous posteriorly; almost coarsely, irregularly and rather densely punctate, the punctures are subequal in size and obsoletely muricate, frequenty there is a tendency to an arrangement into rather distant rows on the dorsum; laterally there is a slight tendency to rugulosity.

Epipleura moderate in width and gradually narrowing from base to apex; superior margin feebly and broadly sinuate beneath the humeri; surface dull, finely and irregularly punctate.

Sterna obsoletely to rather densely and finely punctate, more or less rugose.

Parapleura finely and quite densely punctate.

Abdomen finely, sparsely, and irregularly punctate, more or less rugulose, more coarsely sculptured on the first segment, the fifth coarsely punctate.

Legs rather short and somewhat slender, more or less strongly sculptured. Anterior femora mutic; anterior tibial spurs comparatively small and feebly dissimilar in the sexes. Anterior tarsi with the first joint slightly thickened at tip beneath and a little dissimilar in the sexes.

Male.-Oblong-ovate, moderately slender. Antennæ reaching to the base of the prothorax. Elytra moderately narrowed in apical fourth, arcuately and scarcely obliquely declivous posteriorly. Abdomen moderately oblique and convex, more or less broadly impressed at middle of the first two segments. Anterior spur of the anterior tibiæ about a half longer than the posterior, rather slender and gradually narrowing from base to apex, acute and feebly curved. First joint of the anterior tarsi with a small inconspicuous pencil of modified spinules, surrounded by ordinary spinules on the thickened tip beneath.

Female.-Ovate and robust. Antennæ not quite reaching to the prothoracic base. Elytra feebly narrowed and arcuately, vertically declivous in apical fourth. Abdomen horizontal, strongly convex. Anterior spurs of the anterior tibiæ about a half longer than the posterior, slightly broadened, gradually narrowed from base to apex; both spurs rather strongly curved. First joint of the anterior tarsi with ordinary spinules on the thickened tip beneath. 
'Measurements.-Males: Length, $14.5 \mathrm{~mm}$.; width, $6 \mathrm{~mm}$. Females: Length, 14-16 mm.; width, 7-8 $\mathrm{mm}$.

Genital characters, male.-Edeagophore subfusiform and rather elongate, not arched.

Basale oval-oblong, evenly convex, with sides feebly arcuate.

A picale triangular, slightly elongate; surface evenly convex with a median membranous groove extending from near the tip almost to the base, where it becomes slightly less membranous; sides arcuate in basal half, thence more or less sinuate to apex, the latter very gradually and slightly decurved and very narrowly rounded.

Sternite quite parabolic in outline. Each lobe with the external border quite evenly arcuate; apex rather narrowly rounded, angle not evident; internal border short, straight and oblique; surface slightly convex, glabrous, rather coarsely punctate in apical half, setose, setæ moderate in length; punctures denser and setæ longer at apex. Membrane slightly setose at, bottom of the sinus.

Female.-Genital segment quadrate, somewhat depressed, setose and not strongly chitinized.

Valvula (Plate 4, fig. 24.)-Dorsal plate oblong and glabrous; surface plane, finely and sparsely punctate, with rather short reclining setw arising from the same; external border straight or feebly sinuous, gradually explanate from the basal third to the apical margin, the latter rounded and explanately produced upon the external lobe in outer three-fourths, directly and arcuately continuous with the external border; external apical lobe rather feebly membranous beneath and concealed from view from above; internal lobe moderate and separated from the external by a small sinuation in the apical margin; internal border straight or sinuous; apical region set with a few long, flying, soft setæ.

Appendage slightly visible from above, directed backward and feebly inward, conico-mammilliform. Fossa inferior, rather large, and fringed with long, flying setæ.

Superior pudendal membrane longitudinally rugulose and reaching to the base of the internal apical lobe.

Basal prominences not noticeable.

Ventrolateral surface not strongly convex in basal moiety, more or less concave laterally before the apex, but not transversely so; submarginal groove broad and shallow beneath the explanate external border of the dorsal plate and apical lobe, meeting the fossa at its external edge; external apical lobe not strongly developed beneath; surface finely and irregularly punctulate and very finely setose. Internal margins of the valves contiguous for a short distance at base and apex, between which the fissure is rather broadly fusiform, and closed in basal two-thirds by the inferior pudendal membrane, the latter feebly rugulose. 
Habitat.-New Mexico (Clouderoft, James Canyon, June, Warren Knaus).

Number oî specimens studied, 8 .

Sexitypes in my own collection.

Type-locality.-Clouderoft, New Mexico.

Collector, Warren Knaus.

Salient type-characters.-More or less shining, estriate and moderately convex. Pronotum subquadrate; disc rather finely, irregularly and sparsely punctate, punctures denser at the sides; apex very feebly emarginate; apical angles distinct and not at all prominent anteriorly; basal angles obtuse.

Elytra with the humeri more or less exposed; dise almost coarsely, irregularly, and rather densely punctate, punctures subequal in size and obsoletely submuricate; laterally denser, with a slight tendency to rugulosity. Legs rather short and somewhat slender.

Diagnostic characters. - Resembles the robust form of extricata or rileyi in general outline. If it inhabited the region where parvicollis is found it might be mistaken for that species; some forms of lecontei resemble it. First of all, the genital characters distinguish it from atl the above and associates it with obsoleta which it resembles, but less strongly in general habitus. It is usually confounded with extricata, from which it differs in the mutic anterior femora of the male, the more strongly arcuate sides of the pronotum at anterior two-fourths, and besides the punctuation is quite different.

In riteyi the female has the anterior spurs of the anterior tibiæ strongly developed, while in knausii they are but feebly broadened. The spurs have greater development in the male of rileyi also than in the male of knausii.

In parvicollis and lecontei the lateral margins of the pronotum is distinctly visible from above, while in knausii the pronotal sides are arcuately declivous. The genital and tarsal characters are also distinctive.

Knausii differs from typical obsoleta in its smooth and shining surface and estriate elytra. It is also more robustly ovate than in the smooth form of obsoleta.

I am indebted to Mr. Warren Knaus for this interesting species, and I take pleasure in dedicating it to him.

Knausii appears to bear the same relation to the Carbonaria section that rileyi bears to the Quadricollis section. In this respect the two species are analogous.

There is a specimen before me from Cananea, District of Arizpe, State of Sonora, Mexico, that resembles knausii in form, but it is more alutaceous and smoother, the striæ of punctures are more evident and the interstitial punctures smaller and less conspicuous. The anterior tibial spurs are also feebly developed, and while the study of the 
United States specimens leaves the relationships in doubt, a knowledge of the Mexican contingent would undoubtedly be more elucidative. At present knausii appears as a derivative of obsoleta.

The mentum is more or less trapezoido-parabolic, rather densely punctate and subfoveate laterally, somewhat convex at the middle; the setæe are scarcely evident.

The prosternum is moderately produced behind, feebly convex or horizontal between the coxæ and triangularly dilated behind the median transverse axis of the acetabula; the mucro is small, at times the process is compressed and more or less vertically truncate behind.

The mesosternum is quite vertically declivous and more or less feebly côncave.

The intercoxal process of the abdomen is subquadrate (male) or slightly transverse (female), and about a fourth (male) or a third (female) of its width wider than the metasternal salient.

The metasternum laterally between the coxæ is as long as the width of a mesotibia at apical third.

The post-coxal part of the first abdominal segment is subequal (male) or equal (female) in length to that of the process.

In the male the second segment is equal to the length of the process; the third is about equal to the post-coxal part of the first; the fourth is about two-thirds as long as the second.

In the female the second segment is about twice as long as the fourth, the third is equal to the post-coxal portion of the first.

The legs are noticeably short.

The profemora of the male are moderately clavate and feebly compressed; in the female feebly tumid and moderately compressed; the tibial grooves are limited by feeble but distinct subcariniform margins which meet and become evanescent at the basal fourth.

In both sexes the meso and metafemora are quite similar. The mesofemora have the surface lines feebly but distinctly arcuate, and the femora in outline may be said to be subfusiform. The metafemora have the superior and inferior surface lines quite parallel. The grooves are limited by asperulate margins which converge at basal third on the mesofemora and become evanescent, while on the metafemora they become evanescent about the middle without becoming contiguous.

The tibix are all more or less feebly arcuate, and rather more strongly widened apically than is usually observed; the tarsal grooves are absent and the articular cavities are closed. The protibiæ are observed to be feebly compressed or subcylindrical.

The tarsi are moderately long and rather stout when considered in a comparative sense. The protarsi of the male are about a fourth longer than those of the female. 
The protarsi are about a fourth (male) or two-thirds (female) of their length shorter than a mesotarsus.

The mesotarsi are about a ninth-less in the female-of their length shorter than a metatarsus.

The metatarsi are about a seventh (male) to two-fifths (female) of their own length shorter than their respective metatibia.

The relative proportions of the joints of each tarsus are practically the same as in obsoleta.

\section{ELEODES OMISSA LeConte.}

Eleodes omissa LeConte, Proc. Acad. Nat. Sci. Phila., 1858, p. 186.-Honn, Trans. Amer. Philos. Soc., XIV, 1870, p. 308.

Eleodes interrupta Blaisdel, Ent. News, III, Dec, 1902, p. 241.

Oblong-ovate to ovate, elongate, and more or less shining.

Head twice as wide as long, more or less convex, feebly impressed laterally, frontal suture fine and usually evident, rather finely and not densely punctate, punctures sparser on vertex. Antennce moderate, outer four joints very feebly compressed, scarcely dilated, third joint equal in length to the next two taken together, fourth slightly longer than the fifth, the latter, sixth, and seventh subequal, eighth just the least shorter, subtriangular, and longer than wide, ninth and tenth somewhat circular in outline, eleventh ovate.

Pronotum subquadrate, widest at or in front of the middle as viewed vertically from above, one-fourth to one-third wider than long; disc evenly and moderately convex, more or less arcuately declivous at the sides, finely, sparsely, and more or less irregularly punctulate, punctures just a little coarser and denser laterally; apex feebly emarginate or subtruncate in circular arc, finely or obsoletely beaded; sides evenly and moderately arcuate in the anterior twothirds, thence to the base more or less straight and converging (viewed vertically from above), or evenly and rather broadly arcuate, converging and more or less feebly sinuate (viewed obliquely from the side), finely beaded; base slightly rounded to subtruncate, finely margined, one-ninth to a fourth wider than the apex; apical angles subacute to obtuse, rarely feebly prominent anteriorly; basal angles obtuse, frequently apparently rounded when viewed vertically from above.

Propleurce finely and very sparsely punctate, more or less rugulose, rarely rugose.

Elytra oval, widest at the middle, less than twice as long as wide; base feebly emarginate to truncate, usually scarcely wider than the contiguous prothoracic base; humeri obtuse and not prominent; sides evenly arcuate, apex obtusely rounded; disc moderately convex on the dorsum, rather strongly and evenly rounded laterally, arcuately declivous posteriorly, punctate, punctures frequently of the same 
* size, fine, diffusely arranged, not dense, generally some evidence of a serial order; the strial punctures are frequently slightly the larger, the series are moderately distant and rarely impressed.

Epipleurce moderate in width, gradually narrowing from base to apex, very feebly sinuate along the superior margin beneath the humeral region; surface finely and sparsely punctulate.

Sterna more or less shining, rather densely punctate and more or less rugose.

Parapleurce quite densely punctate.

Abdomen glabrous, finely and very sparsely punctulate, usually more or less distinctly rugulose - almost rugose at times.

Legs moderate in length and stoutness, sometimes moderately thickened; anterior femora mutic and the anterior tibial spurs slightly dissimilar in the sexes; anterior tarsi with the first joint slightly thickened at tip beneath and slightly dissimilar in the sexes.

Male.-Oblong-ovate, rather slender and elongate. Elytra gradually narrowing in the posterior third, arcuately and somewhat obliquely declivous posteriorly. Abdomen oblique, moderately convex, more or less flattened at middle of the first two segments. Anterior spurs of the anterior tibix slightly thickened, nearly twice as long as the posterior, both comparatively short. First joint of the anterior tarsi set with a small tuft of spinules, the modified spinules scarcely evident.

Female.-Ovate and robust. Elytra broadly oval, and somewhat gradually narrowing in the posterior fourth, arcuately and vertically declivous behind. Abdomen horizontal and strongly convex. Anterior tibial spurs rather variable in length, the anterior distinctly broadened and gradually narrowing from base to apex, sometimes with sides slightly arcuate in basal half, and about a third longer than the posterior, both acute, tapering, and stouter than in the male. First joint of the anterior tarsi set with a small transverse tuft of ordinary spinules on the thickened tip beneath.

I have observed only four forms worthy of distinction in the hundreds of specimens before me of this variable species.

Forma typica.-Thorax somewhat transverse, apex feebly emarginate or truncate, angles somewhat obtuse and not at all prominent anteriorly. Femora distinctly thickened.

Male.-Elytra rather more elongate than usual.

Female.-Elytra with the sides more strongly arcuate anteriorly than usual.

Forma catalinæ.-Pronotum more strongly punctate, especially laterally. Femora more or less thickened.

Forma communis.-Thorax as in the typical form. Elytra with the sides less strongly and suddenly arcuate anteriorly. Femora not noticeably thickened. 
Forma emarginata.-Thorax quadrate, apex distinctly emarginate, angles subacute and somewhat prominent anteriorly.

Measurements.-Males: Length, 16-19 mm.; width, 6-7 mm. Females: Length, 18-23 mm.; width, 8-10 $\mathrm{mm}$.

Anomaly.-The specimen described by me ${ }^{a}$ as interrupta belongs here. The prothorax has the side margin at middle rather abruptly interrupted. The elytra has the disc sulcate posteriorly. Length, $16.6 \mathrm{~mm}$.; width, $7.1 \mathrm{~mm}$.

Genital characters, male.-Edeagophore (Plate 2, fig. 1) elongateovate to fusiform, and more or less arched.

Basale feebly oblong-oval to oblong; surface evenly convex; sides feebly arcuate, sometimes converging slightly toward the apex.

Apicale triangular, slightly elongate; surface moderately and evenly convex, with a median longitudinal grove in apical half, sometimes extending from apex to base, slightly dilated and membranous apically, gradually narrowing to become linear basally; sides moderately and evenly arcuate in basal half, thence rather feebly sinuate to apex, the latter subacute; base rather broadly lobed at middle and feebly sinuate laterally.

Sternite (Plate 2, fig. 2) transversely parabolic. Each lobe more or less subparabolic in outline; external border straight to evenly arcuate, the apex being continuously but more narrowly rounded, angle sometimes evident; internal border quite short and feebly arcuate; surface scarcely convex, sparsely punctate and setose in apical three-fourths, setæ rather long on the apical border. Membrane distinctly and-sparsely setose at the bottom of the sinus, the latter short.

Female.-Genital segment (Plate 2, fig. 3) quadrate, moderately explanate laterally and setose.

Valvula.-Dorsal plate oblong, moderately narrow, sides subparallel; surface plane, glabrous, sparsely punctate, impunctate at basal third, setose, setæ moderate and reclining; external border straight to feebly arcuate, continuously so with the more strongly and evenly rounded apical border, which is more or less inwardly oblique; internal lobe short and separated from the external by a small sinuation; external lobe set with rather long setæ, the internal with a few rather short ones; internal border slightly sinuous.

Appendage just visible from above, short mammilliform, with a pencil of setæ at tip. Fossa moderate and in the internal wall of the external apical lobe.

Basal prominences scarcely evident.

Superior pudendal membrane longitudinally rugulose, reaching about to the internal lobe of the apex. 
Ventrolateral surface (Plate 2, fig. 4) moderately convex, slightly concave laterally before the apex; surface sparsely punctate and finely setose; submarginal groove well developed beneath the explanate external border of the dorsal plate, passing obliquely inward beneath apex to the inner angle of the fossa, ending at the internal apical lobe. Internal margins of the valves contiguous at basal sixth; genital fissure quite broadly fusiform, and closed at basal half by the inferior pudendal membrane.

Habitat.-Southern California; Santa Catalina Island.

Number of specimens studied, 500 .

Type is in the LeConte collection.

Type-locality.-San Diego, California.

Salient type-characters.-Longer than usual. Thorax slightly convex, sides broadly rounded, somewhat narrowed posteriorly, finely and sparsely punctulate. Elytra declivous and obliquely narrowed behind, sparsely, finely, and very irregularly punctate. Femora unusually thick (LeConte).

Diagnostic characters.-The most common species in Southern California and always heretofore referred to quadricollis, from which it differs in the smaller and more slender anterior spurs of the anterior tibix (females); from carbonaria, to which it is most closely related, by the punctures of the elytral disc having a less distinct serial arrangement, and by the serial punctures being scarcely larger than those of the intervals, the tendency being toward diffuse punctuation.

Omissa is with greater difficulty separated from the smooth form of carbonaria, where the elytra punctures are small and of the same size; here locality must be relied upon for their separation. All those specimens from the eastern side of the Colorado River are forms of carbonaria, while all those from the western side are to be referred to the present species.

I do not know of a single specimen taken west of the Colorado River ever having been identified as an authentic carbonaria. In fact I consider omissa as a western modification of carbonaria.

Omissa is a variable species in regard to the form of the pronotum, but in the several hundreds which I have studied I found an abundance of all necessary mesotypes, both as regards the form of the pronotum and elytral punctuation.

In a large percentage of those individuals that have the sides of the pronotum evenly arcuate from apex to base, it will be found that they really present a more normal form of the side margin than do those that are widest in front of the middle; for here it will be seen that the sides of the pronotal disc are most strongly declivous behind the middle and that the true margin is displaced downward and not visible when the pronotum is viewed vertically from above; 
when viewed obliquely from the side the normal marginal curve will be seen and that in reality the pronotum is widest at the middle.

It must also be borne in mind that the pronotal disc is normally moderately declivous laterally in the present subgenus.

In many specimens (mostly male, but some females as well) the pronotal sides are less strongly deflexed and appear quite evenly rounded from apex to base, and as a result the pronotum is broader as compared to those with strongly deflexed sides where the thorax is less rounded and more narrowed to the base.

Although the punctuation is variable, usually there is always some evidence of a serial arrangement; rarely, the strial punctures are rather large and even moderately impressed; these specimens approach carbonaria in this respect, but omissa is as a rule more elongate in the male and more broadly ovate in the female.

The strongly punctate individuals are not necessarily confined to the region bounding the Colorado River on the west, but are to be taken at any part of the distributional area.

The larger Southern California specimens are to be referred to omissa, as the characters exhibited by the anterior tibial spurs are those characteristic of the present section of the subgenus; with these conceptions of omissa and the elimination of quadricollis everything becomes clear.

Ampla is a larger, more elongate species with elongate legs.

For the differential characters of the varieties pygmoa and peninsularis see below.

I am indebted to Prof. H. C. Fall for notes on comparisons of specimens with the LeConte type.

The mentum is variable, rather small to moderate in size, and triangulo-trapezoidal to trapezoido-parabolic; surface rather strongly punctate, more or less foveate laterally and convex at middle.

The prosternum is convex or horizontal between the coxæ and mucronate behind; the mucro may be small and subacute; larger and conical in contour, or compressed and obliquely to nearly vertically truncate behind.

The mesosternum is more or less concave, and varies in the degree of its obliquity.

The intercoxal process of the abdomen is quadrate (male) or a little transverse (female), and about a fifth (male) or a sixth (female) of its width wider than the metasternal salient.

The metasternum laterally between the coxæ is as long as the width of a mesotibia at the middle.

The post-coxal part of the first abdominal segment is equal (male) or subequal (female) in length to that of the process.

In the male the second segment is about a half longer than the third and twice as long as the fourth, and equal to the length of the process. 
In the female the second segment is about a third of its length longer than the third and twice the length of the fourth.

The profemora in the typical form are distinctly tumid and clavate, and in the males of the other forms and all females more or less moderately so. The grooves are rather broad and the margins are feebly subcariniform, converging quite close to the base.

The mesofemora are gradually and feebly thickened externally; the metafemora have their superior and inferior borders subparallel. The grooves are dull and feebly subasperate, the margins finely asperulate and more or less evanescent before becoming contiguous.

The protibiæ are more or less feebly arcurate and slightly compressed. All the tibiæ are usually without tarsal grooves, although an occasional specimen exhibits rudimentary grooves on the protibiæ with the articular cavities slightly open, otherwise the cavities are closed.

The tarsi are moderate both as to length and stoutness.

The protarsi in the male are just noticeably longer than in the female, and specimens of corresponding size must be selected, as a large female compared with a small male would not show the true difference.

The protarsi are about two-fifths (male) or three-sevenths (female) of their length shorter than a mesotarsus. Joints two, three, and four are subequal, just noticeably smaller in the female, and together about equal to the fifth in length; the first is about equal to the combined lengths of joints three and four.

The mesotarsi are about a seventh (male) or an eighth (female) of their length shorter than a metatarsus. Joints one and five are subequal in length, and the combined lengths of two, three, and four just a little longer than either.

The metatarsi are about three-fourths (male) or a half (female) of their length shorter than a metatibia. Joint two is a little longer than three; the first is as long as the combined length of third and fourth.

\section{ELEODES OMISSA var. PYGMEA, new.}

Oblong-ovate to ovate, more or less shining and smooth.

Head finely punctate, punctures denser on the epistoma, frons feebly convex to flat. Antenna moderate, outer four joints scarcely dilated, fourth, fifth, sixth, seventh, and eighth subequal in length, ninth and tenth suborbicular and slightly transverse.

Pronotum quite quadrate, widest at or just in front of the middle, one-fifth to one-fourth wider than long; disc evenly and moderately convex from side to side, finely and sparsely punctate; apex truncate in circular arc; sides evenly and not strongly arcuate in anterior twothirds, thence more or less straight and converging to base, or some- 
times apparently quite evenly arcuate from apex to base, the latter quite truncate, equal to the length, a seventh to a fourth wider than the apex; apical angles obtuse, not in the least prominent anteriorly, sometimes feebly rounded; basal angles obtuse.

Elytra oval, quite evenly and more or less moderately convex on the dorsum, more strongly rounded laterally; base scarcely emarginate, equal to or slightly wider than the base of the prothorax; humeri obtuse, scarcely prominent or rounded; sides evenly arcuaté, apex obtusely rounded; disc finely and diffusely punctate, a serial arrangement usually evident, punctures generally of the same size, serial punctures sometimes slightly larger. Otherwise as in omissa.

Male.-Usually quite slender and oblong-oval, frequently more ovate, about three times longer than wide. Elytra scarcely wider than the prothorax in the typical form, at other times wider. Both sexes otherwise as in omissa.

Measurements.-Males: Length, $13-15 \mathrm{~mm}$; width, $4.5-5.2 \mathrm{~mm}$. Females: Length, 13-16.5 mm.; width, 6-7 mm.

Genital characters as in omissa (Plate 2, figs. 1, 9, and 10.)

Habitat.-Southern California (San Diego to Kaweah, Tulare County).

Number of specimens studied, 1,000.

Sexitypes in my own collection.

Type-locality.-San Diego, Cal.

Salient type-characters.-Much smaller than omissa. Thorax quite quadrate. Elytra at the widest point scarcely wider than the prothorax in the male.

Diagnostic characters.-Typical specimens are much smaller than omissa, the larger individuals becoming indistinguishable from it.

Pygmax is of especial interest from the fact that it has been generally distributed as gentitis.

The female type before me was identified as gentilis by Colonel Casey, and is the species referred to by him in his Coleopterological Notices, VII, ${ }^{a}$ where he writes "that a very large series of gentilis which I took at San Diego shows quite clearly that this species should be associated with quadricollis and vicinus, and is out of place in the present arrangement."

Gentilis is a different species altogether and is a race of gigantea.

Pygmaxa is the most abundant species about San Diego, where I have seen it so abundant beneath boards, tin cans, sacks, and cowchips, that they actually carried these things about over the ground. These remarks apply to the early "seventies," when San Diego consisted of scattered houses and the saline flats, covered by ice plants (Mesembryanthemum crystallinum) formed the greater part of the 
maritime landscape, then these insects were gregarious in untold hundreds. I have never found them so plentiful in recent years.

Specimens from Tulare and Kern counties represent a slightly different incipient race, which may be characterized as follows:

Forma borealis.-Males less oblong and a little more ovate.

I am indebted to Mr. Ralph Hopping for the privilege of studying a large series.

In Professor Fall's collection there is a female that is more opaque than usual, but otherwise it does not differ to any extent; it was collected in the San-Bernardino Mountains, California.

Var. peninsularis is larger, glabrous, and shining, found farther south upon the peninsula of Lower California (See below).

I can not determine that Pygmaa has any other characters worthy of mention as distinguishing it from omissa, with which it agrees in mental, sternal, abdominal, and crural characters.

It might be mentioned that the prosternum is more or less convex between the coxæ and mucronate behind; the mucro is small. The mesosternum is feebly oblique and slightly concave.

\section{ELEODES OMISSA var. PENINSULARIS, new.}

Suboblong-ovate to ovate, glabrous and shining, elytra obsoletely subsulcate.

Head quite finely punctate; antenna somewhat slender, eighth joint scarcely shorter than the seventh.

Pronotum subquadrate, widest at the middle, a fifth to a fourth wider than long; disc evenly and moderately convex from side to side, scarcely more arcuately declivous laterally, but distinctly so at the apical. angles, somewhat obsoletely, finely and sparsely punctulate; apex truncate to feebly emarginate in circular arc; sides moderately and rather evenly arcuate, somewhat oblique posteriorly, briefly and very feebly sinuate before the base, as seen obliquely from the side; base feebly rounded, and scarcely to one-fifth wider than the apex; apical angles subacute; with a tendency to become feebly prominent anteriorly; basal angles obtuse and not rounded.

Propleurce obsoletely punctulate and more or less rugulose.

Elytra oval, usually widest behind the middle; disc striato-punctate, punctures generally not distinctly defined, more or less eroded, striæ somewhat impressed, intervals apparently somewhat feebly convex; strial punctures rather moderate in size and rather closely placed, intervals minutely, irregularly and obsoletely punctulate, punctules rather more distinctly defined laterally, but not usually confused.

Epipleurce obsoletely punctulate.

Sterna obsoletely punctate and more or less rugose. 
Legs rather somewhat slender. Femora moderately and rather sparsely punctate; anterior tibial spurs rather feebly developed. First joint of the anterior tarsi very feebly thickened at tip beneath. Otherwise as in omissa.

Male.-More or less oblong-ovate and somewhat slender. Abdomen feebly oblique. First joint of the anterior tarsi with a minute and pointed tuft of modified spinules on tip beneath.

Female.-Ovate, anterior spur of the anterior tibiæ not strongly differentiated and not elongate as usual.

Measurements.-Males: Length, 15-17 mm.; width, 6-6.5 $\mathrm{mm}$. Females: Length, 16-18 mm.; width, 7-8 mm.

Genital characters.-Male.-Edeagophore as in omissa.

Sternite parabolic in outline, slightly transverse. Each lobe subtriangular; external border quite evenly arcuate, with apex introrsely placed and narrowly rounded; internal border straight; surface slightly convex, glabrous and not densely punctate in apical half, setæ moderate in length and not dense. Membrane sparsely setose at bottom of the sinus, the latter rounded and subparabolic.

Female.-Genital segment quadrate; dorsal surface plane and setose.

Valvula.-Dorsal plate oblong, moderately wide and explanate apically; surface nearly plane, very glabrous, sparsely and finely punctate, setæ moderate, longer towards apex; borders subparallel, the external sinuous at basal third, thence feebly arcuate to and continuously so with the broadly and strongly rounded apical margin, which is minutely sinuate at internal fourth; internal margin sinuous. Apical external lobe inferior, the internal small, both with a few long flying hairs.

Appendage small mammilliform, not visible from above; with few long hairs on tip. Fossa moderate and fringed with long soft setæ.

Basal prominences not visible laterally.

Superior pudendal membrane longitudinally rugulose and reaching to the base of the internal apical lobe.

Ventrolateral surface strongly convex at the basal third, thence to apex broadly concave; submarginal groove broad and well marked basally, thence passing into the general concavity; surface in apical two-thirds sparsely and finely punctate and setose. Internal margins of the valves contiguous at basal sixth and subcontiguous in apical two-sixths; fissure broadly fusiform and closed at the basal half by the inferior pudendal membrane, the latter rugulose.

Habitat.-Lower California (Sierra San Lazaro).

Number of specimens studied, 20.

Types in the collection California Academy of Sciences; co-sexitypes in my own.

Type-locality.-Sierra San Lazaro, Lower California. 
Salient type-characters.-Glabrous and shining; elytra obsoletely subsulcate. Pronotum widest at the middle; disc scarcely more arcuately declivous laterally than on the dorsum, distinctly declivous at the apical angles, obsoletely and sparsely punctulate; apical angles subacute with a tendency to be feebly prominent anteriorly. Elytra usually widest behind the middle; disc striato-punctate, punctures more or less eroded, striæ somewhat impressed, intervals apparently somewhat feebly convex and obsoletely punctulate. Legs somewhat slender.

Diagnostic characters.-The salient type characters are sufficient to differentiate peninsularis from the other races of omissa.

It is very interesting to note that it is necessary to use care in recognizing it from the peninsular form of insularis, which occurs in the same region.

In insularis the pronotum is more quadrate and the apical angles are more prominent anteriorly, and the anterior femora are feebly armed in both sexes. The first joint of the anterior tarsi of the male is clothed with a brush of golden pubescence beneath-the latter often dark in old specimens. The genital characters are quite different and subgenerically so in the two species. In the peninsular form the elytra are obsoletely striato-punctate as in omissa var. peninsularis.

Dr. George Horn, in his report of the Coleoptera of Baja California, ${ }^{a}$ referred the specimens here described, as peninsularis to gentitis, and these were confused with the peninsular form of insularis which were also referred to gentilis. (See Promus insularis.)

Three specimens in the academy's collection differed from the type series of peninsularis in being intensely black and highly polished. One female was slightly aberrant; serial arrangement of the elytral punctures distinct, strial punctures distinctly larger than the interstitial; the pronotum had the sides quite strongly margined, the bead thin and reflexed. These specimens were destroyed in the great conflagration of April 18, 1906.

\section{GROUP I. QUADRICOLLIS SECTION.}

\section{ELEODES QUADRICOLLIS Eschscholtz.}

Eleodes quadricollis Eschscholtz, Zool. Atlas, III, 1833, p. 12, pl. xIv, fig. 5.-Mannerheim, Bull. Soc. Nat. Moscow, XVI, 1843, p. 268.-LE Conte, Proc. Acad. Nat. Sci. Phila., 1858, p. 181.-Honn, Trans. Amer. Phil: Soc., XIV, 1870, p. 388.-Casey, Annals N. Y. Acad. Sci., V, Nov., 1890, p. 395.-Champion, Biol. Centr.-Amer., IV, Pt. 1, 1884, p. 80 .

Eleodes tarsalis Casey, Annals N. Y. Acad. Sci., V, Nov. 1890, p. 399.

a Proc. Cal. Acad. Sci., IV, Pt. 1, p. 349.

$59780-$ Bull. $63-09-6$ 
Oblong-ovate to ovate, moderately elongate, shining, sometimes subasperulate at the sides of the elytra.

Head scarcely twice as wide as long, more or less broadly and feebly impressed laterally, frontal suture usually evident and more or less bisinuate; frons broadly flattened to feebly convex, coarsely punctate, punctures finer and sparser on vertex, more coarsely, densely, and somewhat confluent on the epistoma. Antenne moderate in length and comparatively stout, outer four joints very feebly compressed and not dilated, third joint subequal to the combined lengths of the next two, the fourth just noticeably longer than the fifth, the latter, sixth, seventh, and eighth subequal in length, the eighth subtriangular, ninth and tenth suborbicular, eleventh short ovate.

Pronotum more or less subquadrate, usually widest before the middle, occasionally at the middle, from one-sixth to one-third wider than long; disc evenly and moderately convex, arcuately declivous laterally, rather coarsely, almost evenly and rather thickly punctate, punctures generally denser at the sides where it is also more or less rugulose on the declivity; apex subtruncate to very feebly emarginate, finely and more or less obsoletely beaded; sides rather strongly arcuate anteriorly, thence straight and obliquely converging to the base as viewed vertically from above, more broadly and evenly arcuate in anterior three-fourths, thence more or less feebly sinuate to base as viewed obliquely from the side, finely beaded; base subtruncate to feebly rounded, finely margined, one-fifth to one-third wider than the apex; apical angles obtuse and slightly rounded; basal angles obtuse.

Propleurce usually glabrous, sparsely punctulate, and more or less irregularly rugulose.

Elytra oblong-oval to oval, frequently strongly inflated, widest. at the middle; base truncate to feebly emarginate; humeri obtuse, at times slightly prominent, narrowly rounded; sides evenly arcuate, apex obtusely rounded; disc moderately convex on the dorsum, strongly and quite evenly rounded laterally, inflexed sides broadly and feebly concave before the apex, dorsum arcuately declivous posteriorly, strongly, quite evenly and diffusely punctate to striatopunctate, the punctures generally simple but slightly asperate laterally and on apex.

Epipleurce moderate in width, gradually narrowing from base to apex, very feebly and broadly sinuate beneath the humeral region; surface finely and sparsely punctate.

Sterna quite strongly and densely punctate, rugose.

Parapleurce strongly and densely punctate.

Abdomen glabrous and shining, rather thickly punctate and rugulose. 
Legs moderate, strongly punctate, anterior femora mutic; anterior tibial spurs dissimilar; first joint of the anterior tarsi slightly thickened at tip beneath.

Male--Oblong-ovate, comparatively narrow, sometimes subcylindrical. Antennæ reaching to the base of the prothorax. Elytra rather narrowly oblong-oval, gradually narrowed in apical fourth, arcuately and slightly obliquely declivous behind. Abdomen distinctly oblique, very moderately convex and broadly impressed at middle of the first two segments. Femora sometimes slightly thickened; anterior tibial spurs rather short, the anterior about one-half longer than the posterior, feebly thickened and gradually narrowed from base to apex, acute. Anterior tarsi with a tuft of spinules on the thickened tip beneath, the pencil of modified spinules scarcely evident.

Female.-Body robust, ovate, antennæ not reaching the base of the prothorax. Elytra broadly oval, frequently inflated, moderately narrowed at posterior sixth, arcuately and vertically declivous behind. Abdomen horizontal and strongly convex. Anterior spurs of the anterior tibiæ robust and broad, at least twice as long as the posterior, sides arcuate and parallel, narrowed in about apical fourth and subacute. Anterior tarsi with a small transverse tuft of ordinary spinules on the thickened tip of the first joint beneath.

Measurements.-Males: Length, 16.5-21 mm.; width, 6-7.5 mm. Females: Length, 17.5-24 mm.; width, 8-12 mm.

Genital characters, male.-Edeagophore (Plate 2, fig. 8) fusiform to flattened oblong-ovate, rather stout and arched.

Basale oblong; surface rather strongly convex, sides more or less arcuate.

A picale triangular, slightly elongate; surface somewhat strongly and evenly convex, with a median membranous groove in apical half; sides feebly arcuate in basal half, thence broadly and feebly sinuate to apex, the latter somewhat narrow and acute; base with a small rounded lobe at middle and broadly sinuate laterally.

Sternite (Plate 2, fig. 5) transverse. Each lobe slightly quadrate, with the external border quite straight in basal half, thence broadly arcuate to apex, angle narrowly rounded; internal border quite straight; surface moderately convex, sparsely and strongly punctate, setose, setæ moderate, longer and denser in apical area. Membrane sparsely setose at bottom of the sinus, the latter broad.

Female.-Genital segment (Plate 2, fig. 6) quadrate, not deflexed apically and setose.

Valvula.-Dorsal plate oblong, slightly narrowing toward apex, explanate externally and at apex; surface nearly plane, impunctate in basal half, elsewhere sparsely punctate and setose, setæ rather short and reclining; external border nearly straight, converging 
apically; apical border strongly arcuate on the external lobe, the latter occupying the entire apical margin, with a small sinuation separating it from the minute internal lobe; internal border nearly straight, at times more or less sinuous. Apical margin clothed with rather long flying soft setæ.

Appendage not visible beyond the margins of the fossa, short, mammilliform.

Basal prominences not evident.

Superior pudendal membrane longitudinally rugulose, and reaching to opposite the internal apical lobe.

Ventrolateral surface (Plate 2, fig. 7) moderately convex basally and feebly concave before the apex, punctuate and setose, setæ rather short, long about the fossa; submarginal groove moderate beneath the somewhat explanate external border of the dorsal plate, curving inward beneath the external apical lobe to the fossa. Internal margins of the valves contiguous in basal eighth; fissure rather broadly fusiform, closed in the basal half by the inferior pudendal membrane.

Variations in genital characters.-In the most ventricose specimen that I examined the entire apical border was taken up by the external lobe; the internal lobe was not evident from above; the dorsal plate was narrower than usual. The genital segment viewed ventrally showed the inferior border of the valvular membrane as forming the internal wall of the fossa, and that the internal lobe was therefore small and ventral. Appendage slightly compressed.

In a specimen exhibiting marked variation, I found the setæ shorter, and the external lobe of the apex more membranous; the sides of the dorsal plate were quite straight and parallel; the internal lobe was ventral as above, and the inferior pudendal membrane was longer than usual.

Habitat.-California (about the Bay of San Francisco, Eschscholtz; Mount Diablo, Thomas Casey; Monte Bello, near Mountain View, Santa Clara County, Edward Ehrhorn; San Emigdio Canyen, Kern County, Fordyce Grinnell).

Number of specimens studied, 500 .

Type, location unknown to me.

Type-locality.-Foothills near San Francisco.

Salient type-characters.-Thorax punctulate, subquadrate, broadest anteriorly; elytra punctato-striate. Body of the male subcylindrical, of the female obovate (Eschscholtz).

Diagnostic characters.-The strongly developed anterior spurs of the anterior tibiæ (females) characteristic of the present section, separate quadricollis from all the members of the Carbonaria section. But it will be necessary to actually scrutinize the anterior spurs of the very robust examples of omissa, where the anterior spurs are cer- 
tainly strongly developed for that section, and while it will be seen that the spurs are distinctly broadened, they will also be observed to taper more gradually from base to apex, and never so parallel nor so suddenly or apically narrowed as in quadricollis. Unworn spurs must always be taken as the criteria.

The var. anthracina described below is duller in surface luster, less convex, not inflated, and in typical specimens have the elytra just noticeably obsoletely subsulcato-striate, characters never observed in the true quadricollis; the latter by its quite simple elytral punctuation is easily separated from humeralis; in cuneaticollis the elytral sculpturing is distinctly muricato-rugulose. Rileyi is more robustly ovate.

Quadricollis has been up to the present time confused with omissa. Reference to the original description of this species as given by Eschscholtz should quickly close all controversy. That author writes that the elytra are punctato-striate (elytris punctato-striatis) and that this species is plentiful in the foothills about San Francisco ("Bei St. Franzisco auf den Anhöhen häufig"). These remarks can only be applied to the present species.

What has previously been said in regard to the variation of the elytral punctuation in the different species must be recalled at this point.

All those specimens with the elytra punctato-striate are to be regarded as typical. Fully two-thirds of the large series before me have the "sculpture consisting of punctures sometimes fine, at others rather coarse, rather densely but irregularly placed, and never muricate; never arranged in rows" (Horn).

Doctor Horn undoubtedly included omissa in the above definition, but then a large percentage of the examples of that species exhibit a serial arrangement of the punctures. After all, the characters apply to quadricollis, for the punctures are sometimes fine, but generally rather coarse; punctato-striate specimens are not common, and never really muricate in the sense as it is applied to humeralis and its races. Quadricollis and omissa as well have a feeble type of submuricate punctuation at the elytral sides and apex.

I have a male quadricollis at hand, kindly transmitted to me a number of years ago by Colonel Casey. It is not at all inflated, was taken near San Francisco, and is diffusely punctured; bears the label quadricollis in Casey's handwriting. - I consider it a typical specimen, except as regards the punctuation.

Tarsalis is only an inflated form (forma tarsatis) of quadricollis. Colonel Casey himself has made this fact known. ${ }^{a}$

${ }^{a}$ Coleopterological Notices, V, p. 597, Annals N. Y. Acad. Sci., Dec., 1893. 
The student will at times find it very difficult to decide whether a given specimen (especially males) shall be referred to quadricollis or omissa.

In my experience the epistoma in quadricollis is always more coarsely punctate than in omissa. Specific differentiation is no more difficult in this instance than is met with in other sections of the genus Eleodes.

The extreme forms or heterotypes of carbonaria and obsoleta are as difficult of separation as are the above, in fact, all the constituents of the present section of the subgenus Melaneleodes might be considered as races and forms of a single species if viewed from a broad evolutionary standpoint.

The mentum is usually triangulo-trapezoidal, strongly punctate and foveate laterally within the more or less strongly defined margins; the surface is longitudinally ridged at the middle.

The prosternum is more or less strongly protuberant ventrally with the coxæ, and more or less longitudinally convex between the same, usually grooved at the middle and rather distinctly margined around the acetabula; frequently submucronately produced behind and at times nearly vertically subtruncate.

The mesosternum more or less concave and arcuately declivous.

The intercoxal process of the abdomen is quadrate (male) to feebly transverse (female) and about a third of its width wider than the metasternal salient.

The metasternum laterally between the coxæ is as long as the width of a mesofemur at the base.

The post-coxal portion of the abdomen is equal in length to that of the process, and also to that of the third segment.

In the male the second segment is about equal to the width of the process, and the third is a half longer than the fourth. In the female the second is twice as long as the fourth segment.

The profemora are usually moderately clavate in the male and less so in the female. The grooves are limited by rather strong margins, which are more or less asperulate and converge near the base.

The meso- and metafemora have their superior and inferior surfaces quite parallel. The margins of the grooves are not strongly marked, are finely muricate, and become evanescent before becoming contiguous.

The tibiæ are frequently more or less arcuate and without tarsal grooves; the articular cavities are closed.

The tarsi are somewhat variable as regards to stoutness, frequently rather more slender in the female. The protarsi are usually slightly thicker in the male and apparently subequal in the sexes.

The protarsi are about two-fifths of their length shorter than a mesotarsus. Joints two, three, and four are subequal in the male; 
the fourth a little smaller than the preceding in the female; the fifth is quite equal to the combined lengths of the preceding three; the first about a half longer than wide.

The mesotarsi are about two-sevenths (male) or a little less (female) of their length shorter than a metatarsus. Joints two to four are just a little progressively shorter or subequal, and together a little longer than the fifth, which is quite equal to the first.

A metatarsus is about five-ninths of its length shorter than a metatibia. Joint three is just noticeably shorter than the second, both together equal to the length of the first, the fourth a little shorter.

ELEODES QUADRICOLLIS var. ANTHRACINA, new.

Oblong-ovate to ovate, surface subopaque, elytra usually obsoletely subsulcate; antennæ reaching beyond the base of the prothorax in the male.

Head somewhat coarsely punctate, the coarser punctures on the epistoma not confluent nor crowded. Antennæ rather long, slightly stout, feebly clavate, outer four joints slightly compressed and feebly dilated, third joint as long as the next two combined, fourth a little longer than the fifth, the latter, sixth, and seventh subequal, the eighth shorter and subtriangular, ninth and tenth suborbicular, eleventh ovate to oval.

Pronotum subquadrate, usually widest at about the middle, near a sixth wider than long; disc evenly and moderately convex, arcuately declivous laterally, finely and rather sparsely punctulate, scarcely coarser or denser laterally, where it is frequently slightly rugulose; apex subtruncate in circular arc, and finely or obsoletely margined; sides evenly and moderately arcuate in the anterior three-fourths, thence converging to base, frequently rather evenly arcuate from apex to base (viewed vertically from above), margin finely beaded; base slightly rounded, often feebly sinuate at the middle, finely and more or less obsoletely beaded, about one-fourth wider than the apex and equal to the length; apical angles distinet and very narrowly rounded; basal angles obtuse.

Elytra oval, widest at the middle, less than twice as long as wide; base more or less emarginate, frequently slightly sinuate laterally, usually a little wider than the contiguous prothoracic base; humeri obtuse, narrowly rounded and scarcely at all prominent anteriorly; dise moderately convex on the dorsum, more strongly and almost evenly rounded laterally, arcuately declivous posteriorly, surface usually striato-punctate, intervals apparently very feebly convex, giving an obsoletely and faintly subsulcate appearance, strial punctures somewhat small, series moderately distant, rarely impressed, interstitial punctures more or less irregular on the dorsum, quite equal in size to the strial; frequently the punctures of both series are 
arranged without trace of order, nearly always so laterally and on the apical declivity, where they are scarcely ever subasperate.

Otherwise as in quadricollis.

Male.-Antennæ reaching a short distance beyond the base of the prothorax. Pronotum usually widest at the middle.

Female.-Antennæ reaching to the base of the prothorax. Pronotum not usually very noticeably widest before the middle.

Otherwise the sexual characters are as in quadricollis.

Measurements.-Males: Length, 18-19.5 mm.; width, 6.5-7.5 mm. Females: Length, 18-22 mm.; width, 7.5-10.5 mm.

Genital characters, male.-Edeagophore flaxseed-shaped and moderately arched.

Basale oblong, quite evenly convex above; sides slightly arcuate.

A picale triangular and moderately elongate; surface moderately and evenly convex, with a median semimembraneous groove in apical half; sides nearly straight, apex subacute; base rather broadly and arcuately lobed at the middle, and slightly sinuate laterally.

Sternite parabolic in outline and slightly transverse. Each lobe with the external border quite evenly arcuate to apex, the latter narrowly rounded; internal border short and nearly straight; surface feebly convex, impunctate in basal half, sparsely punctate apically, setose, setæ moderate in length, longer about the apex, not dense. Membrane sparsely setose across the bottom of the sinus, the latter short.

Female.-Genital segment quite quadrate, explanate externally in apical two-thirds.

Valvula.-Dorsal plate oblong, moderate in width, sides subparallel; surface quite plane, glabrous, coarsely and sparsely punctate, each puncture with a moderately long reclining seta, impunctate at base; external border more or less straight to feebly arcuate to the apical border, which is strongly rounded on the external lobe and slightly sinuate just external to the minute internal lobe; external lobe about as wide as the dorsal plate, both lobes sparsely set with long setæ; internal margin more or less sinuous.

Appendage not visible from above, short mammilliform and scarcely projecting beyond the margins of the fossa.

Basal prominences scarcely evident.

Superior pudendal membrane longitudinally rugulose, reaching to the internal lobe.

Ventrolateral surface as in quadricollis.

Habitat.-Arizona (Fort Grant, July 10; Hot Springs, June; Oracle, San Simon, Galiuro Mountains, May; Catalina Springs, April; Tucson, Hubbard and Schwarz; Nogales, September, Albert Koebele and F. W. Nunenmacher). 
Number of specimens studied, 150.

Types (Cat. No. 12202) are in the U. S. National Museum collection; cotypes in my own.

Type-locality.-Fort Grant, Arizona.

Salient type-characters.-Integurnents dull in luster. Epistoma somewhat coarsely punctate, punctures not crowded nor confluent. Antennæ in the male reaching beyond, and in the female to the prothoracic base. Thorax in both sexes widest at about the middle and not more strongly arcuate before the same. Elytra striato-punctate, obsoletely and faintly subsulcate.

Diagnostic characters.-Anthracina differs from quadricollis in its salient type-characters. For its separation from carbonaria, humeralis, and cuneaticollis, see differential diagnosis under quadricollis.

I have seen specimens of this race labeled carbonaria, and it is generally labeled quadricollis in collections.

In its dull luster and long antennæ it might be confused with ampla, but the shorter legs and large anterior spurs of the anterior tibiæ in the female will separate it.

Mr. Blanchard has compared it with the LeConte types, especially vicina, and says that it differs from all and is most closely related to quadricollis.

Prosternum as in quadricollis, but less inclined to be submucronate and less frequently grooved at the middle between the coxæ. The mesosternum is frequently slightly more strongly concave.

Otherwise as in quadricollis.

ELEODES QUADRICOLLIS var. LUSTRANS, new.

Oblong-ovate to ovate, moderately elongate, very glabrous and shining.

Head comparatively rather small, frons moderately and quite evenly convex, scarcely to distinctly impressed laterally, frontal suture usually not evident, almost coarsely, rather thickly and evenly punctate, punctures usually not denser on the epistoma. Antennce rather long, somewhat slender, outer four joints scarcely at all compressed or dilated, third joint quite equal in length to the next two taken together, the fourth just visibly longer than the fifth, the latter, sixth and seventh subequal, eighth just the least shorter and subtriangular, ninth and tenth suborbicular, eleventh short ovate or oval.

Pronotum subquadrate, widest at or just a little in front of the middle, one-fourth to one-third wider than long; dise evenly and moderately convex, more or less arcuately declivous at the sides and apical angles, finely and sparsely punctate, sometimes a little more 
coarsely so laterally; apex truncate in circular arc, finely and more or less obsoletely beaded; sides evenly and not strongly arcuate in anterior three-fourths, thence convergent to the base, or more or less arcuate from apex to base, as viewed vertically from above, more broadly arcuate and just the least sinuate before the base as viewed obliquely from the side, rather distinctly and finely beaded; base feebly rounded and more or less finely margined, a seventh to a fifth wider than the apex; apical angles obtuse and not in the least prominent anteriorly; basal angles obtuse.

Elytra oval, widest at the middle, scarcely twice to one-fourth longer than wide; base truncate to feebly emarginate, scarcely to a little wider than the contiguous prothoracic base; humeri obtuse; sides evenly arcuate, apex not very narrowly rounded; disc slightly flattened and moderately convex on the dorsum, rather evenly and not very broadly rounded at the sides, arcuately declivous posteriorly, punctate, punctures rather fine and more or less irregular, usually with a serial arrangement on the dorsum, interstitial punctures more or less irregular, those of both series equal in size or the strial are slightly larger; both series always confused at the sides and on the apex; not at all submuricate.

Legs rather slender.

Otherwise as in quadricollis.

Male somewhat depressed.

Female.-Convex and comparatively less elongate than in anthracina.

Other secondary sexual characters as in quadricollis.

Measurements.-Males: Length, 16-17 mm.; width, 6-7 mm. $\mathrm{Fe}$ males: Length, $16.5-17 \mathrm{~mm}$.; width, 8-8.2 mm.

Genital characters, male.-Sternite with each lobe more or less parabolic in outline. Otherwise as in quadricollis.

Female.-As in quadricollis, except that the ventrolateral surface is strongly convex at basal fourth and broadly concave before the apex, setæ rather long internally.

Habitat.-Arizona (Chiricahua Mountains, June, Hubbard and Schwarz; Catalina Springs, April; Tucson.)

Number of specimens studied, 9.

Types (Cat. No. 12203) in the U. S. National Museum collection. Type-locality.-Chiricahua Mountains, Arizona.

Salient type-characters.-Glabrous and shining. Antennæ reaching beyond (male) or to (female) the base of the prothorax. Body in the female less elongate than in quadricollis. Punctures on the epistoma not coarser than on the frons. Pronotum widest at the middle; disc finely and sparsely punctate, punctures not coarser nor denser laterally. Elytra with the discal punctures arranged in series on the 
dorsum, laterally confused and not submuricate; punctures of both series fine and equal in size.

Diagnostic characters.-Differs from both quadricollis and its race anthracina by the salient type characters. In both sexes the form is smaller and less stout and the female is decidedly less elongate and more robustly ovate. The punctuation is noticeably finer in all the specimens that I have seen, the epistoma is more sparsely and finely punctate, the punctures being not at all confluent. A striking feature in the sculpturing is the very smooth integuments.

The large anterior tibial spurs separate it from all the constituents of the Carbonaria section.

Mr. Blanchard, after careful comparisons made with the LeConte material, writes: "I do not recognize this as belonging to any of the named forms; it is nearest to quadricollis."

The prosternum is more often decidedly mucronate, although not strongly produced. Otherwise as in quadricollis.

\section{ELEODES CUNEATICOLLIS Casey.}

Eleodes cuneaticollis CAsey, Annals N. Y. Acad. Sci., V. Nov. 1890, p. 397.

Oblong-ovate to ovate, elongate, rather shining; elytra coarsely rugulose.

Head twice as wide as long, feebly convex or flattened between the eyes, coarsely and strongly, irregularly and more or less confluently punctate, punctures finer on the vertex. Antenna moderate in length and somewhat stout, scarcely compressed and not dilated, third joint fully as long as the next two combined, the fourth but slightly longer than the fifth, the latter, sixth, seventh, and eighth subequal, ninth suborbicular, tenth transverse, eleventh short ovate.

Pronotum widest at the junction of the anterior and middle thirds, one-third to two-fifths wider than long; disc broadly and moderately convex, more or less declivous laterally and at the apical angles, rather sparsely, coarsely, and deeply punctate, the punctures about twice as large and distinct as those of humeratis, frequently more or less rugulose at the sides; apex truncate or broadly and feebly emarginate in eircular arc, very finely and more or less obsoletely beaded; sides strongly arcuate anteriorly, conspicuously convergent and almost straight in basal half, viewed vertically from above, or more broadly arcuate in anterior three-fourths, thence convergent and more or less sinuate to the base, as viewed obliquely from the side, finely beaded; base truncate to slightly rounded and finely margined, about equal to the length and one-tenth to one-fifth wider than the apex; apical angles obtuse and more or less narrowly rounded; basal angles obtuse. 
Propleurce sparsely punctate and more or less strongly rugulose.

Elytra oval, widest at the middle, less than twice as long as wide; base truncate to feebly emarginate, sometimes sinuate laterally, equal to or slightly wider than the contiguous prothoracic base; humeri obtuse, at times more or less rounded, again slightly prominent; sides evenly arcuate, somewhat pointed at the apex, the latter not broadly rounded; disc more or less moderately convex on the dorsum, quite strongly and evenly rounded laterally, arcuately declivous posteriorly; inflexed sides somewhat oblique; very coarsely, deeply, and densely punctate, punctures irregularly distributed without trace of a serial arrangement, not muricate, but producing a strongly rugulose appearance by mutual semi-coalescence.

Epipleurce moderate in width and gradually narrowing from base to apex, superior margin very broadly and feebly sinuate beneath the humeri; surface sparsely punctate.

Sterna somewhat shining, densely punctate and more or less rugose.

Parapleurce coarsely and densely punctate.

Abdomen glabrous, sparsely punctate, punctures coarser and denser on the fifth segment; surface more or less rugulose.

Legs short and rather robust. Anterior femora mutic; anterior tibial spurs dissimilar in the sexes; first joint of the anterior tarsi thickened at tip beneath, feebly dissimilar in the sexes.

Male.-More or less slender. Antennæ reaching to the base of the prothorax. Elytra arcuately and more or less obliquely declivous behind and gradually narrowed in the posterior fourth. Abdomen more or less distinctly oblique, moderately convex, broadly impressed on first segment, less so on the second. Anterior spurs of the anterior tibiæ slender, acute, and about a third longer than the posterior. First joint of the anterior tarsi with the tuft of spinules obsolete at tip beneath, groove slight and not interrupted on the thickened tip.

Female.-Ovate, robust, antennæ not quite reaching to the prothoracic base. Elytra broadly oval, arcuately and more or less vertically declivous and less strongly narrowed behind. Abdomen horizontal and more or less strongly convex. Anterior spurs of the anterior tibiæ moderately broadened, sides more or less parallel, narrowing in apical fourth, rather acute or blunt if worn. First joint of the anterior tarsi distinctly thickened at tip beneath, tuft of spinules not evident.

Measurements.-Males: Length, 14-17.5 mm.; width, 5.5-6.8 mm. Females: Length, 15-18.8 mm.; width, 7-9.2 $\mathrm{mm}$.

Genital characters, male.-Edeagophore elongate and acutely ovate, and rather strongly arched. 
Basale rather short, suboblong oval; sides feebly arcuate; surface evenly convex.

A picale elongately triangular and rather arched; surface evenly convex, with a rather narrow longitudinal groove in apical twothirds; sides nearly straight, apex acute; base with a rather small rounded lobe at middle and feebly sinuate laterally.

Sternite short and transversely parabolic in outline, each lobe somewhat transverse with the external border broadly arcuate; apex slightly prominent and rather narrowly rounded; internal border rather straight; surface feebly convex, strongly and sparsely punctate, setæ rather long. Membrane very sparsely setose across the bottom of the sinus, the latter short.

Female.-Genital segment quadrate, valves with their external borders feebly converging, setose.

Valvula (Plate 3, fig. 18).-Dorsal plate oblong, feebly explanate externally and nearly plane; surface glabrous, finely and very sparsely punctate, setæ short and reclining; external border more or less feebly arcuate; internal border straight or sinuous; apical margin moderately arcuate in external three-fourths on the external lobe; internal lobe not prominent and separated from the external by a feeble sinuation.

Appendage sometimes visible from above, rather short mammilliform, with a few short setæ at tip. Fossa large and quite terminal, the inferior margin of the valvular membrane forming the internal margin, the latter more prominent than the internal lobe above.

Basal prominences not in the least evident.

Superior pudendal membrane longitudinally rugulose, long, reaching to the internal apical lobe.

Ventrolateral surface moderately convex, not prominent at the base and not transversely concave before the apex; submarginal groove very broad and shallow, forming a lateral concavity before the apex.

Habitat.-California (San Francisco, Marin, Alameda, and San Mateo counties, August). Specimens have been distributed as having been collected in San Diego County, but all of those were undoubtedly collected by Mr. G. W. Dunn and sent out without true locality labels - at least that is the case with a series that I have had for years. Personally I have collected them only in the above-named localities and have no authentic data of their having been taken elsewhere. Colonel Casey's type specimen was without an exact locality label.

Number of specimens studied, 30.

Type in Colonel Casey's collection.

Type-locality.-California; probably from some place about the Bay of San Francisco. 
Salient type-characters.-Head rather large, coarsely and deeply punctate. Antennæ short and robust. Prothorax with apex nearly as wide as the base; sides strongly arcuate anteriorly, conspicuously convergent and almost perfectly straight in basal two-thirds; disc widest at apical third, rather sparsely, coarsely and deeply punctate, punctures about twice as large and distant as those of humeratis.

Elytra distinctly less than twice as long as the prothorax; disc rather depressed above, very coarsely, deeply, and densely punctate, the punctures irregularly arranged without trace of impressed striæ, not muricate but producing a strongly rugulose appearance by mutual semi-coalescence. Legs short and robust (Casey).

Diagnostic characters.-Cuneaticollis differs from all the other species of the present subgenus in having the elytra strongly rugulose from semi-coalescence of the coarse punctures. As Casey writes, it belongs near humeralis, but differs in four important characters, namely: "The much shorter and robust antennæ and legs, the very much coarser and deeper elytral sculpture, and coarser, sparser pronotal punctures, and finally the smaller and much less unequal spurs of the anterior tibiæ in the male, the larger spur in humeratis being nearly four times as long as the smaller one." In the largest females before me the humeri are exposed.

The most noticeable disparity in the elytral characters of Casey's type and the series before me, is that, while in the type the elytra are distinctly less than twice as long as the prothorax, in all the examples before me the elytra are distinctly a little more than twice as long as the same. My series agrees in all other particulars with the original description. I have not seen any other species that could be referred to cuneaticollis; Casey does not mention the number of specimens he had before him at the time of writing his description, but specimens do occasionally have unusually short elytra in other species. In some examples the elytra are vaguely substriate when viewed longitudinally.

The individual specimens of cuneaticollis exhibit considerable variability, more so than in the other related species. The largest female before me has abnormally short legs, another has the sides of the prothorax unusually and strongly rounded in the anterior third; the antennæ are noticeably more robust and shorter in some specimens than others. I believe the present species to be more closely related to quadricollis than to humeralis; the anterior tibial spurs suggest this relationship.

The mentum is subparabolic to triangulo-parabolic, not coarsely but densely punctate, and not noticeably setose; surface more or less foveate laterally and broadly convex centrally.

The prosternum and mesosternum are variable, as in humeralis. 
The intercoxal process of the abdomen is subquadrate (male) or slightly transverse (female) and about one-fourth of its width wider than the metasternal salient.

The metasternum laterally between the coxæ is as long as the width of a mesotibia at the extreme apex.

The post-coxal part of the first abdominal segment is equal in length to the process, and the latter to that of the third segment.

In the sexes the second segment is twice as long as the fourth.

The profemora are more or less distinctly clavate; the grooves are moderately broad and the margins subcariniform, more or less asperulate, becoming contiguous and evanescent at basal third.

The mesofemora are scarcely or very feebly clavate, grooves quite plane, margins feeble and asperulate, evanescent at middle before becoming contiguous.

The metafemora are not at all widened externally and the superior and inferior surface lines are quite parallel; grooves as on the mesofemora.

The tibiæ may be more or less feebly arcuate, tarsal grooves absent, articular cavities closed.

The pro- and mesotibiæ are somewhat inwardly produced at apex. The protibiæ are sometimes quite distinctly carinate externally in basal half, noticeably so in the largest female before me.

Tarsi variable in stoutness. The protarsi are about one-half (male) or one-fourth (female) of their length shorter than a mesotarsus. Joints two, three, and four subequal in size, and together a little longer than the fifth; the first slightly shorter than the third and fourth taken together.

The mesotarsi are about a ninth (male) or a fifth (female) of their length shorter than a metatarsus. Joints two, three, and four feebly decreasing in length in the order named; the fifth subequal to the combined lengths of the second and third, the first to the third and fourth.

A metatarsus is about a half (male) or a third (female) of its length shorter than its metatibia. Joints two and three are subequal, and together about equal to the fourth, which is subequal to the first.

\section{ELEODES HUMERALIS LeConte.}

Eleodes humeralis LeConte, Reports of Explor. and Surveys . . . 47th and 49th Parallel, XII, Appendix No. 1, 1857, p. 50 ; Proc. Acad. Nat. Sci. Phila., 1858, p. 182.-Honn, Trans. Amer. Phil. Soc., XIV, 1870, p. 309.-Champion, Biol. Centr.-Amer., IV, Pt. 1, 1884, p. 80.

Oblong-ovate to ovate, elongate, more or less opaque; elytra densely, rather finely and muricately, or granulato-muricately punctate. 
Head rather less than twice as wide as long, frequently feebly and rather broadly impressed laterally, frontal suture obsolete or feebly evident and scarcely sinuate; frons feebly convex, usually more or less flattened, densely and finely, sometimes a little coarser and more or less confluently punctate, punctures fine on the vertex increasing in coarseness to the epistoma. Antennce long and somewhat slender, feebly compressed and scarcely dilated in the outer four joints, third joint as long as the next two taken together, fourth slightly longer than the fifth, the latter, sixth, and seventh subequal, eighth a little shorter and more or less subtriangular, ninth and tenth suborbicular, eleventh short ovate.

Pronotum subquadrate, widest at or just in front of the middle, about one-third wider than long; disc moderately and quite evenly convex, feebly and rather arcuately declivous laterally, rather finely and densely punctate, usually more or less narrowly subgranulate along the sides; apex truncate or very feebly emarginate in circular arc, usually finely beaded; sides rather broadly and moderately arcuate in the anterior two-thirds; thence to the base convergent and straight or feebly sinuate, marginal bead rather thin, finely reflexed and visible throughout its entire length from above; base truncate or feebly rounded, finely margined, and about one-sixth wider than the apex, about equal to the length; apical angles obtuse, scarcely rounded; basal angles obtuse, not rounded, almost rectangular at times.

Propleura quite densely punctato-rugulose.

Elytra oval, not twice as long as wide, usually widest at the middle; base truncate or more or less feebly emarginate, as wide as or slightly wider than the contiguous prothoracic base; humeri obtuse or slightly prominent; sides evenly arcuate, apex somewhat narrowly rounded; disc more or less slightly depressed on the dorsum, sometimes slightly ogival, arcuately declivous posteriorly, and quite strongly but not broadly rounded laterally, very densely and rather finely muricately punctate or almost granulate, punctures more simple centrally along the suture, the latter frequently impressed; surface at times is obsoletely striate, the inflexed sides are inwardly declivous and with the surface lines somewhat straight.

Epipleurce somewhat narrow, gradually narrowing from base to apex, the superior margin is broadly and rather feebly sinuate beneath the humeri; surface densely and subasperulately punctate.

Sterna more or less shining and very densely punctato-rugulose.

Parapleura densely punctate.

Abdomen more or less shining, rather densely punctato-rugulose. The first segment is more strongly sculptured, and the fifth quite densely punctate. 
Legs moderate in length, comparatively somewhat slender. Femora mutic and not thickened; anterior tibial spurs dissimilar, in the sexes; anterior tarsi with the first joint slightly thickened at tip beneath, groove interrupted at the ventral apical margin, tuft of spinules feebly developed and slightly dissimilar in the sexes.

Male.-Oblong-ovate to ovate, not slender. Antennæ reaching a short distance beyond the prothoracic base. Abdomen feebly oblique, moderately convex, more or less impressed at middle on segments one and two. Anterior spurs of the anterior tibix usually about three times longer than the posterior, slightly broadened and slender, acute, gradually narrowing from base to apex.

Female.-Ovate, robust. Antennæ reaching at least to the prothoracic base. Elytra arcuately and vertically declivous behind. Abdomen horizontal, strongly convex. Anterior spurs of the anterior tibiæ much broadened and produced, about three times as long as the posterior, sides subparallel and narrowed in apical fourth, subacute, worn spurs are obtusely rounded at tip.

In the material before me three forms may be recognized:

Forma typica.-Elytra generally flattened on the dorsum, sides of the disc are not broadly rounded, and the inflexed portions are obliquely and inwardly declivous. Elytral disc very densely and rather finely muricately punctate.

Forma granulato-muricata.-Elytra generally moderately convex on the dorsum, sides more or less broadly rounded, disc moderately densely granulato-muricate, granules fine and shining.

Forma tuberculo-muricata.-Pronotum more arcuately declivous laterally, with the margins more or less invisible from above. Elytra more coarsely and strongly sculptured, subtuberculately muricate, the punctures much sparser than in the typical form.

Measurements.-Males: Length, 14.2-17.5 mm.; width, $6.2-7 \mathrm{~mm}$. Females: Length, 16-20.2 mm.; width, 7.6-8.5 mm.

Genital characters, male.-Edeagophore elongately ovate, pointed and slightly arched.

Basale oblong, evenly convex above; sides feebly arcuate.

Apicale triangular, twice as long as wide, evenly convex above, with a rather wide median membranous groove in apical half; sides straight and convergent to the subacute tip; base with a rounded lobe at middle, feebly sinuate laterally.

Sternite subparabolic, almost as wide as long. Each lobe with the outer border more or less straight in basal two-thirds, thence obliquely subtruncate to apex, tip narrowly rounded; internal margin feebly arcuate; surface scarcely convex, glabrous, very sparsely punctate in apical half and setose, setæ moderately long, longer on apical margin and rather sparse. Membrane with scattered setæ across the bottom of the sinus, the latter quite deep.

59780-Bull. $63-09-7$ 
Female.-Genital segment trapezoidal, valves rather distant and convergent apically, setose; superior pudendal membrane rather widely exposed.

Valvula (Plate 3, fig. 17).-Dorsal plate oblong, feebly explanate externally, moderately narrow; surface plane, finely and sparsely punctate, also setose in apical half, setæ fine and short; borders parallel, straight or feebly sinuous; apical margin feebly arcuate in outer three-fifths on the external apical lobe, the latter slightly defined from the internal lobe by a slight sinuation; internal lobe not prominent. Apical parts set with moderately long setæ.

Appendage not visible from above, short mammilliform, not extending beyond the margins of the fossa, the latter rather large.

Superior pudendal membrane longitudinally rugulose and reaching to the internal lobe.

Ventrolateral surface rather evenly convex, not protuberant, surface lines quite straight when viewed longitudinally, not transversely concave before the apex; submarginal groove broad and shallow, forming a lateral concavity that does not bend inward beneath the apex; surface finely and sparsely punctate and setose, setæ very short. Internal margins of the valves contiguous in basal eighth; fissure rather broadly fusiform, open apically, closed in basal half by the inferior pudendal membrane.

In the granulato-muricata form the genital segment of the female is more quadrate, valves quite parallel. The dorsal plate is explanate externally in apical two-thirds. Otherwise as in the typical form.

Forma typica.-Habitat.-Washington (Walla Walla; Yakima, C. V. Piper); Oregon (George Horn, G. W. Dunn) ; California (northern, George Horn) ; Idaho (Hubbard and Schwarz).

Forma granulato-muricata.-Nevada (Verdi, April, F. E. Blaisdell; Carson City, July ; Reno, H. F. Wickham) ; Utah (C. V. Riley) ; California (Lassen County).

Forma tuberculo-muricata.-Colorado (C. V. Riley; South Park, elevation, 8,000-10,000 feet, Bowditch; Buena Vista, Wickham's List).

Number of specimens studied, 105.

Type in the LeConte collection.

Type-locality.- "Wenass River to Fort Colville."

Salient type-characters.-Opaque, head and thorax densely punctate. Thorax subquadrate, narrowed behind, sides rounded, base truncate, posterior angles obtuse. Elytra depressed on the dorsum, obsoletely striate, sculptured with subacute granules that are more or less thickly and irregularly placed, punctate on each side of the suture. Prosternum perpendicular behind (LeConte).

Diagnostic characters.-Humeratis exhibits a remarkable development in the anterior tibial spurs. In both sexes the anterior spur is 
about three or four times longer than the posterior. In this it differs from all of the other species of the subgenus, except rileyi. The integuments are more or less opaque, and in the typical form from Washington the elytra are densely muricately punctate and more or less flattened on the dorsum.

* Specimens from Lassen County, California, have the elytra discretely granulate; each granule under low power of magnification is polished and shining, under high power minutely pointed. These constitute the heterotypical western form; in the Nevada specimens the granules are smaller, less shining, but discrete.

In the Colorado examples the granules are much larger and sparser, and characterizes the incipient race here designated as forma tuberculo-muricata.

The Idaho specimens are feebly shining and more convex and resemble the species described as schwaraii. The form of the anterior tibial spurs will separate the two. These specimens and those from Colorado have the sides of the pronotum more strongly declivous, so that the marginal head can not be seen from above when viewed vertically. The relationships of these forms are really dubious, but the material at hand does not warrant their separation as distinct species.

I have seen specimens of the granulato-muricata form labeled granulata; the latter species belongs to another subgenus and is different altogether.

Riteyi is smaller, more sparsely punctate, more convex in form, and undoubtedly more closely related to humeralis than to any other species of the subgenus.

The mentum is of moderate size, rather parabolic in outline in the typical form, and more triangulo-trapezoidal in the other forms; the surface is coarsely but not very densely punctate, moderately convex and scarcely foveate laterally; setæ very short.

The prosternum is usually quite semicircularly convex anteroposteriorly between the coxæ; sometimes feebly submucronate or rarely vertically subtruncate behind.

The mesosternum is more or less feebly oblique and concave.

The intercoxal process of the abdomen is slightly transverse in both sexes, and about one-third (male) or a sixth (female) of its width wider than the metasternal salient.

The metasternum laterally between the coxæ is as long as the width of a metatibia at apex.

The post-coxal portion of the first abdominal segment is equal in length to that of the process, and in the female to the length of the third segment. 
In the male the second segment is a little longer than the post-coxal part of the first and twice as long as the fourth. The third is about one-half longer than the fourth.

In the female the second segment is about two and one-half times longer than the fourth.

The profemora are rather feebly and evenly tumid, scarcely clavate; the grooves have well-defined subasperulate margins that become contiguous at basal fourth.

The meso- and metafemora are scarcely at all widened externally. The superior and inferior surface lines are quite parallel. The tibial grooves of the mesofemora are quite well defined by asperulate margins that become evanescent before becoming contiguous. On the metafemora the grooves are similar, but evanescent at middle.

In the typical form the tibiæ are rather slender, and stouter in the other forms. The tarsal grooves are obsolete and the articular cavities closed. The tibiæ are usually not at all arcuate.

The tarsi are moderate in length and stoutness.

The protarsi in the male are apparently a little longer than in the female; about two-sevenths of their length shorter than a mesotarsus. Joints two, three, and four are subequal, and together about equal to the fifth; the first is scarcely as long as the second and third taken together.

The mesotarsi are about a fifth of their length shorter than a metatarsus. Joints two, three, and four slightly decrease in length in the order named, and together a little longer than the fifth; the first is quite equal to the combined lengths of the second and third.

The metatarsi are about five-eighths of their length shorter than a metatibia. Joints two and three are subequal, and together equal to the first, the fourth being slightly shorter.

\section{ELEODES RILEYI Casey.}

Eleodes rileyi CAsEy, Annals N. Y. Acad. Sci., VI, Nov., 1891, p. 57.

Rather robust and convex, somewhat strongly shining, intense black throughout. Head scarcely twice as wide as long, feebly convex, rather broadly and more or less impressed laterally, frontal suture usually distinct, bisinuate, and more or less impressed, coarsely and rather closely punctate; punctures sparser on the vertex, rather coarser on the epistoma. Antennce subequal in length to the head and prothorax, the third joint three times as long as wide and rather longer than the next two combined; the outer joints but moderately robust.

Pronotum from one-fourth to three-fifths wider than long, and widest a little before the middle; dise moderately and evenly convex, arcuately declivous at the sides, rather coarsely, deeply punctate, 
densely so toward the sides, sparsely and unevenly, with large impunctate patches toward the middle; apex broadly and feebly emarginate, more or less obsoletely and finely margined; sides strongly arcuate at apical third, thence strongly convergent and nearly straight to the apex; distinctly sinuate before the base, finely and distinctly beaded; base transverse, generally very broadly, feebly sinuate toward the middle, two-ninths to one-fourth wider than the apex, rather coarsely margined laterally, more or less obsoletely so at middle; apical angles obtuse, but not at all rounded; basal angles slightly obtuse, not much rounded and rather prominent.

Propleurce sparsely, irregularly punctate and more or less rugulose.

Elytra two and one-half times longer than the prothorax, and, in the middle, from one-fifth to nearly one-half wider than the latter, widest at the middle; base truncate or feebly emarginate; humeri narrowly rounded, slightly prominent, and usually distinctly exposed; sides evenly arcuate, apex narrowly rounded; disc moderately convex on the dorsum, rather evenly rounded laterally, and arcuately declivous behind, rather coarsely, feebly and subasperately punctate, sometimes with very feebly impressed distant lines, the punctures rather sparse, not much denser laterally, confusedly disposed, but often having a feeble lineal arrangement.

Epipleurce moderate in width, gradually narrowing from base to apex, superior margin feebly and broadly sinuate beneath the humeri; surface finely, sparsely, and rather obsoletely punctate.

Sterna densely punctate and rugulose.

Parapleura densely punctate.

Abdomen more or less shining, sparsely punctate and rugulose; first segment densely and strongly sculptured, and the fifth more coarsely and densely punctate.

Legs rather short, anterior femora mutic; anterior tibial spurs extremely unequal, the anterior spur robust, long, subparallel, and the posterior spur very small and acute. Anterior tarsi with the first joint feebly thickened at tip beneath, with tuft of ordinary spinules more or less feebly developed.

Male-Oblong-ovate, not noticeably slender. Elytra arcuately and somewhat obliquely declivous behind. Abdomen distinctly oblique and moderately convex, more or less broadly impressed on first two segments. Anterior spur of the anterior tibiæ about onehalf as wide as that of the female, and somewhat gradually narrowed in apical half, and acute.

Female.-Robust, ovate. Elytra arcuately and vertically declivous behind. Abdomen horizontal and rather strongly convex. Anterior spur of the anterior tibiæ much broadened, and narrowed in apical fourth, and subacute.

Measurements.-Length, 12-15 mm.; width, 5.2-7.2 mm. 
Genital characters, male.-Edeagophore elongately ovate, very feebly arched.

Basale oblong, about three times longer than wide; surface evenly and moderately convex; sides feebly arcuate.

A picale triangular; surface evenly and moderately convex, groove semi-membranous and rather broad, extending from near tip to base; sides arcuate in basal third, thence broadly and moderately sinuate to apex, the latter narrowly rounded; base subtruncate.

Sternite subparabolic. Each lobe with the apex somewhat extrorsely terminal; external border rather straight at basal third, thence arcuate to apex, the latter somewhat rounded; internal border arcuate; surface more or less convex, punctate and setose in apical half, setæ moderate in length and sparse. Membrane sparsely setose across the bottom of the sinus, the latter deep.

Female.-Genital segment moderate in size, more or less trapezoidal, valves more or less reflexed externally, somewhat feebly deflexed at apex, setose; external border rather strongly explanate, often less so toward apex.

Valvula.-Dorsal plate oblong, sides slightly converging apically; surface rather plane, glabrous, sparsely punctate and setose, setæ longer in apical moiety; external border usually feebly and broadly sinuate from the rather prominent basal angle; apical margin not distinct from the external lobe, the latter broadly and not very evenly arcuate, very feebly defined from the internal lobe by a minute sinuation; apex clothed with rather long setæ; internal border more or less sinuous; internal lobe small.

Appendage minute within the transverse fossa.

Superior pudendal membrane longitudinally rugulose and not quite reaching the internal apical lobe.

Ventrolateral surface moderatety convex in basal two-thirds, thence broadly and feebly concave to apex; submarginal groove broad beneath the explanate external border of the dorsal plate and becoming continuous with the general concavity; surface sparsely punctate and finely setose, setæ longer on apex. Internal margins of the valves contiguous at basal fifth, subcontiguous apically; fissure rather broadly fusiform, and closed in basal half by the inferior pudendal membrane.

Habitat.-Arizona (Thomas Casey); Idaho (?).

Number of specimens studied, 2 (male and female).

Type in Colonel Casey's collection.

Type-locality.-Arizona.

Salient type-characters. - Rather robust. Head coarsely and rather closely punctate. Prothorax with apex broadly, feebly emarginate; base transverse, very broadly, feebly sinuate toward the middle; sides strongly arcuate at apical third, thence strongly convergent and 
nearly straight to the apex, distinctly sinuate before the base; disc rather coarsely, deeply punctate, densely so at the sides, with large impunctate patches toward the middle. Elytra with disc rather coarsely, feebly, and subasperately punctate, punctures rather sparse, not much denser laterally, confusedly disposed (Casey).

Diagnostic characters.-The structure of the anterior tibial spurs allies this species with humeralis alone. The two specimens before me are smaller and shorter ovate, the punctation is sparser and much less asperate. The female resembles a large cordata in outline.

I am indebted to Colonel Casey for the authentic male in my collection.

I have before me a small series of specimens collected at Soda Springs, Idaho, which I refer to the present species until a larger series shall have been studied. One of the specimens, a male, is more strongly convex than the male received from Colonel Casey, while the females have the facies of a moderately smooth cordata, and the punctuation is slightly coarser, the integuments duller and slightly more asperate. One male from Idaho has the anterior spur of the anterior tibiæ much longer and stouter than in that sex of rileyi; in a single female from the same region the anterior spur is unusually prolonged and attenuated, being about four or five times longer than the posterior, which is very short and unusually slender, in the other females the anterior spurs are at least three times longer than the posterior, much broadened and obtusely rounded at tip; these are undoubtedly worn, and those in the female mentioned above with unusually prolonged spurs represent the normal condition. I believe that a sufficiently large series of rileyi would show what relation exists between these forms; they can be geographical races of either humeralis or rileyi. The genital characters are the same as in rileyi.

In the authentic male of rileyi the mentum is moderate and subtriangular in outline, the surface not coarsely punctate, feebly convex, and scarcely foveate laterally.

The prosternum is not at all produced and vertically truncate behind. The mesosternum is obliquely arcuate and very feebly and broadly concave.

The intercoxal process of the abdomen is evidently slightly transverse and about a third of its width wider than the metasternal salient.

The metasternum laterally between the coxæ is as long as the width of a mesotibia at basal third.

Post-coxal part of the first abdominal segment is equal in length to that of the process, and also equal to the third segment in length; the second is about one-half longer than the fourth.

The profemora are clavate; the grooves have distinct margins that are asperulate and become contiguous at basal third. 
The mesofemora are feebly tumid, and the grooves have feebly formed margins that are finely muricate, becoming contiguous and evanescent at middle.

The metafemora have subparallel surface lines, and the grooves are as on the mesofemora.

The tibiæ are without tarsal grooves and the articular cavities are elosed. All of the tarsi are missing on the authentic specimen under consideration, except a single metatarsus and that is proportioned as in humeratis.

GROUP II.-TRICOSTATA SECTION.

The species of this group differ from those of Group I in the broad, flattened form, with the elytra truncate at base and the humeral angles rectangular; the prothorax is likewise broadened at base, with the angles rectangular, overlapping the humeral angles of the elytra. The pronotal disc is much less declivous laterally and the marginal bead is always visible when the surface is viewed vertically from above; there is consequently scarcely any variation in the characteristic pronotal outline.

The anterior spurs of the anterior tibiæ are distinctly thickened and broadened in both sexes, less so in the male where they are always more so than in the same sex of the preceding group.

The first joint of the anterior tarsi is always more or less thickened at tip beneath and even slightly produced; a tuft is also evident.

In the females the dorsal plates of the genital valves are broad and oblong. (See Plate 1, fig. 11, and Plate 3, fig. 20.)

There is also a development of pubescence in one species at least. The hairs are setiform.

ELEODES TRICOSTATA Say.

Blaps tricostata SAY, Journ. Acad. Nat. Sei. Phila., III, 1823, p. 262.

Eleodes tricostata LeConte, Proc. Acad. Nat. Sci., Phila., 1858, p. 181.Horn, Trans. Amer. Phil, Soc., XIV, 1870, p. 307.

Eleodes planata SoLIer, Studi Ent., 1848, p. 366.

Pimelia alternata KinBy, Fauna Boreali-Amer., IV, 1837, p. 232.

Eleodes robusta LeConte, Proc. Acad. Nat. Sci. Phil., 1858, p. 183.

Oblong to oblong-oval, black, opaque, clothed with short setiform hairs, each arising from a puncture.

Head moderate, feebly convex, rather finely, more or less densely and evenly punctate, punctures more or less sparse on the vertex; frontal suture usually defined, surface more or less broadly impressed across the fronto-epistomal junction. Antenna moderately short, not reaching to the prothoracic base, outer three joints very feebly compressed, scarcely dilated, third joint hardly as long as the next two 
taken together, fourth very slightly longer than the fifth, the latter with sixth, seventh, and eighth subequal in length, the eighth feebly triangular, ninth and tenth suborbicular, eleventh oval.

Pronotum widest at the middle, a little less than one-half wider than long and at least twice as wide as the head; dise moderately convex, with broad, shallow basal impressions, finely, evenly and rather densely punctate, laterally feebly asperate and rugulose; apex evenly and somewhat deeply emarginate, marginal head rather fine; sides broadly, evenly, and rather strongly arcuate in the anterior four-fifths, thence to base oblique or more or less sinuate, marginal bead sometimes fine, at other times rather coarse; base squarely truncate to feebly emarginate, rather coarsely margined and about two-thirds wider than the apex; apical angles distinct, not acute, sometimes slightly rounded; basal angles usually rectangular, rarely slightly rounded or feebly obtuse.

Propleurce quite evenly and rather finely muricately punctate, at times more or less rugulose.

Elytra oblong-oval, usually widest at the base, sometimes at the middle; base truncate, slightly overlapped by and a little wider than the base of the prothorax; humeri quite rectangular, overlapped by the basal angles of the prothorax; sides subparallel to feebly arcuate, more or less arcuately converging in apical third, apex obtuse; dise usually flattened, very feebly to moderately convex, laterally subacutely margined by the subhumeral costæ, arcuately declivous posteriorly, more or less costate, there being a common sutural, two discal, a humeral and subhumeral costa on each elytron, alternating costæ being usually more or less rudimentary or obsolete, sulci more or less shallow; surface scabrous from rather fine, densely placed muricate punctures, which become slightly tuberculiform on the slightly elevated intervals; inflexed sides inwardly and obliquely declivous, surface plane and muricately scabrous; pubescence dual, consisting of nearly erect brownish setæ, and subfusiform, paler, flattened, more fragile and semi-reclining subsquamiform hairs. The costæ are usually more coarsely muricate.

Epipleurce rather narrow and gradually diminishing in width from base to apex, the superior margin rather strongly and broadly sinuate beneath the humeral region; surface evenly and muricately punctate.

Sterna more or less evenly and muricately punctured.

Parapleura rather finely and asperately punctate.

Abdomen somewhat shining, finely, submuricately, and rather sparsely punctulate, sometimes rugulose.

Legs somewhat slender. Anterior femora mutic; anterior tibial spurs dissimilar in the sexes, the anterior spur curved, larger, and longer than the posterior. Anterior tarsi slightly dissimilar in the 
sexes, first joint slightly thickened and feebly produced at tip beneath with a tuft of spinules interrupting the groove.

Male.-Oblong-oval, somewhat elongate. Antennæ reaching to the posterior fifth of the prothorax. Elytra usually widest at the base and thence arcuately narrowing to apex. Abdomen slightly oblique, moderately convex, distinctly impressed at base of the first segment and between the coxæ. Anterior spur of the anterior tibia about onehalf to one-third longer than the posterior, gradually tapering from base to apex, and acute. First joint of each anterior tarsus with a small, subacute tuft of yellowish modified pubescence on the produced tip beneath; second joint slightly thickened at tip beneath with a similar and rather inconspicuous tuft; groove interrupted.

Female.-Oblong, robust. Antennæ reaching to the posterior fourth of the prothorax. Elytra broadly oval and usually widest at the middle, scarcely narrowed but more or less arcuately rounded posteriorly. Abdomen horizontal and rather strongly convex. Anterior spur of the anterior tibia about twice as long as the posterior, curved, distinctly broadened, with sides quite parallel, somewhat narrowing at tip. First joint of an anterior tarsus with a tuft of ordinary piceous spinules on the thickened tip; second joint unmodified.

The present species is quite variable, and I deem it proper to indicate four incipient races, as follows:

Forma typica.-Slightly elongate in form, pubescence usually pale flavate in color. Elytra distinctly flattened, normal costæ well developed, the intermediate completely obsolete or very feebly indicated, intervals broad and flat.

Forma ovalis.-Oval, short and robust in form. Pubescence usually black. Elytra rather strongly convex, normal costæ well developed and somewhat glabrous and shining, intermediate costæ more or less evident.

Forma costata.-General form as in typica but smaller. Elytral costæ more or less strongly and quite equally developed.

Forma robusta.-Form broadly oblong, large. Elytra more or less convex, all of the costæ more or less developed, rather coarsely muricate, at apex becoming subspiculiferous.

Measurements.-Males: Length, 13-22.5 mm.; width, 6.5-10.5 mm. Females: Length, 14-22.5 mm.; width, 7-11.5 mm.

Genital characters, male.--Edeagophore flaxseed-shaped, slightly elongate and not arched.

Basale oblong, evenly convex and more or less gibbous in basal half; sides evenly arcuate.

A picale triangular, slightly elongate, feebly arched; dorsal surface evenly convex, with a moderately wide median membranous groove in apical half; sides feebly arcuate or nearly straight; apex subacute; base more or less broadly arcuate, scarcely sinuate laterally. 
Sternite transversely parabolic. Each lobe with the outer border evenly arcuate; apex more or less rounded; internal border more or less straight; surface feebly convex, shining, sparsely to rather densely punctate, setose, setæ not dense and moderate in length. Membrane slightly setose across the bottom of the sinus, the latter moderate in size.

Female.-Genital segment.quadrate, slightly longer than wide, with a slight antero-posterior convexity, setose.

Valvula (Plate 3, fig. 20).-Dorsal plate oblong, varying more or less in width. Surface glabrous and shining, plane to feebly concave, sparsely punctate in apical. half and along the internal moiety to base, setæ rather short; sides subparallel; outer lobe of apex not differentiated from the apical margin of the plate, evenly rounded, well developed, scarcely defined from the very small and hardly visible internal lobe. The valvular apex obliquely and inwardly truncate, sometimes very slightly sinuate at the inner third, apical area set with rather long and flying setæ.

Appendage small and conical, partly visible from above, directed backward and more or less inward.

Superior pudendal membrane long, reaching to the base of the internal lobe of the apex, and longitudinally rugulose.

Ventrolateral surface more or less evenly and moderately convex, sparsely punctate and setose, setæ rather short; submarginal groove arcuately bending inward to the fossa, well defined beneath the explanate external border of the dorsal plate and external apical lobe, the latter set with quite long flying hairs. Internal margins of the valves contiguous in basal fifth, genital fissure broadly fusiform, margins of the valves not closely approximated at apex. Inferior pudendal membrane visible in basal half of the genital fissure.

Habitat.-Texas (Clifton, Bosque County, G. W. Belfrage; San Diego, E. A. Schwarz; San Antonio, H. Soltau; Alice, E. A. Schwarz; Mobeetee, October); New Mexico (Santa Fé Canyon, 7,000 feet, August, F. H. Snow; Albuquerque, February, collector, H. Soltau; Las Vegas, August, Barber and Schwarz); Oklahoma (South McAlester, June, H. F. Wickham) ; Kansas (Topeka, Hubbard and Schwarz; Riley County, May and September, Popenoe; Finney County, September, H. W. Menke, collection of Ralph Hopping; Onaga) ; Colorado (Colorado Springs, June and April, H. Soltau; Glenwood Springs, June, Hubbard and Schwarz; Denver, H. Soltau; Gulnare, Las Animas County, collection of California Academy of Sciences; La Junta, Golden, Poudre Canyon, near Long's Peak, Estes Park, Lamar, Sterling, Holly, Fort Collins, La Veta, Veta Pass, Wickham's list) ; Iowa (Sioux City, April, H. Soltau); "Taken at Ames by Professor Osborn, while Professor Shimek has taken it in Lyon County (June); eastern Emmet County (August); southern 
Dickinson County (August) and eastern Woodbury County (September) ; it extends as far east as Independence, Buchanan County, September, on a broad, dry sand flat, along theWapsipinicon Bottom" (H. F. Wickham, Iowa Acad. of Sci., 1899); Wyoming (Cheyenne, May; collectors, Hubbard and Schwarz); Montana (Helena, May; Assiniboine, August; collectors, Hubbard and Schwarz) ; Southern Dakota (Sioux Falls, May, H. Soltau) ; British America (Medicine Hat, September, C. V. Riley).

Number of specimens studied, 110.

Type destroyed.

Type-locality given by Say, Missouri and Arkansas.

Salient type-characters.-Body oblong-oval, with numerous minute prostrate hairs. Thorax transversely subquadrate, anterior edge concave; basal edge rectilinear, covering the base of the elytra; lateral edge arcuate; anterior angles rounded; posterior angles excurved. Elytra scabrous, with three elevated lines, a common sutural, and a lateral one on the edge, intermediate spaces broad, flat, not concave, and sometimes with the appearance of a slightly elevated longitudinal line alternating with the others (Say).

Diagnostic characters.-A distinct species, dull in color, sparsely pubescent, and with more or less costate elytra.

In the typical form there is a humeral, a subhumeral, sutural, and two discal costæ, the intervening costæ obsolete or very feebly indieated, with the intervening spaces flat and wide.

In the costate form all of the costæ are developed and of about equal prominence; the individuals are usually under the average size and decidedly oblong in form; males more frequently observed.

The individuals of the oval form are more or less oval and rather convex, the costre are normal, strong, and frequently glabrous, the pubescence may be blackish or of the normal fulvous color.

The robust form is a larger, stouter, and decidedly more coarsely sculptured variety. Laterally and at apex the murications are quite spiculiform.

The mentum is comparatively small, triangular to trapezoidotriangular in general outline; surface feebly convex, more or less slightly impressed along the sides at times, rather finely punctate, each puncture with a short seta.

Prosternum comparatively broad between the coxæ, usually convex antero-posteriorly and more or less arcuate or vertical behind, rarely subtruncate or submucronate.

The mesosternum is usually arcuately vertical and more or less moderately concave, sometimes feebly so.

The intercoxal process of the first abdominal segment is quadrate and equal in length to the post-coxal part of the same segment; it is also equal to the second in length; the third segment is one-half 
longer than the fourth, the latter slightly more than one-half longer than the second (male); in the female the second is slightly longer.

The metasternal process is about one-fifth narrower (male) to equal in width (female) to the abdominal salient.

The metasternum laterally between the coxæ is as long as the width of a mesotibia at middle.

The profemora are moderately robust, slightly tumid, in outline elongately oblong-oval, narrowing a little at base; the tibial grooves are well marked, concave, glabrous, and shining, margins subcarinate, arcuately converging to become contiguous at basal third.

The meso- and metafemora are subparallel in their surface lines, respectively, scarcely at all tumid; the grooves are less strongly defined, the margins becoming contiguous and evanescent at near the middle.

The tibiæ are without tarsal grooves and muricate throughout; the protibial articular cavities are more or less open and slightly advanced upon the outer face of the tibia; the meso- and metatibial articular cavities are closed.

The tarsi are comparatively long and moderately slender.

In the female of forma typica the protarsi are about one-half of their length shorter than a mesotarsus. Joints one to four gradually and slightly diminish in size and length; the fifth is about equal in length to the second, third, and fourth taken together; the first is about equal in length to the second and third taken together.

The mesotarsi are one-fourth of their length shorter than a metatarsus. Joints two, three, and four gradually diminish in length and size; the first and fourth are subequal in length, and about equal to the length of the second and third taken together. Metatarsi about one-half of their length shorter than a metatibia. Joints one to three gradually diminish in width; first joint about as long as the second and third taken together; the fourth is distinctly longer than the second.

\section{ELEODES PEDINOIDES LeConte.}

Eleodes pedinoides LeConte, Proc. Acad. Nat. Sci. Phila., 1858, p. 183. Eleodes asperata LeConte, Proc. Acad. Nat. Sci. Phila., 1858, p. 183.

Oblong to somewhat broadly oval, black, elytrá frequiently more or less reddened along the suture, integuments more or less shining.

Head about twice as wide as long, more or less convex, frequently with small, irregular impressions, moderately coarsely but not very densely punctate, punctures rather evenly placed on the frons and epistoma, vertex with irregular impunctate areas; frontal suture usually distinct and more or less impressed. Antenno moderate in length and stoutness, outer three or four joints feebly compressed, scarcely or very feebly dilated, third joint about equal to the fourth 
and fifth taken together, the fourth slightly longer than the fifth, the latter, with sixth and seventh subequal in length, eighth slightly shorter and feebly triangular, ninth and tenth irregularly orbicular, eleventh oval to subtrapezoidal and scarcely longer than wide.

Pronotum widest at the middle and more than twice as wide as the head, and about one-half wider than long; disc smooth, moderately and evenly convex, frequently with small, irregularly placed impressions, rather finely and more or less sparsely punctate, with rather broad impressions within the basal angles; apex moderately and evenly emarginate, usually distinctly margined, bead moderate; sides evenly, broadly, and rather strongly arcuate in anterior five-sixths, thence to base oblique or more or less sinuate, distinctly and rather coarsely beaded; base feebly emarginate to truncate and rather coarsely margined; apical angles distinct, not acute nor rounded; basal angles rectangular or feebly obtuse.

Propleurce rather finely, thickly, and submuricately punctate and rugulose.

Elytra oval, glabrous, not pubescent, usually narrowing at or sometimes broadest at the base, the latter truncate and more or less sinuate laterally, slightly wider than the contiguous prothoracic base; $h u$ meral angles subrectangular, extending under the basal angles of the prothorax; sides more or less moderately and evenly arcuate, apex obtuse and not produced; disc depressed on the dorsum, slightly convex, sides rather narrowly rounded and inflexed, sometimes slightly carinate at humeri, rather evenly and arcuately declivous posteriorly; surface feebly sulcato-striate, intervals more or less moderately convex, striæ submuricately punctate, punctures irregularly and more or less densely placed; intervals smooth, irregularly and more or less sparsely punctate; inflexed sides inwardly oblique and feebly convex to plane, not in the least striate, irregularly, rather evenly, finely submuricately punctate and rugulose. Occasionally the punctures at the sides near the apex become strongly muricate or subspiculate.

Epipleura slightly wider than in tricostata and gradually diminishing in width to apex, the superior margin beneath the humeri quite broadly sinuate; surface irregularly and rather finely submuricately punctate.

Sterna more or less glabrous and somewhat obsoletely or finely punctate and rugulose.

Parapleurce finely, subasperately and rather densely punctate.

Abdomen more or less glabrous, finely, rather sparsely and more or less obsoletely punctulate and rugulose.

Legs moderate, femora mutic; anterior tibial spurs dissimilar in the sexes, the anterior larger and longer than the posterior; tarsi very 
slightly dissimilar in the sexes, first joint of the anterior tarsi slightly produced at tip beneath.

Male.-Oblong, somewhat elongate and moderately narrow, antennæ reaching to the prothoracic base. Elytra moderately and gradually narrowed in apical third; abdomen slightly oblique, moderately convex from side to side, broadly and indefinitely flattened along the middle; intercoxal process more or less concave. Anterior spur of the anterior tibia about a third longer than the posterior, scarcely curved and moderately thickened, gradually narrowing from base to apex, the latter acute. First joint of the anterior tarsi with a small but definite tuft of silken pubescence on the thickened tip beneath. Second joint simple.

Female.-Oblong-oval, robust. Antennæ reaching to the posterior fifth of the prothorax. Elytra broadly oval and arcuately narrowing in apical fourth. Abdomen horizontal, strongly convex and not impressed. Anterior spur of the anterior tibia slightly more than one-third longer than the posterior, curved, distinctly broadened, sides subparallel and rather suddenly narrowed at apex. First joint of the anterior tarsi with a tuft of piceous spinules upon the produced tip beneath.

Two forms may be recognized:

Forma typica.-Glabrous and not pubescent.

Forma asperata. (LeConte.) - Subscabrous. Antennæ scarcely reaching to the base of the prothorax; sides of the elytra at apex decidedly muricate to subspiculate. Legs sparsely clothed with pale, flavate, recumbent hairs.

Measurements.-Males: Length, 19.5-26 mm.; width, 6.5-10 $\mathrm{mm}$. Females: Length, 19-27 mm.; width, 8.5-12 mm.

Genital characters, male.-Edeagophore more or less elongately fusiform and feebly arched.

Basale more or less elongately suboval, strongly convex and more or less gibbous in basal half, smooth and shining; sides evenly arcuate and converging slightly from apex to base.

A picale triangular, slightly elongate, evenly convex above with a rather broad median membranous groove in apical half; sides feebly arcuate to feebly subsinuate in apical half; apex subacute and very narrowly rounded; base feebly and broadly lobed at middle and feebly sinuate laterally.

Sternite more or less parabolic in outline, about as long as wide. Each lobe with the external margin more or less evenly arcuate, sometimes scarcely subangulate at middle; apex subacute to narrowly rounded; internal margin more or less arcuate; surface feebly convex, shining and glabrous, quite regularly and not densely punctate, setose, setæ, moderate in length and slightly longer in apical 
area. Membrane setose across the bottom of the sinus, the latter moderate in width.

Female.-Genital segment quadrate and somewhat strongly setose.

Valvula (Plate 1, fig. 11).-Dorsal plate oblong and slightly convex antero-posteriorly; external border straight to feebly arcuate, apically not defined from the apical lobe, with internal border feebly arcuate; surface more or less shining, rather coarsely punctate in apical half and along the inner moiety to base, setose, setær rather long and more or less flying. Apex with the outer lobe well developed, evenly rounded and equal in width to the outer two-thirds of the dorsal plate, separated from the small and subacute internal lobe by a more or less well-marked sinuation, both lobes chothed with long flying hairs.

Appendages sometimes visible from above, small and mammilliform.

Superior pudendal membrane long reaching to the base of the small internal lobe, and longitudinally rugulose.

Ventrolateral surface evenly convex, defined from the apex and explanate external border of the dorsal plate, by the submarginal groove which passes arcuately inward to the fossa; surface sparsely punctate and setose, setæ rather short and recumbent. The internal margins of the valves are contiguous in basal fifth; genital fissure quite broadly fusiform with the inferior pudendal membrane visible in the basal half.

Habitat.-Texas (Cameron County, H. F. Wickham; Bosque County, G. W. Belfrage).

Number of specimens studied, 29.

Type in the LeConte collection.

Type-locality.- "Texas;" collected by Messrs. Schott, Haldeman, and Weise.

Salient type-characters.-Somewhat shining. Thorax sparsely punctulate, slightly convex; sides strongly rounded, posteriorly oblique, scarcely sinuate; base truncate; disc with a small impression within the basal angles; apical angles with tips rounded. Elytra with the dorsum deplanate, not margined; humeri acute and slightly prominent; disc sulcato-striate, striæ submuricately punctate, intervals sparsely punctate, towards apex convex and asperate (LeConte.)

Diagnostic characters.-Quickly separated from tricostata and neomexicana by its shining and glabrous integuments. The elytra are feebly sulcate with the intervals more or less moderately convex.

In the asperate form the surface luster is duller and the punctures become more or less muricate, at the sides and apex are acute tubercles which terminate in short yellowish bristles; the femora are also sparsely clothed with recumbent flavate hairs, that are not observed in the typical form. 
Forma asperata appears to connect tricostata and pedinoides.

The mentum, pro- and mesosternum do not differ from those of tricostata.

The metasternal and abdominal processes and abdominal segments are also as in the above species, although well developed females have the second abdominal segment longer and almost twice as long as the fourth.

The femoral and tibial characters are quite similar to those observed in tricostata.

The tarsi are comparatively long and a little stouter than in the last-named species, and the narrowing of the joints from the first to the fourth or third is less evident.

In the female of the typical form the protarsi are about two-thirds of their length shorter than a mesotarsus. Joints two to four are subequal in length and width; the fifth is a little longer than the third and fourth taken together, while the first in distinctly shorter.

The mesotarsi are one-fifth of their length shorter than a metatarsus. The total length of the first joint is about equal to the combined lengths of the second, third, and fourth; the fifth is scarcely as long as the second and third taken together.

The metatarsi are about two-thirds as long as a metatibia. The first joint is distinctly longer than the second and third taken together, while the fourth is distinctly shorter.

\section{ELEODES PEDINOIDES var. NEOMEXICANA, new.}

Closely related to pedinoides, from which it differs as follows: Surface dull, subopaque.

Pronotum evenly and moderately convex, basal impressions obsolete; base broadly and not strongly emarginate at middle.

Elytra with the disk feebly depressed, moderately convex from side to side, laterally somewhat more broadly rounded than in pedinoides, inflexed portions less sharply defined from the dorsum and slightly convex; base emarginate laterally; humeri not carinate; surface obsoletely sulcato-striate, irregularly and rather densely, finely, subgranulato-muricately punctate, the sculpturing becoming feebly asperate about apex.

Epipleurce with the superior margin rather more strongly sinuate beneath the humeri; surface rather densely and muricately punctate. Legs rather less robust.

Measurements.-Females: Length, $23 \mathrm{~mm}$; width, $11 \mathrm{~mm}$.

Genital characters.-As in pedinoides, except that the dorsal plates of the genital segment in the female are comparatively narrower and

59780-Bull. $63-09-8$ 
the superior pudendal membrane slightly shorter, not quite reaching the base of the internal apical lobe.

Habitat.-New Mexico (Cloudcroft, August, elevation 9,000 feet, W. Knaus).

Number of specimens studied, 5. Monotype a female in my own collection.

Type-locality.-Clouderoft, New Mexico; collector, Warren Knaus.

Salient type-characters.-Luster subopaque. Pronotal disk without basal impressions; elytral sculpturing subgranulato-muricate and not sulcato-striate.

Diagnostic characters.-Easily recognized by the salient type characters.

Differs from tricostata by the more convex elytra without any evidence of costæ.

Neomexicana is a distinct and in all probability an extreme variation of pedinoides and in no way related to any other known species.

The asperate form of pedinoides is evidently a connecting link between tricostata and the last-named species. For some time I was undecided as to the propriety of considering it a race of tricostata, but finally decided that it had greater affinity with pedinoides. As a race of tricostata it would be analogous to neomexicana. Its form is variable, sometimes that of the one and again that of the other species; the sculpturing most usually is that of pedinoides, while the sparsely placed flavate pubescence is that of tricostata.

In all. probability a large series would corroborate the opinion already expressed - that it is a connective form.

In neomexicana the prosternum is as in pedinoides, although usually more or less vertically subtruncate behind, rarely feebly submucronate. Other sternal, abdominal, and crural characters are as in pedinoides.

The tarsi are less elongate than in pedinoides and about as stout, and the narrowing of the joints from the first to the fourth is only distinctly evident in the protarsi ; the meso- and metatarsi have their respective joints mutually subequal in width.

In the female the protarsi are about one-half of their length shorter than a mesotarsus.

The mesotarsi are one-ninth of their length shorter than a metatarsus, and a metatarsus about one-half of its length shorter than its metatibia. Otherwise as in pedinoides.

\section{Subgenus LITHELEODES, new.}

Species under moderate size and ovate in form, the elytral sculpturing varying from smooth to tuberculate.

The prothorax is usually subquadrate; the anterior femora of the males are more or less dentate in part of the species; first joint of 
the anterior tarsi in the male may bear a minute tuft of pubescence at tip beneath; in the female the first joint is more or less thickened and slightly more prominent ventrally than the others; in both sexes the plantar groove is quite entire, except at the extreme apical margin of the first joint; it is nearly entire at this point in some males.

The pubescent tuft is most evident in extricata; less in the other species where it is darker in color and frequently quite obsolete.

The subgenus is founded upon the female genital characters, which are distinctive of the present aggregate.

Subgeneric genital characters, male.-Apicale of the edeagophore triangular, sides sinuate, and the apex more or less attenuate; dorsal surface more or less longitudinally grooved at middle.

Female.-Genital segment quadrate to triangulo-parabolic, rather thickly clothed with flying hairs. Dorsal plate of each valve ovaloblong in outline, with the internal moiety reflexed and impunctate, external one-half broadly and slightly reflexed; external border almost straight to more or less arcuate, passing into the apical margin abruptly, forming an angle, or more gradually and arcuately so. Apex small and membranous.

A ppendage large, more or less semi-elliptical, sometimes subconical, flattened, with external border frequently continuing the line of the external margin of the dorsal plate. Fossa narrow and transverse.

Superior pudendal membrane.-Usually scarcely rugulose and variable in length, long in extricata and letcheri, short in arcuata and granulata.

Distribution.-Extricata has a very extensive distribution, occurring in Texas, New Mexico, Arizona, Nevada, Utah, Colorado, Kansas, Nebraska, Wyoming, Idaho, Montana, Dakota, and eastern Oregon.

Arcuata is only known to me from Arizona.

Granulata, in Oregon, northern and eastern California, in the desert regions; and if determinations are correct, in New Mexico and Colorado. If this be true, it will be found to occur in the intervening States.

Letcheri in western Nevada and vandyleei in northeastern California and Oregon.

Genealogy.-Arcuata and extricata have no doubt arisen from a common ancestral ramus, and from the other division of the ancestral trunk granulata and letcheri have had their origin.

Extricata and granulata are no doubt the older stock, and are at present diverging at different parts of their distributional area into a considerable number of incipient races, and continued collecting and study will bring to light and differentiate many more. 
Integuments smooth and not at all asperate:

Anterior femora mutic in the sexes.

arcuata.

Integuments more or less asperate:

Elytra with approximate rows of punctures, which are feebly muricate laterally and on the apex; anterior femora armed in the male; thorax finely punctate.

Elytra not sulcate extricata.

Elytra sulcate var. arizonensis.

Elytra more or less distinctly tuberculate granulata.

Elytra muricately punctate:

Elytra pubescent letcheri.

Elytra not pubescent. var. vandykei.

\section{ELEODES ARCUATA Casey.}

Eleodes arcuata CASEY, Contr. to the Descr. and Syst. Col, of N. A., Pt. 1, 1884, p. 47 ; Annals N. Y. Acad. Sci., V, Nov., 1890, p. 395.

Oblong-ovate to ovate, robust; shining, glabrous, intense black, and very finely sculptured.

Head twice as wide as long, broadly and evenly convex, frequently slightly impressed laterally and along the frontal suture, the latter more or less evident and bisinuate; finely and irregularly punctate, punctures very sparse on the vertex, becoming coarser and slightly denser laterally and on the epistoma, or dense throughout. Antenne moderate, reaching to the prothoracic base, subequal in length in the sexes, outer four joints scarcely compressed or dilated, third joint equal to the next two combined, fourth to the seventh inclusive subequal, eighth slightly shorter and about as wide as long, ninth and tenth suborbicular, eleventh ovate.

Pronotum subquadrate, widest at or just in advance of the middle, one-eighth to one-fifth wider than long; disc moderately convex on the dorsum, more strongly so and arcuately declivous laterally, very sparsely and more or less minutely punctulate; apex broadly emarginate, and quite obsoletely margined; sides rather strongly and nearly evenly arcuate, most strongly so just in advance of the middle, very feebly and minutely sinuate just in advance of the posterior angles, frequently most strongly arcuate at the middle and very feebly and more broadly, but briefly sinuate behind, marginal bead fine; base evenly rounded, equal to the length, one-third to one-fourth wider than the apex, very finely or obsoletely margined; apical angles acute, basal obtuse, but not at all rounded.

Propleurce more or less sparsely punctulate and irregularly, more or less strongly rugulose.

Elytra oval, widest at the middle, about one-third longer than wide; base slightly and evenly emarginate, arlapted to the prothoracic 
base, to which it is equal in width; humeri obtuse, angle distinct or slightly rounded; sides evenly and more or less strongly arcuate, apex obtusely rounded; disc moderately convex, sometimes slightly depressed on the dorsum, quite evenly and strongly rounded at the sides, strongly, arcuately, and more or less vertically declivous behind; punctate, punctures small and arranged in regular series, intervals each with a row of irregularly spaced smaller punctures, punctures confused laterally, sometimes diffusely punctate throughout with series scarcely evident.

Epipleurce somewhat wide, scarcely dilated beneath the humeri, thence gradually narrowing to apex, superior margin feebly and very broadly sinuate in basal fifth; surface glabrous, at times nearly impunctate, often minutely, sparsely and irregularly punctulate.

Sterna usually shining, irregularly punctate and rugulose.

Parapleurce rather coarsely punctate.

Abdomen shining, sparsely and quite regularly punctate, at times more or less rugulose; sculpturing coarser at middle of the first segment, punctures denser and coarser on the fifth segment.

Legs moderate in length and stoutness, anterior femora feebly sinuate and mutic in the sexes; anterior tibial spurs slightly dissimilar in the sexes as well as the anterior tarsi.

Male.-Moderately narrow, oblong ovate. Elytra somewhat rounded behind, arcuately and almost vertically declivous posteriorly. Abdomen moderately oblique, moderately convex, broadly and rather slightly impressed on the first segment. Anterior tibiæ with the anterior spur slightly longer and a little stouter than the posterior; anterior tarsi with the first joint rather simple at tip beneath, the margino-apical tufts of spinules not conspicuous, groove somewhat entire.

Female.-Robust, ovate. Elytra more or less strongly arcuate and vertically declivous behind. Abdomen horizontal and more or less strongly convex; anterior spur of the anterior tibiæ slightly broadened, quite acute, and scarcely longer than the posterior; first joint of the anterior tarsi moderately thickened at tip beneath and set with short piceous spinules, groove obliterated at tip.

Measurements.-Males: Length, $12.2-14 \mathrm{~mm}$; width, $5.2-5.5 \mathrm{~mm}$. Females: Length, 14-16 mm; width, 6.8-7.2 mm.

Genital characters.-Male.-Edeagophore oblong-oval, pointed at the apical extremity, slightly arched.

Basale oblong, surface moderately and evenly convex; sides feebly arcuate.

A picale triangular; surface moderately convex, more or less depressed on the dorsum, with a moderately narrow median groove at middle third; sides arcuate in basal third, thence broadly and moder- 
ately sinuate to tip; apex feebly attenuate and subacute; base with a rounded lobe at middle third, feebly and broadly sinuate laterally.

Sternite quadrato-parabolic, each lobe with the outer border straight and more or less obliquely truncate apically, angle narrowly rounded; internal border straight; surface feebly convex, sparsely punctate and setose, setæ moderately long about apex and not dense.

Female.-Genital segment subequilaterally triangulo-parabolic, rather short and setose.

Valvula (Plate 4, fig. 25).-Dorsal plate oval-oblong, distinctly concave; surface glabous and shining, sparsely punctate, each puncture with a long seta, internal moiety in apical half impunctate and more or less reflexed, outwardly also somewhat reflexed; external border evenly arcuate, angle broadly rounded; apical margin oblique passing onto the apex, the latter triangular, acute and rather slender; angle and apex clothed with quite long flying hairs; internal border arcuate apically, sinuate toward base.

Appendage conical to depresso-conical, moderate in size with a tuft of rather long hairs. Fossa transverse.

Basal prominences not evident.

Superior pudendal membrane scarcely to feebly and distantly longitudinally rugulose, reaching to about the middle of the dorsal plate, opaque; valvular membrane closing the intervalvular cleft apically.

Ventrolateral surface.-Body moderately convex at base and more or less transversely concave before the apex; submarginal groove fine. Margins of the fossa not fringed with hairs. Apex appears sublaminate with the internal angle of the fossa.

Internal margins of the valves contiguous, genital fissure very narrow and closed. Inferior pudendal membrane not visible.

Mabitat.-Arizona (Casey; H. K. Morrison; Chiricahua Mountains, July, Fort Grant, July, Santa Rita Mountains, May, all in the collection of Hubbard and Schwarz; Santa Rita Mountains, 5,000 8,000 feet, June, F. H. Snow).

Number of specimens studied, 24.

Type is in the collection of Col. Thomas Casey.

Type-locality.-Arizona.

Satient type-characters,-Form, robust; shining and glabrous, very finely sculptured.

Interocular surface broadly and evenly convex; between the eyes the punctures are very fine and irregularly scattered, gradually increasing in size and density anteriorly; on the epistoma they are very close and much larger.

Prothorax with base one-fourth longer than the apex; sides strongly and nearly evenly arcuate, most strongly so just in advance of the 
middle, very feebly and minutely sinuate just in advance of the posterior angles; apex broadly emarginate, base very broadly and feebly arcuate; anterior angles acute, posterior obtuse, but not at all rounded; disk moderately convex, minutely granulate, very sparsely and somewhat irregularly punctate, punctures very minute.

Elytra at base as wide as the contiguous pronotum. Surface minutely and regularly creased, very minutely and strongly granulated, rather feebly and minutely punctate, punctures arranged in regular striæ, with a single row of smaller punctures between (Casey).

Diagnostic characters. - Smooth, very finely sculptured, the elytral punctures are arranged in widely spaced rows, with rows of smaller punctures between, frequently the serial arrangement is lost and the punctures are irregular throughout. The anterior femora are mutic in both sexes.

In extricata the anterior femora are armed in the male, and the elytral sculpturing consists of closely placed series of approximate punctures, with an interstitial series of more widely spaced punctures, frequently the punctures of both series are subequal in size and spacing and, as a whole, finer or coarser. The humeri are more prominent anteriorly.

Granulata has the elytra sculptured with rows of more or less elevated and rather smooth, shining tubercles, and the interspaces are opaque. The males have the anterior femora more or less armed.

Letcheri and vandykei are more elongate and in form more like certain smaller Melaneleodes; the pronotal apical angles are never as prominent anteriorly as in the present species. In letcheri the elytra are sparsely clothed with flying hairs, and in vandykei as well the elytral sculpturing is subasperate. Colonel Casey writes that the pronotum and elytra are finely granulate, the latter minutely creased as well, but these are microscopical characters only seen under moderately high power and are of no diagnostic value. Such microscopical sculpturing can be seen in numerous other species; it is to be observed in extricata.

The differences of width between the abdominal intercoxal salient and that of the metasternal salient, as observed in arcuata and extricata, are evident, as Casey states, and are good structural differential points, but are not to be always absolutely relied upon.

In "extricata the intercoxal salient of the first ventral segment is about as wide as the intercoxal salient of the metasternum, while in arcuata the first is very much wider than the second."

I agree with Colonel Casey in considering arcuata a distinct species, although related to extricata. The males of the two species are different. The elytra are more rounded behind as viewed vertically 
from above and strongly declivous in the former, much more attenuated and pointed, and gradually declivous posteriorly in the latter; anterior femora mutic in the former, armed in the latter.

Cognata Haldeman is a form of extricata, and the males have the anterior femora armed and therefore distinct from arcuata.

The large series of some 400 examples of extricata warrant me in drawing the above conclusions. Upon the form of the elytra alone I would not separate arcuata, but as far as I have been able to compare males of the two species, those of arcuata are never armed.

It is possible - as in armata - that extricata may lose the femoral teeth in certain examples, and arcuata to gain them; it is either suppression in the one or atavistic reversion in the other. If it be found a common occurrence there would still be sufficient characters to differentiate arcuata; the latter might be considered out of place in the present subgenus.

The mentum is more or less parabolic in outline and rather more than moderate size; the lateral lobes are small and not usually noticeable; surface longitudinally subcarinate at middle and deeply foveate laterally, scabrous and feebly setigerous.

The prosternum is not suddenly protuberant ventrally with the coxæ, but moderately so and more or less evenly arcuate from the anterior border; the intercoxal portion is subhorizontal or moderately arcuate, gradually narrowed behind and quite strongly mucronate.

The mesosternum is more or less arcuately declivous and concave.

The metasternum laterally between the coxæ is as long as the width of a mesotibia at apex.

The abdominal process is feebly transverse (male) or more strongly so (female), and one-fifth (male) to one-third of its own width wider than the metasternal salient.

The post-coxal part of the first ventral segment is equal in length to the third; the second is about twice as long (male) or distinctly twice as long (female) as the fourth.

The profemora are moderately clavate, the mesofemora just the least thickened outwardly; the metafemora are subequal in width throughout.

The tibial grooves are shallow, the margins not strong.

The tibiæ are without distinct tarsal grooves, which are at times feebly indicated. Articular cavities closed. Tarsi moderate. Protarsi stouter in the female.

Tarsal formula :

\begin{tabular}{rccc} 
Male. -2 & Meso. & Meta. & Metatibia. \\
\cline { 2 - 4 } & $2 \frac{2}{3}$ & 3 & 5 \\
Female. -2 & $2 \frac{1}{2}$ & 3 & $4 \frac{4}{5}$
\end{tabular}


ELEODES EXTRICATA Say.

Blaps extricata SAY, Journ. Acad. Nat. Sci. Phila., III, 1823, p. 261.

Eleodes extricata LeConte, Proc. Acad. Nat. Sci. Phila., 1858, p. 181.-Honn,

Trans. Amer. Phil. Soc., XIV, 1870, p. 309.-CAser, Contr. to the Descr. and System. Col. of N. Amer., Pt. 1, 1884, p. 48.

Eleodes cognata Haldeman, Stansbury's Explor. and Survey, Great Salt Lake, Utah, Appendix C, p. 376.-Casey, Annals N. Y. Acad. Sci., V, Nov., 1890 , p. 395.

Fusiform-ovate to ovate, about twice as long as wide, smooth, shining to subopaque. Anterior femora armed in the male; the first joint of the anterior tarsi is clothed on the slightly thickened tip beneath, with a small subacute tuft of yellowish pubescence (fresh examples).

Head twice as wide as long, moderately convex, more or less impressed laterally and feebly so along the frontal suture, the latter usually more or less vaguely indicated; finely and not very densely punctate, punctures denser on the sides and epistoma. Antenna quite long, outer four joints very feebly compressed and very slightly dilated, third joint subequal to the next two taken together, fourth slightly longer than the fifth, the latter and sixth subequal, seventh subtriangular, eighth triangular, ninth and tenth suborbicular, eleventh ovate.

Pronotum subquadrate, widest at or slightly in front of the middle, about a fourth wider than long; disc more or less moderately convex, rather strongly declivous at the apical angles, finely, evenly, and not densely punctulate, not denser nor granulate at the sides; apex broadly but not strongly emarginate in circular are, or subtruncate, about equal to the length and more or less obsoletely margined; sides evenly and not strongly arcuate, narrowing rather more strongly anteriorly than posteriorly, finely beaded; base feebly arcuate, one-fifth to one-fourth wider than the apex and very finely margined; apical angles somewhat subacute, with the appearance of being slightly prominent anteriorly or subrectangular and not rounded; basal angles obtuse, slightly or not rounded.

Propleurce moderately convex, finely and sparsely or obsoletely punctulate, quite strongly rugulose.

Elytra oval, widest at the middle, a little more than twice as long as wide; base feebly emarginate, adapted to the prothoracic base, which it scarcely exceeds in width; humeri acute and slightly prominent anteriorly, usually more or less adapted to the basal angles of the prothorax; sides evenly arcuate, apex rather narrowly rounded and not produced; disc moderately convex on the dorsum, strongly and more or less broadly rounded laterally, arcuately declivous posteriorly; more or less coarsely and rather densely punctate, with a 
tendency to arrangement in approximate rows of closely placed punctures, with smaller and more widely spaced punctures betwieen, most evident in the smoother and less so in the duller and rougher forms; punctures confused at the sides and scabrous with minute and slightly elevated, appressed points which precede the punctures.

Epipleura moderately narrow, slightly widened at base beneath humeri, thence gradually narrowing to apex, superior margin rather strongly and broadly sinuate in basal fourth, scarcely visible from above at the humeri; surface smooth, finely, sparsely or obsoletely punctulate.

Sterna more or less irregularly punctate and rugose.

Parapleurce: Mesosternal pieces quite strongly and rather densely punctate; metasternal pieces rather sparsely punctate.

Abdomen more or less shining, finely and sparsely punctate, more strongly so and rugulose between the coxæ, with punctures denser on the fifth segment.

Legs rather slender and moderately long; anterior tibial spurs unequal, the anterior a little longer and slightly stouter than the posterior, both slender and acute: anterior tarsi slightly dissimilar in the sexes.

Male.-Fusiform-ovate, somewhat elongate and more or less narrow. Antennæ reaching slightly beyond the base of the prothorax. Elytra distinctly and gradually narrowed behind, more or less gradually and arcuately or obliquely declivous posteriorly; abdomen more or less slightly oblique, moderately convex, first segment flattened at middle, with the intercoxal region more or less concave. Anterior femora armed with a subacute tooth; first joint of the anterior tarsi clothed at tip beneath, with a small subtruncate tuft of golden pubescence-usually darkly discolored; tip not very noticeably thickened, groove interrupted.

Female.-Ovate, rather robust. Antennæ reaching to the base of the prothorax. Elytra arcuately and somewhat vertically declivous posteriorly, moderately narrowing in apical fourth; abdomen horizontal, strongly and evenly convex, intercoxal process convex rather than concave. Anterior femora mutic, or at most but very feebly sinuate in outer fourth; first joint of the anterior tarsi narrowly and transversely thickened at tip beneath, with short piceous spinules, groove interrupted at the ventral apical margin.

In the material before me several forms should be recognized to facilitate the correlation of incipient races:

Forma typica.-Shining. Elytra with the approximate rows of moderately coarse punctures more or less evident and very feebly scabrous; pronotum finely punctulate. Legs moderate. 
Measurements.-Males: Length, 12-15 mm.; width, 4.5-5.5 mm. Females: Length, 12-15 mm.; width, 5-6 mm.

Forma convexicollis.-Form usually small, shorter, and more robust. Pronotal disc quite strongly convex, otherwise as in the typical form.

Measurements.-Males: Length, 11-12 mm.; width, 4.2-4.5 mm. l'emales: Length, 11-12.5 mm.; width, 4.5-5 mm.

Forma cognata typica.-Larger, more robust, smoother. Elytral punctures fine and less scabrous. Surface shining to dull.

Measurements.-Males: Length, $15-17 \mathrm{~mm}$.; width, 5-6.5 mm. Females: Length, 15-17.5 mm.; width, 6.5-8 mm.

Forma cognata punctata.-Pronotal punctures coarse; elytra densely and coarsely punctate, otherwise as in the typical cognata form.

Measurements.-Males: Length, $12.5-17 \mathrm{~mm}$; width, 4.5-7 $\mathrm{mm}$. Females: Length, 11-17.5 mm.; width, 4.5-8 mm.

Forma elongata.-Male with body tapering both ways so as to be quite evenly fusiform, dorsal median line evenly arcuate from head to elytral apex; humeri quite prominent anteriorly; thorax quadrate, apical angles acute and anteriorly prominent. Legs long and slender. Otherwise as in the typical form.

Measurements.-Males: Length, $14-15.5 \mathrm{~mm}$; width, $4.5-5 \mathrm{~mm}$.

Genital characters, male.-Edeagophore of the usual form, moderate in length, elongately oval-oblong and scarcely arched.

Basale oblong, evenly convex above, with sides feebly and evenly arcuate.

Apicale slightly elongate and triangular, evenly convex above, with a short, shallow, linear groove in median third; sides slightly arcuate at basal fourth, thence broadly and feebly sinuate to tip, the latter acute and moderately produced; base broadly lobed at middle and feebly sinuate laterally.

Stemite transversely suboblong. Each lobe with the outer border straight or feebly sinuate in basal half, thence evenly arcuate to apex, the latter rather narrowly rounded; internal border straight or sinuate; surface feebly convex, sparsely punctate and setose, setæ longer but scarcely denser about apical margin. Membrane not setose at bottom of the sinus.

Female.-Genital segment rather short, trapezoidal in outline, and setose.

Valvula (Plate 1, fig. 12).--Dorsal plate somewhat oval-oblong, inner fourth reflexed, glabrous and impunctate, outer three-fourths more or less obliquely and less strongly reflexed, sparsely punctate and setose, setæ moderatly long and flying; external border very feebly 
arcuate; internal border quite strongly arcuate; apical margin transversely or more or less obliquely truncate and scarcely defined from the apex at internal fourth. A pex small, triangular, and acute at tip, finely setose.

Appendage quite large, strongly flattened, and semielliptical, with its external margin directly continuing the line of the external border of the dorsal plate; setose, setæ short and flying. Fossa transverse and narrow.

Superior pudendat membrane reaching to the apical fourth of the dorsal plate, and more or less irregularly rugulose.

Mabitat.-Forma typica.-Kansas; Nebraska; Colorado (Buena Vista, July, elevation 7,900 to 8,000 feet; Robertson, Warren Knaus; Denver, October, H. Soltau; Colorado Springs; summit of Veta Pass, July, C. V. Riley; Gulnare, Las Animas County, July and August, Calif. Acad. Sciences). Texas (El Paso). Oklahoma (Mangum, January, H. S. Barber) ; Utah; Arizona (Winslow, July, Barber and Schwarz; Chiricahua Mountains, June; Fort Grant; Flagstaff, July ; Humphreys Peak at the base, F. H. Snow). New Mexico (Las Vegas, July). Wyoming (Big Horn Mountains, July, R. P. Currie; Dead Indian Creek; Cheyenne). Montana; Dakota; Idaho; Eastern Oregon; British America (Medicine Hat).

Forma convexicollis.-Wyoming (Lamarie); Montana.

Forma cognata typica.-Arizona (Pinal Mountains, Wickham). Colorado (Gulnare); Utah; New Mexico (Cloudcroft, 9,000 feet, August, Warren Knaus).

Forma cognata punctata.-New Mexico; Colorado (Edith, May).

Forma elongata.-Arizona (Pinal Mountains, Wickham).

Number of specimens studied, 500 .

Type destroyed.

Type-locality.- "Country of the Arkansas and Platte" (Say).

Salient type-characters.-Oblong-subovate. Head acutely punctured. Thorax subquadrate, punctures smaller than those of the head and more distant; lateral edge regularly arcuate; apex very slightly emarginate; base nearly rectilinear, a little arcuate each side near the angles, which are obtuse. Elytra destitute of striæ, or distinctly regular series of punctures, scabrous with minute slightly elevated points, each of which precedes a puncture (Say).

Diagnostic characters.-The anterior femora are armed in the males, and in both sexes the elytra are sculptured with approximate rows of rather course punctures, characters not observed in any species of Melaneleodes. In granulata and its races the elytra are sculptured with small, flat tubercles arranged in series, with intervening scattered acute elevated points. In letcheri the elytra are clothed with very sparsely placed, long flying hairs; in vandykei the 
elytra are more or less coarsely and muricately punctate at the sides and not pubescent.

In typical extricata the pronotum is very finely punctulate; in a large series, however, the punctures will be observed to become denser and coarser, until in the punctate form there is an approach to granulata and Zetcheri in that respect.

Arcuata is smooth and finely sculptured throughout and the anterior femora of the males are not dentate.

In doubtful instances the female genital characters should be studied.

The mentum is rather large in the female and subparabolic in outline; smaller and triangulo-parabolic in the male; surface convex at middle and more or less excavated laterally, subscabrously punctate and not noticeably setigerous.

The prosternum is not strongly protuberant ventrally with the coxæ, arcuate antero-posteriorly between the coxæ and more or less strongly mucronate behind.

The mesosternum is more or less strongly concave and arcuate to a varying degree.

The metasternum laterally between the coxæ is as long as the width of the mesotibia at apical third.

The abdominal process is quadrate and equal in width to the metasternal salient; in the most pronounced example of cognata before me the process is just a little wider than long and also just the least wider than the metasternal salient.

The abdominal process, post-coxal part of the same segment, and the third segment are subequal in length; the second is twice the length of the fourth.

The legs are variable in length and stoutness, and what would be expected in a very variable species.

The profemora are more or less clavate, and the tibiæ are without tarsal grooves.

The tarsi are variable in length and stoutness, longest in the elongate form and distinctly stoutest in the punctate form. But slightly longer and stouter in the male.

Tarsal formula:

$\begin{array}{rccc}\text { Pro. } & \text { Meso. } & \text { Meta. } & \text { Metatibiæ. } \\ \text { Male.-1 } \frac{2}{3} & 2 \frac{2}{3} & 3 & 4 \frac{2}{3} \\ \text { Female. }-1 \frac{1}{2} & 2 \frac{1}{3} & 3 & 4 \frac{2}{3}\end{array}$

ELEODES EXTRICATA var. ARIZONENSIS, new.

Ovate, more or less glabrous and shining; elytra sulcate and moderately convex.

Head twice as wide as long, more or less convex, impressed laterally and along the frontal suture, the latter distinct; surface finely, 
sparsely and irregularly punctate, punctures larger and denser on the epistoma. Antennce rather long, outer three joints feebly compressed, scarcely dilated, third joint scarcely as long as the next two taken together, fourth slightly longer than the fifth, the latter, sixth, seventh, and eighth subequal in length, seventh and eighth as wide as long, ninth and tenth rather transversely oval, eleventh subovate.

Pronotum widest at or slightly in advance of the middle, about a third wider than long, length equal to width of apex; disc glabrous, finely and rather sparsely punctulate, evenly and moderately convex from side to side, rather declivous at the apical angles; apex feebly emarginate to subtruncate in circular arc, finely and more or less obsoletely margined; sides feebly to moderately arcuate, slightly narrowing anteriorly to apex, rather straight and convergent posteriorly to base, very finely beaded; base slightly arcuate and finely margined, about one-sixth wider than the apex; apical angles distinct, slightly prominent and not rounded; basal angles obtuse scarcely rounded.

Propleurce usually obsoletely punctulate, quite smooth and distinctly rugulose.

Elytra oval, widest at the middle, usually less than twice as long as wide; base feebly emarginate, scarcely wider than the contiguous prothoracic base; humeri more or less acute and rather prominent anteriorly; sides evenly arcuate, apex obtuse and rather narrowly rounded; disc evenly and moderately convex, feebly depressed, strongly and evenly rounded laterally to the epipleuræ, rather evenly and arcuately declivous posteriorly; surface sulcate, the sulci broad biseriately, uniseriately, or irregularly punctate, punctures rather coarse, intervals distinctly convex, rather narrow, very sparsely or more thickly punctulate; inflexed sides obsoletely sulcate and more irregularly punctate.

Epipleurce obsoletely punctate, glabrous, and moderately narrow.

Sterna obsoletely punctate and irregularly rugose, more or less shining.

Parapleurce subopaque and rather densely punctate.

Abdomen horizontal; rather glabrous, sparsely, minutely punctate and rugulose, more coarsely so on the first ventral segment between the coxæ.

Legs quite slender and moderate in length. Anterior tibial spurs unequal, both acute; anterior tarsi slightly dissimilar in the sexes.

Male.-Body slightly elongated and slender. Antennæ reaching slightly beyond the base of the prothorax. Abdomen very moderately convex, intercoxal process slightly flattened; anterior femora armed with an obtuse tooth; first joint of the anterior tarsi clothed on the slightly proăuced tip beneath, with a minute tuft of more or less golden pubescence. 
Female.-Rather robust, antennæ reaching to the base of prothorax. Abdomen strongly convex. Anterior femora mutic; first joint of the anterior tarsi with groove entire, without the tuft of apical spinules, marginal spinules rather stout.

Measurements.-Male: Length, $13 \mathrm{~mm}$; width, $5.8 \mathrm{~mm}$. Female: Length, $14 \mathrm{~mm}$; width, $6.5 \mathrm{~mm}$.

Genital characters as in extricata, except that the genital segment of the female is subquadrate.

Habitat.-Arizona (Fort Huachuca).

Number of specimens studied, 6.

Sexitypes: Male in H. C. Fall's collection; female in that of my own.

Type-locality.-Fort Huachuca, Arizona.

Diagnostic characters.-Form of a typical extricata, with the elytra more or less sulcate; otherwise as for that species.

\section{ELEODES GRANULATA LeConte.}

Eleodes granulata LeConte, Reports of Explor. and Surveys . . 47th and 49th Parallel, XII, Appendix, No. 1, 1857, p. 50, female.-Horn, Trans. Amer. Phil. Soc., XIV, 1870, p. 309.

Eleodes obtusa LeConte, Proc. Acad. Nat. Sci. Phila., 1861, p. 352, male. Eleodes aspera LeConte, Smithson. Miscell. Coll., No. 167, 1865, p. 115.

(?) Eleodes subaspera SoLIER, Studi Entomol., II, 1848, p. 246.

Elongate ovate, more or less opaque, elytra tuberculate.

Head scarcely twice as wide as long, feebly convex and more or less flattened, broadly and very feebly impressed laterally, rather coarsely, irregular, and quite densely punctate. Antenno rather long, outer three joints very feebly compressed and scarcely dilated, third joint as long as the next two taken together, the fourth slightly longer than the fifth, the latter, sixth and seventh subequal, eighth slightly shorter, sometimes triangular, ninth and tenth slightly transversely oval; eleventh ovate.

Pronotum subquadrate, widest at about the middle, one-fourth to one-third wider than long; disc moderately and evenly convex, frequently quite arcuately declivous laterally, rather coarsely and densely punctate, punctures very much crowded along the sides, with impunctate areas and denser spots centrally; apex truncate to feebly emarginate and more or less obsoletely margined; sides more or less evenly and moderately arcuate anteriorly, rather straight and converging posteriorly, or obsoletely sinuate before the basal angles, finely beaded; base subtruncate, finely margined, equal to or slightly longer than the length, two-ninths to one-fourth wider than the apex; apical angles obtuse, distinct, not prominent nor rounded; basal angles obtuse, at times slightly rounded.

Propleuroe quite densely sculptured, punctato-rugulose. 
Elytra oval, widest at the middle; less than twice as long as wide; base truncate, equal to or slightly wider than the contiguous prothoracic base; humeri obtuse, not rounded, slightly prominent anteriorly; sides evenly arcuate, apex subacute; disc moderately convex, sometimes more or less deplanate, more or less broadly rounded laterally, inflexed sides frequently rather plane, arcuately declivous posteriorly; tuberculate, tubercles sometimes flattened, frequently evenly rounded and moderately elevated, arranged in rows, alternate series at times slightly larger, with intervening scattered, acute, elevated punctures, interspaces more or less opaque, frequently the punctures along the suture are coarsely submuricate, sculpturing more confused at the sides.

Epipleure narrow, scarcely dilated beneath the humeri, and gradually narrowing to apex, superior margin broadly upcurving in basal fifth, not visible from above; surface more or less glabrous, finely punctate.

Sterna scabrous, densely punctate and rugose.

Parapleura quite densely punctate.

Abdomen sparsely punctulate and more or less densely rugulose.

Legs usually moderate in length; anterior femora dentate or sinuate; anterior tibial spurs quite similar in the sexes, the anterior a little longer and larger than the posterior, both slender and acute; anterior tarsi feebly dissimilar in the sexes.

Male.-Elongate ovate, somewhat narrow, antennæ reaching a little beyond the base of the prothorax. Elytra rather gradually and arcuately declivous posteriorly, and somewhat attenuate in apical third. Abdomen feebly oblique, moderately convex, broadly and slightly or scarcely impressed at middle of the first segment. Anterior femora with an obtuse tooth at junction of the middle and outer third, or more or less feebly sinuate in apical fourth; anterior tarsi with the first joint scarcely thickened at tip beneath, groove entire, apico-marginal tuft of spinules rather stout, and distant.

Female.-Ovate, rather robust. Antennæ reaching about to the base of the prothorax. Elytra rather broadly oval, arcuately and at times vertically declivous prosteriorly. Abdomen rather strongly convex and horizontal. Anterior femora feebly or not sinuate in outer fourth; first point of the anterior tarsi feebly thickened at tip beneath, groove entire although shallow, apico-marginal tufts of spinules somewhat approximate.

Measurements.-Males: Length, 14.2-17.2 mm.; width, 5.5-6.5 mm. Females: Length, 16-17.5 mm.; width, 7.2-7 mm.

Genital characters, Male.-Edeagophore rather elongate, pointed oval, not arched.

Basale oblong, moderately convex, sides parallel. 
Apicale triangular, slightly elongate; surface evenly convex, obsoletely grooved at middle third; sides in basal half rather strongly arcuate, thence somewhat strongly sinuate to tip, the latter acute and rather slender; base broadly and feebly rounded at middle, feebly sinuate laterally.

Sternite transverse. Each lobe with the external border : ather broadly and evenly arcuate, continuously so with the apex, angle more narrowly rounded; internal margin oblique and somewhat arcuate; surface feebly convex, quite densely punctate and setose in apical half, setæ moderate in length on the apical border. Membrane not setose at bottom of the sinus, the latter rather broad.

Female (Plate 4, fig. 28).-Genital segment quadrate, valves more or less reflexed externally and quite conspicuously setose.

Valvula.-Dorsal plate suboval, concave, sides reflexed; surface somewhat glabrous, reflexed apical two-thirds of the internal border and about base impunctate, elsewhere rather sparsely and quite strongly punctate, setæ rather long; external border more or less arcuate, angle subrectangular; apical margin rather broadly sinuate, angle with numerous setæ; internal margin more or less broadly arcuate. Apex triangular and rather long, finely setose.

A ppendage strongly flattened, large and transversely oval, its outer margin more or less continuing the line of the external border of the dorsal plate, sparsely clothed with rather long setæ. Fossa narrow and transverse.

Superior pudendal membrane not rugulose and reaching to the middle of the dorsal plate.

Basal prominences very slight.

Ventrolateral surfaces more or less convex across the base and transversely concave laterally before the apices; surface sparsely punctate and finely setose apically; submarginal groove not clearly defined, apparently forming the lateral concavity before the apex. Genital fissure very narrow, searcely open; internal margins of the valves contiguous basally and apically. Inferior pudendal membrane not visible.

Habitat.-Oregon (collection of LeConte). California (Siskiyon County, collections U. S. National Museum and A. Koebele; Los Angeles County, D. W. Coquillett). New Mexico? Colorado (Bowditch) ?

Number of specimens studied, 12.

Type (male) in the LeConte collection.

Type-locality.-Oregon.

Salient type-characters.-The following description is by LeConte:

Elongato-ovata, nigra parum nitida, capite thoraceque subæqualiter punctatis, hoc subquadrato, minus convexo, latitudine paulo breviore, lateribus rotundatis, ad basin vix sinuatim rotundato, angulis posticis obtusis rotundatis. Elytris

59780-Bull. $63-09-9$ 
thorace latiorbus, ovalibus, apice valde declivibus subacutis, dorso minus convexis seriatim granulatis et parce muricato-punctatis, versus suturam subseriatim punctatis; humeris subproductis; prosterno postice producto; femoribus muticis. Long. .58 (LeConte).

Diagnostic characters.-As I have been unable to gain a definite knowledge of the typical form, I have given LeConte's description in full. He states that in form granulata somewhat resembles $E$. quadricollis, but less convex, and that the sculpturing of the elytra consists of small, somewhat shining, flat tubercles, arranged in series, with intervening scattered acute elevated punctures. He has also described two other forms, obtusa from California and aspera from New Mexico, both considered by Doctor Horn as synonyms of the present species. There are two specimens before me which have been compared with the type of obtusa LeConte by Mr. Blanchard and pronounced by him to be that form. LeConte's description is as follows:

E. obtusa.-Elongata, nigra capite thoraceque confertim punctatis, hoc ovato, latitudine paulo breviore, lateribus rotundatis, postice obliquis, angulis posticis obtusis, spatio parvo lævi utrinque ad medium notato, elytris postice oblique attenuatis valde declivibus, basi truncatis humeris obtusis, granulis punctisque intermixtis vix seriatim positis; femoribus anticis subtus obtuse augulatis. Long. .60.

He also writes that the elytra are punctured toward the suture, but behind and at the sides the punctures are replaced by oval elevations of moderate size, which are arranged in rows, though not very distinctly, and the humeral angles are not produced.

The examples from Siskiyou County, California, do not answer to the above descriptions. Mr. Blanchard has compared them with the type and writes as follows: "Not like the type of granulata, a male from Oregon, which is less rough; and obtusa (male from California) has a more convex prothorax than granulata, more rounded on the sides, and more coarsely and densely punctate, being in these particulars more like your Siskiyou specimen. In granulata the disc of the elytra is irregularly punctate and rugose; in obtusa more rugose and less evidently punctate." In another letter he writes that "Your Siskiyou example is perhaps more nearly aspera."

If aspera is a synonym of granulata it will be surprising as found in New Mexico. I shall again give a description of LeConte's in full:

E. aspera.-Nigra, capite thoraceque opacis, fortiter sat dense punctatis, hoc latitudine paulo breviore, obovato modice convexo, apice subemarginato, basi paulo sinuata apica haud angustiore, lateribus tenuiter marginatis rotundatis, postice subsinuatis, angulis posticis obtusis haud rotundatis; elytris ovalibus, thorace duplo latioribus basi emarginatis humeris subacutis, apice valde declivibus oblique attenuatis, dorso deplanatis, lateribus subito inflexis, undique granulis reclinatis nitidis breviter piliferis dense subseriatim positis, et parce transversim rugosis; antennis capite thoraceque vix brevioribus, extrorsum paulo incrassatis; femoribus anticis muticis, Long. .60. 
After a careful review of the literature and a study of the series of examples before me, I can come to only one conclusion, and that is that there are four incipient races involved and to be recognized.

The following forms may therefore be indicated:

Forma typica.-Thorax subquadrate, sides rounded, scarcely sinnate toward the base; basal angles obtusely rounded. Elytra seriately granulate and sparsely muricato-punctate, on each side of the suture subseriately punctate; humeri somewhat produced.

It must be borne in mind that the granulate condition is really composed of small flat tubercles, with intervening muricate punctures.

Forma obtusa.-Thorax ovate, sides rounded, oblique posteriorly, basal angles obtuse; dise with smooth spaces each side of the middle. Elytra with the humeri obtuse, disc punctate about the suture, laterally and about apex with oval elevations of moderate size, which are not very distinctly seriate.

My specimens are opaque and the pronotal punctures are smaller than those of the Siskiyou specimens, and distinctly coarser than in the examples from New Mexico.

Forma aspera.-Thorax strongly and densely punctate, sides rounded and subsinuate behind, basal angles obtuse and not rounded. Eytra with the humeri subacute, dorsum somewhat flattened, sculptured with bright reclinate granules which are briefly piliferous, the granules are densely and subseriately arranged, moderately transversely rugose.

Forma tuberculata.-Thorax as in aspera. Elytra with the humeri subacute; disc sculptured with distinct tubercles, which usually show a serial arrangement, alternate series larger and not at all rugose.

These Siskiyou specimens are larger and more elongate than obtusa, and usually of an intense black and feebly shining. The pronotal punctuation is like that of Upis ceramboides, only that the punctures are distinctly separated and not coalescent. The elytral tuberculation is almost like that observed in granosa.

The development of the tubercles shows considerable variation in the series before me. The interstitial series are the larger, and in the row the tubercles vary in size in different examples, in some subequal in size and rounded, in another some larger and others smaller, rounded or oval, and occasionally they appear to coalesce longitudinally in twos and threes to form an elongate tubercle of about $2 \mathrm{~mm}$. in length, several appearing in the same row; the strial series are small granules, these may be of uniform size, or some larger and others smaller in the same series; both series become irregular laterally and on apex, both as regards size and serial arrangement. One example has the majority of tubercles of moderate size and equal, with few small granules scattered about; another has a dis- 
tinctly serial arrangement, the tubercles in each series of uniform size, the larger very moderate, the strial quite small.

In the specimens of obtusa the arrangement is similar and the sculpturing more opaque, somewhat eroded or of a worn appearance. A large series is needed to fully establish the relationships between these different forms, and also between them and letcheri and vandylei.

Letcheri is of similar form but with the elytra distinctly pubescent, the hairs are long, sparse and flying; the sculpturing is muricato-granulate, but not very asperately so, the granular character is distinct and the surface luster is dull.

In vandykei the luster is more shining and the elytra are not at all pubescent, but distinctly granulo-muricate, with short, stiff setæ, the muricate condition predominates, each eminence is a prickle and the granular character obscured. The sculpturing is not at all coarse.

Granosa is recognized by its coarser sculpturing and much more coarsely and densely rugoso-punctate pronotum.

The anterior femora are mutic and scarcely sinuate; forms of granulata are more or less muricate, granosa less so, and besides the integuments are denser and generally opaque, although Nevada examples are shining.

Solier named a species subaspera, and it is doubtful whether it is the present species or not; Dr. George Horn places it as a doubtful synonym of granulata, and writes that if it should prove identical the present name must be suppressed and Solier's name be reinstated. I have not been able to settle this point.

The mentum is moderately large in the females of the tuberculate form, smaller in the male; rather small in obtusa. Usually subtriangular, rarely subparabolic and more or less scabrously sculptured, scarcely convex, usually somewhat broadly and feebly excavated, and not noticeably setigerous. Lateral lobes small and inconspicuous.

The prosternum is more or less convex between the coxæ, feebly produced and more or less vertically truncate behind, angle sometimes mucroid, that is with an angle having the shape of a mucro. In the type of granulata the prosternum is produced behind and slightly prominent posteriorly in obtusa.

The mesosternum is more or less obliquely arcuate, broadly and more or less deeply concave.

The metasternum laterally between the coxæ is as long as the width of a mesotibia at apical fifth.

The abdominal process is quadrate (male) or slightly transverse (female) and equal in width to (male) or one-fourth of its width wider (female) than the metasternal salient. 
The length of the process is about equal to that of the post-coxal part of the first segment; the second is twice as long as the fourth (male) or a little longer (female), and about one-third (male) to one-half (female) longer than the third.

The profemora are moderately clavate, and in the tuberculate form from Siskiyou County, distinctly dentate, the tooth is short and broad and almost subacute; in obtusa obtuse and less developed.

The tibiæ are without tarsal grooves. The mesotibiæ are at times rather strongly grooved and the metatibiæ are simply flattened externally.

The tarsi are variable in stoutness and moderate in length.

In obtusa the tarsal formula is:

\begin{tabular}{|c|c|c|c|}
\hline $\begin{aligned} & \text { Pro. } \\
\text { Male. } & 2\end{aligned}$ & $\begin{array}{c}\text { Meso. } \\
\quad 3\end{array}$ & $\begin{array}{c}\text { Meta. } \\
3\end{array}$ & Metatibix. \\
\hline emale. -2 & 3 & 3 & $5 \frac{1}{5}$ \\
\hline
\end{tabular}

ELEODES LETCHERI, new species.

Elongate ovate, subopaque, elytra moderately convex and sparsely clothed with flying hairs.

Head feebly convex, vaguely impressed laterally, somewhat finely, quite densely and rather evenly punctate. Antenno moderately long, outer four joints very feebly compressed and scarcely widened, third joint equal in length to the next two taken together, fourth slightly longer than the fifth, the latter, sixth and seventh subequal, eighth triangular and about as wide as long, ninth and tenth transversely oval, eleventh oval to ovate.

Pronotum widest at the middle and a little wider than long; disc moderately and evenly convex, finely, rather densely, and more or less irregularly punctate, the punctures at the sides frequently coalescing to form minute rugulæ; apex feebly emarginate or truncate and very finely beaded; sides evenly and not strongly arcuate in anterior twothirds, thence nearly straight or scarcely sinuate to the base and finely beaded; base feebly arcuate or truncate, finely margined, and a little wider than the apex; apical and basal angles obtuse, not prominent nor rounded.

Propleurce finely and not densely muricato-granulate, finely rugulose.

Elytra oval, not twice as long as wide; base truncate or very feebly emarginate, and slightly wider than the contiguous prothoracic base; humeri subacute and not prominent; sides evenly arcuate, apex obtuse and not produced; disc with the dorsum more or less evenly convex, more strongly so laterally, and more or less suddenly, obliquely or arcuately declivous posteriorly; very irregularly and rather densely punctate, minutely scabrous, the anterior lip of each 
puncture raised into a minute point, which become very small muricate tubercles at the sides and apex; from the punctures arise rather long, erect, dark-brownish and inconspicuous hairs; the pubescence absent on the inflexed sides.

Epipleurce feebly dilated beneath the humeri at base, narrow and gradually narrowing to apex; surface obsoletely and muricately punctulate.

Sterna more or less finely and densely, or obsoletely punctate and rugulose.

Parapleura quite densely punctate, the punctures more or less eroded.

Abdomen finely and rather thickly punctate and rugulose, the first ventral segment coarsely and densely punctate. Horizontal.

Legs moderate in length and rather slender; anterior femora not dentate, but more or less feebly sinuate; anterior spurs of the anterior tibix a little longer and thicker than the.posterior, both acute, scarcely different in the sexes; anterior tarsi feebly dissimilar in the sexes.

Male.-Slightly narrow, ovate. Antennæ reaching slightly beyond the prothoracic base. Abdomen moderately convex; first segment broadly impressed between the coxæ; second and third segments sometimes obsoletely impressed. First joint of the anterior tarsi scarcely thickened at tip beneath, groove quite entire, apico-marginal tufts of dark spinules rather approximate.

Female.-Ovate, somewhat robust, antennæ reaching to the prothoracic base. Abdomen strongly convex from side to side. First joint of anterior tarsi slightly and transversely thickened at tip beneath, with short black spinules, groove entire, although nearly obsolete at tip.

Measurements.-Males: Length, $12.5-14.5 \mathrm{~mm}$.; width, $4.8-5 \mathrm{~mm}$. Females: Length, $13-15 \mathrm{~mm}$.; width, $5.5-6.5 \mathrm{~mm}$.

Genital characters, male.-Edeagophore of the usual form, rather broadly fusiform and scarcely arched.

Basale rather short, not twice as long as wide; surface evenly convex, sides evenly and not strongly arcuate.

Apicale triangular, evenly convex above, and more or less longitudinally impressed at middle third; sides feebly arcuate in basal half and thence feebly sinuate to tip; apex slightly produced and acute; base with a median rounded lobe and sinuate laterally.

Sternite slightly transverse. Each lobe rather narrow, with the external border more or less straight in basal half, thence evenly arcuate to apical angle, the latter narrowly rounded; surface quite strongly and rather densely punctate and setose, setæ not dense and moderately long; internal border more or less straight. Membrane not setose at bottom of the sinus, the latter broad. 
Female.-Genital segment triangulo-quadrate, rather short, shining and sparsely setose.

Valvula (Plate 3, fig. 5).-Dorsal plate suboval to oblong, inner third reflexed and outer two-thirds obliquely reflexed; surface channeled between the obliquely reflexed sides, glabrous, very sparsely punctate and setose, setæ moderately long and flying; external border straight or feebly arcuate; internal border more or less sinuous; apical margin somewhat obliquely truncate, angle more or less rounded; apex short and broadly subtriangular.

Appendage short and broad, strongly flattened, somewhat semielliptical, evenly and broadly rounded or more or less emarginate at tip, about equal in length to the apex. Fossa transverse and narrow. Apex, appendage, margins of the fossa sparsely set with moderately long hairs.

Superior pudendal membrane more or less longitudinally rugulose, reaching to about the apical third of the dorsal plate in the median line, laterally extending directly to the bases of the apical lobes, and appearing triangularly emarginate when the valves are moderately abducted.

Ventrolateral surfaces (Plate 3, fig. 6) moderately tumid in the basal two-thirds, transversely concave at base of the apices, finely and sparsely punctate, setose; submarginal groove not developed. Internal margins of the valves contiguous in basal third, genital fissure fusiform and not broad. Inferior pudendal membrane not well defined.

Habitat.-I collected a series of specimens at Verdi, Nevada, elevation 6,000 feet, in April. They were taken from beneath stones on the level land about the town.

Number of specimens studied, 15.

Cotypes in my own and Dr. E. C. Van Dyke's collection.

Type-locality.-Verdi, Nevada.

Salient type-characters.-Thorax subquadrate, sides evenly arcuate anteriorly, thence nearly straight to base; disc rather densely and irregularly punctured; angles obtuse, and not rounded.

Elytra with the humeri small and subacute, scarcely prominent anteriorly; disc finely muricately punctured and sparsely clothed with flying hairs.

Diagnostic characters.-Letcheri is unique in having only the elytra set with moderately long hairs, it recalls Cratidus osculans, but the pubescence is not nearly so conspicuous as in the latter species.

At first glance it might be taken for a humeralis, especially if the pubescence has been removed, but the small size of the anterior tibial spurs will quickly separate it from the female of that species; the males would be more difficult of separation under such conditions. In letcheri the sides of the pronotum are scarcely sinuate posteriorly 
and the base is truncate. The elytral base is truncate and the humeri scarcely at all prominent anteriorly.

In humeralis the sides of the pronotum are generally broadly and feebly sinuate behind, with the base more or less rounded; the elytral base is distinctly emarginate with the humeri more or less prominent anteriorly. The two species are found together, with nigrina and tenebrosa at Verdi.

Humeralis is more asperately sculptured.

In vandykei the elytra are simply very finely setose and the integuments are shining, in letcheri they are opaque.

Variations.-There are no special variations in the series before me. The males have the pronotum more quadrate and the sides more evenly rounded; in the females the pronotal sides are more strongly arcuate anteriorly and straighter posteriorly (Plate 11, figs. 25 and 26 ), and the elytral disc is frequently more depressed, with the sides consequently more strongly rounded. The pronotal marginal bead at the sides may be obsolete.

This species is dedicated to my friend, the late Beverly Letcher in recognition of many favors.

The mentum is moderate, and the middle lobe quite evenly rounded anteriorly; surface plane and quite evenly punctate.

The muricate punctures of the elytra when viewed longitudinally appear to be subseriately arranged on the sides.

The prosternum is more or less feebly convex antero-posteriorly between the coxæ; compressed and vertically truncate behind, with the angle usually rectangular.

Mesosternum arcuate and more or less vertical, broadly and feebly concave.

The tibial grooves of the femora are distinctly concave, with margins well defined and finely asperate. The floors of the grooves are quite glabrous.

In the males the anterior femora have the anterior margins of the grooves subangulate, thence to the apex sinuate; although the femoral tooth is feeble, the species is no doubt related to species with dentate anterior femora, like granulata for instance.

The external borders of the anterior tibiæ, with those of the middle and posterior near base, are obsoletely carinate.

Tarsal formula :

$\begin{array}{rccc}\text { Pro, } & \text { Meso. } & \text { Meta. } & \text { Metatibix. } \\ \text { Male. }-2 \frac{1}{6} & 3 & 3 & 5 \\ \text { Female. }-2 & 3 & 3 \frac{1}{2} & 5\end{array}$

ELEODES LETCHERI var. VANDYKEI, new.

More or less shining, elytra not pubescent. Antenne with the third joint scarcely as long as the next two combined, fourth joint a little 
longer than the fifth, the latter slightly longer than the sixth, the latter and seventh equal.

Pronotum usually widest at the middle, frequently widest just, in front of the middle.

Elytra irregularly and quite densely muricately punctate, very minutely so on the dorsum, coarser on the sides and apex; from each puncture arises a rather short, stiff, curved, inconspicuous and semirecumbent seta. These are not evident on the inflexed sides.

Otherwise as in letcheri, but a little more robust.

Measurements.-Males: Length, 14.5-16 mm.; width, $5-6.5 \mathrm{~mm}$. Females: Length, $15-16 \mathrm{~mm}$; width $7.5 \mathrm{~mm}$.

Genital characters as in letcheri.

Habitat.-Taken in Modoc County, California, by Dr. E. C. Van Dyke.

Number of specimens studied, 10.

Cotypes in my own and Dr. Van Dyke's collection.

Type-locality.-Modoc County, California.

Diagnostic characters.-In form and sculpturing resembles letcheri, but the surface is smoother and more shining. The elytra are not pubescent.

Prosternum more or less strongly convex antero-posteriorly between the coxæ, compressed and vertically truncate as in letcheri, or with a more or less developed mucro, which is at times feebly deflexed.

Mesosternum as in letcheri.

This form is not in the LeConte collection (Blanchard).

Tarsal formula:

\begin{tabular}{|c|c|c|c|}
\hline $\begin{array}{r}\text { Pro. } \\
\text { Male. }-2 \frac{1}{6}\end{array}$ & $\begin{array}{c}\text { Meso. } \\
3\end{array}$ & $\begin{array}{c}\text { Meta. } \\
3 \frac{2}{3}\end{array}$ & $\begin{array}{c}\text { Metatibiæ } \\
6\end{array}$ \\
\hline emale. -2 & 3 & $3 \frac{1}{3}$ & 6 \\
\hline
\end{tabular}

In the U. S. National Museum collection there is a very interesting series of this species taken at The Dalles, Oregon, July, by Hubbard and Schwarz; the heterotypes are very much smaller but the series lead directly up to the typical form of vandyleei. The genital characters are those of the present subgenus. This small form may be characterized as follows:

Forma parvula.-Small, ovate. Pronotum quadrate, strongly and quite semi-circularly convex from side to side; sides feebly and quite evenly arcuate; apex truncate in circular arc, with angles rectangular; base truncate, angles subrectangular. Elytra distinctly asperate with muricate granules, densely placed and in somewhat evident longitudinal series when viewed antero-posteriorly, more or less transversely rugulose laterally; humeri acute and feebly prominent anteriorly.

Antennæ in the male long, reaching beyond the prothoracic base, scarcely compressed and somewhat incrassate externally. 
Measurements.-Male: Length, $9.5 \mathrm{~mm}$., width, $3.5 \mathrm{~mm}$. Female: Length, $9 \mathrm{~mm}$; width, $3.8 \mathrm{~mm}$.

This small form would no doubt be referred to humeralis upon superficial examination. The anterior spur of the anterior tibiæ in the female is comparatively stouter than in the other species of the subgenus. Such an acute observer as Mr. Blanchard referred it to "near humeratis." Without recourse to examination of the genital segments it would be very difficult to do otherwise; the sculpturing is quite like that of the latter species.

I take great pleasure in giving the species the name of my colleague, Dr. E. C. Van Dyke.

\section{Subgenus TRICHELEODES, new.}

Pubescent species, body clothed with moderately long and more or less erect hairs. The pronotum is coarsely, densely, and more or less rugosely punctate; the humeri are scarcely evident and rounded; the sculpturing is more or less punctato-muricate, becoming muricately tuberculate in some heterotypes.

Subgeneric genital characters, male.-Apical lobe of the edeagophore triangular with a median longitudinal impression.

Female.-Genital segment subequilaterally triangular. Valvula with the dorsal plate arcuate at the external border, apical angle obsolete, internal apical lobe well developed. Appendage short mammilliform. Superior pudendal membrane reaching to the middle of the dorsal plate.

The abdomen is horizontal in the male, and in both sexes the first ventral segment is about as long as the combined lengths of the next two.

Relationships.-The species of the present subgenus in outward habitus most nearly approaches Pseudeleodes, and in the muricately tuberculate heterotypes this becomes more evident.

The female genital characters indicate a common origin with Litheleodes and Promus. In the former there is also a tendency to hirsuteness (letcheri). A vast amount of material must yet be carefully studied before the present question can be at all satisfactorily settled. Increased effort at collecting in the arid regions of the West is a desideratum.

Distribution.- The species prefer the arid regions of Nevada, Utah, and eastern California, one species extending northward into Oregon, and also, according to Linell, into New Mexico.

The two species of this subgenus may be separated as follows:

Larger species more or less opaque, hairs of the elytra distinctly unequal in length and slightly bristly -pilosa.

Smaller species and Amphidora-like in facies; hairs of the elytra shorter, softer, and suequal in length hirsuta. 
ELEODES HIRSUTA LeConte.

Eleodes hirsuta LeConte, Proc. Acad. Nat. Sci. Phila., 1861, p. 352.-Honn, Trans. Amer. Phil. Soc., XIV, 1870, p. 315.

Ovate, scarcely elongate, about twice as long as wide, clothed with black pubescence, coarsely punctate, and more or less shining.

Head very feebly convex, frontal suture evident; densely, strongly, and rather finely punctate, each puncture bearing a more or less erect and rather short hair. Antenne rather long, reaching slightly beyond the prothoracic base, scarcely compressed in outer four joints, feebly incrassate, third joint equal to the next two taken together, fourth just noticeably longer than the fifth, the latter, sixth and seventh, subequal, eighth about as wide as long, ninth and tenth feebly transversely oval; eleventh short ovate.

Pronotum subquadrate, one-sixth to one-third wider than long, widest at the middle; disc rather strongly convex from side to side, laterally arcuately declivous, strongly and densely punctate; interstices more or less glabrous and shining; laterally the punctures more or less coalesce; apex truncate, and quite obsoletely margined, about equal to the length; sides evenly and moderately arcuate anteriorly, less so, and nearly straight, and slightly converging posteriorly, frequently evenly arcuate from apex to base; distinctly margined. bead fine; base scarcely arcuate to truncate, very finely and distinctly margined, slightly wider than the apex; apical angles obtuse, not prominent anteriorly, scarcely rounded; basal angles obtuse.

Propleurce shining and rather coarsely punctate, more or less rugose.

Elytra oval, more or less shining, widest at the middle; base truncate; humeri rounded and angle not evident; sides evenly arcuate; apex obtuse and rounded, not in the least produced; disc moderately convex on the dorsum, more strongly and arcuately rounded laterally. arcuately and more or less vertically declivous posteriorly; surface densely, irregularly punctate, finely muricate, but not asperate, pubescent; hairs moderate in length and flying, soft and subequal in length.

Epipleurce very narrow, gradually narrowing from base to apex; just a little wider beneath the humeri than at a point opposite the first abdominal suture; surface finely and sparsely punctate, shining.

Sterna more or less densely punctate and shining.

Parapleurce coarsely punctate.

Abdomen glabrous and shining; more or less densely punctate, and feebly rugulose. Horizontal.

Legs moderate, rather strongly but not very densely sculptured, clothed with short and semirecumbent hairs; anterior tibial spurs slender and subequal, those of the mesotibæ subequal; the inner spurs 
of the metatibia slightly longer than the external. Anterior tarsi very slightly dissimilar in the sexes; first joint scarcely produced ventro-apically; groove distinet.

Male.-Somewhat narrow, scarcely robust. Elytra about one-third longer than wide. Abdomen moderately convex. Anterior tibial spurs quite short; first joint of the anterior tarsi with the spinules of the apico-marginal angle not noticeably produced.

Female.-Robust. Elytra rather broadly oval, about one-sixth longer than wide. Abdomen strongly convex, anterior tibial spurs moderately long and slightly curved. First joint of the anterior tarsi with the spinules of the apico-marginal angles noticeably produced.

Measurements.-Males: Length, 8.5-10.2 mm.; width, 4-5 $\mathrm{mm}$. Females: Length, 9.8-12 mm.; width, 5.1-6 mm.

Genital characters, male.-Edeagophore of the usual general form, elongate, depressed and scarcely arched.

Basale about five times longer than the apicale, oblong; surface nearly plane and narrowly, rather suddenly convex at the sides, the latter feebly arcuate.

A picale short, equilaterally triangular, convex at the sides and apex, dorsal surface nearly plane with a median linear, longitudinal, membranous groove at middle two-fourths; sides arcuate in basal third, thence moderately sinuate to apex, the latter blunt, the lateral sinuations giving it the appearance of being produced; base nearly evenly arcuate.

Sternite slightly transverse. Each lobe with the external border nearly straight in basal two-thirds, thence evenly arcuate to the internal border, angle obsolete; internal margin straight or feebly sinuate; surface shining, rather densely punctate in apical twothirds, setose, setæ moderately long about apical margin. Sinus deep, narrow and triangular.

Female.-Genital segment subequilaterally triangular, not strongly chitinized, setose.

Valvula.-Dorsal plate rather narrowly and elongately oblongtriangular in outline; surface more or less feebly concave, shining, sparsely, very finely punctate and setose in apical half; external border more or less arcuate; internal border more or less sinuous; apical margin not defined from the apex, angle obsolete; apex short and triangular.

Appendage short conico-mammilliform, fossa small; setæ on apex and appendage sparse, somewhat flying and slightly longest at tip of the appendage.

Superior pudendal membrane reaching to the middle of the dorsal plates and finely longitudinally rugulose. Basal prominences feeble.

Ventrolateral surfaces as in pilosa. 
Habitat.-California (Wickham has taken this species at Bodie in July, elevation 8,475 feet.) Nevada (specimens in the U. S. National Museum collection simply bear the state label-Hubbard and Schwarz; Wickham has taken it at Reno, Carson City, and Queens Station).

A specimen in the Fuchs collection bears a pencil label " Crescent City." I know of only one such locality in Del Norte County, California; on the pin also is a smaller label bearing the letters CC. I do not believe that this species occurs in Del Norte County, and in all probability the specimen was collected at Carson City, Nevada.

Number of specimens studied, 7 .

Type a female in the LeConte collection.

Type-locality.-Utah_-Great Salt Lake Desert" (LeConte).

- Salient type-characters.-Thorax with the sides rounded, posterior angles obtuse. Elytra closely and irregularly punctate, at the sides and apex submuricate (LeConte).

Diagnostic characters.-In form hirsuta resembles Amphidora nigropitosa. The body surface is shining and at times quite dull, especially on the head and thorax. The hairs of the elytra are nearly equal in length, and the sculpturing is quite densely, irregularly and not asperately, submuricately punctate.

This species can only be confused with pilosa, from which it especially differs in being smaller and more robust, with more broadly oval elytra, and in having the sides of the pronotum distinctly margined.

From longipilosa it is quickly recognized by the mutie anterior femora and simple elytral apices.

In hirsuta the pronotum is pubescent, in letcheri it is not.

Variations.-In two examples in the U. S. National Museum collection the punctures of the central area of the pronotal disc are more sparsely placed and slightly less strongly impressed than usual.

The mentum is small and triangular.

The prosternum is variable as in pilosa, and at times horizontal between the coxæ, mucronate behind.

The mesosternum is more or less obliquely arcuate and quite broadly and deeply concave.

The anterior tibiæ have the external borders more or less feebly carinate in basal half and thence more or less finely denticulate to apex. These characters are less evident in the middle tibiæ and nearly or quite obsolete in the posterior. The anterior tibix, and the middle to a less extent, are more or less feebly arcuate, and at times more evidently so. This character is nearly always more pronounced in the males.

"Two males in the LeConte collection have the front and middle tibiæ the least bit incurved at tip " (Blanchard). 
The edges of the tibial grooves of the femora are usually not at all carinate, and not well defined, the marginal line is more or less seabrous; the floors of the grooves are slightly glabrous to punctate, shining or opaque.

First joint of the metatarsi equal in length to the next two taken together.

\section{ELEODES PILOSA Horn.}

Eleodes pilosa Hokn, Trans. Amer. Phil. Soc., XIV, 1870, p. 314.

Elongate ovate, black, more or less opaque to feebly shining, strongly punctate and sparsely clothed with brownish or black, erect, rather coarse and slightly stiff, conspicuous hairs.

Head scarcely convex, feebly impressed laterally, rather coarsely and densely punctate, sparsely clothed with rather short and more or less erect hairs. Antenna moderate, first eight joints moderately pubescent, outer four joints feebly compressed and scarcely dilated, third joint equal in length to the next two combined, joints four to eight inclusive subequal, eighth feebly triangular, ninth and tenth suborbicular, eleventh subacutely ovate.

Pronotum widest at or just in front of the middle, one-sixth to one-half wider than long; disc moderately and evenly convex, very coarsely and densely punctate, the punctures irregularly confluent, the interstices narrow and convex, more or less bright and shining, surface clothed with quite long erect hairs; apex truncate or feebly emarginate and obsoletely margined; sides not strongly, but evenly arcuate in apical two-thirds, thence somewhat straight and feebly converging to the base, or very moderately and evenly arcuate from apex to base, margin hardly evident to distinct or obsolete; base truncate and finely margined, about equal to the length and a little wider than the apex; apical angles obtuse, not rounded nor prominent; basal angles obtuse, sometimes feebly rectangular and not prominent.

Propleurce opaque, evenly granulo-muricate, with short semi-erect setæ.

Elytra oval and about twice as long as wide; base truncate and about as wide as the contiguous prothoracic base; humeri indistinct and rounded; sides evenly arcuate, apex very slightly prominent posteriorly and rounded; disc more or less evenly convex from side to side, rather suddenly and more or less arcuately declivous posteriorly; surface densely and irregularly, finely and muricately punctured on the dorsum, becoming confusedly muricato-tuberculate on the sides and apex; sometimes the surface is faintly substriate, at other times the punctures on the dorsum are arranged in rather distant series, closely placed and unimpressed, with an interstitial series 
of little more distantly and irregularly placed ones; sparsely clothed with rather long, bristling, brownish, or black and conspicuously erect flying hairs, those of the interstitial punctures being much longer than those of the strial series; inflexed sides much less pubescent.

Epipleurce quite narrow at base and gradually narrowing to the apex; surface opaque and sparsely, submuricately punctulate.

Sterna more or less densely and submuricately punctate and rugose, setæ rather short and semi-recumbent.

Parapleurce not densely nor finely punctate, scarcely setose.

Abdomen shining and horizontal, rather sparsely punctate; first segment densely and rather coarsely punctate and rugulose, punctures denser on the fifth segment.

Legs moderate in length and not densely clothed with short semirecumbent hairs, that become longer on the tibial apices and last tarsal joints; anterior femora mutic in both sexes; anterior tarsi quite similar in the sexes, apparently not thickened, without tufts of pubescence, nor the apico-marginal spinules of the first joint being conspicuous.

Male.-Elongate and somewhat narrow, antennæ reaching to the prothoracic base. Abdomen not strongly convex, broadly and quite strongly impressed between the coxæ, less strongly on the second and third segments. Anterior tibial spurs subequal, moderately short, slender, and acute.

Female.-Rather robust. Antenna not quite reaching to the prothoracic base, abdomen strongly convex; tibial spurs longer, the anterior tibial slightly curved, subequal in length and thickness, acute.

Measurements.-Males: Length, $11.5-16 \mathrm{~mm}$; width, $5.5-6 \mathrm{~mm}$. Females: Length, $15-17 \mathrm{~mm}$.; width, $7-7.5 \mathrm{~mm}$.

I have recently received from Mr. Warren Knaus a pair of specimens (male and female) that represent an extreme form of sculpturing, and which is worthy of being recognized as a form, that may be defined as follows:

Forma ordinata.-Elytra with rather distant unimpressed striæ of rather fine and closely placed punctures, each interval with a distinct and regular series of rather distantly placed submuricate tubercles, feeble but distinct near the suture, each series increasing in size to the sides where both series become irregular and confused. Each interval has a few small and sparsely scattered punctures between or about the tubercles, otherwise as in pilosa.

Measurements.-Male: Length, $15 \mathrm{~mm}$; width, $6.5 \mathrm{~mm}$. Female: Length, $15 \mathrm{~mm}$; width, $7 \mathrm{~mm}$.

Genital characters, male.-Edeagophore of the usual form, elongately oblong-ovate, subdepressed not strongly convex nor arched. 
Basale oblong, rather deeply impressed along the middle in apical half; sides feebly and evenlỳ arcuate.

A picale rather elongately triangular; dorsal surface eveniy and not strongly convex, vaguely and narrowly impressed at the middle; sides very feebly sinuate; apex gradually produced and acute; base broadly lobed at middle and feebly sinuate laterally.

Sternite slightly transversely oblong. Each lobe rather narrow and somewhat long; external border quite straight in basal half, thence evenly arcuate to the apex, the latter rounded; internal border sinuate and more or less membranous; surface feebly convex, shining, sparsely punctate and setose, setæ rather long and dense at apex. Sinus rather broad, membrane not setose.

Female.-Genital segment subequilaterally triangular, with the dorsal surface strongly concave, well chitinized and setose, setæ short, subequal, and sparsely distributed over the apex, appendage, and apical moiety of the dorsal plate.

Valvula (Plate 4, fig. 14) reflexed externally. Dorsal plate oblong-oval; surface evenly concave, glabrous, finely and sparsely punctate; external border not well defined from the lateral surface towards base, arcuate apically; internal border arcuate and slightly reflexed in apical half; apical border continuously arcuate with the external and not defined from the apex, angle and external lobe not evident; apex short and triangular.

Appendage short and mammilliform, fully visible from above, directed upwards and backwards; fossa not well defined.

Superior pudendal membrane reaching to the middle of the dorsal plate, finely and longitudinally rugulose.

Basal prominences feeble.

Ventrolateral surfaces smooth and glabrous, very sparsely, evenly punctate and setose, setæ short; surface somewhat semicircularly convex from side to side, narrowly and rather deeply impressed laterally before the inferior border of the fossa; internal margins of the valves contiguous in basal third. Genital fissure fusiform oval, with the inferior pudendal membrane more or less visible in the basal moiety. Submarginal groove fine, not very distinct beneath the apical half of the external border of the dorsal plate.

Mabitat.-Forma typica.-California (Lassen County, Charles Fuchs; Owens Valley, Dr. George Horn; Bodie, elevation 8,475 feet, in July, and at Amedee, elevation 4,200 feet, H. F. Wickham) ; Nevada (western, by Mr. Gabb; Carson, Reno, in July, Humboldt Lake in June, H. F. Wickham) ; Oregon (U. S. National Museum Collection, C. V. Riley) ; New Mexico (Coolidge, U. S. National Museum collection, M. L. Linell).

If Linell's record is correct, pilosa may be looked for in northern Arizona, Utah, and southwestern Colorado. 
Forma ordinata.-Nevada (Las Vegas, April and May, W. Knaus).

Number of specimens studied, 16.

Type in the Horn collection.

Type-locality.-Owens Valley, California.

Salient type-characters.-Thorax subquadrate, feebly narrowed behind, sides moderately rounded, margin hardly evident; apex and base truncate, angles not prominent. Elytra with the humeri indistinct, surface faintly substriate with densely and irregularly placed muricate punctures (Horn).

Diagnostic characters.-The larger and most elongate species of the subgenus. Thorax densely and very coarsely punctate; elytra coarsely, muricately and asperately punctured laterally and on apex; toward the suture the punctures become quite simple. The hairs of the pronotum and elytra are long, quite erect, and somewhat bristling, the interstitial being much longer than the strial hairs. Surface opaque, integuments frequently incrusted with dirt.

The above characters serve to separate it from hirsuta, the latter being smaller in size, more robust, less coarsely but more densely punctate and shining, the elytral hairs are shorter, softer, and quite equal in length.

In longipilosa the anterior femora are dentate and the elytra caudate, in pilosa mutic and not caudate.

In letcheri the thorax is not pubescent and not as strongly punctured.

In the ordinate form each elytral interval has a regular series of submuricate tubercles, with small and irregularly placed punctures.

Variations.-The largest examples before me are two females collected in Oregon, and the smallest a male taken at Carson City, Nevada. In several females and a few males the pronotal margin is wholly absent and the discal surface passes arcuately into the flanks; in the greater number of specimens the margin is more or less evident, while in others it is distinct and beaded.

Pronotal variations (Plate 11, figs. 27, 28, and 29) are noticeable in the series at hand. Typically the sides are slightly narrowed behind and moderately rounded. The males show the greatest amount of narrowing, and in one example the sides are very broadly and feebly sinuate, the basal angles being slightly prominent; in two females the sides are distinctly angulate; in both sexes the sides are frequently evenly rounded from apex to the base.

The anterior tibial spurs, although subequal in length and thickness, appear to vary slightly so as to obscure the true structural relationship. At the most the difference is slight. In males the anterior spur may appear just the least bit the longer and thicker; the same 59780 - Bull. $63-09-10$ 
characters are observed in several females, while in others the posterior spur is just noticeably the thicker.

The variation in length can be accounted for by the wear due to age, yet the variation in thickness can not be put aside in that way; such might be looked upon as fortuitous, and due to the instability of certain inherent morphological tendencies.

In the series before me the general character of the sculpturing is quite constant.

The mentum is variable and comparatively small, triangular with apex subtruncate, or somewhat semicircular, the surface is plane to foveate laterally with a more or less well-marked median ridge.

The prosternum is more or less feebly or strongly convex anteroposteriorly between the coxæ, and moderately produced posteriorly, usually vertically truncate with angle deflexed and mucronate; rarely rounded behind, with mucro obsolete.

The mesosternum is arcuately declivous and quite broadly and deeply concave. Both sterna are clothed with rather long hairs. External borders of the anterior tibire are distinctly carinate nearly to the apex, and on the middle and posterior tibir nearly to the middle, a character more strongly developed here than in hirsuta.

The anterior tibiæ are not noticeably arcuate, although the external borders have a gentle and evenly arcuate outline. The tibial grooves of the femora are not usually strongly defined, and most always more or less subasperately punctate and opaque. In the specimens from Oregon the grooves are rather more strongly defined than in any of the other examples before me.

The first joint of the posterior tarsi is equal to the second and third taken together; the latter two are of equal length.

Subgenus PSEUDELEODES, new.

This subgenus is erected to receive a single species which is remarkably distinct among its congeners. It is based, as usual, mainly upon the female genital characters. Although the general facies of the species is quite unique, it is extremely difficult to portray in words. The general subgeneric characters may be enumerated as follows: Coarsely and tuberculately sculptured, not pubescent, humeri obsolete, anterior femora mutic; and the anterior tarsi simple beneath. Abdomen on the same plane as the sterna, that is, horizontal.

Subgeneric genital characters, male.-Apicale of the edeagophore triangular, evenly convex above, with a median longitudinal groove.

Female.-Genital segment short and parabolic in outline.

Valvula.-Dorsal plate subobovate to oval, extending apically upon the apex beyond the appendage; sides not reflexed. Apex with the internal lobe developed. Appendage short, mammilliform, projecting from beneath the external border of the apical margin of the dorsal 
plate. Superior pudendal membrane reaching to the middle of the dorsal plate. Genital fissure subapical.

General observations.-The internal spurs of the meso- and metatibiæ are slightly longer than the external.

The tarsi are somewhat stout and moderate in length. The protarsi have the four basal joints short, subequal in length, and slightly broader than long. The mesotarsi are about one-fourth of their length longer than a protarsus and slightly shorter than a metatarsus; the first four joints are subequal - the first undoubtedly slightly the longest-and about as wide as long. The metatarsi have the second and third joints subequal, both together slightly longer than the first.

In the male the intercoxal process of the first abdominal segment is subquadrate and just slightly transverse and about equal in length to the post-coxal part, the latter quite equal in length to the second; the third segment is equal to about three-fourths the length of the second, and the fourth is equal to two-thirds the length of the third.

In the female the post-coxal part of the first segment is almost equal in length to the second; the third about two-thirds as long as the second, the latter slightly more than twice as long as the fourth.

The intercoxal process of the abdomen is equal in width to the length of the third and fourth segments taken together, and one-fifth of its own width greater than that of the metasternal salient.

The metasternum laterally between the coxæ in length equals the width of a mesofemur at base.

The epipleuræ at apices are feebly dilated and concave beneath the elytral apex, the latter being very slightly produced. This character is more noticeable in the females.

Distribution.-Granosa inhabits the more arid and desert regions of the West. Thus far it has only been recorded from eastern central and northeastern southern California and western Nevada.

Relationships.-More closely related to Tricheleodes than to any other subgeneric aggregate, this affinity is evident in the resemblance of facies and in the tendency to development of tubercles in pitosa.

\section{ELEODES GRANOSA LeConte.}

Eleodes granosa LeConte, Smithson. Misc. Coll., No. 167, 1865, p. 116.Horn, Trans: Amer. Phil. Soc., XIV, 1870, p. 314.

Ovate, opaque, roughly and coarsely sculptured and strongly convex.

Head about twice as wide as long, moderately convex, coarsely and densely punctate, the punctures at the sides and on the epistoma more or less coalescent, and finely setigerous. Antennce rather short and moderately stout, outer four joints scarcely compressed, gradually and very feebly dilated, third joint about equal in length to the next two taken together, fourth scarcely longer than the fifth, the latter, 
sixth, and seventh subequal, eighth as wide as long, ninth and terith feebly transverse and oval, eleventh subovate.

Pronotum subquadrate, widest at the middle, one-seventh to onefourth wider than long; disc rather strongly and evenly convex, declivous at the sides, coarsely, densely, and quite evenly punctate, the punctures at times more or less confluent and strongly impressed, becoming muricato-granulate laterally; apex truncate and finely or obsoletely margined; sides quite evenly and not strongly arcuate to subangulate at the middle, thence quite straight to base, obsoletely or finely margined; base truncate or very feebly rounded and finely margined, slightly wider than the apex and about equal to the length; apical angles rectangular to obtuse and not rounded, occasionally minutely prominent; basal angles subrectangular to obtuse, not rounded nor prominent.

Propleure granulo-scabrous to muricato-granulate.

Elytra oval, about or less than twice as long as wide; base truncate and equal in width to the contiguous prothoracic base; humeral angles absent, rounded; sides evenly arcuate, apex feebly produced and subacute; diso evenly and strongly convex and almost vertically declivous posteriorly; surface tuberculate, the tubercies arranged in rows, consisting of series of small, evenly and closely placed ones, with interstitial series of much larger and more distantly placed tubercles, those of both series becoming subequal in size at the sides and smaller on the apex, and more or less irregular.

Epipleurce more or less concave toward the base, and finely, sparsely punctate.

Sterna more or less densely granulo-punctate.

Parapleura sparsely and not coarsely punctate.

Abdomen horizontal, quite densely punctate, the punctures becoming somewhat granular at the sides.

Legs moderate. Femora densely and rather finely punctate, the profemora mutic, not sinuate. Anterior tibial spurs about equal in size and length, acute. Tarsi similar in the sexes; first joint of the anterior tarsi not thickened at tip beneath, apico-marginal tufts of spinules acute, grooves entire.

Male.-Somewhat narrow. Antennæ scarcely reaching to the prothoracic base. Abdomen moderately convex, broadly impressed on the first three segments.

Female.-Robust. Antennæ reaching to about the posterior fourth of the prothorax. Abdomen evenly and strongly convex, feebly ventricose.

Measurements.-Males: Length, 9-17.5 mm.; width, $5-7 \mathrm{~mm}$. Females: Length, 17-19 mm.; width, 6-8 mm.

Genital characters, male.-Edeagophore of the usual oblong-ovate form, rather small. 
Basale oblong, quite evenly convex above and not arched.

A picale triangular and slightly elongate; evenly convex above, with a median longitudinal and membranous groove in the middle third; apex produced and quite acute; sides arcuate in basal third, thence broadly and feebly sinuate to tip; base with a rounded lobe at middle and feebly sinuate laterally.

Sternite slightly transverse and strongly chitinized. Each lobe rather narrowly triangular; external border rather evenly arcuate, apex narrowly rounded, internal border sinuate; surface glabrous in basal third, densely punctate and setose in apical two-thirds, setæ rather long and dense. Sinus broad and quadrate and the membrane is not setose.

Female.-Genital segment short and robust, subparabolic in outline.

Valvula (Plate 4, fig. 13).--Dorsal plate subobovate to suboval, about twice as long as wide, sides not reflexed, margins accurate; surface slightly concave and more or less shining, punctate in apical two-thirds; apical margin more or less evenly and strongly rounded, often not distinctly defined from the apex, the latter very small and short, subacute and narrowly rounded.

Appendage small, conically mammilliform, and projecting from beneath the external border of the apical margin of the dorsąl plate. Fossa not visible from above, and small. Apex, appendage, and apical half of the dorsal plate minutely setose.

Basal prominences obsolete.

Superior pudendal membrane reaching to the middle of the dorsal plate and longitudinally rugulose.

Ventrolateral surfaces not inflated, evenly convex, surface lines straight viewed longitudinally. Surface rather densely punctate and the apex finely setose; submarginal groove not developed; inner borders of the valves contiguous in basal third, the genital fissure subapical and fusiform with the inferior pudendal membrane visible in basal half.

Habitat.-California (Panamint and Coso valleys, A. Kobele; Los Angeles County, D. W. Coquillett; Mount Pinos, Kern County, Fordyce Grinnell; Colorado Desert, San Bernardino County, and Oak Creek, eastern Kern County, Dr. E. C. Van Dyke). Nevada (collected by Wm. M. Gabb, Horn).

Number of specimens studied, 24.

Type (male) in the LeConte collection.

Type-locality._-"California."

Salient characters.-Head and thorax strongly and confluently punctate. Thorax subquadrate, sides rounded and not margined. 
Elytra strongly convex, sculptured with series of small, bright tubercles, interstices with small granules uniseriately placed (LeConte).

Diagnostic characters. - One of the most distinct species of the genus. The sides of the pronotum are slightly but not very distinctly sinuate behind the apical angles. The elytral sculpturing consists of a series of well-developed tubercles upon each interval, and series of small granules represent the striæ. The coarseness of the sculpturing is unique and is only approached by that of granulata. The latter species has the form of quadricollis, the humeri are distinct and somewhat produced, and the elytra are sculptured with rows of smooth, moderately elevated, and somewhat elongate tubercles; also more or less subseriately punctate each side of the suture, the anterior femora are more or less sinuate.

Variations.-The post-apical sinuations of the pronotal sides are at times scarcely evident in the males.

The moderate series of examples before me is of special interest and value, on account of the extreme forms of sculpturing that are included.

Two specimens from the Panamint and Coso valleys are remarkable for the extreme coarseness of the sculpturing (Forma fortis). In each specimen the pronotal disc is densely, deeply, and confluently punctate, the interstices smooth and convex. The elytral series of tubercles are notably regular and distinct, except at the extreme sides where confusion and diminution in size occur; elsewhere the interstitial tubercles are three times as large as in the specimens from Los Angeles County, and completely fill the width of the interval; they are very glabrous and shining, very convex to subacute at summit. The strial granules are regular and distinct between the crowded larger tubercles. These insects are less opaque than usual and the largest of the series.

In the Los Angeles County (Mount Wilson) specimens the pronotal punctures are smaller, denser, and shallower, with the interstices narrow, scarcely convex, and distinctly opaque. The elytral series of tubercles are regular on the dorsum, at the sides the tubercles and granules become confused and quite equal in size.

The Kern County specimens present a modification of the typical form of sculpturing. The pronotal punctures are moderate in size, irregularly placed, frequently with impunctate areas; the interstices are flat, smooth, and shining. The general sizes of the sculptural factors of the elytra are as in the Southern specimens; at base, along the suture, and laterally the tubercles become more or less transversely confluent, losing to a greater or less extent their tubercular character, producing a transversely rugose and submuricate effect. 
The prontal margin is usually obsolete and the sides of the pronotal disc are continuously convex with the flanks. Ordinarily, the margin is finely crenulate. In one specimen the margin is distinctly developed in the anterior two-thirds of the pronotum, where it is acute and minutely reflexed.

In the LeConte collection along with the type there is placed a male and female, without locality labels and of peculiar form as follows: The elytra are sculptured as in granosa, the thorax is very opaque with rather close, coarse, and shallow punctures, as if the rugosities seen in the type of granosa had been worn down. The thorax is much broader, with the anterior angles more prominent, the sides slightly sinuate behind; elytra not quite so convex, more elongate and more attenuate posteriorly. The foregoing applies to the female as compared with the female of granosa.

The male has distinctly longer antenna, joints four to eight inclusive being longer; elytra but little wider at middle than the prothorax and consequently appear more convex; the anterior and middle tibiæ scarcely differ from those of the female. The side margin of the pronotum is feebly defined anteriorly and obsolete posteriorly.

I am indebetd to Mr. Blanchard for the above notes, and as I have not seen the specimens I can only surmise that they may be a race of granosa. A Coso Valley specimen is more elongate than any other of the specimens before me and it is decidedly less convex, the elytra being somewhat flattened on the dorsum. In one or two specimens the elytra are slightly ventricose.

Specimens recently collected by Mr. F. W. Nunenmacher at Goldfields, Nevada, are deep black and shining, the sculpturing coarse as in the Panamint Valley specimens above referred to.

The mentum exhibits considerable variation, being moderate in size. triangular or subparabolic in outline, convex at middle and excavated laterally. The prosternum is more or less evenly convex anteroposteriorly between the coxæ, frequently grooved; mucronate behind, the mucro moderate, conical or triangular.

Mesosternum short, very oblique, and broadly concave.

The external borders of the anterior tibiæ are distinctly carinate nearly to the apex, and the middle and posterior tibiæ to a greater or less extent as well.

The tibial grooves of the femora are well defined, the margins are subasperately punctate and the floor of each is more or less punctate and opaque.

The anterior tarsi are subequal in stoutness and length in the sexes.

Tarsal formula :

\begin{tabular}{|c|c|c|c|}
\hline $\begin{array}{l}\text { Pro. } \\
\text { Male. } 2 \frac{1}{2}\end{array}$ & $\begin{array}{c}\text { Meso } \\
3\end{array}$ & $\begin{array}{c}\text { Meta. } \\
3\end{array}$ & $\begin{array}{l}\text { Metatibiæ. } \\
6\end{array}$ \\
\hline Female. $-2 \frac{1}{2}$ & 3 & $3 \frac{1}{2}$ & 6 \\
\hline
\end{tabular}


Subgenus PROMUS LeConte.

The first, or the first and second joints of the anterior tarsi of the male, are more or less thickened and sometimes flattened beneath, and densely clothed with fine pubescence.

These characters are most strongly developed in goryi, where the pubescence is almost spongy and the tufts are distinctly flattened; the first joint of the mesotarsi also have a similar but smaller tuft.

In fusiformis, striolata, and opaca the tufts are smaller and less strongly flattened, and in insularis and subnitens the pubescent pads are smaller and not flattened; in the former the tuft is pointed and in the latter subtruncate, in both the pubescence is slightly longer.

The form is usually more or less fusiform in outline, but in insularis the greatest width of the elytra is behind the middle, and the insect is more ovate than fusiform. Some examples of subnitens are subovate.

The sides of the pronotum nearly always converge anteriorly and the elytra become gradually broader in the same or nearly the same line with the pronotal sides. This is most pronounced in opaca and fusiformis; in striolata, goryi, subnitens, and insularis the sides of the pronotum converge more or less posteriorly, so that the lateral line is interrupted to a greater or less extent.

Subgeneric genital characters, male.-Apicale of the edeagophore distinctly longer than wide, somewhat depressed, dorsal surface moderately convex and marked by a more or less well defined membranous, median groove; apex acute and moderately attenuated; base usually broadly lobed at the middle.

Female.-Genital segment more or less quadrate, internal lobe of the apex well developed, the external being rudimentary. Sides of the dorsal plate reflexed with the surface concave between, outwardly explanate and more or less deflexed at the periphery. The dorsal plate has the external border more or less arcuate, the surface strongly punctate, conspicuously and sparsely setose, the setæ being quite long and flying.

Appendage more or less strongly flattened, conico-ellipsoidal or transversely semiellipsoidal, and usually quite large.

Superior pudendal membrane reaching to the middle or apical third of the dorsal plate, and obsoletely or irregularly longitudinally rugulose.

The genital characters of the female are distinctive and definitely characterize the subgenus. An examination of the plates (4 and 5) will elucidate what has already been said. It will be observed that the appendage in insularis is the smallest and most conical in the series. 
General observations.-The head is usually twice as wide as long, and moderate in size; comparatively large in subnitens and goryi, small in striolata.

Comparison and direct measurement show the head to be subject to considerable variation in size, even among individuals of the same species.

The internal spurs of the meso- and metatibiæ are slightly longer than the external.

The tarsi are the stoutest in subnitens, moderately so in goryi, and slender in striolata, fusiformis, and opaca; less elongate and feebly robust in insularis.

After careful comparative measurements of the tarsal joints, I can not present any useful facts relative to the comparative lengths of the several joints of each tarsus in the different species.

The following are my notes on the tarsi of subnitens:

In the protarsi the second, third, and fourth joints combined are about equal in length to the fifth; the first is slightly longer than the second.

Mesotarsi.-The first joint is subequal to the third and fourth taken together; the second, third, and fourth slightly decreasing in length in the order named.

Metatarsi.-The first joint is a little longer than the second and third taken together; the second very slightly longer than the third; second and third together about equal to the fourth.

The above gives a fair idea of the ratios between the joints of the different tarsi. In striolata the first joint of the metatarsi is about equal to the second and third taken together; the second and third are subequal and together slightly longer than the fourth.

In the male of goryi, the first joint of the protarsi is much thicker than the succeeding ones and as long as the next two taken together.

The differences are so slight that they could not be utilized in the determination of species.

In the males the intercoxal process of the abdomen lies in the same horizontal plane that the meta- and mesosterna do, and the abdomen behind the metacoxæ is deflexed. As a result, its surface is oblique to that of the sterna. This character is scarcely evident in opaca, striolata, very feeble in insularis, and more or less well pronounced in the other species.

In the females the abdomen is always horizontal and in some instances slightly prominent ventrally with the sterna.

The relative length of the abdominal segments has to be considered.

In the male of insularis the intercoxal process of the first abdominal segment is quite quadrate, and about equal in length to the second segment; the post-coxal portion is also subequal in length to that 
of the second, the latter being distinctly twice as long as the fourth; the third is about two-thirds as long as the second.

In the female the abdominal salient is transverse, nearly twice as wide as long; the post-coxal portion of the first segment is about equal to the second in length; the second is nearly two and one-half times as long as the fourth; the third nearly two-thirds as long as the second. The first three segments are relatively longer than in the male.

Subnitens.-The male has the intercoxal process of the first ventral segment just noticeably transverse, and the post-coxal part is scarcely as long as the second; the third is slightly less than twice as long as the fourth.

The female has the intercoxal process slightly transverse, and the post-coxal portion of the first is about equal to the second in length; the third is about three-fourths as long as the second and about twice as long as the fourth.

Goryi.-The intercoxal process in the male is distinctly transverse, and the post-coxal part of the first segment is scarcely as long as the second, the latter being about one-fourth longer than the third; the fourth is about one-half as long as the third.

The female has the intercoxal salient strongly transverse and about equal to the second in length; the post-coxal portion is scarcely as long as the second; the third is about two-thirds as long as the second and about twice as long as the fourth.

Striolata.--In this species the male has the intercoxal process transverse and rather short, about equal to the fourth in length; the postcoxal part of the first ventral segment is about as long as the second, and the fourth is scarcely one-half as long as the latter.

The female has the intercoxal process moderately transverse and scarcely as long as the third segment, and the post-coxal part of the first is nearly as long as the second; the third segment is about threefourths as long as the second, and the fourth is nearly two-thirds as long as the third. The first three segments are comparatively long.

Fusiformis.-The intercoxal process of the male is distinctly quadrate and equal in length to the post-coxal part of the same segment, which is subequal in length to the third; the second is about twice as long as the fourth segment.

The female has the segments proportioned about as in the male, but slightly longer. The intercoxal process is quadrate.

Opaca.-The male has the intercoxal salient short and slightly transverse, the post-coxal portion is equal in length to the third and the second is about twice as long as the fourth.

The abdominal salient of the female is comparatively small and nearly quadrate, and the post-coxal part of the same segment is sub- 
equal to the second; the third is about two-thirds as long as the preceding segment and one-third longer than the fourth.

Insularis has the abdominal salient about equal in width to the length of the third and fourth segments taken together, and about one-fourth of its width broader than the metasternal process. The metasternum laterally between the coxæ is about as long as the width of a metafemur at base.

Subnitens has the intercoxal process equal in width to the length of the second segment and about one-fourth of its own width broader than the metasternal process. The metasternum laterally between the coxæ is as long as the width of a mesotibia at apex.

The intercoxal abdominal salient in goryi is quite wide and equal to the combined lengths of the third and fourth segments and about one-third of its width greater than that of the metasternal process. The metasternum laterally between the coxæ is equal in length to the width of a mesotibia at apex.

In striolata the intercoxal process of the abdomen is quite equal in width to the length of the second segment and about one-third of its width greater than that of the metasternal salient. The metasternum is quite short laterally between the coxæ and about equal in length to the width of a mesotibia at middle. In the female the abdominal process is evidently not as wide as the second segment is long.

Fusiformis has the abdominal process comparatively narrow, being about equal to the length of the third segment and subequal in width with the metasternal salient. The metasternum laterally is short and about equal to the width of the mesotibia at middle. The same results of comparison can be applied to opaca that have been obtained from fusiformis.

The above notes on the relative widths and lengths of the sterna and abdominal segments can only be considered in a general way as being approximately correct, as there is always more or less individual variation in each species.

In summing up it will be noticed that the coxæ are most widely separated, and the intercoxal process of the first abdominal segment reaches its greatest width in insularis and subnitens; that in fusiformis and opaca they reach their greatest approximation, and that the intercoxal salients are quite equal; that goryi and striolata are somewhat intermediate, but really more nearly like the first two named species than the last two.

Distribution.-Insularis, as far as known, is an insular and peninsular species, inhabiting the southern part of Lower California and an adjacent island.

Subnitens inhabits central and southern Arizona. I know of no record of its having been taken in Mexico, but it may occur there.

Goryi is taken in New Mexico, Texas, and Mexico. 
Striolata is found in southern Texas and the adjoining regions of Mexico.

Fusiformis is distributed over an extensive area as follows: Texas, New Mexico, Kansas, Colorado, Nebraska, and southern Wyoming.

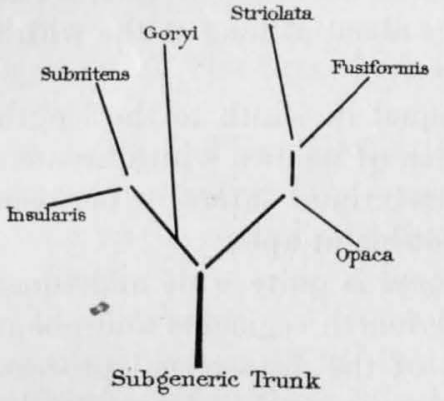

Fig. 2.-Genfalogical digram OF THE SUBGENUS PROMUS.

Opaca also has a wide distribution, being known to me to occur in Texas, Colorado, Kansas, Nebraska, and southern Dakota.

Genealogy.-The results of the comparative measurements indicate quite clearly upon what structural lines that divergence has taken place, while the relationships of the species among themselves have been sufficiently indicated. I believe that striolata and fusiformis have diverged from a common stem much later than did goryi from the insularis-subnitens ramus. Knowledge of the Mexican species may entirely change my views, as it only at present concerns the species in the United States.

Our six species may be separated as follows:

Species with first joint of the anterior tarsi in the male conspicuously pubescent beneath.

Surface shining; thorax distinctly widest at the middle, visibly narrowed at base ; tarsal pubescent tuft conical_ insularis.

Surface dull; thorax scarcely wider before the base; tarsal tuft truncate at tip subnitens.

Species with first two joints conspicuously spongy pubescent beneath.

Femora (anterior) armed in the males.

Elytra with distant series of large dents or punctures_ goryi.

Elytra with approximate series of rather small and closely placed punctures striolata.

Femora mutic in the males.

Elytral margins rounded, surface glabrous, not pubescent_-_-_fusiformis. Elytral margins acute, surface opaque and pubescent_ opaca.

\section{ELEODES INSULARIS Linell.}

Eleodes insularis Lineld, Proc. Ent. Soc. Wash., IV., No. 3, p. 180 (author's extras published March 7, 1899).

Elongate, subovate, black, smooth, more or less shining and moderately convex.

Head more or less convex, rather finely, more or less evenly, or irregularly punctate, punctures not dense, but slightly so on the epistoma and sides. Antennce moderate in thickness, long, reaching beyond the prothoracic base, very feebly compressed and just in the least dilated in the outer three joints, third joint about equal to the next two taken together, fourth slightly longer than the fifth, the latter, sixth and seventh subequal, eighth slightly shorter, ninth 
more or less triangular, tenth scarcely transversely oval, eleventh suboval.

Pronotum subquadrate, rather dull, widest at the middle, onefifth to one-fourth wider than long; disc evenly and moderately convex, very finely, rather evenly but not densely, and more or less obsoletely punctulate; apex more or less emarginate, frequently more noticeably so laterally, very finely or more or less obsoletely margined; sides broadly, evenly and not strongly arcuate, very finely beaded; base more or less arcuate and finely margined, about onefourth to one-third wider than the apex; apical angles subacute, anteriorly prominent and not everted; basal angles obtuse and not rounded nor prominent.

Propleurce finely and irregularly punctulate, more densely and strongly so posteriorly, and more or less finely rugulose.

Elytra oval to subovate, usually widest behind the middle; base more or less emarginate and not wider than the contiguous prothoracic base; humeri obtuse, not rounded nor prominent; sides slightly more strongly arcuate behind the middle, apex not in the least produced and rounded; disc moderately convex on the dorsum, strongly and evenly so laterally, rather suddenly and arcuately declivous posteriorly; finely punctate, punctures arranged in moderately distant series, rather closely placed and at times lodged in shallow and slightly larger dents, intervals more or less obsoletely punctulate; the serial punctures at times more or less obsolete.

Epipleurce moderately narrow, gradually narrowing from base to apex and more or less impunctate.

Sterna more or less moderately punctate and rugulose, finely and sparsely pubescent. The prosternum is frequently more strongly punctate.

Parapleura sparsely and irregularly punctate, punctures rather shallow.

Abdomen very finely or obsoletely and rather sparsely punctulate, more or less finely rugulose; the intercoxal process more or less coarsely sculptured.

Legs moderate in length and slender; anterior femora more or less armed in both sexes; tibial spurs small, the anterior subequal and acute; anterior tarsi dissimilar in the sexes.

Male.-Somewhat narrow. Antennæ extending three or four joints beyond the prothoracic base. Elytra evenly and strongly arcuately declivous posteriorly; abdomen slightly oblique, moderately convex, flattened at the middle on the first three segments and more or less grooved in the middle line. Anterior femora with a distinct but obtuse tooth; anterior tarsi with the first joint slightly thickened and clothed apically beneath with a dense brush of more or less golden pubescence. 
Female.-Rather robust. Antennæ with about one or two joints reaching beyond the prothoracic base. Elytra arcuately and vertically declivous posteriorly. Abdomen horizontal, strongly convex from side to side. Anterior femora obtusely angulate or simply sinuate; anterior tarsi without pubescence beneath.

Measurements.-Males: Length, 14.5-17.6 mm.; width, 5.6-6.8 $\mathrm{mm}$. Females: Length, 16-16.5 mm.; width, $6.5-7.0 \mathrm{~mm}$.

Genital characters, male.-Edeagophore flattened oblong-ovate, and slightly arched.

Basale moderately long, oblong, quite evenly convex above, with sides nearly parallel to feebly arcuate.

A picale triangular, slightly elongate and feebly decurved; surface evenly and moderately convex, with a moderately wide membranochitinous depression at middle third; sides feebly arcuate near the base, thence to the tip slightly sinuate; apex somewhat produced and subacute; base broadly lobed at middle and slightly sinuate laterally.

Sternite transverse and setose. Each lobe rather broadly triangular, with the external border quite evenly and broadly arcuate; internal border more or less arcuate; apex subacute to narrowly rounded; surface quite evenly convex, rather evenly and not densely punctate in apical three-fourths, setæ moderately long. Sinus narrow and the membrane not setose.

Female.-Genital segment quadrato-parabolic in outline, quite strongly convex antero-posteriorly so that the apical moiety appears quite strongly and arcuately declivous apically, setose.

Valvula (Plate 4, fig. 22).-Dorsal plate obovate, quite strongly arcuate antero-posteriorly, broad in apical half and narrowing to base, inner third of the apical half quite strongly reflexed; surface somewhat shining, rather densely punctate and setose, setær rather long and flying, somewhat dense; external border more or less straight in basal half, thence broadly arcuate with the apical margin; internal border arcuate in apical half, thence outwardly oblique to base and more or less arcuate or straight. Apex rather small, subacute at tip and more or less finely setose.

Appendage short mammilliform with few very fine and rather long setæ about tip.

Superior pudendal membrane quite broadly and triangularly exposed and obsoletely longitudinally rugulose.

Ventrolateral surfaces quite evenly convex, the submarginal groove broad and shallow, curving inward beneath the fossa to the base of the apex, the external and apical borders of the dorsal plate appearing quite strongly explanate; surface punctate and setose, setæ quite long and flying. Internal border of the valves contiguous in basal fourth, the genital fissure fusiform and situated at middle twofourths, apparently closed by the inferior pudendal membrane. 
In all of the specimens examined the pudendal membrane passes directly backward, and therefore immediately continuons with the valvular membrane, there being no fornix laterally, the angle formed is in the median line and corresponds to margin of the genital orifice.

Habitat.-Island of Santa Margarita (collected by the Albatross Expedition of 1888, collection of U. S. National Museum); Lower California (El Taste, Gustav Beyer; San Francisquito, Coll. Acad. Nat. Sciences of San Francisco).

Number of specimens studied, $32 ; 22$ from Santa Margarita Island, and 10 from the mainland of Lower California.

Type.-Cat. No. 4169, U. S. National Museum.

Type-locality.-Santa Margarita Island, Lower California.

Satient type-characters.-Feebly shining. Thorax subquadrate, sides broadly and evenly rounded, base slightly wider than the apex, anterior angles subacute, posterior angles obtuse, disc sparsely and finely punctate. Elytra widest at apical third; disc moderately, slightly depressed along the suture in the female, with regular distant series of fine punctures, the intervals very sparsely and minutely punctulate (Linell).

Diagnostic characters.-The species resembles somewhat E. omissa LeConte, from which it can easily be separated by the armed anterior femora and by the first joint of the anterior tarsi of the males being clothed beneath with a tuft of golden pubescence.

From subnitens it is recognized by the shining integuments, smalle: size, and ovate form.

From all other members of the subgenus by not having the two basal joints of the anterior tarsi in the males with pubescent pads beneath.

All of the specimens that I have seen are quite homogeneous and without any tendency to muricate punctuation. Linell's cotypes are before me; most of them are slightly brownish, probably from slight immaturity.

A species found upon the mainland of the peninsula agrees in all essential structural characters with the specimens from the island, and I therefore consider them to be one and the same. Both have the elytra widest behind the middle; the femoral teeth vary in both sexes, sometimes acute and again obtuse in the males. In the peninsular form the body is rather more convex and the elytral punctuation is stronger and the striæ more or less impressed, the intervals almost feebly convex. The tarsal spinules are ferruginous in the insular form and darker in those of the mainland.

Specimens of the peninsular form, collected at San Francisquito, and which were before the great disaster in the collection of the California Academy of Sciences, were referred to gentilis by Doctor 
Horn; the latter species is a race of gigantea, and occurs much farther north in southern California. ${ }^{a}$

Some observers have referred this form also to innocens, which does in some respects resemble it, for instance, in being widest at the posterior fourth of the elytra, the latter having striæ of punctures which are more or less impressed and the intervals more or less convex. Innocens is also more elongate, and the genital characters present a decided subgeneric difference. Compare in Plate 4, figs. 21 and 22.

Relationships.-Insularis is no doubt more closely related to subnitens than to any other species in the United States fauna. It is a true Promus in genital characters, and not intermediate between Blapylis and Eleodes proper as suggested by Linell.

General observations.- The mentum is variable, and moderate in size. The middle lobe is subtrapezoidal in outline, sides more or less arcuate with the apex or converging with the apex more or less rounded.

Prosternum not prominent ventrally. In the insular specimens it is quite evenly but not strongly rounded, antero-posteriorly between the coxæ, with a small mucro behind; in the peninsular form it is quite horizontal between the coxæ and terminating behind in a rather strong and subtriangular mucro. Between the coxæ the surface is more or less strongly punctato-rugose.

The mesosternum is quite gradually oblique and more or less concave.

The tibial grooves of the femora are usually distinctly evident for the whole length of the inferior surface, the floor of each being quite plane and glabrous or more or less punctate; the margins are more or less acute and cariniform. In the peninsular specimens before me the floors are quite glabrous.

The external borders of the anterior tibiæ are distinctly carinate, the carina forming the anterior lip of the tarsal groove, which is here clearly indicated and not at all glabrous.

The middle and posterior tibiæ are evidently very faintly or not in the least carinate externally near the base, and the tarsal grooves are indicated in apical three-fourths, margins more or less well indicated. The grooves are sculptured like the rest of the tibial surface.

The protarsi are about of equal stoutness in the sexes.

Tarsal formula:

\begin{tabular}{|c|c|c|c|}
\hline 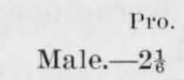 & $\begin{array}{c}\text { Meso. } \\
2 \frac{3}{4}\end{array}$ & $\begin{array}{c}\text { Meta. } \\
3\end{array}$ & $\begin{array}{c}\text { Metatibia } \\
5 \frac{1}{3}\end{array}$ \\
\hline emale. -2 & $2 \frac{3}{4}$ & 3 & $5 \frac{1}{3}$ \\
\hline
\end{tabular}

${ }^{a}$ See Proc. California Acad. Sci., 2 ser., IV, Pt. 1, pp. 306 and 349. 


\section{ELEODES SUBNITENS LeConte.}

Eleodes subitens LeConte, Ann. Lyceum Nat. Hist. N. Y., V 1851, p. 134.-Hokn, Trans. Amer. Phil. Soc., XIV, 1870, p. 319.

Fusiform to elongate ovate, noticeably narrowed anteriorly, surface subopaque, finely punctate and smooth.

Head evenly convex, impressions scarcely evident, frontal suture distinct; surface finely and evenly punctate, punctures quite indistinct over the vertex. Antennce long, rather robust, outer four joints slightly compressed and feebly widened; third joint equal to the next two taken together; fourth just noticeably longer than the fifth, the latter to the eighth inclusive subequal in length; ninth and tenth feebly and transversely suborbicular; eleventh short oval.

Pronotum quadrate, widest at the base and slightly narrowing from base to apex, rarely widest at the middle and narrowing slightly to base as well; disc evenly convex from side to side, very finely and subobsoletely punctulate; apex feebly and broadly emarginate, obsoletely margined and equal to the length; sides feebly and quite evenly arcuate from apex to base, very finely beaded; base broadly and feebly arcuate or subtruncate, about one-fourth longer than the length, onesixth to one-fourth wider than the apex; apical angles subacute and anteriorly prominent; basal angles obtuse and not rounded.

Propleurce smooth, obsoletely punctulate and rugulose.

Elytra oval, widest at or just behind the middle, and moderately attenuate in apical fourth; base feebly and broadly emarginate or subtruncate, slightly wider than the contiguous prothoracic base; humeri obtuse or feebly subacute, scarcely or very feebly prominent anteriorly; sides evenly arcuate, apex subacute or narrowly rounded; disc moderately convex or slightly depressed on the dorsum, laterally regularly rounded, arcuately declivous posteriorly; punctate, punctures fine and closely placed in rather distant unimpressed series, intervals more or less irregularly and very finely punctulate; sculpturing more or less indistinct, not denser nor coarser laterally and on apex.

Epipleurce slightly widened at base, thence gradually narrowed to apex, not wide, the superior margin broadly sinuate basally and curving upward to the humeral angle; surface smooth and obsoletely punctulate.

Sterna smooth and more or less obsoletely sculptured.

Parapleurce smooth and more or less distinctly or obsoletely punctate.

Abdomen smooth, finely punctulate, and more or less indistinctly rugulose; fifth segment finely setose about the margin.

Legs rather long and moderately slender. Anterior femora dentate or sinuate; the anterior spurs of the anterior tibiæ similar in the 59780-Bull. $63-09-11$ 
sexes, and slightly larger and longer than the posterior. Tarsi dissimilar in the sexes and rather robust.

Male.-Body feebly robust and somewhat narrow. Antennæ reaching beyond the prothoracic base. Elytra not broadly oval, noticeably attenuate, and rather obliquely declivous posteriorly; apex not produced; abdomen more or less oblique, moderately convex, and the first segment is more or less broadly impressed at middle. Anterior femora armed with a moderate and acute tooth at outer fifth. Anterior tarsi with the first joint very feebly thickened, and clothed in apical third beneath, with a tuft of silken pubescence; second joint simple with groove entire.

Female.-Robust. Antennæ reaching slightly beyond the prothoracic base. Elytra broadly oval, less attenuate, and arcuately declivous posteriorly. Abdomen rather strongly convex, horizontal. Anterior femora more or less distinctly sinuate in outer fifth; anterior tarsi unmodified.

Measurements.-Males: Length, 21-24.5 mm.; width, $8.2-9 \mathrm{~mm}$. Females: Length, 23-26 mm.; width, 10.5-12 mm.

Genital characters, male.-Edeagophore elongate fusiform, scarcely arched.

Basale oblong-oval, sides subparallel, surface moderately convex.

A picale triangular, about one-half longer than wide; surface moderately convex with a membranous groove in apical half; sides feebly arcuate or straight to the tip, the latter acute; base rather narrowly rounded at middle, broadly and feebly sinuate laterally.

Sternite quadrato-parabolic. Each lobe rather long with the external border evenly arcuate, apical margin rather narrowly rounded, angle not evident; internal border arcuate; surface slightly convex, rather densely and coarsely punctate, setæ long and quite dense. Sinus broad, apical half not closed by membrane, the latter not setose.

Female.-Genital segment subquadrate in outline. Valves explanate externally, deflexed at apex and reflexed laterally and quite densely setose.

Valvula (Plate 5, fig. 3).-Dorsal plate oblong-oval; internal fifth reflexed, glabrous and impunctate, externally upwardly oblique and more or less deflexed peripherally; surface longitudinally channeled, rather densely punctate and setose in outer four-fifths, setæ long and flying; external border quite arcuate; apical margin arcuate externally with the external margin, inwardly sinuate with the internal apical lobe and set with setæ; inner margin broadly arcuate. Apex triangular and rather short, finely setose.

Appendage large and transversely semielliptical, rather thickly set with quite long hairs. Fossa transverse, narrow, and closely fitting the base of the appendage.

Basal prominences not evident. 
Superior pudendal membrane obsoletely rugulose and reaching about to the middle of the dorsal plate.

Ventrolateral surfaces.-Body of the segment quite strongly convex, broadly and quite deeply concave beneath the apex, the concavity continuous with the submarginal groove, the latter broad and shallow from the base beneath the explanate external border of the dorsal plate; surface coarsely punctate and setose, setæ rather short. Genital fissure rather narrowly fusiform, the internal margins of the valves being contiguous in basal and apical fourths. Inferior pudendal membrane apparently closing the fissure.

Habitat.-Arizona (region of the Gila River, LeConte and Horn; Fort Grant; Oracle in April, Hubbard and Schwarz; Prescott, collection Charles Fuchs; Nogales, September 22, Albert Koebele and F. W. Nunenmacher).

Number of specimens studied, 20.

Type in the LeConte collection.

Type-locality._- "Flumen Gila," Arizona (LeConte).

Salient type-characters.-Narrowed anteriorly, generally opaque. Thorax scarcely conspicuously narrowed anteriorly, sides usually straight, finely and sparsely punctate. Elytra finely, distinctly, and seriately punctate (LeConte).

Diagnostic characters. - Similar to goryi in general outline, but less robust and less inflated, and more fusiform than either the above or insularis. The surface is opaque and the elytra sculptured with striæ of fine punctures. The latter are in contrast to the more or less coarse punctures of goryi.

The males have only the basal joint of the anterior tarsi pubescent beneath, which distinguishes it from all other members of the subgenus, except insularis.

The prothorax appears widest at the base when viewed vertically from above, with the sides converging to apex (forma typica); but these characters depend upon the sides being normally arcuately deflexed, otherwise it would appear more or less widest at the middle. The base is always relatively wider, as compared to the apex, than in insularis.

Two males from Prescott, Arizona, have the pronotum widest at the middle, and the sides are feebly sinuate before the basal angles, the base appearing narrower than normal (forma sinuata). Their large size and dull integuments serve to separate them from insularis. Such variations are to be expected; some females exhibit this tendency, the sides of the pronotum becoming more strongly arcuate.

The mentum is variable in form as in insularis. The surface is more or less distinctly excavated laterally and as a result the middle is more or less longitudinally ridged. 
Prosternum is horizontal or feebly arcuate between the coxæ, and quite strongly and subtriangularly mucronate behind. The prosternum gradually slopes from the anterior margin to a point between the coxæ, so that the coxal region appears less suddenly protuberant ventrally than in many other species.

In a larger series than the one before me there would no doubt be greater variation in this respect.

The mesosternum is moderately oblique and quite broadly concave.

The tibial grooves of the femora are much less strongly developed in this species than in insularis. In the anterior femora they are the widest and moderately concave, sides converging from the femoral teeth, becoming evanescent before reaching the base; the middle grooves are less strongly defined and narrower, evanescent before reaching the base; the posterior are the least developed, quite narrow and evanescent near the middle of the femora. The margins of the grooves are obtuse, rising but slightly above the quite flat floors of the same. The anterior margins of the profemoral grooves are carinate, becoming dentately laminate at outer fifth, and thence to apex sinuate and more or less obsolete.

The tibiæ are not noticeably compressed, and not in the least carinate externally; the tarsal grooves are rudimentary and more or less obsolete.

The tarsi are about equally stout in the sexes.

Tarsal formula:

\begin{tabular}{|c|c|c|c|}
\hline $\begin{array}{l}\text { Pro. } \\
\text { Male. }-3 \frac{1}{2}\end{array}$ & $\begin{array}{l}\text { Meso. } \\
4 \frac{1}{3}\end{array}$ & $\begin{array}{l}\text { Meta. } \\
5\end{array}$ & $\begin{array}{c}\text { Metatibæ. } \\
7\end{array}$ \\
\hline Eemale. $-3 \frac{1}{2}$ & $4 \frac{1}{2}$ & 5 & $\overline{8}$ \\
\hline
\end{tabular}

\section{ELEODES GORYI Solier.}

Eleodes goryi Solier, Studi Entomol., 1848, p. 251, pl. x, figs. 14, 15.Champion, Biol. Centr.-Amer., IV, Pt. 1, 1885, p. 93.

Eleodes seriata LeConte, Proc. Acad. Nat. Sci. Phila., 1858, p. 185.-HonN, Trans. Amer. Phil. Soc., XIV, 1S70, p. 319.

Ovate fusiform, more or less shining to subopaque, strongly convex, elytral punctures usually within larger dents.

Head less than twice as wide as long, feebly convex, rather finely and more or less densely punctate. Antenne long, reaching beyond the prothoracic base, outer four joints scarcely compressed and feebly dilated, third joint not as long as the next two taken together, fourth decidedly longer than the fifth, the latter to the eighth inclusive subequal, eighth triangular, ninth and tenth more or less orbicular, eleventh oval.

Pronotum widest at the middle, where it is but slightly wider than the base; disc moderately and evenly convex, finely, rather densely and regularly punctulate; apex moderately deeply emarginate, finely or more or less obsoletely beaded, and scarcely equal to the length; 
sides more or less converging from base to apex, evenly and more or less moderately arcuate and finely beaded; base more or less arcuate to truncate and finely margined, two-fifths to one-half wider than the apex; apical angles subacute and more or less prominent anteriorly; basal angles obtuse and not rounded.

Propleura more or less convex, obsoletely punctulate and more or less rugulose.

Elytra oval, and more or less inflated; base truncate to slightly emarginate and scarcely wider than the contiguous prothoracic base; humeri obtuse and not in the least rounded to subacute, not prominent anteriorly; sides evenly arcuate, apex obtuse and not produced; dise very strongly convex and without any semblance of even an obtuse margin, more or less suddenly and arcuately or vertically declivous posteriorly; striato-punctate, the punctures small to moderate in size and arranged in rather distant series, or more frequently the punctures are sunken within larger dents that vary in size in the same series, the punctures may be rather evenly and closely to irregularly spaced in each series, the intervals are finely, irregularly, and rather thickly punctulate; the dents are usually larger at the sides, scarcely denser, and not evident on the apex.

Epipleurce more strongly widened at base and moderately narrow, gradually narrowing to apex; surface obsoletely punctulate.

Sterna more or less punctate and rugulose.

Parapleurce rather finely and densely punctate.

Abdomen feebly shining, feebly punctate and more or less obsoletely rugulose, punctures denser on the last segment, intercoxal process rather broad.

Legs rather long and more or less moderately stout; anterior femora acutely or obtusely dentate; anterior tibial spurs acute and unequal, the anterior longer and very slightly thicker. Anterior and middle tarsi dissimilar in the sexes.

Male.-Elongate fusiform, scarcely inflated. Abdomen more or less oblique, moderately convex, first segment broadly impressed in its entire length. Anterior femora armed with a short, more or less acute tooth; first two joints of the anterior tarsi thickened and dilated, clothed beneath with dense and more or less spongy pubescence, surface of the pads flat; first joint of the middle tarsi feebly thickened and clothed in apical half beneath with a dense oval pad of pubescence similar to those of the anterior tarsi.

Female.-Ovate fusiform. Elytra more or less strongly inflated and usually vertically declivous posteriorly. Abdomen horizontal, more or less strongly convex, not impressed. Anterior femora with a very obtuse tooth or simply sinuate; anterior and middle tarsi unmodified.

Measurements.-Mates: Length, $15-20.5 \mathrm{~mm}$; width, $5.8-9 \mathrm{~mm}$. Females: Length, 19-22 mm.; width, 8.2-10 mm. 
Genital characters, male.-Edeagophore oblong-oval. rather prolonged and acute at apex, not arched.

Basale oblong, evenly and moderately convex, sidés nearly parallel and very feebly arcuate.

A picale triangular, moderately elongate, more or less arcuately decurved at tip; surface evenly and not strongly convex, with a median linear groove at middle three-fifths, which is slightly dilated in basal third and more or less membranous; sides moderately arcuate in basal third and thence broadly and evenly sinuate to apex, the latter produced and acute; base subacutely lobed at middle, broadly and more or less sinuate laterally.

Sternite subtriangularly parabolic in outline. Each lobe triangular with the external border more or less straight in basal half, thence evenly arcuate to apex, the latter moderately rounded; internal border only defined near apex, thence to base membranous; surface more or less convex, bright and shining and sparsely punctate in the externobasal half, with the interno-apical moiety sloping inwards toward the sinus and membrano-chitinous, densely punctate and setose, setæ quite long. Sinus narrow and nearly closed by membrane, the latter more or less setose.

Female.-Genital segment subquadrate, apical half more or less deflexed and conspicuously setose.

Valvula (Plate 4, fig. 5).--Dorsal plate obovate, with the internal fourth of the apical half reflexed, smooth and glabrous; outwardly plane or feeble convex, surface shining and sparsely punctate, each puncture with a long seta; external border straight to feebly arcuate; apical border more or less arcuate to subtruncate and moderately rounded at the angle; internal border arcuate in apical two-thirds, thence outwardly oblique and more or less sinuate to base; apex moderately short, acute and finely setose.

Appendage flattened, semi-oval, scarcely twice as wide as long, sparsely clothed with rather short setæ. Fossa large and fringed with quite long setæ, longest externally.

Superior pudendal membrane reaching to about the middle of the dorsal plate, reflected apically and continuous with the valvular membrane without fornix, and thereby shortest in the median line.

Ventrolateral surfaces very moderately convex; surface lines straight as viewed longitudinally, rather densely clothed with quite long setæ; submarginal groove broad and oblique beneath the explanate external and apical borders of the dorsal plate, terminating at the internal margin of the fossa. Valves contiguous in basal third, the genital fissure rather broadly fusiform, and closed in the basal half by the inferior pudendal membrane. 
Habitat.-Texas (Brownsville, June, Hubbard and Schwarz, H. F. Wickham; Bosque County, G. W. Belfrage; San Diego, May, E. A. Schwarz; Beeville, April; San Antonio, June, H. Soltau; Dallas; Dimmit County, Hubbard and Schwarz); New Mexico (Dr. George Horn); Mexico (Mirador, Sallé; Rinconado, Höge).

Number of specimens studied, 45 .

Type is in the Solier collection; of seriata in the LeConte collection.

Type-locality.-Mexico (Solier); Texas (LeConte).

Satient type-characters.-Subopaque. Thorax quadrate, slightly narrowing anteriorly, sides feebly rounded; apical angles acute; basal angles obtuse and not rounded. Elytra with the base broadly emarginate, humeri acute, strongly striato-punctate, intervals irregularly, finely and sparsely punctulate (seriata, LeConte).

Diagnostic characters.-Distinct by its coarse punctuation, which consists of distinct rows of coarse punctures or dents in which the punctures are distinctly visible. The elytra are very convex and normally without any semblance of even an obtuse margin. Many examples have the serial punctures fine, and these are frequently confounded with soror (see carbonaria var. soror).

The basal joints of the anterior tarsi in the males are more strongly modified than in any other species of the subgenus.

Any single locality does not appear to produce any particular form of punctuation; the most strongly sculptured specimens before me were collected by Belfrage in Bosque County, Texas.

Specimens from Mexico do not differ from those taken in Texas.

The mentum is variable; surface convex, coarsely punctate and at times more or less excavated laterally.

Prosternum more or less evenly arcuate from the anterior margin to the tip of the intercoxal process; at times more or less horizontal between the coxæ. All of the specimens examined have the prosterna strongly and triangulo-conically mucronate behind.

Mesosternum at times obliquely subhorizontal or feebly arcuately oblique, rarely vertically arcuate, always more or less strongly concave.

The grooves of the anterior femora are inwardly attenuate, about reaching the base; those of the mesofemora extending inwards to about the basal third, while on the metafemora they reach only to about the middle. The anterior margins of the anterior grooves are scarcely carinate, except in the external sixth, where the teeth are developed.

The tibiæ are not compressed and not in the least carinate externally, and the tarsal grooves are obsolete. 
The protarsi in the male stouter than in the female.

Tarsal formula:

$\begin{array}{cccc}\text { Pro. } & \text { Meso. } & \text { Meta. } & \text { Metatibiæ. } \\ \text { Male. }-3 & 4 & 4 \frac{2}{3} & 6 \frac{1}{3} \\ \text { Female. }-3 & 4 & 4 \frac{2}{3} & 6 \frac{1}{3}\end{array}$

ELEODES STRIOLATA LeConte.

Eleodes striolata LeConte, Proc. Acad. Nat. Sci. Phila., 1858, p. 185.Horn, Trans. Amer. Phil. Soc., XIV, 1870, p. 319.

Fusiform to ovate, smooth and more or less shining, briefly caudate; elytra with approximate rows of fine punctures.

Head feebly convex, smooth, finely, not densely and quite indistinctly punctate, impressions very slight and vague; frontal suture evident. Antennce rather long, reaching slightly beyond the prothoracic base, slender, scarcely compressed and feebly incrassate in outer four joints, third joint scarcely as long as the next two taken together, fourth very slightly longer than the fifth, the latter to the eighth, inclusive, subequal, eighth obconical, ninth and tenth orbicular, eleventh ovate.

Pronotum subquadrate, widest at about the middle, very slightly narrowing at the base, and a little more strongly so anteriorly to apex, about one-third wider than long; disc evenly and moderately convex from side to side, finely and obsoletely punctulate; apex evenly and rather broadly emarginate, finely and more or less obsoletely margined; sides evenly arcuate from base to apex, finely beaded; base broadly rounded and very finely margined, one-half wider than the apex and about one-third wider than long; apical angles subacute and slightly prominent anteriorly; basal angles obtuse and more or less rounded.

Propleurce obsoletely punctate, smooth and more or less feebly rugulose.

Elytra oval, widest at the middle, at times slightly more than twice as long as wide; base feebly emarginate and slightly wider than the contiguous prothoracic base; humeral angles slightly acute, not prolonged nor clasping the prothoracic base; sides evenly arcuate, apex slightly produced; disc feebly to moderately convex on the dorsum, laterally rather narrowly rounded, arcuately declivous behind, inflexed sides more or less plane and extending slightly farther than usual upon the sides of the abdomen; punctate, punctures fine and arranged in approximate series, which are scarcely ever impressed; the punctures of each sries are separated by a space that is about equal to their diameters; each interval has a single series of more distantly spaced and very minute punctules which become more or less irregular at times; on the inflexed sides the serial punctures become coarse and more or less impressed. The apex is slightly pro- 
duced, with the tips of the elytra slightly separated and feebly deflexed.

Epipleurce moderately widened beneath the humeri, thence rather narrow to the apex; surface smooth, finely and sparsely punctate; the superior margin at times more or less obsolete in apical two-thirds, being defined by the marginal series of the discal punctures.

Sterna rather smooth and obsoletely punctate and rugulose.

Parapleura more or less obsoletely punctate.

Abdomen smooth and shining, usually obsoletely punctate and more or less finely rugulose; horizontal.

Legs quite long and slender. Anterior femora dentate or sinuate; anterior spurs of the anterior tibiæ about a half longer and slightly thicker than the posterior, both acute and quite similar in the sexes. Anterior tarsi dissimilar in the sexes.

Male.-Body more or less fusiform, slightly elongate and feebly robust. Antennæ reaching a short distance beyond the prothoracic base. Elytra rather gradually declivous posteriorly. Abdomen moderately convex. Anterior femora with a moderately acute tooth at outer fifth; anterior tarsi with the first and second joints feebly dilated and flattened beneath, densely clothed with a fine golden spongy pubescence; mesotarsi unmodified.

Female.-Body ovate and robust. Antennæ reaching slightly beyond the prothoracic base. Elytra arcuately declivous posteriorly. Abdomen quite strongly convex. Anterior femora more or less feebly sinuate in outer fifth; anterior tarsi unmodified.

Measurements.-Males: Length, $18-21 \mathrm{~mm}$; width, $7.5-9 \mathrm{~mm}$. Females: Length, 20-23 mm.; width, 9.5-10.5 mm.

Genital characters, male--Edeagophore elongately fusiform, scarcely arched and rather depressed.

Basale oblong oval, feebly and evenly convex, sides feebly arcuate.

A picale triangular about one-half longer than wide; surface rather feebly and evenly convex, with a narrow membranous groove in middle third; sides rather straight or feebly arcuate, apex acute; base rather narrowly lobed at the middle, broadly sinuate laterally.

Sternite transversely parabolic in outline. Each lobe with the external border evenly and rather broadly arcuate with the apical border, which is narrowly rounded, angle scarcely evident at the internal border, the latter short; surface more or less convex, membranous in the internal half, chitinous externally, sparsely punctate, setose; setæ rather long, slightly longer on the apical edge, not very dense; surface impunctate in basal third. Sinus broad, nearly closed by the membrane, the latter with a few scattered setæ.

Female.-Genital segment subquadrate, valves more or less reflexed and explanate externally, deflexed at apex and distinctly setose. 
Valvula, (Plate 5, fig. 2).-Dorsal plate oblong-oval. Internal border slightly reflexed in apical half and impunctate, externally more or less reflexed; surface slightly concave longitudinally, finely and sparsely punctate, each puncture with a rather long flying seta; external border arcuate; apical margin arcuate in the external half and sinuate within to the internal lobe of apex, the latter moderate and triangular; internal border more or less arcuate apically and sinuous toward base. Apical margin set with a few flying hairs, and the apical lobe is finely setose.

Appendage short and broadly semi-elliptical and set with rather short setx; its external margin is continuously arcuate with the external border of the dorsal plate. Fossa narrow and transverse. Basal prominences not evident.

Superior pudendal membrane reaching to the middle of the dorsal plate, feebly and irregularly longitudinally rugulose.

Ventrolateral surfaces rather strongly convex, narrowly and transversely so laterally, glabrous, sparsely and coarsely punctate, finely setose about the apex; submarginal groove broad, passing quite obliquely to the internal lobe of apex. Genital fissure narrowly fusiform; valves quite contiguous basally and apically. Inferior pudendal membrane not visible.

Habitat.-Texas (Goliad County, October, J. D. Mitchell; San Antonio, Hubbard and Schwarz; Victoria; adjoining regions of Mexico, Dr. George Horn).

Number of specimens studied, 11.

Type a female in the LeConte collection.

Type-locality, Laredo (Webb County) to Ringgold Baracks (Starr County) in southern Texas along the Rio Grande.

Salient type-characters.-Shining, thorax quadrate, slightly narrowed anteriorly and posteriorly; sides moderately rounded, apical angles acute, the posterior obtuse. Elytra with the humeri acute, slightly caudate at apex, punctures of the disc arranged in approximate series, becoming obliterated upon the apex, intervals sparsely and finely punctulate (LeConte).

Diagnostic characters.- Easily recognized by the character of the elytral punctuation, which consists of closely placed series of fine punctures, and by the elytral apices being slightly produced and feebly divergent. The males are quite fusiform and noticeably elongate; the females are more ovate; the legs are quite long and moderately slender in both sexes. It is most closely related to fusiformis and liable to be confused with some of the larger specimens of that species. In striolata the anterior femora are armed in the males and sinuate in the females, the humeral angles are not prolonged and 
do not clasp the prothoracic base; the prothorax is more or less wider at middle than at base. Another distinguishing character is the feebly caudate elytra.

I have seen specimens of striolata labeled fusiformis in collectionslarge examples of the latter may simulate the former by having the elytral punctures arranged in closely placed series. The tarsi in the two species are longer and more slender than in the other species of Promus, opaca excepted.

At the time of writing the Revision Doctor Horn had but three females before him and he had some doubt about placing the species in the present subgenus. I can not find any mention in the literature of a male ever having been studied.

I have a series of eight males before me and find them to be true Promus.

The mentum is quite triangular, with apex rounded, in the specimens examined, and the surface is more or less convex at middle and foveate laterally.

LeConte writes that the prosternum is horizontally produced and acute. In the series at hand I find it quite homogeneous-rounded antero-posteriorly between the coxæ and gradually, more or less evenly subconically mucronate behind. The mesosternum moderately oblique, feebly arcuate, broadly and more or less deeply concave.

The tibial grooves of the femora are not well developed and are more or less concave and glabrous, impunctate. Those of the profemora extend to about the middle and are inwardly attenuate, sometimes obsoletely indicated to the base; margins obtuse, rarely subcarinate, the anterior margin being usually simply dentately laminate to produce the tooth in the male; in the female the anterior grooves are generally quite concave and well defined.

Those of the meso- and metafemora seldom extend inward to the middle, rarely more than the outer third and are more or less poorly defined; at times the posterior grooves are short and evanescent in the females.

The external surfaces of the tibiæ are rounded, and in the examples before me not in the least carinate; the tarsal grooves are obsolete, those of the mesotibiæ being frequently indicated, the external surface is occasionally flattened.

The anterior tarsi are distinctly more robust in the male than in the female.

Tarsal formula:

\begin{tabular}{|c|c|c|c|}
\hline Male. $-\quad \begin{array}{c}\text { Pro } \\
3\end{array}$ & $\begin{array}{c}\text { Meso. } \\
4 \frac{3}{4}\end{array}$ & $\begin{array}{l}\text { Meta. } \\
5\end{array}$ & $\begin{array}{c}\text { Metatibiæ. } \\
\qquad \frac{1}{2}\end{array}$ \\
\hline Female.- $2 \frac{1}{6}$ & 4 & 478 & 7 \\
\hline
\end{tabular}




\section{ELEODES FUSIFORMIS LeConte.}

Eleodes fusiformis LeConte, Proc. Acad. Nat. Sci. Phila., 1858, p. 184.Horn, Trans. Amer. Phil. Soc., XIV, 1870, p. 318.

Fusiform, body narrowing quite evenly both ways, smooth and more or less shining.

Head more or less feebly convex, smooth, usually without impressions, frontal suture distinct, finely and not densely punctate, punctures very sparse over the vertex. Antennce rather long, slightly compressed and incrassate in outer four joints, third joint not quite as long as the next two taken together, fourth to the eighth inclusive subequal, eighth feebly triangular, ninth and tenth very feebly transversely orbicular, eleventh short ovate.

Pronotum trapezoidal widest at the base where it is about onehalf wider than the apex; disc more or less moderately convex from side to side, laterally slightly arcuately declivous, very fineIy, sparsely and indistinctly punctulate; apex moderately and evenly emarginate and more or less obsoletely margined; sides converging anteriorly. not strongly but evenly arcuate, finely margined; base quite broadly rounded, and more or less distinctly margined; apical angles quite prominent anteriorly and subacute, sometimes feebly rounded; basal angles obtuse and more or less rounded.

Propleura quite smooth, obsoletely punctate, and more or less rugulose.

Elytra ovate to oval, widest at or a little in advance of the middle; base broadly emarginate with the humeral angles clasping the basal angles of the prothorax, slightly wider than the contiguous base of the same; humeri more or less acute and anteriorly prominent; sides evenly arcuate, apex not produced but rather narrowly rounded; disc more or less feebly convex on the dorsum, rather narrowly rounded at the sides but not suddenly inflexed, arcuately declivous posteriorly; inflexed sides quite plane and oblique; surface subseriately punctate, the series quite closely placed and at times quite distinct, intervals with a single series of more distantly spaced, at times irregularly arranged punctures, the serial punctures usually slightly larger than the interstitial. Often they are subequal and more or less confused, and always more or less so laterally and on apex.

Epipleurce on the same plane as the inflexed sides of the elytral disc, moderately wide and gradually narrowing from base to apex; surface smooth, finely and sparsely punctate.

Sterna somewhat glabrous, more or less obsoletely punctate and rugulose.

Parapleurce quite coarsely and more or less obsoletely punctate.

Abdomen glabrous and shining, finely and sparsely punctate with the intercoxal process more coarsely sculptured. 
Legs rather long, the anterior comparatively short; anterior femora mutic; anterior spurs of the anterior tibiæ and the anterior tarsi are dissimilar in the sexes.

Male.-Rather robust. Antennæ reaching a little beyond the prothoracic base. Abdomen slightly oblique, moderately convex and somewhat broadly impressed on the first two segments. Anterior spurs of the protibiæ about twice as long and slightly stouter than the posterior, slender and acute. Anterior tarsi with the first joint scarcely dilated, slightly compressed so that the vertical diameter is slightly greater than the transverse; the first in the apical moiety and the second densely clothed beneath with a flattened pad of more or less spongy, golden pubescence.

Female.-Quite robust. Antennæ reaching just beyond the prothoracic base. Abdomen rather strongly convex and horizontal. The anterior spurs of the protibiæ about one-half longer than the posterior, feebly thickened and subacute; anterior tarsi unmodified, the first joint scarcely thickened at tip beneath, with groove narrow and distinct.

Measurements.-Males: Length, 13.2-17 mm.; width, 6-7.5 mm. Females: Length, $11.8-18 \mathrm{~mm}$; width, $5.8-9 \mathrm{~mm}$.

Genital characters, male.-Edeagophore small and short oblongovate, not arched.

Basale scarcely twice as long as wide, oblong and not strongly convex, sides feebly arcuate.

A picale triangular, about one-half longer than wide, the surface is feebly convex, with a feebly developed membranous groove in apical half; sides arcuate in basal third, thence to tip broadly and feebly sinuate, apex acute; base subacutely lobed at middle and broadly sinuate laterally.

Sternite transversely trapezoidal. Each lobe with the external border at base quitê straight to feebly arcuate and thence slightly converging apically, the apical margin moderately arcuate or truncate; internal border is scarcely evident; surface scarcely convex, chitinous externally and membranous internally, sparsely punctate and setose, setæ moderately long, with longer ones about the apical margin. Sinus broad and closed by the membrane, the latter not setose at bottom of the former.

Female.-Genital segment quadrato-parabolic, valves reflexed laterally and slightly deflexed apically, setose.

Valvula (Plate 4, fig. 3).-Dorsal plate oval, with the internal third of the apical half reflexed and impunctate, also glabrous; outwardly explanate and slightly deflexed, with the surface plane sloping obliquely downward and inward. The surface is sparsely punctate and setose in outer two-thirds, with the hairs rather long; external 
border moderately arcuate; apical border slightly rounded and feebly sinuate just external to the apical lobe, the latter small and triangular; internal border broadly arcuate. The apical margin has a few long setæ.

Appendage rather short and transversely semi-elliptical, finely setose, and equal in width to the outer two-thirds of the dorsal plate. Fossa transverse and narrow.

Basal prominences not evident. The external border is angulate at the base.

Superior pudendal membrane reaching to the middle of the dorsal plate, finely and more or less regularly longitudinally rugulose.

Ventrolateral surfaces are evenly and moderately convex, glabrous. The submarginal grooves are very broad beneath the explanate external borders of the dorsal plates. Each curves inward around to the inner lobe of the apex, so that the apical margin appears explanate when viewed from below; surface very sparsely punctate and setose; genital fissure very narrowly fusiform.

Habitat.-Texas. Specimens without definite locality labels and collected by C. V. Riley, others by Hubbard and Schwarz are the largest in the series before me. One specimen from Dallas is also large and well developed. A pair collected in Bexar County by Charles Drury agree in size with other examples from this State. Many years ago I received similar specimens that were collected in Bosque County by G. W. Belfrage.-Wyoming. Specimens taken at Cheyenne by $H$. Soltau are the smallest specimens before me. Two specimens with indistinct labels, but apparently from this locality, are larger and moderate in size. Dr. George Horn stated that this species is never very abundant, and also as occurring on the plains of Nebraska and southward into New Mexico.-Kansas (WallaceW. Knaus). Professor Wickham, in his "List of the Coleoptera of Colorado," writes that it occurs at Bellevue, and at La Junta on authority of Bowditch.

Number of specimens studied, 24.

The type in the LeConte collection bears a green disc label, and was probably collected in Colorado, in the Platte River Valley, near Fort Laramie.

Salient type-characters.-Fusiform. Thorax trapezoidal, narrowing anteriorly; posterior angles rounded with the base; anterior angles acute; disc finely punctate. Elytra with base emarginate, clasping the base of the prothorax; humeri anteriorly produced; disc rather densely subseriately punctate. Antennæ slightly incrassate. Prosternum produced (LeConte).

Diagnostic characters.-Distinguished from all of the other species of the subgenus - except opaca-by the mutic anterior femora. From 
opaca it is recognized by the black and shining surface, being neither opaque nor pubescent as in that species.

The elytral punctuation is rather fine and closely subseriate. In the large specimens with distinct and closely placed series of punctures an approach is made toward striolata. (See p. 171.)

Relationships.-It would be very interesting to determine if, in a very large series of specimens collected from all parts of its distributional area, any examples of fusiformis could be found with a tendency to having the anterior femora sinuate or feebly dentate, these characters with any tendency to slight prolongation of the elytral apices would show a transition into striolata. I expect this.

General observations.-The mentum is variable. Usually subtriangular with the apex more or less rounded, and at times slightly transverse with the anterior margin arcuately rounded from side to side; the surface may be longitudinally convex at middle and more or less foveate laterally, or more or less evenly convex with the fover obsolete.

The prosternum is feebly arcuate between the coxæ or subhorizontal, produced and compressed behind into a stout triangular mucro; anteriorly as in subnitens. The prosterna in the series at hand are quite homogeneous.

The mesosternum is arcuately oblique and more or less deeply and broadly concave.

The tibial grooves of the femora are distinctly margined, although not cariniform, the margins are more or less narrowly rounded; the floors are rather concave and glabrous, inwardly and evenly attenuate, and not quite reaching the bases of the femora.

The tibiæ are more or less cylindrical in transverse section and not in the least carinate externally; the tarsal grooves are obsolete. although the external surfaces are at times slightly fattened in the apical half.

The anterior tarsi are slightly stouter in the male than in the female.

Tarsal formula :

\begin{tabular}{|c|c|c|c|}
\hline $\begin{array}{l}\text { Pro. } \\
\text { Male. }-2 \frac{1}{2}\end{array}$ & $\begin{array}{c}\text { Meso. } \\
3_{3}^{\frac{2}{3}}\end{array}$ & $\begin{array}{l}\text { Meta. } \\
4 \frac{2}{3}\end{array}$ & $\begin{array}{c}\text { Metatibix } \\
6\end{array}$ \\
\hline Female. $-2 \frac{1}{2}$ & $3 \frac{2}{3}$ & 5 & 6 \\
\hline
\end{tabular}

Blaps opaca SAY, Journ. Acad. Nat. Sci. Phila., III, 1823, p. 262.

Eleodes opaca LeConte, Proc. Acad. Nat. Sci. Phila., 1858, p. 182; Classif. Coleopt. North Amer., 1861, p. 226 (Promus).-Hons, Trans. Amer. Phil. Soc., XIV, 1870, p. 318.

Fusiform oval, black, opaque, sparsely clothed with whitish or subflavate subsquamiform recumbent hairs, with the dorsum of the elytra quite flat. 
Head scarcely twice as wide as long, slightly convex, very feebly and quite regularly punctulate. Antennæ moderate, scarcely reaching beyond the prothoracic base, outer four joints very slightly compressed and dilated, third joint about equal to the next two taken together, fourth to the eighth, inclusive, subequal, eighth subtriangular, ninth and tenth suborbicular, eleventh short oval.

Pronotum widest toward the base, where it is at least one-half wider than the apex, and about twice as wide as the head; disc evenly and moderately convex, rather densely and very finely punctulate; apex emarginate and more or less obsoletely margined; sides feebly arcuate and converging from base to apex, very finely beaded; base broadly arcuate, frequently very feebly sinuate at middle, finely margined; apical angles acute, rather prominent anteriorly, never everted; basal angles broadly and rather obtusely rounded.

Propleura obsoletely punctulate.

Elytra pointed oval to ovate, scarcely twice as long as wide; base deeply emarginate, humeral angles acute and anteriorly prominent clasping the obtuse basal angles of the prothorax; sides acutely margined, evenly arcuate and continuing the lines of the sides of the pronotum, apex obtusely rounded; disc flattened and more or less feebly convex, sides acutely inflexed and not suddenly arcuately declivous posteriorly; surface finely, irregularly, and inconspicuously punctulate and estriate, rarely striate; inflexed sides with surface quite plane, feebly concave at the humeri, and sculptured as on the dorsum.

Epipleurce smooth and narrow, very gradually narrowing from base to apex; surface obsoletely punctulate.

Sterna very finely muricately punctured, and more or less obsoletely rugulose.

Parapleurce finely punctate.

Abdomen more or less shining and smooth, finely and quite regularly punctate, and more or less rugulose.

Legs moderate. Femora mutic in both sexes; anterior tibial spurs unequal, the anterior longer and slightly larger than the posterior. Tarsi dissimilar in the sexes.

Male.-Moderately narrow and fusiform. Abdomen moderately convex and more or less impressed on the first segment between the coxæ; slightly oblique to the intercoxal process and sterna. First two joints of the anterior tarsi slightly widened and clothed beneath with dense pads of more or less spongy pubescence, surface of the pads quite flat.

Female.-More or less broadly fusiform oval. Abdomen more or less strongly convex; anterior tarsi unmodified.

Measurements.-Males: Length, 10.5-12 mm.; width, 4.8-5 mm. Females: Length, 10.5-14 mm.; width, 5.5-7 mm. 
Genital characters, male.-Edeagophore oblong-ovate as usual and not arched.

Basale short oblong, evenly convex, with the sides more or less arcuate.

A picale triangular, nearly twice as long as wide; surface evenly convex, with a median groove at middle four-sixths, gradually dilating from the middle to base; sides feebly arcuate in basal third, thence very feebly sinuate to apex, the latter acute; base rather broadly lobed at the middle and more or less sinuate laterally.

Sternite transverse. Each lobe rather short, with the external border more or less straight in basal half, thence evenly and broadly arcuate to the internal border, angle scarcely evident; internal border broadly membrano-chitinous and not defined; surface feebly convex, sloping inward from the middle to the sinus, glabrous in basal and external third, elsewhere punctate and setose; punctures and hairs sparsely placed, the latter rather long. Sinus narrow and closed by membrane; the latter may be more or less setose.

Female.-Genital segment quadrate in outline, rather short, setose and not deflexed apically.

Valvula (Plate 4, fig. 4).-Dorsal plate more or less broadly obovate, with the internal third in apical half reflexed, impunctate, and glabrous; surface more or less oblique in the outer two-thirds, and consequently rather concave, coarsely and sparsely punctate, setæ moderate in length and more or less flying; external border more or less arcuate and continuously so with the arcuate apical margin, angle scarcely evident; internal border arcuate in apical half, thence to base more or less sinuate. A pex small and triangular, subacute, finely setose, and continuous with the reflexed internal border of the dorsal plate.

Superior pudendal membrane reaching to about the middle of the dorsal plate, and reflexed apically to be directly continuous with the valvular membrane, fornix absent, irregularly and obsoletely rugulose.

Ventrolateral surfaces.-Body semicircularly and evenly convex and glabrous, rather strongly impressed across the bases of the apices; submarginal groove broad and arcuate to the internal margin of the fossa, beneath the more or less explanate external and apical border of each dorsal plate and fossa, sparsely setose; internal border of the valves contiguous in the basal fourth. Genital fissure long and narrowly fusiform with the inferior pudendal membrane visible in the basal half.

Habitat.-Oklahoma (Fort Supply, Coll. H. S. Barber); Texas (Mobeetee, July, H. S. Barber; Coll. Charles Fuchs); Nebraska (Sand Hills, September, C. V. Riley; Chadron, August, Lawrence 59780-Bull. 63-09-12 
Bruner; Dodge County, Coll. F. E. Blaisdell) ; Southern Dakota (Alexandria; Volga, Coll. E. C. Van Dyke) ; Kansas (Gove County, 2,500 feet, F. H. Snow, Warren Knaus, Hubbard and Schwarz; Plains, Dr. George Horn) ; Colorado (Dr. George Horn; Trinidad; Colorado Springs, F. H. Snow; West Las Animas, H. F. Wickham).

Number of specimens studied, 38.

Type not in existence.

Type-locality as given by Say is Missouri and Arkansas.

Satient type-characters.-Opaque, clothed with whitish hairs; thorax with acute anterior and obtusely rounded posterior angles; sides hardly arcuate. Elytra with base emarginate to receive the prothoracic base; humeral angles acute; lateral edge acute. Lateral . curve of the body continuous (Say).

Diagnostic characters.-Distinct from its congeners in having the dorsal surface of the elytra quite flat, with the lateral margins quite acute; the surface is opaque and rather sparsely covered with short, recumbent, setiform hairs.

It resembles fusiformis in having the anterior femora unarmed and in having the elytral base deeply emarginate with the humeral angles embracing the obtusely rounded basal angles of the prothorax.

Structurally these two species are closely related and undoubtedly originated from the same basic stock. In opaca the elytral base more strongly clasps the prothoracic base than in fusiformis, and in the latter more than in striolata, where this character is at its minimum, and entirely absent in goryi, subnitens, and insularis.

It is to be observed that the relations of the prothoracic and elytral bases give to the lateral margins of the insect a continuity of outline which is most marked in opaca and the least developed in insularis, these two species constituting the extremes of the subgeneric series.

Mr. Say, in his description of the species, says that the "lateral edge" of the elytra is not reflected, but in all the specimens before me it is slightly and distinctly reflected in basal half of the elytra and gradually becomes evanescent as it approaches the apex.

Variations.-In a series of seven specimens collected at Fort Supply, Oklahoma, and Mobeetee, Texas, there is distinct evidence of three elytral costæ-in other words, the sutural and every fourth interval is feebly but noticeably convex, with feebly but clearly defined striæ of fine and closely placed punctures. Normally the " elytra are destitute of striæ."

General observations.-The mentum is variable, usually triangular and rounded at apex, or less frequently subparabolic in outline; surface feebly convex and more or less foveate laterally.

Prosternum evenly arcuate antero-posteriorly in the median line, sometimes horizontal between and behind the coxæ; produced posteriorly into a more or less strong mucro, which is usually compressed 
and vertically triangular; rarely tuberculiform and sometimes deflexed.

The mesosternum is arcuate in different degrees of obliquity and strongly concave. The tibial grooves of the femor are glabrous and more or less concave and distinctly defined, with margins narrowly rounded. Each groove is inwardly attenuate, the anterior scarcely reaching the femoral base, while those of the meso- and metafemora scarcely attain a slight distance beyond the middle. The external surfaces of the tibiæ are rounded and more or less obsoletely flattened apically.

Anterior tarsi slightly stouter in the male than in the female. Tarsal formula :

$\begin{array}{rrcc}\text { Pro. } & \text { Meso. } & \text { Meta. } & \text { Metatibiæ. } \\ \text { Male. }-2 & 2 \frac{2}{3} & 3 & 4 \frac{1}{2} \\ \text { Female. }-2 & 2 \frac{2}{3} & 3 \frac{2}{3} & 5\end{array}$

Subgenus HETEROPROMUS, new.

Anterior femora mutic. Tarsi slender and spinulose beneath; the anterior of the male not dilated nor thickened, and with a small transverse tuft of golden pubescence on the ventro-apical margins of the first and second joints. Anterior spurs of the anterior tibiæ thicker than the posterior.

Subgeneric genital characters, male-Apicale of the edeagophore triangular, surface convex and more or less obsoletely grooved along the median line.

Female-Genital segment triangular in outline, setose, not strongly chitinized, dorsal plate not defined from the apex, appendage and fossa obsolete.

Superior pudendal membrane reaching to the apical third of the dorsal surface of the valves; internal margins of the valves beneath contiguous in basal fourth. Genital fissure long, evenly fusiform, and not wide.

Distribution.- Thus far the single species of this subgenus is only known from southeastern Texas-from counties bordering on the Gulf of Mexico.

Relationships.-Veterator appears to be quite isolated in the tribe Eleodiini, in fact in many respects might be considered as constituting a distinct genus. It only resembles Promus (opaca) in external facies and no way suggests to my mind any conception of its ancestral origin.

\section{ELEODES VETERATOR Horn.}

Eleodes veterator Hons, Trans. Amer. Ent. Soc., V, 1874, p. 33.

Oval, black, opaque, subdepressed above, sparsely clothed with short, recumbent yellowish hairs, and slightly more than twice as long as wide. 
Head slightly more than twice as wide as long, moderately convex, more or less impressed laterally and along the frontal suture, sparsely punctulate and pubescent. Antenne rather short, outer four joints feebly compressed and very slightly dilated, third joint scarcely as long as the next two taken together, fourth to the seventh inclusive subequal, eighth slightly shorter and subtriangular, ninth suborbicular, tenth very feebly transversely oval, eleventh rather broadly oval.

Pronotum nearly twice as wide at base as long, and about oneseventh longer than width at apex; disc feebly convex, sparsely punctulate and pubescent; apex rather deeply and semi-circularly emarginate, obsoletely margined; sides regularly arcuate and gradually convergent from base to apex, very finely beaded; base squarely truncate, very finely margined and slightly over-lapping the elytral base; apical angles slightly prominent anteriorly and subacute; basal angles subrectangular and rather narrowly rounded.

Propleurce very finely, sparsely punctulate, pubescent, and rugulose; broadly and moderately excavated beneath and internally to the basal angles.

Elytra triangularly shield-shaped, squarely truncate at base and slightly wider than the contiguous prothoracic base; humeri narrowly rounded; sides evenly arcuate and gradually converging to apex, and from the base regularly continuing the curve of the sides of the pronotum; apex obtuse and not produced; disc feebly convex, quite suddenly deflexed at the sides with margin narrowly rounded, but acute in basal third, evenly and strongly arcuately declivous posteriorly; finely, evenly, and not densely punctulate and pubescent, the pubescence arranged so that the surface appears substriate; inflexed sides plane.

Epipleurce rather narrow and feebly dilated at base beneath the humeri, very gradually narrowing from base to apex; surface finely punctate and sparsely pubescent.

Sterna rather densely punctate and feebly shining; prosternum obsoletely punctate anteriorly.

Parapleurce very finely and sparsely punctate.

Abdomen distinctly horizontal in the sexes, glabrous and shining, quite coarsely and densely punctate on the first segment, the punctures becoming finer and less dense on the succeeding segments, rather strongly and evenly convex from side to side.

Legs rather small and slender; femora mutic, and finely, sparsely punctate; tibiæ straight; anterior tibial spurs slightly unequal in length and stoutness, the internal spurs of the meso- and metatibix a little longer than the external; tarsi feebly dissimilar in the sexes.

Male.-Feebly elongate oval. Antennæ reaching to about the posterior fifth of the pronotum; elytra widest at the base, sides 
noticeably converging to apex. Intercoxal process of the abdomen flattened or more or less slightly concave. Anterior spur of the protibiæ about one-third longer than the posterior; anterior tarsi with joints distinctly grooved beneath, first joint very feebly and transversely produced at the ventro-apical margin, with a small transverse tuft of golden pubescence upon the same; the second joint also has a smaller and similar tuft on the ventro-apical margin.

Female.-Broadly oval. Antennæ reaching to the posterior fourth of the pronotum. Elytra widest in basal fourth, sides rather strongly arcuate and less noticeably converging to apex. Anterior spur of the protibiæ about a fourth longer than the posterior and slightly stouter; first joint of the protarsi not modified beneath.

Measurements.-Males: Length, $10.5 \mathrm{~mm}$; width, $5.5 \mathrm{~mm}$. Females: Length, $11.5 \mathrm{~mm}$; width, $6.0 \mathrm{~mm}$.

Genital characters, male.-Edeagophore of the usual oblong-ovate form, elongate and feebly arched.

Basale short, oblong-oval, evenly convex above with the sides evenly arcuate.

A picale elongately triangular and very feebly decurved apically; surface evenly convex, obsoletely grooved along the median line; sides with feeble lobes at basal fourth, thence feebly sinuate to apex, the latter moderately produced and acute; base acutely lobed at the middle and feebly sinuate laterally.

Sternite feebly transverse. Each lobe parabolically rounded, with the surface feebly convex, sparsely punctate and setose, setæ longer on the apical margin and not dense. Sinus acutely triangular, membrane not visible between the lobes.

Female.-Genital segment equilaterally triangular in outline when the valves are adducted, small, setose, glabrous, and shining, not strongly chitinized.

Valvula (Plate 4, fig. 17).--Dorsal plate suboblong, nearly three times longer than wide and not defined from the apex, nearly plane, finely and sparsely punctulate, punctures denser at apex, each with a rather long, delicate, flying hair; external border somewhat straight in basal half, evenly arcuate to apex; internal border more or less sinuous; apex with the outer lobe obsolete, the internal not defined from the general surface. Fossa and appendage obsolete.

Superior pudendal membrane reaching to the apical third of the valves and longitudinalìy rugulose.

Ventrolateral surfaces evenly convex, not inflated nor excavated, finely and sparsely punctate, setose as above; submarginal groove not developed; internal margins of the valves contiguous in basal fourth. Genital fissure long and evenly fusiform, not wide. Inferior pudendal membrane visible in basal half. 
Habitat.-Texas (Alligator Head, Calhoun County, February, J. D. Mitchell, collector; Corpus Christi, Nueces County, May). A series of nineteen specimens from the Hubbard and Schwarz collections (U. S. National Museum) ; others from the collections of Fall, Fuchs, and Van Dyke.

Number of specimens studied, 24.

Type in the Horn collection.

Type-locality.-."Texas."

Salient type-characters.-Opaque, subdepressed, sparsely clothed with short yellowish hairs. Form elongate (male) or broadly (female) oval. Base of the pronotum squarely truncate and slightly overlapping the base of the elytra. Pubescence of elytra arranged so as to appear substriate. Sides of the body forming continuous and evenly arcuate lines from head to the elytral apices (Horn).

Diagnostic characters.-One of the most isolated species of the gerius.

The regularly oval form, equally narrowed anteriorly and posteriorly, the thorax squarely truncate at base, with the sides regularly arcuate and gradually narrowing from base to the apex, are characters which serve to distinguish it from all other species of Eleodes.

The anterior tarsi are not dilated in the male. There is a wonderful degree of homogeneity of structure among the individuals of the series before me-in fact, one would think that they had been cast in the same mold. It bears a superficial resemblance to opaca in its opaque integuments and sparse setiform pubescence, but the above characters will quickly separate it.

The genital characters place it in a distinct subgenus. I consider it a primitive form that has undergone but little modification in recent years.

Mentum variable, triangular, trapezoidal or evenly rounded at apex, convex at middle and more or less narrowly concave laterally. Prosternum usually horizontal between the coxæ-and sloping gradually upward anteriorly to the anterior margin; rarely feebly arcuate between the coxæ; feebly dilated behind the equator of the coxæ, scarcely produced, vertically truncate behind, with angle rectangular, or feebly produced and sometimes feebly deflexed at the angle.

Mesosternum vertically and arcuately declivous, more or less feebly concave. The intercoxal process of the abdomen is subquadrate and feebly transverse; equal in width to the third and fourth ventral segments taken together, the post-coxal part of the first segment is equal in length to the second; the third one-fourth of its length longer than the fourth.

The abdominal salient is about one-fourth of its width broader than the metacoxal process. The metasternum laterally between the coxæ is a little shorter than the width of a mesotibia at apex. 
The tibial grooves of the femora are well defined and concave, glabrous and impunctate and prolonged inwardly upon the femora; their margins are subcarinate. External borders of the tibiæ punctate and pubescent and not in the least carinate.

The tarsi are slender and apparently slightly compressed.

A protarsus is about one-third of its length shorter than a mesotarsus; joints small, the first distinctly larger and longer than the second, the latter about as long as wide; the third just slightly shorter, and the fourth still smaller, both slightly wider than long. In the female the first joint is less robust.

The mesotarsi are about one-fourth of their length shorter than a metatarsus; the first joint of each is about as long as the third and fourth taken together; the second a little longer than wide, and the third and fourth about as wide as long, each gradually and slightly decreasing in size and length in the order mentioned.

The metatarsi are about one-fifth of their length shorter than their metatibiæ; first joint of each is just slightly longer than the next two taken together, the second distinctly longer than the third, the latter a little more than half as long as the fourth.

\section{Subgenus ELEODES Eschscholtz.}

In the present subgenus the species have the anterior femora more or less dentate in one or both sexes; the teeth are abortive in caudifera and longipilosa.

The anterior tarsi of both sexes are simply spinous beneath, or at the most the first joint may bear a small tuft of modified spinules in one or both sexes, and the first one or two joints are never dilated in the male, although in a few species the first joint may be thickened at apex beneath.

The internal spurs of the meso- and metatibiæ are longer than the external.

For the positive recognition of the constituents of this subgenus the female genital characters must be relied upon.

The male genitalia have undergone but little differentiation along the lines of specific specialization and are valueless for the diagnosis of species.

They may be enumerated as follows:

Subgeneric genital characters, male-Apicale of the edeagophore distinctly longer than wide; dorsal surface moderately convex, with a more or less complete membranous median groove, which at times is strongly developed, at others feebly so; apex acute and not distinctly attenuated; base distinctly lobed at the middle.

Female.-Genital segment more or less trapezoidal in outline and robust, conspicuously setose in apical moiety with evident tufts of 
hairs on the tips of apex and appendage, and also at the external angle of the fossa on or beneath the apical angle of the dorsal plate.

Internal lobe of the apex developed, the external rudimentary.

Appendage variable, from conical to depresso-semi-ellipsoidal.

Dorsal plate oblong and more or less strongly concave, the margins being reflexed.

Submarginal groove more or less visible from above.

Superior pudendal membrane never reaching beyond the middle of the dorsal plate and narrowly exposed.

The following groups may be defined:

All those species that have the first joint of the protarsi in both sexes thickened at apex beneath and bearing a tuft of modified spinules upon the same; humeri obtuse OBscura Group.

All those species that do not have the first joint of the protarsi thickened at apex beneath and without a tuft of modified spinules; grooves entire.

Humeri obsolete Grandicolisis Group. Humeri obtuse DENTIPEs Group.

The Dentipes Group is divided into the following sections:

Section A.-All those species which are genetically related by having the inferior surface of the cauda, when present, formed by the dilated apical extremity of the epipleuræ. Such species are more or less opaque and more or less asperately scuíptured.

Section B.-All those species which are genetically related by having the inferior surface of the cauda, when present, simply margined by the undilated apical extremity of the epipleuræ; the inferior surface of the cauda being formed by the general internal surface of the elytra. Such species are glabrous and more or less shining and never distinctly asperately sculptured.

\section{OBSCURA Group.}

This group may be characterized by having the first joint of the protarsi distinctly thickened at apex beneath, and bearing a tuft of modified spinules upon the same. In the males the protibial spurs are somewhat equal in size, although the posterior may be slightly longer than the anterior; in the female the posterior spur is more or less thickened and distinctly longer, and in both sexes the spurs are decidedly divergent.

The constituents of this group are among the largest of our species.

The articular cavities of the tibiæ are open and continuous with the tarsal grooves of the same. The middle lobe of the mentum and the exposed surfaces of the basal divisions of the maxillary palpi are more strongly and conspicuously setose than in any other species known to me.

The head appears to be comparatively long, and the abdomen is more or less distinctly oblique in the male. 
The group genital characters are as follows:

Male.-Apicale of the edeagophore triangular, dorsal surface moderately convex, with a median longitudinal linear groove, and the base has a rounded lobe at middle. Sternite with an interlobar circular membranous area.

Female.-Dorsal plate canaliculate, sides reflexed and retracted, submarginal groove completely visible from above; apex but slightly longer than the appendage, the latter short and conic; superior pudendal membrane not longitudinally rugulose and not reaching posteriorly beyond the middle of the dorsal plate.

The three species known to me may be separated as follows:

Females,-The posterior spur of the protibiæ distinctly larger and longer, more obtuse, than the anterior.

Thorax convex and smooth.

Elytral margins rounded

obscura.

Elytral margins acute at humeri

acuta.

The posterior spur very slightly thicker or longer than the anterior: both spurs gradually narrowing from base alike, both acute.

Thorax flat or concave; elytral margin acute throughout

Males.-Anterior spurs of the protibiæ quite similar; abdomen oblique.

Thorax convex and smooth.

Elytral margins rounded obscura.

Elytral margius acute at humeri acuta.

Thorax flat or concave.

Elytral margin acute throughout. suturalis.

The genital characters appear to present the following specific differences. The males as usual present no distinct differential characters.

Female.-Internal lobe of apex well developed. Genital segment trapezoidal in outline, robust; basal prominences well developed.

Apical margin of the dorsal plate rounded.

Apical margin evenly rounded obscura.

Apical margin rounded externally and oblique within suturatis. Apical margin truncate.

Apical angle subrectangular acuta.

A linear arrangement of our species may be given as follows:

Thorax convex $\left\{\begin{array}{l}\text { dispersa. } \\ \text { deleta. } \\ \text { obscura. } \\ \text { sulcipennis. } \\ \text { arata. }\end{array}\right.$
Thorax concave $\left\{\begin{array}{c}\text { with its } \\ \text { two } \\ \text { acutreme forms. }\end{array}\right.$
texana.


Genealogy.-The accompanying diagram will give my idea of the relationships of the species. It will be observed that from the ancestral trunk divergence probably occurred along two lines- $(a)$ one where the prothorax acquired acute margins, and consequently a concave disc; at the same time the spurs underwent but slight differentiation, and as a result, in the course of time there were produced forms, which being plastic to a moderate extent, became capable of being recognized as a series, the heterotypes of which are our suturalis and texana. These two races are united by true mesotypes.

(b) The other line of divergence resulted in a less differentiation of the dorsal body wall, but a greater change occurred in the tibial spurs. Here the dichotomous changes resulted in the present acuta with less calcarine development and obscura where the tibial calcars are the most differentiated. It appears as if acuta has reacted less to modifying factors, while obscura has gradually been the most re-

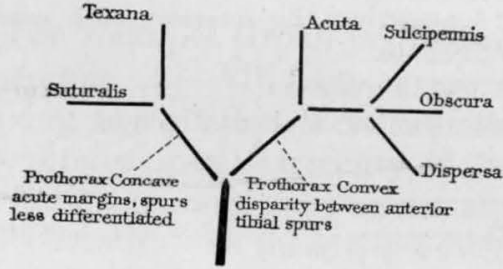

Fig. 3.--Genealogical diagram of the Obscura Group, Subgenus Eleodes. active as evidenced by the recognizable races; the heterotypes being united by an unbroken line of mesotypes.

So in the lineal arrangement of the species and their modifications two distinct breaks in the chain are noticeable: First, suturatis and acuta are distinctly defined species as regards each other; second, acuta and sulcipennis (obscura) while less divergent in structure are not united by any known mesotypes, the heterotypes of acuta more likely only simulate obscura on the one hand and texana on the other. These are only suggestions, for no one can be sufficiently positive to assume the true relationships of forces that bring about such interesting forms.

I also wish to call attention to another fact: In dispersa the tarsal grooves of the tibix are the most strongly developed, and the articular cavities open the most widely into them, and these characters gradually diminish so that in suturatis they are found at their minimum in the present group.

By the open articular cavities - the floors of which are directly continuous with those of the tibial grooves, both being on the same plane in the most strongly differentiated examples-greater functional power is given to the tarsi, i. e., they must be more strongly extensible and capable of being more strongly brought into juxtaposition to the tibial surface.

Distribution.-As known to me the present group is distributed through the following 15 States: Texas, New Mexico, Arizona, Kansas, Colorado, Utah, Nevada, northern California, Oregon, Washington, Idaho, Wyoming, Nebraska, southern Pakota, and Oklahoma. 
Table of distribution.

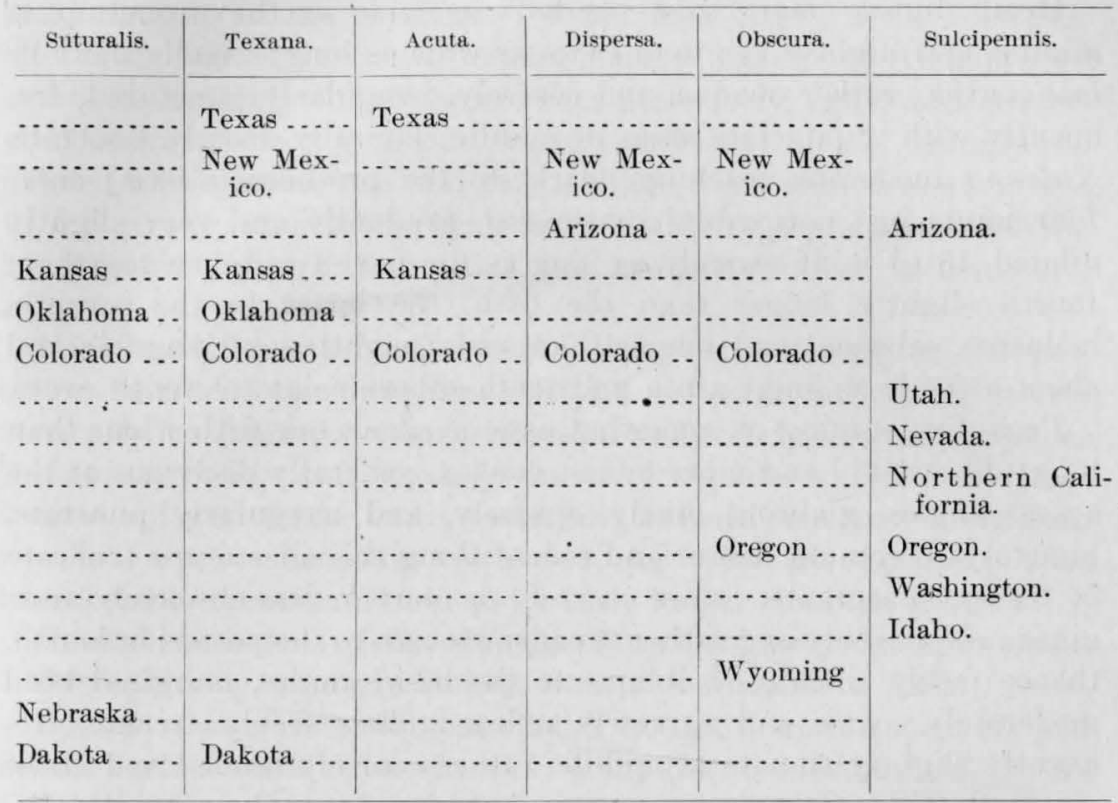

It will be seen that suturalis inhabits the more central and northeastern part of the region west of the Mississippi River; texana, the southern and southern central; acuta, probably the same, like texana; dispersa, central and more southern western; obscsera, central and to the northwest, western and northwestern, and probably none are found west of the Sierra Nevada Mountains. Sulcipennis extends southward into Sonora, Mexico (Morrison), and is probably the most widely dispersed member of the group, while dispersa is the least widely distributed.

\section{ELEODES OBSCURA Say.}

Blaps obscura SAY, Journ. Acad. Nat. Sci. Phila., III, 1823, p. 259; Amer. Entomology, I, 1824, p. 32, pl. xvi, fig. 3.-LeConte, Complete Writings of Th. Say, I, 1859, p. 32.

Eleodes obscura SAY, Proc. Acad. Nat. Sci. Phila., 1858, p. 181.-HonN, Trans. Amer. Phil. Soc., XIV, 1870, p. 306.

Eleodes dispersa LeConte, Proc. Acad. Nat. Sci. Phila., p. 182.-Honn, Trans. Amer. Phil. Soc., XIV, 1870, p. 305.

Eleodes deleta LeConte, Proc. Acad. Nat. Sci. Phila., 1858, p. 182.Horn, Trans. Amer. Phil. Soc., XIV, 1870, p. 305.

Eleodes sulcipennis Mannerherm, Bull. Soc. Nat. Moscow, XVI, 1843, p. 266; Mag. Zool., XIII, 1843, No. 128 (fig.).-LeConte, Proc. Acad. Nat. Sci. Phila., 1858, p. 182.-Honn, Trans. Amer. Phil. Soc., XIV, 1870, p. 306.-Champion, Biol. Centr. Amer., IV. Pt. 1, 1884, p. 79.

Eleodes arata LeConte, Proc. Acad. Nat. Sci. Phila., 1858, p. 182.-Horn, Trans. Amer. Phil. Soc., XIV, 1870, p. 306. 
Black or brownish, oblong, elongate.

Head slightly more than one-half as wide as the pronotum at middle, and slightly less than twice as wide as long; usually more or less convex; rather opaque, and coarsely, irregularly punctured, frequently with impunctate areas at middle; laterally densely punctate. Antennce moderate, reaching nearly to the prothoracic base; outer four joints just noticeably compressed, gradually and very slightly dilated, third joint scarcely as long as the next two taken together; fourth slightly longer than the fifth, the latter to the seventh, inclusive, subequal and longer than wide; eighth subtriangular and about as wide as long; ninth and tenth suborbicular; eleventh ovate.

Pronotum shining or somewhat opaque, about one-fifth wider than long; disc evenly and more or less convex, generally declivous at the apical angles, glabrous, finely, sparsely, and irregularly punctate, punctures becoming denser and coarse along the sides; apex truncate or feebly emarginate, rather coarsely or more or less obsoletely margined; sides evenly and rather broadly arcuate to the posterior fourth, thence feebly sinuate or oblique to the basal angles, marginal bead moderately coarse and narrowly reflexed; base feebly arcuate, frequently slightly sinuate at middle, rather coarsely beaded and about one-sixth wider than the apex; apical angles obtuse; basal angles distinct, more or less rectangular, sometimes very narrowly rounded.

Propleurce impunctate and rugulose; frequently sparsely punctate centrally.

Elytra oblong to oblong-oval about twice as long as wide; base scarcely emarginate, scarcely to slightly wider than the contiguous prothoracic base; humeri slightly prominent and obtuse; sides evenly and not strongly arcuate, apex not produced and rounded; disc generally widest at or frequently behind the middle, more or less depressed and convex, laterally always more or less broadly rounded throughout, rather suddenly declivous posteriorly; surface more or less striate and sulcate, more or less irregularly, muricately punctured.

Epipleura, sterna, and parapleurce more or less obsoletely and rather densely punctate, rugulose. The epipleuræ are moderate in width and not more suddenly widened beneath the humeri.

Abdomen finely and more or less obsoletely punctate, rugulose; fifth segment more densely punctate.

Legs moderately long and quite stout; anterior femora armed in the sexes; anterior tarsi with the first joint (Plate 8, figs. 8 and 9) thickened and slightly produced at apex beneath, groove obliterated, the produced tip bearing a tuft of more or less golden (fresh specimens) modified spinules; other joints with the plantar groove entire, with the usual apico-ventral tufts of spinules separated by the groove; similar in the sexes. 
Male.-Elongate oblong, somewhat narrow. Antennæ reaching to basal margins of the prothorax; elytra occasionally with sides parallel or moderately arcuate, dorsum more or less distinctly depressed and quite suddenly obliquely declivous posteriorly. Abdomen moderately convex from side to side, broadly and more or less strongly impressed on segments one and two, oblique. Anterior femora armed with a strong, moderately acute tooth; tibial spurs similar; the anterior about equal, rather stout and convexo-concave in transverse section.

Female.-Elongate oval, robust. Antennæ reaching to the posterior fourth of the pronotum. Elytra rather broadly oval, nearly vertically declivous posteriorly; dorsum moderately convex. Abdomen horizontal, evenly and strongly convex from side to side. Anterior femora with an obtuse tooth, sometimes reduced to a mere sinuation; protibial spurs dissimilar (Plate 8, fig. 14), the posterior spur broader, more robust, obtuse, and a little longer than the anterior.

Genital characters, male.-Edeagophore elongately oblong-ovate.

Basale oblong, strongly arched, stout and variable in form.

Apicale triangular, elongate; sides straight, apex produced and acute; surface evenly convex, with a fine linear, membranous groove extending from the apex nearly to the base, the latter with a broad, rounded lobe at middle and not strongly sinuate laterally.

Sternite (Plate 4, fig. 15).-Quadrate and strongly chitinized, with an interlobar circular membranous area. Lobes elongate, with the external borders subparallel in basal half and thence evenly arcuate to apex. Apex of each lobe moderately subacute; internal border short, straight to feebly arcuate; surface strongly and densely punctate in apical half, setose, setæ quite long and very dense at apex, and scattered across the membrane at bottom of the sinus, the latter not conspicuously deep.

Female.-Genital segment subtriangular, robust, strongly, sparsely punctate, and setose; setæ moderately long, semi-erect, and rather evenly distributed.

Valvula (Plate 1, figs. 13, 15, and 16).--Dorsal plate oblong, with the sides rather strongly reflexed, retracted, and subparallel; surface concave, sometimes slightly convex within near apex; internal margin slightly sinuous to subangulate at basal and middle thirds; apical margin more or less evenly rounded, not sharply defined. Submarginal groove entirely visible from above, limited externally by the margin of the lateral plate which is visible throughout its entire length. A pex short, slightly or scarcely more prominent posteriorly than the appendage, coarsely punctate and setose, setæ not forming an apical tuft; external angle of the fossa forming the subapical angle, with setæ rather condensed. 
Appendage short, stout, and conical, setose, setæ at tip forming a loose tuft.

Superior pudendal membrane reaching to a point about midway between the base and apex, not closely longitudinally rugulose.

Basal prominences well developed.

Valvular membrane more or less visible from apex to the pudendal membrane, and minutely setose.

Ventrolateral surfaces.-Body rather strongly inflated in basal half, rather deeply, broadly, and transversely concave before the apices, quite strongly setose. Internal margins of the valves contiguous for a very short distance at base and apex, intervening fissure fusiform, and closed in basal half by the inferior pudendal membrane.

The present species is very variable, both as regards to form and sculpturing. The following three races are founded upon elytral sculpturing alone:

\section{ELEODES OBSCURA var. DISPERSA LeConte.}

Elytra with indistinct striæ of closely placed punctures, intervals flat and quite densely, very irregularly and muricately punctured.

Measurements.-Males: Length, 25-33 mm.; width, 9.2-11.5 mm. Females: Length, 30-35 mm.; width, 12-14 mm.

\section{ELEODES OBSCURA Say (typical variety).}

Elytra feebly sulcate, intervals not strongly convex, sparsely, muricately punctate. Each stria with a series of closely placed feebly muricate punctures; intervals with a series of more distantly spaced and slightly more muricate punctures. Frequently the sculpturing is denser, always more strongly and irregularly so laterally and on apex.

Measurements.-Males: Length, 26-30 mm.; width, 10.2-11.8 mm. Females: Length, 25-31 mm.; width, 10.5-13.2 mm.

\section{ELEODES OBSCURA var. SULCIPENNIS Mannerheim.}

Elytra strongly sulcate; intervals quite strongly convex, smooth, with a single series of irregularly, distantly spaced, feebly muricate punctures, which become decidedly muricate on the apical declivitv: sulci about equal in width to the intervals, with closely placed muricate punctures which become more densely placed toward apex; inflexed sides of the elytra obsoletely sulcate and irregularly muricately punctured. 
Measurements.-Males: Length, 25-31.5 mm.; width, 10.2-11.5 mm. Females: Length, 24-33.5 mm.; width, $8.5-13.8 \mathrm{~mm}$.

The following varietal genital characters may be correlated with the above forms of elytral sculpturing, and although they are not always as clearly defined, yet they seem to be sufficiently so as to warrant their being recorded.

Dispersa.-Genital segment rather elongate, and generally more strongly chitinized and sculptured.

Obscura.-Genital segment subtriangular, sides more convergent, apex less truncate; moderately strongly chitinized and sculptured.

Sulcipennis.-Genital segment rather broadly trapezoidal, slightly elongate. Valves broadened apically, and not strongly chitinized nor sculptured.

Habitat.-Dispersa: Arizona (C. V. Riley; Coll. Beverly Letcher; Keams District, Navajo Reservation, April, collected by A. W. Barber); New Mexico (Coll. Charles Fuchs; H. F. Wickham; Coolidge, Hubbard and Schwarz; Aztec, April, Coll. C. F. Baker); Colorado (San Luis Valley, Mr. Bowditch).

Obscura.-Colorado (Colorado Springs, August, Collector H. Soltau; Rocky Mountains, Coll. Hubbard and Schwarz; Greenhorn, Trinidad, and San Luis Valley, Hayward); Wyoming (Cheyenne, April, Hubbard and Schwarz; May, H. Soltau, National Park, August, H. Soltau; Saratoga, Coll. E. C. Van Dyke); New Mexico (Santa Fé, Coll. C. V. Riley; Las Vegas, August, Coll. Barber and Schwarz); State of Washington (Coll. J. B. Smith); Oregon (Coll. C. V. Riley).

Sulcipennis.-Arizona (Bright Angel, July, Barber and Schwarz; Santa Rita Mountains, May, Hubbard and Schwarz; Pinal Mountains, Coll. E. C. Van Dyke; Fort Grant, July; Walnut, September, H. F. Wickham; Williams, July, Barber and Schwarz; Ash Fork, June; Nogales, September, Koebele and Nunenmacher; along the Colorado River, Charles Fuchs); Idaho (Camas Creek, L. Bruner); Nevada (Hubbard and Schwarz); Oregon (Hubbard and Schwarz); State of Washington (C. V. Riley; Wawawai, Coll. C. V. Piper); northern California, Nevada (Doctor Horn).

\section{ELEODES DISPERSA LeConte.}

Number of specimens studied 20.

Type in the LeConte collection.

Type-locality.- "Creek Boundary;" collected by Doctor Woodhouse (LeConte).

Salient type characters.-Oblong, bright. Thorax moderately finely punctate; sides strongly rounded, toward base subsinuate; 
basal angles rectangular. Elytra elongate, densely punctate, punctures on the dorsum subseriate, laterally and on the apex transversely confluent and muricate (LeConte).

Diagnostic characters.-Easily separated from obscura and sulcipennis by its obsolete striæ and finely muricate punctuation, by the comparatively more elongate and narrower form. Even in a moderate series the three races are united by an ample number of examples exhibiting all degrees of intermediate sculpturing.

The mentum has the middle lobe moderate, and about as wide as long; sides more or less arcuate; apex also rounded, slightly reflexed, truncate or feebly emarginate; surface strongly punctate, slightly prominent along the median line, feebly and broadly concave laterally and clothed with stiff hairs that curve forward.

The prosternum is triangularly dilated behind the equator of the coxæ, and more or less protuberant ventrally with the same; posteriorly compressed, vertically truncate, and more or less produced; at times it is arcuately declivous.

Mesosternum quite vertically declivous or oblique and more or less concave.

The abdominal process is subquadrate, about one-sixth of its width wider than long, its width is also equal to the post-coxal portion of the same segment. The second segment is a little more than twice as long as the fourth; the third is about equal to the post-coxal part of the first; the fourth is about one-third of its length shorter than the third.

The abdominal salient is about a sixth of its width greater than the same of the metasternal process.

Metasternum laterally between the coxæ is as long as the width of a mesotibia at apex.

The tibial grooves of the femora are not entire. Those of the profemora are quite broad, the floors rather feebly concave, smooth and impunctate; the margins are strong and gradually converge to meet just before attaining the base, the anterior is more or less dentately laminate, forming an obtuse (female) or an oblique tooth (male).

On the mesofemora the grooves become evanescent at internal third, but are well defined externally, floors feebly concave and smooth.

The metafemora have the grooves evanescent at middle without convergence of the sides, which are well marked externally.

The tibiæ are very densely muricate. Each protibia is moderately compressed and quite strongly carinate externally in basal half, where it is also more or less arcuate; the carina is smooth and the middle of the protibia becomes the anterior boundary of the tarsal groove, where it also becomes muricate to the apex. The tarsal groove is quite strongly defined and its floor is glabrous and impunctate, open- 
ing at apex into the articular cavity, the margins of which become continuous with the sides of the groove.

Each mesotibia may be very briefly carinate at base externally; the external surface is quite deeply channeled, to a greater or less length by the tarsal groove, the sides of which are quite abrupt and densely muricate; the groove opens into the articular cavity as in the protibia, but is narrower and the cavity is less widely open. The floor of the groove is quite glabrous. The metatibiæ are obsoletely carinate at base externally and also with the tarsal grooves running nearly the whole length; each groove is rather shallow and not suddenly formed, densely muricate and continuous with the articular cavity.

The tarsi are robust.

The protarsi are about a fourth of their length shorter than a mesotarsus. The first joint is about one and a half times longer than wide; the second, third, and fourth joints are subequal in size and length, wider than long, and together about equal to the fifth. Each mesotarsus is about a third of its length shorter than a metatarsus. The first and fifth joints are quite equal in length; the second, third, and fourth are subequal, just visibly longer than wide, and together longer than the fifth.

The metatarsi are about a half of their length shorter than a metatibia; second and third joints subequal and distinctly longer than wide and together about equal to the fourth, the latter about equal to the first.

\section{ELEODES OBSCURA Say.}

Number of specimens studied, 30.

Type, destroyed.

Type-locality.- "Country bordering the River Platte within a hundred miles of the Rocky Mountains." (Say).

Satient type-characters.-Say's description is too brief and indefinite to give a clear idea of the type: "Elytra scabrous, grooved, margin rounded; thoracic margin not reflected."

Diagnostic characters.-Easily recognized from its races by the feebly sulcate and scabrous elytra. It is also less elongate.

The prosternum is convex antero-posteriorly, subtruncate behind, vertical or oblique and more or less compressed.

Mesosternum arcuately declivous and more or less concave.

The tibial grooves of the femora are about as in dispersa.

The sculpturing of the tibiæ is variable, sometimes strongly muricate and at others subscabrous. Otherwise the tibial characters are relatively the same as in dispersa. The articular cavities are really less open, as the margin is frequently continued across the confines 59780-Bull. $63-09-13$ 
between the groove and cavity; the tarsal grooves are usually more contracted and more apt to be roughly sculptured.

The relative widths and lengths of the tarsal elements, abdominal segments, and sterna are about the same as in the preceding variety, and the analysis of its exoskeletal characters indicates its truly intermediate position.

\section{ELEODES SULCIPENNIS Mannerheim.}

Number of specimens studied, 54 .

Type in the Mus. Imp. Acad. Scient. St. Petersburg.

Type-locality is (northern) California.

Salient type-characters.-Elongate. Thorax subcordate, sides narrowly reflexo-marginate, finely punctulate, elytra oblong and deeply sulcate, posteriorly very slightly dilated, apex attenuate and strongly declivous (Mannerheim).

Diagnostic characters.-Quickly separated by the strongly sulcate elytra.

Some specimens from Colorado are intermediate between obscura and sulcipennis, and have the scabrous elytra of the former and the distinct sulci of the latter.

LeConte described a female collected in New Mexico by Captain Pope as deleta. It was only an intermediate variation and can be placed as forma deleta, connecting dispersa and obscura. It was characterized by LeConte as follows: Form of sulcipennis, absence of elytral grooves, except at the sides behind the middle, where some faint traces are seen; the punctures are submuricate and arranged in striæ distinct on the back, confused at the sides; between the rows are distinct punctures as in obscura; posteriorly abruptly declivous and furnished with rows of tubercles, alternately large and small, the latter corresponding to the striæ of the anterior portion. Anterior femoral teeth very obtuse.

Other specimens, male and female, collected in Arizona, which are the heterotype of sulcipennis, were also described by him under the name arata.

These strongly developed specimens can be labeled forma arata, and may be recognized from the following brief description.

\section{ELEODES ARATA LeConte.}

Form of sulcipennis, thorax more convex, less flattened and less punctured at the sides, and more finely margined; elytral grooves deeper, interstices smooth and shining, with much fewer scattered punctures.

The student will recognize the five forms, just considered, as expressions of variations in the same species, and these forms may be arranged in the following morphological sequence: dispersa, deleta, 
obscura, sulcipennis, and arata; which makes the series complete as far as known.

The mentum is more or less distinctly trapezoidal, rather large; apex truncate, feebly emarginate or slightly arcuate; surface coarsely punctate, foveæ more or less obsolete, and rather densely setose; setæ black, moderate in length and directed forwards.

The prosternum is slightly convex between the coxæ, compressed and usually vertically truncate posteriorly, the inferior angle submucronate or rounded, sometimes oblique, or more rarely evenly rounded antero-posteriorly.

Mesosternum variable as in dispersa and obscura.

The tibial, femoral, tarsal, abdominal, and sternal characters are practically the same as for the other races, but dispersa appears to have the most pronounced form of sculpturing, not including the elytral sulci.

\section{ELEODES ACUTA Say.}

Blaps acuta SAY, Journ. Acad. Nat. Sci. Phila., III, 1823, p. 258; Amer. Entomology, I, 1824, p. 31, pl. I, fig. 1.-LeConte, Complete Writings of Thomas Say, I, 1859, p. 31.

Eleodes acuta LeConte, Proc. Acad. Nat. Sci. Phila., 1858, p. 181.-Honn, Trans. Amer. Phil. Soc., XIV, 1870, p. 306.

Black, elongate oblong, depressed dorsally, usually more or less reddish along the suture.

Head nearly twice as wide as long, and a little less than one-half as wide as the pronotum at middle, feebly convex and more or less transversely impressed along the frontal suture, rather opaque, moderately coarsely, irregularly, and densely punctate. Antenna quite stout, not reaching to the prothoracic base, outer four joints scarcely dilated or compressed, the third about equal to the next two combined, fourth slightly longer than the fifth, the latter to the seventh inclusive, very slightly decreasing in length in the order named, the seventh just a little shorter than the fourth, eighth subtriangular and scarcely as wide as long, ninth and tenth subglobular, eleventh short ovate.

Pronotum usually widest at the middle and about three-eighths wider than long; disc more or less glabrous and shining, finely and sparsely punctate, laterally more or less impressed along the margin ; impressed area opaque, irregularly or transversely rugulose and finely granulate; apex moderately emarginate and finely margined; sides broadly and evenly arcuate to near the base, then more or less sinuate and more coarsely margined, margin narrowly reflexed; base truncate to feebly arcuate, feebly and broadly sinuate at middle, coarsely margined, and about one-third wider than the apex; apical angles obtuse; basal angles more or less rectangular. 
Propleurce opaque, smooth, very sparsely and finely punctate; usually more or less rugulose.

Elytra oblong to elongate oval, nearly twice as long as wide, feebly shining, at times more or less opaque; base feebly emarginate or sinuate laterally within the humeri beneath basal angles of the pronotum, scarcely to slightly wider than the contiguous prothoracic base; humeri scarcely prominent, obtuse; sides evenly and not strongly arcuate, frequently subparallel at middle, apex not produced and rather broadly rounded; disc quite strongly depressed, slightly convex, suddenly deflexed laterally with margin narrowly rounded but acute at humeri, posteriorly more or less suddenly obliquely declivous; surface sulcate, intervals slightly convex with a single series of irregularly placed punctures, first four sulci with a single series of fine muricate punctures, the remaining outer sulci more densely muricately punctured; apical declivity more strongly sulcate and muricate; inflexed sides obsoletely sulcate and irregularly muricately punctate. Scutellum broad and impunctate.

Epipleurce moderate in width, somewhat rapidly but gradually and slightly dilated immediately beneath the humeri; surface glabrous and shining, more or less obsoletely or finely and very sparsely punctate.

Sterna and parapleurce more or less obsoletelv or strongly punctate and rugose.

Abdomen finely and more or less obsoletely punctate and rugulose; fifth segment more strongly punctate.

Legs moderately long and stout, and the anterior femora are armed; anterior tibial spurs dissimilar in the sexes; first joint of the protarsi thickened and feebly produced in apical half beneath, and bearing a tuft of golden pubescence, nearly similar in the sexes.

Male.-Elongate. Antennæ reaching to the basal fifth of the prothorax. Elytra nearly twice as long as wide, with the sides slightly arcuate or subparallel, dorsum strongly depressed, quite rapidly arcuate and obliquely declivous posteriorly. Abdomen oblique, moderately convex, broadly impressed on first two segments. Femora much thickened and armed with a strong, oblique, slightly produced subacute tooth; protibial spurs similar and about equal; first joint of the protarsi with a small, dense, obtusely rounded tuft of yellowish pubescence on the produced tip beneath, groove obliterated.

Female.-Robust. Antennæ reaching to about the posterior third of the prothorax. Elytra broadly oval, with dorsum moderately depressed and convex, about one-half longer than wide, and nearly vertically declivous posteriorly. Abdomen horizontal, evenly and strongly convex. Profemora with a small obtuse tooth; tibial spurs long, the posterior spur of the protibiæ more robust, slightly longer and more obtuse, more strongly divergent than the anterior; first 
joint of the protarsi obliquely produced beneath and clothed with short pubescence at tip, forming an acute transverse tuft, groove apparently obliterated.

Measurement.-Males: Length, 28-35 mm.; width, 13-15 mm. Females: Length, 30-33 mm.; width, 13.5-16.2 mm.

Genital characters, male.-Edeagophore of the usual oblong-ovate form.

Basale oblong, stout, and more or less arched, variable.

Apicale slightly longer than wide, triangular, sides straight to feebly arcuate, becoming slightly sinuate before the apex, the latter somewhat produced and acute; base broadly lobed at middle and more or less sinuate laterally; surface evenly convex, grooved at middle three-fifths, groove more or less linear, with sides impressed, forming a fusiform depression.

Sternite broader than long. Lobes moderate, each with the external border rather broadly arcuate; apex obtuse, and the internal border is short and quite straight; surface densely punctate in apical half, densely setose in apical third, setæ moderately long and not extending upon the membrane across the bottom of the sinus, the latter nearly closed by the former. The lobes are separated centrally at base by a transversely oval membranous area, just cephalad to the sinus, the inner borders of the lobes at base are thus rendered semicircularly sinuate.

Female.-Genital segment subtrapezoidal, robust, rather strongly, sparsely punctuate and setose; setæ rather long, flying, semi-erect, and quite evenly distributed.

Valvula (Plate 1, fig. 17).-Dorsal plate oblong, with sides quite strongly reflexed and parallel, scarcely retracted; external border quite straight; internal slightly angulate and sinuate near base; apical margin quite truncate, angle evident and set with longer setæ; surface strongly concave. Submarginal groove shallow and broad at base, visible from above but less strongly defined toward apex. Apex short, finely setose, and noticeably longer than the appendage.

Basal prominence: strongly developed and setose.

Appendage short, not prominent, conical, setose, with a loose pencil of quite long setæ at tip.

Valvular membrane more or less visible in the intervalvular space, caudad to the pudendal membranes.

Superior pudendal membrane reaching about midway between the base and apex, not longitudinally rugulose.

Ventrolateral surfaces not very strongly inflated, setose in apical half, scarcely transversely concave before the apex; internal margins of the valves contiguous in basal half, genital fissure rather widely fusiform and the inferior pudendal membrane is not visible. 
Habitat.-Texas (Beeville, Coll. Hubbard and Schwarz); Kansas (Gove County, elevation 2,500 feet, F. H. Snow) ; Colorado (Denver, April, H. Soltau) ; Dakota (Buffalo Gap, Collector A. E. Hill).

Number of specimens studied, 28.

Type destroyed.

Type-locality.- "Near Council Bluffs, Missouri" (Say).

Salient type-characters.-Elytra scabrous, grooved; sutural margin reddish-brown; external edge narrowly rounded and acute at humeri. Thoracic margin not reflected (Say).

Diagnostic characters.-From obscura it is known by the elytra being quite suddenly inflexed laterally and therefore very narrowly rounded at the sides, and by the margins being acute at the humeri; from suturalis by the pronotal disc being convex and not reflexed laterally.

In some specimens the elytral margins are subacute and the disc quite flat, so that the passage to suturalis becomes easy. The form of the pronotum is quite constant.

The heterotypes of the series before me resemble obscura on the one hand and texana on the other.

The middle lobe of the mentum is moderate, subtrapezoidal or subparabolic, apex arcuate or subtruncate with the sides straight and converging to apex; surface strongly and rather densely punctate, scarcely convex, obsoletely foveate laterally and quite densely setose.

The prosternum is strongly prominent ventrally with the coxæ, surface usually nearly horizontal, moderately compressed behind and vertically truncate, scarcely produced. These characters are most often observed in those specimens which have the elytral disc quite flat and margins subacute; frequently the prosternum is convex antero-posteriorly and oblique behind, these characters being observed in those examples with convex elytral disc and more broadly rounded margins; rarely it is continuously convex between the coxæ.

Mesosternum variable. Usually obliquely declivous and more or less concave; frequently quite arcuately declivous to somewhat vertically so and more or less feebly concave.

The abdominal intercoxal salient is subquadrate, slightly transverse, and about as wide as the post-coxal portion of the first segment is long; third segment about one-third of its length shorter than the second; the fourth one-fourth shorter than the third.

The metasternal process is scarcely one-half narrower than the abdominal. Metasternum laterally between the coxæ is as long as the width of a mesotibia at apex.

The tibial grooves of the femora are entire on the profemora and variable in length on the meso- and metafemora.

The profemora have the tibial grooves rather broad, with the sides slightly arcuate and converging quite to the femoral base; their 
floors are glabrous and impunctate; margins scarcely acute, the anterior more or less dentately laminate at about junction of the fourth and outer fifth; tibial grooves of the mesofemora are usually short, margins evanescent, and the inferior surface rounded to base and sculptured as usual; the grooves on the metafemora are similarly developed.

The protibiæ are more or less carinate externally, straight or moderately arcuate, and more or less moderately compressed; the tarsal grooves are not usually well developed, roughly sculptured, and open into the articular cavities.

The mesotibiæ are flattened externally and the tarsal grooves are usually well developed and variable in length, with floors glabrous and sides well defined by muricate edges; they open into the articular cavities.

The metatibæ are flattened and more or less broadly marked by a shallow groove externally; the floors of the grooves are muricately sculptured and the articular cavities are open.

The tarsi are stout.

The protarsi are about one-half of their length shorter than a mesotarsus. Joints two, three, and four are subequal, short, and wider than long; the first is slightly longer and quite abruptly narrowed at base; the fifth is scarcely longer than the three preceding ones combined.

The mesotarsi are one-sixth of their length shorter than a metatarsus. The first and fifth joints are about equal in length; the second, third, and fourth are subequal and a little longer than wide, and together distinctly longer than the fifth.

The metatarsi are a little more than one-half of their length shorter than their metatibia. The first and fourth joints are subequal in length; the second and third are subequal and distinctly longer than wide, and together about equal to the fourth.

\section{ELEODES SUTURALIS Say.}

Blaps suturalis SAY, Journ. Acad. Nat. Sci. Phila., III, 1823, p. 257 ; Amer. Entomology, I, 1824, p. 30, pl. xvi, fig. 2.-LeConte, Complete Writings of Thomas Say, I, 1859 , p. 30.

Eleodes suturalis LeConte, Proc. Acad. Nat. Sci. Phila., 1858, p. 181.Horn, Trans. Amer. Phil. Soc., XIV, 1870, p. 306.

Var. texana LeConte, Proc. Acad. Nat. Sci. Phila., 1858, p. 182; in Thomson's Arcana Naturæ, III, 1860, p. 124, pl. xII, fig. 5, female.Horn, Trans. Amer. Phil. Soc., XIV, 1870, p. 306; Trans. Amer. Ent. Soc., V, 1874, p. 34 .

Oblong, more or less strongly elongate, dorsum flattened and slightly concave, black, frequently with a broad reddish band along the elytral suture, epipleuræ often tinged with the same color. 
Head a little less than twice as wide as long, and scarcely one-half as wide as the pronotum; surface plane to slightly convex, frequently more or less impressed along the frontal suture, sometimes transversely so between the eyes, and laterally within the moderately prominent sides of the frons, opaque, moderately, coarsely, irregularly, and densely punctate, usually with small impunctate areas. Antenne rather stout, scarcely reaching the prothoracic base; outer four joints slightly compressed and just perceptibly dilated; third joint about equal to the next two combined; fourth, distinctly longer than the fifth; the latter to the seventh, inclusive, subequal and slightly longer than wide; eighth, triangular and about as long as wide; ninth and tenth, suborbicular; eleventh, short ovate.

Pronotum widest at the middle and about one-half wider than long; dise opaque, smooth, slightly convex, finely and sparsely punctate, with small impunctate areas about the center, frequently with irregular impressions; laterally longitudinally impressed from within the apical angles to a very short distance in advance of the basal angles, terminating in feeble basal impressions, the depressions are generally transversely rugulose; apex deeply emarginate and more or less obsoletely margined; sides broadly and more or less strongly reflexed, evenly arcuate or sometimes very feebly and broadly angulate at middle, slightly sinuate in front of the basal angles, marginal bead moderately coarse; base truncate and feebly trisinuate, distinctly margined, two-fifths to one-half wider than the apex; apical angles acute, subacuminate, prominent and more or less everted; basal angles rectangular.

Propleurce opaque and smooth, very finely and sparsely to obsoletely, muricately punctate, more or less rugulose at times, and defined from the reflexed pronotal margin by a longitudinal concavity.

Elytra oblong, one-third to twice as long as wide and more or less opaque; base feebly emarginate, and about equal to the contiguous prothoracic base; humeri obtuse and not prominent, rounded beneath the basal angles of the pronotum; sides evenly arcuate to subparallel, apex scarcely to feebly produced; disc plane to slightly convex, very suddenly deflexed laterally, angle of deflexion forming an acute and moderately reflexed margin, which becomes obsolete a short distance before the apex, more or less suddenly obliquely declivous posteriorly; surface sulcate, intervals feebly convex, each with a single series of rather distantly placed punctures, the four inner sulci with but a single series of closely placed submuricate punctures, remaining sulci with numerous closely and irregularly placed punctures, which become denser and rather more strongly muricate toward margin; apical declivity somewhat more strongly sulcate and scabrous; inflexed sides not convex, obsoletely sulcate, irregularly and muricately punctured. 
Epipleurce moderately narrow, uncinately dilated beneath the humeri, and gradually narrowing to apex; surface usually more or less obsoletely punctate.

Sterna and parapleurce more or less obsoletely or strongly punctate and rugulose.

$A b d o m e n$ finely and more or less sparsely, obsoletely punctate and rugulose.

Legs moderate. Anterior femora armed in the sexes; protibial spurs and protarsi nearly alike in the sexes, the spurs are quite strongly divergent. The first joint of the protarsi is more or less thickened and slightly produced at apex beneath, bearing a tuft of yellowish pubescence.

Male.-About twice as long as wide. Antennæ scarcely reaching to the basal margin of the prothorax. Elytra moderately, suddenly, and obliquely declivous posteriorly; apex slightly acuminate. Abdomen slightly oblique, moderately convex, broadly impressed on the first two segments. Anterior femora with an acute tooth about onefourth distance from the apex; posterior spur of the protibiæ apparently a little longer and slightly stouter than the anterior, frequently they appear to be quite equal in length, both are rather stout and acute; first joint of the protarsi with the produced tip beneath rather thick and bearing a small obtuse tuft of modified spinules, groove not evident.

Female.-Less than twice as long as wide. Antennæ reaching to about the posterior fifth of the prothorax. Elytra quite suddenly obliquely or vertically declivous posteriorly. Apex obtuse. Abdomen horizontal, evenly and strongly convex. Anterior femora with a small obtuse tooth, sometimes scarcely more than sinuate in outer fourth; posterior spur of the protibix a little longer and stocter than the anterior, both are acute, moderately thick, and gradually narrowed from the base; first joint of the protarsi slightly and transversely produced at tip beneath, bearing a transverse tuft of spinules, which is more or less acute, groove more or less obsolete.

The male genital characters do not apparently show any racial differentiation.

Male.-Edeagophore of the usual oblong-ovate form.

Basale oblong, scarcely arched, and may be sparsely punctate laterally at apex.

A picale rather broadly triangular, moderately depressed, surface more strongly convex apically, with a median membranous groove in apical half; sides rather straight to slightly arcuate; apex scarcely produced and more or less deflexed, subacute; base broadly lobed at middle, and sinuate laterally. (See Plate 1, fig. 19.)

Sternite transverse. Each lobe with the external border more or less evenly arcuate, and the internal short and straight to feebly 
arcuate, with apex rounded; surface densely punctate and setose in apical two-thirds, setæ quite long and not extending upon the membrane across the sinus; the latter nearly closed by the same.

The lobes internally at base and cephalad to the sinus are rendered semicircularly sinuate by an interlobar transversely oval membranous area, the membrane of which is frequently transversely rugose.

By the form of the elytra two races may be recognized as follows:

ELEODES SUTURALIS (typical variety).

Oblong, sides of the elytra evenly arcuate from base to apex, size smaller.

Measurements.-Males: Length, 26-26 mm.; width, 11-11.2 mm.; Females: Length, 21.5-28 mim.; width, 9.5-12.2 mm.

\section{ELEODES SUTURALIS var. TEXANA LeConte.}

Elongate oblong. Sides of the elytra more or less distinctly parallel, size larger.

Measurements.-Males: Length, 30-35 mm.; width, 11-14 mm.; Females: Length, 30-32 mm.; width, 11-13 mm.

Female genital characters.-Suturatis: Genital segment subtrapezoidal, slightly elongate, rather robust and setose, the flying semierect hairs not very long and somewhat evenly distributed.

Valvula (Plate 1, fig. 14).-Dorsal plate oblong, with the sides more or less reflexed, scarcely retracted, quite parallel; externai border quite straight, the internal more or less arcuate and the apical margin is rounded and prominent externally, becoming inwardly oblique internally; surface deeply concave, finely, sparsely punctate and setose, setæ quite long. Submarginal groove visible from above, broad and shallow toward base, fine toward apex, the side of the lateral plate visible and limiting it externally.

A pex short and inconspicuous, scarcely more prominent posteriorly than the appendage, finely setose.

Appendage short, conical, and inconspicuous, with a pencil of rather long hairs at tip; margin of the fossa with many setæ, especially at apical margin of the dorsal plate, setæ soft and moderately long.

Basal prominences moderate.

Superior pudendal membrane reaching about one-third to one-half of the distance from the apex and not rugulose.

Ventrolateral surfaces.-Body rather strongly and transversely inflated in basal half, moderately transversely concave laterally before the apices; surface finely punctate and setose in apical half. Internal margins of the valves contiguous for a short distance at base. Genital fissure long and fusiform.

Female genital characters.-Texana.-Genital segment subtrapezoidal, rather short, robust, and setose. 
Valvula (Plate 1, fig. 23).-Dorsal plate oblong, rather narrow, sides strongly reflexed, retracted externally; external border more or less broadly sinuate, the internal angulate at basal third, and the apical margin is more or less truncate and rather prominent at angle, the latter more or less rounded; surface very deeply concave, finely and very sparsely punctate, setose, setæ small.

A pex short, tip very blunt and not prominent, slightly longer than the appendage, with sparsely placed and short setæ, without pencil at tip.

Submarginal groove not always strongly marked and entirely visible from above; sides of the lateral plate largely visible externally.

Appendage short, conical, and broadly rounded at tip and not conspicuous; setose, with apical tuft of moderately short hairs.

Basal prominences strongly developed. Superior pudendal membrane reaching scarcely half way from the base, and with two or three longitudinal grooves.

Ventrolateral surfaces.-Body quite strongly inflated at base and transversely concave before the apices, strongly so laterally, sparsely setose; apex rather thick-viewed from below. Internal margins of the valves contiguous in about basal third. Genital fissure rather broadly fusiform.

Habitat-Suturalis (var. typica).-Texas (C. V. Riley); Colorado (Denver, October, H. Soltau; Golden, May, Dyar and Caudell; La Junta, Berkeley, Orchard, canyons near Boulder, H. F. Wickham); Nebraska (Dodge County, collections, C. V. Riley, Hubbard and Schwarz, and F. E. Blaisdell); Kansas (Riley County, July to August, Popenoe; Wallace County, elevation 3,000 feet, F. H. Snow ); Oklahoma (Mangum, September, collection National Museum); Dakota (Buffalo Gap, A. E. Hall; Volga, collector, E. C. Van Dyke; Southern at Alexandria).

Var. texana LeConte--Oklahoma (Mangum, September, H. S. Barber); Kansas (collections of Snow, Fuchs, Hubbard, and Schwarz); Colorado (Robinson, coll. E. C. Van Dyke) ; New Mexico (Alberquerque, coll. National Museum); Texas (San Diego, October, Hubbard and Schwarz; Bosque County, G. W. Belfrage).

Suturatis.-Number of specimens studied, 50.

Type destroyed.

T'ype-locality apparently not mentioned by Say.

Salient type-characters.-Reddish-brown along the suture. Thorax with the edge deeply concave in front, lateral margin dilated and reflected; anterior angles with a small excurved point. Elytra scabrous, grooved, lateral edge reflected, slightly elevated and acute (Say).

Var. texana LeConte--Number of specimens studied, 20. 
Type in the LeConte collection.

Type-locality.-Ringgold Barracks, Texas.

Satient type-characters.-Thorax with the disc slightly convex, sides broadly depressed and slightly reflexed, sides greatly rounded, subsinuate behind; anterior angles acutely acuminate; basal angles rectangular. Elytra with dorsum plane, sides parallel and margined (LeConte).

Diagnostic characters.-Conspicuous among its congeners by the acute and more or less reflexed elytral margins, with the pronotal margins acute and reflexed and the disc concave.

The typical race is less elongate with the elytral margins distinctly arcuate; var. texana differs in its elongate and parallel form.

The form is quite constant in this species. The mentum is of moderate size and subtrapezoidal in form; frequently more or less arcuate anteriorly, at other times the sides are straight, converging anteriorly and the apex more or less truncate, often the apex is rounded and narrowly inflexed, giving it a truncated appearance; the surface is scarcely convex, coarsely punctured, more or less even or ridged along the middle, feebly and broadly foveate laterally and setose, setæ short, scarcely dense and less conspicuous than in the other species of the group.

Prosternum very variable and as in acuta. In the more strongly developed examples of texana, the intercoxal prosternal surface is slightly oblique, downward and backward so that the posterior angle is prominent and subacutangular to the strongly truncate and vertical posterior edge.

In the smaller specimens of suturalis the prosternum is strongly convex antero-posteriorly.

The mesosternum is variable as in acuta. The abdominal intercoxal process is nearly quadrate, its width is equal to the length of the third segment; the second segment is about equal to the postcoxal portion of the first, and twice as long as the fourth; in texana it is a little longer; the third is about one-fourth of its length shorter than the second segment.

The abdominal salient is about one-sixth of its width wider than the metasternal process (males) or subequal (females).

The metasternum laterally between the coxæ is about as long as the width of a mesotibia at apex.

The tibial grooves of the profemora are nearly entire, their sides are well defined and the floors are glabrous; the anterior margin of each is dentately laminate at about the outer fourth, it may be simply sinuate.

The grooves of the meso- and metafemora are poorly defined and short, scarcely ever extending beyond the middle and generally only 
present in the external fourth; their margins are rapidly evanescent; when the grooves reach the middle of the femora the margins are about contiguous.

The protibiæ are more or less distinctly carinate externally, slightly compressed, and the external surface line is more or less arcuate from apex to base; the articular cavities are open, but less so than in the other members of the group, and the tarsal grooves are poorly defined, usually scabrous, sometimes more or less glabrous. The articular cavities of the meso- and metatibiæ are nearly or quite closed. The external surface of the mesotibiæ is more or less flattened and more or less feebly grooved, scabrous, scarcely ever glabrous except near the apex.

The metatibiæ are scarcely flattened or grooved externally, although they are at times, the surface is scabrous. The mesotibiæ are sometimes feebly and briefly carinate at base.

The tarsi appear to be variable in stoutness without relation to the size of the specimen; they are slightly more elongate than in the other species of the group.

A protarsus is about one-third of its length shorter than a mesotarsus. The first four joints are short and subequal, the first slightly the longest, the others wider than long; the fifth is about equal to the preceding three taken together.

A mesotarsus is but slightly shorter than a metatarsus. Joints two, three, and four are subequal and a little longer than wide, taken together longer than the fifth; the first is scarcely equal to the next two combined.

The metatarsi are just a little more than one-half as long as their respective metatibia. Joints two and three are subequal and distinctly longer than wide, and together equal in length to the first and fourth individually.

\section{GRANDICOLLIS Group.}

The single species constituting this group has been the only disturbing element thus far met with in the study of the present subgenus.

It is without doubt intermediate between the Obscura and Dentipes groups, or to be more exact between obscura and dentipes themselves. At first I was inclined to treat it as a subsection of section B of the Dentipes group. In that position it was completely isolated and far from being a contributing member to the harmony exhibited by the other species.

In the smooth and shining integuments it is allied to the Dentipes group; its large size, oblong form, broadened tibial spurs, and oblique abdomen of the male show strong affinity with the Obscura group, while the obsolete humeri make it a unique element in the subgenus. 
The elytra at base are not margined nor adapted to receive the prothoracic base, as is the case in the majority of species of the Dentipes group; on the other hand the elytral base declines, corresponding exactly in structure with obscura.

In either group it would prove a disturbing element and the only course to pursue in the search for taxonomical harmony is to place it in a group as here indicated. It is also very evident that it is a distinct species, which has undergone practically no differentiation into distinct races-in this it is analogous to veterator-although it is slowly yielding to the modifying influences of environment.

It probably represents a very slightly changed branch of the common ancestral stem from which the earlier antecedents of the present Obscura and Dentipes groups took their origin. In a genealogical scheme it must be placed to show the greatest affinity for dispersa. Divergent elements can not be arranged in a linear series of morphological or specific sequence.

The form of the prothorax is not so very different from that observed in obscura.

The tibial spurs are broader and larger than is seen in the Dentipes group, and resemble those of obscura. In the male the spurs are of the same form, but smaller, shorter, and narrower; in the female the protibial spurs are more strongly divergent than in dentipes, and less so than in obscura.

It remains for a critical research into the faunal congeneric constituents of Mexico to further elucidate the relationships of this interesting species.

The group genital characters are as follows:

Male.-A picale of the edeagophore elongately triangular; surface convex and not grooved; sides nearly straight; base with an obtuse lobe at middle and feebly sinuate laterally. Sternite slightly transverse, each lobe broadly rounded at tip, not separated at base by a distinctly oval membranous area, and the membrane is not setose across the base of the sinus.

Female.-Genital segment triangulo-trapezoidal. Valvula: Dorsal plate oblong, surface broadly concave, more deeply so internally, internal border strongly reflexed, externally not at all retracted; apical margin truncate. Apex short and triangular.

Appendage conical and truncate. Superior pudendal membrane not reaching beyond the middle of the dorsal plate and longitudinally rugulose. Submarginal groove feeble and not visible from above.

The genital characters show greater affinity with the Dentipes group; the external characters show greater resemblance to the Obseura group.

It is undoubtedly intermediate. Compare Plate 1, figs. 8, 15, and 16; Plate 3, figs. 12 and 13. 
ELEODES GRANDICOLLIS Mannerheim.

Eleodes grandicollis Mannerheim, Bull. Soc. Nat. Moscow, XVI, 1843, p. 266; Mag. Zool., XIV, 1844, No. 130 (fig.).-HonN, Trans: Amer. Phil. Soc., XIV, 1870 , p. 312.

Eleodes valida Boнемan, Freg. Eugen. Resa, Ins., 1858, p. 90.

Large and robust, oblong oval, black, and shining.

Head twice as wide as long and more or less feebly convex, quite coarsely and rather irregularly, sparsely, and at times densely punctate; punctures denser at the periphery. Antenne rather short and stout, reaching to about the posterior fourth of the prothorax and subequal in the sexes; outer joints slightly compressed and not noticeably dilated; third joint equal in length to the next two taken together; the fourth slightly longer than the fifth; the latter, sixth, and seventh subequal in length; eighth and ninth about as long as wide; tenth slightly wider than long; eleventh smaller, trapezoidal and longer than wide.

Pronotum widest at about the middle, less than one-third wider than long, and more than twice as wide as the head; disc smooth and shining, quite strongly convex, and rather strongly declivous at the angles; surface finely, evenly, and rather sparsely punctate, narrowly opaque, and asperate along the lateral margins; apex truncate or feebly emarginate and rather finely beaded; sides broadly and evenly arcuate, somewhat straight, and converging posteriorly, scarcely ever sinuate, finely beaded; base slightly arcuate and rather coarsely margined; apical angles distinct and deflexed, at times more or less rounded; basal angles obtuse and never prominent.

Propleura smooth, more or less strongly rugulose and at times sparsely punctate.

Elytra oval, usually estriate, smooth, and shining, about twice as long as wide, widest at the middle; not emarginate nor abruptly declivous at the base, the latter slightly narrower than the contiguous prothoracic base; humeral angles absent; sides evenly arcuate, apex obtuse and rounded; disc very convex, suddenly and rather obliquely declivous posteriorly; surface finely and quite evenly punctate, punctures arranged in moderately distant, unimpressed series, the individual punctures not closely placed; intervals with a series of distantly and regularly placed punctures, the punctures becoming subasperate at the sides, and more strongly so on the apex.

Epipleurce moderately narrow and very gradually and evenly narrowing from the base to the apex; surface smooth and sparsely punctate.

Sterna moderately and quite densely punctate and rugulose.

Parapleurce rather strongly and quite evenly punctate. 
Abdomen sparsely and quite evenly punctate, more or less irregularly and reticulately rugulose; punctures denser on the fifth segment and finely setose.

Legs moderate in length and very stout. Anterior femora in both sexes, armed with an acute tooth near the external fourth; tibial spurs slightly broadened, those of the protibiæ equal and acute. Tarsi similar in the sexes and rather strongly spinulose.

Male.-Robust. Elytra oblong oval and at least twice as long as wide, nearly vertically declivous posteriorly. Abdomen moderately oblique, not strongly convex; segments one and two broadly and more or less strongly impressed. Tibial spurs feebly broadened.

Female.-Very robust. Elytra broadly oval and less than twice as long as wide, vertically declivous posteriorly. Abdomen horizontal rather strongly convex, and not impressed. Tibial spurs noticeably broadened.

In the material before me two forms can be recognized, notably those from central California, and those from southern California, Arizona and Lower California. Mannerheim's type was undoubtedly collected somewhere in the vicinity of San Francisco.

Forma typica.-Thorax narrower with the sides not strongly rounded, and the apical angles frequently less strongly marked. Elytra less broadly oval, so that the general form is less robust and narrower.

Measurements.-Males: Length, 27-29 mm.; width, 10.5-11.5 mm. Females: Length, $29 \mathrm{~mm}$; width, 11.5-12 mm.

Forma valida.-Thorax broader and more strongly rounded at the sides; elytra broadly oval, and the general form much more robust.

Measurements.-Males: Length, 29.-32. mm.; width, 10.5-11.5 mm. Females: Length, 32.5-34. mm.; width, 14.-15.5 mm.

Genital characters, male.-Edeagophore comparatively small and elongate oval.

Basale suboval, widest in basal half, evenly convex from side to side, slightly arched; dorsum with a rather strong antero-posterior convexity and not gibbous in basal half, apically much narrower than at middle and the sides rather strongly arcuate.

A picale small and rather elongately triangular; surface evenly convex, not grooved; sides nearly straight, scarcely sinuate, the apex being slightly produced and very narrowly rounded at tip; base with the median third obtuse, not rounded nor acute and feebly sinuate laterally.

Sternite slightly transverse. Each lobe rather long, broadly rounded at tip, angle scarcely evident; external border nearly straight and rather strongly convergent apically; internal margin slightly arcuate or straight; surface quite densely punctate in apical 
two-thirds, setose, setæ dense at tip and rather long. Membrane not setose across the bottom of the narrow sinus.

Female-Genital segment triangulo-trapezoidal, rather robust, comparatively small and setose.

Valvula (Plate 1, fig. 8).-Dorsal plate oblong, glabrous; surface broadly concave, more deeply so along the strongly reflexed inner side, sparsely punctate, each puncture with a long flying seta; external border rather straight, and the internal somewhat sinuous; apical margin truncate, angle quite rectangular and set with quite long setæ. Apex rather short, semi-chitinous and finely setose, with a tuft of rather long setæ at tip. Fossa large and fringed with rather long setæ.

Appendage conical, truncate, moderate in size and setose, with a loose pencil of hairs at tip.

Basal prominences rather strongly developed.

Superior pudendal membrane not reaching to the middle of the dorsal plate.

Ventrolateral surfaces rather strongly and transversely prominent in the basal moiety, broadly and rather deeply concave before the apex; apical region punctate and rather thickly set with quite long flying setæ. Submarginal groove feeble. Internal margins of the valves contiguous in basal fifth.

Forma typica.-Habitat.-Central California (San Francisco, Van Dyke; Marin County, Charles Fuchs; Calaveras County, elevation 2,000 feet, F. E. Blaisdell; Monterey County; Tulare County, Ralph Hopping).

Forma valida.-Southern California (San Diego, Los Angeles, Monterey, San Bernardino, and Kern counties); Arizona (Yuma Desert, March; Santa Maria River).

Lower California (San José del Cabo; Lower Paraiso; San Pedro Martir).

Number of specimens studied, 59 .

Location of type unknown to me.

Type-locality.- "California" (Mannerheim).

Salient type-characters.-Elongate, convex, and shining. Head deeply punctate. Thorax with sides strongly rounded, margin reflexed, finely punctulate. Elytra oblong, moderately narrowed each side of the apex, obsoletely striato-punctate. Anterior femora dentate (Mannerheim).

Diagnostic characters.-The only species in the subgenus with obsolete humeri. One of our largest and finest species, very distinct and with obseure relationships. I believe that a study of the Mexican species is necessary before much light can be thrown upon the origin of not only grandicollis and dentipes, but armata.

59780-Bull. 63-09-14 
In the series of examples before me the mentum is variable. Although large, it is moderate when taken in a comparative sense, varying from trapezoidal to quadrato- or parabolo-trapezoidal; apex truncate to evenly arcuate; surface scarcely convex, strongly punctate and almost scabrous, feebly foveate at the basal angles.

The prosternum is variable and strongly protuberant ventrally with the coxæ, being almost declivous from the anterior margin. It is usually longitudinally grooved between the coxæ, rounded anteroposteriorly, and not mucronate behind, or with an abruptly developed mucro; at times convex between the coxæ and subtruncate behind, with a deflexed mucro.

The mesosternum is arcuately or obliquely declivous and more or less strongly concave.

The abdominal process is about a fourth of its width wider than the metasternal salient, subquadrate, and equal in length to the postcoxal portion of the first segment, which is also equal to the third, the latter one-sixth of its length shorter than the second; the fourth is one-half of its length shorter than the second.

Metasternum laterally between the coxæ is about as long as the width of a mesotibia at apex.

Femora stout. The profemora are thickest at the junction of the outer and middle thirds, from that point gradually narrowing each way. Tibial grooves moderately large, edges rather thick, subcariniform, very feebly arcuate, and converging to become contiguous a short distance before the base; floors very feebly concave, subopaque, and extremely, finely, and reticulately rugulose. Anterior margin dentately laminate at the outer fourth.

Meso- and metafemora of nearly the same width throughout; sides quite parallel.

Mesofemora with the grooves moderate in width, margins feebly cariniform, converging very gradually to become evanescent a short distance from the base; floors of the grooves scarcely concave, opaque as on the profemora.

The metafemora have the grooves about moderate in width, with the sides feebly cariniform, gradually converging to become evanescent at basal third; the floors are as on the profemora.

The protibiæ are slightly compressed, carinate in basal half externally, with the tarsal grooves more or less feebly developed, asperate and limited posteriorly by a muricato-serrulate margin, articular cavities closed.

Mesotibiæ more or less rounded, briefly or obsoletely carinate externally just before the base; tarsal grooves simply indicated by a smooth opaque line, or feebly channeled surrounding surfaces muricate; articular cavities closed. 
The metatibiæ rounded, rather small at base and gradually thickening to apex; tarsal grooves obsolete or feebly indicated, articular cavities closed.

Tarsi rather long and stout.

The protarsi are about a fifth of their length shorter than a mesotarsus. Joints two, three, and four equal in length, rather short and distinctly wider than long, and together equal to the length of the fifth; first about as long as wide.

Mesotarsi just a little shorter than a metatarsus. Joints two, three, and four equal in length, scarcely as long as wide, and together about equal to the length of the fifth; first joint a little longer than wide.

The metatarsi are about half as long as their metatibia. Joints two and three equal in length and scarcely longer than wide, and together about as long as the fourth; first joint about one-and-ahalf times longer than wide.

\section{DENTIPES GROUP, Section A.}

The constituents of the present section have the integuments more or less opaque, more or less asperately and muricately sculptured; the surface is never normally entirely glabrous nor shining; furthermore, the species are undoubtedly genetically related by having the inferior surface of the cauda, when present, formed by the dilated apical extremity of the epipleuræ.

A part of the species are ecaudate, the elytral apices being but slightly produced, and in the indifferent stage of development. There is also a tendency to hirsuteness. With the development of the elytral cauda, the femoral teeth become abortive.

The protibial spurs are acute and quite similar in the sexes, not strongly divergent as in the Obscura Group, and instead have a tendency to become parallel and backwardly curved.

The mentum is distinctly bearded in a part of the species, but here it occurs as a part of a tendency to general pilosity. The head is moderate; the articular cavities of the tibiæ are nearly closed, and as a rule the tarsal grooves of the tibiæ are scabrous. The abdomen is horizontal in both sexes, and the intercoxal salient is always distinctly wider than the metasternal process.

The genital characters of this section are not sufficiently characteristic to be of practical use when tabulated.

The male genital characters present nothing more than those enumerated as subgeneric. The most important character is the presence of the membranous groove on the apicale.

In the female the genital segment is triangular or trapezoidal in outline, the dorsal plate of the valves is concave and not retracted, the submarginal groove is scarcely visible from above, the appendage flattened or conical, the superior pudendal membrane does not reach 
beyond the middle of the dorsal plates, and the genital fissure is open and fusiform.

Our species may be separated as follows:

Species ecaudate.

Elytra sulcate, intervals more or less convex hispilabris.

Elytra substriate, intervals flat sponsà.

Species caudate.

Dorsal surface of body not clothed with long, flying hairs caudifera.

Dorsal surface clothed with long, flying hairs Tongipilosa.

The female genital characters may be tentatively formulated as follows :

Genital segment more or less quadrato-trapezoidal; appendage flattened and subtriangular.

Dorsal plate oblong, sides parallel; apical margin subtruncatesponsa. Dorsal plate irregularly oblong; apical margin more or less arcuate.

hispilabris.

Genital segment more or less triangular; appendage conical.

Dorsal plate oblong, sides subparallel; apical margin more or less oblique.

caudifera.

Dorsal plate oblong-oval, sides arcuate; apical margin more or less arcuate

longipilosa.

Genealogy.-An examination of the accompanying diagram will elucidate the apparent relationships and lines of descent. The lines

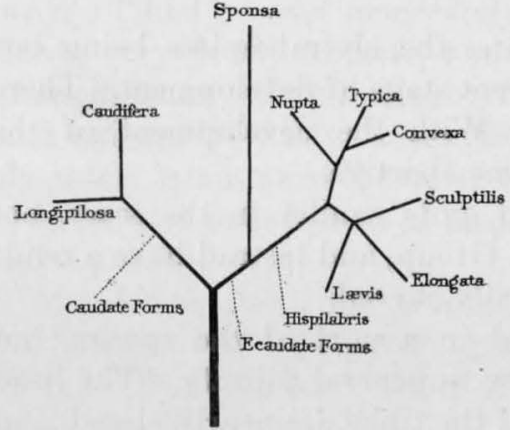

Fig. 4.-Genealogical Diagram OF THE Dentipes Grodp, Section A, Subgenus ELEODES. of divergence are apparently the acquisition of the elytral cauda on the one hand and the elytral apices remaining indifferent on the other; in the former the development of an unusual degree of pubescence with the disappearance of the femoral teeth are very striking morphological coincidents along the lines of correlated characters.

Tracing the divergencies along the ecaudate ramus of the genealogical tree, it will appear as if sponsa diverged, retaining a comparatively simple form of elytral sculpturing and has apparently reacted less than hispilabris to its environment.

Hispilabris has, indeed, undergone a wonderful amount of differentiation into a number of incipient races, primarity by the sculpturing remaining comparatively simple with rather fragile integuments, and, secondarily, by a more decided character of sculpturing having been acquired along with an increased thickness of the exoskeletal wall. In the former instance forma typica and nupta were evolved, the latter by increased ventricosity of the body; in the latter 
case sculptilis took on a stronger form of elytral seulpturing, elongata an elongate form, and lavis by robustness and a less pronounced form of sculpturing.

This method of intuitively working out and presenting these genealogical data-possibly more theoretical than real-may at least lay a foundation upon which to erect a more substantial knowledge by stimulating biological research and criticism.

Distribution.-The four species under consideration are distributed through the following States:

Texas, Arizona, New Mexico, Oklahoma, Colorado, Kansas, Nebraska, Nevada, northeastern California, Oregon, Washington, Montana, and Wyoming.

Sponsa is southern in habitat, occurring in Texas, Arizona, New Mexico, and Colorado.

Hispilabris has the most extensive distribution, the typical form occurring in Texas, New Mexico, Oklahoma, Kansas, Colorado, Nebraska, and Wyoming; forma nupta has thus far been found in Texas and Oklahoma; forma convexa in Texas; forma sculptitis in Arizona, Colorado, northeastern California, Wyoming, Montana, and south into Mexico; forma elongata in Arizona; forma lavis in Utah, Oregon, and Washington.

Caudifera from Texas, Arizona, New Mexico, and Colorado.

Longipilosa thus far from the desert regions of Nevada and northeastern California.

\section{ELEODES SPONSA LeConte.}

Eleodes sponsa LeConte, Proc. Acad. Nat. Sci. Phila., 1858, p. 184.-Horn, Trans. Amer. Phil. Soc., XIV, 1870, p. 313.

Subovate, elongate, black to nigro-piceous.

Head twice as wide as long, slightly convex, and more or less impressed laterally and along the frontal suture; surface more or less evenly punctate, punctures moderate, sometimes with small impunctate areas. Antennce more or less slender and quite long, reaching slightly beyond the base of the prothorax, outer four joints slightly compressed, feebly and gradually dilated; third joint about equal to the next two taken together, fourth slightly longer than the fifth, the latter, with sixth and seventh subequal, eighth about as wide as long and triangular in outline, ninth and tenth wider than long and transversely oval, eleventh subovate.

Pronotum widest scarcely in advance of the middle, about onefourth wider than long, less than twice as wide as the head, and with the length equal to the apex; dise smooth and feebly shining, moderately and quite evenly convex, more or less declivous at the apical angles, frequently very narrowly impressed laterally along the mar- 
gins in anterior half, scarcely opaque, rather finely and more or less evenly and sparsely punctate; apex feebly emarginate or subtruncate, generally finely margined laterally and obsoletely so at middle; sides evenly and moderately arcuate anteriorly, less so or rather straight and convergent from middle to the base, sometimes feebly sinuate in front of the basal angles, marginal bead fine; base feebly arcuate, finely beaded, and equal to the apex; apical angles acute, prominent anteriorly and frequently everted; basal angles subrectangular or slightly obtuse.

Propleurce smooth, obsoletely punctulate and rugulose, or impunctate.

Elytra elongate oval, feebly shining to slightly opaque, about twice as long as wide, usually widest at the middle; base very feebly emarginate and equal to or slightly wider than the contiguous prothoracic base; humeri obtuse, sometimes slightly prominent; sides evenly arcuate, sometimes narrowing towards base, apex more or less obtuse, never produced; disc more or less evenly convex from side to side, or somewhat flattened, more or less rapidly and arcuately or obliquely declivous posteriorly; surface feebly substriate, the striæ with rather coarse, closely placed, and more or less impressed punctures, the intervals flat or at times slightly convex and with a more or less uneven series of submuricate punctures; sometimes the punctures are indented, both series becoming more strongly muricate at the sides and apex.

Epipleurce moderately narrow, with a broad and gentle upward curve at base, thence narrowing gradually to apex; surface smooth and obsoletely punctulate.

Sterna usually more or less feebly punctate and rugulose.

Parapleurce more or less strongly punctate.

Abdomen horizontal, usually smooth and obsoletely punctulate, fifth segment rather more strongly punctate.

Legs moderate in length and rather slender, profemora more or less armed in the sexes; protibial spurs quite equal and acute; tarsi similar in the sexes.

Male.-Somewhat narrow. Antennæ with about three joints reaching beyond the prothoracic base. Elytra rather rapidly, arcuately, and obliquely declivous posteriorly, apex moderately acute. Abdomen moderately convex. Profemora with an acute or obtuse tooth at outer fourth.

Female.-Somewhat robust. Antennæ with about one joint extending beyond the prothoracic base. Elytra arcuately and nearly vertically declivous posteriorly; apex more or less obtuse. Abdomen strongly convex. Profemora mutic or with a very obtuse tooth at about the outer fourth. 
Two forms are to be recognized, namely:

Forma typica.-Thorax moderate in width, sides not very strongly rounded; elytral punctuation more or less muricate, disc striatopunctate, interstitial punctures smaller or at most subequal to the strial punctures, and usually not at all indented.

Forma convexa.-Thorax wider, form more convex, punctuation not at all muricate, elytral punctures moderately coarse, the strial closely placed, the interstitial larger or subequal and more or less indented, and more or less irregular in some intervals or laterally.

Measurements.-Males: Length, 22-25 mm.; width, 8-10 mm. Females: Length, 22.5-26 mm.; width, 9.5-10 mm.

Genital characters, male.-Edeagophore moderate in size and of the usual oblong-ovate form.

Basale oblong and moderate in length.

A picale about twice as long as wide at base, triangular and evenly convex above, with a feebly impressed linear depression in middle third; sides very feebly arcuate from base to apex, the latter narrowly rounded and obtuse; base broadly and subacutely lobed at the middle and sinuate laterally.

Sternite transverse. Each lobe triangular with the external border evenly arcuate from base to apex; internal margin straight; apex subrectangular and narrowly rounded; surface sparsely punctate and setose in apical two-thirds, setæ moderately long and not very dense. Membrane not setose across the bottom of the sinus.

Female.-Genital segment subquadrato-trapezoidal and moderately setose.

Valvula (Plate 4, fig. 8).-Dorsal plate oblong, with the surface more or less broadly concave, margins more or less reflexed and subparallel; finely and sparsely punctate, setose; external margin feebly sinuate to slightly arcuate; internal margin arcuate; apical margin subtruncate or feebly rounded, with a few short setæ. Angle more or less rounded. Apex short and triangular, acute at tip and very finely setose.

Appendage short and depressed, wider at base than long, broadly rounded at tip, setose, setæ rather short forming a loose tuft; external angle of the fossa fringed with a few quite long setæ.

Submarginal groove small and sometimes visible from above.

Superior pudendal membrane reaching to about the middle of the dorsal plate and longitudinal rugulose.

Ventrolateral surfaces.-Body transversely inflated and with the basal prominences moderate; quite strongly concave laterally and less so centrally in front of the apices; quite strongly punctate in apical three-fourths, each puncture with a rather short semi-erect hair. Genital fissure moderately narrow. 
Habitat.-New Mexico (Santa Fé, Hubbard and Schwarz; Coolidge, Coll. E. C. Van Dyke; Aztec, April, Coll. C. F. Baker; Highrolls, June 11) ; Colorado (southern, George Horn); Texas (Marfa, elevation 4,600-4,800 feet, and at Alpine, July, 4,400-6,000 feet, H. F. Wickham) ; Arizona (M. L. Linell).

Number of specimens studied, 20.

Type in the LeConte collection.

Type-locality.-New Mexico; collected by Mr. Fendler.

Salient type-characters.-Thorax a little convex and somewhat rounded, sparsely punctate, anteriorly broadly emarginate, apical angles subacuminate; sides rounded; base subrotundate with the angles subrectangular. Elytra at apex obtusely acuminate; disc punctato-striate, laterally and at apex muricate, intervals sparsely uniseriately punctate (LeConte).

Diagnostic characters.-Sponsa is to be separated from hispilabris by the elytra being feebly substriate and with the intervals flat, rarely feebly convex and rather coarsely muricately punctate. In some specimens the interstitial punctures are in slightly larger dents and the sculpturing is not at all muricate but smooth. The thorax is usually less rounded on the sides and nearly quadrate, but there is considerable variation.

The elytral sculpturing sometimes resembles specimens of hispit$a b r i s$ which have the intervals scarcely convex. In a complete series the transition from the one species to the other is evident. In sponsa the elytral disc is usually flattened. LeConte mentioned a specimen collected in New Mexico that had the elytra not at all muricate.

The mentum is variable. In size it may be comparatively large or small, varying in outline from parabolo-trapezoidal, trapezoidal to trapezoido-triangular, rarely the apex is subacute; surface coarsely punctate to almost impunctate, evenly convex or more or less foveate laterally.

The prosternum and mesosternum as in hispilabris; the latter is sometimes quite vertical and deeply concave at middle.

The abdominal process is about as wide as the third segment is long, the post-coxal part of the first is shorter than the second segment, and the latter is twice as long as the fourth; the third is about one-fourth of its length shorter than the second.

The abdominal salient is but slightly wider than the metasternal process.

The metasternum laterally between the coxæ is scarcely as long as the width of a mesofemur at base.

The tibiæ and femora are about the same as in hispilabris.

The articular cavities of the tibiæ are very narrowly open as a rule or closed. 
The tarsi are moderate, more slender in the smaller individuals and stouter in the larger.

The protarsi are about three-fifths of their length shorter than a mesotarsus. Joints two, three, and four are subequal, and just a little wider than long, the three combined about equal to the fifth; the first is distinctly longer than wide.

The mesotarsi are about as long as a metatarsus. Joints two, three, and four subequal and about as long as wide; together about equal to the fifth; the first joint is scarcely twice as long as wide.

The metatarsi are about one-half as long as a metatibia. Joints two and three are subequal and distinctly longer than wide, together subequal to the fourth; the first is scarcely as long as the fifth.

\section{ELEODES HISPILABRIS Say.}

Blaps hispilabris SAY, Journ. Acad. Nat. Sei. Phila., III, 1823, p. 259 ; Amer. Entomology, I, 1824, p. 32.-LeConte, Complete Writings of Thomas Say, I, 1859 , p. 32.

Eleodes hispilabris LeConte, Complete Writings of Thomas Say, II, 1859, p. 152.-Honn, Trans. Amer. Phil. Soc., aIV, 1870, p. 313.-СнамPIoN, Biol. Centr.-Amer., IV, Pt. 1, 1884, p. 79.

Eleodes suicata LeConte, Proc. Acad. Nat. Sci. Phila., 1852, p. 67; 1858, p. 181 .

Eleodes lecontei Gemminger, Coleopt. Hefte, VI, 1870, p. 122 (new name).

Eleodes connexa LEConte, Reports of Explor. and Survey, . . . 47th and 49th parallel, XII, Pt. 3, 1857, p. 49.

Eleodes nupta LeConte, Proc. Acad. Nat. Sei. Phila., 1858, p. 183.

Eleodes compositus CAsex, Annals N. Y. Aead. Sci., VI, Nov., 1891, p. 58.

Elongate ovate, somewhat shining, more or less convex and sulcate; color black, frequently reddish along the suture.

Head about twice as wide as long, feebly convex, finely and not densely punctate, feebly impressed laterally. Antennce long, moderate in stoutness, reaching to the prothoracic base, outer four joints slightly compressed and noticeably dilated; third joint equal in length to the fourth and fifth combined, fourth a little longer than the fifth, the latter, sixth, and seventh subequal, eighth equilaterally triangular in outline, ninth and tenth transversely oval, eleventh irregularly ovate to subtrapezoidal.

Pronotum widest at about the middle, about one-fifth to less than one-third wider than long, and less than twice as wide as the head; disc smooth and more or less shining, quite evenly and moderately convex, more or less declivous at the apical angles, finely, sparsely, and quite evenly punctate, very narrowly opaque and granulate laterally; apex more or less feebly and broadly emarginate, finely beaded laterally and obsoletely so at middle; sides broadly and evenly arcuate anteriorly, converging and more or less straight posteriorly, or slightly sinuate before the basal angles, finely to rather coarsely 
beaded, and very narrowly or more or less reflexed; base feebly arcuate and more strongly margined, a little wider than the apex and equal to the length; apical angles acute and more or less everted; basal angles obtuse.

Propleurce smooth, more or less rugulose and nearly impunctate.

Elytra oval, sulcate, usually less than twice as long as wide, widest at the middle; base very feebly emarginate, usually very little wider than the contiguous prothoracic base; humeri obtuse and not prominent; sides evenly arcuate, apex more or less acute and usually very slightly produced; dise more or less convex, frequently depressed, and more or less suddenly obliquely declivous posteriorly ; surface usually deeply sulcate, sulci deep and about as wide as the intervals, each with a series of more or less evenly and closely placed, small asperate punctures; the intervals are more or less strongly convex, smooth and shining, each with a single irregular series of distantly placed punctures. The deflexed sides are more coarsely, irregularly punctate and subsulcate.

Epipleurce moderate in width, gradually narrowing from base to apex, where they may be feebly dilated beneath the elytral apices and sightly excavated at that point; surface smooth, frequently impunctate, at other times very sparsely and finely punctulate.

Sterna moderately punctate and rugulose.

Parapleurce usually quite smooth and sparsely but not deeply punctate.

Abdomen horizontal, smooth, very finely punctulate and rugulose; fifth segment more strongly punctate.

Legs somewhat slender. Anterior femora armed in the sexes; protibial spurs subequal, frequently the posterior appears to be just the least longer and stouter than the anterior. Tarsi grooved beneath and similar in the sexes.

Male.-Somewhat narrow and elongate. Antennæ reaching slightly beyond the base of the prothorax. Length of the pronotum slightly greater than the width of base and about one-fifth wider than long. Elytra arcuately and obliquely declivous posteriorly. Abdomen moderately convex from side to side. Anterior femora with a moderate and acute tooth at about the outer third.

Female.-More or less robust, and rather broad. Antennæ reaching to or slightly beyond the prothorax, the latter with the base equal to the length and about one-third wider than long. Elytra rather suddenly and arcuately declivous posteriorly. Abdomen strongly convex. Anterior femora with a more or less obtuse tooth at about the outer third.

Genital characters, male.-Edeagophore of the usual oblong-ovate form and small. 
Basale rather short, not a great deal longer than the apicale, not usually arched nor strongly convex.

A picale elongately triangular, quite evenly convex above, with a linear impression in middle third; sides feebly arcuate from base to apex, the latter subacute; base rather acutely lobed at middle and scarcely sinuate laterally.

Sternite transverse. Lobes rather small; each with the external border straight and converging from base to apex, the latter rounded, angle introrse and scarcely developed; internal margin straight; surface punctate and moderately thickly setose, setæ moderate in length and not extending upon the membrane across the bottom of the sinus, the latter short but rather broad.

Female.-Genital segment quadrato-trapezoidal, width at base about equal to the length, surface rather conspicuously setose.

Valvula (Plate 3, fig. 19).-Dorsal plate more or less irregularly oblong, quite deeply concave, with margins reflexed; surface very finely and sparsely punctate, setæ rather long and flying; external margin feebly sinuate to slightly arcuate; internal border rather broadly arcuate, sometimes subangulate near base; apical margin evenly rounded and set with quite long flying hairs, angle rounded. Apex short and triangular, acute at tip, finely setose; external angle of the fossa quite thickly set with rather long hairs. Lateral plate visible from above external to the dorsal plate, with submarginal groove between the two and more or less visible.

Appendage depressed, more or less triangular and rounded at tip, not longer than the apical lobe; surface set with quite long setæ.

Superior pudendal membrane reaching to about the middle of the dorsal plate, and longitudinally rugulose.

Ventrolateral surfaces.-Body rather strongly convex at base, not inflated, glabrous, more or less strongly and transversely concave before the apices; apical moiety sparsely punctate, with setæ rather long. Internal margins of the valves contiguous at base for a short distance. Genital fissure rather wide and fusiform, closed in basal half by the inferior pudendal membrane.

Satient type-characters.-More or less shining. Elytra frequently more or less depressed, and somewhat narrowly rounded laterally, frequently more or less reddish along the suture; sulci moderate in depth, intervals more or less convex. The apical angles of the pronotum are acute and more less everted. Say's description is too brief as to the essential characters.

The following incipient races or forms should be recognized:

Forma typica.-See salient type-characters.

Measurements.-Males: Length, 20-25.5 mm.; width, 8.5-10.5 mm. Females: Length, 18-28 mm.; width, 8.8-12 mm. 
Number of specimens studied, 150.

Type destroyed.

Type-locality.- "Inhabits Missouri," a badly defined geographical region in Say's day.

Forma nupta LeConte.-Elytra with the dorsum slightly and the sides strongly convex (LeConte). The elytra are more or less evenly convex from one epipleura to the other, usually somewhat inflated, sometimes quite strongly so. Some of the smaller examples are quite cychriform.

Measurements.-Males: Length, 21-27 mm.; width, 9.5-11.2 mm. Females: Length, 19-29 mm.; width, 9.8-14 mm.

Number of specimens studied, 15.

Type in the LeConte collection.

Type-locality.-Laredo to Ringgold Barracks, Texas.

Forma sculptilis.-Integuments dull and rather thick. Head and thorax more or less shining. Elytra more or less convex, sulci usually opaque and deep, with the intervals strongly convex, shining and conspicuous, quite abruptly limiting the grooves.

Measurements.-Males: Length, 19-23 mm.; width, 7.8-8.5 mm. Females: Length, 19-24 mm.; width, 8-10 mm.

Number of specimens studied, 40.

Forma elongata.-General form distinctly elongate and narrower as compared to the other forms; black. Elytra are sulcate, but less strongly so than in sculptitis; the intervals at times are feebly convex. The prothorax is noticeably larger and the legs stout.

Measurements.-Males: Length, $26.5 \mathrm{~mm}$; width, $9 \mathrm{~mm}$. Females: Length, $29 \mathrm{~mm}$; width, $10.2 \mathrm{~mm}$.

Number of specimens studied, 6 .

Forma convexa LeConte.-Elongate, black and bright. Thorax moderately punctulate, sides rounded, anterior angles acute and slightly prominent; basal angles obtuse. Elytra elongate oval, intervals subconvex and rugose; subacute posteriorly.

Measurements.-Length, .9; width of elytra, .32; thorax, .23 (LeConte).

Specimens not at hand.

Type is in the LeConte collection.

Type-locality.-Prairie Paso, Texas; collector, Dr. Cooper.

Forma lævis.-Robust, integuments decidedly black, thick and alutaceous, also quite smooth. Thorax rather large. Elytra usually evenly convex from side to side, sulci very shallow, intervals very feebly convex, subobsoletely sculptured. Legs somewhat slender.

Measurements.-Males: Length, $23 \mathrm{~mm}$; width, $8 \mathrm{~mm}$. Females: Length, 23-26 mm.; width, 9.2-10 mm.

Number of specimens studied, 8. 
The following species described by Colonel Casey evidently belongs here :

Forma composita Casey.-Moderately robust, convex, intense black throughout, the pronotum dull and strongly alutaceous; elytra shining, very feebly alutaceous, glabrous.

Head densely, finely, rather sparsely punctate and dull; antennæ rather long and stout, fully as long as the head and thorax, third joint between three and four times as long as wide, outer joints slightly broader, the ninth and tenth somewhat transversely oval.

Pronotum about as long as wide; disc evenly convex, very minutely, sparsely punctate; apex broadly, very feebly emarginate; sides parallel, broadly arcuate or subangulate just before the middle, very feebly sinuate just behind the apical angles, feebly convergent and nearly straight to the base; base arcuate and equal to the apex in width; apical angles right, slightly blunt, not prominent; basal angles broadly obtuse.

Elytra about two and two-thirds times as long as the prothorax, and, in the middle, one-half wider than the latter, about twice as long as wide; humeri not at all exposed; sides broadly arcuate, apex acutely angulate; disc strongly declivous behind, deeply sulcate, the ridges strongly convex and shining, each with a single rather uneven series of small, moderately distant punctures, the intervals as wide as the ridges, deep, opaque, each with a single series of rather small, close-set, asperate punctures.

Legs slender, the femora shining, rather finely but strongly punctate, the anterior alone with a strong acute tooth near the apex; tibiæ strongly rugose except toward base, the spurs of the anterior small, acute, and nearly equal. Prosternum with the apex slightly reflexed, acute and tuberculiform.

The above is Casey's original description.

Measurements of the type.-Male: Length, $16 \mathrm{~mm}$.; width, $6.6 \mathrm{~mm}$. Unknown to me.

Type: a unique in Colonel Casey's collection.

Type-locality.-Texas.

Forma typica.-Habitat.-Missouri (Say). Colorado (August, C. V. Riley; Denver, April and June, Coll. H. Soltau; May, Colls. Dyar and Caudell; Colorado Springs, June, elevation 6,000-7,000 feet, H. F. Wickham. In his List of the Coleoptera of Colorado, Professor Wickham gives the following localities, the forms are not differentiated: La Junta, West Las Animas, Canyon City, San Luis Valley, Fort Garland, Trinidad, Holly, Fort Collins). Kansas (collections of Chas. Fuchs, C. V. Riley, F. H. Snow, and F. E. Blaisdell). New Mexico (Las Vegas; August, Colls. Barber and Schwarz; Albuquerque, Coll. E. C. Van Dyke). Texas (Mobeetee, October, Coll. H. S. Bar- 
ber.) Oklahoma (Fort Supply, Coll. H. S. Barber.) Wyoming (Cheyenne, June, Colls. Hubbard and Schwarz). Nebraska (Sand Hills, September, Coll. C. V. Riley).

Forma nupta.-Oklahoma (Fort Supply, Coll. H. S. Barker; Texas (Alice, E. A. Schwarz; Fort Creek, E. A. Mearns; San Diego, April and May, Hubbard and Schwarz; Goliad County, October, J. D. Mitchell).

Forma sculptilis.-Arizona (Walnut, July, H. F. Wickham; Oracle, July, Coll. Hubbard and Sehwarz; Williams, May, Coll. Barber and Schwarz; Fort Grant, July, Coll. Hubbard and Schwarz; Ash Fork, June; Yuma, Chas. Fuchs). New Mexico (Las Vegas, August, Coll. Barber and Schwarz). Colorado (Denver, May, Coll. Dyar and Caudell). Utah (Salt Lake City, April, Coll. H. Soltau). California (northeastern, Coll. Hubbard and Schwarz). Wyoming (Cheyenne, May, H. Soltau; June, Hubbard and Schwarz). Montana (Helena, May, Henry Ulke, Hubbard and Schwarz). Mexico (Cananea, district of Arizpe, State of Sonora, elevation 4,500-6,000 feet, Dr. W. C. Alvarez).

Forma elongata.-Arizona (Coll. Beverly Letcher, Prescott).

Forma convexa.-Texas (Prairie Paso, Doctor Cooper).

Forma lævis.-Utah (Salt Lake, June, Coll. Hubbard and Schwarz). State of Washington (Walla Walla, Charles Fuchs).

Diagnostic characters.-Hispilabris is recognized from the members of the Obscura Group by the prominent dentiform apical angles of the prothorax and by the simple tarsi; from all species of the subgenus Eleodes by the more or less deeply sulcate elytra with convex intervals, and in never being caudate.

I consider the typical form to have more or less depressed elytra, the latter with the intervals feebly to moderately convex and frequently reddish along the suture; the integuments are generally thinner than in the other forms.

The five incipient races, which I have recognized are simply extremes along particular lines of divergence in the ample series before me, and they are all united into one continuous series by an abundance of mesotypes.

They ought to be readily recognized by the brief diagnoses that I have given. Their salient characteristics may be epitomized as follows:

Nupta with its strongly convex and more or less ventricose elytra. Integuments as in typical hispilabris.

Sculptitis with the elytral intervals very strongly and prominently convex, with the sulci deep and opaque. Denser integuments.

Elongata by its elongate and moderately convex form, elytral intervals more or less moderately convex. Black and denser integuments. 
Convexa by its elongate form. Elytra with subconvex and rugose intervals.

Lavis by its robust convex form; integuments black and alutaceous; large prothorax and somewhat eroded sculpturing.

Composita Casey has evidently the elytral sculpturing of forma sculptitis and the general structure of hispilabris, except that it has an aberrant prothorax. But here the difference is no proof that it is specifically distinct. Analogous aberrations are observed in dentipes in particular, and hispilabris is fully as variable as that species.

The unique described by me as interrupta in the subgenus Melaneleodes was simply an example of symmetrical fortuitous variation of sculpturing, and was an anomalous omissa. I must hold that the present form, which is a unique and undoubtedly related to a very variable species, is an aberration, and the collection of others like it must give it a greater claim to more than an incipient race.

The mentum is moderate in size and quite constant in form, and more or less trapezoidal; the sides are quite straight and converging to the apex, the latter distinctly truncate, or slightly arcuate; the sides are not noticeably curved. In fact, I have not yet seen an example with the middle lobe evenly rounded anteriorly.

The prosternum is variable. Usually moderate in width behind the equator of the coxæ, evenly convex, or precipitously so behind; frequently submucronate, vertically truncate, and feebly compressed behind in nupta.

Mesosternum variable; oblique to arcuately declivous and more or less concave.

The metasternum laterally between the coxæ is about equal in length to the width of a mesofemur at base.

The abdominal process is subquadrate, slightly transverse, and in width about equal to the length of the post-coxal portion of the same segment; second segment slightly longer than the post-coxal part of the first and about twice as long as the fourth; the third is about one-third of its length shorter than the second.

The abdominal salient is about one-fourth of its width wider than the metasternal process.

It is to be observed that the elytral apices have a tendency to be slightly produced, and especially in forma sculptilis, and that the epipleuræ dilate at tip to form the inferior surface of this feeble but evidently produced elytral apex. This character becomes of importance when taken in relation with the caudal characters of caudifera and tongipilosa.

The tibial grooves of the femora are not usually quite entire and rather narrow. Those of the profemora may have their margins feeble or strongly defined; the floors are glabrous and rather flat or 
feebly concave. The margins are scarcely arcuate, and converge a short distance from the femoral base; the anterior margin is dentately laminate at about the junction of the outer fifth and sixth sevenths.

The grooves of the meso- and metafemora are more or less defined by sharp margins, which converge to become contiguous somewhere near the inner third, less frequently near the middle.

The tibiæ are variable. Protibiæ more or less feebly compressed, obsoletely to distinctly carinate externally ; the external edge scarcely arcuate. The tarsal grooves are sometimes feebly marked and asperate, or at other times quite well defined and more or less glabrous. The articular cavities are scarcely open, or feebly so at the most.

The articular cavities of the meso- and metatibiæ are usually quite closed.

The tarsal grooves of the mesotibiæ are sometimes defined for nearly the whole length of the external surface, floor of each quite flat and more or less glabrous; usually the grooves are poorly defined and asperate.

The external surface of each metatibia is more or less flattened and the groove generally feebly defined.

The tarsi vary in stoutness according to the general habitus of the individual.

In some examples of the typical form the tarsi appear comparatively longer than in the more robust forma lavis. In the typical form a protibia is $6 \mathrm{~mm}$. long and its tarsus $3.5 \mathrm{~mm}$. in length; in forma lavis the protibia is $6 \mathrm{~mm}$. and the tarsus $3 \mathrm{~mm}$. in length. The actual lengths of parts are of no value, but only when taken relatively.

It appears as.if the shortening is done at the expense of the length alone. In the typical form joints two, three, and four are evidently longer than wide; in forma lavis the same joints are distinctly wider than long. In each instance they are subequal to each other, and combined equal to the length of the fifth. The first joint is about one-half longer than wide.

In the typical form the protarsi are three-sevenths of their length shorter than a mesotarsus and in the forma lavis one-third shorter.

The mesotarsi in the typical form are about one-ninth of their length shorter than a metatarsus - to the unaided eye they appear subequal. Joints two, three, and four are longer than wide and slightly decreasing in length in the order named; together they are a little longer than the fifth; first joint about equal in length to the second and third taken together.

In forma lavis the meso- and metatarsi are subequal, and the mesotarsi have joints two to four, inclusive, quite equal. 
Forma typica has a metatarsus half as long as a metatibia; in forma lavis it is distinctly less than one-half as long. In the former type form joints two and three are subequal in length and about one and one-half times longer than wide, and together equal to the fourth; the first joint is a little shorter than the fourth. In forma lavis the relative lengths are practically the same.

It appears that with each slight variation in size the relative proportions between the tarsi and their joints also correspondingly vary, and at the same time the essential specific characters were homogeneous in the examples tested.

Of course, these variations must be within normal specific limits. These facts become taxonomic pabulum for those students who recognize a new species every time certain structural elements present slight differences in their relative proportions. There are times, of course, when these characters are of great value, but specific instability must determine their value in a given case, and normal specific variations must be recognized.

\section{ELEODES CAUDIFERA LeConte.}

Eleodes caudifera LeConte, Proc. Acad. Nat. Sei. Phila., 1858, p. 184.Hors, Trans. Amer. Phil. Soc., XIV, 1870, p. 314.

Elongate, ovate, caudate.

Head about twice as wide as long, feebly convex and more or less impressed laterally along the frontal suture; surface irregularly and rather finely punctate, sparsely so with impunctate areas at center, and densely punctate laterally. Antennce moderate, scarcely compressed, last four joints very slightly and gradually dilated, third joint very slightly longer than the fourth and fifth combined; fourth to the seventh, inclusive, subequal; eighth slightly shorter and broader; tenth and eleventh about as wide as long, the latter ovate.

Pronotum widest in front of the middle, about one-third wider than long and about twice as wide as the head; disc rather shining, quite smooth, moderately convex, and slightly declivous at apex and basal angles, more or less impressed and opaque laterally along the margins in the anterior two-thirds, finely and very irregularly punctate with impunctate areas at middle; laterally the opaque area is more or less transversely rugulose and granulate; apex feebly emarginate or truncate, very finely or obsoletely margined; sides evenly and quite strongly arcuate in anterior one-half, quite straight or feebly sinuate and convergent from middle to base, marginal bead fine or obsolete; base slightly arcuate and very finely margined, wider than apex; apical angles rounded, obtuse or minutely dentiform and everted; basal angles obtuse.

59780-Bull. $63-09-15$ 
Propleura smooth and opaque, rugulose, with few scattered granules, especially upon the acetabular convexities.

Elytra oval, shining, and more or less sulcate, less than twice as long as wide-apical prolongation not included-widest at middle and truncate at base, where they are slightly wider than the contiguous prothoracic base; humeri obtuse and more or less rounded; sides evenly arcuate, apex horizontally produced; disc moderately convex, slightly flattened and arcuately rounded laterally, obliquely declivous posteriorly passing into the cauda; surface striate, striæ more or less impressed and strongly punctate, the punctures murieate and closely placed, intervals more or less convex but not strongly so, uniseriately punctate, the punctures distantly placed and muricate, those of the outer intervals more or less confused and at times rather densely and muricately subrugoso-punctate; inflexed sides obsoletely striate and quite densely and irregularly muricately punctate and at times slightly concave at base of apex.

Cauda moderately long, granulo-muricate, above with the suture impressed, tip emarginate; beneath concave, sparsely muricatogranulate, the surface of each lateral half being a dilatation of the apical epipleural surface of the corresponding side; in the median line the two inferior epipleural margins are contiguous.

Epipleurce rather narrow and gradually narrowing from base to apex, where they dilate to become the inferior surface of the cauda; surface opaque, smooth, and sparsely muricately punctulate, except at base.

Sterna more or less irregularly, submuricately punctate and rugulose.

Parapleurce more or less irregularly punctate.

Abdomen horizontal, rather finely, sparsely, and evenly submuricately punctate.

Legs moderately long and more or less slender. Femora rather thickly clothed with moderately long appressed setæ, with an occasional long flying hair on the external surface. Tibiæ densely muricate and rather sparsely set with long flying hairs; anterior spurs quite equal in length and size and more or less backwardly curved. 'Tarsi similar in the sexes and clothed with rather long hair-like setæ, those on the last joint of each tarsus projecting noticeably beyond the ungues.

Male.-Somewhat narrow. Antennæ reaching slightly beyond the prothoracic base. Elytra rather gradually and obliquely declivous posteriorly, becoming sinuate in passing into the horizontal cauda; the latter may be equal to about one-sixth of the entire elytral length. Abdomen feebly ventricose to the fourth segment. Anterior femora with a broad and very obtuse tooth or mutic. 
Female.-Rather robust. Antennæ reaching scarcely to the prothoracic base. Elytra somewhat suddenly obliquely declivous posteriorly and sinuate at base of apex. Cauda equal to about one-eleventh of the entire elytral length. Abdomen quite strongly ventricose to the fourth segment. Anterior femora quite mutic.

Measurements without and with the cauda.-Males: Length, 21 and $24 ; 25$ and $29.5 \mathrm{~mm}$; width, $8-10 \mathrm{~mm}$. Females: Length, 22 and $24 ; 26.5$ and $29.5 \mathrm{~mm}$; width, $9.5-12 \mathrm{~mm}$.

Genital characters, male.-Edeagophore of the usual oblong-ovate form.

Basale short and oblong, subequal in length to the apicale.

A picale elongate and suboblong-triangular, moderately convex and slightly flattened, with a linear membranous groove in middle third; sides parallel in basal half, thence arcuate, becoming slightly sinuate at apex, the latter acute and slightly produced; base arcuate, scarcely sinuate laterally.

Sternite subquadrate. Each lobe about twice as long as wide, broadly rounded at apex; external margin nearly straight; internal margin rather arcuate; surface glabrous, not very thickly punctate and setose, setæ moderately long.

Female.-Genital segment triangular, subtruncate, length about equal to the width at base.

Valvula (Plate 4, fig. 7).-Dorsal plate oblong with the surface broadly concave, margins reflexed and nearly parallel; surface finely punctured in apical two-thirds, each puncture bearing a short semirecumbent seta; external border nearly straight; internal margin slightly sinuous; apical margin more or less oblique, asperate, set with moderately long and evenly distributed setæ, which are not longer at the angle, the latter more or less rounded and never prominent. Apex membrano-chitinous, scarcely longer than the appendage, acute; surface set with fine setæ, apical tuft rather short.

Appendage chitinous, conical, quite long and nearly as long as the apex, blunt, and asperate in apical half, set with rather long setæ, tuft at tip quite long.

Superior pudendal membrane scarcely reaching one-third from the base.

Ventrolateral surfaces.-Body moderately convex but not noticeably inflated, slightly and transversely concave before the apices, finely punctate and set with very fine, short setæ in apical two-thirds. Submarginal groove obsolete. External margin of the dorsal plate not prominent laterally. Genital fissure long and fusiform, with the inferior pudendal membrane visible in basal half.

Habitat.-New Mexico (Aztec, April, C. F. Baker; Coolidge, Coll. E. C. Van Dyke and Hubbard and Schwarz; Santa Fé, C. V. Riley; 
Luna, Hubbard and Schwarz); Arizona (Adamana, May, H. S. Barber; Winslow, July, Coll. Barber and Schwarz; Holbrook, Coll. E. C. Van Dyke, Charles Fuchs, and Beverly Letcher); Colorado (Henry Ulke; Eastern, George Horn); Texas (El Paso, March, Coll. H. Soltau).

Number of specimens studied, 40 .

Type in the LeConte collection.

Type-locality.-New Mexico; collector, Mr. Fendler.

Salient type-characters.--Thorax scarcely convex, slightly punctate, laterally a little concave and transversely rugose; anteriorly broadly emarginate, apical angles not acuminate; sides strongly rounded, narrowed posteriorly; posterior angles obtuse. Elytra slightly flattened, substriate with seriate punctures, intervals uniseriately and sparsely punctate, at the sides and apex muricate, posteriorly obliquely declivous and prolonged. Anterior femora mutic (female) (LeConte).

The following forms are before me:

Forma glabra.-More or less shining and glabrous, not at all muricat, except on the cauda. Elytra striate, striæ impressed, with quite coarse and closely placed punctures; intervals moderately convex, with a single series of small, distantly placed punctures. Legs quite slender. Cauda gradually narrowing from base to apex.

Measurements.-Male: Length, $25 \mathrm{~mm}$.; with cauda, $31 \mathrm{~mm}$.; width, $9.5 \mathrm{~mm}$. Female: Length, $20 \mathrm{~mm}$; with cauda, $22.5 \mathrm{~mm}$; width, $9 \mathrm{~mm}$.

Habitat.-Texas (El Paso), Arizona.

Forma sublævis.-Subopaque to feebly shining. Antennæ slender and rather long. Elytra with series of unimpressed punctures; intervals flat with a series of distantly spaced punctures, which are as large as those of the striæ. Sculpturing submuricate. Legs rather slender.

Measurements.-Female: Length, 25 and $28 \mathrm{~mm}$; width, $10 \mathrm{~mm}$. Habitat.-Arizona.

Forma typica.-See salient type-characters.

Forma scabra.-More or less shining. Elytra with unimpressed strix of very closely placed and minute muricate tubercles; intervals with a single series of distantly placed and larger muricate tubercles, which become distinctly larger laterally and more tuberculiform. Inflexed sides of the elytra rugoso-muricate. The general surface is very minutely rugulose. Size of forma typica. Legs rather short.

Habitat.-New Mexico (Aztec).

Diagnostic characters.-Both sexes are caudate. Thorax widest just in advance of the middle; body not noticeably pubescent, tibiæ and tarsi with long flying hairs. These characters serve to differentiate caudifera from sponsa, hispilabris, and longipilosa. 
Doctor Horn in the Revision failed to mention that the female was caudate.

Forma glabra is a rather striking variation, on account of the smooth integuments and in having the cauda longer than usual in the male, and moderately arcuately decurved in its apical third, being gradually narrowed from base to apex.

Forma sublævis has the sculpturing of sponsa, and forma scabra has the elytra tuberculo-scabrous. The mentum is comparatively rather small and triangulo-trapezoidal in outline. The sides converge anteriorly and are scarcely at all arcuate; the apex is more or less rounded and the surface is more or less foveate as well as coarsely punctured.

The mentum and sides of the epistoma are set with rather long black hairs.

The prosternum is variable, moderately wide between the coxæ and somewhat triangularly dilated behind the equator of the coxæ; more or less convex antero-posteriorly, or feebly convex to subhorizontal between the acetabula; more or less moderately produced and compressed, oblique to vertically truncate behind, at times submucronate.

The mesosternum is variable as to the degree of obliquity and more or less concave.

The abdominal process is subquadrate, slightly wider than long and about as wide as the post-coxal portion is long, the latter equal in length to the second segment; the third is twice as long as the fourth, and about one-third of its length shorter than the second.

The abdominal salient is about one-seventh of its width wider than the metasternal process.

The metasternum laterally between the coxæ is about as long as a mesofemur is wide at base.

The tibial grooves of the femora are not entire, the floors are glabrous, quite plane, and limited by rather well defined edges. Those of the profemora are moderate in width; the anterior margin is scarcely dentately laminate at the outer third in the male and less so in the female; the posterior margin is obsolete internally before becoming contiguous with the anterior, neither one reaching the femoral base.

The mesofemoral grooves are obsolete at the internal third of the femora and the margins do not become contiguous; on the metafemora they scarcely extend basally beyond the middle, where they become evanescent before becoming contiguous.

The protibiæ are somewhat compressed and distinctly carinate externally; the tarsal grooves are scarcely developed and muricate. 
The mesotibiæ are feebly compressed and the external surface is ridge-like, and the tarsal grooves are evident, although more or less feeble and muricate.

The metatibiæ are flattened externally, obsoletely grooved, and muricate. Both the meso- and metatibiæ are more or less carinate in basal third externally.

The tarsi are quite stout.

The protarsi are scarcely one-third of their length shorter than a mesotarsus. Joints two, three, and four are subequal, just a little wider than long, and together about equal to the fifth; the first is a little longer than wide.

The mesotarsi are about one-seventh of their length shorter than a metatarsus. Joints two, three, and four are subequal, a little longer than wide, and together just the least longer than the fifth; the first is about one-half longer than wide.

The metatarsi are scarcely one-half as long as a metatibia. Joints two and three are subequal, distinctly longer than wide, and together scarcely as long as the fourth; the latter is a little longer than the first.

\section{ELEODES LONGIPILOSA Horn.}

Eleodes longipilosa Hopn, Trans. Amer. Ent. Soc., XVIII, Feb., 1891, p. 42, pl. I, fig. 13.

Elongate oval, moderately shining, surface sparsely clothed with long, black, flying hairs; caudate.

Head twice as wide as long, more or less moderately convex, coarsely and more or less irregularly punctate, hairs long and flying. Antenna moderate in length and thickness, scarcely compressed or dilated in outer four joints, third joint equal to the next two taken together, fourth to the eighth inclusive subequal, seventh conicotriangular, eighth triangulo-quadrate, ninth and tenth suborbicular, eleventh ovate and pointed; clothed with rather long hairs.

Pronotum widest at or slightly in advance of the middle, about onefourth wider than long, and twice as wide as the head; disc moderately convex, coarsely, irregularly, and more or less sparsely punctate, rather narrowly opaque and granulate along the sides, frequently with impunctate areas at center; apex slightly emarginate, finely or more or less obsoletely margined; sides arcuate in front (occasionally subangulate) and obliquely converging posteriorly, marginal bead fine or obsolete and replaced by minute granules; base more or less arcuate, finely margined, one-tenth to one-fourth wider than apex and about equal to the length; apical angles small, subacute, not everted or subdentiform and feebly everted; basal angles obtuse and scarcely rounded.

Propleura sparsely muricate and rugulose. 
Elytra elongate oval, widest at middle and more attenuated posteriorly; base truncate or feebly emarginate, slightly wider than the contiguous prothoracic base; humeri obtuse and more or less rounded; sides evenly arcuate and slightly sinuate at apex, the latter produced, forming a moderately long, horizontal, or slightly downwardly oblique cauda; disc feebly convex on the dorsum, rather strongly rounded laterally, and somewhat gradually, arcuately declivous posteriorly; surface more or less striato-punctate, very vaguely sulcate, punctures near the suture scarcely muricate, more strongly so laterally and on the apex, serial punctures of the striæ moderate in size and closely placed, the interstitial series similar and more distantly spaced, both series becoming irregular laterally and on the apex; suture impressed on the cauda, the latter emarginate at tip; each puncture with a long flying hair.

Epipleurce moderate in width and gradually narrowing from base to apex, where they dilate to form the inferior surface of the cauda; surface opaque and obsoletely punctulate.

Sterna more or less punctate and rugose, sparsely clothed with long brownish hairs.

Parapleurce coarsely punctate and not noticeably pubescent.

Abdomen horizontal and more or less ventricose in both sexes, quite closely punctate, most densely so on the first and fifth segments.

Legs moderate in length and thickness, densely sculptured and clothed with long, flying, sparsely distributed hairs. Anterior femora mutic in both sexes; anterior tibial spurs acute, subequal, moderate in length, and more or less curved. Tarsi similar in the sexes.

Male.-Somewhat narrower than the female. Antennæ reaching to the prothoracic base. Elytra slightly narrowly oval. Abdomen very feebly flattened on first two segments.

Female.-Rather robust. Antennæ scarcely attaining the prothoracic base. Elytra quite broadly oval. Abdomen strongly convex.

Measurements without and with the cauda.-Males: Length, 19 and 21.5 ; 19.5 and $22.5 \mathrm{~mm}$; width, $7.2 \mathrm{~mm}$. Females: Length, 19 and 21 ; 20 and $22.2 \mathrm{~mm}$; width, $8.2 \mathrm{~mm}$.

Genital characters, male--Edeagophore of the usual oblong-ovate form, rather elongate, and scarcely arched.

Basale rather short oblong, evenly convex; sides feebly arcuate.

A picale elongate, nearly as long as the basale, and triangular; surface quite evenly and moderately convex, with a narrow median and more or less obsolete groove in basal two-fifths; sides moderately arcuate in basal half, thence more or less sinuate to apex, the latter produced and acute, not deflexed; base broadly rounded at middle, and more or less sinuate laterally. 
Sternite quadrato-parabolic and slightly transverse. Lobes slightly elongate, each with the external border feebly sinuate in basal half, thence evenly and rather broadly arcuate to apex, the latter rounded; internal border membrano-chitinous and not well defined in basal half; surface more or less convex, from the middle gradually sloping to the sinus, rather coarsely punctate and setose; setæ rather long at apex and moderately dense; membrane not setose across the bottom of the sinus; the latter broad.

Female.-Genital segment somewhat equilaterally triangular, slightly flattened, and setose.

Valvula (Plate 4, fig. 23).-Dorsal plate oblong oval; sides more or less reflexed; surface more or less concave, smooth, and shining; finely and sparsely punctate, each puncture with a fine and rather short seta; external margin more or less feebly arcuate; apical margin feebly arcuate, angle scarcely evident; internal margin more or less arcuate, feebly sinuate in basal half; apex short, triangular, subacute at tip, and finely setose. Valvular membrane visible in apical half.

Appendage about as long as the apex, conical, with a loose tuft of fine and not very long hairs at tip.

Superior pudendal membrane finely and not closely longitudinally rugulose, not quite attaining the middle of the dorsal plate.

Ventrolateral surfaces.-Body evenly but not strongly convex, and not transversely concave before the apex, shining and glabrous, finely, sparsely punctate and setose; submarginal groove obsolete; internal margins of the valves contiguous in basal fifth. Genital fissure long, fusiform, and rather wide, closed by the inferior pudendal membrane in basal half, apically by the valvular membranes.

Habitat.-Nevada (Humboldt Valley, Mr. Krause), California (Amedee, Lassen County, July, elevation 4,200 feet., H. F. Wickham). Number of specimens studied, 16.

Type in the Horn collection.

Type-locality.-Humboldt Valley, Nevada; collector, Mr. Krause. Salient type-characters.-Clothed with long, black, flying hairs. Thorax about a fourth wider than long; sides arcuate in front, obliquely narrowed posteriorly; disc moderately convex, coarsely, sparsely, irregularly punctate; apex slightly emarginate, anterior angles subacute, but not everted. Elytra with disc feebly convex, very vaguely sulcate; surface irregularly, sparsely muricate, the two grooves nearest the suture coarsely punctate. Elytra prolonged at tip in a cauda. (Male.) (Horn.)

Diagnostic characters.-Remarkably distinct among its congeners on account of being clothed throughout with long black or brownish flying hairs; caudate in both sexes with the anterior femora obsoletely dentate. 
The mentum is quite trapezoidal in the females, and also rather broad; triangulo-trapezoidal and smaller in the males. The sides are more or less straight, and converge to apex, the latter arcuate or truncate; surface more or less strongly punctate, scarcely foveate, and set with long hairs.

The prosternum is somewhat variable, usually feebly convex and longitudinally grooved between the coxæ, compressed and vertically truncate behind, with the angle more or less prominent and submucronate; sometimes oblique and feebly mucronate.

Mesosternum scarcely to strongly concave, and more or less arcuately oblique.

The abdominal process is about equal in width to the length of the post-coxal part of the same segment, and subquadrate. The second segment is longer than the post-coxal portion of the first; the third is half of its length shorter than the second, and about twice as long as the fourth.

The abdominal salient is a little wider than the metasternal intercoxal process.

The metasternum laterally between the coxæ is as long as the width of a metafemur at base.

The tibial grooves of the femora are not entire, their margins are distinct and granular, their floors flat and very sparsely granulate at the sides.

On the profemora the sides of the grooves become contiguous a short distance from the femoral base; on the meso- and metafemora they are somewhat contiguous near the middle, thence to base the femora are rounded beneath.

On the profemora the anterior margins of the grooves are not visibly laminate.

The protibiæ are quite distinctly carinate externally; the meso- and metatibiæ are also in basal fourth externally; tarsal grooves on the protibia evident, but feebly and coarsely sculptured; the grooves are less evident on the mesotibiæ and densely sculptured; metatibiæ quite circular in transverse section and not grooved, coarsely sculptured. The protibia are slightly compressed, with the articular cavities more or less feebly open; on the meso- and metatibiæ the cavities are closed.

The tarsi are moderate in length and rather stout, with joints rather closely articulated.

The protarsi are about a fifth of their length shorter than a mesotarsus. Joints two, three, and four rather short and subequal, distinctly wider than long, and together about equal in length to the fifth; the first about as long as wide.

The mesotarsi are about equal in length to a metatarsus; joints two, three, and four about as long as wide and subequal, together 
about equal to the length of the fifth; first joint just a little longer than wide.

The metatarsi are about one-half as long as a metatibia; joints two and three subequal in length, a little longer than wide, and together shorter than the fourth; the first about a half longer than wide.

DENTIPES GROUP, Section B.

The present section contains those species that have the integuments glabrous and more or less shining, and never distinetly asperately sculptured. The caudal characters, as already defined, show, without doubt, a genetic relationship not' heretofore recognized. As in Section $\mathbf{A}$ rome of the species are ecaudate, but unlike those in that section, there is here no tendency to hirsuteness among its constituent species; on the other hand there is a tendency to complete non-development of such epidermal structures; spines and spinules are developed here as in the species of the preceding Section.

The anterior tibial spurs are similar in the sexes, acute and moderately divergent, at times feebly curved backward.

The abdomen is horizontal and the intercoxal salient of the first segment is always wider than the metasternal process.

The genital characters are the same in this section as in the preceding one.

The species may be tabulated as follows:

All of the femora armed.

Femoral teeth strongly developed, long and acute; elytra more or less vertically declivous behind______armata.

Femoral teeth rudimentary but distinct on the mesofemora and obsolete on the metafemora var. impotens.

Femoral teeth quite equilaterally triangular, shorter, broader, and less acute; elytra evenly and arcuately declivous behind and more attenuate.

Femoral teeth smaller and obtuse, otherwise as in militaris_-var. femorata. Anterior femora alone armed.

Thorax strongly constricted at base.

Thorax strongly transverse and very strongly rounded at the sides.

Disc with sides narrowly impressed and granulate, more or less evenly and moderately convex; elytral apex more or less attenuately produced or caudate. acuticauda.

Disc with sides broadly impressed and granulate, less convex; punctuation finely muricate; elytra more or less attenuate and not caudate var. laticollis.

Thorax moderately strongly and evenly rounded at the sides; elytra not attenuate behind with apex obtusely rounded, never acute nor produced _dentipes.

Thorax feebly constricted at base.

Thorax transverse; elytra striato-punctate, series quite closely placed and impressed, intervals more or less convex subpinguis. 
Thorax subquadrate, sides not strongly rounded; elytra smooth, not at all muricately punctate.

Elytral striæ rather closely placed gracilis.

Elytral striæ distant var. distans.

Thorax subcylindrical, sides evenly and feebly arcuate throughout; elytra with unimpressed distant rows of nearly simple punctures. subcylindrica.

Thorax not constricted at base; males more or less caudate.

Elytra strongly ventricose; apical angles of prothorax moderately prominent anteriorly; first joint of the protarsi (male) clothed at apex beneath with a transverse tuft of golden modified spinules. ventricosa.

Elytra feebly ventricose; apical angles of prothorax larger, more prominent anteriorly, acute and more or less reflexed; first joint of anterior tarsi without transverse tuft of spinules -var. falli.

Elytra rarely ever ventricose and distinctly striato-punctate. Apical angles of prothorax feeble and not prominent anteriorly. eschscholtzii.

Apical angles usually well developed, acute and anteriorly prominent var. тиск.

Elytra not distinctly striato-punctate and elongate oval.

Apical angles of prothorax everted

tenuipes.

Apical angles not everted wickhami.

The student must bear in mind that in all probability he will find the above table inadequate as an aid in the determination of all specimens. If the examples be more or less typical there should be no trouble, but among species so polymorphous, puzzling forms will constantly be found.

In the text I have given attention to the most marked incipient races as well as to uniques and aberrations when at hand.

Genealogy.-To speculate upon lines of descent of the species constituting the present section involves great doubt as to the correctness of the assumptions, but may be a useful working hypothesis. Nevertheless I must present my convictions; for there is no doubt in my mind but that the ancestral stock had the femora strongly armed as in armata, and that this species is a direct and somewhat modified modern exponent of that stock.

A typical armata does not have the sides of the prothorax sinuate or constricted before the base. Now, I have before me examples of armata which have the sides of the prothorax as strongly sinuate as in any dentipes, and all of the femora are well armed.

I advance the theory that all of the species now constituting the present section of the Dentipes Group in our fauna-which includes Lower California as well as all of that territory north of Mexicohave had their origin from the ancestral armata stock. It may be asked when did this divergence take place? I would answer, first, that which took place in early times, and, second, that which has taken place in more recent times. 
To the first class belong those forms which have had origin from the primitive eschscholtaii, gracilis, and acuticauda rami.

The accompanying genealogical diagram will elucidate my meaning.

The more recent derivatives of the eschschottzii ramus are our present eschscholtzii, luca, and tenuipes-wickhami; of the gracitis ramus, our present gracitis, distans, and subcylindrica (?) ; of the acuticauda ramus, the present acuticauda, and laticollis. Around each of these more recent forms are the present incipient species and races which render our species so polymorphous.

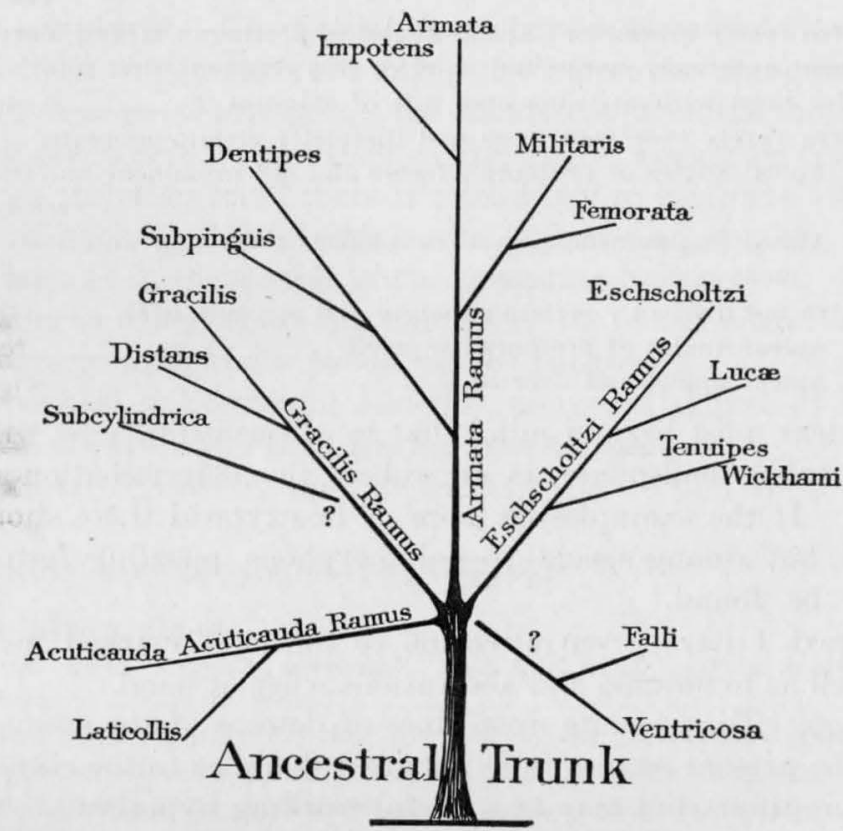

Fig. 5.-Genealogical diagram of the Dentipes Group, Section B, Subgends Eleodes.

The recent derivatives of armata, are militaris and femorata by the modification of general form and slow atrophy of the femoral teeth; there are edentate forms derived from these species at the present time in Lower California, and two of them are before me.

An example of this loss of the femoral teeth is our impotens. I have studied very instructive series of armata from Fresno and Merced counties. These series show all intermediate stages between a typical armata and a typical dentipes.

These remarks are sufficient to indicate my ideas on this subject.

Distribution.-The species of Section B are found inhabiting six States or regions: Mexico, Texas, New Mexico, Arizona, California, and Lower California. 
Table of Distribution.

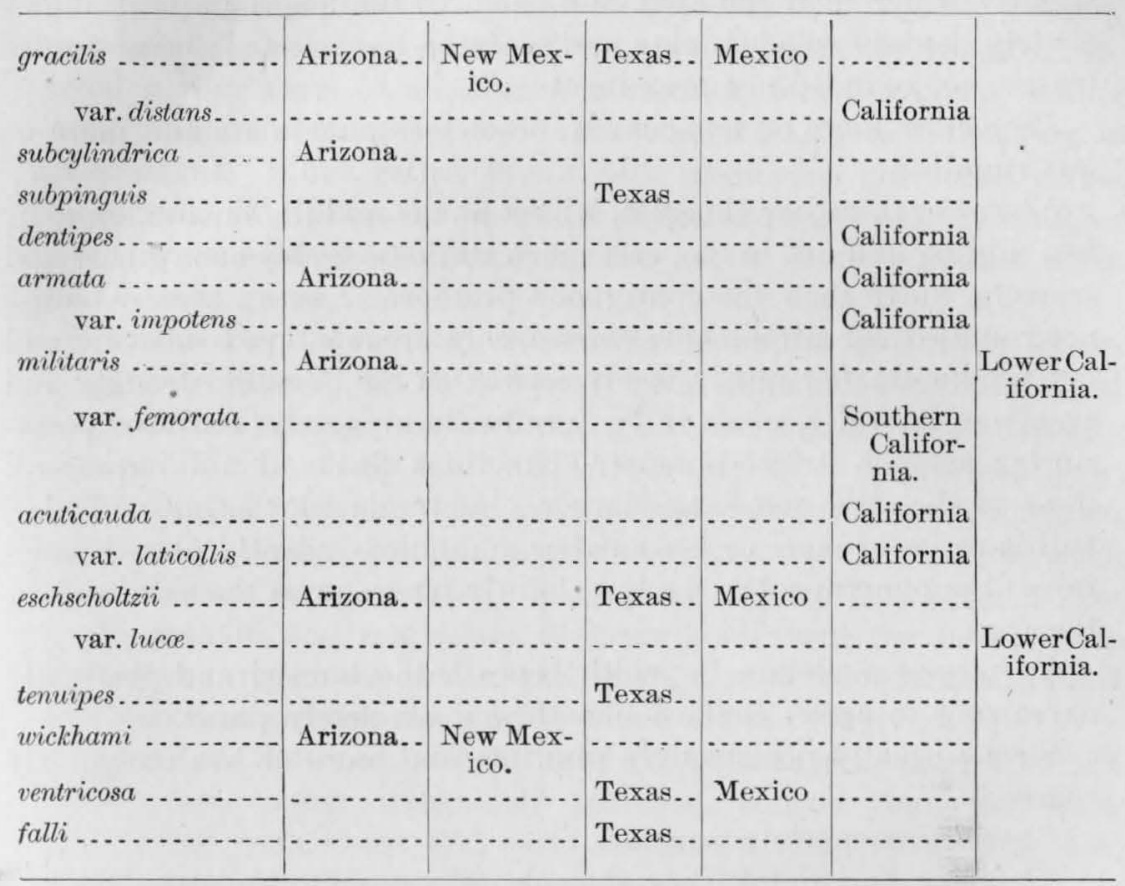

ELEODES GRACILIS LeConte.

Eleodes gracilis LeConte, Proc. Acad. Nat. Sci. Phila., 1858, p. 184.-HonN, Trans. Amer. Phil. Soc., XIV, 1870, p. 312.-Снамpion, Biol. Centr. Amer., IV, Pt. 1, 1884, p. 79.

Elongate oval, subfusiform, black, sometimes slightly piceous, smooth, shining and moderately convex, never caudate.

Head twice as wide as long, slightly convex, more or less feebly impressed laterally, sometimes along the frontal suture and less often transversely so before the vertex; surface finely, irregularly, and not densely punctate. Antennce rather long, reaching a little beyond the prothoracic base, slightly incrassate and feebly compressed in outer four joints, third joint subequal to the next two combined, fourth longer than the fifth, the latter, sixth and seventh subequal, eighth triangular, ninth and tenth transversely oval, eleventh ovate.

Pronotum widest at or slightly in front of the middle, about onefifth wider than long and more or less subquadrate; disc more or less moderately convex, finely and more or less sparsely punctulate, scarcely granulate along the sides; apex subtruncate or feebly emarginate, very finely and more or less obsoletely margined; sides very moderately and evenly arcuate in anterior two-thirds, rather more feebly arcuate, straight or subsinuate and converging in basal third, 
marginal head fine; base more or less arcuate and finely margined, slightly wider than the apex and equal to the length; apical angles acutely dentate or acuminate and more or less everted; basal angles obtuse, not rounded nor prominent.

Propleurce more or less convex, obsoletely punctulate and more or less rugulose.

Elytra oval, rather elongate, widest at the middle, smooth, more or less shining and not in the least muricate; base feebly emarginate and scarcely wider than the contiguous prothoracic base; humeri obtuse not rounded nor prominent; sides evenly arcuate, apex subacute and not produced; diso rather feebly convex on the dorsum, strongly and evenly so laterally, more or less gradually arcuately declivous posteriorly; surface striato-punctate, punctures fine and not impressed, those of the striæ sometimes larger, closely placed, the intervals flat, with a series of more or less smaller and quite distantly placed punctures; the punctures become but slightly irregular at the sides and on the apex.

Epipleurce moderate in width beneath the humeri and gradually narrowing to apex; surface smooth and obsoletely punctate.

Sterna usually not strongly punctate and more or less irregularly rugose.

Parapleurce sparsely punctate.

Abdomen horizontal, very sparsely, finely, and obsoletely punctulate, more or less finely and obsoletely rugulose; most distinctly punctate on the fifth segment.

Legs moderate in length, rather slender but variable. Anterior femora armed in the sexes, with a moderate more or less acute tooth. Anterior tibial spurs equal and acute in the sexes. Tarsi similar.

Male.-Elongate and rather slender. Elytra rather gradually narrowed and arcuately declivous posteriorly. Abdomen rather moderately convex, somewhat flattened on the first two segments and very feebly impressed at middle.

Female.-Elongate and slightly robust. Elytra rather suddenly and arcuately declivous posteriorly. Abdomen evenly and rather strongly convex.

Measurements.-Males: Length, 21-26 mm.; width, 6.5-9 $\mathrm{mm}$. Females: Length, 20-27.5 mm.; width, 8-10.8 mm.

Genital characters, male.-Edeagophore oblong-ovate, somewhat flattened and not arched.

Basale about twice as long as wide, evenly convex, sides evenly and feebly arcuate.

Apicale long triangular, evenly convex above, with a moderate median groove in apical third; sides evenly and slightly arcuate from base to apex, the latter subacute; base rather broadly lobed at middle and feebly sinuate laterally. 
Sternite transverse. Each lobe with the external border quite evenly arcuate, or rather straight in basal half, and quite broadly rounded at apical border, angle introrse and narrowly rounded; internal border more or less sinuate; surface feebly convex, rather densely punctate in apical two-thirds and setose, setre quite long in apical third. Sinus rather broad with membrane not setose across the bottom. The lobes are separated cephalad to the sinus by a rather broad oval membranous area, which is not as sharply defined as in the Obseura group.

Female.-Genital segment trapezoidal in outline and finely setose. Valvula (Plate 4, fig. 19).-Dorsal plate oblong, the internal third in apical half strongly reflexed and glabrous; surface longitudinally concave, shining, finely and not densely punctate, setose, setæ fine; outwardly the surface is obliquely reflexed; external margin rather feebly and broadly sinuate; internal border arcuate in apical half, thence to base sinuate; apical margin not reflexed and more or less evenly arcuate and not easily differentiated from the base of the appendage, angle rounded. Apex triangular and moderate, clothed with very fine inconspicuous setæ, which are not longer at tip.

Appendage flattened, as broad at base as the apical margin of the dorsal plate, rather irregularly semioval, shorter than the apex, finely setose, setæ short and soft; margins of the fossa thin and closely applied to base of the appendage.

Superior pudendal membrane attaining the middle of the dorsal plate, finely and longitudinally rugulose.

Basal prominences rather small.

Ventrolateral surfaces.-Body of the genital segment with the surface evenly convex but not noticeably inflated in basal half, quite strongly and transversely concave before the apices; surface shining, finely punctate and setose, setæ fine. Internal margins of the valves contiguous in basal fourth. Genital fissure long and evenly fusiform, inferior pudendal membrane visible in basal half.

Habitat.-New Mexico (LeConte and Horn; Warren Knaus; H. C. Fall; collection of Hubbard and Schwarz); Arizona (H. K. Morrison; Walnut, July, M. L. Linell; Santa Rita Mountains, June; Sulphur Springs, May; Fort Grant, July; San Simon, July; Chiricahua Mountains, May, Hubbard and Schwarz; collections Chas. Fuchs and C. V. Riley); Texas (Alpine, June, elevation 4,400-4,600 feet, H. F. Wickham; Fort Bliss, collection H. C. Fall) ; Mexico (State of Sonora, Morrison).

Number of specimens studied, 40.

Type in the LeConte collection.

Type-locality.-Arizona (or Sonora, type bears a silver disc indicative as given); collectors, Webb and Schott. 
Salient type-characters.-Elongate. Thorax rotundato-quadrate, moderately convex; disc finely and sparsely punctulate; sides rounded, posteriorly subsinuate; posterior angles obtuse, anterior angles acute and more or less acuminate. Elytra with dorsum slightly convex, more strongly so laterally, scarcely sulcate, punctatostriate, intervals with very few punctures. (LeConte.)

Diagnostic characters.- Known by its elongate form and smooth surface. Elytra not at all muricate; pronotum subquadrate, with sides not strongly rounded. The elytra are not at all caudate.

The prothorax is much narrower than in dentipes. It is with more difficulty separated from sponsa, and especially forma convexa (see p. 215). Here its general form, glabrous integuments, and finer punctuation must be depended upon. The character of the sculpturing is the most important. Occasionally rather strongly punctate examples are met with, but the sculpturing is simple; if muricate it is to be referred to sponsa. Sponsa forma convexa is smooth, and here the interstitial punctures are usually large and somewhat indented.

Var. distans is usually more robust and has thicker integuments, and is found in a different geographical region; the elytral intervals are wider and the punctures are very distinctly defined.

For other specific differentiations consult the diagnostic characters of Group A of the present subgenus.

I can not see that gracilis has any close affinity or resemblance to Zucce as suggested by Doctor Horn.

The specimens collected in Lower California and referred to this species by Dr. George Horn ${ }^{a}$ and in the collection of the California Academy of Sciences, do not belong to this species at all, but to a distinct species described in this paper as tibialis.

I doubt that true gracilis occurs in Lower California. All data thus far collected are surely negative. It does occur in the State of Sonora, Mexico, and might possibly extend westward upon the peninsula.

The mentum is moderate. The middle lobe is rather short and somewhat equilaterally triangular, with apex rather narrowly rounded; at times reflexed at tip so as to appear truncate; surface coarsely punctate, rather broadly and feebly convex centrally and more or less distinctly foveate laterally, not noticeably setose.

The prosternum is variable; convex between and behind the coxæ, sometimes feebly mucronate.

The mesosternum is more or less arcuately precipitous or oblique, and more or less concave.

${ }^{a}$ See Proc. Calif. Acad, Sci., 2 d ser., IV, p. 349. 
The abdominal process is subquadrate, just noticeably transverse, and in width about equal to the length of the post-coxal portion of the same segment, and also to that of the third; the second segment is about a fourth of its length longer than the third, the latter is slightly less than twice as long as the fourth.

The abdominal salient is about a fifth wider than the metasternal process.

The metasternum laterally between the coxæ is as long as the width of a mesofemur at base.

The tibial grooves of the profemora are rather broad apically; the sides, which are distinct, converge regularly and rather rapidly to become contiguous a short distance from the femoral base; the floors are nearly flat and quite glabrous, each anterior margin is more or less acutely and dentately laminate at the outer fourth in both sexes.

The grooves of the meso- and metafemora are rather narrow; sides rather well defined and asperate, becoming obsoletely contiguous at about basal third; the floors are more or less opaque, glabrous or rugulose and subasperate.

The protibiæ are more or less distinctly carinate externally, and slightly compressed; the tarsal grooves are not very well defined and usually scabrous, with the posterior margins more or less serrulate; the articular cavities are more or less slightly open.

The meso- and metatibiæ are not at all carinate externally in the series before me, and the articular cavities are quite closed; grooves of the mesotibix are more or less defined, and at times moderately deep, extending to about the middle of the tibiæ, and their floors are more or less glabrous or scabrous.

The external surfaces of the metatibiæ are flattened, more or less scabrous, and the grooves may be distinct.

The tarsi are moderate and variable in length and stoutness.

The protarsi are about one-sixth of their length shorter than a mesotarsus. Joints two, three, and four subequal, quite short and wider than long, and together equal to the fifth; the first is distinctly longer than wide.

The mesotarsi are about a seventh of their length shorter than a metatarsus. Joints two, three, and four distinctly longer than wide and slightly shortening in length in the order named, and together a little longer than the fifth; the second and third combined about equal in length to the first.

The metatarsi are about half as long as a metatibia. Joints two and three are about one and a half times longer than wide and not equal, together equal in length to the fourth, the first being very slightly shorter.

$59780-$ Bull. $63-09-16$ 
ELEODES GRACILIS var. DISTANS, new variety.

Elongate ovate or oval, slightly robust, integuments firm, glabrous and shining; elytra with distant striæ of very sharply defined punctures.

Head about twice as wide as long, feebly and quite evenly convex, broadly and slightly impressed laterally, frontal suture not generally evident, finely, rather sparsely and somewhat evenly punctate, slightly more densely so laterally. Antennce rather long, attaining a short distance beyond the prothoracic base, feebly compressed and a little incrassate in outer four joints, third joint about equal to the next two taken together, the fourth a little longer than the fifth, the latter to the eighth inclusive subequal in length, eighth about as wide as long and triangular, ninth and tenth feebly transversely oval, eleventh short and subtrapezoidal or ovate.

Pronotum widest at about the middle and about one-fifth wider than long; disc moderately and quite evenly convex, more or less declivous at the apical angles, polished and shining, rarely subalutaceous, very finely and sparsely punctulate, laterally in anterior four-fifths narrowly and feebly impressed, impressed area subopaque and more or less obsoletely granulato-rugulose; apex feebly and broadly emarginate, rather coarsely beaded laterally, obsoletely so at the middle; sides broadly, evenly, and not strongly arcuate in anterior three-fourths, thence to base less arcuate, straight or scarcely subsinuate, rather coarsely beaded; base broadly and slightly arcuate, coarsely beaded, about one-fourth wider than the apex and equal to the length; apical angles acute, not large, subdentiform and frequently slightly everted; basal angles obtuse, distinct, and not rounded.

Propleurce smooth and opaque, very sparsely and obsoletely punctulate, more or less rugulose.

Elytra oval, widest at the middle, polished and shining; base broadly, feebly, and distinctly emarginate, very slightly wider than the contiguous prothoracic base; humeri obtuse, distinct, and not prominent; sides evenly arcuate, somewhat gradually narrowed posteriorly, apex obtusely rounded; dise more or less moderately convex, 'rarely slightly flattened on the dorsum, evenly and broadly rounded laterally, arcuately but not suddenly declivous behind; surface striato-punctate, striæ distant and not impressed, regular and usually very distinct, punctures distinctly defined, those of the striæ close and separated by a distance equal to their diameters, moderately small, intervals flat with a series of very fine and distantly spaced minute punctules; punctures simple, but somewhat feebly submuricate on apex, scarcely confused laterally. 
Epipleurce moderate in width beneath the humeri, thence gradually narrowing to apex; surface smooth, subopaque, and usually impunctate.

Sterna not strongly punctate and more or less rugulose.

Parapleurce sparsely and obsoletely punctate.

Abdomen horizontal, obsoletely punctate on first three segments, more strongly so on the fourth and fifth segments.

Legs moderate in length, slender to somewhat robust; anterior femora armed with an acute tooth in both sexes; tibial spurs similar in the sexes, the anterior subequal and acute. The tarsi are simple and similar in the sexes.

Male.-Elongate and scarcely robust. Elytra somewhat gradually narrowing posteriorly, arcuately and slightly obliquely declivous. Abdomen moderately convex, slightly and broadly impressed on first two segments.

Female.-Elongate and rather robust. Elytra not noticeably narrowed behind and arcuately declivous, abdomen somewhat strongly and evenly convex.

Measurements.-Mates: Length, 19-26 mm.; width, 8-9 mm. Fémales: Length, 20-28.5 mm.; width, 8-10.8 mm.

Genital characters, male.-As in gracitis, except that the median groove of the apicale extends to the basal fourth and becomes wider and more membranous.

Female (Plate 5, fig. 19).-Genital segment trapezoidal, moderately robust and sparsely setose.

Valvula.-Apparently oblique at the apex. Dorsal plate oblong, concave, inner fourth reflexed and glabrous, external three-fourths obliquely and gradually reflexed; surface glabrous and shining, sparsely punctate and setose, setæ moderately short and fine; external border nearly straight; internal margin arcuate in apical threefourths thence sinuate to base; apical margin arcuate and at the internal fourth continuous with the surface of the apex, angle not evident, each set with a few rather long setæ. Apex triangular, with its external border giving the valve an obliquely truncate appearance as it passes into the inferior margin of the fossa, chitino-membranous, setose, setæ mostly fine, a few longer on tip.

Appendage semi-oval, slightly longer than wide, quite evenly rounded, flattened and transverse, finely setose, with a very loose tuft of longer setæ at apex. Fossa transverse between the apical margin of the dorsal plate and external border of the apex.

Basal prominences not large but distinct.

Superior pudendal membrane reaching to about the middle of the dorsal plate and somewhat distantly longitudinally rugulose. 
Ventrolateral surfaces.-Body not very stout, moderately convex and very slightly swollen, broadly and feebly concave before the apices; surface smooth and sparsely punctate in apical two-thirds, setose, setæ fine and small; submarginal groove small and distinct between external margin of the dorsal plate and the thin external border of the lateral plate, terminating at the external angle of the fossa. Internal margins of the valves contiguous in basal fourth. Genital fissure in middle two-fourths and fusiform, closed in basal half by the inferior pudendal membrane.

Habitat.-California (Fort Tejon, April 19-21, Fuchs and Hopping; Los Angeles County, Dr. E. C. Van Dyke; Fairmount, April 23, Fuchs and Hopping; Norwalk, December 25, Antelope Valley, August 5, H. C. Fall; Oak Creek, Kern County; Tèhachapi Valley, June 15).

Number of specimens studied, 60.

Types in my own collection (males and females).

Type-locatity.-Fairmount, Los Angeles County, California. Collectors, Fuchs and Hopping.

Salient type-characters.- Somewhat robust and elongate, integuments firm, smooth and polished. Pronotum scarcely subquadrate, sides broadly. arcuate in anterior two-thirds, thence quite straight and converging to base; apical angles acuminate and dentiform, slightly everted; basal angles obtuse and distinct; disc very sparsely and minutely punctulate. Elytra with distant and distinct unimpressed striæ of rather small punctures, intervals flat with a series of very minute and distantly spaced punctules.

Diagnostic characters.-In collections distans is usually associated with gracitis and is to be differentiated like that species. It is more robust than gracitis; the intense black and firm body wall, highly polished and shining surface are quite characteristic. Elytral striæ are more distinct than in gracitis and the punctuation is more distinctly defined.

A very interesting fact is that the most heterotypical form-a large robust example with pronotal disc subalutaceous, is amphitypical of hispilabris forma lavis, but the punctuation is perfectly simple and typical of the present race; the other heterotypes of the series resemble gracitis in form, but the sculpturing still remains characteristic of distans.

The interesting series at hand leads me to the following speculation: It appears that distans is the smooth modification of hispilabris forma lavis, the latter being more northern and the former more southern in habitat, distans passing into the typical form of gracitis, from which it can not be sharply defined; in fact it may be the transitional form uniting gracitis and hispilabris-if there is a break in 
the chain it is between forma lavis and distans, for the latter is truly more closely united to gracitis than to the former.

General observations.-The mentum is nearly as in gracilis. It is larger and the middle lobe is less foveate.

The prosternum is prominent ventrally with the coxæ, convex between the same and vertically truncate behind, the angle a mucro; sometimes simply with a small mucro and not truncate.

Mesosternum usually rather vertically declivous and broadly concave.

The abdominal process is subquadrate, slightly transverse, about equal in width to the length of the post-coxal portion of the same segment; the second segment is slightly more than twice as long as the fourth; the third about a third of its length shorter than the second.

The abdominal salient is about a fourth of its width wider than the metasternal process.

The metasternum laterally between the coxæ is about equal in length to the width of a mesofemur at base.

The tibial grooves of the profemora are rather broad apically, the sides are rather strong and finely scabrous, becoming contiguous a short distance from the base; their floors are more or less concave and smooth. On the mesofemora the grooves are moderate in width; the sides converge but become obsolete before becoming contiguous, onefourth from the base. The grooves of the metafemora are narrower, margins rather strong and obsolete at basal third, before becoming contiguous.

The protibiæ are quite distinctly carinate externally and slightly arcuate. In the males the base is somewhat constricted. The tarsal grooves behind the carinæ are narrow and scabrous; the articular cavities are more or less open.

The articular cavities of the meso- and metatibiæ are narrowly open or closed. The grooves of the mesotibiæ are usually strongly developed, concave with the floors, smooth and opaque, margins muricately scabrous, and they extend to the basal third. The metatibir are flattened externally and also grooved in apical three-fourths, and the grooves are more or less smooth or asperate at bottom.

The tarsi are rather stout. The protarsi are about two-fifths of their length shorter than a mesotarsus. Joints two, three, and four short, distinctly wider than long and subequal, together slightly shorter than the fifth; the first about as long as wide.

The mesotarsi are about a seventh of their length shorter than a metatarsus. Joints two, three and four subequal and about as long as wide, together about as long as the fifth; the first is a little shorter than the next two taken together. 
The metatarsi are distinctly less than a half as long as a metatibia. Joints two and three subequal, a little longer than wide and together about equal to the first and not quite as long as the fourth.

\section{ELEODES SUBCYLINDRICA Casey.}

Eleodes subcylindrica Casey, Annals N. Y. Acad. Sci., V, Nov. 1890, p. 400.

Form cylindrically convex, rather slender, finely, very strongly alutaceous and smooth throughout, black; elytra castaneous.

Head moderate, sparsely and rather finely punctate. Antennce rather long and slender, about as long as the head and prothorax, third joint nearly four times as long as wide.

Prothorax subcylindrical, about one-fifth wider than long; disc transversely, moderately but very evenly convex throughout, longitudinally very feebly convex, very sparsely and extremely minutely punctate throughout; apex very nearly as wide as the base, subtruncate between the apical angles; sides evenly and feebly arcuate throughout; base broadly and very feebly arcuate; apical angles acute, very strongly advanced but not at all everted; basal angles obtuse, not in the least rounded, and not at all prominent.

Elytra more than three times as long as the prothorax and rather less than one-third wider; base very feebly emarginate, exactly equal in width to the contiguous base of the pronotum; humeri very obtuse, not rounded, not at all prominent; sides feebly convergent and arcuate near the humeri, parallel and almost perfectly straight thence to the posterior third; apex narrowed rather gradually in apical third, acutely rounded at tip; disc with unimpressed distant rows of very small, nearly simple punctures, the intervals with single rows of extremely widely distant but almost similar punctures, the punctuation not denser towards the sides.

Legs long and very slender; anterior femora with a small but acute tooth slightly beyond apical third, the remaining femora simple, but with the groove of the lower edge fine, very deep and conspicuous, extending almost to the base, with the cariniform edges finely, unevenly serrate; tibiæ strongly arcuate, spurs of the anterior short, nearly equal and slender.

Measurements.-Length, 21-23 mm.; width, 7.5-7.8 mm.

Habitat.-Arizona (collected by Mr. G. W. Dunn).

Species unknown to me. Number of specimens studied by Colonel Casey, 2.

Type in Colonel Casey's collection.

Type-locality.-Arizona (exact place not given).

Colonel Casey considers this species totally distinct in general habitus from any other which is known to inhabit the United States, 
and not described in the Biologia Centrali-Americana. He advises that it be placed near gracilis. I have been unable to recognize it in the large amount of material which has passed through my hands.

ELEODES SUBPINGUIS, new species.

Elongate oval to ovate, rather robust, subopaque to feebly shining, somewhat ventricose and not muricately punctured; elytra striatopunctate, intervals feebly convex, more strongly so on apex.

Head less than twice as wide as long, feebly convex, broadly impressed laterally and along the frontal suture, sometimes transversely so before the vertex, somewhat sparsely and irregularly punctate at middle and rather densely so laterally, punctures moderate. Antenna long, distinctly reaching beyond the prothoracic base in both sexes, slightly compressed and incrassate in outer four joints, third joint about equal in length to the next two combined, fourth just slightly longer than the fifth, the latter with sixth and seventh subequal, eighth triangular and about as long as wide, ninth and tenth slightly transversely oval, eleventh trapezoidal.

Pronotum noticeably transverse, less than one-half wider than long, widest at the middle; disc very moderately convex, somewhat impressed laterally, very finely and sparsely punctulate; apex subtruncate, scarcely emarginate, very distinctly and rather coarsely margined laterally, less strongly so at middle; sides evenly and moderately arcuate to basal fourth, thence feebly sinuate to base, margin distinct, moderate and slightly reflexed; base distinctly but not strongly arcuate, one-third wider than the apex, and coarsely margined; apical angles simply acute or minutely dentiform and not everted; basal angles obtuse, distinct, not rounded nor prominent.

Propleurce opaque, impunctate, and more or less obsoletely rugulose.

Elytra oval, about twice as long as wide and somewhat ventricose, widest at the middle; base very feebly emarginate, scarcely wider than the contiguous prothoracic base; humeri obtuse, not prominent nor rounded; sides evenly arcuate from base to apex, somewhat gradually converging posteriorly, apex obtusely rounded; disc moderately and quite evenly convex on the dorsum, more strongly and broadly so laterally, arcuately declivous posteriorly; surface striatopunctate, some of the striæ apparently duplicated, punctures quite coarse, usually separated by less than their own diameters and somewhat impressed on the dorsum and more strongly so laterally; striæ near the suture not duplicated, intervals more or less feebly convex, quite strongly so on the apical declivity, widest near the suture and narrower laterally, with a single series of minute and not very distantly spaced punctures. 
Epipleurc rather narrow, gradually narrowing from base to apex; surface obsoletely punctulate and smooth.

Sterna subglabrous, more or less obsoletely punctate and rugose.

Parapleurce more or less obsoletely punctate.

Abdomen horizontal, smooth and more or less shining, very sparsely and obsoletely punctulate, most strongly punctate on the last two segments, more or less rugulose.

Legs moderate in length and quite slender; anterior femora armed in both sexes; tibial spurs similar, the anterior subequal and acute; anterior tarsi simple.

Male.-Elongate, oval, scarcely robust or ventricose, somewhat attenuated behind; elytra arcuately and obliquely declivous posteriorly, apex rather narrowly rounded; abdomen moderately convex and rather broadly impressed on the first three segments; anterior femora with an acute and moderate tooth.

Female.-Ovate and somewhat ventricose, not noticeably attenuated behind; elytra arcuately declivous posteriorly. Abdomen rather strongly and evenly convex. Anterior femora obtusely and not strongly dentate.

Measurements.-Male: Length, $25 \mathrm{~mm}$; width, $10.2 \mathrm{~mm}$. Female: Length, $29 \mathrm{~mm}$.; width, $11.5 \mathrm{~mm}$.

Genital characters, male-Edeagophore elongately fusiform, scarcely arched and somewhat depressed.

Basale oblong oval, narrowing cephalad, moderately convex, sides slightly arcuate.

A picale triangular, rather broad, subdepressed; surface very moderately convex, with a median and slightly widened linear membranous groove at middle two-fourths; sides feebly arcuate from base to apex, the latter subacute and not in the least produced; base rather broadly lobed at middle and broadly sinuate laterally.

Sternite transverse. Each lobe rather short and broad, and subtriangulo-parabolic in outline; external border arcuate to apex, the latter broadly rounded and quite continuously so with the internal margin; surface slightly convex externally, glabrous and shining in basal two-thirds and coarsely punctate, setose in the apico-internal third; setæ quite long and rather dense. Sinus broad and apparently closed by membrane, the latter not setose at bottom.

Female.-Genital segment trapezoidal, comparatively small, sides reflexed and more or less concave, not conspicuously setose.

Talvula (Plate 5, fig. 18).-Dorsal plate oblong-oval, with a moderate antero-posterior convexity, concave, internal fourth reflexed, external three-fourths gradually and obliquely so; surface smooth and glabrous, not noticeably punctate nor setose; external and internal borders more or less feebly arcuate; apical margin evenly arcuate, 
not setose. Apex short, triangular, chitino-membranous and very finely setose.

Appendage short, rather broad and obtusely subtriangular, flattened and partly concealed by the swollen superior margin of the fossa, finely setose, with two or three longer setæ at tip. Fossa transverse, margins more or less swollen and very finely setose and without conspicuous setæ.

Superior pudendal membrane reaching to about the middle third of the dorsal plate and rather distantly longitudinally rugulose.

Basal prominences moderately prominent laterally; submarginal groove not visible from above.

Ventrolateral surfaces.-Body moderately stout, rather strongly convex and swollen in basal half and transversely concave before the apices; surface glabrous, very finely punctulate and sparsely setose in apical half, setæ minute and fine. Submarginal groove small beneath the feebly laterally prominent external margin of the dorsal plate, and terminating at the external angle of the fossa. Inferior margin of the apex continuous with the inferior margin of the fossa. Internal margins of the valves contiguous in basal fourth. Genital fissure long and rather broadly fusiform, with basal half closed by the inferior pudendal membrane.

Habitat.-Texas (Cameron County, August, H. F. Wickham).

Number of specimens studied, 2 (male and female).

Sexitypes in Prof. Wickham's and my own collections.

Type-locality.-Cameron County, Texas.

Salient type-characters.-Somewhat opaque to feebly shining, elytra slightly ventricose. Thorax very moderately convex and evidently transverse; sides moderately arcuate and very slightly sinuate before the base; apical angles small, simply acute to feebly dentiform; basal angles obtuse. Elytra with striæ of rather coarse, closely placed punctures, intervals feebly convex, distinctly convex on the apical declivity. Some of the striæ duplicated. Intervals with a single series of minute punctules.

Diagnostic characters.-The two specimens before me appear to be quite distinct. The slightly ventricose elytra, transverse and rather short pronotum, with the sides rather strongly rounded, small apical angles; elytra with strix of rather coarse punctures, which are coarser laterally, the intervals more or less convex and distinctly so on the apical extremity, general surface smooth and not at all muricate, with the integuments dull, give quite a characteristic facies.

The female in form somewhat resembles the larger form of nupta (see hispilabris).

Subpinguis is apparently most closely related to gracilis and dentipes. From the former it is separated by the much broader 
pronotum; from the latter by the subopaque integuments and shorter and broader pronotum, and it inhabits a different zoological region.

General observations.-The mentum is triangular, rounded at apex, sometimes reflexed so as to appear truncate. The inflexed lobes are moderate in size. Surface coarsely punctate and feebly convex centrally, foveate laterally within the margins. The prosternum is strongly arcuate antero-posteriorly between the coxæ and strongly protuberant ventrally with the coxæ; triangular behind the equator of the coxæ and vertically truncate, also compressed behind, with the angle rounded or quite strongly mucronate; surface longitudinally grooved between the coxæ.

Mesosternum quite vertical and more or less arcuate, broadly concave.

The abdominal process is subquadrate and noticeably transverse, in width about equal to the length of the second segment; the latter is slightly longer than the post-coxal part of the first; the third is a little more than twice as long as the fourth, while the second is about a third of its length longer than the third.

The abdominal salient is about a fifth wider than the metasternal salient. Metasternum laterally between the coxæ is scarcely as long as the width of a mesofemur at base.

The tibial grooves of the profemora are moderate in width and slightly concave, floors glabrous; sides carinate, quite straight and contiguous before the base; the anterior margin of each groove is more or less dentately laminate at about the outer fourth.

On the mesofemora the grooves are glabrous, with the floors quite flat, the sides moderately cariniform, becoming evanescent at basal fourth without becoming contiguous. Those of the metafemora are similar but evanescent at basal third.

The protibiæ are slightly compressed and carinate externally. The tarsal grooves are more or less feeble, with their floors glabrous in apical moiety; the articular cavities are more or less feebly open.

The meso- and metatibiæ are not carinate externally and the articular cavities are quite closed; the external surfaces are flattened and scarcely grooved, glabrous on the mesotibiæ, subglabrous and obsoletely sculptured on the metatibiæ.

The tarsi are moderately stout and somewhat elongate.

The protarsi are about a third of their length shorter than a mesotarsus. Joints two, three, and four subequal, apparently just a little wider than long and together about equal to the fifth; the first is slightly longer than wide.

The mesotarsi are about one-eighth of their length shorter than a metatarsus. Joints two, three, and four subequal, just a little longer than wide and together just a little longer than the fifth; the first is scarcely as long as the third and fourth combined. 
The metatarsi are equal in length to half the length of a metatibia. Joints two and three are subequal and distinctly longer than wide, and together equal to the fourth; the first is slightly shorter.

ELEODES DENTIPES Eschscholtz.

Eleodes dentipes Eschscholтz, Zool. Atlas, III, 1833, p. 10, pl. xIV, fig. 4.Mannerheim, Bull. Soc. Nat. Moscow, XVI, 1843, p. 267 ; Mag. Zool., 1834, p. 31, pl. cxvir.-LeConte, Proc. Acad. Nat. Sei. Phila., 1858, p. 181.-Honn, Trans. Amer. Phil. Soc., XIV, 1870, p. 314.

Eleodes prominens Casey, Annals N. Y. Acad. Sci., V, Nov., 1890, p. 401. Eleodes elegans Casey, Annals N. Y. Acad. Sci., V, Nov., 1890, p. 401.

Eleodes confinis Blaisdell, Ent. News, VI, no. 7, Sept., 1895, p. 237.

Elongate oval or ovate, smooth, and convex.

Head twice as wide as long, feebly convex, very feebly and vaguely impressed laterally, rather coarsely, irregularly and densely punctate. Antenna usually moderate, but variable in length, outer four joints compressed, slightly and gradually dilated, third joint quite equal to the next two combined, fourth slightly longer than the fifth, the latter, sixth, and seventh subequal, eighth subtriangular in outline and very slightly shorter than the seventh, ninth, and tenth transversely oval or suborbicular, eleventh trapezoido-ovate.

Pronotum widest at middle, about one-third wider than long, less than twice as wide as the head; disc more or less bright and shining, moderately convex, rather finely, sparsely, and irregularly punctate, usually obsoletely impressed, narrowly opaque, and granulo-punctate laterally along the margin in middle four-sixths, rather declivous at apical and basal angles; apex moderately and rather arcuately emarginate, obsoletely margined; sides broadly and evenly arcuate, distinctly sinuate in basal fifth, and briefly subparallel before the angles, more or less finely margined, margin reflexed; base feebly arcuate and very finely margined, slightly wider than the apex; apical angles moderately acuminately produced and more or less everted; basal angles subrectangular or slightly prominent.

Propleurce more or less finely and irregularly granulato-muricate with a large smooth area posteriorly.

Elytra oval, smooth and shining, slightly more than twice as long as wide, widest at the middle; base feebly emarginate, scarcely wider than the contiguous prothoracic base; humeri obtuse, not prominent nor rounded; sides evenly arcuate, apex obtuse and not rounded; disc evenly and rather strongly convex from side to side, more or less gradually arcuately declivous posteriorly ; surface rather finely punctate, punctures arranged in moderately distant unimpressed series and quite closely spaced, intervals with a series of finer punctules, which are more distantly spaced, and become more irregular and denser along the suture; the punctures become more confused and 
very feebly muricate laterally and on apex; sometimes the punctures are subequal and diffuse.

Epipleurce moderately wide at the humeri and thence gradually narrowing to apex; surface very finely and obsoletely punctate.

Sterna more or less densely punctate and rugulose.

Parapleurce rather coarsely punctate.

Abdomen horizontal, rather finely and evenly punctate, rugulose, the punctuation denser on the fifth segment.

Legs variable in length, form and stoutness. Anterior femora armed in both sexes; tibial spurs similar in the sexes, the anterior equal and acute; tarsi similar in the sexes.

Male.-Elongate, subfusiform oval, and somewhat narrow. Antennæ usually scarcely reaching to or slightly beyond the prothoracic base. Elytra gradually narrowed, and evenly, not rapidly arcuately declivous posteriorly; apex narrowly rounded and obtuse. Abdomen moderately convex, first two segments scarcely impressed. Anterior femora with a moderate and acute tooth at about outer third; posterior tibiæ straight or arcuate.

Female.-Rather robust. Antennæ usually attaining the posterior third or about to the base of the prothorax. Elytra more or less broadly oval, rather suddenly arcuately declivous posteriorly, with apex rather broadly rounded. Abdomen quite strongly convex and not at all impressed. Anterior femora armed with a more or less obtuse tooth; posterior tibiæ not arcuate.

Genital characters, male.-Edeagophore of the usual flattened oblong-ovate form and rather small.

Basale quite short and oblong, scarcely arched, but gradually gibbous dorsally toward base.

A picale triangular; surface evenly convex, rather slightly depressed and with a feeble membranous groove in middle two-fourths; sides slightly arcuate and apex simply acute; base more or less arcuately lobed at middle and broadly sinuate laterally.

Sternite slightly transverse. Each lobe with the external border evenly and broadly arcuate in apical half and quite parallel toward base; internal border straight; apex narrowly rounded; surface densely and strongly punctate in apical moiety. Setæ rather long and dense. Membrane not setose across the bottom of the sinus, the latter moderately narrow.

Female.-Genital segment subtrapezoidal, rather robust, apex more or less chitinous and setose.

Valvula (Plate 3, figs. 9 and 11).-Dorsal plate oblong, glabrous; surface moderately concave, very sparsely punctate, setæ rather short; sides feebly reflexed; margins quite parallel, the external straight to feebly sinuate; internal border slightly arcuate; apical 
margin truncate to somewhat arcuate, not always well defined from apex internally; angle subrectangular. Apex short, rather coarsely punctate, setæ rather short; fossa fringed with quite long hairs at outer margin, the hairs extending inward along the apical margin of the dorsal plate.

Appendage short, scarcely as long as the apex, rather stout and conical, rounded at tip and set with rather short setæ which form a loose tuft.

Basal prominences rather strongly developed.

Superior pudendal membrane not quite reaching to the middle of the dorsal plate and distantly longitudinally rugulose.

Ventrolateral surfaces (Plate 3, fig. 10) moderately swollen at base and rather broadly concave laterally before the apices, glabrous, sparsely punctate and setose in apical moiety, setæ moderately long, especially along the ventral margins of the fossæ. Submarginal groove more or less developed. Internal margins of the valves contiguous in basal fourth; genital fissure fusiform and rather wide, with the inferior pudendal membrane visible in basal half.

The above descriptions are applicable to the greater number of examples in the series before me. The present species is indeed the most variable and polymorphic of any in the genus.

The large series at my disposal presents a complex of incipient races that are most bewildering. It is not wise nor practicable to give names to these forms and thus burden our faunal lists with names of races which can not be distinctively defined. These forms appear to diverge along certain lines of development and at the same time to pass directly into one another by the gradual diminution or augmentation of characters, as the case may be. It seems to me that it is best to select a few of the heterotypical forms as centers, around which the more incipient races may be clustered.

Undoubtedly dentipes is unusually reactive to its environment, for each geographical region produces some peculiar modification of the typical form, and yet more or less typical examples are taken in the same regions.

In accordance with the ideas just expressed I shall indicate the following forms for cabinet arrangement:

Forma pertenuis.-Comparatively small and slender. Pronotum widest at or in advance of the middle; sides evenly arcuate and converging posteriorly, scarcely sinuate to distinctly so before the angles. Legs long and very slender. In the males the hind tibiæ are feebly arcuate in basal half, thence scarcely straight or gradually thickened to apex.

In one specimen the elytral surface is very minutely reticulately rugulose, punctuation scarcely distinguishable. 
Measurements.-Males: Length, 18.5-19.5 mm.; width, 7-7.8 mm. Females: Length, $17.8 \mathrm{~mm}$; width, $7.2 \mathrm{~mm}$.

Forma elongata.-Comparatively large and distinctly elongate. Two subforms can be recognized.

Forma elongata lævis.-Alutaceous; antennæ reaching to or beyond the prothoracic base; elytra very finely and obsoletely punctate, legs long, posterior tibiæ very slender, and more or less arcuate in basal half in the males.

Measurements.-Males: Length, 19.5-29 mm.; width, 6.5-9 mm. Females: Length, 24-29.5 mm.; width, 8.5-10.5 mm.

Forma elongata punctata.-This is more or less shining; antennæ reaching to or beyond the prothoracic base; elytra with the serial punctures rather coarse and more or less impressed, the interstitial punctures are small but distinct. Legs moderately long and rather stout, posterior tibiæ in the males stout and straight.

Measurements.-Males: Length, 24-28.5 mm.; width, 7.5-9.5 mm. Females: Length, $27.5 \mathrm{~mm}$; width, $10.5 \mathrm{~mm}$.

Forma typica.-Glabrous, very bright and shining; thorax with the sides strongly sinuate in front of the basal angles; legs moderate (see salient type-characters).

Variations.-Examples of the typical form taken about San Francisco Bay and in the series before me frequently present the following variations: Antennæ rather stout or slender, varying in length irrespective of sex, rarely two of different lengths in the same individual; the relative length of joints differs in individuals of the same sex; outer four joints may be noticeably dilated, subclavate, again not in the least dilated; anterior pronotal angles simply acute and not prominent to acuminately produced and very strongly everted, the pronotum itself may be subquadrate; elytra sometimes widest behind the middle.

Measurements.-Males: Length, 22-28.5 mm.; width, 6.5-8.5 mm. Females: Length, 23-28 mm.; width, 8.5-9.5 mm.

Forma prominens Casey.-Form somewhat as in dentipes, convex, smooth, and alutaceous throughout.

Head moderate, finely, sparsely punctate, more densely so toward the sides of the epistoma. Antenne short and very robust, much shorter than the head and prothorax, third joint about twice as long as wide and equal in length to the next two.

Prothorax about one-sixth wider than long; disc rather strongly convex throughout, finely and sparsely punctate, strongly alutaceous, the side margins very minutely beaded; apex broadly arcuate, sinuate laterally, and subequal to the base; sides broadly arcuate anteriorly, rather strongly convergent in basal half, and strongly sinuate near the basal angles; base broadly, evenly, very feebly arcuate; 
apical angles acute, very prominent anteriorly, and distinctly everted; basal angles acute and prominent.

Scutellum strongly transverse, broadly rounded behind, highly polished, and impunctate.

Elytra at base broadly, feebly emarginate and about as wide as the contiguous prothoracic base; humeri obtuse, but not rounded nor prominent; sides evenly arcuate, the elytra gradually narrowed and acute at apex; disc widest at the middle, where it is rather more than one-third wider than the prothorax, feebly alutaceous, finely, sparsely punctate, the punctures nearly simple, arranged in widely distant, rather feebly defined, unimpressed rows, the intervals with a few widely distant and nearly similar punctures.

Legs rather short and slender, the anterior femora with a short obtuse tooth near the outer third; middle and hind femora simple; spurs of anterior tibiæ moderate in length, slender, similar, and very nearly equal.

Measurements.-Length, $19 \mathrm{~mm}$; width, $7.8 \mathrm{~mm}$.

Forma robusta.-Very robust, elytra less narrowed toward base, prothoracic base wide, integuments very smooth and subalutaceous; punctuation very fine or obsolete. Prothorax comparatively large, apex arcuate at middle and sinuate laterally; sides more or less sinuate before the base. Antennæ and legs quite stout to somewhat slender.

Measurements.-Máles: Length, 24-28 mm.; width, 9-10 mm. Females: Length, 22-27 mm.; width, 9-10.5 mm.

Forma confinis Blaisdell.-( See Plate 3, fig. 13.)

Rather robust and alutaceous, very convex. Head large; antennæ robust, reaching to the posterior third of the prothorax. Pronotum widest just in front of the middle, sometimes at the middle, posteriorly straight, convergent and not in the least constricted or sinuate in front of the basal angles, the latter obtuse. Legs moderately slender.

Measurements.-Males: Length, $24 \mathrm{~mm}$; width, $7.5 \mathrm{~mm}$. Females: Length, $24 \mathrm{~mm}$.; width, $8.5 \mathrm{~mm}$.

The following unique, described by Colonel Casey, may be simply a form of dentipes or an aberration:

Eleodes elegans Casey.-Moderately robust, strongly convex, strongly alutaceous, the elytra moderately shining; integuments nearly smooth.

Head moderate, somewhat finely, sparsely punctate. Antennce rather short but slender, not quite as long as the head and prothorax, third joint about two and one-half times as long as wide, scarcely as long as the next two, fourth much longer than the fifth.

Prothorax nearly one-third wider than long; dise rather strongly convex throughout, widest just before the middle, somewhat sparsely 
but deeply and rather coarsely punctate; apex transversely truncate, a very little narrower than the base; sides strongly, almost evenly arcuate throughout, and very minutely beaded; base very feebly, evenly arcuate; apical angles small but acute, anteriorly prominent, dentiform, and feebly everted; basal angles very obtuse, not rounded, but not in the least prominent.

Elytra about three times as long as the prothorax, gradually acute at apex, inflated, widest at the middle, where they are about threefourths wider than the prothorax; base just visibly wider than the base of the prothorax; humeri obtuse but not rounded, not at all prominent; sides evenly arcuate; disc confusedly, finely creased, rather coarsely and distinctly granulato-reticulate, very finely and sparsely punctate, the punctures nearly simple throughout and not denser laterally, arranged in very feebly defined unimpressed rows, approximate toward the suture, then widely distant, with an uneven and sparser row along the middle of the intervals.

Legs moderate in length and very slender; anterior femora not dentate but with a very broad and obtuse rounded salient near the apex; spurs of the anterior tibiæ very slender and almost exactly equal.

Measurements.-Length, $13 \mathrm{~mm}$; width, $6 \mathrm{~mm}$.

Colonel Casey writes that there is no described species with which it can be compared, and says that it should be placed near dentipes. If the sexes have the anterior femora armed it can be placed nowhere else. The type is evidently a female and the femoral tooth should be more acute in the male. It does not differ any more than many other aberrant forms of dentipes which I have seen.

The following Aberrations represented by uniques may be mentioned to make known extreme forms that are probably fortuitous:

Aberration No. 1.-Antennæ slender; sides of the pronotum evenly arcuate from apex to base; basal angles obtuse. Elytra widest behind the middle. Legs slender and moderate in length; anterior femora with a small subacute tooth at about outer third; posterior tibiæ quite slender, the anterior moderately arcuate. Integuments glabrous and shining. Female.-Length, $20.5 \mathrm{~mm}$.; width, $8.5 \mathrm{~mm}$. Taken with typical specimens at Berkeley, California.

Aberration No. 2.-Moderately robust, subopaque, and alutaceous, antennæ reaching slightly beyond base of the pronotum, the latter subquadrate; base and apex truncate and equal to each other; sides evenly but not strongly arcuate, feebly sinuate just before the basal angles, the latter rectangular.

Legs rather long and slender.

This specimen might at first glance be taken for a female quadricollis. The apical angles of the pronotum are very acute and everted at right angles. 
Female.-Length, $21.5 \mathrm{~mm}$; width, $9 \mathrm{~mm}$.

Taken at Mokelumne Hill, Calaveras County, California.

In the latter aberration the anterior femora have a small obtuse salient. In other respects both possess other characters as in dentipes.

Habitat.-California.

Forma pertenuis.-Kaweah, Tulare County, Ralph Hopping; Watson Springs, May; Martinez, Contra Costa County, January, collection U. S. National Museum; Colony Mills, Tulare County, elevation 5,415 feet, Fuchs and Hopping.

Forma elongata-Lávis.-Mokelumne Hill, Calaveras County, elevation 2,400 feet, March to August; Fresno County.

Punctata.-Placerville, Eldorado County; Corning, Tehama County; Martinez, Contra Costa County; San Jose, San Mateo County.

Forma typica.-Counties bordering the Bay of San Francisco; Port Harford, San Luis Obispo County; Ocean Beach, Los Angeles County, J. J. Rivers; Napa County, F. C. Clark; Trinity County, E. C. Van Dyke; San Joaquin County; Argus Mountains; Yosemite Valley; San Bernardino Mountains.

Forma prominens.-Port Harford, San Luis Obispo County, Col. Thomas Casey.

Forma robusta.-Fairmount, Los Angeles County; Fort Tejon, Fuchs and Hopping; Kern County, Fordyce Grinnell; Tulare County; Calaveras County; Napa County.

Forma confinis.-Mokelumne Hill, Calaveras County, elevation 2,300 feet; Napa County; Santa Clara County; Tulare County; Sonoma County.

Forma elegans.-Hoopa Valley, Humboldt County, Col. Thomas Casey.

Number of specimens studied, 960 .

Disposition of the type unknown to me.

Type-locatity.-San Francisco; "on the hills beneath rocks."

Sabient type-characters.-Elongate and shining. Head and thorax finely granulato-punctate; thorax with sides rounded and strongly sinuate at base; apical angles acuminate. Elytra finely striato-punctate, the punctures granuliferous (Eschscholtz).

Diagnostic characters.-A very variable species both as to sculpturing and general form.

From acuticauda it is recognized by the less strongly rounded sides of the pronotum and in being less strongly and rather less suddenly constricted at base, not broadly granular at the sides of the disc and the elytra are never decidedly produced.

In forma elongata the sides of the pronotum are most distinctly granulate of any of the variations, but less so than in acuticauda var.

59780-Bull. $63-09-17$ 
Zaticollis, from which it is at times difficult to separate, but here the form of the pronotum must be relied upon.

Armata and mititaris have all of the femora armed, while in the present species only the anterior bear a tooth.

Dentipes is undoubtedly genetically related to armata (see p. 262). The chief incipient races have already been sufficiently indicated and must only serve as centers for cabinet arrangement, for the mesotypes are multitudinous and defy limitations.

The middle lobe of the mentum is moderate and subtriangular, at times sub-trapezoidal or more or less parabolic, and varies independent of race or form; the apex is usually more or less distinctly arcuate; surface coarsely punctate and very faintly convex and quite narrowly but not strongly foveate laterally within the margin.

The prosternum variable; usually rounded between and behind the coxæ; frequently with a small, and less frequently with a welldeveloped mucro. In forma confinis some specimens have it subtruncate and feebly compressed behind, with the angle mucroid.

Mesosternum quite obliquely precipitous and more or less concave.

The abdominal process is subquadrate, slightly transverse and in width about equal to the length of the third abdominal segment; the post-coxal part of the first is about equal to the second, and the latter is about twice as long as the fourth.

The abdominal salient is about a fourth of its width wider than the metasternal process.

The metasternum laterally between the coxæ is about as long as the width of a mesotibia at apex.

The tibial grooves of the femora are well developed, with edges more or less cariniform, and their floors vary in the degree of concavity. Those of the profemora do not quite attain the femoral base; on the mesofemora the grooves extend inwards to about the basal fourth and there the margins become evanescent before becoming contiguous; on the metafemora they only attain the internal third and there become evanescent before uniting.

The tibiæ vary greatly in sculpturing, at times very densely and coarsely muricate and at others rather feebly so. The articular cavities are nearly always closed and the grooves are always more or less roughly sculptured with their floors more or less shining, and variable in degree of development. The external borders of the protibiæ are more or less distinctly carinate, the mesotibiæ scarcely at all so.

The tarsi are very variable in length and stoutness, even in the same race.

In an average typical specimen the protarsi are about a sixth of their length shorter than a mesotarsus. Joints two, three, and four 
are subequal and slightly wider than long; and together about equal to the fifth; the first about a half longer than wide.

The mesotarsi are about a seventh of their length shorter than a metatarsus. Joints two, three, and four about as long as wide and subequal, and together about equal to the fifth; the first is about one and a half times longer than wide.

The metatarsi are about half as long as a metatibia. Joints two and three subequal and distinctly longer than wide, together scarcely as long as the fourth, and slightly longer than the first.

\section{ELEODES ARMATA LeConte.}

Eleodes armata LeConte, Ann. Lyc. Nat. Hist. N. Y., V, 1851, p. 134; also in Thomson's Arcana Nat., 1859, p. 125, pl. xII, fig. 2; Proc. Acad. Nat. Sci. Phila., 1858, p. 181.-Honn, Trans. Amer. Phil. Soc., XIV, 1870, p. 310.

var. impotens Blaisdel., Ent. News, VI, no. 7, Sept., 1895, p. 236.

Elongate, somewhat oblong-ovate, shining, sometimes alutaceous.

Head twice as wide as long, moderately convex, more or less impressed laterally, frequently the frons is broadly and transversely impiessed with vertex more strongly convex; surface rather coarsely, moderately, densely, and irregularly punctate. Antennce not reaching to the base of the prothorax, outer four joints slightly compressed and scarcely dilated, third joint scarcely longer than the next two combined, fourth longer than the fifth, the latter to the seventh, inclusive, subequal, eighth obconico-triangular, ninth and tenth scarcely transversely oval, eleventh ovate.

Pronotum widest at or slightly in advance of the middle, about a third wider than long; disc smooth, moderately and evenly convex, rather declivous at the apical angles, rather sparsely and evenly punctulate; apex rather deeply and broadly emarginate, usually finely margined laterally; sides broadly arcuate anteriorly, more or less straight, or feebly arcuate to base, sometimes sinuate before the base, finely beaded; base not strongly arcuate and rather coarsely margined, about a sixth wider than the apex; apical angles acute, more or less dentiform, frequently everted; basal angles obtuse.

Propleurce smooth, with small setigerous punctures anteriorly, along posterior margin and on the acetabular convexity.

Elytra oval, smooth, about twice as long as wide, widest at the middle, rarely behind the same; base scarcely emarginate, and hardly wider than the contiguous prothoracic base; humeri obtuse and not prominent; sides evenly arcuate, apex́ obtuse and more or less narrowly rounded; disc smooth, evenly convex from side to side, more or less arcuately declivous posteriorly; surface more or less finely punctate, punctures arranged in moderately distant, unimpressed 
series, the punctures sometimes rather coarse, at other times fine and quite closely placed in the series, intervals flat, with a single more or less regular series of widely spaced and very fine punctures; the punctuation becomes more or less irregular on the sides and apex.

Epipleurce moderate in width at the humeri, thence gradually narrowing to the apex; surface smooth, finely and very sparsely punctulate, or impunctate, frequently finely rugulose and feebly concave.

Sterna more or less punctate.

Parapleura rather coarsely and evenly punctate.

Abdomen horizontal, sparsely, finely, and quite evenly punctured, punctures slightly denser on the fifth segment.

Legs moderately long; all of the femora coarsely and quite densely punctate, and each armed with a long, acute, and strongly developed tooth; all of the tibiæ generally more or less arcuate in basal half; anterior tibial spurs equal and acute; tarsi simple and similar in the sexes.

Male.-Elongate, slightly narrower than the female. Antennæ reaching about to the posterior fifth of the prothorax. Elytra sometimes distinctly narrowed posteriorly and more or less obliquely declivous; apex obtuse, not produced, and rather narrowly rounded. Abdomen moderately convex, and broadly, very feebly impressed on the first two or three segments.

Female.-More or less robust. Antennæ scarcely attaining the posterior fifth of the prothorax. Elytra more or less evenly arcuately declivous posteriorly; apex rather broadly rounded. Abdomen strongly convex and not impressed.

Measurements.-Males: Length, 25-28.5 mm.; width, 8-9 $\mathrm{mm}$. Females: Length, 24-32 mm.; width, 8-11.5 mm.

Genital characters, male.-Edeagophore of the usual flattened oblong-ovate form and but slightly arched.

Basale about a third of its length longer than the apicale, evenly convex above, with the sides evenly arcuate.

Apicale very slightly elongate, triangular, evenly convex above, with a narrow, membranous median groove in apical half; sides slightly arcuate or straight, apex subacute, not produced and narrowly rounded; base broadly and evenly rounded at middle, feebly sinuate laterally.

Sternite with sides converging apicad. Each lobe rather small; external border straight in basal half and arcuate apically, with the apex broadly and evenly rounded; internal margin slightly arcuate; surface rather densely punctatè and set with quite long and densely placed setæ, especially at apex and apical border. Membrane not setose at bottom of the sinus, the latter rather broad.

Female.-Genital segment trapezoidal, moderate in size, usually not strongly setose. 
Valvula (Plate 1, fig. 18).--Dorsal plate oblong, with the internal border strongly reflexed in apical half, external three-fourths gradually reflexed and outwardly oblique; surface glabrous, very slightly concave, strongly so along the reflexed internal border, very sparsely and finely punctate, setæ short and not conspicuous; external border nearly straight or slightly arcuate; internal margin more or less sinuous; apical margin subtruncate, angle broadly and evenly rounded, with a few rather short and not very conspicuous setæ. Apex small and about as long as the appendage, finely setose and without tuft.

Appendage somewhat flattened, subconical, and more or less concealed by the apical margin of the dorsal plate; finely setose and without a conspicuous tuft.

Superior pudendal membrane attaining the middle of the dorsal plate.

Basal prominences usually not well developed.

Ventrolateral surfaces.-Body not inflated nor strongly convex, slightly concave before the apex and laterally; surface smooth, with few fine punctures and setæ about the fossa; apices finely setose. Submarginal groove fine and normal under the slightly prominent external margin of the dorsal plate. Internal margins of the valves contiguous in basal third. Genital fissure narrowly fusiform, with the inferior pudendal membrane closing its basal half.

Habitat.-California (eastern San Diego County; Los Angeles County; Kern County; Coso Valley; Panamint Valley, and Death Valley, April; Needles; Fresno; Tulare County; Palm Springs; Merced County; Mono County; Amedee, Lassen County, July, elevation, 4,200 feet, H. F. Wickham; Fort Tejon; Argus Mountains) ; Arizona (Tacna, April, Hubbard and Schwarz; Fort Yuma; Prescott; Martinez (Congress Junction); Bill Williams Fork, F. H. Snow). Lower California (coll. Calif. Acad. Sciences).

Number of specimens studied, 112.

Type in the LeConte collection.

Type-locality.-California (gold disc label) in the desert near the Colorado River.

Salient type-characters.-Thorax finely and scarcely densely punctate; sides rounded, and narrowed posteriorly; basal angles obtuse. Elytra convex, apex slightly attenuate, punctures more or less distinctly seriately placed. Femora always with a long and acute tooth beneath (LeConte).

Diagnostic characters.-Quickly recognized from all other species north of Mexico - except militaris and femorata-by having all of the femora armed.

Armata differs from the above two species mainly in its larger size and in having the elytra less attenuate, also, rather more sud- 
denly declivous behind. The femoral teeth are also usually much stouter, longer and more acute, but these last characters are variable and in a large series lose their differential value.

In the typical race the apical angles of the pronotum are acute, usually prominent anteriorly and dentiform. The angles present considerable variation in a large series of specimens, and if the examples be arranged according to the form of the angles, they will be found to pass from that observed in the typical, to small, acute, dentiform and everted in the other extreme of the series.

These remarks apply also to the femoral teeth; in the extreme forms as opposed to the normal, they become long, slender, and acicular, or even shorter and triangular, even obtuse or entirely aborted on the meso- and metafemora (forma subedentata), even where there is no change in the bodily form.

In the collection of the California Academy of Sciences there is a specimen from Lower California, and referred to lucce by Dr. George Horn, that has only the anterior femora armed and without any evidence of the other femoral teeth; this specimen has the facies of armata-the elytra being unusually and very gradually attenuated posteriorly, without any signs of the formation of a definite cauda. I believe this specimen to be a subedentate armata.

A most interesting series was received from Fresno County, California, by Mr. Fuchs for the California Academy of Sciences. To my mind this series demonstrated the fact that armata passes into dentipes by the failure of development in the teeth upon the mesoand metafemora. In the series were specimens with the teeth in different degrees of atrophy, and some with only the anterior femora armed; in general facies they could not be separated from the undoubted typical forms in the same series (see impotens). Many specimens of fully armed armata have the pronotum nearly as strongly sinuate posteriorly as in dentipes.

General observations.-The mentum is also variable. The middle lobe may be moderate or smaller in size, subtriangular to trapezoidal, the apex evenly rounded or subtruncate. The surface is coarsely punctate and not noticeably setose, feebly convex centrally and more or less strongly foveate laterally, or quite plane and not foveate.

The prosternum is strongly sculptured and strongly micronate, usually horizontally so, and flat between the coxæ; frequently convex between the same and horizontally mucronate, or rarely with a small mucro; sometimes vertically truncate behind, with the angle rectangular or strongly mucroid and prominent.

Mesosternum short, scarcely at all horizontal, nearly entirely and obliquely vertical, more or less strongly concave.

The abdominal process is subquadrate, a little transverse and just a little wider than the third segment is long. The second segment is 
about equal in length to the post-coxal part of the first; the fourth is half as long as the third.

The abdominal salient and that of the metasternum are subequal in width.

The metasternum laterally between the coxæ is about equal in length to the width of a mesofemur at base.

The tibial grooves of the femora are strongly developed and defined; the margins are more or less cariniform; the floors are glabrous and more or less concave. The profemoral grooves nearly attain the femoral base, while those of the meso- and metafemora become more or less obsolete at the basal fourth or third, respectively.

The anterior margin of each groove is more or less laminate, and dentately so at about the outer fourth. The femora are distinctly sinuate external to the teeth, and the anterior surface is longitudinally and inwardly impressed from the bases of the teeth. It must also be noted that the metatibiæ, while arcuate in basal half, may also be straight and slightly widened in the apical half (see wickhami).

The tibiæ are distinctly arcuate in basal half. The articular cavities are more or less open and the tarsal grooves more or less well developed, although rather narrow and usually defined by asperate margins. The floors are quite smooth.

The protibiæ are distinctly carinate externally, and the meso- and metatibiæ are scarcely at all carinate externally.

The tarsi are usually quite stout and moderate in length.

The protarsi are about a sixth of their length shorter than a mesotarsus. Joints two, three, and four are short, subequal, and distinctly wider than long, and together distinctly shorter than the fifth; the first is slightly longer than the second.

Each mesotarsus is about a seventh of its length shorter than a metatarsus. Joints two, three, and four are subequal and evidently just a little wider than long, and together about equal to the fifth; the first is about as long as wide.

The metatarsi are distinctly less than half as long as a metatibia. Joints two and three are subequal and longer than wide, and together decidedly shorter than the fourth; the first is about one-half longer than wide.

ELEODES ARMATA var. IMPOTENS Blaisdell.

Elongate, subovate, convex, and moderately shining.

Head about twice as wide as long, moderately convex, irregularly and rather sparsely punctate, punciures moderate in size and denser at the periphery. Antenno short, moderately slender, subclavate, outer four joints compressed and rather moderately dilated, third joint equal to the next two combined, fourth slightly longer than the 
fifth, the latter, sixth, and seventh equal and cylindrical, eighth triangular, ninth and tenth transversely oval, eleventh ovate.

Pronotum widest a little in front of the middle and slightly wider than long; disc evenly and a little more than moderately convex, more or less declivous at the apical angles, finely and sparsely punctate; apex truncate to feebly emarginate, finely margined laterally; sides evenly arcuate in the anterior two-thirds, thence less so or somewhat straight and converging to base, sometimes feebly sinuate, very finely margined; base feebly arcuate, not coarsely margined and slightly wider than the apex; apical angles small and acutely dentiform, at times strongly everted; basal angles subrectangular and not prominent.

Propleurce opaque, more or less finely and very sparsely punctate, frequently the acetabular convexities are strongly rugulose.

Elytra oval and more or less elongate, smooth, widest at the middle; base truncate or feebly emarginate, and about equal to the contiguous prothoracic base; humeri obtuse and not prominent; sides evenly arcuate, apex obtuse; dise evenly and quite strongly convex or somewhat depressed, more or less arcuately declivous posteriorly; surface finely punctate, punctures closely and quite regularly placed in the rather close series, intervals with a single series of more distantly and regularly placed punctures, that often become larger in the outer intervals; both more irregular and denser at the periphery.

Expipleuræ moderately wide and gradually narrowing from base to apex; surface obsoletely and sparsely punctulate.

Sterna usually rather finely punctate and frequently quite strongly rugose.

Parapleurce rather opaque, more or less sparsely, irregularly, and rather coarsely punctate.

Abdomen finely and sparsely punctate, punctures denser on the fifth segment, the first frequently rugulose. Horizontal.

Legs slender to moderately stout, and also moderate in length; femora quite densely punctate, and all armed; the anterior with an acute tooth, the middle with a smaller and obtuse salient, the posterior with a still smaller and very obtuse salient; tibial spurs rather slender and moderately long and acute, the anterior subequal; tarsi similar in the sexes.

Male.-Elongate and rather narrow. Antennæ reaching to about the posterior fourth of the prothorax. Elytra rather gradually arcuato-obliquely declivous posteriorly. Abdomen moderately convex and broadly impressed and with a stronger longitudinal median impression. Posterior tibiæ more or less arcuate in basal half.

Female.-Elongate and rather robust, antennæ usually not attaining the posterior fourth of the prothorax. Elytra more or less broadly oval and somewhat suddenly arcuato-obliquely declivous 
posteriorly. Abdomen strongly convex, not impressed. Posterior tibiæ scarcely arcuate.

Measurements.-Males: Length, 21.5-28 mm.; width, 7-9.5 mm. Females: Length, 21-28 mm.; width, 7.5-10.5 mm.

Genital characters, male.-Edeagophore of the usual depressed oblong-ovate form, and slender.

Basale not arched, sides nearly parallel; surface evenly convex, scarcely gibbous.

A picale triangular, slightly elongate, feebly decurved; surface evenly convex, feebly depressed, with a linear groove in apical half and not extending upon the apex; sides evenly and very moderately arcuate; apex very narrowly rounded and subacute; base broadly lobed at the middle, scarcely sinuate laterally.

Sternite moderately transverse. Each lobe subparabolic with the external border evenly arcuate and moderately converging to apex; apical margin rather broadly rounded, angle scarcely evident; internal border subarcuate; surface feebly convex and rather densely punctate and setose; setæ long and quite dense at apical margin. Membrane not setose across the bottom of the sinus.

Female.-Genital segment subtrapezoidal, moderate in size, and setose.

Valvula.-Dorsal plate oblong, concave internal border rather strongly reflexed in apical two-thirds and impunctate, longitudinally subcanaliculate external to the same; surface glabrous, finely, evenly, and sparsely punctate and setose in apical two-thirds; setæ reclinate and rather short; external border feebly arcuate; internal margin more or less arcuate, sinuate near base; apical margin evenly arcuate, angle rounded. Apex rather long, subacute at tip, not densely punctate, setæ small and slightly denser at tip; superior margin of the fossa set with rather long setæ, not denser at angle.

Appendage flattened, moderately wide, subconico-semiellipsoidal, and covered with rather long setæ in apical half.

Superior pudendal membrane reaching to the middle of the dorsal plate and longitudinally rugulose.

Basal protuberances moderate.

Ventrolateral surfaces.-Body slightly inflated, not strongly concave laterally, but feebly transversely so before the apices; surface finely and sparsely punctate, setose, setæ short, longer on the inferior margin of the fossa. Submarginal groove small; external margin of the dorsal plate slightly prominent laterally. Internal margins of the valves contiguous in basal third. Genital fissure narrowly fusiform, inferior pudendal membrane visible in the basal half.

Variations.-Apex small; appendage as long as the apex and subconical; apical margin of the dorsal plate less arcuate, with angle 
narrowly rounded. Dorsal plate with a slight antero-posterior convexity.

Habitat.-California (Livingston, Merced County, July, F. E. Blaisdell, Charles Fuchs; Fresno, collection of the California Academy of Sciences, and the collection of E. A. Schwarz; San Joaquin County, D. W. Coquillett).

Number of specimens studied, 22.

Type in my own collection, female.

Type-locality.-Livingston, Merced County, California.

Salient type-characters.-Pronotum moderately convex; disc smooth, very finely and sparsely punctate; apex truncate; apical angles dentiform, small, acute, and strongly divergent; sides moderately arcuate in the anterior two-thirds, thence feebly convergent to base, scarcely sinuate; basal angles almost rectangular and not prominent. Elytra with punctures moderately fine, arranged in rather closely placed, feebly impressed series, intervals with similar, sparsely, and irregularly placed punctures. The anterior femora with an acute tooth, the middle with an obtuse process, the posterior with a very small and obtuse salient.

Diagnostic characters.-Form variable. It differs in a general way from armata by being more slender and usually considerably smaller, and especially in having the teeth of the hind femora rudimentary or obsolete, while those of the mesofemora are distinct or rudimentary, and no doubt obsolete at times, and such individuals (forma subedentata) are scarcely separable from dentipes. The thorax may be as in typical armata or more or less constricted at base as in dentipes. Individuals of armata with normal femoral teeth occasionally have the prothorax constricted nearly as in dentipes and can be spoken of as forma sinuata.

No doubt but that impotens is a transitional form between armata and dentipes, as it occurs chiefly at the periphery of the area of distribution of armata. Dentipes appears to be found mainly beyond the area inhabited by armata. Some examples of impotens have the general form of gigantea.

General observations.-The middle lobe of the mentum is rather large, trapezoidal and slightly broader than usual, apex more or less arcuate, and the surface evenly and feebly convex.

The sterna and abdomen as in armata.

The articular cavities of the protibiæ are more or less open. The other tibiæ and femora are as in armata.

The tarsi may be slender or stout and moderate in length.

The protarsi are scarcely a fourth of their length shorter than a mesotarsus. First four joints subequal, the first apparently as long as wide, the others a little wider than long, and together about equal to the fifth. 
The mesotarsi are about equal in length to a metatarsus. First four joints apparently subequal and just a little longer than wide; joints two to four, inclusive, together a little longer than the fifth.

The metatarsi are a little less than a half as long as their metatibiæ. Joints two and three subequal and distinctly longer than wide, and together shorter than the fourth; first joint the least bit longer than the second.

\section{ELEODES MILITARIS Horn.}

Eleodes militaris Horn, Trans. Amer. Phil. Soc., XIV, 1870, p. 310.

Elongate oval, moderately shining and convex.

Head twice as wide as long, usually moderately convex, and more or less impressed about the eyes, not coarsely and rather sparsely punctate at middle, punctures becoming denser at the periphery. Antenno moderate, outer four joints feebly or not at all dilated, slightly compressed, third joint nearly twice as long as the fourth, the latter subequal to the fifth, sixth, and seventh individually, the latter and eighth about as wide as long, ninth and tenth suborbicular, eleventh truncate ovate.

Pronotum subquadrate, widest at the middle, a fifth to a third wider than long; disc evenly and rather strongly convex, more or less declivous laterally at apex, finely and evenly punctate, punctures but slightly denser at the sides; apex rather deeply emarginate, finely margined; sides evenly and moderately arcuate, scarcely oblique posteriorly or at times converging to base, finely margined; base truncate or feebly arcuate and not very coarsely margined; apical angles acute, not dentiform and moderately advanced, or rarely subdentiform and feebly everted; basal angles obtuse and not prominent.

Propleurce smooth, with a few scattered punctures posteriorly and on the acetabular convexities, more or less rugulose.

Elytra elongate oval, smooth, moderately attenuated behind, widest at the middle; base subtruncate or feebly emarginate, and equal to the contiguous base of the prothorax; humeri subobtuse, not rounded nor prominent; sides evenly arcuate, apex more or less produced and rather narrowly rounded; disc strongly convex, gradually arcuately declivous behind; surface finely punctate, punctures arranged in distant unimpressed series, those of each series rather closely placed, intervals with a single series of distantly placed punctures, punctuation becoming denser and irregular at the sides and apex.

Epipturce rather wide and gradually narrowing from base to apex; surface smooth and obsoletely punctate.

Sterna not densely and more or less coarsely punctate; prosternum anteriorly finely and sparsely punctate and more or less transversely rugulose.

Parapleurce moderately sparsely and not coarsely punctate. 
Abdomen horizontal, rather finely and sparsely punctate, denser on the fifth segment.

Legs moderate, sometimes quite robust; all of the femora armed with an acute triangular tooth in both sexes, and coarsely, densely punctate; all of the tibiæ more or less arcuate in basal half; tibial spurs acute and subequal on their respective tibiæ; tarsi similar in the sexes.

Male.-Antennæ reaching to the posterior fifth of the prothorax, the latter with base one-half wider than the apex and a fourth greater than the length, a third wider than long. Abdomen moderately convex, broadly and not strongly impressed. Femora robust, very coarsely and rather strongly punctate, punctures often deeply impressed. Sometimes the femoral teeth are very strong.

Female-Antennæ scarcely reaching to the posterior fifth of the prothorax, the latter with the base about equal to the length, about a fifth wider than long, and a fourth wider than the apex. Abdomen evenly and strongly convex.

Measurements.-Male: Length, 22.5-28 mm.; width, 7.5-9.5 mm. Female: Length, 22-25 mm.; width, 7.5-8.5 mm.

Genital characters, male.-Edeagophore of the usual flattened oblong-ovate form, and somewhat oblong.

Basale with the sides scarcely parallel, about two and a half times longer than wide, slightly or not arched, very strongly and quite abruptly convex from side to side, with rather a strong antero-posterior convexity, the disc appearing gibbous at middle.

A picale triangular, slightly elongate and decurved apically; surface evenly and moderately convex, and with a linear groove in apical half, that does not extend upon the apex; sides arcuate at base, feebly sinuate towards apex, the latter slightly produced and narrowly rounded at tip; base broadly lobed at middle, scarcely sinuate laterally.

Sternite moderately transverse. Each lobe subtriangular; external border nearly evenly arcuate; internal margin nearly straight, with apex rounded; surface strongly punctate in apical half, setose, setæ not dense, and moderate in length. Sinus rather broad, membrane not setose across the bottom of the same.

Female.-Genital segment trapezo-triangular, moderate in size and rather strongly setose.

Valvula (Plate 1, fig. 20).--Dorsal plate oblong, concave, sides evenly reflexed; surface finely, evenly, and not very densely punctate throughout, setæ short and reclinate; external border quite straight; internal border more or less sinuous; apical margin more or less arcuate, angle obtuse. Dorsal margin of the fossa conspicuously fringed with rather long setæ, those at the angle a little longer and denser. Apex moderate and triangular, tip acute with few short hairs. 
Appendage flattened, semi-ellipsoidal, comparatively large, punctate, and strongly setose at apical moiety, setæ long.

Superior pudendal membrane attaining the middle of the dorsal plate and longitudinally rugulose.

Basal protuberances rather well developed.

Ventrolateral surfaces.-Body not inflated and very feebly concave laterally and before the apex; finely and sparsely punctate, setose throughout, setæ small and reclinate; inferior margin of the fossa with a few rather long setæ. Submarginal groove not well developed, dorsal plate scarcely expanded laterally. Internal margins of the valves contiguous in basal third. Genital fissure narrowly fusiform, closed in basal half by the inferior pudendal membrane.

Habitat.-Lower California (collection of Hubbard and Schwarz; Comondu, San José del Cabo, San Quintin, collection of California Academy of Sciences; Santa Margarita Island, March, collected by Charles D. Haines, collection of Charles Fuchs). Arizona (Charles Fuchs).

Number of specimens studied, 12.

Type in the Horn collection; collected by William M. Gabb.

Type-locality.-Lower California.

Salient type-characters.-Male, thorax subquadrate, sides rounded, feebly converging at base; apex rather deeply emarginate, angles acute, not dentiform, basal angles not prominent. Female, thorax a third broader than long, moderately rounded at the sides, not converging at base, apex as in the male, base notably broader than apex. Elytra strongly attenuated behind, with distant rows of rather fine and distinct punctures (Horn).

Diagnostic characters.-Mititaris is separated from armata by the femoral teeth being less produced, broader and more equilaterally triangular. The anterior angles of the prothorax are less prominent and less strongly dentiform, everted or not: The elytra are more attenuated behind.

The insect appears more obtuse in front on account of the stronger discal convexity of the pronotum. A large series would no doubt show variations in the femoral teeth; the male specimen from Santa Margarita Island has the teeth more produced than those from the mainland. In a single specimen from Calamajuet, Lower California, all of the elytral punctures are rather coarse and very distinct, not impressed and the femoral teeth approach those of armata in form.

There is in this species a greater antero-posterior dorsal convexity than is observed in armata.

In another specimen before me the general form is that of a male acuticauda - the elytra being gradually produced at apex with the dorsal outline continuously arcuate; the punctures are small; length, $28 \mathrm{~mm}$; width, $9 \mathrm{~mm}$. 
The series at hand does not support Doctor Horn's statement in regard to the form of the prothorax in the two sexes. A male from Santa Margarita Island has the base of the prothorax notably wider than the apex and the sides do not converge at base; a series of six females from Lower California (mainland) have the prothorax subquadrate, base slightly wider than the apex, and the sides converge.

The series is not large enough to decide this question; evidently the prothorax is variable; it is to be noted that the specimens are from two separate and distinct regions. The male is often more robust than the female.

In several males before me the femora are very stout, compressed, and quite broad; the femoral teeth are stout and subequilaterally triangular.

The elytral striæ may be quite strongly impressed at times, with the intervals feebly or moderately convex.

This species is probably a southwestern modification of armata. Forms occur in Arizona which can not be separated from this species.

A specimen collected at Palm Springs, California, and recently received for identification, has the integuments more opaque, form more robust and oblong, elytra with the sides feebly arcuate and more rapidly narrowing in apical fourth; elytral punctures fine and equal in both series; antennæ slender and elongate, the femora comparatively slender and the anterior femoral teeth small.

Two specimens under examination have the general form of militaris, although more elongate; the anterior femora are alone armed, the middle and posterior being edentate. One of these specimens was collected at San Quentin, Lower California (collection California Academy of Sciences), and referred to Tuca by Doctor Horn. I do not believe that it should be referred to that species, for the facies is not that of luca, and I have found that the prothorax may vary sufficiently in almost any species to simulate that of another. I have demonstrated to my own mind that armata may become subedentate by loss of the teeth of the middle and posterior femora, and thus pass into dentipes; furthermore, I see no reason why mititaris and femorata should not vary in a similar way.

In both specimens the epipleuræ at the elytral apices are dilated a little more than usual for species of the present section, but I consider this character more of a fortuitous exaggeration of the indifferent stage of the caudal development, or possibly it is atavistic reversion. The relationship of this interesting form can not be determined until better collecting has been done on the peninsula. I therefore for the present define this form as follows:

Forma subedentata.-Form as in mititaris, with the anterior femora alone armed. 
It will be observed that the sides of the front at the junction with the epistoma are frequently slightly emarginate at the suture.

General observations.-The mentum is moderate and the middle lobe is nearly parabolic, being arcuately rounded in the examples that I have seen; the surface is very feebly convex and sometimes very feebly foveate laterally.

The prosternum is horizontal or more or less convex between the coxæ, surface longitudinally grooved or concave posteriorly; mucronate behind, truncate or subtruncate. The ante-coxal portion is quite short at times and with the coxæ prominent ventrally.

Mesosternum as in armata.

The abdominal process is subquadrate, slightly transverse, and about as wide as the post-coxal portion is long; the second segment is about twice as long as the fourth; the third about a third of its length shorter than the second.

The abdominal salient is slightly wider than the metasternal salient.

The metasternum laterally between the coxæ is about as long as the width of a mesotibia at apex.

The tibial grooves of the femora are well developed and strongly defined, broader in the peninsular examples and somewhat contracted in the insular specimens. The anterior margins of all are quite cariniform, most strongly so in the robust examples, and strongly dentately laminate, internally rather gradually passing into the teeth. The floors are opaque, sometimes subasperate on the profemora, generally so on the meso- and metafemora. The anterior grooves have the sides more or less arcuate and quite attaining the femoral base; on the other femora the sides of the grooves are more or less evanescent internally; on the mesofemora the grooves attain the inner fifth and on the metafemora to about the inner fourth. All of the femora are longitudinally impressed inwardly from the tooth along the lower part of the anterior surface.

The protibiæ are more or less arcuate externally and distinctly carinate; the tarsal grooves are more or less developed and scabrously sculptured. In the peninsular specimens the articular cavities are closed and in the insular more or less open.

The mesotibiæ are more or less carinate in basal third externally. The metatibiæ are not carinate, and both have the articular cavities closed. The tarsal grooves of the mesotibiæ are more or less evident and scabrous. The metatibix are flattened or feebly grooved and muricate externally; quite cylindrical in transverse section.

The tarsi are variable, moderately slender to quite stout, quite moderate in length.

The protarsi are about a fifth of their length shorter than a mesotarsus. Joints quite closely articulated, second, third, and fourth 
subequal, wider than long, and together about equal to the fifth; the first but little longer than the second.

The mesotarsi are about a sixth of their length shorter than a metatarsus. Joints two, three, and four are subequal and about as long as wide, together a little longer than the fifth; the first is about as long as wide.

The metatarsi are just a little more than a third as long as a metatibia. Joints two and three subequal, just a little longer than wide, together subequal to the fourth and a little longer than the first.

ELEODES MILITARIS var. FEMORATA LeConte.

Eleodes femorata LeConte, Ann. Lyc. Nat. Hist. N. Y., V, 1851, p. 134; Proc. Acad. Nat. Sci. Phila., 1858, p. 181.-Hons, Trans. Amer. Phil. Soc., XIV, 1870, p. 311.

Elongate oval, more or less shining, smooth and convex.

Head rather small, twice as wide as long, moderately convex, obsoletely impressed laterally and along the frontal suture; rather finely but not densely punctate, punctures slightly denser at the sides. Antennce moderate, feebly compressed in outer five joints, very gradually and very feebly dilated, third joint about equal in length to the next two taken together, fourth just noticeably longer than the fifth, the latter to the seventh, inclusive, subequal in length, the seventh nearly quadrate, eighth as wide as long, ninth and tenth very feebly transversely oval, eleventh subtrapezoidal.

Pronotum widest at middle, slightly wider than long and nearly twice as wide as the head; disc quite strongly and evenly convex, finely and evenly punctulate; apex broadly and feebly emarginate. very finely beaded; sides evenly, broadly and moderately arcuate with a feeble tendency to become sinuate posteriorly, very finely beaded; base very feebly arcuate or truncate and finely beaded, about a fourth wider than the apex and about equal to the length; apical angles small, subacute, not prominent anteriorly, with a slight tendency to eversion; basal angles obtuse, not rounded nor prominent.

Propleure smooth, obsoletely punctulate and more or less rugulose.

Elytra oval, more or less gradually attenuated posteriorly, feebly emarginate or truncate at base and equal in width to the base of the prothorax; humeri obtuse, not rounded nor prominent; sides evenly arcuate, apex subacute; disc quite evenly convex from side to side, gradually and arcuately declivous posteriorly; surface finely and irregularly but not densely punctate, punctures never impressed and scarcely denser at the sides, frequently showing a serial arrangement centrally, with the interstitial punctures distantly and irregular placed; suture on the apical declivity usually more or less impressed. 
Epipleurce moderately wide at the humeri and gradually narrowing to apex; surface subopaque and obsoletely punctulate.

Sterna more or less sparsely punctate and irregularly rugose.

Parapleurce more or less sparsely punctate.

Abdomen horizontal, finely, quite evenly, and rather sparsely punctate, more or less rugulose.

Legs rather long and quite densely sculptured. All of the femora armed in both sexes with small and more or less acute teeth, the acuity diminishing from before backward, so that the teeth of the metafemora are very small and obtuse; tibiæ more or less arcuate in basal third; anterior tibial spurs about equal in size and length. Tarsi similar in the sexes.

Male.-Moderately narrow. Antennæ attaining the posterior fifth of the prothorax. Elytra strongly attenuate behind, very evenly and very gradually arcuately declivous posteriorly. Abdomen rather strongly convex and feebly or obsoletely impressed at middle of first two segments. Posterior tibiæ rather strongly arcuate in basal third.

Female.-Rather robust. Antenna attaining the posterior fourth of the prothorax. Elytra not strongly attenuated behind, moderately and gradually arcuately declivous posteriorly. Abdomen evenly convex from side to side. Posterior tibiæ not more strongly arcuate than the mesotibiæ.

Measurements.-Males: Length, 22-23 mm.; width, 8-8.5 mm. Females: Length, $25 \mathrm{~mm}$; width, $9.6 \mathrm{~mm}$.

Genital characters, mate.-Edeagophore flattened oblong-ovate, very feebly arched in apical half, moderate in size and elongate.

Basale oblong, evenly convex from side to side, sides evenly and feebly arcuate.

Apicale rather elongately triangular; surface strongly convex, without or with a very faint median membranous groove; sides feebly sinuate in apical two-thirds or straight; apex more or less produced and rather slender, quite acute; base with a median subacute lobe, quite broadly and distinctly sinuate laterally.

Sternite transverse. Each lobe subquadrate, with the external border quite straight, meeting the apical margin at somewhat of an angle; apical margin feebly and evenly arcuate and nearly transverse, angle introrse and subacute; internal border more or less sinuous; surface scarcely convex, subglabrous, finely and evenly but not densely punctate, setose, setæ quite long and subequal and not dense. Membrane not setose across the bottom of the sinus, the latter short and oblong.

Female.-Genital segment subtrapezoidal in outline, quite strongly chitinized, setose and rather shining.

$59780-$ Bull, $63-09-18$ 
Valvula (Plate 4, fig. 18).--Dorsal plate suboblong, and widened somewhat in basal half; surface deeply concave, very sparsely and finely punctate, setulose; margins more or less reflexed; external border subangulate at junction of the middle and basal thirds, thence straight or feebly sinuate to apical margin, the latter more or less feebly arcuate with the angle evenly and rather broadly rounded; internal margin more or less feebly arcuate. A pex narrow and more or less chitinous, rather acute and finely setose at tip, setæ quite short and not noticeable over the general surface.

Appendage strongly flattened, quite large and semioval, about as long as the apex, quite densely punctate in apical half and rather densely set with long hairs. Fossa narrow, margin fringed with sparsely placed and moderately long setæ that become rather dense at the angle. Submarginal groove very fine and more or less visible from above.

Superior pudendal membrane reaching slightly beyond the middle of the dorsal plate, and with three or four longitudinal rugulæ. Valvular membranes visible beyond the pudendal membrane.

Ventrolateral surfaces.-Body evenly convex in basal half and more or less transversely and rather broadly impressed before the apices; surface smooth and shining, rather evenly punctate and setose, setæ short and reclinate. Internal margins of the valves contiguous in basal half. Genital fissure very narrowly fusiform and nearly closed.

Habitat.-Three specimens before me were collected by myself at San Diego on the Coronado peninsula. They were in company with omissa, beneath some roots of Yucca baceata.

Number of specimens studied, 3. More recently 9 others.

Type in the LeConte collection.

Type-locality.-San Diego, California.

Salient type-characters.-Thorax finely and not densely punctate, sides rounded, somewhat narrowed posteriorly, basal angles obtuse. Elytra with apex attenuated, punctures more or less distinctly serially arranged, intervals sparsely punctulate. Femora always somewhat briefly dentate (LeConte).

Diagnostic characters.-This race is to be separated from militaris by the femoral teeth being more obtuse. The thorax is less broad, especially in the females (?), and the elytra are slightly more attenuated at apex; the antero-posterior convexity of the dorsal surface of the insect is slightly more evident.

In my opinion femorata is undoubtedly a more northern modification of militaris, and in a large series this view would, no doubt, be verified.

It is interesting to note that LeConte's descriptions of armata and femorata are the same, word for word, except: "elytris parum 
attenuatis, femoribus * * * longe acuteque dentatis" (armata), and "elytris *** apice attenuatis, *** femoribus ** * breviter dentatis" (femorata).

Femorata is quite distinct from armata, the chief differences being the form of the elytra and the femoral teeth-both very variable characters.

General observations.-The mentum is subparabolic. In one specimen it is subtrapezoidal; surface scarcely convex and not foveate laterally.

The prosternum in the specimens at hand is arcuately rounded antero-posteriorly, with a small and abruptly developed mucro behind, which may be horizontal or deflexed. Mesosternum as ir armata.

The abdominal process is subquadrate, feebly transverse; the postcoxal portion of the first segment is equal to the second in length; the third is as long as the width of the metasternal salient; the fourth is about one-half as long as the second.

The intercoxal process of the abdomen is about a fourth wider than the metasternal salient.

The metasternum laterally between the coxæ is as long as the width of a mesotibia at apex.

The tibial grooves of the femora are well developed and distinctly defined; their floors are opaque and quite plane. Those of the profemora are subentire, those of the meso- and metafemora nearly attain the femoral base, and the carinate margins are somewhat evanescent internally. The anterior margin of each groove is more or less dentately laminate externally.

The protibiæ are somewhat compressed and distinctly carinate externally; their tarsal grooves are more or less developed, opaque, and asperately sculptured. The articular cavities are more or less open.

The mesotibiæ are carinate externally in basal third; the grooves are more or less indicated, opaque, and muricate. The articular cavities closed.

The metatibiæ are more or less finely subcarinate externally, and the grooves are scarcely evident, muricately sculptured; articular cavities closed. Both the meso- and metatibiæ are slightly compressed.

Tarsi moderate in length and rather stout. The protarsi are about a sixth of their length shorter than a mesotarsus. Joints one to four, inclusive, subequal and a little wider than long; joints two to four combined equal in length to the fifth.

The mesotarsi are about a seventh of their length shorter than a metatarsus. Joints two to four inclusive subequal and very little 
longer than wide; together scarcely longer than the fifth; the first joint is about one and a half times longer than wide.

The metatarsi are a little less than half as long as a metatibia. Joint two is evidently just the least longer than the third, both are longer than wide, and together distinctly shorter than the fourth, also a little longer than the first.

\section{ELEODES ACUTICAUDA LeConte.}

Eleodes acuticauda LeConte, Ann. Lyc. Nat. Hist. N. Y., V, 1851, p. 135 ; Proc. Acad. Nat. Sei. Phila., 1858, p. 181.-Hons, Trans. Amer. Phil. Soc., XIV, 1870 , p. 314.

Var. laticollis LeConte, Ann. Lyc. Nat. Hist. N. Y., V, 1851, p. 135.

Elongate, more or less shining, strongly convex, elytra more or less strongly produced and not suddenly caudate.

Head slightly more than twice as wide as long, quite evenly convex, moderately finely and evenly punctate. Antenno rather stout, moderately short, outer four joints slightly compressed, more or less feebly and gradually dilated, third joint equal in length to the next two combined, fifth, sixth, and seventh subequal in length and each slightly shorter than the fourth, eighth trapezoidal in outline, ninth and tenth wider than long, eleventh subtrapezoidal.

Pronotum widest at about the middle, about four-sevenths wider than long and more than twice as wide as the head; disc more or less bright and shining, moderately convex, noticeably declivous at base and apex, rather narrowly and more or less impressed and opaque laterally, finely, irregularly and somewhat densely punctate, sometimes granulate laterally; apex moderately emarginate, obsoletely or distinctly margined; sides very strongly arcuate in anterior twothirds, thence to base less so or somewhat straight and converging, and strongly sinuate in front of the basal angles, more or less finely margined; base moderately arcuate and rather coarsely margined, a little narower than the apex; apical angles small, acuminately produced and dentiform, very acute and more or less everted; basal angles obtuse, sometimes quite prominent.

Propleurce smooth, obsoletely punctulate and rugulose.

Etytra elongate oval, smooth and more or less shining, widest at the middle; base feebly emarginate and not wider than the contiguous prothoracic base; humeri obtuse and not at all prominent; sides evenly arcuate, frequently broadly and feebly sinuate at sides of apex, the latter gradually produced; disc quite evenly and strongly convex from side to side, more or less gradually and arcuately declivous posteriorly, or sometimes more or less broadly sinuate before the apex; surface smooth, punctate, the punctures closely placed in longitudinal series, the latter moderately closely placed, intervals 
irregularly and more or less sparsely punctulate, punctures usually not noticeably denser laterally. Elytral suture on apex more or less deeply impressed. Apex or cauda concave beneath, the surface of which is formed by the internal elytral surface.

Epipleurce slightly widened at base, thence gradually narrowing to apex, where it narrowly margins the inferior surface of the produced apex or cauda; surface smooth and usually impunctate.

Sterna more or less punctate and rugose.

Parapleura more or less punctate.

Abdomen horizontal, obsoletely or rather strongly punctate, rugulose.

Legs more or less moderate, anterior femora armed in the sexes; anterior tibial spurs equal and acute. Tarsi similar in the sexes.

Male.-Elongate. Antennæ attaining the posterior fourth of the prothorax. Elytra usually more than twice as long as wide and more or less strongly and gradually produced at apex. Abdomen rather strongly convex, scarcely at all flattened or impressed. Legs somewhat stout, especially the anterior femora, which are armed with a very acute tooth; posterior tibiæ more or less arcuate.

Female.-Robust. Antennæ attaining the posterior third of the prothorax. Elytra suboval, and usually less than twice as long. as wide, rather moderately obliquely declivous posteriorly; apex more or less produced. Abdomen strongly convex. Legs moderate; anterior femora with a more or less acute tooth; posterior tibiæ straight.

Genital characters, male.-Edeagophore of the usual oblong-ovate form and rather elongate.

Basale slightly or not arched, quite evenly convex.

Apicale triangular, slightly elongate, not decurved at tip; surface rather evenly convex more strongly so apically where the sides appear compressed, groove at middle two-fourths, fine toward apex and slightly dilated toward base; sides feebly sinuate in apical twothirds; apex rather acute and gradually narrowed; base broadly lobed at middle, lobe rounded, laterally sinuate.

Sternite transverse, sometimes quite oblong, lobes longer than wide. Each lobe with the external border evenly and broadly arcuate apically, quite straight toward base; internal margin nearly straight; apex narrowly rounded; surface punctate and setose. Membrane not setose across the bottom of the sinus, the latter rather broad.

Female.-Genital segment trapezoidal, moderate in size, glabrous and setose.

Valvula (Plate 3, fig. 7).-Dorsal plate oblong, slightly concave, sparsely punctate and setose in apical two-thirds, setr moderately short, semirecumbent; external border straight or feebly and broadly sinuate; internal margin quite strongly reflexed in apical half, more 
or less sinuate toward base; apical margin squarely truncate and transverse; angle rectangular or narrowly rounded, with a few rather long setæ that are also sparsely distributed along the apical margin. Apex small, subacute, with a tuft of a few rather short setæ. Fossa rather large.

A ppendage quite large, flattened and triangular or semi-elliptical, broad as long, setose toward tip, with a tuft of quite long setæ.

Superior pudendal membrane attaining the middle of the dorsal plate and quite distantly longitudinally rugulose.

Ventrolateral surfaces (Plate 3, fig. 8).-Body slightly inflated at base, rather strongly and transversely concave before the apex, rather strongly and sparsely punctate; setæ along the ventral margin of the fossa rather long and flying. Apex quite densely setose beneath. Submarginal groove well developed beneath the projecting external border of the dorsal plate. Internal margins of the valves contiguous in basal third, genital fissure rather broadly fusiform and closed in basal half by the inferior pudendal membrane.

Two forms may be recognized as follows:

Forma typica.-Glabrous. Elytra with striæ of small unimpressed punctules or punctures which are frequently not very evident, intervals somewhat or very irregularly punctulate. Males dimorphic. The typical males are very strongly but not suddenly caudate; the atypical males with the females have the elytral apices moderately or scarcely produced, and not caudate.

Measurements.-Males: Length, 16.5-30 mm.; width, 5-10.5 mm. Females: Length, 24.5-28.5 mm.; width, 8-9.5 mm.

Forma punctata.-Glabrous. Antennæ stout, attaining the posterior third of the prothorax. Elytra with serial punctures moderately large, often eroded and feebly impressed, the series rather closely placed and often irregularly duplicated, intervals irregularly and finely punctulate, rather more densely so laterally, males apparently homomorphic and with the females have the elytral apex moderately produced and not strongly caudate. Legs rather stout.

Measurements.-Males: Length, 22-28 mm.; width, 8-8.5 mm. Females: Length, 22.5-26.5 mm.; width, 8.5-10.5 mm.

Mlabitat.-Forma typica.-California (San Diego County; San Diego, elevation 50-300 feet. F. E. Blaisdell, E. C. Van Dyke, Charles Fuchs, and collection U. S. National Museum; Poway, elevation 700 feet, F. E. Blaisdell; Los Angeles County, E. C. Van Dyke; Santa Barbara ; Fort Tejon, April 19-21, Fuchs and Hopping; Tulare County; San Bernardino County); Lower California (San Pedro Martir, collection California Academy of Sciences).

Forma punctata.-California (Los Angeles County, E. C. Van Dyke).

Number of specimens studied, 120. 
Type in the LeConte collection.

Type-locality.-San Diego, California.

Salient type-characters.-Thorax finely punctate, broad and greatly rounded at the sides, which are subdepressed, narrowed behind; basal angles obtuse, somewhat more prominent than usual. Elytra strongly convex, finely and seriately punctate, posteriorly declivous, strongly attenuated, and produced (LeConte).

Diagnostic characters.-The prothorax is usually at least one-half wider than long, sides very strongly rounded and strongly constricted at base; anterior angles acute, prominent and dentiform, but generally smaller than in laticollis, and frequently everted. The elytra in the typical form are elongate and strongly produced in the males, not suddenly caudate, and directed obliquely downward.

In examples from Fort Tejon the males have the elytra distinctly caudate, the cauda horizontal and formed nearly as in lucke. In the other forms the elytra are less elongate and moderately produced. The elytra are never sulcate, but simply with striæ of small punctures that are at times rather coarse and rarely impressed.

The elytral surface is never muricate, and is in this character separated from laticollis, the latter having the pronotum more strongly punctate, duller, and rather broadly impressed and granulate laterally; in acuticauda the pronotum is narrowly or not at all impressed nor granulate laterally.

From dentipes it must be separated by the form of the pronotum. In acuticauda the sides of the pronotum are more strongly and less broadly arcuate and the constriction is more rapidly formed and larger; in dentipes the sides of the pronotum are less strongly and more broadly arcuate, the sinuation is shorter and more gradually formed. In some examples of acuticauda the pronotum is not wider than in dentipes, and these are the difficult specimens to place, but the form of the arcuation still remains the same, and a quick eye can readily catch the difference.

In forma typica the males may have the hind tibiæ arcuate in basal half and more or less gradually thickened apically.

General observations.- The middle lobe of the mentum is moderate and rather wide, subparabolic, sometimes subtrapezoidal in outline, the apex is seldom truncate; surface slightly convex centrally and more or less feebly foveate laterally within the margin.

The prosternum is variable, usually convex or horizontal between the coxæ and with a moderate mucro behind; rarely rounded or subtruncate behind. The mucro may be horizontal or deflexed.

Mesosternum is more or less oblique and concave.

The abdominal process is quite quadrate and in width equal to the length of the third segment; the post-coxal part of the first segment 
is twice as long as the fourth; the second is a little longer than the post-coxal part of the first.

The abdominal salient-is about a fourth of its width broader than that of the metasternal process.

The metasternum laterally between the coxæ in length is about equal to a mesotibia at middle.

The tibial grooves of the femora are well developed and scarcely entire, the margins are cariniform and become evanescent, usually at the internal fourth; their floors are smooth and quite flat.

The anterior margin of the profemoral grooves become quite suddenly dentately laminate at about the external fourth.

The protibiæ are more or less distinctly carinate externally and feebly compressed, their tarsal grooves are more or less evident and scabrous and the articular cavities are closed.

The mesotibiæ have the grooves more or less developed and muricate and the articular cavities are closed; externally obsoletely carinate in basal fourth. The metatibiæ are more or less flattened externally and roughly sculptured, not at all carinate and the articular cavities closed.

The tarsi are moderate in length and quite stout.

The protarsi are about a third of their length shorter than a mesotarsus. Joints two, three, and four are quite closely articulated, subequal, wider than long and together about equal to the fifth; the first is about as long as wide.

The mesotarsi are very little shorter-about an eighth of their length - than a metatarsus. Joints two, three, and four are subequal, as long as wide, and together quite equal to the fifth; the first is slightly shorter than the next two taken together.

The metatarsi are a little less than half as long as a metatibia. Joints two and three are subequal and distinctly longer than wide, together just the least shorter than the fourth, and a little longer than the first.

\section{ELEODES ACUTICAUDA var. LATICOLLIS LeConte.}

Elongate oval, more or less shining and smooth, strongly convex and not caudate, interstitial punctures of the elytra more or less muricate.

Head rather large, twice as wide as long, rather moderately convex, very feebly and broadly impressed laterally, finely, irregularly and rather sparsely punctate, quite densely so laterally, punctures finely muricate, frontal suture obsolete. Antenna moderately stout, reaching to the base of the prothorax, outer four joints feebly compressed and very slightly dilated, third joint very slightly longer than the next two combined, fourth slightly longer than the fifth, the 
latter, sixth, and seventh subequal, eighth triangular to trianguloconical, ninth and tenth suborbicular in outline, eleventh subtrapezoidal.

Pronotum widest at about the middle, almost a half wider than long; disc moderately convex, more strongly so at the angles, rather finely, distinctly, irregularly and not densely punctate, rather broadly impressed and granulo-punctate laterally; apex broadly and quite evenly emarginate, distinctly margined laterally, and obsoletely so at the middle; sides greatly rounded in anterior threefourths, thence strongly sinuate and converging to base, rather coarsely margined; base feebly arcuate, equal to the apex and coarsely margined; apical angles strong, acuminately produced and dentiform, more or less everted, and somewhat reflexed at times; basal angles subrectangular and more or less prominent.

Propleure rather smooth, irregularly and sparsely granulo-muricate, obsoletely rugulose.

Elytra oval to elongate oval, widest at the middle; base subtruncate, more or less slightly wider than the contiguous prothoracic base; humeri obtuse, not rounded nor prominent; sides evenly arcuate, apex gradually narrowed, rarely attenuated and not produced; disc moderately convex on the dorsum and more strongly so laterally, arcuately declivons posteriorly; surface punctate, punctures arranged in rather distant series, moderately small and rather closely placed, intervals with a series of similar punctures, slightly more distantly spaced, on the dorsum very faintly muricate, laterally distinctly so and frequently more distantly spaced, both series becoming more irregular and finely muricate on the apex, punctures minutely setigerous.

Epipleurce moderate at the humeri and gradually narrowing to apex; surface sparsely and finely submuricately and obsoletely punctate.

Sterna more or less densely, submuricately punctate, and rugose.

Parapleurce rather coarsely and irregularly punctate, punctures rather shallow.

Abdomen horizontal, rather densely, somewhat finely, submuricately punctate and rugulose.

Legs rather long and somewhat stout; anterior femora armed in both sexes; anterior tibial spurs subequal and acute. Tarsi similar in the sexes.

Male.-Somewhat narrow. Elytra arcuately and rather obliquely declivous behind. Abdomen moderately convex and slightly flattened at middle on the first three segments. Anterior femora armed with an acute tooth. Metatibiæ more or less arcuate. 
Female.-Somewhat robust. Elytra arcuately declivous posteriorly. Abdomen evenly convex. Anterior femora with an obtuse or subacute tooth. Metatibiæ straight.

Genital characters, male.-Edeagophore oblong-oval, depressed and not arched.

Basale oblong; surface moderately convex and the sides quite parallel.

Apicale subequilaterally triangular; surface evenly convex, coarsely and sparsely punctate, median groove linear and fine in middle three-fifths; sides feebly arcuate from base to apex, the latter subacute and not produced; base broadly and arcuately lobed at middle, feebly sinuate laterally.

Sternite transversely subcrescentiform. Each lobe wider than long; external border broadly and evenly arcuate from base to apical angle, which is introrse at the internal margin, the latter short; angle rounded; surface moderately convex, quite densely punctate in apical three-fourths; setose, setæ quite long and quite dense. Membrane not setose across the bottom of the sinus, the latter short.

Female.-Genital segment rather small, setose, and triangularly trapezoidal in outline, moderately short.

Valvula (Plate 3, fig. 12).-Dorsal plate oblong with sides slightly reflexed and moderately concave; surface glabrous, very sparsely punctate and setose, setæ moderate in length and somewhat erect; external border straight or feebly sinuate; internal margin feebly arcuate; apical margin subtruncate, angle narrowly rounded, both fringed with rather long hairs, which are somewhat dense at the angle; apex small and short, triangular, finely setose, with a tuft of slightly longer hairs at tip.

Appendage rather small and conical, equal in length to the apex, finely setose, with a tuft of longer hairs at tip.

Basal prominence small and not very evident.

Superior pudendal membrane attaining the middle of the dorsal plate; finely but not strongly longitudinally rugulose.

Ventrolateral surfaces.-Body scarcely swollen in basal half, broadly concave laterally before the apices; setose, setæ rather long, especially upon the inferior margin of the fossa and at angle; surface glabrous. Internal margins of the valves contiguous in basal fourth. Genital fissure fusiform, widest in apical half, closed by the inferior pudendal membrane in basal moiety.

It is proper to recognize two forms, as follows:

Forma typica.-Elongate, usually large and more or less shining. Interstitial punctures finely muricate and moderately distant, the punctures laterally and on the apex more decidedly prickly, each with a very small stiff seta. Elytral apex gradually narrowed and slightly 
produced in the male; scarcely produced and obtuse in the female. Legs long and rather stout.

Measurements.-Males: Length, 24.5-34 mm.; width, 9-10 mm. Females: Length, 26-32 mm.; width, 10.5-10.5 $\mathrm{mm}$.

Forma minor.-Somewhat robust and more or less shining. Interstitial punctures quite distant and very distinctly prickly laterally and on the apex. Sexes quite homomorphic. Elytral apex scarcely produced and more or less abtuse. Legs moderate.

Measurements.-Males: Length, 22.5-27 mm.; width. 8-9.5 mm. Females: Length, 21.5-26.5 mm.; width, 9.2-8.5 mm.

Mabitat.-Forma typica.-California (San Diego County, Los Angeles County; collections Charles Fuchs, E. C. Van Dyke, F. E. Blaisdell, and U. S. National Museum; Fort Tejon, April 19-21, Fuchs and Hopping) ; St. Nicholas Island (collection U. S. National Museum).

Forma minor.-California (Poway, elevation 700 feet, F. E. Blaisdell; Fort Tejon, Fuchs and Hopping; collection U. S. National Museum).

Number of specimens studied, 125.

Type in the LeConte collection.

Type-locality.-San Diego, California.

Salient type-characters.-Thorax broad, sides greatly rounded and subdepressed; narrowed behind; basal angles rectangular, somewhat unusually prominent; anterior angles acuminate. Elytra finely and seriately punctate; apex declivously attenuated (LeConte).

Diagnostic characters.-This race is separated from acuticauda by the form of the pronotum, elytral apices, and sculpturing.

Acuticauda has the pronotum very narrowly granulate and very feebly impressed laterally along the margin; the disc is nearly evenly convex from side to side; in laticollis the sides are quite broadly impressed and granulate; consequently the surface is less evenly and less strongly convex.

In acuticauda the punctuation is simple, while laticollis is remarkable for having the interstitial punctures very finely muricate; on the elytra laterally the interstitial punctures are distinctly prickly, on the apex irregular and likewise muricate.

In laticollis the elytra are never caudately produced, although at times somewhat gradually narrowed, but never as strongly as in acuticauda.

Dentipes forma elongata may have the pronotum somewhat impressed laterally and more or less granulate, but here the form of the prothorax must be the diagnostic criterion. (See acuticauda and synopsis.) 
A series of laticollis from St. Nicholas Island is almost distinctive of another race (forma insularis) or insular form. The pronotum is notably bright and shining, and the general form is rather more elongately robust.

General observations.-The middle lobe of the mentum is moderate and subparabolic or subtrapezoidal in outline; the surface is very feebly convex and coarsely punctate, rarely feebly foveate laterally.

The prosternum is but moderately prominent ventrally with the coxæ, evenly arcuate antero-posteriorly and mucronate behind, or subhorizontal with the tip mucronate; frequently deeply and longitudinally grooved between the coxæ.

The mesosternum is more or less arcuately declivous and more or less broadly concave.

The abdominal intercoxal salient is quite quadrate and in width is a little shorter than the third segment; the post-coxal part of the first is a little longer than the third; the second twice as long as the fourth, and the third is a third of its length shorter than the second.

The abdominal process is about a fourth of its width wider than the metasternal salient.

The metasternum laterally between the coxæ is quite short and in length is about equal to the width of a mesotibia at middle.

The tibial grooves of the femora are well developed, and the margins are quite cariniform; the floors are quite flat, opaque, and frequently slightly granular, especially on the meso- and metafemora.

The profemoral grooves are subentire, the margins slightly evanescent before the base, and the anterior margins are dentately laminate near the outer third. The mesofemoral grooves are evanescent at basal fourth, those of the metafemora at basal third.

The external surface of the protibiæ is more or less distinctly carinate and the tarsal grooves are more or less evident, sometimes feebly glabrous toward apex, but generally scabrous; the articular cavities are not strongly closed.

The meso- and metatibiæ have the articular cavities strongly closed and margined; the tibiæ are not carinate. Externally both have the grooves evident in apical two-thirds, with rest of the surface very densely, strongly, and muricately sculptured.

The tarsi are quite stout. The protarsi are about two-sevenths of their length shorter than a mesotarsus. Joints two, three, and four are subequal and slightly wider than long, together about equal to the fifth; first joint about as long as wide.

The mesotarsi are about a ninth of their length shorter than a metatarsus. Joints two, three, and four are subequal and about as long as wide, together longer than the fifth; the first is about one and a half times longer than wide. 
The metatarsi are not quite equal to half of the length of a metatibia. Joints two and three are subequal, together shorter than the fourth and longer than the first.

\section{ELEODES ESCHSCHOLTZII Solier.}

Eleodes eschscholtzii Solif:, Studi Entomol., II, 1848, p. 254.-Сhampion, Biol. Centr.-Amer., IV, Pt. 1, 1884, p. 77, pl. ㅍ, fig. 24, male.

Var. luce LeConte, Smithsonian Miscell. Coll., 167, Pt. 1, 1866, p. 114.Horn, Trans. Amer. Phil. Soc., XIV, 1870, p. 312.

Elongate, fusiform oval, smooth and more or less shining, strongly and more or less caudate.

Head about twice as wide as long, more or less convex, feebly impressed within the sides of the frons, rather finely, more or less irregularly, and not very densely punctate. Antenno long and moderately slender, outer four joints feebly compressed, gradually and feebly dilated, third joint scarcely as long as the next two combined, fourth to the seventh inclusive subequal, eighth subtriangular, ninth and tenth more or less orbicular to feebly oval, eleventh ovate and obliquely truncate at tip.

Pronotum quadrate, widest at the middle, an eighth to a fourth wider than long; disc moderately and evenly convex, declivous at the apical angles, finely to obsoletely, evenly and rather sparsely punctulate; apex truncate to more or less evenly emarginate, finely margined, obsoletely so at the middle; sides evenly and feebly to moderately arcuate, finely margined; base feebly arcuate and finely beaded, and about a fourth wider than the apex; apical angles subrectangular to obtuse and not rounded, or acute and more or less advanced; basal angles obtuse and not rounded.

Propleurce obsoletely punctulate and more or less rugulose.

Elytra oval, widest at the middle; base truncate to feebly emarginate, very slightly wider than the contiguous prothoracic base; humeri obtuse, not rounded nor prominent; sides evenly arcuate, apex more or less produced; disc evenly and strongly convex from side to side, obliquely to arcuately and more or less gradually declivous posteriorly; surface striato-punctate, punctures moderate in size, closely and regularly placed, in moderately distant and more or less impressed series, the intervals with a series of irregularly and more or less distantly spaced, very fine punctures; punctures not becoming confused at the sides or apex, the intervals scarcely convex, but becoming slightly so on the apex, where the suture is more or less impressed.

Epipteurce rather narrow and gradually narrowing from base to apex, where they extend narrowly along the sides of the inferior sur- 
face of the cauda or produced apex; surface finely and obsoletely punctulate.

Sterna more or less finely, densely, obsoletely punctate and rugulose.

Parapleura more or less finely and rather densely punctate.

Abdomen horizontal, finely, obsoletely punctulate and rugulose, punctures denser on the fifth segment.

Legs quite slender and moderately long, usually not strongly sculptured; anterior femora armed in both sexes; anterior tibial spurs subequal and acute; tarsi similar in the sexes.

Male.-Elongate and somewhat slender. Antennæ attaining a slight distance beyond the prothoracic base, the latter a little greater than the width of the prothorax. Elytra very obliquely declivous, then subhorizontally produced at apex into a long cauda, the latter frequently with the sides more or less converging to tip, which is slightly deflexed. Abdomen quite strongly convex, feebly, longitudinally, and narrowly impressed at middle on first three segments. The anterior femora armed with a moderate and acute tooth; posterior tibiæ quite strongly arcuate to slightly beyond the middle, then rather suddenly dilated and straight to apex.

Female.-Quite robust. Antennæ not quite attaining the prothoracic base, the latter equal to the length. Elytra moderately broadly oval, arcuately declivous posteriorly, apex slightly produced and subacute. Abdomen strongly convex. Anterior femora with a more or less obtuse tooth, and the metatibia straight without being widened apically.

Measurements.-Males: Length, 27-29 mm.; width, 9-9 mm. Females: Length, 24-25.5 mm.; width, 9-9.5 $\mathrm{mm}$.

Genital characters, male.-Edeagophore elongately subfusiform and feebly arched.

Basale more or less oblong, evenly convex above, and the sides evenly and moderately arcuate.

A picale elongately triangular and very feebly decurved; surface moderately and evenly convex above, with a narrow median longitudinal groove; sides feebly arcuate or straight; apex not produced and narrowly rounded; base acutely lobed at middle, broadly and feebly sinuate laterally.

Sternite subparabolic in outline. Each lobe triangular; external border more or less evenly arcuate; apex rather broadly rounded; internal margin more or less sinuate; surface glabrous, rather evenly, moderately densely punctate and setose in apical three-fourths, setæ moderate in length, becoming long on the apex. Membrane not setose across the bottom of the sinus, the latter rather triangular.

Female.-Genital segment robust, subquadrate and strongly chitinized. 
Valvula.--Dorsal plate more or less oblong, glabrous and shining, sides very strongly reflexed; surface deeply concave, very finely, sparsely punctate and finely setose; external border rather strongly arcuate; internal margin more or less sinuous; apical margin prominent, evenly and moderately arcuate, angle rounded. Apex short and triangular; valvular membranes strongly exposed between the apices caudad to the pudendal membrane.

Appendage subsemielliptical, rather equal in length and size to the apex. Appendage, apex, and margin of the fossa finely punctate and setose, setæ short and inconspicuous.

Superior pudendal membrane attaining the middle of the dorsal plate and longitudinally rugulose.

Ventrolateral surfaces.-Body moderately inflated and glabrous, transversely and broadly concave before the apices, the latter finely punctate and setose. Submarginal groove more or less obsolete. Internal margins of the valves contiguous in basal third; genital fissure narrowly fusiform and closed in basal half by the visible inferior pudendal membrane.

Habitat.-Mexico (Sinaloa, coll. Chas. Fuchs; Alamos, BuchauHepburn; Presidio, Forrer). United States (Texas).

Number of species studied, 5 (8?).

Type is probably with the Solier collection.

Type-locality.-Mexico (Alamos?).

Salient type-characters.-Thorax quadrate; disc very finely punctulate; apex feebly emarginate; apical angles subacute and slightly prominent anteriorly; sides evenly but not strongly arcuate; basal angles obtuse. Elytra striato-punctate, punctures moderate and closely placed in the series, intervals scarcely convex and with a series of rather distantly spaced punctules; cauda horizontal.

Diagnostic characters.-The figure given in the Biologia I take to represent what is probably a typical form of this species. I can not see that it differs very much from some of the less strongly developed forms of lucœ. The prothorax is quadrate, with the sides feebly and evenly rounded from base to apex; apical margin feebly emarginate, angles small, acute, and just feebly prominent anteriorly.

In the specimens before me the sides of the prothorax are rather less rounded, apical margin very feebly emarginate or truncate and the apical angles scarcely at all prominent. The general form of the body is rather more slender, with outline more evenly fusiform. The cauda narrows somewhat to tip.

I do not believe that a large series could be separated from a similarly large series of luce.

In a series of five examples (4 males and 1 female) mentioned in the Biologia, the largest male measures $35 \mathrm{~mm}$., including the 
caudal prolongation of $6 \mathrm{~mm}$.; similar large males are common in the series of luce taken in Lower California. The hind tibiæ are curved in basal half, straight and thickened toward apex as in luca.

General observations.-The middle lobe of the mentum in the examples at hand is triangulo-trapezoidal, more or less arcuately rounded at apex; surface is coarsely punctate, just noticeably convex and scarcely at all foveate laterally.

The prosternum in the series under examination is rounded anteroposteriorly, feebly mucronate or not. In the larger examples it would no doubt be strongly mucronate as in luca. In a large male without locality and in the U. S. National Museum collection, the prosternum is horizontally and triangularly mucronate, exactly as in the large specimens of luca; the specimen measures $33 \mathrm{~mm}$. Two accompanying females have similar prosterna. These specimens are without doubt from Mexico.

The mesosternum is the same as in luca, except that it is less vertically oblique.

The abdominal process is subquadrate and feebly transverse, in width equal to the length of the third segment; the post-coxal portion of the first segment is equal in length to that of the second; the third is scarcely twice the length of the fourth and about a third of its length shorter than the second.

The abdominal process is about a fourth of its width greater than that of the metasternal salient.

The metasternum laterally between the coxæ is about equal in length to the width of a mesotibia at apex.

The tibial grooves of the femora are well defined, margins cariniform, floors plane, opaque and smooth. Those of the profemora nearly attain the femoral base and the margins become contiguous. The margins of the grooves on the mesofemora become evanescent at the internal fourth before becoming contiguous. On the metafemora the margins are evanescent at internal third. The meso- and metafemora have the grooves somewhat narrow. On the profemora the anterior margin of each groove is dentately laminate at external fourth.

The protibiæ are more or less carinate externally and not compressed; the articular cavities are more or less open, and the tarsal grooves are more or less developed and scabrous.

The meso- and metatibiæ are not carinate externally and the articular cavities are closed. The tarsal grooves of the mesotibiæ are quite well defined in apical two-thirds; the sides of the grooves are muricate and the floors smooth and opaque. The metatibiæ are simply flattened externally or feebly grooved and muricate.

The tarsi are moderate in length and stoutness. 
The protarsi are about a third of their length shorter than a mesotarsus. Joints two, three, and four subequal, apparently very slightly wider than long, and together about equal to the fifth; the first about as long as wide.

The mesotarsi are very slightly shorter than a metatarsus. Joints two, three, and four subequal, scarcely longer than wide, and together just a little longer than the fifth; the first about one and a half times longer than wide.

The metatarsi are a little shorter than half of the length of a metatibia. Joints two and three subequal, distinctly longer than wide and together scarcely as long as the fifth, a little longer than the first.

\section{ELEODES ESCHSCHOLZII var. LUCÆ LeConte.}

Elongate, more or less shining, convex and more or less caudate.

Head twice as wide as long, moderately and evenly convex, rather finely, quite evenly and not densely punctate. Antenne long and slender, subequal in length in the sexes, outer four joints feebly compressed and slightly dilated, third joint subequal in length to the next two combined, fourth very slightly longer than the fifth, the latter to the seventh inclusive subequal, eighth a little shorter and obconical, ninth and tenth scarcely wider than long, eleventh more or less ovate.

Pronotum more or less quadrate, widest at the middle, usually about a sixth to a third wider than long, and less than twice as wide as the head; disc smooth, moderately and evenly convex, slightly declivous at the apical angles, very finely, evenly and sparsely, or obsoletely punctulate; apex deeply emarginate, finely or obsoletely margined; sides evenly and not strongly arcuate, very finely margined; base feebly arcuate, finely beaded, and about a sixth wider than the apex; apical angles porrect and acute, at times dentiform and more or less everted; basal angles obtuse.

Propleurce smooth, more or less rugulose and finely punctulate anteriorly.

Elytra more or less oval, smooth, usually widest at the middle; base subtruncate to feebly emarginate and a little wider than the contiguous prothoracic base; humeri obtuse, not rounded nor prominent; sides evenly arcuate, apex more or less caudate; disc evenly convex and punctato-striate, striæ slightly impressed with the punctures rather coarse and closely placed, intervals scarcely convex with a series of extremely fine punctules that are more or less irregularly placed, not becoming asperate at the sides and apex. Cauda slightly deflexed at tip, above with the elytral suture impressed, beneath concave, the concavity being formed by the general internal surface of the elytra.

59780-Bull. $63-09-19$ 
Epipleurce quite wide at the humeri, thence gradually and rather rapidly narrowing for a short distance, then less rapidly to apex, where they narrowly margin the sides of the inferior surface of the cauda; surface smooth, generally impunctate.

Sterna more or less punctate and rugulose.

Parapleurce not strongly punctate.

Abdomen horizontal, finely, sparsely, quite evenly punctate and more or less rugulose.

Legs rather long and quite slender; anterior femora armed with a straight, acute tooth in both sexes; tibial spurs similar in the sexes and rather small, the anterior being equal and acute. Tarsi similar in the sexes.

Male.-Elongate and dimorphic. Pronotum nearly quadrate, about a sixth to less than a third wider than long. Elytra gradually declivous posteriorly; apex briefly produced or strongly and horizontally caudate, and accordingly two forms may be recognized:

Forma typica with the cauda equal to about a fourth of the entire length of the elytra. Abdominal segments one to three usually broadly and longitudinally impressed; posterior tibiæ quite strongly arcuate in basal half, thence to apex straight and distinctly widened.

Forma ecaudata with the elytral apex simply obliquely and briefly produced, acute at tip. Abdomen evenly convex from side to side; posterior tibiæ not arcuate and not more suddenly widened toward apex.

Female.-Robust. Pronotum slightly transverse and about a fourth to a third wider than long. Elytra more or less broadly oval and slightly ventricose, quite strongly, suddenly and obliquely declivous posteriorly; apex simply acute. Abdomen evenly convex. Posterior tibiæ straight.

Genital characters, male.-Edeagophore oblong-ovate, rather small and slightly arched.

Basale evenly convex, oblong, with the sides subparallel, and about twice as long as the apicale.

A picale longer than wide at base, triangular; surface evenly convex, with a very fine median groove extending from near the base to the apex, where it becomes wider; sides nearly straight or feebly arcuate; apex acute and not produced; base subacutely lobed at the middle and sinuate laterally.

Sternite truncately subtriangular. Each lobe with the external border straight in basal two-thirds converging toward apex, thence evenly arcuate to angle; internal margin rather arcuate, apex narrowly rounded; surface rather strongly and densely punctate throughout, setose, setæ quite long and dense at tip. Membrane not setose across the bottom of the sinus, the latter rather broad. 
Female.-Genital segment subquadrate, not strongly developed at base, moderate in size, and setose.

Valvula (Plate 1, fig. 21).-Dorsal plate, oblong, with sides more or less reflexed; surface moderately concave, finely and sparsely punctate, and with rather short setæ; external border moderately arcuate; internal margin quite straight and parallel; apical margin subtruncate and fringed with a few very short hairs; angle subrectangular and without conspicuous setæ. Apex short, stout, and triangular, with few very short hairs at tip.

Appendage moderately large, as long as the apex, flattened, semielliptical, and broadly rounded at tip, with two or three long setæ, others short and scattered over the surface. Fossa moderate in size and not conspicuously fringed with setæ, situated beneath the external half of the apical margin of the dorsal plate.

Superior pudendal membrane attaining about the middle of the dorsal plate and longitudinally rugulose. Valvular membranes visible between the apices caudad.

Ventrolateral surfaces.-Body slightly swollen at base, moderately and transversely concave before the apex, the latter covered with short setæ. Submarginal groove normal and linear, more or less visible from above, especially in dried specimens; lateral plate not visible externally when viewed from above. Internal margins of the valves contiguous for a short distance at base; genital fissure long and fusiform, closed in basal half by the inferior pudendal membrane.

The three following forms are to be recognized:

Forma typica.-Moderate in size. Males more or less caudate. Elytra striato-punctate and not noticeably inflated.

Measurements.-Males: Caudate form: Length, 20-28 $\mathrm{mm}$; with cauda, 23-31.5 mm.; width, 8-10.5 mm. Ecaudate form: Length, $24-28 \mathrm{~mm}$. ; width, 9-9.5 mm. Females: Length, $22-27 \mathrm{~mm}$.; width $9.2-11.5 \mathrm{~mm}$.

Forma inflata.-Quite robust. Elytra striato-punctate and more or less distinctly inflated (Plate 1, fig. 22).

Measurements.-Males: Not at hand. Females: Length, 26.5-32 mm.; width, $11.5-13.2 \mathrm{~mm}$.

Forma graridis.-Very robust and elongate, smooth, body very evenly and gradually narrowed behind. Elytral striæ more or less obsolete.

Measurements.-Male: Length, $37 \mathrm{~mm}$; width, $13.5 \mathrm{~mm}$.

Habitat.-Lower California.

Forma typica.-Cape St. Lucas; Santa Rosa, Gustav Beyer; San Jose del Cabo, collections of Charles Fuchs and California Academy of Sciences 
Forma inflata.-San Jose del Cabo, collection Charles Fuchs.

Forma grandis.-Calmalli mines, collection California Academy of Sciences.

Number of specimens studied, 140.

Type in the LeConte collection.

Type-locality.-Cape St. Lucas, Lower California.

Salient type-characters.-Thorax quadrate, apex deeply emarginate, apical angles porrect and acute, but not acuminate; sides moderately rounded, basal angles obtuse; disc moderately convex and sparsely punctulate. Elytra oval and convex, acutely attenuate behind, strongly striato-punctate, striæ slightly impressed, intervals punctulate (LeConte).

Diagnostic characters.-The characters that separate this race from eschscholtzii are very feeble. In tuce the apical angles of the prothorax are more strongly prominent anteriorly and the apical margin more strongly emarginate. The prothorax is less typically quadrate and the cauda is less attenuated toward tip. From the differences presented by the series before me, I have no doubt but that a larger series from the different geographical regions would prove these differential characters of no value.

In the strongly developed males with long caudæ the hind tibiæ are more or less arcuate in the basal half and rather abruptly dilated in the apical moiety, these characters are not evident in the ecaudate form.

From the forms of acuticauda it is separated by the striato-punctate elytra, by the sides of the pronotum being quite feebly rounded, and by the elytral apices being more abruptly attenuate, the cauda being horizontal.

From dentipes it is readily known by the quadrate prothorax with feebly rounded sides.

Forma inflata has to be separated from ventricosa by the sides of the pronotum being less convergent anteriorly and by the greater width of the apex as compared with the base; the elytra are not so decidedly inflated and the apices are not produced in the females. This form appears to lead toward ventricosa - in fact may be intermediate, but undoubtedly has great affinity with 7uca. A large series of both species would no doubt demonstrate this relationship. The males are probably ecaudate.

Forma grandis is a wonderful specimen of gigantism-such phenomenal development makes the limiting of species exceedingly difficult in the absence of an ample series. The epipleuræ are wide at the humeri and rather rapidly narrowing to opposite the metasternal epimera, thence narrower, with margins gradually converging to apex. Fourteen series of very fine punctules are clearly indicated upon each elytron. 
General observations.-The middle lobe of the mentum is variable, but nearly always triangular, in the large examples quite equilaterally so; the apex is scarcely truncate, generally distinctly rounded; surface more or less irregular from the broad, shallow, lateral foveæ.

The prosterna in the series before me are exceedingly variable. In the more strongly developed examples the prosternum is horizontal and triangularly, strongly mucronate; in the smaller specimens it is rounded antero-posteriorly and without a mucro, at other times it is more or less mucronate behind and more or less convex between the coxæ. The prosternum is not strongly prominent ventrally with the coxæ.

The prosternum in forma grandis has an extraordinary development. It is horizontal between the coxæ and uncinately produced and slightly but evenly decurved, arcuately sinuate above the mucro.

The mesosternum is more or less oblique and concave.

The abdominal process is subquadrate, slightly transverse, with its width about equal to the length of the post-coxal part of the first segment, and also to the length of the third; the second is about twice the length of the fourth.

The abdominal salient is about a fourth of its width broader than the metasternal process.

The metasternum laterally between the coxæ is about as long as the width of a mesotibia at middle.

The tibial grooves of the femora are well developed, with the margins more or less distinctly cariniform. The profemoral grooves are moderately wide, with the sides feebly arcuate or quite straight, the latter becoming contiguous at the femoral base; the anterior margins are quite acutely dentately laminate at the outer third; the floors are nearly flat, opaque, and smooth.

The mesofemoral grooves have the sides evanescent at about basal fifth, while those of the metafemora become evanescent at basal fourth. The floors of the grooves on both are flat and glabrous.

The protibiæ are feebly compressed and the mesotibiæ just noticeably so. The protibiæ are distinctly carinate externally; the tarsal grooves are more or less well marked and scabrous; the articular cavities are nearly always closed.

The metatibiæ are variable in form and carinate to a slight extent the grooves are more or less well marked and at times rather deep, subglabrous, and opaque; the articular cavities are closed.

The metatibiæ are variable in form and carinate to a slight extent externally in basal fourth; the grooves are more or less obsolete or feeble and the articular cavities are closed.

The tarsi are more or less variable in length and thickness; usually moderate. The protarsi are about a third of their length shorter than a mesotarsus. Joints two, three, and four are subequal, the 
fourth is at times very slightly longer than the second, all are wider than long and together a little shorter than the fifth; the first is about as long as wide.

The mesotarsi are about an eighth of their length shorter than a metatarsus. Joints two, three, and four are subequal, scarcely longer than wide and together slightly longer than the fifth; the first is about one and a half times longer than wide.

The metatarsi are slightly shorter than half the length of a metatibia. Joints two and three are subequal and a little longer than wide, together scarcely as long as the fourth, and noticeably longer than the first.

\section{ELEODES TENUIPES Casey.}

Eleodes temuipes Casex, Ann. N. Y. Acad. Sci., V. Nov., 1890, p. 399.

Elongate-ovate, rather smooth and shining. Caudate.

Head twice as wide as long, finely and sparsely punctate, very slightly convex. Antenno moderate, scarcely compressed and not dilated in outer four joints, third joint a little longer than the next two taken together, fourth just a trifle longer than the fifth, the latter to the eighth, inclusive, subequal, eighth subtriangular, ninth and tenth suborbicular, eleventh ovate.

Pronotum quite quadrate, about a seventh wider than long, widest just at or a little in advance of the middle; disc evenly and moderately convex, minutely and very sparsely punctulate; apex quite truncate, more or less finely and obsoletely margined; sides quite evenly and not strongly arcuate from base to apex, finely beaded; base broadly and very feebly arcuate, about equal to the apex and about a sixth shorter than the length; apical angles very acute, small, dentiform, and everted; basal angles obtuse, feebly or scarcely rounded.

Propleurce quite smooth externally, more or less obsoletely punctate and rugulose.

Elytra elongate oval, widest at the middle; base feebly emarginate, and equal to the contiguous prothoracic base; humeri obtuse, not in the least prominent; sides evenly arcuate, apex more or less produced; disc moderately convex on the dorsum, quite evenly rounded laterally, arcuately and obliquely declivous behind, punctate, punctures arranged in distant unimpressed rows of fine, simple, moderately approximate punctures, the intervals each with a single series of still finer and widely spaced punctures, which are generally simple, but which laterally toward apex become very coarse sparse asperities.

Epipleurce moderate in width beneath the humeri, thence gradually narrowing to apex, where it narrowly margins externally the inferior surface of the elytral prolongation; surface smooth, sparsely and very finely punctate toward apex. 
Sterna more or less obsoletely punctate and very feebly rugulose.

Parapleurce coarsely and somewhat obsoletely punctate.

Abdomen horizontal, quite smooth, very finely and sparsely punctulate, finely rugulose.

Legs rather long and slender. Anterior femora more or less armed; anterior tibial spurs subequal and rather stout. Tarsi similar in the sexes, with the spinules beneath quite slender.

Male.-Body moderately slender, antennæ attaining the base of the prothorax. Elytra produced at tip forming a cauda, which is nearly horizontal and $4 \mathrm{~mm}$. more or less in length, with its inferior surface formed by the general internal surface of the elytra. Abdomen moderately convex, more or less feebly impressed along the median line on the first three segments. Anterior femora armed with a slender and acute tooth at the outer third.

Measurements.-Males: Length, with cauda, 30.5-31 mm.; width, 10-10.8 mm. Females: Unknown to me.

Genital characters, male.-Edeagophore elongately fusiform, not arched.

Basale elongate oblong, very moderately convex, with sides slightly arcuate.

Apicale elongate, triangular, nearly twice as long as wide, moderately convex above, groove very fine and linear; sides feebly arcuate, just noticeably sinuate in apical half, tip subacute; base with a broad rounded lobe at central two-fourths, laterally feebly sinuate.

Sternite transversely parabolic. Each lobe rather short, with the external border evenly arcuate and continuously so with the apical border, which is rather broadly arcuate, angle not evident; internal border short, feebly arcuate or straight; surface feebly convex, sparsely punctate and setose, setæ quite long, longer and denser on the apical margin, impunctate in basal fourth. Membrane not setose across the bottom of the sinus, the latter rather broad.

Habitat.-Texas (El Paso).

Number of specimens studied, 1 male; type not seen.

Type a male in the collection of Colonel Casey. Collector, G. W. Dunn.

Type-locality.-El Paso, Texas.

Salient type-characters.-Prothorax with the apex very nearly as wide as the base, broadly, feebly emarginate in circular arc, the apical angles very acute and in the form of small everted teeth; base very feebly arcuate; basal angles extremely obtuse; sides almost evenly and distinctly arcuate; disc widest just visibly before the middle, rather strongly and evenly convex, minutely and very sparsely punctate. Elytra with humeri not prominent; disc with distant unimpressed rows of fine simple moderately approximate punctures, the intervals each with a single line of still finer and ex- 
tremely widely spaced punctures, which are generally simple, but which laterally toward apex become very coarse sparse asperities (Casey).

Diagnostic characters.-In tenuipes the apical angles of the prothorax are strongly everted, the sides are quite evenly arcuate; in wickhami the apical angles are not everted and the sides are oblique posteriorly; in tenuipes and in a specimen received from Professor Wickham-the latter I refer to wickhami-the elytra are similar and more elongately oval than in luca. In the specimen of temipes before me the elytra are very slightly widened behind the middle and this character is less evident in Wickham's specimen. In both the length of the prothorax is comparatively greater as compared to the width than in luce; the latter when well developed have the apical angles of the prothorax acute and prominent anteriorly, with the apex distinctly and evenly emarginate, and in the ecaudate form these characters are less strongly marked. Professor Wickham's specimen is of interest, combining the characters of tenuipes and wickhami.

Some specimens of luca have the apical angles of the prothorax more or less strongly everted.

In the specimens of eschscholtzii before me the prothoracic apex is quite truncate and the angles are subacute and not prominent anteriorly.

General observations.-The middle lobe of the mentum is moderate in size, with the apex arcuate, the surface is moderately coarsely punctate and feebly scabrous, not noticeably setose.

The prosternum is arcuately convex between the coxæ, and with them protuberant ventrally. It is not mucronate nor longitudinally grooved in the specimen before me.

The mesosternum is arcuately and vertically declivous, broadly and moderately concave.

The abdominal intercoxal salient is quadrate and about a third of its length shorter than the post-coxal portion of the segment, the latter being slightly shorter than the second, which is about a fourth longer than the third, the latter being less than twice as long as the fourth.

The abdominal salient is about a sixth of its width wider than the metasternal process.

The metasternum laterally between the coxæ is about as long as the width of a mesofemur at base.

The tibial grooves of the femora are well defined by cariniform margins, the floors are glabrous and shining, and nearly plane. Those of the profemora are moderately wide and nearly attain the femoral base; the margins are scarcely arcuate and gradually converge to the base, where they become contiguous; the anterior margins are acutely and dentately laminate at the apical fourth. On the mesofemora the 
grooves are narrower and gradually converge to become evanescent at basal fourth without becoming contiguous.

The metafemora have the grooves moderately narrow and evanescent at basal third, where the margins are distant.

The protibiæ are slightly compressed and distinctly carinate externally in basal two-thirds; the tarsal grooves are not strongly developed and limited posteriorly by a series of rather coarse and sparse denticulations, and the floors are subscabrous; the articular cavities are more or less closed.

The mesotibiæ are scarcely compressed and feebly carinate externally in basal fourth; the tarsal grooves are rather well developed, rather broad apically, gradually narrowing toward base, and their floors are subglabrous, being limited by muricate margins; articular cavities closed.

The metatibix are somewhat rounded, obsoletely carinate in basal third externally, thence to apex more or less flattened and concave; surface of the grooves more or less shining and sparsely subasperate; articular cavities closed.

The tarsi in the specimen at hand are moderately long and rather stout.

The protarsi are about a third of their length shorter than a mesotarsus. Joints two, three, and four are subequal, wider than long, and together equal to the fifth; the first is about as long as wide.

The mesotarsi are subequal in length to a metatarsus. Joints two and three about as wide as long, the fourth scarcely as wide as long, apparently very slightly decreasing in length from the second to the fourth, together subequal to the fifth; the first is a little longer than wide.

The metatarsi are about four-tenths as long as a metatibia. Joints two and three about equal in length and size, a little longer than wide and together scarcely as long as the fourth; the first is about one and a half times longer than wide.

\section{ELEODES WICKHAMI Horn.}

Eleodes wickhami HonN, Trans. Amer. Ent. Soc., XVIII, Feb., 1891, p. 41, pl. I, fig. 12.

Elongate, more or less shining and caudate.

Head twice as wide as long, rather opaque, feebly convex, finely and very sparsely punctate, frontal suture distinct. Antennce rather long, reaching to or slightly beyond the prothoracic base, not compressed nor dilated in outer three joints, third joint a little longer than the next two taken together, fourth very little longer than the fifth, the latter to the seventh inclusive subequal, eighth slightly shorier and a little more robust, ninth and tenth orbicular, eleventh ovate. 
Pronotum subquadrate, one-sixth wider than long, slightly narrowed behind, widest at or just in advance of the middle; disc moderately convex, sparsely, very finely and indistinctly punctulate; apex slightly emarginate to subtruncate, finely and more or less obsoletely margined; sides slightly and evenly arcuate anteriorly, and more or less oblique posteriorly, sometimes slightly sinuate before the basal angles, finely margined; base feebly arcuate and finely beaded, about one-seventh wider than the apex; apical angles more or less distinct, acute, not everted although sometimes feebly reflexed; basal angles obtuse, not rounded.

Propleurce smooth, obsoletely punctate and more or less rugulose.

Elytra elongate oval, widest at the middle; base feebly emarginate, very slightly wider than the contiguous prothoracic base; humeri obtuse, not prominent nor rounded; sides evenly arcuate or subparallel, attenuate posteriorly and arcuately declivous with the apex more or less caudate; disc slightly and evenly convex on the dorsum, more strongly so and broadly rounded laterally, punctate, punctures fine and more or less indistinct and arranged in series, sometimes feebly impressed, intervals with a single row of fine, widely spaced punctures, which are generally simple, but may become small asperities on sides about apex.

Epipleura moderate in width beneath the humeri and gradually narrowing to the apex; surface smooth and more or less obsoletely punctulate.

Sterna rather smooth and more or less obsoletely punctate and rugose.

Parapleurce more or less coarsely and obsoletely punctate.

Abdomen horizontal, somewhat shining, indistinctly, sparsely punctulate, and more or less transversely rugulose.

Legs rather. long and moderate in thickness; anterior femora armed in one sex at least; anterior tibial spurs subequal and rather stout. Tarsi similar in the sexes with the spinules beneath moderately stout.

Male.-Body slightly robust. Elytra arcuately and obliquely declivous behind, prolonged into a narrow, horizontal cauda, whose under surface is a part of the general internal surface of the elytra, the epipleuræ passing narrowly along the sides to tip, the latter slightly decurved. Abdomen feebly and broadly impressed at middle, especially on the second segment: Anterior femora with an acute and rather stout tooth at outer fourth; anterior tibiæ more or less constricted at base. Middle and posterior femora simple; posterior tibiæ frequently slightly arcuate and narrow in basal half, generally more or less abruptly dilated in apical moiety; both the middle and hind tibiæ generally with the surface quite asperate in apical half. 
Measurements.-Males: Length, 27-34 mm.; including cauda, 33-39 mm.; width, $12 \mathrm{~mm}$. Females: Unknown to me.

Genital characters, male.-Edeagophore elongate oblong oval, not slender.

Basale oblong, about twice as long as wide, moderately convex, sides subparallel.

A picale rather broadly triangular, a little longer than wide, feebly convex, without median groove; sides nearly straight to tip, the latter acute; base with a rather narrowly rounded lobe at middle third, laterally broadly and feebly sinuate.

Sternite as in tenuipes.

Habitat.-Arizona (Tueson, H. F. Wickham); New Mexico (Las Cruces).

Number of specimens studied, 1 male.

Type, a male in the Horn collection.

Type-locality.-Tucson, Arizona ; collector, H. F. Wickham.

Salient type-characters.-Thorax subquadrate, a little wider than long, slightly narrowed behind, sides slightly arcuate in front, oblique posteriorly, anterior angles not everted; disc moderately convex, sparsely very finely and indistinctly punctate, elytra elongate oval, attenuate posteriorly; disc convex with rows of extremely fine indistinct punctures (Horn).

Diagnostic characters.-(See tenuipes.) Without doubt, to my mind the two species just described are extreme forms (heterotypes) of the same species, but on account of the paucity of material known to me, I have deemed it best to retain them separate until a larger series shall have been collected.

At most wickhami can only be a race of temuipes, Casey's name having priority of three months (tenuipes, November, 1890 ; wickhami, February, 1891). Unfortunately only males are known to me.

Both forms have been compared with luca by their authors. They do show greater affinity to that species than to any other, except gracilis. From luck they can be recognized by the elytra being sculptured with rows of fine punctures, and not strongly striate nor with the intervals at all convex; the elytra are slightly more inflated and more suddenly declivous behind.

The prothoracic characters are too variable to be relied upon. By direct comparison I can not say that the legs are always longer than in lucee.

The form of the hind tibiæ in wickhami is not peculiar to that species, as the same character is seen in the males of a number of other species, notably in the caudate form of luce. It is strange that such characters should have been overlooked or ignored by previous writers. 
From gracitis the two species under consideration differ in the caudate elytra of the males and in having the prothorax slightly longer.

The prothorax in tenuipes is indeed almost as in the typical gracilis. The type of tenuipes and wickhami were practically collected in the same geographical region, the latter extending into New Mexico (Wickham's specimen); gracitis occurs in the same area.

My specimen of tenuipes was obtained from Mr. G. W. Dunn, who collected it at El Paso, Texas; it was probably one of the same lot from which Colonel Casey obtained his type.

General observations.-The following analytical remarks are founded upon Professor Wickham's New Mexico specimen:

Mentum moderate in size and triangular, with apex rounded; surface very feebly convex and quite coarsely punctate.

The pro- and mesoternal characters are identical, as are also the tarsal characters, with those of tenuipes.

The abdominal and metasternal salients and abdominal segments do not differ relatively from those of tenuipes.

The metasternum laterally between the coxæ is about as long as the width of a mesofemur at base.

The femoral and tibial characters are the same as in tenuipes, except that the protibiæ have the articular cavities widely open. The metatibiæ are just noticeably arcuate in basal half and gradually but distinctly dilated toward apex.

\section{ELEODES VENTRICOSA LeConte.}

Eleodes ventricosa LeConte, Proc. Acad. Nat. Sci. Phila., 1858, p. 186.Honn, Trans. Amer. Phil. Soc., XIV, 1870, p. 311.-Champion, Biol. Centr. Amer., IV, Pt. 1, 1884, p. 78.

Fusiform ovate, robust, elytra usually strongly inflated, smooth, and more or less shining.

Head twice as wide as long, more or less moderately convex, frequently slightly and transversely impressed between the eyes, with the vertex more strongly convex, frontal suture distinct, finely, sparsely, and irregularly punctate. Antennce moderately long, attaining a slight distance beyond the prothoracic base, comparatively slender, very feebly compressed, and slightly clavate; third joint about equal to the next two combined, fourth a little longer than the fifth, the latter to the seventh, inclusive, subequal in length, eighth shorter and slightly subtriangular, ninth and tenth suborbicular, eleventh ovate.

Pronotum slightly transverse, widest at the middle, one-fourth to one-third wider than long, narrowing moderately anteriorly, slightly posteriorly; disc quite evenly and moderately convex, finely and sparsely punctate; apex slightly emarginate, finely and more or less 
obsoletely margined; sides moderately arcuate from base to apex, finely margined, the margin frequently more or less narrowly reflexed; base moderately arcuate and rather coarsely margined, about one-third wider than the apex and distinctly greater than the length; apical angles distinct and more or less prominent anteriorly, generally acute and not dentiform; basal angles distinctly rounded, frequently subobtuse.

Propleurce sparsely punctate and more or less rugulose, frequently smooth externally.

Elytra broadly oval and usually strongly inflated, always less than twice as long as wide, widest at the middle; base moderately emarginate, usually as wide as the contiguous prothoracic base; humeri obtuse, not prominent nor rounded; sides evenly and quite strongly arcuate, apex more or less produced; disc quite evenly and strongly convex from side to side, at times more or less feebly depressed on the dorsum, and more strongly rounded laterally, evenly and arcuately declivous posteriorly; surface punctate and feebly suleate, punctures more or less coarse and arranged in moderately distant series, intervals at times feebly convex, at others flat, with a single series of fine punctures, which are more or less regularly or irregularly arranged; laterally and on the apex the punctures become much coarser and the intervals at times strongly convex.

Epipleurce moderately narrow at base and very gradually narrowing to apex, superior margin near base broadly and feebly sinuate; surface smooth, very finely and distinctly or obsoletely, sparsely punctate.

Sterna more or less shining, moderately densely punctured and rugose.

Parapleurce more or less coarsely punctate.

Abdomen horizontal, moderately convex, shining, and glabrous, very sparsely punctulate and more or less rugulose.

Legs rather long and moderate in thickness. Anterior femora armed in one sex. Anterior tibial spurs similar in the sexes, the anterior slightly longer than the posterior, both acute. Tarsi nearly similar in the sexes; each joint, except the last, of all the tarsi with a slender and acute tuft of golden-yellow and somewhat modified spines on apical angles beneath. (See male.)

Male.-Elytra rather gradually and arcuately declivous behind and produced at tip into a moderately long cauda, which is not horizontal; elytral sides and dorsum feebly and broadly sinuate before the produced apex, the latter with its inferior surface a part of the general internal elytral surface and narrowly margined at the sides by the epipleuræ. Abdomen more or less broadly impressed in the median line on first three segments. Anterior femora armed with a rather long, acute, and rather strongly curved tooth at outer fourth. 
First joint of the anterior tarsi with the tip slightly and transversely produced beneath, the same bearing a tuft of modified spines which obstructs the groove.

Female.-Elytra quite evenly arcuately declivous behind, with the apex feebly produced or simply subacute. Abdomen not impressed. Anterior femora more or less sinuate in outer fourth.

Measurements.-Males: Length, 30-33 mm. (with cauda) ; width, 13-14 mm. Females: Length, 26-33.2 mm; width, $13.5-15 \mathrm{~mm}$.

Genital characters, male.-Edeagophore elongately oval, depressed and not arched.

Basale oblong, very moderately and evenly convex, sides feebly arcuate.

Apicale triangular, very slightly longer than wide and rather broad; surface rather feebly convex and not grooved; sides evenly and not strongly arcuate to tip, the latter subacute; base with a subtriangular lobe at middle, which is narrowly rounded at tip, feebly sinuate laterally.

Sternite transversely parabolic. Each lobe with the external margin evenly arcuate to apex, the latter somewhat broadly rounded; internal border straight to feebly arcuate; surface very feebly convex, shining, not very strongly chitinized at inner and basal third, sparsely punctate, setæ not long, those on the apical margin longer and not very dense. Membrane not setose across the bottom of the sinus, the latter broad.

Female.-Genital segment robust, trapezoidal, valves reflexed externally, strongly chitinized and setose.

Valvula (Plate 5, fig. 1).-Dorsal plate oblong, strongly concave, margins more or less reflexed; surface glabrous, sparsely and strongly punctate, setose, setæ rather short and inconspicuous; external margin straight or feebly sinuate; apical margin inwardly obliquely truncate, angle acute and as prominent apically as the apex, the latter quite short, robust and triangular, both sparsely set with short setæ; internal margin arcuate or straight. Submarginal groove more or less visible from above and quite moderate.

Appendage short and flattened, semielliptical, projecting but a short distance beyond the margin of the fossa and eccentrically placed. Fossa terminal, rather large and transverse.

Superior pudendal membrane attaining the middle of the dorsal plate and feebly longitudinally rugulose.

Basal prominences quite well developed.

Ventrolateral surfaces strongly convex, glabrous basally and more or less concave before the apex laterally, very sparsely and coarsely punctate. Internal margins of the valves contiguous in basal and apical fourths. Genital fissure rather broad and fusiform. Inferior pudendal membrane closing the fissure in basal half. 
Habitat.-Texas (Brownsville, Charles Drury, H. F. Wickham; Uvalde, Wickham; Wades, Alice, and San Diego, Hubbard and Schwarz, collection U. S. National Museum). Mexico (coll., F. Bates).

Number of specimens studied, 15.

Type in the LeConte collection.

Type-locality.-Texas, near the Rio Grande River.

Satient type-characters.-Thorax finely punctate, anteriorly moderately and posteriorly slightly narrowed; sides rounded; anterior angles acute; base broadly rounded, humeri scarcely acute. Elytra striato-punctate, intervals uniseriately punctulate (LeConte).

Diagnostic characters.-Quickly recognized by its robust form, the elytra being strongly ventricose in both sexes, moderately caudate in the males, the cauda being oblique and not horizontal; in the females the elytral apex is slightly produced.

The apical angles of the prothorax are distinct and not dentiform; the basal are rather broadly rounded, the angles may be sometimes feebly evident; the sides narrowing moderately anteriorly.

As LeConte writes the punctures composing the striæ of the elytra vary very much in size; sometimes they are very large, while at others they are hardly different from the more distant interstitial punctures.

Two examples in the series before me have the elytral intervals perfectly flat and the striæ not in the least impressed.

The antennæ are noticeably feebly clavate on account of the joints one to eight, inclusive, being elongate and retaining the same width throughout, while joints nine to eleven, inclusive, are slightly widened at the middle and more or less transverse. The same structure is observed in eschscholtzii and tuca, only that the eighth joint is also feebly widened. This may also be the case in ventricosa.

This species is separated from luco forma inflata by the basal angles of the prothorax in the latter being obtuse, distinct, and not at all rounded.

See var. falli, p. 306.

General characters.-The mentum is large, more or less trapezoidal, rarely subquadrate; apex truncate or feebly arcuate, slightly reflexed, and frequently impressed at middle so as to appear more or less emarginate; surface coarsely punctate, setæ very short, subfoveate at the basal angles; inflexed lobes rather stout.

The prosternum is quite variable. Convex between the coxæ, with which it is quite strongly protuberant ventrally and also moderately short before the acetabula; compressed and perpendicularly truncate behind, rising into a small mucro at the ventral angle; at times subtruncate behind, with a moderate mucro, at others rounded and not at all mucronate. 
The mesosternum is quite short, obliquely declivous, and rather strongly concave.

The abdominal process is about one-fourth of its width broader than the metasternal salient, nearly quadrate, slightly transverse, and equal in length to the post-coxal portion of the same segment, the latter being equal to the third in length; the second is twice as long as the fourth.

The metasternum laterally between the coxæ is about as long as the width of a mesotibia at apex.

The tibial grooves of the profemora are well developed and defined by smooth cariniform margins, that are scarcely at all arcuate, quite evenly and gradually convergent, to become contiguous a short distance from the base; floors glabrous and shining, feebly concave; the anterior margins at the outer fourth are dentately laminate in the males; in the female more or less sinuately atrophic in the outer fourth.

On the mesofemora the sulci are less strongly defined by cariniform margins, that become quite evanescent at the inner third; the floors are glabrous, shining, and very feebly concave.

The metafemoral tibial grooves are rather narrow and with rather feeble margins, that become evanescent without becoming contiguous at about the middle.

The protibiæ are scarcely compressed, not carinate, but smooth externally; tarsal sulci more or less feebly developed and subasperate; posterior surface muricately sculptured, but not coarsely so; articular cavities usually closed.

The mesotibiæ are more or less rounded and not coarsely muricately sculptured, smooth, and not carinate in basal third externally; tarsal grooves more or less obsolete and subasperate; articular cavities closed.

Metatibiæ quite cylindrical, not coarsely muricately sculptured, more or less feebly flattened and rarely grooved externally; articular cavities distinctly closed.

The tarsi are moderately long and stout.

The protarsi are about one-fourth of their length shorter than a mesotarsus. Joints two, three, and four are subequal in length and slightly wider than long, together about equal to the fifth; the first is slightly longer than wide.

The mesotarsi are just slightly shorter than a metatarsus. Joints two, three, and four subequal in length and very slightly longer than wide, together equal to the length of the fifth; the first is about a half longer than wide.

The metatarsi are equal to half the length of a metatibia. Joints two and three subequal in length, distinctly longer than wide and 
together scarcely as long as the fourth; first joint with a total length of about twice as long as wide.

The ungues are comparatively long.

\section{ELEODES VENTRICOSA var. FALLI, new.}

Elongate-ovate, smooth and shining, elytra scarcely inflated, simply punctate and more or less caudate in the male.

Antenna as in ventricosa.

Prothorax quadrate, about one-eighth wider than long, not noticeably more narrowed anteriorly than posteriorly; apex broadly and quite strongly emarginate; sides evenly and quite moderately arcuate from base to apex; base one-fifth to one-fourth wider than the apex and more or less greater than the length; apical angles strongly prominent anteriorly, acute, rather large, slightly reflexed and not everted; basal angles obtuse and not rounded.

Propleurce quite smooth and quite obsoletely sculptured.

Elytra rather broadly oval, scarcely inflated, sides eveniy and moderately arcuate, with the apex more or less produced; disc quite evenly arcuate from side to side, sometimes slightly depressed on the dorsum, not sulcate, punctate, punctures fine and usually of the same size; the serial punctures may be coarser, scarcely more strongly sculptured laterally. Cauda feebly impressed along the suture and a little longer than in ventricosa.

Sterna and parapleuræ more or less obsoletely sculptured and glabrous.

Legs usually rather slender; anterior tibiæ slightly constricted at base, otherwise as in ventricosa.

Male.-Body somewhat robust. Elytral cauda about $4 \mathrm{~mm}$. long and less oblique than in ventricosa. The tuft of spinules on the first joint of the anterior tarsi is interrupted at middle and does not close the groove. Otherwise as in ventricosa.

Female.-Body moderately robust. Elytral apex more or less slightly produced and subacute. Otherwise as in ventricosa.

Measurements-Male: Length, $32.2 \mathrm{~mm}$. with cauda; width, 12.5 mm. Females: Length, 30-33 mm.; width, 13.2-14 mm.

Genital characters, male.-As in ventricosa.

Female-Compares with ventricosa as follows: The genital segment has the apical margin of the dorsal plate of a valve less oblique and sometimes feebly arcuate; angle about as or less prominent.

The ventrolateral surfaces are less strongly but more evenly convex, and the surface lines straight when viewed longitudinally.

The appendage is larger, subconico-semiellipsoidal, completely filling the fossa and projecting beyond the margins of the dorsal plate, not as long as wide. 
Fissure narrower, otherwise as in ventricosa. One of the specimens from El Paso, Texas, has the apical margin of the dorsal plate as in ventricosa.

Habitat.-Texas (El Paso, March, H. Soltau ; Fort Bliss, collection of H. C. Fall).

Number of specimens studied, 3 ( 1 male and 2 females).

Co-types distributed as follows: Male in the collection of H. C. Fall; female types in the collection of the U. S. National Museum.

Type-locality.-Texas (El Paso and Fort Bliss).

Diagnostic characters. - Falli is separated from ventricosa by the less transverse prothorax, the very acute, anteriorly prominent, and more or less reflexed apical angles of the same; the basal angles are distinctly obtuse and not rounded; the elytra are much less inflated, and consequently appear more elongate, and the cauda in the male is longer.

From luca forma inflata it is recognized by the more strongly developed apical angles of the prothorax, the oblique cauda of the male, and the mutic anterior femora of the female.

From tenuipes, which it approaches, it is quickly recognized by the well-developed anterior prothoracic angles; the cauda in temuipes is slightly oblique at times, but more horizontal in wickhami. Tenuipes is less inflated and therefore narrower and more elongate.

Falli is undoubtedly intermediate between tenuipes and ventricosa, and differs with the latter from all other members of the subgenus by the character of the vestiture of the anterior tarsi and the mutic anterior femora in the female.

General characters.-The mentum is exactly as in ventricosa, and the prosternum is more or less rounded behind and feebly mucronate. The mesostermum is as in ventricosa.

The relative size of the metasternal and abdominal salients are the same as in ventricosa.

The post-coxal portion of the first segment is a little longer than the process and quite equal to the third in length; the second is about a fourth of its length longer than the third, the latter being about twice as long as the fourth.

The metasternum laterally and the femora are as in ventricosa.

The protibiæ are more or less distinctly carinate externally, and the articular cavities are more or less open; the tarsal sulci are quite well developed, as they also are on the mesotibiæ.

Otherwise the tibiæ and the tarsi are relatively as in ventricosa.

Subgenus BLAPYIIS Horn.

The present subgenus is based chiefly upon the character of tarsal pubescence. The males have two or three basal joints of the anterior 
tarsi feebly thickened at tips beneath, and there clothed with quite dense, silken, yellowish or brownish pubescence.

The first joint of the middle tarsi also bears a small tuft of similar pubescence at tip beneath, and at times the second exhibits a very small one.

The species naturally associate themselves into groups, the relationships by which this is accomplished result from their genealogical development; and, accordingly, the pubescent tufts may be flat, slightly longer and truncate, or still longer, usually smaller and subacute.

In most females the first joint of the anterior tarsi is more or less transversely thickened at tip beneath, and simply clothed with ordinary spinules across that point where the groove is more or less interrupted.

In the males the pubescent tufts always interrupt the grooves which are evident on the remaining joints, and in all except the first in the female.

At times there is a slight tendency to a lateral compression of the tarsi, but this is not always evident. The femora are always mutic; at times the anterior femora are slightly sinuate at apex beneath.

The pronotum is never declivous at the sides; the disc is always evenly convex from side to side, but in the parvicollis section there is some flattening along the lateral margins corresponding to the granulate area, the sides appearing somewhat dilated as a result. The marginal head is always distinctly visible from above, entire in those species which are very slightly sinuate or constricted at the base, and obsolete or simply continuing as a mere line to the basal angles in those species which are more strongly constricted. The base is at times so strongly constricted as to appear almost pedunculated.

The general form is oval to ovate, some species are slightly more elongate and oblong. The elytra are oval, with sides more or less strongly rounded, apex never produced; the humeral angles are always more or less rounded, except in tibiatis, where they are distinctly angulate.

There is in this subgenus a tendency for the anterior tibiæ to become constricted at base, most evident in tibiatis. The tibial spurs are quite similar in the sexes.

Among the species of Blapylis are to be found our smallest Eleodes.

With the subgeneric tarsal characters are to be correlated the following:

Genital characters, male.-Apicale of the edeagophore triangular and without a median groove, except in tibialis (see p. 316) for remarks upon this species). 

line.

Female.-Genital segment triangular or triangulo-parabolic in out-

Valvula.-Dorsal plates oblong, with a few scattered punctures and setæ, apical margins not always well defined (see Synopsis); apices membranous or chitinous, always finely setose, generally with a pencil of longer hairs at tip (penicillate).

Appendage small, mammilliform and penicillatę. Superior pudendal membrane nearly attaining the apical fourth of the dorsal plate, or only the middle (cordata); genital fissure in the apical third of the segment.

General characters.-The crural characters are quite variable within certain limits in each species. The profemora are more or less clavate, the mesofemora at times feebly so in external two-thirds; the metafemora have their opposed surfaces quite parallel.

The protibiæ are at times subcarinate in basal half externally and the tarsal grooves are not developed, although sometimes indicated; the mesotibiæ are frequently obsoletely grooved on their external surfaces, and the metatibiæ more or less flattened on those surfaces.

The articular cavities are closed on all the tibiæ.

The relative lengths of the tarsi and of the joints in each are practically the same as in the other subgenera.

The protarsi of the male are a little longer than in the female.

The stoutness and length of the legs differ very much in the same species, but for purposes of comparative measurements, normal examples have been selected.

Distribution.-Of the seventeen species given in this paper all but three occur in California; out of six races only two are not found in that State.

Tibialis is apparently peculiar to Lower California; lecontei to Colorado and New Mexico; snowii to Colorado, New Mexico westward to the Colorado River in Arizona; tenebrosa and its var. nana to Nevada and eastern central and northern California.

Inculta may possibly occur on the mainland in California; it is authentically abundant on Santa Rosa Island off the Santa Barbara coast; consobrina occurs from Los Angeles County to Siskiyou County; scabripennis is from the Fort Tejon region; blanchardii at Indio and the mountains in eastern San Diego County; neotomce in southern California, and I have taken it in numbers from the woodrats nests on the hillsides of Mission Valley, San Diego County.

Fuchsii occurs in the high mountains and forests of eastern Tulare County; hornii from the eastern central and northern parts of the State:

Parvicollis from ledges on the hills near the coast in central parts of the State; var. planata in the western central, and producta in the 
mountains and foothills from the southern to the northern parts of California.

Hoppingii is at present only known from Eldorado County; clavicornis and scabrosa maritime and lovers of sand-dunes.

Cordata occurs from Los Angeles to northern parts of the State and at all extreme points of its northern distribution passes into pimetioides, which has the largest distribution of any species of $B l a-$ pytis, occurring in Colorado, Montana, Wyoming, Idaho, Utah, Nevada, Oregon, Washington, Vancouver Island, British Columbia, its var. brunnipes in Idaho, Wyoming, Colorado, and Nevada.

Most of the species are developing into a considerable number of incipient races.

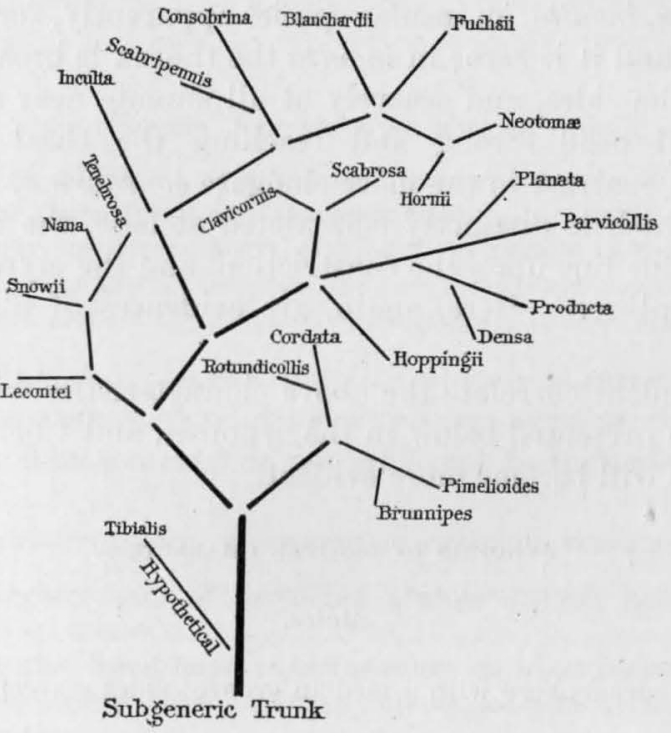

Fig. 6.-Genealogical diagram of the subgends Blapylis.

Genealogy.-It is doubtful if by any herculean effort a biologist could in the period of a few years, with the comparatively small series of specimens at hand from the different regions which they inhabit, work out a correct history of descent.

The individuals of the species making up the present subgenus are very protean in their divergences.

They have evidently diverged along three main lines from the ancestral subgeneric trunk (see diagram). It is quite hypothetical whether tibiatis belongs to Blapylis at all; if not, it must have congeners in Mexico. If it does belong here it diverged early.

Taking the degree of constriction of the prothoracic base as the criterion of divergence, two lines of descent are evident-cordata and pimelioides with a cordate type of prothorax and the lateral margin 
obsolete upon the strong basal constriction, and the other line continuing reactive to a greater degree, again may have diverged dichotomously, evolving the tenebrosa strain, with the sides of the prothorax evenly or nearly arcuate from apex to base; the other being the consobrina-parvicollis ramus. Parvicollis is not only plastic, but prolific, populating the regions it inhabits with puzzling variations, many of them at the beginning of their incipient racial development. In these forms the sculpturing is rather fine, abdomen not coarsely sculptured, pronotal base quite strongly constricted, the prothorax is broader and less strongly convex and more or less impressed along the sides.

The consobrina ramus apparently departed from an interesting strain; that is, inculta, an insular species apparently, for if it be found on the mainland it is rare; in inculta the thorax is broad, very feebly rounded at the sides, and scarcely at all sinuate near the base, with the marginal bead strong and reaching the basal angles-these characters in contrast to the more elongate consobrina, with narrower prothorax which is distinctly constricted at base, the marginal bead becoming a fine line upon the constriction, and the elytra more tuberculately sculptured. Here, again, are evidences of plasticity to environment.

Let the student correlate the above characteristics with the genital characters as presented below in the synopsis, and I believe the above relationships will become more evident.

SYNOPSIS OF GENITAL CHARACTERS.

Males.

Apicale of the edeagophore with a median groove; sides scarcely arcuate.

Apicale without a median groove.

tibialis.

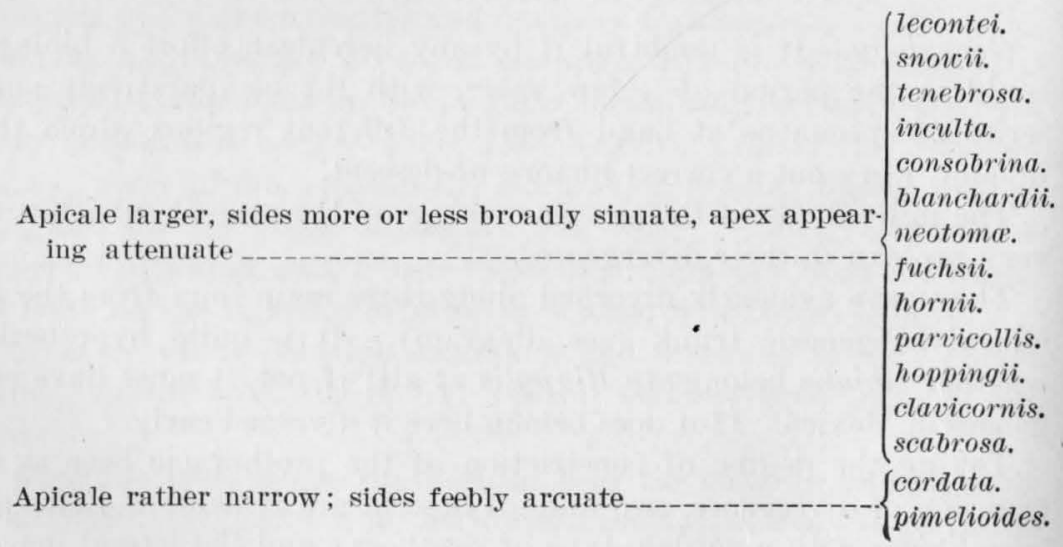


Females.

Superior pudendal membrane long, attaining the apical fourth of the dorsal plate.

Apical margin of the dorsal plate not defined from the apex; appendage flattened mammilliform and subapical tibialis.

Apical margin usually well defined from the apex and more or less arcuate; appendage true mammilliform and more at base of the apex.

Dorsal plate rather broad, not more than three times as $\left\{\begin{array}{l}\text { lecontei. } \\ \text { snowii. } \\ \text { tenebrosa. } \\ \text { inculta. } \\ \text { consobrina. } \\ \text { blanchardii. } \\ \text { neotoma. } \\ \text { fuchsii. } \\ \text { hornii. }\end{array}\right.$

Dorsal plate elongate, four times as long as wide------ $\left\{\begin{array}{l}\text { clavicornis. } \\ \text { scabrosa. }\end{array}\right.$

Apical margin of dorsal plate not well defined from the apex, parvicollis. the latter more frequently semichitinous_____________ hoppingii. Superior pudendal membrane short, attaining the middle of the dorsal plate.

Apical margin of the dorsal plate more or less truncate; angle cordata. evident and more or less rounded; appendage at base of apex_\{pimelioides.

Caseyi is aberrant. In the male the apicale is grooved and in the female the superior pudendal membrane is long, attaining the base of the apex. The material is not sufficient to indicate the relationships.

\section{ANALYTICAL KEY TO SPECIES OF SUBGENUS BLAPYLIS.}

Lateral marginal bead of prothorax always distinct and entire, attaining the basal angles...______

Lateral marginal bead more or less obsolete on basal constriction _-_-_-_-_5

1. Thorax transversely suboblong-oval, lateral margins feebly or not at all sinuate at base

Thorax quadrate, not at all sinuate at base; form very elongate and depressed; surface smooth and shining

2. Surface more or less shining 3

Surface opaque; elytra sculptured with small granules, densely and irregularly placed.

Size larger, length 14-18.5 mm.; granules shining and rounded_tenebrosa. Size smaller, length 10-12 mm.; granules coarser and submuricate laterally, more evidently setigerous______________var. nana.

3. Thorax moderately transverse, sides rather strongly rounded______-_-_-_4

Thorax distinctly transverse, sides very feebly arcuate, scarcely sinuate at base; form robust_-_-__-_- inculta.

4. Sculpturing rather finely muricato-granulate laterally; sides of the pronotum evenly rounded from apex to base, sometimes briefly sinuate at base; form elongate. snowii.

Sculpturing more coarsely muricato-granulate; pronotum briefly, feebly, and broadly sinuate at base; elytra flattened (or convex) on the dorsum; surface dull -lecontei. 
5. Thorax transversely suboblong-oval; somewhat coarsely and discretely

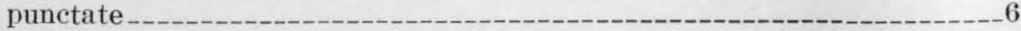

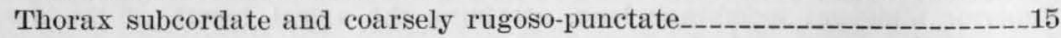

6. Propleuræ not hairy

Propleuræ hairy

7. Genæ not produced______

Genæ produced; sculpturing more or less coarse______________blanchardii.

8. First three abdominal segments densely, coarsely punctate and more or less rugose

First three abdominal segments more finely and sparsely punctate, the first somewhat rugulose.

9. Pronotum and elytra moderately convex, surface dull; elytra fconsobrina. more or less tuberculate laterally, asperate_____ scabripennis.

Pronotum and elytra very strongly convex; surface shining; elytra subasperately sculptured___-___-___-_-

10. Humeri more or less obtusely rounded, frequently prominent anteriorly___11 Humeri obsolete; elytra equal to the prothoracic base, very gradually widening to middle, causing the thorax to appear somewhat remote; surface smooth, shining or dull; antennæ long_-_____________hornii.

11. Humeri obtusely rounded and not prominent to prominent anteriorly; thorax noticeably transverse

Humeri obtusely to broadly and evenly rounded, not at all prominent anteriorly; thorax not noticeably transverse, more as in consobrina, frequently subcordate (female); surface dull.

fuchsii.

12. Surface muricato-granulate laterally and on apex; epipleural margin at

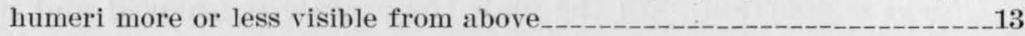

Surface finely and densely muricato-granulate; thorax somewhat finely punctate; form oblong-oval and depressed; antennæ short; humeri rounded______________._.

13. Surface shining; elytra short oval, convex, rather rapidly declivous behind; humeri obtusely rounded, not at all prominent; pronotum rather coarsely punctate _-

Surface more or less dull.

Elytral base not broad; humeri rounded, feebly obtuse and not conspicnous; elytra somewhat attenuate at apex, sides evenly rounded, dise gradually declivous behind (male). Elytral base broad, humeri rather broadly rounded and somewhat obtuse, conspicuous and not prominent anteriorly; apex less attenuate; disc more rapidly declivous behind (female)________anata.

Elytral base broad; humeri conspicuous and more or less prominent anteriorly and margined by the epipleuræ; elytra oblong, dise flattened, narrowing behind the middle, sides parallel; prothorax strongly transverse var. producta.

Elytral base broad; humeri as in producta; elytra oblong, dise flattened usually, coarsely and densely rugoso-punctate centrally, muricatotuberculate laterally and on apex; thorax more sparsely and coarsely punctate; female often with the form of cordata____-var. constricta.

14. Pronotum not noticeably transverse; disc with rather long erect hairs laterally in the granulate area; propleural hairs rather long_-__clavicornis.

Pronotum distinctly transverse; disc with very short, erect setæ laterally; propleural hairs shorter than in clavicornis______________scabrosa.

15. Thorax strongly constricted at base________

Thorax less strongly and more briefly constricted; sides broadly, strongly, and evenly rounded as in scabrosa________-__-_-_var. rotundipennis. 
16. Sides of pronotum more strongly arcuate in front of middle, behind narrowing rather suddenly and more or less subangulate, or more evenly rounded and less gradually narrowing behind.

Elytra coarsely rugoso-punctate cordata.

Elytra sculptured with distinct tubercles, which vary in size, rounded or submuricate.

Tubercles distinct, rounded, not noticeably setigerous; legs black ___________ pimelioides.

Tubercles more evidently setigerous; legs brown_-_-_ar. brunnipes. Sculpturing finer, distinctly pubescent throughout, somewhat like hirsuta, hairs shorter than in that species; legs reddish or brownish caseyi.

The reader will no doubt appreciate the difficulty of formulating a table that will make it possible to place all specimens, especially in a genus so protean as Eleodes. I desire to impress on the student the importance of first determining the subgenus to which the specimen under consideration actually belongs, then try to determine whether it is typical specifically or exhibiting considerable variation. The most important diagnostic tests are those considering the general form, form of thorax with its sculpturing, form and sculpturing of the elytra. Color plays very little part in Eleodes, although surface luster is often helpful.

\section{ELEODES TIBIALIS, new species.}

Elongate, oblong-ovate, nearly three times longer than wide, very smooth and shining, strongly depressed.

Head about twice as wide as long, feebly convex, more or less obsoletely impressed laterally, frontal suture obsoletely indicated, very finely, sparsely, and irregularly punctate, punctures just noticeably denser laterally and on the epistoma. Antenno moderate in length and stoutness, outer three joints very feebly compressed, feebly and very gradually dilated, third joint about equal to the next two taken together, fourth slightly longer than the fifth, the latter, sixth, and seventh subequal in length, eighth more or less triangular, ninth and tenth orbicular, eleventh short ovate.

Pronotum quadrate, widest at or just a little in front of the middle, about a third wider than long; disc evenly, very moderately convex. frequently somewhat depressed, more or less declivous at the apical angles, very minutely punctulate, obsoletely so at times, punctules sparse; apex truncate to moderately emarginate, very finely and more or less obsoletely margined; sides quite evenly and not strongly arcuate, slightly less so and at times somewhat straight in the posterior third, marginal bead entire and fine; base truncate, sometimes feebly sinuate at middle, margin fine, a little wider than the apex; apical angles more or less prominent anteriorly, obtusely and narrowly rounded; basal angles obtuse and not in the least rounded. 
Propleurce smooth, obsoletely punctulate, and more or less feebly rugulose.

Elytra elongately oval, smooth, widest at the middle, sometimes more posteriorly; base truncate and at times just noticeably wider than the contiguous prothoracic base; humeri obtusely angled, not rounded nor prominent; sides evenly arcuate, obliquely narrowing in apical third, apex not very narrowly rounded; disc depressed, feebly convex, sides more or less suddenly inflexed and almost evenly rounded, quite evenly and arcuately declivous posteriorly; surface usually obsoletely punctulate or finely and irregularly so, a serial arrangement often evident, the interstitial punctures of the same size as those of the series, often very feeble and eroded striæ are evident; punctules usually denser on the sides and apex, those about the latter with small brownish hairs.

Epipleurce moderately wide, gradually narrowing from base to apex, superior margin rather strongly defined, especially toward apex, beneath the humeri feebly and broadly sinuate; surface at times feebly concave, smooth, obsoletely punctulate, and more or less feebly rugulose.

Sterna rather smooth, more or less obsoletely and sparsely punctate, rugose.

Parapleura rather evenly and not densely punctate.

Abdomen finely and sparsely punctulate, more densely so on the fifth segment, where it is also more or less finely setose along the margin.

Legs moderate in stoutness and somewhat long; femora mutic, finely and sparsely punctate, the profemora very feebly sinuate in apical fifth; anterior and middle tibiæ more or less strongly constricted at base; anterior tibial spurs similar in the sexes, the anterior a little stouter and just a little longer than the posterior, both acute. Anterior tarsi dissimilar in the sexes.

Maie.--Rather narrow, elongately oblong-ovate. Antennæ attaining the base of the prothorax, the latter with base equal to the length. Elytra with the sides not strongly arcuate. Abdomen somewhat oblique apically, rather feebly convex, broadly, more or less strongly impressed on the first two segments, and the metasternum feebly concave, the mesosternum rather prominent. Anterior tibiæ suddenly constricted at base; first joint of the anterior tarsi feebly thickened at tip beneath and clothed with golden hairs.

Female.-Rather more robust. Antennæ not attaining the base of the prothorax, the latter with the base less than the length. Elytra more broadly oval, sides more strongly arcuate. Abdomen horizontal and moderately convex. Anterior tibiæ moderately and rather gradually constricted at base; first joint of the protarsi scarcely thickened at tip beneath, groove entire. 
Two forms are recognized-

Forma typica.--Elongate-ovate, strongly depressed and very finely punctulate; anterior tibia quite strongly constricted at the base.

Forma oblonga.-Elongate oblong-ovate, not strongly depressed, rather strongly punctate; anterior tibiæ not constricted at base.

Measurements._Males: Length, 20-22 mm.; width, $6.5-8 \mathrm{~mm}$. Females: Length, 20-23 mm.; width, 9-9.2 mm.

Genital characters, male.-Edeagophore of the usual oblong-ovate form and depressed.

Basale oblong; sides broadly and evenly areuate; surface rather evenly convex, not gibbous nor noticeably arched.

A picale triangular; surface rather evenly convex, with a median shallow and rather broad groove extending to the apical fourth; sides scarcely arcuate; apex acute and slightly produced; base with a rounded lobe at middle and feebly sinuate laterally.

Sternite feebly transverse and subparabolic in outline. Each lobe with the external border evenly arcuate; apex obtuse; internal margin straight to feebly arcuate; surface glabrous and shining, not densely punctate, setose, setæ moderately long and not dense. Membrane at bottom of the sinus, not setose.

Female.-Genital segment elongately triangulo-parabolic in outline.

Valvula (Plate 4, fig. 16).-Dorsal plate elongate oblong, moderately narrow, sides subparallel and not reflexed; surface more or less feebly concave, glabrous, finely and sparsely punctate in apical third; external margin nearly straight in basal three-fourths and rather moderately arcuate in apical fourth; internal border more or less sinuous; apex very short, subacute, very feebly chitinized and setose; setæ moderately long and fine, those on apical fourth of the dorsal plate sparsely distributed.

Appendage short, more or less flattened and somewhat semicircular in outline, setæ at tip rather short, and subapical in position upon the apex.

Superior pudendal membrane longitudinally rugulose, attaining the apical fifth of the dorsal plate.

Ventrolateral surfaces not inflated, surface lines straight when viewed longitudinally, regularly convex from side to side, glabrous and very sparsely punctate. Apex finely and sparsely setose. Submarginal groove rather broad beneath the more or less explanate external border of the dorsal plate, the latter sometimes more or less translucent. Internal margins of the valves contiguous in basal three-fourths; fissure apical and triangular between the slightly diverging ventral plates. Inferior pudendal membrane attaining the base of the apices and visible in the apical fissure.

Habitat.-Lower California. 
Forma typica.-Sierra Laguna and La Chuparosa.

Forma oblonga.-San Francisquito.

Remarlss.-Tibiatis has been heretofore wrongly identified, and unrecognized as a distinct species. The following will correct the erroneous report as given by Doctor Horn. ${ }^{a}$ The specimens were in the collection of the academy, but were destroyed in the recent conflagration (April 18, 1906) in San Francisco.

Forma typica.-Female from Sierra Laguna labeled and reported as humeralis; two females from La Chuparosa reported as gracitis, and a female from the same place was also given as gracilis.

Forma oblonga.-A male and female from San Francisquito, reported as humeratis.

Number of specimens studied, 6 .

Type in my own collection (male), co-types in that of Mr. Fuchs.

Type-locality.- Sierra Laguna, Lower California.

Salient type-characters. - Surface smooth and more or less alutaceous. Body elongate and depressed. Prothorax widest at the middle, sides not strongly arcuate, less so posteriorly, marginal bead entire; apical angles slightly prominent anteriorly and narrowly rounded; basal angles obtuse and not rounded. Elytra with the humeri obtusely angled; surface finely, irregularly and obsoletely punctulate. Anterior tibiæ strongly and suddenly constricted at base.

Diagnostic characters.-Tibialis is a unique and very distinct species in the United States fauna. I could not recognize it among the Mexican species given in the Biologia. Although aberrant it will have to constitute a group in the present subgenus until more material can be studied; it is not far out of place, as the first joint of the protarsi is clothed with yellow pubescence beneath and the genital characters are more in harmony here than elsewhere. It differs from all other species in its elongate, depressed, and subnyctobatoid form; the protibiæ are constricted at base in the typical form, but not in the oblong form.

General observations.-The mentum is moderate in size, paraboloquadrate in form; inflexed lobes small, apex truncate or more or less arcuate and more or less deflexed; surface moderately densely punctate, punctures not crowded nor noticeably setigerous, laterally more or less feebly foveate and feebly convex centrally; base of the ligula rather more exposed than usual.

The prosternum is not strongly prominent ventrally, evenly convex antero-posteriorly between the coxæ and also behind, smooth and in the specimens before me not in the least produced posteriorly.

${ }^{a}$ Proceedings, California Academy of Sciences, 2d Ser., IV, Pt. 1, pp. 349-350. 
The mesosternum is subvertical in its anterior two-thirds and more or less arcuate; surface smooth, broadly and more or less concave.

The abdominal process is quadrate (male) or slightly transverse (female) and about a fourth of its width wider than the metasternal salient.

The post-coxal part of the first segment is longer than the process and equal in length to the third (male) or a little longer in the female; second segment is about twice as long as the fourth.

The metasternum laterally between the coxæ is as long as the width of a metafemur at base.

The profemora are moderately clavate; the tibial grooves are rather wide externally, gradually and quite evenly narrowing in basal twothirds; floors quite concave externally, margins distinct, irregularly and unevenly, minutely subcrenulate, becoming contiguous at base; both margins are more or less obsolete opposite the tibial constriction.

The mesofemora are scarcely subclavate, although feebly and evenly tumid; grooves rather narrow, with margins as on the profemora, but less strongly marked and less sinuate at apex.

Metafemora very feebly increasing in width from base to apex; grooves less developed than on the mesofemora, margins obsolete at middle and continued to base as lines of asperities.

The tibiæ may be more or less feebly arcuate, most noticeably so in the protibiæ, the latter more or less carinate externally in basal half or two-thirds; tarsal grooves not present and the articular cavities are closed.

The tarsi are apparently slightly elongate and moderate in stoutness.

The protarsi in the male are just noticeably stouter and slightly longer than in the female. They are about a third (male) or a fourth (female) of their length shorter than a mesotarsus.

The mesotarsi are about an eighth (male) or a seventh (female) of their length shorter than a metatarsus, the latter about a half of its own length shorter than its metatibia.

\section{ELEODES SNOWII, new species.}

Oblong-ovate, more or less shining, about twice as long as wide; sides of the pronotum evenly rounded from apex to base; elytra more or less muricately granulate and not distinctly flattened on the dorsum.

Head twice as wide as long, more or less feebly convex, more or less feebly impressed laterally, frontal suture more or less evident, rather finely and irregularly punctate, slightly denser and coarser laterally and on the epistoma, sparser on the vertex. Antenna moderate, very feebly compressed and not noticeably incrassate, third joint about 
equal in length to the next two combined, fourth to the seventh inclusive subequal, eighth subtriangular, ninth and tenth suborbicular, eleventh short ovate.

Pronotum transversely oval, about one-half wider than long, widest at the middle; disc moderately and evenly convex, not very finely and quite densely punctate, denser and granulate laterally; apex more or less feebly emarginate and more or less obsoletely margined; sides quite evenly and moderately rounded, rarely just the least feebly sinuate before the basal angles, marginal bead fine and entire; base quite truncate, more or less finely and obsoletely margined, subequal to or about a seventh wider than the apex, frequently a little shorter than the length; apical angles obtuse, narrowly rounded at tip and not prominent; basal angles obtuse and not rounded.

Propleurce more or less shining, irregularly muricato-granulate and rugulose.

Elytra oval, less than twice as long as wide, widest at the middle; base not emarginate and evidently wider than the contiguous prothoracic base; humeri usually broadly rounded, sometimes obtusely and less broadly so; sides evenly arcuate, apex not very narrowly rounded; dise more or less feebly or moderately convex on the dorsum, laterally more strongly rounded, not suddenly inflexed, although somewhat so occasionally, arcuately declivous posteriorly; surface rather finely and submuricately punctate centrally, laterally and on apex muricato-granulate, granules and punctures irregularly but closely placed; punctures usually more or less simple at centre of the disc.

Epipleurce at middle as wide as the mesofemur at base, gradually narrowing from base to apex, superior margin straight beneath the humeri when viewed longitudinally from the apex; surface smooth, and obsoletely punctate.

Sterna more or less densely punctate.

Parapleurce quite densely punctate.

Abdomen shining, more or less densely punctate, more or less rugulose, frequently reticulately so; last segment occasionally rufous.

Legs moderate in length and stoutness; anterior femora more or less sinuate in outer fifth and mutic; anterior tibiæ more or less constricted at base, spurs quite similar in the sexes, the anterior slightly longer and stouter than the posterior; anterior tarsi with the first joint feebly thickened at tip beneath, and dissimilar in the sexes.

Male.-Body somewhat slender, antennæ attaining the base of the prothorax; elytra quite evenly, arcuately and feebly obliquely declivous posteriorly. Abdomen slightly oblique, not very moderately convex; first two segments broadly and not strongly impressed at middle. Anterior tarsi with the first two joints clothed with golden 
pubescence at tips beneath, tuft of the second joints about one-half the size of the first.

Female.-Rather robust, antennæ scarcely attaining the base of the prothorax. Elytra somewhat broadly oval, arcuately and more or less vertically declivous behind. Abdomen horizontal, and rather strongly convex. Anterior tarsi without golden pubescence on the first two joints beneath, the produced tips clothed with the ordinary ferrugineous spinules that may interrupt the groove.

Measurements.-Males: Length, 14-17.5 mm.; width, 6-7 $\mathrm{mm}$. Females: Length, 15.2-18 mm.; width, 7-8.5 mm.

Genital characters, male.-Edeagophore oblong fusiform; not arched.

Basale oblong, scarcely three times as long as wide, evenly convex; sides quite parallel.

Apicale small, nearly equilaterally triangular; surface moderately convex, without groove; sides more or less sinuate, tip acute; base broadly lobed, feebly sinuate laterally.

Sternite transversely quadrate. Each lobe long and narrow, triangular; external margin sinuate basally, obliquely arcuate apically; apex very narrowly rounded; internal border quite straight; surface very feebly convex, rather densely punctate in apical half, setose, setæ moderately long. Membrane not setose across the bottom of the sinus, the latter broad.

Female.-Genital segment triangular, slightly longer than wide, superior surface plane.

Valvula (Plate 4, fig. 12).-Dorsal plate very slightly narrowed from base to apex, sides feebly convergent or parallel; surface plane, glabrous, sparsely punctate, setæ not evident; margins nearly straight; apical margin more or less evenly rounded, often rather prominent internally. Apex long and slender, sometimes moderate, subacute, external lobe obsolete, finely setose.

Appendage short mammilliform, clothed with a few short setæ, three or four longer ones at tip. Fossa at the base and external surface of apex.

Basal prominences not evident.

Superior pudendal membrane reaching to near the apical margin of the dorsal plate, longitudinally rugulose.

Ventrolateral surfaces as in tenebrosa.

Habitat.-Colorado (Ouray, elevation 7,500-8,000 feet, July, H. F. Wickham); New Mexico (Santa Fé Canyon, elevation 7,000 feet, August, F. H. Snow; Clouderoft, March and August, Warren Knaus) ; Arizona (Williams and Flagstaff, Barber and Schwarz; Oak Creek, August 2, Eug. Smith, from Knaus; along the Colorado River, Charles Fuchs).

Number of specimens studied, 26. 
Sexitypes in my own collection.

Type-locality.-Santa Fé Canyon, New Mexico; Prof. F. H. Snow, collector.

Salient type-characters.-More or less shining. Sides of the pronotum evenly arcuate from base to apex, surface not very finely punctate, punctures rather densely placed, denser laterally, where it is also granulate. Elytra convex not distinctly flattened, although somewhat so in the male; not very suddenly rounded, and inflexed laterally; rather finely and submuricately punctate centrally; muricato-granulate laterally and on apex.

Diagnostic characters.-In snowii the sculpturing is not strongly muricato-granulate as in lecontei, where the elytra are more muricato-tuberculately sculptured. In snowii the tendency is toward a simpler form of muricate punctuation, and, besides, the form is more elongate and the elytra usually moderately convex. Snowii has not the facies of a planipennis; typical lecontei has.

The side margins of the pronotum are at times similar in snowii, inculta, tenebrosa, and hornii. In inculta the body is much more robust and the pronotum distinctly transverse, the elytral punctuation is rather finely muricate; tenebrosa is opaque and the elytra sculptured with fine shining granules; hornii has the pronotum more narrowed at base, antennæ longer, humeri absent, and the elytra slowly widening from the base.

A series of specimens collected at Williams and along the Colorado River in Arizona are more elongate than the types or other New Mexican specimens, and several of them have the pronotal sides distinctly and briefly sinuate in front of the basal angles. Others from the same place, and taken at the same time, have the sides evenly arcuate from apex to base; in every other respect they are identically the same; one female is more robust and quite like a female from Cloudcroft, New Mexico. Specimens from Colorado and New Mexico also show this variation; tenebrosa and inculta present analogous variations.

A female example collected at Oak Creek, Arizona, and before me, is more robust, somewhat like a large variety of parvicollis, but from some specimens of nigrina of similar facies it is almost impossible to separate it, in fact it was impossible until I examined the genital segment, which agreed exactly with those from Williams and along the Colorado River.

I have no hesitation in referring the above specimens to the present species, as there is nothing to warrant me in separating them; the genital characters agree. It might be suggested that those specimens with sinuate side pronotal margins approach consobrina, but the latter is more robust in form and with coarser sculpturing and more strongly punctate abdomen. I have never seen a true consobrina 
east of the Colorado River. I would sooner believe that they were variations of tenebrosa. A single specimen taken in New Mexico and in the U. S. National Museum collection is robust and resembles consobrina in this respect, but I would still refer it to snowï, even if I did not know the locality from which it came.

A much larger amount of collecting must be done and larger series obtained before the relationship can be worked out, and besides we must learn something about hybrids and atavistic reversions.

The Arizona specimens are not as strongly sculptured, and more shining, with the humeri more obtusely angled than the New Mexican examples, which have the humeri broadly and evenly rounded.

The typical, sinuate, and robust forms must be recognized and so labeled in our collections.

General observations.- The mentum is somewhat small and parabolic or trapezoido-parabolic in outline, the apex may be slightly deflexed; the surface is feebly convex, very slightly foveate laterally and not strongly punctate, the punctures are not noticeably setigerous.

The prosternum is more or less prominent ventrally with the coxæ, sometimes very slightly so; horizontal between the coxæ, submucronate to vertically truncate behind, or arcuately convex anteroposteriorly; surface more or less longitudinally grooved between the coxæ.

The mesosternum is arcuately convex and more or less broadly concave.

The metasternum laterally between the coxæ is as long as the width of a mesotibia at apex.

The abdominal process is quadrate (male) or very slightly transverse (female) and from a fourth to a third of its width broader than the metasternal salient.

The post-coxal part of the first abdominal segment is equal in length to the process and also to that of the third; the second is about one-half (male) or not twice as long (female) as the fourth.

The tarsi are moderate, the anterior in the male is noticeably slightly longer than in the female.

The protarsi are about one-half (male) or a fourth (female) of their own length shorter than a mesotarsus.

The mesotarsi are subequal to (male) or a little shorter (female) than a metatarsus.

The metatarsi are about two-thirds of their length shorter than a metatibia.

\section{ELEODES LECONTEI Horn.}

Eleodes lecontei HonN, Trans. Amer. Phil. Soc., XIV, 1870, p. 316.

Eleodes subaspera LeConte, Smithson. Miscell. Coll., 167, Pt. 1, 1866, p. 114.

Ovate, about twice as long as wide, surface rather dull, elytra distinctly flattened and muricately punctured.

$59780-$ Bull. $63-09-21$ 
Head about twice as wide as long, scarcely convex between the eyes, very feebly impressed laterally, punctures rather fine, somewhat densely placed and quite evenly distributed. Antenno long, rather slender, outer three joints very feebly compressed and not dilated, third joint scarcely as long as the next two combined, fourth just noticeably longer than the fifth, the latter, sixth, and seventh subequal in length, eighth just the least shorter, slightly wider and subtriangular, ninth and tenth suborbicular, eleventh irregularly short-ovate.

Pronotum somewhat transversely oval, about a third wider than long; dise moderately and evenly convex, rather coarsely and densely punctate, the punctures crowded and granular laterally; apex scarcely emarginate and more or less obsoletely beaded; sides rather strongly rounded, scarcely briefly sinuate before the basal angles and finely beaded; base truncate to feebly arcuate, obsoletely margined, about a seventh wider than the apex and quite equal to the length; apical angles distinct and subacute, not in the least prominent anteriorly; basal angles obtuse.

Propleurce rather densely punctate and rugulose.

Elytra oval, about a half wider than the thorax, widest at the middle; base truncate; humeri very obtuse and rounded; sides evenly arcuate, apex rather narrowly rounded; diso very feebly convex, typically depressed, rather suddenly and somewhat narrowly rounded laterally and inflexed, dorsum frequently more strongly convex, arcuately declivous posteriorly; surface muricato-granulately punctate, punctures irregularly and quite densely placed, becoming distinctly granular and setigerous laterally and on apex, setæ short and inconspicuous, the granules are small and scarcely subseriately arranged.

Epipleurce moderate in width, gradually narrowing from base to apex, superior margin quite straight beneath the humeri; surface more or less obsoletely punctate.

Sterna rather densely punctate and more or less rugose.

Parapleurce rather densely but not strongly punctate.

Abdomen more or less shining, quite evenly and not very densely punctate, punctures denser on the fifth segment, the first more strongly sculptured.

Legs moderate in length and somewhat slender; anterior femora mutic; anterior tibial spurs rather short and apparently subequal in length and stoutness, and probably similar in the sexes; anterior tarsi dissimilar in the sexes.

Male.-Unknown to me.

Female.-Body rather broadly ovate, antennæ reaching a little beyond the base of the prothorax. Elytra arcuately and more or less vertically declivous behind; abdomen horizontal and rather 
strongly convex; anterior tibiæ somewhat constricted at base; anterior tarsi with the first joint slightly thickened at tip beneath, and there clothed with a small tuft of piceous spinules.

Measurements.-Female: Length, $16.2 \mathrm{~mm}$; width, $8 \mathrm{~mm}$.

Genital characters, male.-Not studied.

Female.-Genital segment triangular and somewhat depressed, glabrous, very sparsely setose, and well chitinized.

Valvula (Plate 5, fig. 21).-Dorsal plate suboblong, slightly widest at base, external border slightly convergent apically and slightly explanate; surface somewhat outwardly declivous, feebly convex but slightly concave before the apex, glabrous, with a few coarse, scattered, setigerous punctures, setæ short; external border feebly arcuate or straight, passing arcuately into the apical border, the latter defined from the apical surface, angle not evident; internal border more or less feebly sinuous.

Apex fully chitinized, feebly convex above, scarcely excurved, rather broadly rounded at tip, with a number of moderately short setæ over the base along the apical margin of the dorsal plate; internal valvular membrane densely clothed with very short setæ; fossa an excavation at the base of the external surface of the apex and beneath the apical margin of the dorsal plate.

Appendage small and mammilliform, not conspicuous, with a tuft of moderately long setæ at tip.

Superior pudendal membrane longitudinally rugulose and attaining the apical third of the dorsal plate.

Ventrolateral surfaces flattened centrally with the surface lines straight when viewed longitudinally, laterally moderately arcuate and sparsely setose; surface glabrous; submarginal groove distinct beneath the slightly explanate external border of the dorsal plate and terminating in the fossa. Apex somewhat concave beneath and somewhat densely set with short setæ. Internal margins of the valves contiguous at basal two-thirds; fissure apical, apices not contiguous. Inferior pudendal membrane not visible.

Habitat.-Colorado (no special locality indicated by the labels).

Number of specimens studied, 1 female, which was carefully compared with type and pronounced typical by Mr. Blanchard; the specimen is in his collection.

Type in the LeConte collection.

Type-locality.-Colorado.

Salient type-characters.-Somewhat shining. Head and thorax thickly and finely punctate, the latter with apex scarcely emarginate; apical angles acute, not prominent; sides finely margined and strongly rounded, not sinuate posteriorly; base strongly truncate and scarcely narrower than the apex; basal angles obtuse. Elytra with the dorsum slightly convex, apex strongly declivous, sides suddenly inflexed, 
with subseriately placed small granules, on each side and apex briefly piliferous. Antennæ slightly incrassate externally. Length .60 (subaspera) (LeConte).

Diagnostic characters.-The present species was originally described by LeConte as subaspera; this name having been used by Solier at an earlier date. Doctor Horn renamed it in honor of Doctor LeConte.

The single female specimen before me has been kindly loaned for study and pronounced by Mr. Blanchard as being exactly typical. In its general facies it is suggestive of planipennis. The elytra are distinctly flattened on the dorsum, and the sides of the pronotum are evenly rounded nearly to the basal angles where they become slightly subsinuate.

Leconte $i$ is much less shining than planipennis and the sculpturing is distinctly more asperate; the head and thorax are more coarsely punctate. Although the male is unknown to me, it is safe to assume that the secondary sexual characters are the same as in snowii.

I believe that the elytra are more fortuitously depressed than normally so and that the average specimens will have the elytra normally convex. I surmise that I have examined such examples and erroneously referred them to snowii before I fully recognized the species under consideration.

The genital characters in the female are the extreme for the subgenus Blapylis, the valvular apex is fully chitinized, it is also setose and not produced, characters not observed in planipennis from which it is perfectly distinct and not at all closely related.

From snowii, which appears to be worthy of specific standing-if not, at least it would be a good race of lecontei-it must be carefully differentiated. For a long time I have confused the two species; the sculpturing is quite similar in the two, but much less strongly and coasely granulate and more of the muricate type in snowii, where also the elytra are less broadly oval and more elongate and shining.

In parvicollis and cordata and their races the pronotum is more or less strongly constricted at the base, less so in consobrina, where the body is more robust.

In lecontei the marginal bead of the pronotum attains the base.

General observations.- The mentum is moderate and rather parabolic in outline, finely and not deeply punctate, very feebly convex, and obsoletely foveate.

The prosternum is moderately prominent ventrally with the coxæ, arcuately convex antero-posteriorly, and not in the least mucronate behind.

The mesosternum is feebly areuate and oblique, very slightly concave. 
The metasternum laterally between the coxæ is as long as the width of a mesotibia at the apex.

The intercoxal process of the abdomen is slightly transverse and about a third of its width broader than the metasternal salient.

The post-coxal portion of the first abdominal segment is equal in length to the process and also to that of the third; the second is about twice as long as the fourth.

The protarsi are about a fourth of their length shorter than a mesotarsus; the mesotarsi are about a fifth of their length shorter than a metatarsus; the metatarsi are about three-eighths of their length shorter than a metatibia.

\section{ELEODES TENEBROSA Horn.}

Eleodes tenebrosa Horn, Trans. Amer. Phil. Soc., XIV, 1870, p. 316.

Oblong-oval, about two and a third times longer than wide; elytral sculpturing consisting of very small shining tubercles arising from a very opaque base.

Head twice as wide as long, feebly convex, moderately impressed laterally and frequently along the frontal suture, which is usually not evident, not coarsely and more or less densely punctate, punctures distinctly crowded laterally and on epistoma. Antennce moderate in length, slightly robust, outer four joints very feebly compressed and just noticeably wider, third joint equal to the next two taken together, fourth just the least longer than the fifth, the latter, sixth, and seventh subequal in length, eighth about as wide as long and subtriangular, ninth subtrapezoidal, tenth suborbiculo-trapezoidal, eleventh frequently slightly smaller and short-ovate.

Pronotum transversely oval, widest at the middle, a third to a half wider than long; disc moderately and quite evenly convex, rather coarsely and densely punctate, granulate at the sides; apex slightly emarginate, and more or less obsoletely margined; sides evenly and strongly arcuate from apex to the basal twelfth, then rather quickly sinuate and nearly straight and parallel to basal angles, more rarely evenly arcuate from angle to angle, marginal bead moderate, feebly reflexed and entire; base subtruncate in circular arc and finely margined, slightly wider than the apex, and not quite equal to the length; apical angles obtuse and more or less narrowly rounded; basal angles slightly prominent and quite rectangular, sometimes subobtuse.

Propleurce smooth and opaque, sparsely and quite evenly granulate, acetabular convexities frequently rugulose.

Elytra oblong oval, about a half longer than wide, scarcely at all wider than the prothorax, widest at the middle; base not emarginate; humeri quite broadly rounded, angle sometimes obtusely indicated; sides evenly and not strongly arcuate, frequently subparallel, apex ob- 
tusely rounded and not very narrowly so, not in the least produced; disc more or less feebly to modertaely convex on the dorsum, sides evenly and moderately rounded, arcuately declivous behind; surface rather densely and irregularly covered with small, rounded, shining tubercles, arising from a very opaque base.

Epipleurce smooth, opaque, sparsely and evenly subasperately punctate, moderate in width, superior margin scarcely to feebly and broadly sinuate beneath the humeri, as viewed longitudinally.

Sterna quite densely punctate.

Parapleurce quite densely and coarsely punctate.

Abdomen somewhat shining, smooth, and rather densely punctate; fifth segment frequently more or less rufous; intercoxal process at times quite rugose.

Legs moderate and quite strongly sculptured; anterior femora mutic; spurs of the anterior tibiæ quite similar in the sexes, the anterior slightly longer than the posterior; anterior tarsi dissimilar in the sexes, middle tarsi similar.

Male.-Somewhat narrow. Antennæ attaining the prothoracic base. Elytra arcuately declivous behind. Abdomen slightly oblique and quite moderately convex, broadly impressed at middle of the first two segments. Anterior tarsi with the first joint slightly thickened at tip beneath and invested with a moderately obtusely pointed tuft of golden, silken pubescence, which is inclosed by a few ordinary spinules; second joint very feebly thickened with tuft not evident, or at most scarcely half as large as that of the first.

Female.-Rather broadly oblong. Antennæ not quite attaining the prothoracic base. Elytra arcuately and vertically declivous posteriorly. Abdomen horizontal and rather strongly convex. Anterior tarsi with the first joint slightly thickened at tip beneath, groove interrupted by ordinary piceous or ferruginous spinules.

Measurements.-Males: Length, 14-16 mm.; width, 5.5-6.5 mm. Females: Length, 15-18.5 mm.; width, 7-7.5 mm.

Genital characters, male.-Edeagophore flattened oblong-ovate and not arched.

Basale oblong oval; surface rather feebly convex, with the sides moderately arcuate.

A picale rather small, triangular, and about a half longer than wide; surface evenly convex, not grooved; sides somewhat arcuate in basal sixth, thence feebly and very broadly sinuate to apex, the latter subacute; base broadly lobed at middle and feebly sinuate laterally.

Sternite transversely parabolic. Each lobe with the outer border more or less evenly arcuate; apical margin broadly and evenly rounded; internal margin feebly arcuate; surface very feebly convex, very sparsely punctate and setose, setæ moderately long, slightly 
longer on apical margin, impunctate in basal fourth. Membrane not setose across the bottom of the sinus, the latter narrowly triangular.

Female.-Genital segment elongately triangular, superior surface plane.

Valvula (Plate 1, fig. 9).-Dorsal plate elongately oblong; surface plane, glabrous, obsoletely punctate and sparsely setose; sides more or less feebly arcuate and subparallel; apical margin feebly arcuate or subtruncate, scarcely rounded internally over the apical lobe, angle evenly rounded. Apex rather long and slender, subacute and finely setose, with a few long setæ at tip; external apical lobe not in the least evident.

Appendage short mammilliform, with about two to four long setæ at tip. Fossa in basal and external surface of apex.

Superior pudendal membrane reaching to the apical fourth of the dorsal plate and longitudinally rugulose.

Basal prominences not evident, evenly rounded at base.

Ventrolateral surfaces (Plate 1, fig. 10).-Body quite triangular and evenly convex from side to side, glabrous, surface lines straight as viewed longitudinally, very feebly punctate and setose about the apex.

Submarginal groove moderate beneath the slightly explanate external border of the dorsal plate and attaining the fossa. Internal margins of the valves contiguous in about basal three-fourths; genital fissure very narrow in apical fourth; the inferior pudendal membrane is not visible.

Habitat.-California (Owens Valley, Dr. George Horn; Bodie, elevation 8,475 feet, July, Wickham; Lundy, 7,000-8,000 feet, July) ; Nevada (western, Mr. Gabb; Verdi, April, Blaisdell).

Number of specimens studied, 125.

Type in the Horn collection.

Type-locality.-Owens Valley, California; collector, George Horn.

Salient type-characters.-Opaque. Head rather coarsely punctured. Thorax one-third broader than long, very coarsely punctured, becoming granular at the sides; sides strongly rounded, margin entire, basal angles moderately prominent, rectangular. Elytra elongate oval, moderately convex, sides moderately rounded; basal angles obtuse; surface rather densely and irregularly covered with small, rounded, shining tubercles, arising from a very opaque base (Horn).

Diagnostic characters.-The salient type characters differentiate tenebrosa from all other species of the subgenus-in fact it is quite unique among its congeners by not having the elytra broader at the widest part than the thorax.

Occasionally specimens are observed with the sides of the pronotum evenly rounded from base to apex and in this character resemble snowii, but here the surface is more or less shining and the 
pronotal disc is less coarsely punctured. These remarks apply especially to the Arizona or elongate form of snowii.

I have seen a few specimens that were rather ovate in form, with the elytra showing a tendency to become less elongate and wider than the prothorax. Such variations are expected and must be recognized.

General observations.-The mentum is usually quite parabolic in outline, sometimes subtriangular; surface very slightly convex, not coarsely but quite densely punctate laterally, where it is sometimes subfoveate; the punctures are not noticeably setigerous.

The prosternum is variable, more or less prominent ventrally with the coxæ, and moderately widened behind the axes of the acetabula, frequently grooved at the middle. In the more strongly developed individuals it is horizontal between the coxæ and mucronate behind; in others, arcuate antero-posteriorly and with a more or less welldeveloped mucro at the middle of the posterior border; again, it is evenly arcuate and not at all mucronate.

The mesosternum is vertically arcuate, or more obliquely so, deeply concave, appearing somewhat bilobed; the concavity varies in depth.

The metasternum laterally between the coxæ is as long as the width of a protibia at apex.

The abdominal process is quadrate and about a fourth of its width wider than the metasternal salient, and equal in length to the postcoxal portion of the first segment; also about equal to the length of the second segment (male).

In the male the second segment is one-half longer than the fourth, and the third about a third longer than the same segment. In the female the second is twice as long as the fourth and about a fourth longer than the third.

The tarsi are moderate in length and somewhat stout.

The protarsi are about two-fifths (male) to three-eighths (female) of their length shorter than a mesotarsus.

The mesotarsi are about a seventh (male) to an eleventh (female) of their length shorter than a metatarsus.

The metatarsi are about three-eighths (male) to two-thirds of their length shorter than a metatibia.

\section{ELEODES TENEBROSA var. NANA, new.}

As in tenebrosa, except smaller, more strongly and densely sculptured. Sides of the pronotum slightly tuberculate, margin more strongly sinuate before the basal angles. Elytral tubercles larger and more distinct, more evidently setigerous at the sides; humeri obtuse, scarcely rounded to subrectangular, with the epipleural margin often visible at the angle.

Measurements.-Males: Length, 10.5-12.5 mm.; width, 5-5.5 mm. Females: Length, $12 \mathrm{~mm}$; width, $6 \mathrm{~mm}$. 
Genital characters as in tenebrosa.

Habitat.-Nevada (Carson City, July, Wickham; Verdi, April, Blaisdell) ; California (U. S. National Museum collection-no exact locality given).

Diagnostic characters.-Nana is more coarsely sculptured; the tubercles of the elytra are denser, confluent, and submuricate, but most of them still remain bright and shining. The humeri are more often subangulate. This form inhabits the same region as the typical race.

\section{ELEODES INCULTA LeConte.}

Eleodes inculta LeConte, Proc. Acad. Nat. Sci. Phila., 1861, p. 352, male.Hons, Trans. Amer. Phil. Soc., XIV, 1870, p. 315.

Robust, oblong ovate, about twice as long as wide, black, often somewhat piceous, feebly shining to somewhat dull; elytra irregularly and subasperately muricately punctate.

Head about twice as wide as long, feebly convex, more or less broadly impressed laterally and along the frontal suture, the latter more or less evident; irregularly and not very finely punctate, rather densely so laterally and on the epistoma. Antenno moderately long, somewhat slender, outer four joints feebly compressed and feebly incrassate, third jeint scarcely as long as the next two taken together, fourth just the least longer or subequal to the fifth, the latter, sixth, and seventh subequal, eighth just a little shorter and more or less subtriangular, ninth and tenth suborbicular in outline or very feebly transverse, eleventh short-ovate.

Pronotum more or less transversely quadrate, a third to a half wider than long, widest at the middle; disc moderately and very evenly convex, distinctly, irregularly, and not coarsely punctate, punctures separated by an interval equal to or twice their own diameters, narrowly subgranulate laterally; apex broadly, evenly, but not strongly emarginate, finely and somewhat obsoletely margined; sides evenly, broadly, and not strongly arcuate, very feebly subsinuate before the basal angles, and less so behind the apical angles, marginal bead fine and entire; base very feebly and broadly rounded, subtruncate, rather coarsely margined, one-sixth to one-third wider than the apex, equal to or a little greater than the length; apical angles subacute, slightly prominent anteriorly, and with a slight tendency to eversion; basal angles obtuse and not in the least rounded, just in the least prominent.

Propleurce smooth and shining, sparsely and distinctly submuricately punctate and rugulose.

Elytra oval, less than a third longer than wide, widest at the middle; base subtruncate. Humeri more or less broadly rounded, epipleural margin not visible from above; sides evenly arcuate, apex 
not very narrowly rounded; disc moderately to rather strongly convex on the dorsum, sides not broadly rounded, inflexed portions scarcely arcuate, arcuately declivous posteriorly; surface irregularly and quite densely, more or less distinctly subasperately and muricately punctate, sculpturing not strong, simple centrally and not distinctly granulate laterally and on the apex.

Epipleurce moderately wide, gradually narrowing from base to apex, superior margin not strong and almost straight beneath the humeri; surface smooth, impunctate toward base, obsoletely and sparsely punctate toward apex.

Sterna.-Prosternum scabrously rugoso-punctate; meso- and metasterna more or less shining, glabrous and rugoso-punctate.

Parapleurce rather densely, more or less evenly, and somewhat coarsely punctate.

Abdomen shining, sparsely and finely punotate, more or less rugulose.

Legs rather short and somewhat slender; anterior femora mutic and not noticeably sinuate; tibial spurs rather slender and moderate in length, similar in the sexes; anterior spurs of the protibiæ slightly longer than the posterior; anterior and middle tarsi dissimilar in the sexes.

Male.-Oblong-ovate, somewhat slender. Antennæ reaching a little beyond the base of the prothorax. Elytra evenly and arcuately declivous posteriorly. Abdomen slightly oblique apically, moderately convex, segments one and two broadly impressed at middle. First three joints of the protarsi not noticeably thickened and clothed with golden pubescence beneath, surface of the pads flat; first two joints of the mesotarsi similarly pubescent, first joint in apical half, the second with a much smaller tuft at tip.

Female.-Distinctly robust. Antennæ about attaining the base of the prothorax. Elytra broadly oval, arcuately and more or less vertically declivous behind. Abdomen horizontal and strongly convex. First two joints of the anterior and middle tarsi a little more pubescent than usual beneath, grooves not evident.

Measurements.-Males: Length, 13.5-14 mm.; width, 6.5-6.5 mm. Females: Length, 14-17 mm.; width, 7.5-8 mm.

Genital characters, male.-Edeagophore flattened oblong-ovate, acutely pointed at apex and scarcely arched.

Basale oblong-suboval, moderately convex, sides feebly arcuate and nearly parallel.

A picale triangular. Surface very moderately convex, without groove; sides briefly arcuate at base, thence broadly and more or less strongly sinuate, so that the apex appears more or less attenuated in apical half; base evenly rounded and scarcely lobed at middle. 
Sternite parabolic and slightly transverse. Each lobe triangular; external border slightly oblique, and more or less feebly sinuate in basal half, thence subtruncate and feebly arcuate to apex, the latter moderately rounded; internal border more or less sinuate; surface feebly convex, rather coarsely and densely punctate in apical threefourths, setæ rather long, denser on apical margin.

Female.-Genital segment (Plate 5, fig. 13) triangular, about a third longer than wide; surface about plane, finely setose on apex.

Valvula.-Dorsal plate oblong, elongate, about three times longer than wide; surface plane, more or less declivous laterally at base, smooth and shining, very sparsely and finely punctulate in apical half, setæ very fine and not distinct; external border about straight, feebly sinuous and very feebly converging apically; apical margin more or less arcuate and rather distinct from apex; internal margin quite straight. Apex short and scarcely more prominent than the appendage, subacute, membranous, finely setose, with a few rather long setæ at tip.

Appendage short mammilliform, with a pencil of quite long setæ at tip. Fossa nearly occupying the external surface of the apex.

Basal prominences not evident.

Superior pudendal membrane scarcely longitudinally rugulose and attaining the apical fourth of the dorsal plate.

Ventrolateral surfaces.-Body triangular, surface lines straight as viewed longitudinally, smooth and shining, feebly punctate and setose in apical third; submarginal groove distinct beneath the slightly explanate external border of the dorsal plate. Internal margins of the valves contiguous in basal three-fifths, fissure in apical two-fifths, narrow and nearly closed.

Habitat.-Nearly all of the specimens before me were taken on Santa Rosa Island, which lies off the coast of Santa Barbara County, California. One specimen bears a "Santa Barbara Co." label and another simply a "Cal.," while in Mr. Fuchs' collection is one labeled "Alameda County." There are no differences noticeable in the specimens. I am not sure that this species is found on the mainland.

Number of specimens studied, 19.

Type a male in the LeConte collection.

Type-locality.- Santa Rosa Island; collector, Mr. C. M. Bache.

Salient type-characters.-Subopaque. Head and thorax rather densely punctate; thorax with the sides strongly rounded, briefly sinuate behind; basal angles obtuse and slightly prominent; base broadly rounded. Elytra oval, apex attenuate and strongly declivous; humeri broadly rounded, dorsum deplanate, punctures small and granular, irregularly placed, granules on each side briefly piliferous. Antennæ a little incrassate at tip (LeConte). 
Diagnostic characters.-Inculta is a distinct species, with a shorter, more robust form, distinctly transverse prothorax (female), and feebly subasperate (subgranular) punctuation. The sides of the prothorax are scarcely at all sinuate before the basal angles-in some specimens not in the least and in others feebly so; the basal angles are obtuse, distinct, and with the appearance of being just a little prominent; the lateral bead is distinctly entire.

I do not believe inculta to be a synonym of scabripennis. The type of the latter is a female and was taken at Fort Tejon. Doctor Horn made so many wrong determinations in Eleodes that I can not believe him right in this instance.

Mr. Blanchard has very carefully compared a female inculta (which is before me) with the female type of scabripennis. His comments are as follows: "Shorter and less convex than the type of scabripennis, thorax much broader. It seems nearer inculta of which the type is a male with base of the prothorax more constricted." Later and in another sending I submitted a male specimen, which he unhesitatingly pronounced inculta. I sent the female first intentionally with a request to compare it with scabripennis.

The form of the thorax in snowii (male and female) and the male of inculta is quite similar, but the apical angles in the latter are more acute and prominent, and in every example studied the sides are just the least subsinuate behind the angles so as to give them an appearance of having a slight tendency to eversion.

The form of the prothorax should readily separate inculta from hornii, neotomo and consobrina-none have it so transverse in the female, nor the sides so feebly sinuate at base as a constant character. In consobrina the apical angles are as prominent, but scarcely as acute, the sides may be feebly sinuate behind the apical angles and more or less strongly sinuate before the base.

General observations.-The mentum is moderate in size, sometimes rather small in the male, subtruncate and parabolically rounded; surface feebly convex, scarcely subfoveate laterally, finely punctate, the punctures not distinctly defined nor noticeably setigerous.

The prosternum is moderately prominent ventrally with the coxæ, moderately arcuate antero-posteriorly between the coxæ and usually with a small mucro behind at middle; at other times more feebly areuate and more or less vertical behind, with the angle mucroid.

The mesosternum is arcuately declivous and more or less deeply and not broadly concave.

The metasternum laterally between the coxæ is as long as the width of a mesotibia at apex.

The abdominal intercoxal salient is subquadrate (male) or slightly transverse (female) and a little (male) to a fourth (female) of its own width broader than the metasternal process. 
The post-coxal portion of the first abdominal segment is equal in length to the process, also to that of the third (male).

In the male the second segment is a third of its length longer than the fourth; in the female the second is twice as long as the fourth and a little longer than the third.

The tarsi are slender and moderate in length.

The protarsi are about two-fifths (male) to a fourth (female) of their length shorter than a mesotarsus.

The mesotarsi are about a seventh (male) to a fifth (female) of their length shorter than a metatarsus.

The metatarsi are about a fourth (male) to two-thirds (female) of their length shorter than their respective metatibiæ.

\section{ELEODES CONSOBRINA LeConte.}

Eleodes consobrina LeConte, Ann. Lyc. Nat. Hist. N. Y:; V. 1851, p. 135.Hons, Trans. Amer. Phil. Soc., XIV, 1870, p. 316.

Eleodes veseyi LeConte, Proc. Acad. Nat. Sci. Phila., 1858, p. 187.

Oblong-ovate, robust, elytra coarsely and submuricately punctate centrally and tuberculate laterally; surface dull or feebly shining.

Head about twice as wide as long, more or less feebly convex, slightly impressed laterally and often along the frontal suture, which is generally evident as a more or less smooth line, sides of the frons not usually prominent, more or less evenly, rather densely and somewhat finely punctate, punctures slightly denser laterally. Antenno rather stout, moderate in length, scarcely compressed, very feebly and gradually widened in outer four joints, third joint comparatively short and scarcely as long as the next two combined, fourth to the eighth, inclusive, quite equal, ninth and tenth feebly transversely oval, eleventh short-ovate.

Pronotum somewhat transversely oblong-oval in outline, twosevenths to a third wider than long, widest at the middle; disc moderately to rather strongly and evenly convex, quite densely, evenly, or irregularly punctate, punctures moderately coarse, becoming granulate at the sides; apex evenly and moderately emarginate, obsoletely margined; sides more or less strongly arcuate and constricted at basal twelfth or eighth, thence briefly straight or feebly oblique to the basal angles, marginal bead rather thin and fine, at times somewhat coarser and more or less entire and reflexed; base slightly rounded and not very coarsely beaded, equal to or a fourth wider than the apex and about equal to the length; apical angles subacute to feebly rounded and rather prominent anteriorly; basal angles minute, obtuse or rectangular, feebly prominent at times.

Propleurce opaque, not densely muricato-granulate, and more or less rugulose about the acetabular convexities. 
Elytra suboblong-oval, about a half longer than wide, widest at the middle; base rather truncate and more or less sinuate. Each side of the middle equal to or distinctly wider than the contiguous prothoracic base; humeri more or less obtusely rounded; sides evenly and moderately arcuate, apex more or less feebly attenuate, not very narrowly rounded; dise moderately convex, not noticeably flattened, evenly and strongly rounded laterally, arcuately declivous posteriorly; surface irregularly, densely and coarsely, slightly submuricately punctate on the dorsum, sides and apex densely sculptured with reclinate granules or tubercles, rarely the punctures are feebly subseriate on the dorsum each side of the suture.

Epipleurce comparatively moderate in width, gradually narrowing from base to apex, superior margin nearly straight-at most but feebly sinuate beneath the humeri, somewhat decurving apically, rarely visible from above at the humeri; surface very sparsely submuricately punctulate.

Sterna densely punctato-rugulose.

Parapleura more or less shining and coarsely punctate.

Abdomen more or less shining, more or less densely and coarsely punctate, more strongly so and rugulose to rugose about the coxæ, less densely and more finely sculptured on the last two segments.

Legs moderate in length, somewhat stout, and densely but not very coarsely seulptured; anterior femora mutic; tibial spurs similar in the sexes, the anterior of the protibiæ slightly longer than the posterior; tarsi dissimilar in the sexes.

Male.-Oblong-ovate, somewhat narrow. Antennæ scarcely reaching beyond the prothoracic base. Elytra somewhat attenuate in apical fourth, arcuately and rather obliquely declivous behind. Abdomen more or less oblique and moderately convex, more or less broadly impressed at middle on the first two segments. First two joints of the protarsi slightly thickened at tip beneath, and there clothed with blunt tufts of yellowish pubescence, the second smaller than the first; first joint of the mesotarsi with a similar but moderate tuft, obliterating the groove.

Female.-Robust, ovate. Antennæ scarcely attaining the prothoracic base. Elytra arcuately and quite vertically declivous behind. Abdomen horizontal and rather strongly convex. First joint of the protarsi slightly thickened at tip beneath, groove almost entire.

Measurements.-Males: Length, $15-16.5 \mathrm{~mm}$.; width, 6-6.5 mm. Females: Length, 16-19 mm.; width, 7.5-9 mm.

Genital characters, male.-Edeagophore flattened oblong-ovate, very slightly arched.

Basale oblong, slightly more than twice as long as wide; sides feebly arcuate, subparallel; surface moderately convex. 
A picale triangular, moderately convex above, without groove; sides slightly prominent at base, thence feebly sinuate to tip, the latter subacute; base with a moderate and rounded lobe at middle, feebly arcuate laterally.

Sternite transversely parabolic. Each lobe triangular; surface glabrous, feebly convex, impunctate in basal third, punctate elsewhere, more densely so about apex, setose, setæ moderately long; external border obliquely arcuate; apex narrowly rounded, and continuously so with the internal border which becomes sinuate. Membrane not setose, sinus rather broad and triangulo-oval.

Female.-Genital segment parabolo-triangular, rathè depressed, dorsal surface quite plane and not noticeably setose, except at apex, glabrous.

Valvula (Plate 4, figs. 9 and 10).-Dorsal plate oblong, quite horizontal, with the sides subparallel; surface plane or very slightly concave, obsoletely punctulate; internal and external borders slightly arcuate; apical border more or less evenly rounded, angle not in the least evident. Apex triangular, rather broad, very finely setose, setæ at tip moderately long. Fossa at base of the external surface of the apex behind the dorsal plate.

Appendage short mammilliform, with a pencil of quite long setæ at tip.

Superior pudendal membrane longitudinally rugulose and rather broadly exposed, attaining the apical fourth of the dorsal plate.

Basal prominences very small.

Ventrolateral surfaces triangularly plane at center to base; surface lines quite straight as viewed longitudinally and moderately convex transversely; surface smooth and impunctate. Submarginal groove well developed beneath the distinctly explanate external margin of the dorsal plate, extending obliquely across the base of the apex as a shallow concavity; apex finely setose.

Internal margins of the valves contiguous in basal three-fourths; genital fissure in apical fourth and rather narrowly fusiform. Inferior pudendal membrane not visible.

Habitat.-California (San Diego County; San Bernardino Mountains; Los Angeles County; Santa Barbara County; Fort Tejon, Fuchs and Hopping; San Francisco County; Shasta and Siskiyou counties).

Number of specimens studied, 45.

Type.-A male in the LeConte collection.

Type-locality.-Mountains about Santa Isabel, California.

Salient type-characters.-Oblong. Thorax rounded, apex emarginate, thickly punctate, sides granulate, margin reflexed, posterior angles minute. Elytra thickly and coarsely punctate, sides and posteriorly rough and reclinately granulate, apex attenuate (LeConte). 
Diagnostic characters.-It would appear from a careful study of LeConte's description that the type (male) had the sides of the pronotum rounded nearer to the base than in the majority of the specimens before me, in consequence there is a less degree of constriction and the angles smaller; such is the case in a specimen which has been compared with the type by Professor Fall, and in his collection, and which I take to be quite typical. The example was collected in the San Bernardino Mountains.

In all of the specimens making up a small series taken at Fort Tejon by Fuchs and Hopping, the sides of the pronotum are more strongly constricted, straight, and parallel in about the basal eighth; the angles are therefore larger and rectangular, but some of the specimens approach Professor Fall's specimen, so that this character is simply a variation and of no specific value.

The Fort Tejon specimens no doubt belong to the form described by LeConte as veseyi, the type of which is a large male and remarkable for the attempt at striæ of large punctures near the middle of the elytra (LeConte). Mr. Blanchard writes me that veseyi is so near the type of consobrina that he is surprised that LeConte should have given it a name; it is no doubt a heterotype and therefore a true synonym of consobrina. In veseyi the pronotum is more strongly constricted and the basal angles larger and subrectangular; therefore it is related to the specimens above mentioned from Fort Tejon.

An interesting specimen from Lower California was referred to consobrina by Doctor Horn ; ${ }^{a}$ it was destroyed with the Academy in the recent disaster before I had an opportunity to study it.

It is very difficult oftentimes to satisfactorily separate this species from some forms of parvicollis; as a rule in consobrina the pronotum is more strongly and evenly convex from side to side, and not at all impressed or flattened within the lateral margins; in parvicollis, when the pronotal surface is evenly arcuate from side to side, it generally arises more suddenly and strongly from the margins.

In consobrina the humeri are more rounded and the superior epipleural margin not visible from above; the elytral sculpturing is also coarser and tuberculate. These characters are valuable when the pronotal ones are weak or exhibit an approach to parvicollis, as they do sometimes. The heterotypes of both species are at times no doubt amphitypical.

In consobrina the marginal bead is not so reliable a character as in tenebrosa, inculta, and snowii, for instance; the species is always more robust.

It is often necessary to examine the genital segment of the female to more satisfactorily place some particular specimen, and males from the same region can be placed with the females.

${ }^{a}$ Proc. California Acad. Sciences, 2 d ser., IV, Pt. 1, p. 350. 
Specimens from the Farallone Islands have been determined as consobrina by Doctor Horn, but I prefer to consider them as a form of parvicollis, for the following reasons:

The general facies is more like the latter species, although in some specimens the marginal bead is entire, the specimens are decidedly less convex, and the pronotal disc is feebly impressed laterally, the basal constriction is stronger, and the sculpturing is plainly more muricate laterally than tuberculate. Again, parvicollis is much more abundant along the coast on the mainland at points opposite the islands than is consobrina, so that in all probability when that body of land became separated from the mainland it was populated with the form of parvicollis existing at that time, and as this change occurred in comparatively recent times, the species has undergone but slight change since and is practically identical with that which is now found along the coast on the mainland.

I have collected for several years about San Francisco Bay and have not taken a single specimen of consobrina, while I have found parvicollis abundant. Consobrina is surely more abundant south than north of San Francisco.

In consobrina the genæ are not produced as in blanchardii, and for remarks on scabripennis see p. 338 . In fuchsii the prothorax is comparatively smaller and less convex.

In some specimens (females from Los Angeles County) the elytra are densely and distinctly tuberculate throughout.

General observations.- The mentum is triangulo-parabolic to parabolic in outline; surface convex at middle and more or less foveate along the sides, rather densely but not distinctly punctate and not noticeably setose.

The prosternum is not strongly prominent ventrally with the coxæ, coarsely sculptured, usually distinctly grooved along the middle, horizontal; rarely feebly arcuate antero-posteriorly between the coxæ, strongly and horizontally mucronate behind; often vertically truncate posteriorly with the angle more or less well developed as a mucro, which may be deflexed or oblique.

The mesosternum is arcuately and obliquely declivous, deeply and rather broadly concave, so that it appears somewhat bilobed.

The metasternum laterally between the coxæ is as long as the width of a mesotibia at middle or base.

The abdominal process is subquadrate (male) to moderately transverse (female) and a third (male) to a sixth (female) wider than the metasternal salient.

In the male the post-coxal part of the first abdominal segment is equal in length to the process, and also to that of the second; the latter is twice as long as the fourth; the third is a half longer than the fourth.

59780-Bull. $63-09-22$ 
In the female the second segment is equal in length to the process; the third is equal to that of the post-coxal part of the first and about a third longer than the fourth.

The tarsi are moderate in length and more or less stout.

Tarsal formula:

$\begin{array}{rccc}\text { Pro. } & \text { Meso. } & \text { Meta. } & \text { Metatibia. } \\ \text { Male. }-2 \frac{1}{2} & 3 \frac{1}{3} & 4 & 6 \\ \text { Female.- } 2 & 2 \frac{3}{4} & 3 \frac{1}{3} & 5 \frac{1}{2}\end{array}$

\section{ELEODES SCABRIPENNIS LeConte.}

Eleodes scabripennis LeConte, Proc. Acad. Nat. Sci. Phila., 1859, p. 77, female.-Horn, Trans. Amer. Phil. Soc., XIV, 1870, p. 315.

The original description is as follows:

"Atra, ovata, subnitida, thorace latitudine paulo breviore, subquadrato, lateribus rotundatis, postice sensim paulo angustato, angulis posticis obtusis dense punctato, ad latera subasperato, elytris ovalibus, thorace latioribus, dorso parum convexis, postice valde declivibus, grauulis parvis inordinatis dense exasperatis, et versus suturam punctatis, tibiis muticis, prosterno postice oblique submucronato, antennis extrorsum parum incrassatis. Long. .65."

Habitat.-California (Fort Tejon).

Diagnostic characters.-Mr. Blanchard writes me that the type is a robust female, with the following remarks upon the same: Stout, convex. Thorax convex, wider than long, sides very briefly sinuate at hind angles, coarsely, densely punctate, more closely and asperately on sides, base margined; flanks opaque, rather closely and distinctly granulate. Elytra convex, sides strongly rounded, coarsely granulate; epipleuræ broad, sparsely granulate, antennæ rather stout, joints 4-7 subelongate, 8th scarcely longer than wide.

LeConte compares it with veseyi, saying that it has the same sculpturing and size, but differing by the thorax being much less rounded on the sides, by the posterior angles not being at all prominent.

I have not seen a single specimen in the material at hand which I could refer to this species, and personally I have no idea of its habitus. Fortunately I can rely upon the observations of such careful workers as Mr. Blanchard and Professor Fall.

Mr. Blanchard has compared all likely specimens with the type at Cambridge and has failed to refer any examples to the present species. For remarks upon inculta see p. 332.

Professor Fall compared a series with the LeConte type and labeled a male example as scabripennis. It was collected at Santa Barbara, California. This specimen has the form of a male consobrina, from which it differs no more than the males of that species differ among themselves. The elytral sculpturing is more like sharpened granules than tubercles, finer and dense, with punctures simple each side of the suture; the pronotal punctuation is denser than in 
consobrina. The specimen is distinctly consobrina-like in general, and not at all like inculta.

If this specimen is to be considered as an exponent of scabripennis, I would have no hesitation in pronouncing it as a synonym of consobrina.

One fact is evident, that no student besides LeConte ever had any true conception of this species. Doctor Horn did not, for he referred the Santa Barbara specimens (inculta?) to this species. I know of only one authentic specimen, and that is the type.

A specimen in Doctor Van Dyke's collection was doubtfully referred to scabripennis; it was collected at Indio, California. It is very opaque and sordid in appearance; the sculpturing is rather coarse and dense, but upon examination I found the genæ produced, and it is therefore blanchardii, although rather strongly sculptured and larger (16.5 mm.-8 mm.) than any example of the series studied. It makes a good companion for Casey's specimen referred to under blanchardii.

Until more collecting has been done about Fort Tejon and Santa Barbara, I recommend that scabripennis be retained on our lists.

LeConte writes that the prosternum is a little more prominent behind than in veseyi.

\section{ELEODES BLANCHARDII, new species.}

Oblong-ovate, somewhat robust at times, scarcely twice as long as wide, elytra coarsely punctate and subtuberculate laterally; genæ distinctly produced; surface somewhat dull.

Head scarcely twice as wide as long, feebly convex, more or less feebly and broadly impressed laterally, sometimes feebly so along the frontal suture, the latter more or less evident as a smooth line; rather thickly punctate, punctures rather coarse and somewhat granulate, denser laterally and on the epistoma. Antennce moderate in length and stoutness, feebly compressed and slightly dilated in the outer four joints, third joint about equal in length to the next two combined, fourth just the least longer than the fifth, the latter to the eighth inclusive subequal in length and slightly longer than wide, the eighth sometimes subtriangular, ninth and tenth orbicular to slightly transverse in outline, eleventh truncate-ovate and about as long as wide.

Pronotum somewhat transversely suboval, about a half wider than long, widest at the middle; disc moderately evenly convex, rather densely and more or less evenly punctate, punctures moderate in size, becoming granulate at the sides; apex subtruncate in circular arc, obsoletely beaded; sides evenly and rather strongly rounded, more or less constricted or sinuate at basal ninth, thence straight or oblique 
to angles, marginal bead more or less reflexed and somewhat entire; base feebly rounded and feebly beaded, scarcely a seventh wider than the apex and equal to the length; apical angles obtuse, sometimes distinct and at others feebly rounded; basal angles subrectangular and not at all prominent.

Propleurce more or less coarsely and rather sparsely muricatogranulate, more or less rugulose on the acetabular convexities.

Elytra oval to somewhat oblong-oval, about a third longer than wide and widest at the middle; base subtruncate, wider than the contiguous prothoracic base; humeri more or less obtusely rounded; sides evenly arcuate, apex not broadly rounded; disc more or less moderately convex on the dorsum, rather strongly, evenly, and not very broadly rounded at the sides, arcuately declivous posteriorly; surface coarsely punctate, punctures irregularly placed, with a tendency to coalesce in twos and threes, rather simple and with a feeble corroded appearance on either side of the suture, becoming muricato-tuberculate laterally and on the apex.

Epipleurce moderate in width, gradually narrowing from base to apex, superior margin rather strong, scarcely sinuate beneath the humeri, where it is sometimes slightly visible at the angle from above; surface usually impunctate and smooth.

Sterna densely and rather scabrously sculptured.

Parapleura coarsely and rather densely punctate.

Abdomen more or less shining, quite coarsely and densely rugosopunctate, especially about the coxæ; last two segments more finely, less densely punctate, and not rugose.

Legs moderate in length and stoutness; anterior femora mutic; anterior tibial spurs rather small and similar in the sexes, the anterior slightly longer and just noticeably stouter than the posterior; anterior and middle tarsi dissimilar in the sexes.

Male.-Oblong-ovate, somewhat narrow. Antennæ attaining the prothoracic base. Elytra arcuately and somewhat obliquely declivous behind. Abdomen slightly oblique, moderately convex, broadly and rather strongly impressed at middle of the first two segments. Anterior tarsi with the first two joints not noticeably thickened at tip beneath, each with a small tuft of yellowish pubescence, tufts subacute; first joint of the middle tarsi bearing a small tuft.

Female.-Ovate, somewhat robust. Antennæ not attaining the prothoracic base. Elytra arcuately and almost vertically declivous posteriorly. Abdomen horizontal and rather strongly convex. Anterior tarsi with the first joint slightly thickened at tip beneath, groove scarcely interrupted by the apico-marginal spinules.

Measurements.-Males: Length, $15 \mathrm{~mm}$; width, $6.3 \mathrm{~mm}$. Females: Length, 14.5-17 mm.; width, 7.3-7.5 mm. 
Genital characters, male.-Edeagophore elongately oblong-ovate and slightly arched.

Basale elongate oblong, slightly narrowing apically; surface evenly convex and the sides feebly arcuate.

A picale triangular; surface moderately convex, without groove; sides quite strongly sinuate in apical two-thirds, apex appearing attenuate and acute; base obtusely lobed at the middle and sinuate laterally.

Sternite transversely parabolic in outline. Each lobe subtriangular; surface feebly convex and glabrous, punctate and setose in apical three-fourths, punctures rather dense, especially about apex, setæ moderate in length, longer about apical margin; external margin more or less arcuate to apex, the latter introrse and rather narrowly rounded; internal margin quite straight. Membrane not setose across the bottom of the sinus, the latter rather deep and triangular.

Female.-Genital segment triangular, obtuse at apex and moderately depressed; surface nearly plane, well chitinized, and sparsely setose.

Valvula (Plate 6, fig. 1). Dorsal plate oblong, four times as long as wide; surface glabrous and shining, slightly concave, very sparsely punctate and setose in apical moiety, setæ fine; sides parallel and more or less feebly arcuate or sinuous; apical margin evenly rounded. Apex short and more or less chitinized, finely and rather densely setose, setæ slightly longer at tip.

Appendage short mammilliform with pencil of moderately long setæ at tip; fossa in the external surface of apex and not covered by apical margin of the dorsal plate, setæ just noticeably longer about its margins.

Superior pudendal membrane longitudinally rugulose and attaining the apical fourth of the dorsal plate.

Basal prominences scarcely evident.

Ventrolateral surfaces flattened centrally to base, triangular, surface lines straight, viewed longitudinally; laterally moderately rounded. Submarginal groove well developed beneath the slightly explanate external border of the dorsal plate, and attaining the fossa, surface scarcely at all concave before the apex. Internal margins of the valves contiguous in basal two-thirds; genital fissure narrow in apical third, inferior pudendal membrane not visible.

Habitat.-California (San Diego County). I have taken this species upon the Bolcan Mountain, which borders Warner's ranch. It probably occurs throughout the Cuyamaca Range, also at Poway (elevation, 700 feet). Examples are before me from the Blanchard collection, and others received from D. W. Coquillett a number of years ago, all, however, from the above-named county. 
Number of specimens studied, 9.

Types in my own and Mr. Blanchard's collections.

Type-locality.--San Diego County, California.

Salient type-characters.-The buccal processes of the genæ are produced and anteriorly prominent. Pronotum moderately convex; apex subtruncate in circular arc; sides rather strongly rounded, constricted at basal ninth, thence straight to the basal angles, the latter subrectangular; apical angles obtuse and distinct. Elytra about a third longer than wide; humeri obtuse and rounded, epipleural margin just visible from above; disc coarsely punctate, punctures somewhat eroded, noticeably coalescing in twos and threes, simple about the suture, muricato-tuberculate laterally and about apex; the most peripheral are distinct and shining tubercles.

Diagnostic characters.-Smaller and similarly sculptured to consobrina, to which it is closely related, and easily separated by the unusually developed buccal process of the genæ that are anteriorly produced and somewhat acute.

An example before me, and kindly given me for study by Colonel Casey, apparently belongs here. It has the thorax very coarsely and densely punctate. There is also a tendency for the punctures to coalesce. In fact, it is more strongly sculptured throughout than any other specimen of blanchardii at hand. A female taken on the Bolcan Mountain approaches it and connects it with the typical specimens. Casey's specimen has the buccal processes very slightly prominent and not narrowed. It is without doubt heterotypical of the present species; in form it agrees with a male in Mr. Blanchard's collection.

It should be noted that the elytra are shorter than in consobrina.

I take great pleasure in remembering the kind and painstaking aid accorded me by Mr. Frederick Blanchard.

General observations.-The mentum is comparatively large, but variable in size, slightly transverse and parabolic in outline, sometimes less strongly rounded at the sides; surface rather broadly convex at the center and narrowly subfoveate within the lateral margins; not noticeably setose.

Pro- and mesosternum as in consobrina. The metasternum laterally between the coxæ is as long as the width of a mesotibia at the middle.

The abdominal process is subquadrate, and a fifth (female) to a third (male) of its width broader than the metasternal salient, also equal to the post-coxal part of the same segment, equal to the length of the third (female).

In the male the second segment is twice as long as the fourth, the third being a third of its own length longer than the fourth.

In the female the second is twice as long as the fourth.

The tarsi are of moderate length and not as stout as in consobrina. 
Tarsal formula :

\begin{tabular}{|c|c|c|c|}
\hline Male. ${ }^{\text {Pro. }}$ & $\begin{array}{l}\text { Meso. } \\
2 \frac{3}{4}\end{array}$ & $\begin{array}{c}\text { Meta. } \\
3\end{array}$ & $\begin{array}{c}\text { Metatibia. } \\
5\end{array}$ \\
\hline Female.-2 & $2 \frac{1}{2}$ & $2 \frac{3}{4}$ & 5 \\
\hline
\end{tabular}

ELEODES FUCHSII, new species.

Ovate, subopaque, prothorax comparatively small. Elytra subasperately granulate laterally and on apex. Head about twice as. wide as long, more or less feebly convex, impressed laterally and usually along the frontal suture, the latter more or less bisinuate and fine, sides not very prominent, more or less evenly punctate, punctures moderately fine and not very densely placed. Antenno rather long, feebly compressed and slightly widened in the outer four joints, third joint scarcely as long as the next two combined, the fourth to the eighth inclusive subequal in length, the eighth slightly widened, ninth as wide as long and subtriangular, tenth orbicular or triangulo-orbicular, eleventh ovate.

Pronotum scarcely to moderately transverse, a fourth to a half wider than long, widest at about the middle; disc moderately and evenly convex, rather densely and somewhat finely punctate, becoming more or less granulate along the sides; apex slightly and evenly emarginate or truncate in circular arc, obsoletely margined; sides rather strongly arcuate, less so behind the middle, where they appear somewhat oblique to the rather strong constriction at basal seventh, which may not be very suddenly or at other times rather gradually formed, thence to the angles more or less straight and parallel; marginal bead rather fine and somewhat obsolete at basal constriction; base slightly rounded, finely to obsoletely margined, very slightly wider than the apex and about equal to the length; apical angles distinct and subacute, or slightly obtuse; basal angles subrectangular or obtuse and not in the least rounded.

Propleurce smooth and subopaque, sparsely muricato-granulate and more or less rugulose on the acetabular convexities.

Elytra oval, about a third longer than wide, widest at the middle; base equal to or distinctly wider than the contiguous prothoracic base; humeri evenly or obtusely rounded; sides broadly and moderately arcuate, moderately attenuate at apex, the latter not broadly rounded; dise moderately convex, not depressed, quite evenly and not very broadly rounded laterally, arcuately declivous posteriorly; surface with the punctures rather coarse, densely and irregularly placed, at times vaguely seriate when viewed longitudinally, punctures simple on each side of the suture, asperately granulate laterally and on the apex, minutely setigerous.

Epipleurce moderate in width, gradually narrowing from base to apex, superior margin straight or very feebly sinuate beneath the 
humeri, where it is at times somewhat visible from above; surface smooth, opaque, sparsely and quite obsoletely punctate.

Sterna irregularly and densely punctato-rugulose.

Parapleurce rather coarsely but not densely punctate.

Abdomen more or less glabrous, variable in dullness, rather sparsely and somewhat finely punctate, more coarsely, densely, and rugulosely sculptured about the coxæ, last two segments more finely so.

Legs moderate in length and stoutness; anterior femora mutic and more or less sinuate in outer fifth; tibial spurs similar in the sexes and rather small, the anterior slightly longer than the posterior; tarsi dissimilar in the sexes.

Male.-Moderately narrow. Antennæ reaching a little beyond the base of the prothorax. Elytra a little narrowed posteriorly, arcuately and rather obliquely declivous apically. Abdomen slightly oblique and moderately convex, impressed on the first two segments at middle. First two joints of the protarsi slightly thickened at tip beneath with pubescent tufts upon the same; the tufts are truncate, that of the first moderate in size and about twice as large as that of the second. First joint of the middle tarsi with a very small tuft at tip; all the tufts golden yellow.

Female.-Robust. Antennæ just slightly reaching beyond the base of the prothorax. Elytra arcuately but scarcely vertically declivous posteriorly. Abdomen horizontal and rather strongly convex. Anterior and middle tarsi simple beneath, grooves distinct.

Measurements.-Males: Length, 13-16 mm.; width 6-7 mm. Females: Length $14.5-17 \mathrm{~mm}$; width $7-8.2 \mathrm{~mm}$.

Genital characters, male.-Edeagophore somewhat flattened oblong-ovate, moderately elongate and slightly arched.

Basale oblong, sides feebly arcuate, surface moderately convex.

A picale triangular, rather strongly convex and without a groove; sides rather strongly sinuate so that the apex appears produced, the latter acute; base with a small rounded median lobe and feebly sinuate laterally.

Sternite small, slightly transversely oblong. Each lobe small and subtriangular; surface almost impunctate in basal third, thence to apex sparsely to densely punctate at apical margin, setose, setæ small, increasing in length to apex where they are moderately long; sides sinuate and somewhat oblique in basal two-thirds, thence to apex truncately subarcuate; apex introrse and subacute; internal margin straight or feebly sinuate. Membrane not setose, sinus triangulooblong.

Female.-Genital segment trapezo-triangular, dorsal surface very slightly ogival, very feebly setose and moderately depressed.

Valvula.-Dorsal plate slightly oblique, being externally declivous, elongately oblong, sides subparallel and moderately explanate exter- 
nally; surface scarcely concave, very sparsely punctate and setose, setæ very small; external and internal borders straight; apical margin oblique externally and arcuate internally, angle broadly rounded. apex small and short, triangular and finely setose, without longer setæ at tip; fossa at middle of the external surface.

Appendage small and short mammilliform, with a pencil of moderately long setæ at tip.

Superior pudendal membrane more or less longitudinally rugulose and attaining the apical fourth of the dorsal plate.

Basal prominences not evident.

Ventrolateral surfaces flattened centrally to base, rounded laterally; surface smooth and not noticeably setose; sides feebly concave laterally before the apices, and the submarginal groove broad beneath the explanate external border of the dorsal plate. Internal margins of the valves contiguous in basal two-thirds; genital fissure in apical third, moderately wide and fusiform. Inferior pudendal membrane not visible.

Habitat.-California (Tulare County, at Colony Mills, elevation 5,415 feet, Giant Forest; Marble Fork, Kaweah River, elevation 5,200 feet, Kaweah to Progress Springs, elevation, 1,000-1,740 feet. Collected by Charles Fuchs and Ralph Hopping).

Number of specimens studied, 90.

Sexitypes in my own collection; co-types in the collections of Van Dyke, Fuchs, Hopping, and my own.

Type-locality.-Colony Mills, Tulare County, California.

Salient type-characters.-Pronotum comparatively small, apparently subcordate, the sides rather strongly arcuate anteriorly, behind the middle less arcuate and very slightly converging, constricted in basal seventh, thence quite straight to the basal angles, which are subrectangular; disc rather finely and densely punctate, becoming granular laterally; apical angles distinct and subacute; apex feebly and evenly emarginate.

Elytra about a third longer than wide, in the female broadly oval and apparently inflated in contrast to the small prothorax; disc moderately convex on the dorsum, punctures rather coarse, densely and irregularly placed, simple about the suture and exasperately granulate laterally and about the apex.

Diagnostic characters.-This species is variable in form, typically the females are subcychriform; the heterotypes resembling consobrina on the one hand and parvicollis on the other.

In typical specimens the prothorax is comparatively small and apparently subcordate, the elytra broadly oval in the female, giving the effect of inflation, when there is none the dorsum is moderately convex; the humeri are broadly rounded in both sexes. Such examples resemble consobrina. 
In other specimens the humeri are obtusely rounded and the superior epipleural margin is often visible from above, the thorax wider and more evenly rounded at the sides, and the general form resembles parvicollis. The integuments are more or less opaque.

Fuchsii appears to be intermediate between consobrina and parvicollis. I at first associated it with the former and then with the latter as a race, but could not satisfy myself as to which species it is most closely related, and therefore determined on the intermediate course and give it specific standing.

It can be recognized from consobrina by the more finely and much less densely sculptured abdomen and more cordate prothorax; from parvicollis by the narrower prothorax and the more consobrina-like habitus.

From neotoma it is separated by the much less convex form and less strongly sculptured abdomen.

Producta has a much more transverse prothorax, the humeri strongly prominent with the superior epipleural margin very distinctly visible from above, the elytra very evidently flattened, form oblong-oval and broad at base. The males are more difficult to separate, the sides of the pronotal dise are usually distinctly flattened and granulate; in fuchsii the pronotal disc is not usually depressed at the sides and quite strongly and evenly convex.

Hornii is more depressed, with very oval elytra, the humeri being obsolete.

General observations.-The mentum is usually parabolic in outline, although at times somewhat triangular; the surface is rather narrowly convex at middle from apex to base and more or less broadly foveate laterally, finely scabrous, punctures not distinctly defined and not noticeably setigerous.

The prosternum is quite gradually prominent from the anterior margin so that the intercoxal process is not strongly nor suddenly protuberant ventrally; at times it is evenly arcuate antero-posteriorly or feebly arcuate between the coxæ and subtruncate behind, with the mucro more or less produced or small and more or less deflexed.

Mesosternum more or less vertically arcuate and with a varying concavity.

The metasternum laterally between the coxæ is as long as the width of a mesotibia at middle.

The abdominal process is more or less quadrate and a third (male) to a fourth (female) of its width broader than the metasternal salient, as long as the second segment in the male and to the postcoxal part of the first segment, as well as the third, in the female.

In the male the post-coxal part of the first segment is equal to the length of the third, the latter about a fourth longer than the fourth. In the female the second is twice as long as the fourth. 
The tarsi are moderate in length and not very short; there is evident variation in the individuals of the series before me.

Tarsal formula:

$\begin{array}{cccc}\text { Pro. } & \text { Meso. } & \text { Meta. } & \text { Metatibia. } \\ \text { Male. }-2 \frac{1}{2} & 3 \frac{1}{5} & 3 \frac{1}{2} & 6 \\ \text { Female. }-2 & 2 \frac{2}{3} & 3 \frac{1}{5} & 5 \frac{1}{2}\end{array}$

ELEODES NEOTOM E, new species.

Ovate, moderately robust, shining, and smooth, strongly convex; Elytra scarcely asperately muricately punctate.

Head twice as wide as long, feebly convex, more or less impressed laterally and along the frontal suture, the latter usually evident as a glabrous line, quite evenly and not very densely punctate, punctures moderate, sides scarcely at all prominent. Antennce moderate in length, rather stout, scarcely compressed or widened in outer four joints, third hardly as long as the next two taken together, fourth to the eighth, inclusive, subequal and rather short, the eighth just the least subtriangular, ninth and tenth scarcely transversely oval, eleventh short-ovate.

Pronotum transversely oval, about a third wider than long, widest at the middle; disc evenly and strongly convex, irregularly and somewhat densely punctate, punctures dense and granulate laterally along the margins; apex not strongly emarginate and more or less obsoletely margined; sides evenly and moderately strongly arcuate, constricted at basal tenth, thence parallel or feebly oblique to the basal angles, margin fine and entire; base slightly rounded and rather finely margined, slightly wider than the apex and about equal to the length; apical angles subacute, not rounded and rather prominent anteriorly; basal angles more or less rectangular, sometimes feebly prominent.

Propleura sparsely muricato-granulate and more or less rugulose on the acetabular convexities.

Elytra rather broadly oval, scarcely a third longer than wide, widest at the middle; base not at all wider than the contiguous prothoracic base; humeri rounded and quite continuously so with the strongly arcuate sides, apex not narrowly rounded nor produced; dise rather strongly and evenly convex on the dorsum, evenly and somewhat broadly, more strongly, rounded laterally, arcuately declivous posteriorly; surface densely, coarsely and not deeply, evenly and diffusely submuricately punctate on the dorsum, slightly denser and muricato-granulate laterally and on apex.

Epipleurce somewhat wide, gradually narrowing from base to apex, superior margin very broadly and feebly sinuate beneath the humeri, not visible from above; surface opaque, sparsely and obsoletely submuricately punctate at base, becoming more strongly muricate apically. 
Sterna densely punctato-rugose.

Parapleurce coarsely and rather densely punctate.

Abdomen shining, coarsely and more or less strongly punctatorugulose, more densely and strongly so about the coxæ, last two segments more finely and sparsely punctate, not usually rugulose.

Legs moderate in length and rather stout, densely and somewhat coarsely sculptured; anterior femora mutic and deeply sinuate in outer fifth; tibial spurs rather small and similar in the sexes, the anterior of the protibix slightly longer than the posterior; tarsi dissimilar in the sexes.

Male.-Slightly robust, but somewhat narrow. Antennæ scarcely reaching beyond the base of the prothorax. Elytra arcuately declivous posteriorly. Abdomen rather strongly oblique, moderately convex, first two segments very broadly and slightly flattened at middle. First and second joints of the anterior tarsi slightly thickened at tips beneath and with somewhat flattened tufts of golden pubescence; first joint of the middle tarsi with smaller tufts.

Female.-Robust. Antennæ scarcely attaining the prothoracic base. Elytra strongly, arcuately and vertically declivous behind. Abdomen moderately oblique, rather strongly convex. First joint of the anterior tarsi thickened at tip beneath, marginal spinules rather dense, groove scarcely interrupted at tip.

Measurements.-Males: Length, 13-15.5 mm.; width, $6.2-7 \mathrm{~mm}$. Females: Length, 14.5-15.5 mm.; width, 7.5-8 mm.

Genital characters, male.-Edeagophore fusiform oblong-ovate and feebly arched.

Basale about two and a half times longer than wide, dorsal surface evenly and not strongly convex, sides feebly arcuate.

A picale triangular; surface quite strongly convex, without groove; sides broadly and feebly sinuate; tip subacute; base broadly rounded.

Sternite rather short and somewhat transverse. Each lobe triangular and rather small; surface feebly convex externally, and declivous internally, smooth in basal third, finely and not very densely punctate, setose, setæ gradually increasing in length to apex where they are moderately long; external border oblique in basal half, thence arcuate to apex, the latter rounded but not broadly so; internal margin oblique and more or less straight. Membrane not setose across the bottom of the sinus, the latter triangular.

Female.-Genital segment distinctly triangular, surface very slightly ogival, feebly setose, rather depressed and well chitinized.

Valvula (.Plate 4, fig. 2).-Dorsal plate elongately oblong-triangular, sides more or less converging to apex; surface slightly outwardly declivous, feebly concave, glabrous and shining, very sparsely punctate, each puncture with a minute seta, few apically; external border straight; apical margin arcuate to subacutely rounded; in- 
ternal border sinuate to feebly arcuate. Apex small and triangular, finely setose, tip apparently without longer setæ, fossa at the base of the external surface.

Appendage short mammilliform, with tuft of moderately long setæ at tip.

Superior pudendal membrane not rugulose and attaining the apical fourth of the dorsal plate.

Basal prominences very small.

Ventrolateral surfaces flattened centrally to base and convex laterally; each lateral surface smooth, sparsely and finely punctate, setose, setæ minute, slightly concave before the apex. Submarginal groove small beneath the external border of the dorsal plate, which is not explanate, apex finely setose. Internal margins of the valves contiguous in basal two-thirds; genital fissure in apical third, not very narrow and fusiform. Inferior pudendal membrane not visible.

Habitat.-California (San Diego County; Port Harford, San Luis Obispo County).

I have taken this species from old stumps at Poway, elevation 700 feet; from wood-rats' nests on the hills bordering Mission Valley, near San Diego, elevation 300 feet.

Number of specimens studied, 14.

Sexitypes and co-types in my own collection.

Type-locality.-Mission Valley, near San Diego.

Salient type-characters. - Strongly convex, shining. Elytra scarcely asperately sculptured. Pronotum strongly convex, apex emarginate, sides rather strongly arcuate and constricted in basal tenth, apical angles not at all rounded and somewhat prominent anteriorly, basal angles rectangular. Elytra with the humeri rounded, and quite continuously so with the strongly arcuate sides; punctures rather coarse, not deep, rather simple centrally and muricato-granulate laterally. Abdomen very strongly and densely sculptured, last two segments much less so.

Diagnostic characters.- One of the most convex species of the subgenus Blapylis, and can not be confounded with any species, except inculta, hornii, consobrina, and parvicollis.

Professor Fall has very carefully compared it with types in the LeConte collection and found it not to correspond with any named species.

Inculta is more robust and with the pronotum more transverse, especially in the female, the integuments are duller. The prothorax is not distinctly constricted at base and the abdomen is finely sculptured.

Neotomo is no doubt closely related to consobrina, but can readily be separated by its greater convexity, the circularly oval elytra, not 
oblong-oval as in the latter species; there is also much less difference in general form in the sexes than is observed in other species.

A single female taken at Port Harford evidently belongs here; the elytra are broader at base and the humeri more obtusely rounded.

Hornii is more depressed than convex and the antennæ longer, the abdomen is not strongly sculptured nor the pronotum strongly constricted at base.

In parvicollis the pronotum is broader, the abdomen never as strongly sculptured, although in producta it is at times nearly so, but here the elytra are distinctly flattened and the humeri prominent.

The strongly convex pronotum and elytra of neotome are very striking characteristics. The abdomen is rather oblique in the female, an unusual character for that sex.

General observations.-The mentum is rather small, usually parabolically rounded, at times subtriangular; surface rather densely punctate, scarcely convex or foveate and not noticeably setose.

The prosternum is very densely sculptured and scabrous, moderately prominent ventrally with the coxæ, grooved along the middle, subhorizontal, compressed behind and quite vertically truncate, angle mucroid and more or less deflexed.

The mesosternum is rather obliquely and arcuately declivous and more or less deeply concave.

The metasternum laterally between the coxæ is as long as the width of a mesotibia at middle.

The abdominal process is quadrate (male) or slightly transverse (female) and a fifth (male) or a third (female) of its width wider than the metasternal salient.

In the male the second abdominal segment is equal in length to that of the process and twice as long as the fourth; the third is equal to the post-coxal part of the first.

In the female the post-coxal part of the first segment is equal in length to the process; the second about a half longer than the third and a fourth longer than the fourth segment.

The tarsi are moderate in length and rather stout.

The relative lengths of the tarsi were constant in the series studied. Tarsal formula:

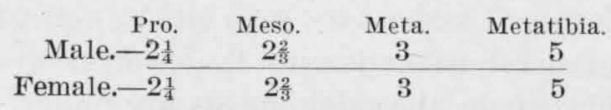

ELEODES HORNII, new species.

Oval to ovate, about twice as long as wide, more or less shining, subglabrous; elytra feebly submuricately punctate laterally, and gradually widening from the base to middle; humeri obsolete. 
Head about twice as wide as long, slightly convex, feebly impressed laterally, frontal suture not evident, distinctly, ratherly coarsely, and quite densely punctate. Antennce quite long, moderate in stoutness, outer three joints slightly compressed and feebly dilated, third joint equal to the next two taken together, fourth to the seventh inclusive subequal, eighth scarcely shorter and slightly triangular, ninth and tenth triangulo-orbicular in outline, eleventh subovate.

Pronotum widest at the middle, about a half wider than long; dise moderately convex, distinctly and quite densely punctate, more densely and narrowly punctato-granulate laterally along the margins, the punctures are not very strongly marked at the center and rather small; apex feebly emarginate or truncate in circular are and obsoletely margined; sides evenly and moderately arcuate, moderately and not suddenly sinuate in basal seventh, becoming rather briefly straight to the angles, marginal bead rather fine, slightly reflexed and entire; base slightly rounded, obsoletely margined, and about equal to the apex, and also to the length; apical angles obtuse and more or less narrowly rounded and not prominent; basal angles minutely prominent.

Propleurce rather sparsely muricato-granulate and more or less irregularly rugulose.

Elytra distinctly oval, widest at the middle, scarcely a half longer than wide; base about equal-not wider-to the contiguous prothoracic base; humeri obsolete or subobsolete; sides evenly and moderately arcuate, gradually widening from the base to the middle, thence more or less gradually narrowing to apex, the latter not broadly rounded; disc moderately convex and somewhat depressed on the dorsum, rather strongly and not very broadly rounded laterally, arcuately declivous posteriorly; surface punctate, punctures distinct, rather densely and irregularly placed, rather coarse, simple on the dorsum, becoming submuricate laterally with a tendency to coalesce transversely in twos or fours.

Epipleurce moderate in width, gradually narrowing from base to apex, superior margin quite strong, especially beneath the humeri, where it is broadly and feebly sinuate; surface subopaque and more or less obsoletely punctate.

Sterna densely, subscabrously, and rather finely punctato-rugulose. Parapleurce distinctly and rather coarsely punctate.

Abdomen irregularly and sparsely punctate, quite densely so and rugose on the first segment, elsewhere rugulose, except on the fifth segment, where the punctures are denser at the periphery.

Legs moderate in length and somewhat slender. Anterior femora mutic; tibial spurs rather small, the anterior of the protibiæ slightly thicker and longer than the posterior. Tarsi dissimilar in the sexes. 
Male.-Somewhat narrow, antennæ reaching beyond the base of the prothorax. Elytra slightly wider than the prothorax, evenly arcuately declivous posteriorly, abdomen distinctly oblique, moderately convex, feebly and broadly flattened on first two segments. Anterior tarsi with the first joint slightly thickened at tip beneath. (In the type the tarsi are entirely denuded of spinules, but the first two joints in all probability have pubescent tufts on the tips beneath, the first larger than the second; the first joint of the middle tarsi although not noticeably thickened at tip, undoubtedly bears a small tuft of golden hairs.) Such is the case in the Calaveras specimens, and besides the third joint of the protarsi and the second of the mesotarsi have smaller tufts at tips.

Female.-Moderately robust, antennæ attaining the prothoracic base. Elytra rather broadly oval and distinctly wider than the prothorax, arcuately and vertically declivous posteriorly. Abdomen horizontal and rather strongly convex. Anterior tarsi with the first joint slightly thickened at tip beneath, grooves entire.

Measurements.-Male: Length, $13 \mathrm{~mm}$; width, $5.5 \mathrm{~mm}$. Female: Length, $13.5 \mathrm{~mm}$; width, $6.5 \mathrm{~mm}$.

Genital characters, male.-Edeagophore oblong-ovate, somewhat flattened and quite strongly arched.

Basale oblong, about twice as long as wide, rather strongly convex; sides moderately arcuate.

A picale triangular, moderately convex above, without groove; sides moderately sinuate, apex subacute and apparently produced; base with a moderate, rounded median lobe and sinuate laterally.

Sternite rather short and transverse, triangulo-parabolic in outline. Each lobe subtriangular; surface feebly convex, glabrous, rather finely and quite densely punctate toward apex, setose, setæ moderate and rather fine, not very long; external border oblique and feebly sinuate in basal half, thence obliquely truncate to apex, or feebly arcuate so as to appear subangulate at middle; apex subacute and distinct; internal margin straight or feebly sinuate and oblique. Membrane not setose across the bottom of the sinus, the latter triangular.

Female.-Genital segment (Plate 5, fig. 15) obtusely triangular, moderately depressed, dorsal surface of each valve more or less slightly declivous externally, apex setose.

Valvula.-Dorsal plate oblong, glabrous, almost impunctate; surface more or less distinctly concave; external border slightly arcuate, the internal more or less sinuate; apical margin more or less evenly rounded. Apex short and rather thick, finely setose, setæ at tip rather long. Fossa at the middle of the external surface of the apex, the setæ rather long around its margin. 
Appendage short mammilliform, with a pencil of rather long setæ at tip.

Superior pudendal membrane apparently not rugulose and rather broadly exposed, reaching about to the apical fifth of the dorsal plate.

Basal prominences not evident.

Ventrolateral surfaces slightly triangular from base to middle, sides quite evenly convex and with a few rather coarse punctures. Submarginal groove moderate beneath the feebly expanded external margin of the dorsal plate, more concave at base of the apex laterally. Internal margins of the valves contiguous in basal two-thirds, genital fissure fusiform in apical third, and the inferior pudendal membrane is not visible.

Habitat.-California (Plumas County, elevation, 1,200 feet; Mokelumne Hill, Calaveras County, elevation, 1,300 feet.-Blaisdell).

Number of specimens studied, 5 ( 4 males, 1 female).

Sexitypes in my own collection.

Type-locality.-Plumas County, California; collector, Dr. Walther Horn, of Berlin, to whom I dedicate the species.

Salient type-characters.-Subglabrous and shining. Pronotum with disc moderately convex, rather finely, distinctly, and quite densely punctate, punctato-granulate along the margins laterally, punctures not strongly marked at center; sides evenly and moderately arcuate, not suddenly sinuate at basal seventh, thence rather briefly straight to the basal angles. Elytra gradually widening from each extremity to middle, humeri obsolete, surface with simple punctures at center of the dorsum, becoming submuricate laterally, with a tendency to coalesce transversely in twos and fours.

Diagnostic characters.-By its smaller size and more graceful form, smooth integuments, narrower and distinctly oval elytra, rather proportionally larger prothorax, which is somewhat remote from the elytra, and distinctly less convex form, hornii is sufficiently distinct from consobrina although derived from the same ancestral stock.

Neotome compared with hornii is larger and strongly convex; the male is much less narrow.

In fuchsii the integuments are opaque and the humeri are more distinct, although often broadly rounded; the elytra are broader and much more strongly convex - even somewhat inflated (female).

In parvicollis the humeri are generally strongly evident and the prothorax distinctly constricted near the base. Parvicollis var. constricta more nearly approaches hornii in the degree of convexity, but the sculpturing is different-coarser and roughly muricato-granulate-the humeri are distinct, and the elytra in the males are more oblong oval and not narrowing somewhat equally each way from the middle.

$59780-$ Bull. $63-09-23$ 
In scabrosa the coarse sculpturing as well as the setose propleuræ will serve to differentiate it from hornii.

Three males out of the five specimens before me were collected at Mokelumne Hill, Calaveras County, and are no doubt heterotypical; they are subopaque, larger, the elytra are a little more strongly sculptured than in the types; the prothorax is a little more strongly constricted at the base and the basal angles are rectangular.

The narrow elytral base, with the sides very gradually widening to the middle, and the obsolete humeri (see Plate 12, fig. 33) give hornii a characteristic facies, the prothorax appearing somewhat remote from the elytra.

General observations.-The mentum is rather small and subparabolic in outline; the surface is distinctly convex at the middle and subfoveate laterally; the punctures are fine and quite dense laterally, not noticeably setose.

The prosternum in the types before me is not suddenly protuberant ventrally with the coxæ, although rather strongly and gradually so, evenly arcuate antero-posteriorly, and not in the least mucronate behind.

Mesosternum arcuately declivous, feebly and broadly concave.

The metasternum laterally between the coxæ is as long as the width of a mesotibia at middle.

The abdominal process is subquadrate and about a fourth of its width broader than the metasternal salient, equal to the length of the post-coxal portion of the same segment, and also to the second.

In the male the third segment is about a fourth of its length longer than the fourth. In the female the third is slightly shorter than the second and about a fifth of its length shorter than the fourth.

The tarsi are moderate in length and rather slender. The protarsi of the male are noticeably longer than in the female, and about a fourth (male) or two-fifths (female) of their length shorter than a mesotarsus.

The mesotarsi are about a fifth (male) or about two-sevenths of their length shorter than a metatarsus.

The metatarsi about a half (male) or a third (female) of their length shorter than a metatibia.

Tarsal formula :

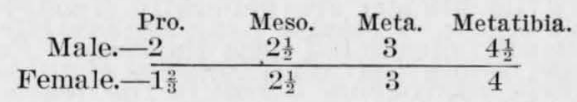

\section{ELEODES PARVICOLLIS Eschscholtz.}

Eleodes parvicollis Eschscholtz, Zool. Atlas, III, 1833, p. 11.-MANnerheim, Bull. Soc. Nat. Moscow, XVI, 1843, p. 271.-LeConte, Proc. Acad. Nat. Sei. Phil., 1858, p. 182.-HokN, Trans. Amer. Phil. Soc., XIV, 1870 , p. 317. 
var. planata Eschscholtz, Zool, Atlas, III, 1833, p. 11.-MaNnerheim, Bull. Soc. Nat. Moscow, XVI, 1843, p. 270.-Honn, Trans. Amer. Phil. Soc. XIV, 1870 , p. 317.

var. producta Mannerheim, Bull. Soc. Nat. Moscow, XVI, 1843, p. 271Horn, Trans. Amer. Phil. Soc., XIV, 1870, p. 317.

var. constricta LrConte, Proc. Acad. Nat. Sci. Phila., 1858, p. 187.

Subovate, about twice as long as wide, more or less shining, thorax rather coarsely but not confluently punctate, evenly rounded at the sides and distinctly constricted at the base; elytra oval, one-fourth to one-third longer than wide, coarsely punctate at middle, submuricatogranulate laterally and on apex.

Head twice as wide as long, feebly convex, more or less impressed laterally, sometimes more or less so along the frontal suture, which is more or less obsoletely indicated; irregularly and rather coarsely punctate, punctures sparse on vertex and center of frons, small impunctate areas frequently present, denser on the sides and epistoma. Antennce somewhat long and rather slender, feebly compressed and slightly widened in outer four joints, third joint hardly as long as the next two taken together, fourth scarcely longer than the fifth, the latter to the eighth inclusive subequal, the eighth subtriangular, ninth triangulo-oval, tenth just the least transversely oval, eleventh short-ovate and as long as wide.

Pronotum somewhat transversely oblong-oval, two-fifths to a half wider than long, widest at about the middle; disc evenly and moderately convex, somewhat arcuately declivous at the apical angles, quite densely, irregularly, and coarsely punctate, punctures not confluent, becoming granulate at the sides; apex evenly but not deeply emarginate, and more or less obsoletely and finely margined; sides evenly and broadly rounded, strongly constricted at about basal sixth, thence more or less straight and parallel to the basal angles, marginal bead thin and fine, feebly reflexed, becoming a mere line on the constriction; base truncate, rather coarsely or indistinctly margined, equal to or slightly wider than the apex and about equal to the length; apical angles obtuse and not prominent, frequently more or less feebly rounded; basal angles more or less rectangular.

Propleurce smooth, very sparsely and finely punctato-granulate, more or less feebly rugulose.

Elytra oval, widest at the middle, a fourth to a third longer than wide; base subtruncate, distinctly wider than the contiguous prothoracic base; humeri rounded, more or less obtusely so, not prominent; sides evenly arcuate, apex not very narrowly rounded; disc moderately convex, not distinctly flattened on the dorsum, strongly and not very broadly rounded laterally, inflexed portion but feebly convex, arcuately declivous posteriorly, coarsely punctate, punctures quite simple on either side of the suture and without any sign of order, 
submuricato-granulate, subasperately and feebly rugosely so laterally and on apex.

Epipleurce somewhat wide, distinctly dilated beneath the humeri, thence gradually narrowing to apex; superior margins feeble, a little stronger at the humeri, where it is arcuate and more or less visible from above, thence feebly and broadly sinuate for a fourth of its length; surface smooth, very sparsely and finely punctate.

Sterna quite densely but not coarsely rugoso-punctate.

Parapleurce more or less coarsely punctate.

Abdomen smooth and shining, sparsely and not coarsely punctate, more or less rugulose; quite densely sculptured about the coxæ, last two segments less strongly so.

Legs comparatively slender, and about moderate in length. Anterior femora mutic; anterior tibial spurs quite similar in the sexes, the anterior slightly longer and just the least thicker than the posterior; anterior and middle tarsi dissimilar in the sexes.

Male.-Somewhat narrow, subovate. Antennæ reaching a little beyond the base of the prothorax. Elytra somewhat feebly convex on the dorsum and rather narrowly rounded at the sides, areuately and slightly obliquely declivous behind, somewhat distinctly narrowed apically. Abdomen more or less oblique, moderately convex, first two segments more or less broadly flattened or impressed at middle. Anterior tibiæ moderately constricted at base. Anterior tarsi with the first two joints feebly thickened at tips beneath, each with a moderately small truncate tuft of golden pubescence; first two joints of the middle tarsi with very small tufts at tips beneath, grooves feebly interrupted.

Female.-Robust and ovate. Antennæ scarcely reaching beyond the base of the prothorax. Elytra more or less evenly and arcuately declivous, or vertically so posteriorly. Abdomen rather strongly convex and horizontal. Anterior tarsi with the first joint slightly thickened at tip beneath, grooves distinct.

Two forms may be recognized:

Forma typica.-Moderate in size, surface somewhat shining, shorter ovate. Elytra submuricato-granulate laterally and on the apex. In the males the elytra are rather obliquely narrowed in apical third; females have the elytra moderately convex on the dorsum.

Measurements.-Males: Length, 13-14 mm.; width, 6-6.5 mm. Females: Length, 13.5-16 mm.; width, 7-8 mm.

Forma farallonica.-Larger, somewhat dull, slightly longer ovate, thorax a little more transverse. Elytra more granulate laterally. In the females the elytra are scarcely more convex than in the male.

Measurements.-Males: Length, 16-16.5 mm.; width, 7-7.5 mm. Females: Length, 13-17.5 mm.; width, 7-8.5 mm. 
Genital characters, male.-Edeagophore elongately oblong-ovate, . flattened and very feebly arched.

Basale elongate, oblong; surface moderately convex, sides feebly arcuate.

A picale rather small, triangular, moderately and rather evenly convex above, without groove; sides broadly and moderately sinuate, apex acute and somewhat slender; base subacutely lobed at the middle and sinuate laterally.

Sternite transversely parabolic in outline. Each lobe triangular; external border quite straight or feebly arcuate in basal two-thirds, thence subtruncate or feebly arcuate to apex, the latter obtuse; internal margin straight and oblique; surface feebly convex, very sparsely punctate and setose, setw rather short, moderately long about the apical margin. Membrane not setose across the bottom of the sinus, the latter deep and triangular.

Female.-Genital segment not broadly triangular, less than a half longer than wide, dorsal surface of each valve slightly obliquely declivous externally, feebly setose.

Valvula (Plate 5, fig. 4).--Dorsal plate elongate oblong, slightly narrowing from base to apex; surface smooth, feebly convex, very sparsely and feebly setose in apical fourth; external border moderately arcuate, scarcely at all expanded; apical margin not defined from the apex, scarcely wider than the apex at base, angle obsolete; internal border broadly and feebly sinuate. Apex small and more or less membrano-chitinous, feebly setose.

Appendage small mammilliform with a pencil of quite long setæ at tip. Fossa small and at the middle of the external surface of the apex.

Basal prominences scarcely evident.

Superior pudendal membrane longitudinally rugulose, and attaining the apical fourth of the dorsal plate.

Ventrolateral surfaces.-Body triangular, surface lines straight when viewed longitudinally, quite evenly convex laterally. Submarginal groove small, slightly widened apically beneath the scarcely explanate external border of the dorsal plate. Internal margins of the valves contiguous in basal two-thirds; genital fissure narrowly fusiform in apical third, and the inferior pudendal membrane is not visible.

Habitat.-California (region about San Francisco Bay; San Joaquin and Sacramento valleys; hills along the coast in the central part of the State), Farallone Islands.

Number of specimens studied, 375 .

Type in the Eschscholtz collection?

Type-locality.-Near San Francisco. 
Salient type-characters.-Antennæ filliform. Thorax rounded, base narrowed, punctate. Elytral dorsum with larger and slightly impressed punctures, sides granulate (Eschscholtz).

Diagnostic characters.-Eschscholtz says that the thorax is a little broader than long, the greatest width being in front of the middle, sides strongly rounded and smaller behind; the apex is faintly emarginate; the humeri are prominent and the sharp epipleural margin can be seen from above. The sides of the elytra are rugosely granulate.

I have examples before me which have been identified by Casey, Fall, and Blanchard.

A female compared by $\mathrm{Mr}$. Blanchard with the specimen received by LeConte with others from Europe ${ }^{a}$ as typical parvicollis Eschscholtz, is pronounced by him as "an exact copy" of LeConte's typical specimen. Professor Fall's and Colonel Casey's specimens, while a little larger, present no notable differences.

My typical specimen does resemble-a large female scabrosa, but it is without the hairs upon the sides of the prothorax. It is well to note that my series of typical parvicollis was taken from ledges upon the hills about San Francisco, and not about the sand dunes where scabrosa abounds.

I do not agree with Doctor Horn in considering the large aggregate of specimens referable to parvicollis as one species without the recognition of well-marked races; in so doing I consider that it would be a retardation to our knowledge of these forms, and I shall in this paper consider planata, producta, and constricta as valid races.

I have studied an immense series and feel warranted in so doing. My disposal of scabrosa will probably be a surprise to many, but it appears out of place when associated with parvicollis.

In parvicollis the pronotum is rather less convex and the base more strongly constricted than in consobrina, where the sides of the elytra are more coarsely and tuberculately sculptured.

Producta is oblong, flattened on the elytral dise, sides parallel with prominent humeri, which are strongly margined by the superior epipleural margin.

Planata has the elytra less flattened, humeri less prominent, with the elytral sides evenly arcuate and more gradually narrowed behind.

Parvicollis is shorter and more ovate.

Producta inhabits the mountain regions chiefly and planata the valleys and foothills where there are oak groves and where smaller examples of producta are also found. Constricta occurs chiefly in the middle altitudes of the Sierra Nevadas as far north at least as Mount Shasta. These races overlap in their distributional areas; so do other races and species. 
General observations.-The mentum is variable, small, and parabolic (male) or comparatively large and trapezoidal or triangulotrapezoidal; surface very feebly convex at middle, and broadly, very feebly subfoveate laterally, finely but not distinctly punctate, not noticeably setose.

The prosternum is not strongly protuberant with the coxæ, and quite evenly arcuate antero-posteriorly between the coxæ, sometimes more or less vertical behind; rarely submucronate. Mesosternum arcuately declivous and more or less concave.

The metasternum laterally between the coxæ is as long as the width of a mesotibia at apex.

The abdominal process is quadrate (male) or slightly transverse (female) and about equal to (male) or a fourth (female) of its width broader than the metasternal salient.

In the male the post-coxal part of the first abdominal segment is about equal in length to the second segment; the third is equal to that of the process and about a third longer than the fourth.

In the female the post-coxal part of the first segment is about equal in length to the process, also to that of the third; the second is twice as long as the fourth.

The tarsi are variable in length and stoutness; although moderate in length they are noticeably longer and slender in some males and females, and stouter in others, and this appears to be independent of size in the specimen.

Tarsal formula :

$\begin{array}{cccc}\text { Pro. } & \text { Meso. } & \text { Meta. } & \text { Metatibia. } \\ \text { Male. }-2 \frac{1}{8} & 3 & 3 \frac{1}{3} & 5 \\ \text { Female. }-2 & 2 \frac{1}{2} & 3 & 4 \frac{2}{3}\end{array}$

ELEODES PARVICOLLIS var. PLANATA Eschscholtz.

Subfusiform-ovate to ovate, integuments feebly shining, twice as long as wide. Antennæ long. Elytra depressed and granulate laterally.

Head twice as wide as long, feebly convex, rather strongly and broadly impressed laterally, also more or less along the frontal suture, the latter rather feebly evident, supra-antennal convexities quite strong; surface rather densely, not very coarsely punctate, punctures denser laterally and on the epistoma. Antenna rather long, moderately slender, outer four joints slightly compressed and feebly dilated, third joint a little shorter than the next two combined, fourth apparently just the least longer than the fifth, the latter to the eighth inclusive equal in length, the eighth subtriangular and longer than wide, ninth triangular and as wide as long, tenth triangulo-oval, eleventh subovate and as long as wide. 
Pronotum somewhat transversely oblong-oval, widest at the middle, and more than a half wider than long; disc evenly and moderately convex, more or less flattened along the lateral margins, quite densely, more or less irregularly, and rather coarsely punctate, punctures not confluent, granulate on the impressed sides; apex evenly but not deeply emarginate, more or less obsoletely and finely margined; sides evenly and broadly rounded, strongly constricted at about basal eighth, thence somewhat oblique, straight, or sinuate to angle, marginal bead thin and rather distinctly reflexed, becoming a mert line on the constriction; base truncate or feebly rounded, not strongly margined, a fifth to a sixth wider than the apex and a little greater than the length; apical angles obtuse and not prominent; basal angles slightly prominent.

Propleurce as in parvicollis.

Elytra oval, widest at the middle, a third to a fifth longer than wide; base subtruncate, equal to or distinctly wider than the contiguous base of the prothorax; humeri obtusely rounded, sometimes prominent; sides evenly arcuate, apex somewhat attenuate, not broadly rounded; disc depressed and moderately convex, strongly but not broadly rounded laterally, inflexed sides oblique and feebly convex, arcuately declivous posteriorly; surface coarsely and irregularly punctate, somewhat foveolately so, punctures quite simple about the suture, series evident centrally when viewed longitudinally, not coarsely muricato-granulate laterally and about apex.

Epipleurce distinctly dilated beneath the humeri, where the superior margin is usually visible as an arcuate line; otherwise as in parvicollis.

Legs comparatively slightly thicker than in parvicollis.

Otherwise as in parvicollis.

Male.-Elytra at base scarcely wider than the contiguous prothoracic base; humeri scarcely prominent, sides thence evenly arcuate, apically gradually convergent so as to appear somewhat attenuate, the dise being gradually arcuately declivious behind. Anterior tarsi with the first three joints bearing pubescent tufts beneath, the tuft on third joint sometimes obsolete; middle tarsi with the first two joints bearing small tufts at tips beneath. Otherwise as in parvicollis.

Female.-Elytra broadly oval; humeri prominent and rounded; base comparatively rather broad; sides evenly arcuate.

Otherwise as in parvicollis.

Measurements.-Males: Length, 15-16 mm.; width, $6.5-7.5 \mathrm{~mm}$. Females: Length, 16-16.5 mm.; width, 7.8-8.5 mm.

Genital characters, male.-Edeagophore and sternite as in parvicollis.

Female.-Dorsal plate sometimes feebly concave and very sparsely setose. Apex chitinous and setose, setæ a little longer than usual and 
abruptly terminating where the apical margin of the dorsal plate should be. Pencil of hairs at tip of appendage quite long. Otherwise as in parvicollis.

Mabitat.-California (Russian settlement, Fort Ross, Eschscholtz). My series is without definite locality data and were probably collected by Mr. G. W. Dunn.

Number of specimens studied, 61 .

Type in the Eschscholtz collection?

Type-locality.-Russian settlement, Fort Ross, California.

Salient type-characters.-Thorax transverse, densely punctate; sides rounded; base coarctate. Elytra depressed on the dorsum and foveolato-punctate. Antennæ subfiliform (Eschscholtz).

Diagnostic characters.-Eschscholtz says that the thorax is much broader than long, strongly rounded on the sides and with the narrow margins more or less strongly reflexed. Elytra with the dorsum distinctly flattened (but convex) and not markedly declivous behind; side margins of the humeri very distinct; coarsely punctured at middle, seriate and granulate laterally.

The type must have been a male. My series, althongh not exactly typical, consists of both sexes. Mr. Blanchard has kindly made the necessary comparisons in Cambridge, and writes that a male (now before me) "is not quite typical, being less convex." It must be noted, in order that the above descriptive remarks be not considered inconsistent, that the elytra are depressed and at the same time moderately convex.

Typical parvicollis resembles scabrosa more than it does planata; the latter has the sides of the pronotum impressed, the elytra are more distinctly oval, and more gradually declivous behind in the male, and not as roughly sculptured; there is more or less evidence of a serial arrangement of the punctures on the dorsum; there the punctures are simple and the strial punctures are arranged in a straight line as usual, but greatly obscured by the very irregularly diffused interstitial punctures, both being of the same size.

I can not discover any signs of a serial arrangement in the typical parvicollis, where the sculpturing is coarser and more scabrous.

Producta is distinctly oblong, with the sides of the elytra parallel, the dorsum distinctly flattened and with the humeri very prominent in both sexes.

Of course the extremes are more difficult to separate, but I consider them no more so than in some parts of the subgenus Melaneleodes.

Two males before me are very coarsely and densely sculptured. One from Trinity County is especially so; the elytral punctures on the dorsum show evidence of serial arrangement of the interstitial punctures; both series are of the same size and submuricate, laterally the punctures are muricato-tuberculate, approaching consobrina and 
hornii, from which it is separated by the epipleuræ being dilated beneath the humeri and the superior margin distinctly visible from above, there forming the sharp arcuate margin of the rounded humeri. A Humboldt County specimen is similar, but less strongly developed.

General observations.-The mentum, pro- and mesosternum, are as in parvicollis.

The metasternum laterally between the coxæ is as long as the width of a mesotibia at the middle.

The abdominal process is subquadrate and a third (male) to a fourth (female) of its width broader than the metasternal salient.

In the male the post-coxal part of the first abdominal segment is equal in length to that of the process, also to that of the third; the second is one-half longer than the fourth.

In the female the second segment is equal in length to the process; the third to the post-coxal part of the first and a third longer than the fourth.

The tarsi are variable in thickness, but moderate in length. Usually more slender in the male.

Tarsal formula :

\begin{tabular}{|c|c|c|c|}
\hline $\begin{array}{l}\text { Pro. } \\
\text { Male. }-2 \frac{1}{2}\end{array}$ & $\begin{array}{c}\text { Meso. } \\
3\end{array}$ & $\begin{array}{c}\text { Meta. } \\
4\end{array}$ & $\begin{array}{c}\text { Metatibia } \\
5\end{array}$ \\
\hline Female. -2 & 3 & 3 & 5 \\
\hline
\end{tabular}

ELEODES PARVICOLLIS var. PRODUCTA Mannerheim.

Distinctly oblong to oblong-ovate, thorax transverse; elytra depressed, sides parallel, humeri prominent and obtusely rounded.

Head twice as wide as long, feebly convex, slightly impressed laterally and along the frontal suture, the latter more or less obsolete, densely, evenly, or irregularly and somewhat coarsely punctate, punctures denser laterally. Antenna somewhat long, stout, very feebly compressed and scarcely dilated in outer four joints, third joint about as long as the next two combined, fourth just the least longer and stouter than the fifth, the latter to the eighth, inclusive, equal in length, the eighth not noticeably wider than the preceding two, ninth triangulo-oval, tenth feebly transversely oval, tenth ovate.

Pronotum transversely oblong-oval, widest at the middle, a half to three-fifths wider than long; disc moderately convex, feebly impressed laterally so as to appear somewhat dilated, rather coarsely and somewhat densely punctate, denser and somewhat finely granulate laterally on the impressed area; apex more or less feebly and broadly emarginate, more or less obsoletely beaded; sides broadly and quite strongly arcuate to basal eighth, thence constricto-sinuate to the angles, at times quite abruptly and tubularly constricted, with sides parallel to the angle, bead thin and reflexed, a mere line on the basal construction; base truncate or very feebly rounded, and usually 
obsoletely beaded, a fifth wider than the apex and greater than the length; apical angles somewhat distinet or obtuse and not prominent; basal angles rectangular or minutely prominent.

Propleurce smooth, not densely granulato-muricate and more or less rugulose.

Elytra oblong-ovate, arcuately attenuate from the middle posteriorly, about a third longer than wide; base broad and truncate, distinctly wider than the contiguous base of the prothorax; humeri obtusely rounded and more or less prominent; sides parallel in basal one-half, thence arcuate to apex, somewhat attenuate in apical third or fourth, apex moderately rounded; disc distinctly flattened, more or less moderately convex, and arcuately declivous posteriorly, arcuately, but not broadly, rounded laterally; surface densely, somewhat coarsely punctate, punctures very irregular, at times granuliferous or simple on the dorsum, more or less muricato-granulate or distinctly subrugose laterally and on apex.

Epipleurce distinctly dilated beneath the humeri where the superior margin is coarse and arcuately prominent, as viewed from above. Otherwise as in parvicollis.

Abdomen rather densely and somewhat coarsely punctate, usually distinctly rugulose.

Legs stout and comparatively moderate in length. Anterior tibial spurs rather stout, the anterior more so than the posterior. Otherwise as in parvicollis.

Male.-Oblong, somewhat narrow, antennæ just reaching beyond the base of the prothorax. First two joints of the protarsi moderately thickened at tip beneath and there clothed with small tufts of piceo-flavate pubescence; the first joint of the mesotarsi has a small tuft also. Otherwise as in parvicollis.

Female.-Oblong to ovate, somewhat broad. Antennæ scarcely attaining the prothoracic base. Otherwise as in parvicollis.

Measurements.-Males: Length, 15-17.5 mm.; width, 7-7.5 mm. Females: Length, 14.5-18.5 mm.; width, 7.5-8 mm.

Genital characters, male.-As in parvicollis.

Female.-The genital segment as in planata, apparently more equilaterally triangular. The apex of each valve is distinctly chitinous, rounded at tip, with a slight tendency to become coneave beneath. These characters foreshadow those observed in Metablapylis.

Habitat.-California (Giant Forest, Tulare County, Fuchs and Hopping; Yosemite, Mariposa County ; Tuolumne County ; Calaveras County, Big Trees, elevation, 4,702 feet; Amador and Eldorado counties).

Number of specimens studied, 300.

Type in the Mannerheim collection? 
Type-locality.-California; no special locality is mentioned by Mannerheim. Collector, D. Blaschke.

Satient type-characters.-Oblong. Thorax with the sides rounded, thinly margined, base narrowed and equal to the apex; dorsum thickly punctate and densely granuliferous at the sides. Elytra oblong-ovate, attenuate behind the middle, dorsum gently punctate, the punctures granuliferous, on each side asperate, humeri rounded and anteriorly prominent and somewhat produced (Mannerheim).

Diagnostic characters.-According to Mannerheim it differs from parvicollis in being much larger and narrower, the thorax longer and broader; elytra at the periphery asperate, chiefly distinctly subrugose.

Examples compared with specimens in the LeConte collection by Mr. Blanchard were unhesitatingly referred to the present distinctly marked race.

Mannerheim's type was undoubtedly more asperately sculptured on the elytra than the majority of specimens before me, but there are many that exactly agree with his description.

These more strongly sculptured examples must be separated from the var. constricta; in the latter the head and thorax are much more coarsely and less densely punctured, the elytra are quite strongly asperate.

Any student ought not to have any trouble in recognizing this distinctly oblong variety, the elytra flattened, with the base broad, the humeri prominent and distinctly margined by the epipleuræ.

A fact already bronght to the reader's notice is that all Eleodeswith very few exceptions - vary in form, and the heterotypes may simulate (be amphitypical of) other species so closely as to often be very difficult of recognition.

For example, a specimen before me could easily be mistaken for consobrina, but the broader thorax with impressed sides and more prominent humeri renders the diagnosis certain.

Smaller and less characteristic forms will be found in the lower levels westward even as far as the coast.

General observations.- The mentum is usually distinctly parabolic in outline and variable in size, the surface is very broadly and obsoletely foveate laterally, centrally more or less feebly convex, finely sculptured, and not noticeably setose.

Prosternum not very prominent ventrally with the coxæ; often arcuate antero-posteriorly, or feebly convex between the coxæ and vertically truncate behind; rarely distinctly mucronate.

Mesosternum variable, sometimes deeply excavated at middle and lobed laterally; usually more or less broadly concave.

The metasternum laterally between the coxæ is as long as the width of a mesotibia at middle. 
The abdominal process is quadrate (male) or transverse (female) and equal (male) to or a sixth (female) of its width broader than the metasternal salient.

In the male the post-coxal part of the first abdominal segment is equal in length to that of the process; the second, twice as long as the fourth; the third, a third longer than the fourth. In the female the post-coxal part of the first is equal to the second; the third to the length of the process and a half longer than the fourth.

The tarsi are somewhat short and very stout. The anterior and posterior are apparently slightly compressed. The basal joint of each is noticeably stout, the others gradually smaller, so that each looks somewhat attenuate.

Tarsal formula:

$\begin{array}{cccc}\text { Pro. } & \text { Meso. } & \text { Meta. } & \text { Metatibia. } \\ \text { Male. }-\frac{21}{3} & 3 & 3 \frac{3}{5} & 5_{4}^{\frac{3}{4}} \\ \text { Female. }-2 & 3 & 3 \frac{1}{2} & 5_{4}^{\frac{3}{4}}\end{array}$

\section{ELEODES PARVICOLLIS var. CONSTRICTA LeConte.}

Oblong-ovate, twice as long as wide; surface dull to shining, head and thorax more or less coarsely punctate. Elytra flattened on the dorsum, rugoso-punctate, laterally sculptured with setigerous reclinate tubercles; humeri strong and more or less anteriorly prominent; punctures throughout minutely setigerous.

Head twice as wide as long, frons feebly convex, impressed laterally and along the frontal suture, which is usually not evident; surface coarsely and densely punctate, impunctate areas frequently observed about the middle, laterally the punctures are closely crowded. Antenna somewhat long, third joint scarcely as long as the next two combined, fourth to the eighth, inclusive, subequal in length, the eighth more or less triangular, ninth and tenth orbicular in outline, or the former orbiculo-triangular and the latter feebly transversely oval, eleventh short-ovate.

Pronotum transversely oblong-oval, widest at the middle, a little to a third wider than long; disc moderately and evenly convex, scarcely impressed laterally, coarsely and more or less irregularly punctate, impunctate areas frequently observed about the middle, intervals flat and smooth, laterally densely rugoso-granulate along the margins; apex feebly emarginate to subtruncate, obsoletely margined; sides evenly and strongly arcuate to basal seventh, there strongly constricted with sides parallel to base, sometimes less strongly arcuate or very feebly oblique behind the middle to constriction, margin fine, thin, and reflexed, a mere line on the constriction; base very feebly rounded or truncate, obsoletely margined, a fourth or less wider than the apex, and about equal to the length; apical angles distinct and 
obtuse, not prominent, sometimes feebly rounded; basal angles rectangular.

Propleurce sparsely and evenly muricato-granulate, more or less rugulose, especially about the acetabular convexities.

Elytra oblong ovate, widest at the middle, a fifth to a fourth longer than wide; base subtruncate and distinctly wider than the contiguous prothoracic base; humeri obtusely rounded and more or less prominent; sides evenly arcuate, apex rather narrowly rounded; disc more or less depressed, rather feebly to somewhat strongly convex, rather narrowly to somewhat broadly rounded at the sides, arcuately declivous behind; surface more or less rugoso-punctate centrally along the suture, punctures sometimes rather simple, more or less strongly muricato-tuberculate laterally and on apex.

Epipleurce with the superior margin arcuately margining the humeri and more or less distinctly visible from above; otherwise as in parvicollis.

Abdomen somewhat thickly punctate and rugulose, most so about the coxæ, punctures moderate in size.

Otherwise as in parvicollis.

Male.-Somewhat narrow; antennæ just slightly reaching beyond the prothoracic base. Elytra arcuately or also slightly obliquely declivous behind and ordinarily attenuate in apical fourth; anterior tibia not noticeably constricted at base; first two joints of the anterior tarsi feebly thickened at tips beneath with quite small tufts of brownish yellow pubescence; that on the first joint of the mesotarsi somewhat obsolete. Otherwise as in parvicollis.

Female--More or less robust; antennæ about attaining the prothoracic base. Otherwise as in parvicollis.

Measurements.-Males: Length, 12.5-15 mm.; width, 5.9-6.5 mm. Females: Length, 13.5-15.5 mm.; width, $6.5-8 \mathrm{~mm}$.

Genital characters, male.-As in parvicollis.

Female.-The dorsal plate is not defined at apical margin from the apex, the latter subchitinous and subacute at tip; also somewhat deflexed, so that the junction with dorsal plate appears somewhat prominent. Otherwise as in parvicollis.

Habitat.-California (Sacramento, LeConte; Tallac, Riverton, Strawberry Valley, 6,000 feet elevation, Eldorado County; Big Trees, elevation 4,702 feet, Calaveras County).

Number of specimens studied, 53.

Type in the LeConte collection.

Type-locality.-Sacramento, California; collector, Mr. Wittick.

Salient type-characters.-Somewhat shining, prothorax with the sides strongly rounded, tubulately constricted at base, finely margined; dorsum thickly and laterally rugoso-punctate. Elytra slightly convex, sides greatly rounded; humeri a little produced, rounded, and 
margined; dorsum densely subseriately punctate, laterally and on apex scabrous from reclinate granules. Antennæ slightly incrassate externally. Length .52. (LeConte.)

Diagnostic characters.-This race is remarkable on account of the coarse and dense elytral sculpturing, somewhat like that observed in cordata, but with the muricate character predominating; the head and thorax is more coarsely punctured than in parvicollis or its races above considered; in size the punctures approach those in cordata, but the intervals are perfectly flat and smooth and small impunctate areas are usually present.

The humeri are prominent and the elytral disc flattened on the dorsum in the males especially. It is interesting to note that the females are apt to be robust and in form quite like cordata, so much so that most of them have heretofore been placed with that species; the broader prothorax with sides broadly rounded separates constricta; in rotundipennis the prothorax is rugoso-punctate.

I have carefully examined the genital segments, and find the dorsal plate not at all angulate at the apical margin, but possessing the characteristics of the parvicollis group.

It would be very instructive and an advance in our knowledge if it were possible to determine why the heterotypes of many species or races mimic other more or less closely related species. Is it atavism, hybridism, or environment?

If LeConte's description of constricta be compared with the one given above, they will be found to agree in most points.

A specimen before me, and which has been compared with the type by Mr. Blanchard, is pronounced by him as undoubtedly that form described by LeConte, from a specimen collected near Sacramento. The thorax is "ante basin tubulatim constricto."

It is possible that I am making a mistake in applying LeConte's name to this mountain form. I have not seen any specimens from the vicinity of Sacramento. It is possible, of course, that the rivers may have carried individuals down from the higher altitudes, and in this way populated this particular region and elsewhere, for that matter.

I will quote LeConte's remarks upon constricta:

Related to E. producta, but the base (prothoracic), though not narrower than the apex, is much more constricted than in that species, so that the sides become impressed. The elytra are broader, more rounded on the sides, the humeri are less broadly produced and conspicuously margined, and the sides are more rough with small, reclinate tubercles. This species agrees with the description of E. parvicollis, given by Mannerheim, ${ }^{a}$ except that the base of the thorax is not narrower than the apex; Eschscholtz does not, in his description, mention that the sides of the thorax are scabrous, but adds that the base of 
the thorax is nearly as wide as the widest portion of the thorax, whereby the latter appears small. A specimen from the St. Petersburg Museum, sent me as a type, is not allied at all to this species, but rather to E. cordata.

It is well to mention here that the typical parvicollis resembles a large scabrosa, and the latter can easily be confused with cordata. A collector with any diagnostic acumen at all will not make such mistakes.

To satisfactorily work out the races of parvicollis has given me more trouble and consumed more time than any other whole subgenus, and while I feel that I might be wrong in some of my conclusions, I have Mr. Blanchard's careful comparisons to support my opinions, which are, besides, based upon the study of large series of specimens and much careful dissection of material.

General observations.-The mentum, pro- and mesosterna as in parvicollis. The metasternum laterally between the coxæ is as long as the width of a mesotibia at apical third.

The abdominal process is subquadrate and about a third of its width broader than the metasternal salient.

In the male the process is equal in length to the post-coxal part of the first segment and equal to the second; the latter is a fourth longer than the third, which is slightly longer than the fourth.

In the female the post-coxal part of the first segment of the abdomen is equal in length to the third, the latter equal to that of the process; the second is twice as long as the fourth.

The tarsi are slender and moderate in length.

Tarsal formula :

$\begin{array}{cccc}\text { Pro. } & \text { Meso. } & \text { Meta. } & \text { Metatibia. } \\ \text { Male. }-2 & 2 \frac{2}{3} & 3 & 4 \frac{1}{2} \\ \text { Female. }-1 \frac{4}{5} & 2 \frac{1}{2} & 3 & 4 \frac{1}{2}\end{array}$

ELEODES HOPPINGII, new species.

Oblong-oval, about twice as long as wide, somewhat depressed, surface rather dull, punctures of the head and thorax scarcely coarse; elytral sculpturing rather fine and dense, muricato-granulate laterally, punctures throughout finely setigerous.

Head less than twice as wide as long, rather evenly convex, feebly impressed laterally, obsoletely so along the frontal suture, the latter not evident; surface densely punctured. Antenne short, attaining the posterior fourth of the prothorax, moderate in stoutness, feebly compressed and slightly widened in the outer four joints, third joint equal to the next two combined, fourth to the eighth inclusive subequal in length and scarcely longer than wide, the eighth triangular, ninth and tenth feebly transversely oval, eleventh short-ovate.

Pronotum transversely oblong-oval, widest at the middle, less to about a half wider than long; disc scarcely moderately and evenly 
convex, densely and somewhat finely punctate, finely granulate laterally; apex feebly and evenly emarginate, obsoletely margined; sides broadly, evenly, and rather strongly rounded to basal twelfth, thence sinuate to the basal angles, finely beaded almost to the base, the latter very feebly rounded, not distinctly margined, a seventh to a fifth wider than the apex and about equal to the length; apical angles obtuse and not rounded; basal angles subrectangular.

Propleurce sparsely and distinctly granulate and more or less rugulose.

Elytra oval, about a third longer than wide, widest at the middle; base subtruncate and a little wider than the contiguous prothoracic base; humeri obtusely rounded and not prominent; sides evenly arcuate, gradually converging in apical fourth, apex rather narrowly rounded; disc rather feebly and evenly convex, somewhat flattened on the dorsum, rather narrowly, evenly, and somewhat strongly rounded laterally, arcuately declivous behind; surface densely and rather finely sculptured, punctures about simple centrally along the suture, muricato-granulate laterally and on apex.

Epipleurce moderately wide, not dilated beneath the humeri, superior margin not visible from above; surface very sparsely and finely punctate.

Sterna not coarsely punctato-rugulose.

Parapleurce densely and not distinctly punctate.

Abdomen more or less shining, quite densely punctate and rugulose, most so about the coxæ.

Legs short and moderate in stoutness. Anterior femora mutic; anterior tibial spurs similar in the sexes, the anterior a little stouter than the posterior; anterior tarsi dissimilar in the sexes.

Male.-Somewhat narrow. Elytra arcuately declivous posteriorly. Abdomen feebly oblique, moderately convex and impressed at middile of the first two segments. First two joints of the protarsi not noticeably thickened at tips beneath, each bearing a minute, brownish, and rather pointed tuft of pubescence; first joint of the mesotarsi without tuft, groove distinct.

Female.-Somewhat robust. Elytra arcuately and vertically declivous behind. Abdomen horizontal and rather strongly convex. First joint of the protarsi noticeably thickened at tip beneath, groove quite distinct.

Measurements.-Males: Length, 12.5-13 mm.; width, $5.5 \mathrm{~mm}$. $\mathrm{Fe}$ males: Length, $13 \mathrm{~mm}$; width, $6.2 \mathrm{~mm}$.

Genital characters, male.-Edeagophore elongately oblong-ovate, acute at tip and slightly arched.

Basale oblong, two and a half times longer than wide, evenly convex, sides parallel and slightly arcuate.

59780 -Bull. $63-09-24$ 
A picale triangular, a little longer than wide; surface moderately convex, without groove; sides strongly and broadly sinuate, apex appearing attenuate; base obtusely lobed at middle, feebly and broadly sinuate laterally.

Sternite transverse; each lobe triangular; surface feebly convex, not very densely punctate, setose; setæ imoderate in length, gradually longer about apex; external border rather evenly arcuate and oblique, apex introrsely placed and obtuse; internal border more or less sinuate and oblique. Membrane not setose across the bottem of the sinus, the latter triangular.

Female.-Genital segment somewhat depressed, about equilaterally triangular, dorsal surface feebly ogival, feebly setose.

Valvula.-Dorsal plate oblong, three times longer than wide, sides just the least converging apically; surface more or less feebly concave, glabrous, very sparsely and finely punctured, setæ short; external border feebly arcuate; internal border more or less sinuous; apical margin more or less arcuately rounded and only apparently defined from the semi-chitinous apex; the latter small, short and scarcely more prominent posteriorly than the appendage, blunt and more or less rounded, sparsely and finely setose with longer hairs, tip with a pencil of moderately long hairs. Fossa large, in the external surface of the apex.

Appendage short triangulo-conical, with a pencil of long hairs at tip.

Superior pudendal membrane longitudinally rugulose, attaining the apical fourth of the dorsal plate.

Basal prominences not evident.

Ventrolateral surfaces plane centrally to base, surface lines straight when viewed longitudinally, laterally rounded; surface glabrous, with a few coarse punctures scattered about, continuous with the semichitinous apex, not at all concave before the apex, the latter finely setose. Submarginal groove feeble at base, but well developed in apical two-thirds beneath the feebly dilated external edge of the dorsal plate. Internal margins of the valves contiguous in basal two-thirds; fissure narrow and in apical third, about closed, and the inferior membrane is not visible.

Habitat.-California (Eldorado County, on the way to the summit above Riverton, July).

Number of specimens studied, 3.

Sexitypes in my own collection.

Type-locality.-Western slope of the Sierra Nevada Mountains, above Riverton, Eldorado County, California.

Salient type-characters.-See general description.

Diagnostic characters.-This species differs from parvicollis and its races in the more oval and somewhat depressed form, finer and 
denser sculpturing. The prothorax, while it retains the same form observed in parvicollis, is more broadly rounded and more briefly sinuate at the base, the marginal line nearly attains the angle. Constricta, which occurs in the same region, is much more strongly and coarsely sculptured, the prothorax is strongly constricted at base.

The wider pronotum, smaller and less robust form, distinguishes hoppingï from consobrina.

The pubescent tufts on the protarsi are smaller than in any other species of Blapylis known to me. The antennæ are also shorter than in any other closely related species.

The female before me was compared with types in Cambridge by Professor Fall, and found to be quite different from anything there.

I have named it in honor of my friend, Ralph Hopping, in recognition of many favors.

General observations. - The mentum is moderate and parabolic in outline, slightly triangular in the males; surface finely and not distinctly punctate, broadly and feebly foveate laterally.

The prosternum is not strongly protuberant ventrally with the coxæ, arcuately rounded antero-posteriorly between the same, and not in the least mucronate.

The mesosternum is arcuately declivous and feebly concave.

The metasternum laterally between the coxæ is as long as the width of a mesotibia just before the apex.

The abdominal process is subquadrate (male) or slightly transverse (female), and about a fourth of its width broader than the metasternal salient; it is also equal to the length of the post-coxal part of the same abdominal segment; it is also equal to the length of the second segment, the latter being twice as long as the fourth; the third is one-half longer than the fourth. It is quite unusual for these relative proportions of parts to correspond in the two sexes.

The tarsi are slender and of moderate length.

Tarsal formula :

$\begin{array}{rccc}\text { Pro. } & \text { Meso. } & \text { Meta. } & \text { Metatibia. } \\ \text { Male.- }-1 \frac{1}{2} & 2 \frac{1}{3} & 2 \frac{3}{5} & 4 \\ \text { Female.- } 1 \frac{1}{3} & 2 & 2 \frac{1}{3} & 3 \frac{1}{2}\end{array}$

ELEODES CLAVICORNIS Eschscholtz.

Eleodes clavicornis Eschscholtz, Zool. Atlas, III, 1833, p. 11.-MANneRherm, Bull. Soc. Nat. Moscow, XVI, 1843, p. 269.-LeConte, Proc. Acad. Nat. Sci. Phila., 1858, p. 182.-HonN, Trans, Amer. Phil. Soc., XIV, 1870 , p. 315.

Eleodes impressicollis Boheman, Freg. Eugen. Resa. Ins., 1858, p. 90.

Oblong-ovate, about twice as long as wide, small, pronotal disc not noticeably transverse and with moderately long erect setæ along 
the sides, also upon the propleuræ. Punctures setigerous distinctly throughout.

Head twice as wide as long, feebly convex, more or less impressed laterally and along the frontal suture, the latter more or less obsolete; surface irregularly and sparsely punctate at middle, also on the vertex, more densely and coarsely so laterally and on the epistoma. Antennce rather long, quite slender, outer four joints feebly compressed and distinctly and gradually incrassate, third joint scarcely as long as the next two taken together, fourth just the least longer than the fifth, the latter to the seventh inclusive subequal in length, the seventh slightly broadened and subtriangular, eighth just the least shorter and more or less triangular, ninth triangulo-oval and feebly transverse, tenth transversely oval, eleventh transversely suboval.

Pronotum slightly transversely suboval, widest at the middle, about or a little more than a third wider than long; disc moderately convex, distinctly arcuately declivous laterally and at the apical angles, sparsely, distinctly, and very irregularly punctate, with scattered impunctate areas, punctures coarser and denser laterally on the declivities, where each bears a moderately long erect seta; apex subtruncate in circular arc, finely and more or less obsoletely margined; sides more or less evenly and moderately arcuate, somewhat straight and convergent posteriorly, feebly or not at all sinuate before the basal angles, marginal bead fine and entire; base very feebly rounded and finely beaded, about a fifth to a fourth wider than the apex and equal to or slightly greater than the length; apical angles obtuse, not in the least prominent, and more or less feebly rounded; basal angles obtuse or minutely rectangular and just the least prominent.

Propleurce opaque, sparsely punctate, each puncture with a moderately long, erect, and brownish seta.

Elytra oval, not over one-half longer than wide, widest at the middle; base subtruncate and about equal to the contiguous prothoracic base; humeri rounded; sides evenly arcuate, apex not very narrowly rounded and not in the least produced; disc almost evenly convex from side to side, dorsum scarcely flattened, arcuately declivous posteriorly; surface punctate, punctures coarse and impressed, rather dense and scarcely arranged in series, at the sides and apex the punctures are more irregular, submuricate, each with a rather short suberect seta, which become less evident on the dorsum.

Epipteurce rather wide, gradually narrowing from base to apex, superior margin rather feebly and broadly sinuate beneath the humeri and not visible from above; surface smooth, sparsely and coarsely punctate.

Sterna obsoletely punctate and rugulose, sparsely pubescent, hairs short and erect. 
Parapleura somewhat sparsely punctate, hairs short.

Abdomen horizontal, glabrous and shining, very sparsely punctate, hairs short.

Legs comparatively moderate in length and rather slender. Anterior femora mutic; protibial spurs about similar in the sexes, the anterior a little longer than the posterior; tarsi dissimilar in the sexes.

Male.-Body rather slender. Antennæ reaching a short distance beyond the base of the prothorax. Elytra evenly arcuately declivous posteriorly. Abdomen moderately convex, first two segments distinctly impressed at middle. Protibial spurs subequal, slender, and acute. Protarsi with the first two joints very feebly thickened at tips beneath, each bearing a small tuft of silken pubescence that obliterates the groove.

Female.-Body rather robust. Antennæ reaching just slightly beyond the prothoracic base. Elytra rather broadly oval, arcuately and almost vertically declivous posteriorly. Abdomen quite strongly convex. Anterior spurs of the protibix a little longer than the posterior, both slightly thickened and acute. Anterior tarsi with the first joint slightly thickened at tip, groove interrupted by a few paler spinules, that are transversely arranged on tip.

Measurements.-Males: Length, 10.2-12.5 mm.; width, $4.2-5 \mathrm{~mm}$. Females: Length, 12-13 mm.; width, 5.2-6 mm.

Genital characters, male.-Edeagophore elongately oval and scarcely arched.

Basale oblong, not three times as long as wide; surface evenly convex, with sides feebly arcuate.

Apicale subequilaterally triangular; surface rather strongly convex, without groove; sides distinctly sinuate in apical two-thirds, arcuate in basal third; apex more or less attenuate and acute; base broadly lobed at middle and feebly sinuate laterally.

Sternite transverse. Each lobe triangular, with the external border more or less sinuate in basal half, thence more or less obliquely truncate to apex, the latter narrowly rounded; internal border more or less straight; surface feebly convex, sparsely punctate in apical half, setose, setæ quite long, still longer on apical margin. Membrane not setose across the bottom of the sinus, the latter rather broad.

Female.-Genital segment elongately triangular,-superior surface plane.

Valvula (Plate 4, fig. 11).--Dorsal plate narrow and elongately oblong; surface plane, glabrous, very sparsely and obsoletely punctate, setose; sides subparallel; apical margin evenly rounded and clearly defined from apex, the latter small and finely setose; external lobe obsolete. 
Appendage very short mammilliform, with three or four long hairs at tip; fossa on the basal and external surface of apex, small.

Superior pudendal membrane long, attaining the apical sixth of the dorsal plate and longitudinally rugulose.

Basal prominences not evident, evenly rounded about base.

Ventrolateral surfaces.-Body quite evenly convex from side to side, surface lines straight when viewed longitudinally, feebly concave laterally before the- apex; apex finely setose. Submarginal groove distinct and moderate beneath the very narrowly prominent external margin of the dorsal plate. Internal margins of the valves contiguous in basal third; fissure rather long and quite narrowly fusiform; inferior pudendal membrane not visible.

Habitat.-California (common about the sand dunes under vegetation, along the coast of central California; Doctor Horn reports it as extending northward to the head of the Sacramento Valley; as far south as Los Angeles County).

Number of specimens studied, 600.

Type in the Eschscholtz collection.

Type-locality.-California near San Francisco.

Salient type-characters.-Oblong-ovate. Antennæ slender and subclavate. Pronotal disc not noticeably transverse, arcuately declivous laterally, with moderately long erect setæ on the declivous portions; apical angles obtuse, feebly rounded; sides rather evenly rounded, rather straight and converging posteriorly, just the least sinuate before the basal angles. Elytra coarsely punctate, with slight evidence of a serial arrangement when viewed longitudinally, sides more irregularly and submuricately punctate. The punctures are setigerous throughout.

Diagnostic characters.-Claveornis is a very distinct species and quickly recognized by its small size and setose sides of the pronotal disc. No other species of the subgenus Blapylis has the propleuræ so distinctly pubescent. Scabrosa is the most closely related species, and differs in its distinctly larger and transverse pronotum, the discal sides of which are not in the least declivous, although set with very short erect setæ. Clavicornis has the elytra rather coarsely and densely punctate, the punctures are impressed, the sculpturing is quite like that observed in scabrosa.

The punctures are noticeably setigerous throughout. The antennæ are usually feebly clavate.

The species named by Boheman as impressicollis is simply specimens which have two thoracic foveæ. Such accidental variations are common (see p. 27) ; sometimes only one fovea is present; this variation is frequently observed in other species. 
General observations.-The mentum is small and more acute at apex than in other species; the surface is rather strongly convex at middle, finely and not strongly punctured, not noticeably setose.

The prosternum is variable. Feebly widened or subparallel behind the coxæ, more or less arcuate antero-posteriorly, frequently subtruncate behind or feebly mucronate; surface usually distinctly grooved at middle.

Mesosternum vertically arcuate or obliquely declivous, and more or less distinctly concave.

The metasternum laterally between the coxæ is as long as the width of a metatibia at apex.

The abdominal process is quadrate (male) or slightly transverse (female) and a fifth (male) to a fourth (female) of its width broader than the metasternal salient, subequal in length to the second segment (male) or equal to that of the post-coxal portion of the first segment (female).

In the male the post-coxal part of the first segment is a little shorter than the process and about a half longer than the fourth.

In the female the second segment is about twice as long as the fourth.

The protarsi are about two-fifths (male) or a half (female) of their length shorter than a mesotarsus.

The mesotarsi are about a seventh (male) of their length shorter or subequal (female) to a metatarsus.

The metatarsi are about a fourth (male) or about two-thirds (female) of their length shorter than a metatibia.

\section{ELEODES SCABROSA Eschscholtz.}

Eleodes scabrosa Eschscholtz, Zool. Atlas, III, 1833, p. 11.-Mannerheim, Bull. Soc. Nat. Moscow, XVI, 1843, p. 272.-LeConte, Proc. Acad. Nat. Sci. Phila., 1858, p. 182.-Horn, Trans. Amer. Phil. Soc., XIV, 1870 , p. 317.

Suboblong-ovate, somewhat robust, shining, about twice as long as wide; pronotum transverse and with very short erect setæ laterally on the disc and propleuræe.

Head twice as wide as long, feebly convex, usually impressed laterally and along the frontal suture, the latter more or less evident. coarsely and irregularly punctate, frequently with impunctate areas on the frons and vertex, punctures crowded laterally and on the epistoma. Antennce moderate in length and stoutness, outer three or four joints slightly compressed and noticeably dilated, third joint about equal in length to the next two combined, fourth and fifth subequal, sixth and seventh apparently just the least shorter and subequal, eighth a little shorter, broader, and subtriangular, ninth and tenth transversely oval, eleventh ovate, apparently broader than long. 
Pronotum transverse, widest at the middle, about a half wider than long; disc moderately and evenly convex, not dectivous laterally, coarsely and irregularly punctate, impunctate areas usually present, laterally the punctures are denser, becoming granulate and scabrous, each puncture with an erect and very short seta for a short distance from the side margins; apex truncate or feebly emarginate in circular arc, obsoletely beaded; sides very evenly and rather strongly arcuate to basal eighth, there feebly constricted and sinuate, thence parallel or feebly convergent to the basal angles, marginal bead fine and usually entire; base feebly rounded, marginal bead not evident, slightly wider than the apex, equal to or slightly greater than the length; apical angles obtuse and scarcely rounded; basal angles obtuse or subrectangular, not at all prominent.

Propleurce smooth, very sparsely punctate, punctures submuricate, each with a moderately short and erect seta, more or less regulose.

Elytra oval, about a third longer than wide, widest at the middle; base subtruncate, wider than the contiguous prothoracic base; humeri obtusely rounded or subangulate; sides evenly arcuate, apex rather narrowly to somewhat broadly rounded and not in the least produced; dise moderately and evenly convex on the dorsum, strongly but not very broadly rounded laterally, arcuately declivous behind; surface punctate, punctures coarse, moderately impressed, diffused, without order, sometimes a slight serial arrangement evident when viewed longitudinally, punctures simpler on the dorsum, denser and muricatogranulate with a tendency to coelscence in transverse rugæ laterally and on apex; the punctures are minutely setigerous.

Epipleura shining, rather wide, gradually narrowing from base to apex, superior margin more or less broadly sinuate beneath the humeri; surface submuricately punctate.

Sterna densely punctate and somewhat rugulose.

Parapleurce coarsely and more or less densely punctate.

Abdomen smooth and shining, evenly and sparsely punctate, first segment on and about the process densely sculptured; fifth segment more densely punctate at the periphery; each puncture with a short seta.

Legs moderate in length, somewhat stout; anterior femora mutic; anterior tibial spurs quite similar in the sexes, the anterior slightly longer and stouter than the posterior, both acute; tarsi dissimilar in the sexes.

Male.-Somewhat robust. Antennæ scarcely reaching beyond the prothoracic base. Elytra arcuately and feebly obliquely declivous posteriorly. Abdomen feebly oblique and moderately convex, first two segments more or less feebly impressed at middle. Anterior tarsi with the first joint slightly thickened at tip beneath and bearing a 
small subacute tuft of yellowish pubescence enveloped by a few ordinary spinules, groove distinct on the second joint.

Female.-Robust. Antennæ not quite attaining the prothoracic base. Elytra rather broadly oval, arcuately and vertically declivous behind. Abdomen horizontal and rather strongly convex. Anterior tarsi with the first joint transversely thickened at tip beneath, and with a transverse line of piceous spinules upon the same.

Measurements.-Males: Length, 10-12 mm.; width, 4.5-5.8 mm. Females: Length, 12-13 mm.; width, 6-6.8 mm.

Genital charucters, male.-Edeagophore flattened oblong-ovate and feebly arched.

Basale oblong, about two and one-fourth times longer than wide, surface evenly convex, the sides parallel and very feebly arcuate.

A picale triangular, surface evenly and not strongly convex, without groove; sides arcuate in basal third, thence broadly and quite strongly sinuate to apex, the latter subacute; base lobed at middle, slightly sinuate laterally.

Sternite parabolic in outline. Each lobe triangular; external border rather evenly and not strongly arcuate; internal border quite straight; apex somewhat introrsely placed and rather narrowly rounded; surface very feebly convex, glabrous and shining, sparsely punctate and setose in apical half, setæ moderate in length, longer about apex, membrane not setose across the bottom of the sinus, the latter deep and triangular.

Female.-Genital segment triangular, elongate, about twice as long as wide, surface plane, not conspicuously setose.

Valvula (Plate 5, fig. 22).-Dorsal plate very elongate, oblong, about four times longer than wide; surface plane, glabrous, very sparsely punctate and setose, setæ fine and inconspicuous; sides parallel and nearly straight; apical margin parabolically rounded. Apex very small, slightly longer than the appendage, quite narrow and finely setose.

Appendage mammilliform, about half as large as the apex, with a pencil of about five hairs at tip; fossa at base of the external surface of the apex.

Superior pudendal membrane reaching to the apical fourth of the dorsal plate and longitudinally rugulose.

Basal prominences not evident.

Ventrolateral surfaces feebly convex from side to side, glabrous, sparsely setose in apical moiety. Each valve very feebly and broadly concave apically, submarginal groove broad beneath the laterally prominent external border of the dorsal plate, and quite evanescent before the fossa, which is distinctly lateral in position. Internal margins of the valves contiguous in basal two-thirds; fissure apical and rather narrow. Inferior pudendal membrane not visible. 
Habitat.-Plentiful about sand dunes along the coast of California, northward to Oregon.

Number of specimens studied, 400.

Type in the Eschscholtz collection?

Type-locality.-San Francisco, California.

Salient type-characters.-Thorax transverse, densely punctate, sides rounded and scabrous. Elytral punctures on the dorsum simple, granulate laterally. Antennæ clavate (Eschscholtz).

Diagnostic characters.-The following characters seem to show conclusively that scabrosa is more closely related to clavicomis than to parvicollis with which it has for a long time been associated by the more recent authorities: the sculpturing is quite similar in the two species, the setose sides of the pronotal disc and propleuræ, clavate antennæ, elongate and narrow dorsal plates of the valves of the genital segment in the female characters not observed in parvicollis; the sculpturing is also much coarser than is observed in the latter species.

Scabrosa differs from clavicornis in having the antennæ shorter, a coarser and denser cephalic and pronotal punctuation, a much broader pronotum, which is not so declivous at the sides and more strongly sinuate before the basal angles, the very short discal setæ, those of the propleuræ being noticeably shorter; the male is also more robust.

The present species is smaller than the average individuals of parvicollis. So, in view of these differential facts I am forced to restore this species of Eschscholtz's to specific standing.

The elytral sculpturing is quite similar to that observed in cordata, but in the latter species the pronotal sides are more strongly rounded anteriorly and more suddenly narrowed behind, becoming subangulate at times; the pronotal punctuation is much coarser and the intervals convex, the pronotum is more cordate in the one and more transversely oval in the other. I am indebted to Professor Fall for comparisons made with the LeContian specimens at Cambridge.

General observations.-In scabrosa the mentum is larger and more broadly rounded at apex than in clavicornis (compare figs. 5 and 6 of Plate 8); usually quite parabolic in outline, sometimes subtriangular; surface convex along the median line and slightly subfoveate laterally, moderately punctate, setæ not noticeable.

The prosternum is quite prominent ventrally with the coxæ, rounded antero-posteriorly between the same and not mucronate.

The metasternum laterally between the coxæ is as long as the width of a mesotibia at apex.

The intercoxal process of the abdomen is quadrate (male) or more or less transverse (female), and a fourth to a third of its width broader than the metasternal salient; the post-coxal portion of the 
first segment is slightly shorter than the process; the second segment is about twice as long as the fourth.

In the male the third segment is about equal in length to that of the process and about a third of its own length shorter than the second.

In the female the second segment is about equal in length to the process, and the third is about a fourth of its length shorter than the second.

The protarsi are about three-eighths (male) or a third (female) of their length shorter than a mesotarsus.

The mesotarsi are about four-elevenths (male) or a fourth of their length shorter than a metatarsus.

A metatarsus is abogut a third (male) or three-fifths of its length shorter than its metatibia.

\section{ELEODES CORDATA Eschscholtz.}

Eleodes cordata Eschscholtz, Zool. Atlas, III, 1833, p. 12.-Mannerheim, Bull. Soc: Nat. Moscow, XVI, 1843, p. 272.-LeConte, Proc. Acad. Nat. Sci. Phila., 1858, p. 182.-Horn, Trans. Amer. Phil. Soc., XIV, 1870 , p. 317 .

Eleodes tuberculata Eschscholtz, Zool. Atlas, III, 1833, p. 12,-ManNerHerm, Bull. Soc. Nat. Moscow, XVI, 1843, p. 274.

Eleodes intricata Mannfrherm, Bull. Soc. Nat. Moscow, XVI, 1843, p. 273. Eleodes stricta LeCoste, Reports of Explor. and Surveys, 47th Parallel, XII, Appendix No. 1, 1857, p. 50.

var. rotundipennis, LeConte, Reports of Explor. and Surveys, 47th Parallel, XII, Appendix No. 1, 1857, p. 50.

Moderately robust, subovate, more or less shining, about twice as long as wide, prothorax strongly constricted at base, pronotum confluently and very coarsely punctate; elytra rugosely muricato-tuberculate.

Head about twice as wide as long, feebly convex, lateral impressions not strongly marked, frontal suture not evident, very coarsely and confluently punctate. Antenno moderate and somewhat stout, outer four joints very feebly compressed and very slightly widened, third joint equal in length to the next two combined, fourth searcely longer than the fifth, the latter to the eighth inclusive subequal, eighth subtriangular, ninth transversely oval and frequently slightly robust, tenth transversely oval, eleventh short ovate and usually slightly smaller than either of the two preceding joints.

Pronotum subcordate, about a half wider than long, widest at about the middle; disc moderately convex, more or less declivous at apical and basal angles, coarsely, densely, and more or less confluently punctate, interstices more or less convex; apex feebly emarginate to truncate, obsoletely margined; sides more strongly rounded in front, narrowing rather suddenly behind the middle, causing them to appear somewhat angulate, frequently more evenly arcuate to the 
constriction, which is usually at basal sixth, thence straight and parallel to the basal angles; the fine margin is very feebly reflexed and obsolete on the constriction; base truncate in circular arc, finely or obsoletely margined, about equal to the length and slightly to a fourth wider than the apex; apical angles obtuse, not in the least prominent anteriorly and more or less rounded; basal angles rectangular and not prominent.

Propleurce more or less sparsely granulate and rugulose.

Elytra rather broadly oval, about a fourth longer than wide, widest at the middle; base truncate and wider than the contiguous prothoracic base; humeri rounded, scarcely at all angulate; sides evenly arcuate, apex obtuse and moderately rounded; disc moderately convex on the dorsum, rather strongly and evenly rounded laterally, strongly and arcuately declivous posteriorly, generally quite vertically so; surface densely, irregularly, and rugosely muricato-tuberculate, less strongly sculptured along the suture; punctures minutely setigerous.

Epipleurce moderate in width, slightly dilated beneath the humeri, superior margin feebly and very broadly sinuate in basal fourth and scarcely visible at humeri when viewed from above; surface smooth, sparsely and rather coarsely punctate.

Sterna more or less densely punctato-rugose, punctures setigerous, noticeably so on the mesosternum; setæ short, black, and rather stiff.

Parapleura densely punctate.

Abdomen smooth, sparsely and distinctly punctate; first segment punctato-rugose, the fifth rather densely punctured.

Legs moderate in length and thickness and quite strongly sculptured, the punctures bearing short black setæ. Anterior femora mutic in the sexes. Anterior tibial spurs quite similar, the anterior slightly longer than the posterior. Anterior and middle tarsi dissimilar in the sexes.

Male.-Moderately robust, somewhat narrow, antennæ reaching to or just beyond the base of the prothorax. Elytra about a fourth longer than wide. Abdomen moderately convex, slightly oblique, broadly impressed at middle of the first segment. Spurs of the protibiæ quite slender and acute. First two joints of the protarsi clothed with flattened tufts of golden pubescence beneath; first joint of the middle tarsi with a well-developed and similar tuft at apical third beneath; pubescent joints not noticeably thickened at tip.

Female.-Robust. Antennæ about reaching to the prothoracic base. Elytra broadly oval and about a fifth longer than wide. Abdomen quite strongly convex. Spurs of the protibiæ slightly thickened and acute. First joint of the protarsi slightly thickened at apex beneath, groove more or less distinct.

Measurements.-Males: Length, 13-15.2 mm.; width, $6-6.8 \mathrm{~mm}$. Females: Length, 12-17 mm.; width, 6.8-9 mm. 
Three forms may be recognized according to the character of the sculpturing:

Forma sublævis.-Similar in form to the typical form, but smoother, with the sculpturing somewhat obsolete.

Forma typica.-Strongly and roughly sculptured; elytra rugosely punctate, the interstices between the punctures elevated and convex, and more or less confluent transversely.

Forma intermedia.-Sculpturing more strongly muricato-tuberculate, with the intervals between the punctures less convex and consequently less rugose, approaching pimelioides.

Genital characters, male.-Edeagophore stoutly fusiform, feebly arched.

Basale oblong, about twice as long as wide; surface evenly convex; sides feebly arcuate, and the apex quite deeply and triangularly emarginate.

A picale triangular, rather narrow, usually distinctly narrower at base than the basale at apex; surface strongly convex, without groove; sides nearly straight or feebly arcuate, slightly prominent at base; apex acute; base acutely lobed at middle, laterally feebly sinuate.

Sternite subparabolic. Each lobe triangular; external border more or less straight or feebly and broadly sinuate in basal twothirds, thence quite evenly arcuate to apical margin, angle narrowly rounded; internal margin feebly sinuate; surface very feebly convex, punctate and setose in apical half, setæ moderate in length, not dense, longer toward and on apical margin. Membrane not setose across the bottom of the sinus, the latter more or less triangular and apparently not closed by the membrane.

Female.-Genital segment triangulo-trapezoidal, surface of the valves slightly declivous, setose.

Valvula (Plate 4, fig. 6).-Dorsal plate oblong, feebly narrowed from base to apex. Surface plane or feebly concave, smooth, punctures scattered, each with a rather long flying seta; borders quite straight; apical margin oblique, angle obtuse and feebly rounded; internally not distinctly defined from the apex, the latter rather short and membranous, rounded at tip and clothed with moderately long setæ.

Appendage mammilliform, with a pencil of quite long hairs at tip. Fossa rather large at base of the external apical surface.

Basal prominences not evident.

Superior pudendal membrane longitudinally rugulose, and attaining the middle of the dorsal plate.

Ventrolateral surfaces.-Body triangular, surface lines straight when viewed longitudinally, quite evenly convex laterally, sparsely setose in apical half. setæ moderate and more or less flying. Sub- 
marginal groove well developed beneath the slightly expanded external border of the dorsal plate and terminating at the fossa beneath the angle. Internal margins of the valves contiguous in basal twothirds; fissure narrowly fusiform in apical third, and the inferior pudendal membrane is not visible.

Habitat.-California. Forma sublaevis, about San Francisco Bay ; Forma typica, central California, along the coast; San Joaquin and Sacramento valleys; Calaveras County; Tulare County, Ralph Hopping; Los Angeles County, Doctor Van Dyke; Forma intermedia, northern California, southern Oregon, western slopes of the Sierra Nevada Mountains.

Professor Wickham in his "Coleoptera of Colorado" says that Professor Snow has reported one specimen from Colorado. It is in all probability a variation of pimetioides.

Number of specimens studied, 500.

Type in the Eschscholtz collection?

Type-locality._-"California."

Satient type-characters.-Ovate, robust, shining. Head and pronotum coarsely and confluently punctate; thorax subcordate, apex feebly emarginate, angles obtuse; sides more strongly rounded in front, narrowing rather suddenly behind the middle, causing them to appear somewhat angulate; strongly constricted at base; angles rectangular. Elytra oval; humeri much rounded and obtuse; dise arcuately and vertically declivous posteriorly; surface densely and rugosely muricato-tuberculate, less strongly so along the suture.

Diagnostic characters. - Cordata differs from all other species in the subgenus Blapylis, except pimelioides, in having the sides of the prothorax more or less subangulate. This character is especially marked in the males. The prothorax is more evenly rounded behind the middle in most females, but always strongly constricted at base, giving it with the above characters a subcordate appearance. The marginal bead does not reach the base.

The coarse sculpturing will cause it to be frequently confused with scabrosa, but the setose propleuræ of the latter will readily separate the two, besides the pronotal sculpturing is quite different in the two species. Clavicornis is much less strongly sculptured, and the sides of the pronotal disc are distinctly setose along, with the propleuræ.

In pimetioides and brunnipes the elytra are sculptured with rows of small and rounded tubercles; in the latter species the legs are brown or reddish.

In studying a large series of cordata it is very evident that the sculpturing varies toward pimelioides, so that in the heterotypes it is quite difficult to tell where one species leaves off and the other begins: 
cordata acquires a rugoseness of sculpturing and pimetioides a tuberculate form of elytral markings.

They are to be considered as two divergent forms derived from a common ancestral ramus.

Specimens from Oregon have the prothorax rounded on the sides, as in parvicollis and scabrosa (see rotundipennis).

Specimens from southern California collected by Doctor Van Dyke are remarkable among those of the large series before me on account of their elongate form, measuring: Length, $15 \mathrm{~mm}$; width, $6.5 \mathrm{~mm}$; elytra more elongately oval (forma elongata). These specimens approach an unique male from Amador County, in which the form is elongate oblong, thorax as in cordata, antennæ long and stout, and the elytra are distinctly tuberculate and not rugose. The whole habitus is that of a stout, oblong cordata (forma oblonga). Length, $16 \mathrm{~mm}$; width, $7 \mathrm{~mm}$. These are remarkable variations from the monotonous short, robust, normal form.

Mannerheim's types of intricata were taken about Fort Ross, California, by Doctor Fischer, and I can not see that it differs in any essential characters to give it even varietal standing. Many females have the "thorace transverso, lateribus valde rotundatis." In a large series of cordata a variation in the length and stoutness of the antennæ and legs, independent of sex, may frequently be observed. The humeri vary considerably also, never prominent, but frequently subangulate and always more or less rounded.

Tuberculata Eschscholtz is to be disposed of in the same way as intricata. For sticta, see p. 384.

General observations.-The mentum is usually more or less triangulo-trapezoidal and rather small, finely sculptured, feebly foveate laterally, and very slightly convex at middle.

The prosternum is variable, usually rather prominent ventrally with the coxæ, and quite strongly arcuate antero-posteriorly, without a mucro; frequently a small mucro is present at middle of the posterior edge; rarely horizontal, subtruncate behind, and more or less feebly mucronate.

The mesosternum is vertically arcuate and more or less broadly and deeply concave.

The metasternum laterally between the coxæ is as long as the width of a mesotibia at middle.

The abdominal process is subquadrate, equal in width (female) or a third (male) of its width broader than the metasternal salient.

In the male the post-coxal part of the first segment is equal in length to the third; the second to that of the process and twice as long as the fourth and about a fifth longer than the third.

In the female the post-coxal part of the first segment is equal in length to that of the process and also to the second, the latter being 
about twice as long as the fourth; the third is about one-half longer than the fourth.

The tarsi are usually moderate in length and stoutness.

Tarsal formula :

\begin{tabular}{|c|c|c|c|}
\hline Male. -2 & $\begin{array}{l}\text { Meso. } \\
2 \frac{1}{2}\end{array}$ & $\begin{array}{l}\text { Meta. } \\
3\end{array}$ & $\begin{array}{l}\text { Metatibia. } \\
4 \frac{1}{3}\end{array}$ \\
\hline emale. $-1 \frac{4}{5}$ & $2 \frac{1}{3}$ & 3 & $4 \frac{1}{3}$ \\
\hline
\end{tabular}

ELEODES CORDATA var. ROTUNDIPENNIS LeConte.

Pronotal sides evenly and broadly rounded (as in parvicollis), basal constriction short and the angles rectangular.

Otherwise as in cordata.

LeConte was very much in doubt as to the propriety of separating this form even as a race. The constancy of form in the prothorax, which, taken in conjunction with the coarse elytral sculpturing, make it appear at first sight as a northern modification of scabrosa; this is not so; the propleuræ are without distinct setæ, and besides the pronotal punctuation is quite different, being as in cordata; this is in fact the only superficial character which separates and prevents it from being naturally associated with the parvicollis section. I consider it a good race, and the series before me shows conclusively that it varies more toward typical cordata than pimetioides.

Habitat.-Oregon (Koebele); British Columbia (Victoria and North Bend, Hubbard and Schwarz) ; Washington (H. K. Morrison, Easton and Olympia).

Number of specimens studied, 11.

Type in the LeConte collection.

Type-locality.- " Oregon."

I have taken this variety at Oregon City, near Portland, Oregon.

Stricta LeConte, according to the author, has the "thorax less suddenly but very much constricted at base, fully one-half wider than long; elytra more coarsely and less densely punctured," and is to be taken as a synonym of the present race.

\section{ELEODES PIMELIOIDES Mannerheim.}

Eleodes pimelioides Mannerheim, Bull. Soc. Nat. Moscow, XVI, 1843, p. 274; Mag. Zool., XIII, 1843, no. 129, fig. - LeConte, Proc. Acad. Nat. Sci. Phila., 1858, p. 182.-Honn, Trans. Amer. Phil. Soc., XIV, 1870 , p. 318.

Eleodes viator LeConte, Proc. Acad. Nat. Sci. Phila., 1858, p. 188.

Eleodes subligata LeConte, Reports of Explor. and Surveys, 47th Parallel, XII, Appendix no. 1, 1857, p. 50.

var. brunnipes CAsey, Ann. N. Y. Acad. Sci., V, Nov., 1890, p. 402.

Moderately robust, ovate, feebly shining to opaque, about twice as long as wide; prothorax more or less strongly constricted at base, densely rugoso-punctate; elytra sculptured with small tubercles, which may be rounded or reclinate and more or less piliferous. 
Head densely punctate, antenna somewhat slender, ninth joint triangulo-orbicular to transversely oval, tenth more or less transversely oval.

Pronotum subcordate to transversely suboval, widest near the middle, a fourth to scarcely a half wider than long; sides evenly and quite strongly arcuate to basal seventh, or subangulate at middle, rounded in front and quite rapidly converging posteriorly and sinuate at basal fourth, thence in each instance quite straight and parallel to the basal angles; base equal to the length or in some males shorter than the length; apical angles obtuse, frequently not in the least rounded, at other times more or less so.

Elytra quite broadly oval to subquadrate, widest at or behind the middle, a fourth to a third longer than wide; disc more or less deplanate on the dorsum, strongly, arcuately, and vertically declivous posteriorly; surface densely tuberculate, tubercles apparently arranged in rows on the dorsum or irregular throughout; each bears a very short, black seta near apex; when arranged in rows there are very small muricate punctures scattered sparsely and irregularly between, always less distinct along the suture centrally; the tubercles are more or less rounded and shining, the interstices between more or less opaque. Otherwise as in cordata.

Male.-First two joints of the protarsi with tuft of yellowish pubescence near tip beneath; that of the second joint is rather small; tuft on the first joint of the mesotarsi quite small. Tufts somewhat long and truncate at tips. Otherwise as in cordata.

Female.-First joint of the anterior tarsi distinctly thickened at tip beneath. Otherwise as in cordata.

Measurements.-Males: Length, 12-14.5 mm.; width, 6-7 $\mathrm{mm}$. Females: Length, 13-15.2 mm.; width, 6.5-8 mm.

Genital characters, male.-As in cordata.

Female.-Genital segment triangular, surface quite plane and slightly setose.

Valvula (Plate 5, fig. 5).-Dorsal plate oblong, feebly or scarcely narrowed apically, slightly explanate externally; apical margin nearly transverse to feebly oblique, inwardly not defined from the surface of the apex, angle obtuse and more or less feebly rounded.

Ventrolateral surfaces.-Submarginal groove distinct and well defined beneath the expanded external border of the dorsal plate. Otherwise as in cordata.

Habitat.-California (Shasta, Siskiyou, Butte, Lake, and Humboldt counties); Oregon (The Dalles, Hubbard and Schwarz; Clackamas County, Charles Fuchs) ; Utah (Alta, Wasatch in July, American Fork Canyon in July, Hubbard and Schwarz; Park City) ; Nevada (Elko, H. F. Wickham); Washington (Easton, C. V. Riley; $59780-$ Bull. $63-09-25$ 
Pullman, Palouse, A. M. Warren; Olympia, E. C. Van Dyke; Walla Walla, Charles Fuchs; Everett, July, Wickham and Van Dyke); Idaho (Camas Prairie, C. V. Riley; Cour d'Alene, June, H. F. Wickham); Montana (Helena, August, Hubbard and Schwarz); Colorado (Central City, Garland, C. V. Riley; Buena Vista, July, Hubbard and Schwarz; Golden, Glenwood, Horse Fly Peak, Idaho Springs, Aspen, Fort Collins, Leavenworth Valley $(9,000-10,000$ feet), Roaring Fork, Monument Gulch to Montrose, Little Willow Creek, Canyon of Big Blue, Montrose and adjacent mountains, H. F. Wickham in the "Coleoptera of Colorado"); Wyoming (Natural Park, July) ; British Columbia (Vancouver Island, collection of Dr. E. C. Van Dyke).

Number of specimens studied, 90.

Type in the Mannerheim collection.

Type-locality.--"California."

Salient type-character.-Opaque. Thorax with the sides rounded, densely rugoso-punctate. Elytra subquadrate, apex strongly declivous, dorsum deplanate, densely granulate, granules reclinate, rough and piliferous (Mannerheim).

Diagnostic characters.-In general form like cordata, from which it differs in having the elytra sculptured with small rounded tubercles. The -form of the tubercles differs, in some specimens distinctly rounded, in others reclinate and often more or less muricate. In some males there is evidence of rows.

The series from Walla Walla, Washington, have the elytra deplanate and subquadrate; these characters are less marked in the other specimens. In the race bmonnipes the legs are brownish and more distinctly piliferous, at least in those specimens from Nevada.

Viator, described by LeConte from Fort Bridger, is a male, with the elytral tubercles large and extending almost to the suture. Colonel Casey also considers that this form does not differ from ordinary males of pimelioides.

Subligata is one of the forms associated with cordata by LeConte; he obtained specimens from Oregon. Doctor Horn considered it a synonym of the present species, and which is undoubtedly correct.

For remarks upon variation in sculpturing see cordata.

The legs are variable, usually more slender in the males and stouter in the females. The thorax and humeri vary as in cordata.

ELEODES PIMELIOIDES var. BRUNNIPES Casey.

Rather robust, moderately convex, coarsely, densely sculptured and dull, black; legs dark brown throughout.

Head large, fully two-thirds as wide as the prothorax, coarsely, extremely densely punctate and scabrous. Antennce longer than the 
head and prothorax, rather slender, third joint about four times as long as wide.

Prothorax scarcely a third wider than long; disc moderately, evenly convex throughout, very coarsely, deeply, and confluently punctate; apex subtruncate; sides strongly angulate at the middle, thence very feebly arcuate to the apex and broadly sinuate to the base; base subtruncate and nearly equal to the apex in width; apical angles obtuse, not distinctly rounded, not at all prominent; basal angles right and not rounded.

Elytra at base nearly a third wider than the contiguous prothoracic base, very slightly more than twice as long as the latter, abruptly and obtusely rounded behind when viewed vertically; sides strongly arcuate behind, gradually convergent and straighter thence to the humeri, which are slightly obtuse but scarcely at all rounded; disc widest behind the middle, where it is from a third to two-fifths wider than the prothorax, feebly convex on the dorsum, strongly so laterally; surface coarsely, densely, asperately punctate, the asperities arranged without trace of order.

Legs moderate in length, somewhat slender.

Male and female secondary sexual characters as in pimetioides.

Measurements.-Length, $9.2-9.5 \mathrm{~mm}$.; width, $4.3-4.6 \mathrm{~mm}$. A female taken at Verdi, Nevada, has a length of $15 \mathrm{~mm}$. ; width, $7.5 \mathrm{~mm}$.

Genital characters, male.-As in pimelioides.

Female.-In the specimens referred to this species and which are not typical, the genital segment is triangular.

Dorsal plate moderately narrow and elongately oblong; apical border feebly oblique with the angle rounded. A pex rather short; fossa shallow.

A ppendage subspheroidally mammilliform.

Habitat.-Idaho (Casey); Wyoming (Casey; Green River, H. F. Wickham) ; Colorado (Buena Vista, July, elevation, 7,900-8,000 feet, Wickham). Professor Wickham says that this race is not rare about the roots of gooseberry bushes at Buena Vista ("Coleoptera of Colorado"). Nevada (Verdi, in April).

Number of specimens studied, 8.

Type in Colonel Casey's collection.

Type-locality.-Idaho.

Diagnostic characters.-Colonel Casey's specimens are small, and to me their most conspicuous difference from pimelioides is the color of the legs, which are brownish and sometimes quite reddish; in all probability this color is due to the failure of normal pigmentation. This same character is observed in tenebrosa (var. nana) and in caseyi. 
The individuals of cordata and pimelioides vary greatly, and the present race appears to be but a well-marked heterotype; this relation is quite clearly demonstrated in the large series thefore me.

In examples of brunnipes from Pocatello, Idaho, and which agree quite well with the description, the setæ are longer and more evident throughout.

Otherwise as in pimelioides.

\section{ELEODES CASEYI, new species.}

Ovate, about twice as long as wide, legs reddish-brown, distinetly pubescent throughout. Pronotum rather coarsely, densely, and more or less rugosely punctate; elytra rather finely and densely granulate, granules submuricate laterally.

Head about twice as wide as long, feebly convex, more or less impressed laterally and along the frontal suture, very densely and scarcely coarsely punctate. Antennce long, very feebly compressed and scarcely at all dilated in outer three or four joints, third joint scarcely as long as the next two combined, fourth to the eighth inclusive subequal, the eighth subtriangular, ninth somewhat trianguloorbicular, tenth orbicular, eleventh ovate.

Pronotum transversely oblong-oval, widest at the middle, about a third wider than long; dise moderately convex, declivous about the apical angles, very densely, rather coarsely, and more or less confluently rugoso-punctate, granulate laterally; apex truncate in circular are, marginal bead nearly obsolete; sides evenly and moderately strongly arcuate, feebly sinuate in basal eighth and not noticeably constricted, marginal bead rather fine and almost entire; base truncate in circular arc, obsoletely beaded, equal in width to the apex and also to the length; apical angles obtuse and slightly rounded and not in the least prominent; basal angles nearly obtuse and distinct.

Propleurce opaque and densely granulate.

Elytra oval, a fifth to a third longer than wide, widest at the middle; base subtruncate, distinctly wider than the contiguous prothoracic base; humeri obtusely rounded and not in the least prominent; sides evenly arcuate, apex rather broadly rounded and not in the least produced; disc moderately convex on the dorsum, strongly rounded laterally, arcuately and more or less vertically declivous posteriorly; surface densely and irregularly granulate, granules more or less shining, simple and smaller along the suture, submuricate laterally and on apex, where they are larger and more discrete.

Epipleurce moderately narrow, not dilated beneath the humeri and gradually narrowing from base to apex, superior margins nearly straight beneath humeri when viewed longitudinally and not visible from above; surface smooth, finely and sparsely punctate. 
Sterna finely punctato-rugulose.

Parapleura densely punctate.

Abdomen somewhat shining and densely punctate, punctures moderate.

Legs rather short and moderate in stoutness, quite densely punctured; anterior femora mutic; anterior tibial spurs comparatively small, the anterior slightly longer and a little stouter than the posterior; similar in the sexes. Anterior tarsi dissimilar in the sexes.

Male.-Somewhat narrow. Antennæ reaching beyond the prothoracic base. Abdomen distinctly oblique, moderately convex and distinctly and broadly flattened at middle of the first two segments. Protarsi with the first two joints scarcely thickened at tips beneath, each with a very small but distinct tuft of pubescence, tufts subacute, grooves interrupted. Middle tarsi simple.

Female.-Broader ovate. Antennæ attaining the prothoracic base. Elytra rather broadly oval. Abdomen horizontal and rather strongly convex. First joint of the protarsi not noticeably thickened at tip. beneath, groove entire.

Measurements-Male: Length, $10 \mathrm{~mm}$; width, $4.5 \mathrm{~mm}$. Female: Length, $13 \mathrm{~mm}$.; width, $6.2 \mathrm{~mm}$.

Genital characters, male.-Edeagophore somewhat oblong-ovate, apicale greatly and suddenly narrowed in apical two-thirds.

Basale elongate oval, moderately convex with the sides moderately arcuate.

A picale subtriangular in outline, suddenly narrowed at basal and middle thirds so that the apical two-thirds appear greatly narrowed, convex above, with a linear groove extending from near the tip to the base; sides very prominent in basal third, subangulate, thence strongly sinuate to the tip, the latter flattened, narrowly rounded, and somewhat reflexed at tip; base lobed at middle and feebly sinuate laterally.

Sternite moderately transverse. Each lobe subtriangular, with the external border sinuate in basal half, thence arcuate to apex, the latter rather prominent, obtuse, and rather introrse; internal border more or less oblique and sinuous; surface feebly convex, rather coarsely punctate in apical three-fourths, punctures rather dense toward apex, setæ moderately long especially about the apical margin. Membrane not setose across the bottom of the sinus, the latter triangular.

Female.-Genital segment (Plate 6, fig. 3) rather equilaterally triangular, surface somewhat convex from side to side and feebly setose.

Valvula.-Dorsal plate somewhat oblong-triangular, sides feebly converging apically; surface glabrous, more or less concave, with a few scattered and fine punctures, each with a short and fine seta; 
external border feebly arcuate; apical border briefly truncate and internally angulate with the internal border, which is briefly and obliquely truncate, thence more or less sinuous to base. Apex short and somewhat deflexed, narrowly rounded at tip, finely setose, with few longer hairs.

Superior longitudinal membrane longitudinally rugulose, reaching about to the apex of the dorsal plate.

Basal prominences scarcely evident.

Ventrolateral surfaces.-Body triangular, flattened, surface lines straight when viewed longitudinally and convex laterally; surface glabrous, rather coarsely and sparsely punctate. Submarginal groove strongly developed beneath the explanate external border of the dorsal plate, narrow at base, thence widening broadly, so as to involve the whole side before the fossa, at which it terminates. Appendage showing distinctly beneath the apical border of the dorsal plate, apex finely setose. Margin of the valves contiguous in basal four-fifths, fissure in apical fifth and narrow. Inferior membrane not visible.

Habitat.-Nevada (Verdi, Blaisdell); California (Bodie, elevation, 8,475 feet, July 1-7, Wickham).

Number of specimens studied, 2.

Sexitypes: Male in Wickham's, female in my collection.

Type-localities.-Verdi, Nevada, and Bodie, California.

Diagnostic characters.-Caseyi, by its pubescence, will naturally be associated with Tricheleodes, and by being Amphidora-like in facies it will most likely be referred to hirsuta. In color and pubescence it reminds one of Stenotrichus.

It is aberrant, and, for the present at least, will have to remain as representative of a group in the present subgenus, analogous in this respect to tibialis. Unfortunately the types are all the examples I have seen, and this fact aceounts for the obscurity of the relationships.

The grooved apicale of the edeagophore in the male and the pubescence in both sexes indicates an apparent approach at least toward Tricheleodes; on the other hand, the dorsal plate is more like that observed in Blapylis; the pudendal membrane is also unusually long. A larger series must be studied before any definite conclusion can be arrived at. The two first joints of the protarsi have pubescent tufts such as are observed in Blapylis, but not in Tricheleodes.

General observations.-The mentum is rather small and subtriangulo-trapezoidal in outline; the surface is more or less foveate laterally and densely punctured.

In both types the prosternum is but feebly prominent ventrally with the coxæ, slightly convex antero-posteriorly between the coxæ, and with a subacute, small but distinct mucro behind, dorsad to which the posterior edge is vertically truncate. 
The mesosternum is strongly prominent ventrally, areuately and vertically declivous, but feebly concave.

The metasternum laterally between the coxæ is as long as the width of a mesotibia at middle.

The abdominal intercoxal process is quadrate (male) or transverse (female) and a fourth (male) to a third (female) of its own width broader than the metasternal salient.

The abdominal process is equal in length to the second segment; the post-coxal part of the first is equal to the length of the third. In the male the third is but slightly longer than the fourth; in the female the third is about one-half longer than the fourth.

The profemora are moderately clavate; the mesofemora feebly widened, with the superior and inferior surface lines slightly arcuate; the metafemora are subequal in width throughout, with the superior and inferior surface lines parallel.

The tibial grooves reach nearly to the femoral base on all of the femora, but more or less evanescent internally on the meso- and metafemora; their margins are feebly developed and subasperate.

The tibiæ are without tarsal grooves; the articular cavities are closed. The protibiæ are slightly carinate externally in basal half.

The tarsi are comparatively moderate in length and stoutness.

Tarsal formula:

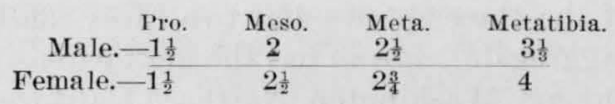

Subgenus METABLAPYIIS, new.

The mentum has the middle lobe very small and the lateral lobes fully exposed (Plate 6, fig. 16). These characters appear unique in the genus Eleodes, although in some parts the middle lobe is reduced in size, but never so completely and persistently.

The anterior tarsi are similar in the sexes, simple beneath, the grooves entire.

The anterior femora are more or less sinuate beneath in apical fifth, never dentate, although in nigrina the rudiments are present. The anterior tibiæ are more or less constricted at base, and recalls similar characters in Blapylis and planipennis (Discogenia); this appears to be an atavistic character, and bears an inverse relation to the femoral teeth; it is at times feebly indicated in nearly all of the subgenera.

Schwarzii forms an exception, and in the strict sense does not belong here; the first joint of the protarsi is distinctly and unmistakably thickened at tip beneath, and can only be considered as a temporary constituent of the present subgenus until more can be learned of its relationships, and this depends upon more extensive collecting. 
It is also at variance in Blapylis, and rather than create another subgenus it is best to do as I have done and retain it as a section in the present aggregate.

Tibiatis, planipennis, and schwarzii are all disturbing elements in the subgenera in which they are placed, and their true position in all probability will only be known when the Mexican species shall have been carefully studied.

The genital characters give the essential definition to the present subgenus :

Male.-Apicale of the edeagophore more or less equilaterally triangular, more or less depressed, apex not in the least attenuate, the dorsal surface with a broad central membrano-chitinous area. In schwarzii a well-developed groove is present and the apex attenuate.

Female.-Genital segment more or less triangular; apex chitinous, flattened, and moderately produced, but narrow and evenly rounded at tip, convex above and concave beneath. Dorsal plates of the valves oblong with the external edge converging apically, angle not evident. Appendage small and mammilliform, penicillate. Superior pudendal membrane rather broadly exposed and reaching to the apical fourth of the dorsal plate. Genital fissure nearly closed.

In schwaraii the female characters are as discordant here as elsewhere.

Distribution.-Of the three species and two races constituting the present subgeneric aggregate, nigrina has the most extensive distribution, occurring in Oregon, Washington, Northern California, Nevada, Arizona, Colorado, New Mexico, Nebraska, Kansas, Idaho, and the Dakotas. It is to be inferred that it occurs in the intervening States not mentioned above, but representatives are not at hand.

Dissimilis appears to be abundant in Arizona. It also occurs in New Mexico.

Nevadensis, in Nevada, southward into Arizona and the Colorado Desert of eastern southern California.

Perlonga is only known to me from Wyoming.

Schwarzii occurs in Washington. It will be observed that Metablapylis only occurs in California within its northern and eastern confines. Closely related species are undoubtedly plentiful to the southward in Mexico.

Genealogy.-Very little can be expressed in regard to the origin of the species enumerated above. Too little is known of schwaraii; nigrina and dissimilis without doubt arose from a common ancestral trunk, and each again is diverging into well-marked races, as represented by perlonga and nevadensis, while many no doubt are yet to be discovered.

Nevadensis exhibits evidences of several incipient races. 
A synoptical tabulation of the genital characters will prove instructive:

Males.-Apicale equilaterally triangular and depressed, central area of the dorsal surface feebly concave and membranochitinous; apex not in the least attenuate

nigrina. var. perlonga. dissimilis. var. nevadensis.

Apicale triangular, not depressed, with a definite median longitudinal groove; apex attenuate schwarzii.

Females.-Valvular apex chitinous, flattened and moderately nigrina. produced, tip rounded, convex above and concave beneath; var. perlonga. superior pudendal membrane longitudinally rugulose, reach- dissimilis. ing at least to the apical fourth of the dorsal plate var, nevadensis.

Valvular apex apparently chitinous, short, triangular, somewhat deflexed; superior pudendal membrane reaching to the apical third of the dorsal plate, and not rugulose in the examples studied schwarzii.

ANALYTICAL KEY TO SPECIES OF SUBGENUS METABLAPYLIS.

First joint of the anterior tarsi not thickened at tip beneath, groove distinct and entire.

Sculpturing submuricate on the elytral sides and apex.

Surface luster subopaque nigrina.

Surface very bright and shining-males frequently very elongate.

Sculpturing smooth, not at all subasperate. var. perlonga.

Surface luster more or less shining; form fusiform-ovate to ovate: ventral surface not distinctly pubescent____________dissimilis. Surface subopaque and alutaceous; both sexes typically of the same form, elongately cylindrical; ventral surface with rather long, sparse, flying hairs var. nevadensis.

First joint of the protarsi in both sexes, thickened at tip beneath, groove interrupted schwarzii.

\section{ELEODES NIGRINA LeConte.}

Eleodes nigrina, LeConte, Proc. Acad. Nat. Sci. Phila., 1858, p. 186.-Horn, Trans. Amer. Phil. Soc., XIV, 1870, p. 313.

Elongately oblong-ovate to ovate, upiform, usually about three times longer than wide, subopaque; elytra muricato-granulate laterally and on the apex.

Head less than twice as wide as long, feebly convex, more or less impressed laterally and very vaguely along the frontal suture, the latter not evident; surface scarcely coarsely, irregularly, and densely punctate, punctures denser laterally and on the epistoma, where they bear minute setæ. Antenna moderate in length and equal in the sexes, somewhat stout, very feebly compressed, and more or less slightly dilated in outer four joints; the third equal to the next two combined; fourth and fifth equal in length and apparently just the least shorter than the sixth or seventh, which are subequal; eighth about as wide as long and subtriangular; ninth and tenth more or less transversely oval; eleventh ovate, truncate at tip. 
Pronotum subquadrate, widest at or just in front of the middle, an eighth to a fifth wider than long, less than twice as wide as the head; disc moderately to quite strongly convex, arcuately rounded laterally and at the apical angles; surface almost finely, densely, and irregularly punctate, becoming very densely granulate laterally; apex truncate to feebly emarginate in circular arc and more or less obsoletely margined; sides evenly, broadly, but not strongly rounded, behind the middle slightly converging and straight or feebly subsinuate as viewed from above, but quite evenly rounded from apex to base as viewed from the side, marginal bead fine, entire, feebly limiting the disc from the propleuræ, the former not in the least dilated laterally; base subtruncate to feebly arcuate, occasionally broadly and feebly sinuate at middle, rather finely beaded, and a little wider than the apex; apical angles obtuse, not rounded nor prominent anteriorly ; basal angles obtuse to subrectangular, never prominent.

Propleurce distinctly convex, moderately finely, more or less evenly and not very densely, granulately punctate, frequently rugulose.

Elytra elongate oval, usually widest at the middle, sometimes behind the same, scarcely twice as long as wide; base subtruncate, scarcely to slightly wider than the contiguous base of the prothorax; humeri rounded, but not broadly so; sides more or less evenly arcuate, not strongly so, apex hardly produced and not broadly rounded; disc moderately convex, frequently somewhat depressed on the dorsum, rather obliquely attenuate in apical fourth and more or less arcuately declivous behind; surface punctate, punctures somewhat fine, usually arranged without order, frequently more or less striate, almost simple about the suture on the dorsum, muricato-granulate laterally and on apex; when the punctures are serially arranged, those of the striæ are closely placed and frequently almost larger than the interstitial punctures, which are more distantly spaced and quite regular, almost serial; laterally the punctures are always confused and minutely setigerous.

Epipleurce moderate in width, very feebly widened beneath the humeri, thence gradually narrowing to apex; superior margin very broadly and slightly sinuate in basal fourth, as viewed longitudinally; surface sparsely, irregularly, and finely punctate, at times obsoletely so.

Sterna quite densely punctate and rugose, sometimes strongly so.

Parapleurce irregularly and at times densely punctate.

Abdomen horizontal, rather finely and almost densely punctate, each puncture minutely setigerous; surface very finely or at times coarsely rugose, fourth and fifth segments generally less densely punctate and frequently more or less rufous. 
Legs moderate in stoutness and length. Femora rather densely punctate, each puncture with a very small appressed seta, the anterior mutic and more or less sinuate in apical fifth; tibiæ quite strongly muricate; anterior tibial spurs about equal and acute; anterior tarsi quite similar in the sexes, the first joint slightly thickened at tip beneath, groove entire, the marginal and apico-marginal spinules rather prominent.

Male.-Somewhat narrow. Elytra with the sides not strongly arcuate, at times subparallel at the middle, and more or less arcuately and somewhat gradually obliquely declivous posteriorly; apex more or less obliquely narrowed. Abdomen slightly flattened at middle of first two segments, otherwise moderately convex.

Female.-Somewhat robust, elytra more or less broadened, sides evenly arcuate, apex somewhat arcuately narrowed; disc arcuately and almost vertically declivous posteriorly, abdomen strongly convex.

Measurements.-Males: Length, 20-25 mm.; width, $5.5-6.2 \mathrm{~mm}$. Females: Length, 20-22.5 mm.; width, 8-8.5 mm.

Genital characters, male.-Edeagophore somewhat oblong-fusiform.

Basale oblong, sides more or less arcuate, scarcely arched and quite evenly convex, with a linear median groove in apical half.

A picale (Plate 1, fig. 3) triangular, surface more or less convex, generally depressed and more or less broadly membrano-chitinous at middle; sides feebly arcuate and more or less feebly sinuate near apex, the latter rather narrowly rounded and not recurved; base more or less acutely lobed at middle and sinuate laterally.

Sternite transverse and semicircular in outline. Each lobe triangular, with the external border quite evenly arcuate to the apex, the latter narrowly rounded; internal border slightly sinuous; surface feebly convex, rather densely punctate in apical half, setæ moderately long and dense, most so at apex; membrane not setose across the bottom of the sinus, the latter more or less triangular.

Female.-Genital segment triangular to oblong-triangular in outline, feebly setose, apex chitinous.

Valvula (Plate 1, fig. 1).-Dorsal plate oblong, sides slightly converging apically, glabrous; surface more or less concave, feebly, sparsely, and irregularly punctate, punctures with fine reclinate setæ, sides not reflexed; margins subparallel, the external nearly straight, or occasionally feebly arcuate to sinuous, and the internal more or less feebly sinuous or straight; apical margin more or less obliquely truncate, occasionally not well defined from the apical membrane internally; angle rounded but evident, occasionally with two or three setæ. Apex well developed and moderately produced, flattened, more or less convex above, broadly and evenly rounded at tip, chitinous, with or without a few rather short setæ; apical valvular membrane quite largely exposed within on apex and opposite the apical fourth 
of the dorsal plate, finely and densely setulose. Fossa largely visible from above and rather capacious, margins with a few scattered setæ.

Appendage moderate in size, mammilliform and penicillate, setæ quite long, two or three extending beyond apex.

Basal prominences slightly evident.

Superior pudendal membrane longitudinally rugulose, rather broadly exposed and attaining the apical fourth of the dorsal plate.

Ventrolateral surfaces (Plate 1, fig. 2) not swollen, surface flattened centrally to base and convex laterally. Apex concave beneath. Submarginal groove shallow and passing into a broad lateral and apical concavity; surface not noticeably setose; internal margins setulose at apex. Internal margins of the valves contiguous in basal half, the genital fissure in apical half, very narrow and nearly closed.

Mabitat.-Oregon; Washington (Pullman, May, C. V. Piper); Northern California (Modoc County) ; Nevada (Verdi, April, abundant) ; Arizona (Williams, June, Barber and Schwarz; Humphrey's Peak at the base, F. H. Snow); Colorado (mountains southwest of Montrose; Durango; South Park; San Luis Valley; Ouray; Veta Pass, 9,200 feet; Buena Vista; Colorado Springs; Florissant; Garland; Idaho Springs; Georgetown; near Long's Peak; Fort Collins, Wiekham's List. South Park, elevation 8-10,000 feet, August, Golden, Dyar and Caudell; Chenney Gulch); New Mexico (Santa Fé, LeConte) ; Nebraska (Black Hills, LeConte; Sioux County, Coll. Univ. Nebraska); Idaho; Western Kansas; Dakota.

Number of specimens studied, 350 .

Type in the LeConte collection.

Type-locality.-Black Hills, Nebraska.

Salient type-characters.-Elongate, subopaque. Thorax subquadrate, narrowed behind, sides broadly rounded, apex almost truncate, moderately convex, sharply and rather densely punctate. Elytra declivous behind and obliquely narrowed, irregularly punctate, punctures especially at the sides muricate and very briefly setiferous. Legs muricato-punctate; anterior femora obtusely sinuate (LeConte).

Diagnostic characters.-Nigrina by its subopaque integuments and more or less muricate sculpturing differs from all the other species of the subgenus Metablapylis.

In the race perlonga the body surface is very bright and shining.

In dissimitis the form is more ovate, usually less elongate and more depressed; the elytra are smoothly sculptured and the striæ more evident and distant.

Schwarzii more robust and the form is more like some Aside, as convexa, the pronotum is less convex, more transverse, more dilated at the sides, so that the margin is distinct and prominent.

Nevadensis is much more slender in every way, more or less alutaceous and opaque. 
Nigrina is quite variable in form. There is before me a female that has the form of humeralis and was for years associated with that species, until I examined the genital segment, which revealed its true relationship. An examination of the tibial spurs and punctuation showed that it agreed with the present species.

Another specimen, a male, has the form of a moderately large gigantea, the pronotum is strongly convex. These two specimens are amphitypes.

General observations.-The middle lobe of the mentum is more or less triangular and comparatively small; the lateral lobes much exposed and larger; surface finely scabrous and punctate, not noticeably setigerous.

The prosternum is generally moderately protuberant ventrally with the coxæ, convex antero-posteriorly between the same and mucronáte behind, the mucro is more or less subacute, the posterior edge may be vertically truncate.

The mesosternum is areuately declivous and more or less concave.

The metasternum laterally between the coxæ is as long as the width of a mesotibia at apex.

The abdominal process is quadrate and equal in width to the metasternal salient.

In the male the post-coxal part of the first segment is equal in length to the second, twice as long as the fourth and a little longer than the third.

In the female the post-coxal part of the first segment is a little longer than the third; the second twice as long as the fourth and a little longer than the post-coxal portion of the first.

The profemora are moderately clavate and usually feebly compressed; the tibial grooves have flat floors, their margins more or less asperulate, the anterior somewhat arcuately laminate for a short distance internal to the apical sinuation; the margins converge to base. The mesofemora are not clavate, but somewhat parallel sided; the grooves as on the profemora, but a little narrower and with the margins contiguous at basal fourth.

The metafemora have the superior and inferior surface lines subparallel, grooves as on the mesofemora and with the margins evanescent at basal third.

The tarsal grooves on the tibiæ may be more or less indicated and asperately sculptured; the protibiæ are more or less distinctly carinate externally in basal two-thirds; the articular cavities are closed.

The tarsi are variable in length and stoutness.

The relative lengths of the joints in each tarsus are apparently as in Melaneleodes, where the test was fully applied. 
Tarsal formula :

\begin{tabular}{rccc} 
Pro. & Meso. & Meta. & Metatibia. \\
Male. $-2 \frac{2}{3}$ & $3 \frac{1}{2}$ & 4 & 7 \\
\hline Female.- $-2 \frac{1}{2}$ & $3 \frac{1}{6}$ & 4 & $6 \frac{1}{3}$
\end{tabular}

\section{ELEODES NIGRINA var. PERLONGA, new.}

Elongate, very bright and shining, sculpturing as in nigrina, but somewhat finer. Elytra obliquely narrowing in apical fourth, usually distinctly pointed behind with apex narrowly rounded and subacute; disc somewhat flattened on the dorsum, arcuately and obliquely declivous behind.

Otherwise as in nigrina.

Measurements.-Males: Length, $18.5-22 \mathrm{~mm}$; width, $6.5-7 \mathrm{~mm}$.

Habitat.-Wyoming (June).

Diagnostic characters.-The present race differs mainly from nigrina in its very black and highly polished surface, as well as its very elongate form. Males are only known to me and I have seen eight examples all together.

\section{ELEODES DISSIMILIS, new species.}

Elongate, fusiform-ovate, or oblong-ovate to ovate, very black, moderately depressed, smooth, elytral striæ rather distant.

Head twice as wide as long, frons more or less plane, lateral impressions very feeble, frontal suture usually quite obsolete, distinctly but not very coarsely punctate, punctures dense laterally and on the epistoma. Antennce moderately long, somewhat stout, very feebly compressed, scarcely or very gradually widened in outer four joints, third joint about as long as the next two taken together, fourth evidently just the least longer than the fifth, the latter to the seventh inclusive subequal, eighth slightly shorter and subtriangular, ninth and tenth scarcely transversely oval, eleventh short-ovate, truncate at tip.

Pronotum subquadrate, widest at or just a little in front of the middle, about a sixth to a fifth wider than long, slightly depressed; disc moderately and evenly convex, more or less arcuately declivous laterally, finely but distinctly, evenly and rather sparsely punctulate, punctules frequently somewhat obsolete in the central area. Apex slightly and evenly emarginate to subtruncate, more or less obsoletely margined; sides moderately and quite evenly arcuate, apparently more or less convergent behind the middle, where at times they may be somewhat straight or rarely feebly subsinuate, marginal bead fine; base feebly rounded, and finely margined, scarcely wider than the apex; apical angles obtuse, feebly rounded or distinct, scarcely prominent anteriorly; basal angles obtuse and not in the least prominent. 
Propleurce distinctly convex, smooth, finely and sparsely or obsoletely punctulate, more or less rugulose.

E7ytra oval, about twice as long as wide, somewhat depressed, widest at or behind the middle; base subtruncate and distinctly adapted to the prothoracic base which it scarcely exceeds in width; humeri obtuse, angle distinct although small and not in the least prominent; sides evenly or more strongly arcuate behind the middle, more or less convergent in apical fourth, apex not broadly rounded; disc more or less moderately convex, rather evenly, quite strongly and somewhat narrowly rounded at the sides, more or less arcuately and obliquely declivous behind; surface punctate, punctures arranged in rather distant, not strongly marked and usually unimpressed series, the strial punctures are small and quite closely placed, the interstitial are serial and regular or irregular, fine and more cistantly spaced, both series may be more or less irregular laterally and on apex, frequently of the same size.

Epipleurce comparatively rather wide, not noticeably dilated beneath the humeri, narrowing gradually from base to apex, superior margin more or less visible at humeri when viewed from above; surface smooth, frequently slightly concave, dull in luster and quite impunctate.

Sterna more or less feebly punctate and rugose, mesosternum slightly pubescent; metasternum less so, hairs short.

Parapleurce not strongly punctate.

Abdomen horizontal, smooth, sparsely and rather indistinctly punctulate, finely and inconspicuously piliferous, and more or less feebly rugulose.

Legs moderate in length, and in stoutness to somewhat slender. Anterior femora more or less sinuate beneath at apex, mutic; spurs of the protibiæ similar in the sexes, usually rather slender and acute, the anterior slightly longer than the posterior; protarsi similar in the sexes, the first joint not thickened beneath, groove distinct and entire.

Male.-Fusiform-ovate to oblong-ovate, somewhat narrow. Antennæ reaching beyond the prothoracic base. Elytra rather gradually and arcuately to almost obliquely and rather quickly declivous posteriorly. Abdomen very moderately convex, sometimes feebly impressed on first two segments. Anterior femora occasionally with the anterior margin of the tibial groove, feebly and broadly subdentate within the sinuation.

Female-Ovate, rather broad, antennæ attaining the prothoracic base. Elytra rather broadly oval, arcuately but not vertically declivous posteriorly. Abdomen not very strongly convex.

Measurements.-Males: Length, 14.5-19 mm.; width, 5.5-6.7 mm. Females: Length, 14.5-19 mm.; width, 6-7.5 mm. 
Genital characters, male.-Edeagophore elongate, oblong-subfusiform, scarcely arched.

Basale oblong, moderately convex with the sides feebly arcuate.

A picale subequilaterally triangular, moderately depressed, broadly impressed and membranous at middle; sides feebly arcuate and converging to apex, the latter not in the least attenuate and narrowly rounded; base subobtusely lobed at middle and feebly sinuate laterally.

Sternite rather short and slightly transverse, somewhat parabolic in outline. Each lobe short and triangular; external border straight or feebly sinuate in basal two-thirds, thence to apex feebly arcuate to subtruncate, apex obtuse; internal border oblique and feebly sinuate; surface very feebly convex, coarsely and sparsely punctate in apical two-thirds, at apex rather densely so, sparsely setose, setæ longer and denser on apex. Membrane not setose across the bottom of the sinus, the latter triangular and rather broad.

Female.-Genital segment triangular, dorsal surface quite plane and feebly setose.

Talvula (Plate 5, fig. 12).-Dorsal plate elongate oblong; surface plane or feebly concave, smooth and shining, with very few short setæ scattered over the apical half; external border nearly straight, slightly converging apically and more or less explanate; apical margin more or less defined from the apex and rounded with the angle; internal border quite straight or feebly sinuous. Apex membranochitinous, feebly everted, slightly prolonged, tip rounded, convex above and feebly concave beneath, with two or three long setæ near tip, valvular membrane within finely setose; fossa at base of the external surface.

Basal prominences not evident.

Appendage short mammilliform, smooth, with a tuft of some three or four quite long setæ.

Superior pudendal membrane longitudinally rugulose, attaining the apical sixth of the dorsal plate.

Ventrolateral surfaces.-Body triangular, ventral surface lines straight when viewed longitudinally, laterally very feebly convex in basal moiety, thence very slightly concave to apex; surface smooth and impunctate. Surface of apex finely setose, submarginal groove broad and shallow beneath the explanate external border of the dorsal plate. Internal margins of the valves contiguous in basal four-fifths, fissure in apical fifth and closed. Valves anteriorly produced in median line beneath.

Habitat.-Arizona (Fort Grant, July, Santa Rita Mountains, Chiricahua Mountains, Oracle, Hubbard and Schwarz; Williams, Barber and Schwarz, all in the U. S. National Museum collection. 
Oak Creek, September, E. G. Smith, collector, Warren Knaus); New Mexico (Highrolls, May).

Number of specimens studied, 32.

Type-Cat. No. 12232, U.S.N.M.; co-types in my collection.

Type-locality.-Chiricahua Mountains (males), Santa Rita Mountains (female), Arizona. Collectors Hubbard and Schwarz.

Salient type-characters.- Smooth; punctures simple; thorax subquadrate, widest just before the middle, somewhat narrowed behind; disc finely and rather sparsely punctulate; apex feebly and broadly emarginate; sides evenly and moderately arcuate, convergent behind the middle; apical angles obtuse, very slightly rounded at tip; basal angles obtuse, not rounded nor in the least prominent. Elytra widest at the middle; humeri obtuse with angle distinct but small; dise moderately convex, striato-punctate; strial punctures rather small and quite closely placed and not impressed; series rather distant, interstitial series of fine and more distantly spaced punctules, more or less irregular in arrangement; both series more irregular laterally and on apex.

Male subfusiform oval. Elytra distinctly narrowed in apical fourth, disc gradually declivous behind.

Female ovate. Elytra rather broadly oval, arcuately declivous at apex.

Diagnostic characters.-This species is quite distinct from nigrina in its shining surface, smooth sculpturing and more depressed form; the females are less elongate.

Schwaraii is dull in lustre and more robust and not depressed, besides the sculpturing is subasperate; the sides of the pronotum is more dilated and as a whole transverse, with edge more strongly rounded and less convergent behind.

Nevadensis is opaque; both sexes are typically subcylindrical; legs slender and the ventral surface distinctly but sparsely pubescent; the thorax is smaller.

Dissimitis has heretofore been referred to some six species. There is nothing like it in the LeConte collection.

A single male before me answers quite exactly to Colonel Casey's description of nitidus and it is possible that my name may have to be suppressed and Casey's substituted. He refers nitidus to near longicollis.

If dissimilis is nitidus no one who has compared my examples in the East has recognized this relationship, but it has invariably been associated with nigrina. The types are in the U. S. National Museum collection, and anyone can make comparisons.

General observations.-The middle lobe of the mentum is very small and triangular, the lateral lobes entirely exposed. more so than $59780-$ Bull. $63-09-26$ 
in nigrina. This character has not been observed elsewhere in the genus Eleodes. The surface of the middle lobe is finely scabrous; the lateral lobes bear a few rather long setæ, while the middle lobe is not noticeably setigerous.

The prosternum is not strongly protuberant ventrally with the coxæ, and distinctly setigerous. Between the coxæ it is more or less convex antero-posteriorly, sometimes horizontal. Generally with a small mucro behind, sometimes nearly vertically truncate with a mucronate angle.

The mesosternum is arcuately declivous and more or less concave, with numerous small setæ.

The metasternum laterally between the coxæ is as long as the width of a mesotibia at middle.

The abdominal process is quadrate (male) or subquadrate (female) and about a fourth (male) of its width broader than the metasternal salient or subequal to it (female).

The post-coxal part of the first segment is equal in length to the second; the latter is twice as long as the fourth.

In the male the third is about three-fourths longer than the fourth, in the female it is about two-thirds longer than the same segment.

The profemora are clavate, the mesofemora slightly swollen, and the metafemora somewhat narrowing toward base; the grooves are shallow and flat, the margins feebly subcariniform and sometimes feebly asperulate. The anterior margin of the profemoral grooves is not so distinctly sublaminate internal to the apical sinuation as in nigrina. On the meso- and metafemora the grooves vary as to their degree of convergence before evanescence.

The tibiæ are without tarsal grooves; the external faces of the mesoand metatibiæ are somewhat flattened but not glabrous, and the articular cavities are closed. The protibiæ may or may not be carinate externally.

The setæ and spinules on the femora and tibiæ are usually blackish, but frequently somewhat ferruginous on the tibiæ; on the tarsi they are nearly always ferruginous.

The tarsi are somewhat slender, but frequently they appear moderately stout.

Tarsal formula :

$\begin{array}{rccc}\text { Pro. } & \text { Meso. } & \text { Meta. } & \text { Metatibia. } \\ \text { Male. }-2 \frac{1}{3} & 3 \frac{1}{3} & 3 \frac{4}{5} & 5 \frac{1}{2} \\ \text { Female.-2 } & 3 & 3 \frac{1}{3} & 5\end{array}$

ELEODES DISSIMILIS var. NEVADENSIS new.

Cylindrico-fusiform to ovate, elongate, moderately depressed, opaque, more or less alutaceous and slender; thorax obsoletely punctulate; elytra striato-punctate; antennæ, tibiæ, and tarsi with the 
setæ and spinules more or less strongly ferruginous; ventral surface distinctly pubescent.

Head about twice as wide as long, frons frequently planate, or more or less convex, broadly and shallowly impressed laterally, frontal suture not evident, rather finely and not densely punctate, punctures denser at the periphery, each with a short reclining seta. Antennce long and moderately slender, outer four joints very feebly compressed and scarcely dilated, third joint about equal to the next two taken together, fourth to the seventh, inclusive, equal in length and almost twice as long as wide, eighth shorter and subtriangular, ninth and tenth suborbicular to feebly transversely oval, eleventh ovate.

Pronotum subquadrate, widest at or slightly in advance of the middle, about one to two-sevenths wider than long; disc rather strongly convex and more or less declivous at the apical angles, quite obsoletely to evenly and not densely punctulate, the punctules slightly denser laterally; apex truncate in circular are to feebly emarginate, more or less finely to obsoletely margined; sides evenly and moderately arcuate in anterior two-thirds, more feebly so or more or less straight behind the middle, converging to base, finely margined; base truncate or feebly rounded and about equal in width to the apex, finely margined; apical angles obtuse and not prominent; basal angles obtuse and not in the least rounded, rarely minutely prominent.

Propleurce finely, sparsely, and obsoletely punctulate, more or less feebly rugulose, most strongly on the acetabular convexities.

Elytra elongate oval, smooth, widest usually at the middle; base truncato-emarginate and adapted more or less to the prothoracic base, which it scarcely exceeds in width; humeri obtuse, angle distinct although small and not prominent; sides evenly arcuate, apex not broadly rounded; disc slightly depressed and moderately convex on the dorsum, strongly and not very broadly rounded laterally, arcuately declivous behind; surface striato-punctate, serial punctures small, closely placed in moderately distant rows, interstitial punctules more or less minute in a slightly irregular series, serial arrangement more or less evident laterally and on apex.

Epipleurce moderately wide, not dilated beneath the humeri and gradually narrowing to apex, superior margins feebly visible at humeri when viewed from above; surface smooth, more or less concave and obsoletely punctulate.

Sterna more or less finely, densely, irregularly punctate and rugulose, sparsely clothed with erect and rather long ferruginous hairs.

Parapleura more or less obsoletely and irregularly punctate. 
Abdomen finely punctate and rugulose, each puncture with a rather long, erect ferruginous hair; fourth and fifth segments frequently more or less rufous; horizontal.

Legs slender and somewhat long. Femora finely and not very densely punctate, each puncture with a rather short reclinate seta; profemora feebly sinuate in both sexes. Anterior tibial spurs subequal and acute. Tarsi similar in the sexes; setæ and spinules ferruginous throughout.

Male.-Elongate, cylindrically subfusiform. Prothorax rather strongly convex. Elytra with sides not strongly arcuate, sometimes subparallel at middle, obliquely narrowed in apical fourth, arcuately, more or less obliquely and rather gradually eleclivous behind. Abdomen moderately convex and very feebly impressed along the middle on the first two segments.

Female.-Typically of the same form as the male, or more or less robust and ovate. Elytra with the sides moderately strongly arcuate, frequently broadened behind and narrowing more or less to base, rather suddenly arcuately declivous behind, slightly narrowed just before the apex (ovate form). Abdomen evenly and rather strongly convex.

Measurements.-Males: Length, 16.5-18 mm.; width 4-6 mm. Females: Length, 17-17.5 mm.; width 7-6.5 mm.

Genital characters, male.-Edeagophore rather small and fusiform.

Basale evenly convex.

A picale quite equilaterally triangular; surface depressed and feebly membranous at middle; sides more or less feebly arcuate and slightly sinuate before the apex, the latter not recurved, blunt and evenly rounded; base broadly lobed at middle and very feebly sinuate laterally.

Sternite subparabolic in outline. Each lobe with the external border evenly arcuate to apex, the latter narrowly rounded; internal border more or less sinuate; surface rather densely and strongly punctate, setose, setæ moderate in length. Membrane not setose at bottom of the sinus.

Female.-Genital segment triangular, surface of the valves more or less inwardly declivous, feebly setose.

Valvula (Plate 5, fig. 11).-Dorsal plate elongately triangular, narrowing from base to apex, smooth and shining, quite impunctate, more or less feebly concave; external border not explanate, quite straight; apical margin narrow, not wider than the base of apex, angle not evident, rounded internally with the internal margin, the latter quite straight; apex quite narrow and slightly produced, convex above, slightly concave beneath, chitino-membranous, tip rounded and but slightly narrowed, smooth and shining, 'with few 
fine setæ on the internal surface; fossa small, located at base of the external surface.

Appendage short mammilliform, smooth, with a pencil of some four short setæ at tip.

Basal prominences not in the least evident.

Superior pudendal membrane rather long, quite attaining the apical margin of the dorsal plate, longitudinally rugulose.

Ventrolateral surfaces.-Body surface lines nearly straight when viewed longitudinally, slightly swollen in basal half, smooth, feebly setose apically; submarginal groove nearly obsolete, external margin of the dorsal plate being scarcely at all prominent laterally. Internal margins of the valves contiguous in basal two-thirds; fissure in apical third and closed.

Habitat.-Arizona (Tueson and Pinal mountains, Wickham; Prescott); Nevada (Pioche); California (Palm Springs, March).

Number of specimens studied, 12.

Type male in my collection; female (Cat. No. 12233) U. S. National Museum collection.

Type-localities.-Male, Tucson, Arizona; female, Palm Springs, California.

Salient type-characters.-Both sexes elongate and subcylindrical. Antennæ long. Head finely punctulate. Thorax small, a little wider than long; disc more or less obsoletely punctulate, rather strongly convex; apex feebly emarginate; sides moderately arcuate, narrowing posteriorly, marginal bead fine; base very feebly rounded; apical angles obtuse, distinct, not rounded nor prominent; basal angles obtuse, not rounded. Elytra at base more or less adapted to the prothoracic base, which it scarcely exceeds in width; humeri obtuse, angle distinct and small ; disc more or less moderately convex, striatopunctate, strial punctures closely placed and rather small, striæ moderately distant, interstitial punctules fine, slightly irregular and rather distantly spaced in a series, scarcely different laterally. Sterna and abdomen with distinct and sparse hairs; legs slender. Hairs and spinules ferruginous.

Diagnostic characters.-The most slender and subcylindrical species of the subgenus.

Easily recognized by its smooth, opaque, and alutaceous integuments, the antennæ are long and the legs slender, the ventral surface is sparsely clothed with erect and rather long hairs. All hairs and spinules are ferruginous in color.

The females are dimorphic. The type is of the same form as the male, while others are ovate and depressed like that sex in dissimilis.

If it were not for this fact, I would consider nevadensis as very distinct; but as it is, there is difficulty at times in separating the females of the two races. 
The hairs of the ventral surface are easily lost, and specimens must be young or unworn.

The hairs on the ventral surface of dissimitis are short and dark. A male from Pioche, Nevada, represents a form with large prothorax, and the elytra are more oblong, with sides parallel at middle third.

General observations.-The mentum is as in dissimitis, but smaller.

The prosternum in all of the examples at hand is not at all prominent ventrally with the coxæ, feebly convex antero-posteriorly between the coxæ and distinctly mucronate behind, the mucro varying in size, but small and rounded.

The mesosternum is small, quite vertically arcuate, and deeply excavated, so that the sides appear like lobes.

The metasternum laterally between the coxæ is as long as the width of a mesotibia at apical fourth.

The abdominal process is subquadrate and about a third of its width broader than the metasternal salient.

The post-coxal part of the first segment is equal in iength to the second, the latter twice as long as the fourth (male).

The third segment is about two-thirds (male) as long, or twice as long (female) as the fourth.

The tarsi are long and slender.

Tarsal formula:

$\begin{array}{rccc}\text { Pro. } & \text { Meso. } & \text { Meta. } & \text { Metatibia. } \\ \text { Male. }-2 & 2 \frac{3}{5} & 3 & 5 \\ \text { Female. }-2 \frac{1}{3} & 3 & 3 \frac{1}{3} & 5 \frac{1}{2}\end{array}$

It is worthy of note that the female has unusually long tarsi as compared with the male; the types are quite similar in size.

ELEODES SCHWARZII, new species.

Suboblong-oval to suboblong-ovate, subopaque, rather robust. Thorax almost coarsely and densely punctate. Elytra submuricate laterally and on apex.

Head twice as wide as long, feebly convex, moderately impressed laterally and somewhat along the frontal suture, the latter very slightly and vaguely indicated, densely and subscabrously punctate, punctures moderate. Antennce moderate in length and stoutness, outer four joints feebly compressed and slightly dilated, third joint about as long as the next two taken together, fourth very slightly longer than the fifth, the latter to the eighth, inclusive, subequal, the latter subtriangular, ninth about as long as wide, tenth slightly transversely oval, eleventh short-ovate.

Pronotum somewhat transversely suboblong-oval, about a third wider than long, widest at about the middle; disc moderately and evenly convex, densely punctate, punctures almost coarse, granulate 
laterally; apex feebly and broadly emarginate, finely and more or less distinctly margined; sides rather strongly and quite evenly arcuate, feebly narrowed behind and slightly oblique, margin acute and prominent, marginal bead fine and thin, very narrowly reflexed; base very feebly rounded, finely and distinctly margined, about equal to the apex; apical angles obtuse, not prominent nor rounded; basal angles obtuse and not in the least prominent.

Propleurce rather finely, sparsely and evenly muricato-granulate, more or less rugulose.

Elytra oval, less than twice as long as wide, widest at the middle; base transverse and not in the least margined; humeri rounded; sides evenly arcuate, apex obtusely rounded but not broadly so; disc slightly convex on the dorsum, rather strongly and somewhat broadly rounded laterally, areuately declivous behind; surface somewhat densely and scarcely subasperately punctate, the punctures about equal in size and in evident, rather closely placed series, laterally submuricate and irregular.

Epipleurce moderate in width, not dilated beneath the humeri, gradually narrowing from base to apex, superior margin not visible from above; surface smooth, dull, and obsoletely punctate.

Sterna and parapleura more or less densely but not coarsely punctate.

Abdomen more or less sparsely and subasperately punctate, irregularly regulose, surface more or less flattened at middle of the first two segments in both sexes.

Legs moderate and quite densely sculptured. Anterior femora mutic and more or less sinuate beneath in outer fifth; spurs of the protibiæ similar in the sexes, the anterior slightly longer than the posterior, both quite slender and acute; anterior tarsi quite alike in the sexes, first joint moderately thickened and prominent beneath at apex, groove obliterated.

Male.-Scarcely robust, slightly narrow. Antennæ reaching to the base of the prothorax. Elytra evenly arcuate and gradually declivous behind. Abdomen noticeably oblique to the sterna, moderately convex and usually distinctly concave at middle on first three segments.

Female.-Moderately robust. Antennæ attaining the posterior third of the prothorax. Elytra rather broadly oval, evenly and arcuately, but not vertically declivous posteriorly. Abdomen quite strongly convex and feebly flattened at middle toward base.

Measurements.-Male: Length, $18 \mathrm{~mm}$; width, $7 \mathrm{~mm}$. Females: Length, 19-20 mm.; width, 8.2-9 mm.

Genital characters, male.-Edeagophore elongate, oblong-ovate, sides subparallel and moderately arched. 
Basale elongate oblong, moderately and evenly convex above, sides scarcely arcuate.

A picale triangular, slightly elongate, apex slightly recurved and flattened; surface moderately and evenly convex, with a narrow median groove from apex to base; sides feebly and broadly sinuate to near apex, thence briefly more convergent to tip, the latter subacute and narrowly rounded; base obtusely lobed at middle, laterally feebly sinuate.

Sternite subparabolic in outline. Each lobe triangular and moderately distant from each other; external border broadly sinuate in basal half, thence arcuate to apex, the latter subacute; internal margin nearly straight; surface feebly convex, strongly and rather densely punctate in apical two-thirds, setose, setæ long, shorter at the internal margin. Membrane not setose across the base of the sinus, the latter rather broad and deep.

Female.-Genital segment (Plate 5, fig. 10) subquadrate, dorsal surface quite plane, glabrous and slightly setose.

Valvula.-Dorsal plate oblong, smooth and shining; surface feebly and irregularly concave, coarsely and very sparsely punctate, each puncture with a rather long seta ; external border feebly and broadly arcuate, more or less explanate apically; apical margin truncate and transverse, angle rounded; internal border more or less feebly sinuate. Apex small and subacute, apparently membrano-chitinous, very feebly and inconspicuously setose.

A ppendage small and mammilliform, with a pencil of short setæ.

Basal prominences not evident.

Superior pudendal membrane not usually rugulose, quite broadly exposed and reaching about to the apical third of the dorsal plate.

Ventrolateral surfaces.-Body subequilaterally triangular; ventral surface lines nearly straight when viewed longitudinally, laterally at base slightly prominent, thence inwardly oblique and then broadly sinuate to apex, scarcely transversely concave before the apex; surface smooth, sparsely setose, setæ short. Submarginal groove broad and shallow beneath the moderately expanded external border of the dorsal plate. Inferior surface of apex finely setose. Internal margins of the valves contiguous in basal two-thirds; fissure about closed.

Habitat.-Washington (Pullman, May, C. V. Piper, U. S. National Museum collection).

Number of specimens studied, 3.

Sexitypes in the U. S. National Museum collection (Cat. No. 12234). Type-locality.-Pullman, Washington.

Diagnostic characters.-Quite distinct in its more robust form, more transverse pronotum, the sides of which are more strongly rounded and dilated. 
The dull luster and sculpturing is nearly as in nigrina, although in the latter it is rather more coarse. In nigrina the pronotal disc is usually rather feebly defined from the sides by the comparatively feeble margins, which are often a mere line.

In dissimitis the integuments are more shining and smooth, the pronotum rather quadrate and altogether it is a much more depressed species, the vertical diameter of schwarzii being about a third greater.

Nevadensis is a slender species, but the females tend toward schwarzii in their broader form, and the surface luster is opaque and alutaceous.

General observations.-The mentum is comparatively large and subtriangular rather than parabolic; surface is rather coarsely and distinctly punctate, somewhat feebly and broadly foveate laterally, setose, but inconspicuously so.

The prosternum is not prominent ventrally with the coxæ. In the single male before me it is arcuately rounded antero-posteriorly and not in the least mucronate; in one female, rounded between the coxæ and distinctly mucronate behind, and in another example very slightly mucronate.

The mesosternum is feebly arcuate, but obliquely declivous and very slightly and broadly concave.

The metasternum laterally between the coxæ is as long as the width of a mesotibia at the middle.

The abdominal process is subquadrate and about a fifth (male) to a fourth (female) of its width broader than the metasternal salient.

The process is equal in length to the post-coxal part of the first segment, also to the third; the second is about two-thirds longer than the fourth. These proportions appear quite similar in the two sexes.

The femora are quite like those of nigrina, the grooves on the mesoand metafemora are more evanescent and the margins weaker.

The tibiæ are quite like those of nigrina; the protibiæ in the male are quite strongly constricted at base: this is also observed in perlonga.

The tarsi are quite stout and somewhat long.

Tarsal formula :

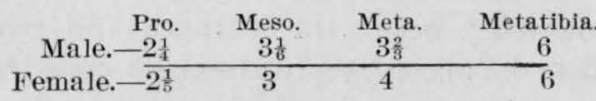

Subgenus STENELEODES, new.

As in other subgenera of the genus Eleodes, the present one is founded upon the female genital characters. which are very distinctive.

Otherwise the subgenus would be difficult to characterize on account of the paucity of intrinsic superficial characters, although the specific constituents possess a more or less distinctive habitus. 
The salient subgeneric qualities are as follows: Anterior femora mutic, integuments smooth, the form elongate and more or less attenuate.

Other characters of less diagnostic value may be mentioned: The humeri are feebly developed, except in innocens, where they are distinct; the first joint of the anterior tarsi in the male is slightly thickened at tip beneath and bears a small transverse tuft of yellowish or brownish modified spinules, which interrupts the groove.

The elytra are never caudate; the anterior tibial spurs are similar in the sexes and usually subequal, although subject to a slight variation in their relative lengths, the anterior often appear slightly longer than the posterior and both may be longer, slightly larger in the female, but the males often exhibit this variation among themselves.

The internal spurs of the meso- and metatibiæ are always noticeably longer than the external.

The abdomen is horizontal in the males of gigantea and gentitis, slightly oblique in estriata and most so in innocens; always horizontal in the females.

Subgeneric genital characters, male-Apical lobe of the edeagophore triangular, dorsal surface broadly depressed and concave, central area more or less membranous; apex blunt and not produced; base broadly rounded at the middle third.

Female.-Genital segment subparabolic and not setose, external lobe of the apex obsolete, the internal chitinous and more or less strongly developed, produced, convex above and excurved.

Appendage minute and quite rudimentary.

Dorsal plate of the valves elongate oval to subfalcate.

Superior pudendal membrane broadly exposed by the distant dorsal plates.

In the form of the apices of the genital segment and the minute appendages the present subgenus appears closely related to Discogenia.

Distribution.-Gigantea occurs on the peninsula of Lower California and in California as far north as the vicinity of San Francisco Bay in the north central part of the State.

Gentilis undoubtedly occurs in southern and central California; no definite locality has been recorded except San Diego. Specimens collected at San Diego by Colonel Casey and others received from Lower California by Doctor Horn, and therefore recorded from definite localities, were not gentilis at all, but either omissa or its race pygmaa. All specimens of gentilis that I have seen had simply a "Cal." label, and these were carefully compared with a LeContian type by Mr. Blanchard and myself and the identification is correct. The species probably occurs in Lower California.

Estriata is only known from the San Franciscan peninsula and adjoining region. 
Longicollis has a wide range of distribution. In Mexico it occurs in the States of Coahuila, Chihuahua, and Sonora.

In the United States it is abundant in Texas, Arizona, New Mexico, Kansas, and Colorado. It probably extends into Nebraska, Wyoming, and Utah. A specimen in the National Museum collection bears a label "Oregon." I believe this is erroneous; at any rate it remains to be verified. Longicollis occurs in Colorado at an elevation of 7,000 feet (Wickham). Innocens thus far is only known to occur in Lower California. I have no knowledge of it occurring on the mainland in Mexico.

Genealogy.-It would appear after a careful survey of the large series before me representative of the subgenus Steneleodes that the species have descended from a common ancestral stock along two distinct and divergent lines. Of course this only applies to those species included in our fauna. Similar study of the Mexican species would be the only way to definitely settle this question.

The Mexican forms related to innocens I know nothing about. Longicollis and gigantea are closely related, and I believe the former had its birth in Mexico, diffusion taking place to the northward, a western modification resulting in the latter.

Unfortunately I have not seen any marked races of longicollis; there are undoubtedly some to be found in Mexico. Gigantea has apparently thrown off two divergent formsgentilis, the older, and estriata, the more recent. I might say that innocens is the more heteromorphic; longicollis, gentilis, and gigantea as the more homomorphic. Estriata

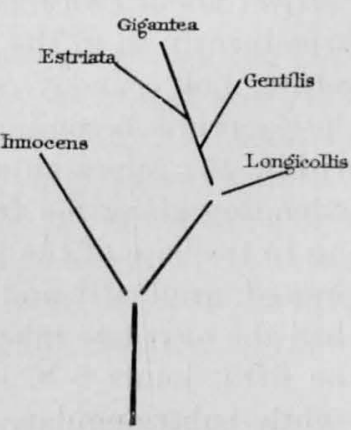

Fig. 7.-Gendalogical diGRAM OF THE SUBGENUS STENELEODES. is slightly intermediate.

Innocens has the abdomen oblique in the male; longicollis, gentilis, and gigantea have the abdomen horizontal in both sexes; estriata has the abdomen slightly, but undoubtedly, oblique. This may be an atavistic reversion to the primitive form, which may have had an oblique abdomen.

Our species and their races may be separated as follows:

Elytra estriate; surface luster shining and bright.

Pronotum feebly convex antero-posteriorly, normally strongly convex from side to side; sides rather evenly arcuate when viewed from above. East of the Colorado River. longicollis.

Pronotum rather strongly convex antero-posteriorly; sides strongly arcuate anteriorly. West of the Colorado River and Sierra Nevada Mountains gigantea.

Pronotum moderately and evenly convex, subquadrate. 
Surface very smooth and shining, punctures very fine; legs slender; elytra widest at middle (male) or widest behind the middle (female) _____ estriata.

Surface less shining, punctuation coarser; legs stouter; elytra widest at the middle (male); female unknown___________var. gentilis.

Elytra more or less striate; surface luster dull innocens.

The above is the best table that I can devise at the present time. More material is necessary to elucidate the difficulties, that are very evident.

\section{ELEODES GIGANTEA Mannerheim.}

Eleodes gigantea Mannerheim, Bull. Soc. Nat. Moscow, XVI, 1843, p. 267; Mag. -Zool., XIII, 1843, pl. 127-LeConte, Proc. Acad. Nat. Sci. Phila., 1858, p. 181-HonN, Trans. Amer. Phil. Soc., XIV, 1870, p. 312. var. gentilis LeConte, Proc. Acad. Nat. Sei. Phila., 1858, p. 187.-HorN, Trans. Amer. Phil. Soc., XIV, 1870, p. 311.

var. estriata Casey, Ann. N. Y. Acad. Sci., V, Nov., 1890, p. 398.

Strongly elongate, convex, smooth, and moderately shining.

Head about twice as wide as long, moderately convex, often more prominently so in the median line of the frons as far as the frontal suture, not coarsely, somewhat sparsely and irregularly punctate, the punctures becoming denser at the sides; frons generally impressed within the supra-antennal convexities, the impressions frequently extending along the frontal suture; antenna rather stout, not reaching to the base of the prothorax; outer four joints very slightly compressed, gradually and very feebly dilated, third joint slightly longer than the next two taken together, fourth just perceptibly longer than the fifth, joints 5-8, inclusive, subequal in length, the seventh and eighth subtriangular, ninth suborbicular, tenth transversely oval, eleventh subovate.

Pronotum widest just in advance of the middle and about one-fifth wider than long; disc strongly convex, arcuately declivous laterally, finely, evenly, and rather sparsely punctulate, punctures becoming slightly denser laterally; apex truncate or very foebly emarginate in. circular are, finely to obsoletely margined; sides evenly and rather strongly arcuate in the anterior two-thirds, thence nearly straight and converging to the base, at times evenly and moderately arcuate throughout, finely margined; base very feebly arcuate, more strongly margined, about one-fourth wider than the apex; apical angles small, subacute, and rarely slightly everted; basal angles obtuse, not rounded nor prominent. lose.

Propleurce opaque, obsoletely or very sparsely punctulate and rugu-

Elytra elongate oval, usually widest at the middle; base scarcely emarginate and about as wide as the contiguous prothoracic base; humeri obtuse; sides evenly arcuate; apex feebly produced and narrowly rounded; disc convex; suture frequently slightly impressed; 
dorsum sometimes depressed, arcuately declivous posteriorly; surface finely, irregularly, and evenly punctate, rarely with closely placed series of slightly larger punctures, the intervals with a more or less irregular series; the punctures are slightly denser at the sides and on the apex, never asperate.

Epipleurce moderately wide beneath the humeri, evenly and gradually narrowing to the apex; surface finely and sparsely or obsoletely punctate, more or less finely rugulose.

Sterna rather strongly and sparsely punctate and rugose; the prosternum anteriorly and the metasternum between the coxæ laterally, frequently obsoletely punctate.

Parapleurce strongly punctate anteriorly, sparsely so posteriorly.

Abdomen horizontal, finely and sparsely punctate, the punctures becoming denser at the periphery of the fifth segment; surface more or less rugulose, at times strongly so.

Legs moderately long. Femora not usually densely punctate, the anterior mutic in the sexes. Anterior tibial spurs subequal. Protarsi slightly dissimilar in the sexes.

Male.-Very elongate and attenuate. Antennæ attaining the posterior fifth of the prothorax. Elytra gradually narrowed and very gradually arcuately declivous posteriorly. Abdomen moderately convex and very feebly, broadly impressed on first three segments. Posterior tibiæ more or less arcuate. Anterior tarsi with the first joint slightly thickened at apex beneath; apico-marginal tufts of spinules somewhat attenuate, brownish or yellowish, those of the first joint more or less transversely confluent and slightly modified; groove subentire.

Female.-Elongate and rather broad. Antennæ scarcely attaining the posterior fifth of the prothorax. Elytra slightly depressed on the dorsum, not gradually attenuate and less gradually or more strongly arcuately declivous posteriorly. Abdomen strongly convex. Posterior tibiæ quite stout and scarcely arcuate. Apico-marginal tufts of spinules of the tarsi rather stout, those on the first joint of the protarsi not transversely confluent; groove entire.

Measurements.-Males: Length, 31-35 mm.; width, 9.5-10 mm. Females: Length, 28-35 mm.; width, 10.5-13 mm.

Genital characters, male.-Edeagophore oblong-ovate and somewhat fusiform, moderately arched.

Basale elongate oblong, longitudinally convex, and evenly so from side to side; apex with a rounded emargination.

A picale (Plate 1, fig. 6) triangular. Surface broardly and strongly depressed, very broadly membrano-chitinous and with a linear median groove at middle two-fourths; sides nearly straight, feebly sinuate at apex, the latter narrowly rounded, gradually and feebly recurved; base with a rounded lobe at middle third and sinuate laterally. 
Sternite subhemispherical in outline. Each lobe quite triangular; external border evenly arcuate, apex broadly rounded, with the internal margin more or less arcuate; surface densely punctate and setose in apical half, setæ long and dense. Membrane not setose across the bottom of the sinus, the latter moderately wide.

Female.-Genital segment (Plate 1, fig. 4) subparabolic in outline, strongly chitinized, not setose. Superior pudendal membrane broadly exposed, dorsal plates widely separated.

Valvula.-Dorsal plate subfalcate, with surface more or less concave, and rather coarsely, sparsely punctate; margins slightly converging to the apical margin, which is more or less rounded. Internal surface of the valve inwardly declivous and more or less exposed, finely and densely punctate, slightly excavated beneath the apex, the latter chitinous, semi-oval in outline, flattened, projecting upward and backward, moderately divergent, tip broadly and evenly rounded, with the surface feebly convex and quite strongly punctate.

A ppendage minute, scarcely projecting beyond the margins of the minute fossa.

Basal protuberances feeble.

Superior pudendal membrane attaining the apical fourth of the segment, longitudinally rugulose.

Ventrolateral surfaces conjointly ogival when viewed from below, straight when viewed longitudinally and not inflated, sparsely punctate. Apex concave beneath, the concavity extending forward and laterally, so that the dorsal plate appears expanded and the submarginal groove broad. Internal margins of the valves contiguous, the genital fissure closed.

Habitat.-California (San Diego, Orange, Los Angeles, Kern, and Santa Cruz counties). Lower California (San Pedro Martir).

Number of specimens studied, 51.

Location of type not known.

Type-locality.- "California" (Mannerheim).

Salient type-characters.-Elongate, shining. Thorax, convex and rounded; femora, mutic; elytra, finely granulato-punctate (Mannerheim).

Diagnostic characters.-Readily recognized by the elongate and attenuated form of the males; the females, while elongate, are also more robust, at times decidedly so. The most common form of sculpturing observed is that in which the elytra are smooth, polished, minutely and rather sparsely punctate, the punctures being diffusely placed.

I have many specimens with more or less distinctly indicated and closely placed series of punctures on the elytra, and they were not from any one region. Mannerheim's type had the elytra finely granulato-punctate. This form of sculpturing is less common. The thorax is finely and sparsely punctulate. 
From longicollis (see p. 427) it is separated by feeble characters.

In gigantea the thorax is usually much more strongly arcuate at the sides, the disc less strongly arcuately declivous and inflexed, the pronotum appearing broader, as compared to longicollis where the side margins are more strongly declivous and inflexed, the margins appearing less strongly arcuate and the pronotum longer.

In gigantea the thorax has a much stronger antero-posterior convexity.

The mutic profemora of both sexes distinguishes gigantea from all of the members of the subgenus Eleodes, except sponsa, caudifera, and longipilosa; these species are roughly sculptured, or caudate, and therefore not easily mistaken for gigantea.

The genital characters serve to separate it from all other subgenera if there be any doubt.

The form found about San Francisco Bay and named by Colonel Casey as estriata is related to gentitis (see p. 423); the typcial form is rare, but found there.

Some of the smaller individuals might be more difficult to separate from the larger specimens of nigrina. The latter species has dull integuments and the sculpturing is coarser, especially that of the prothorax.

I have one specimen of nigrina that was collected at Verdi, Nevada, which simulates gigantea quite perfectly; it measures $24 \mathrm{~mm}$. in length, which is larger than some of the smaller examples of gigantea.

General observations. - The mentum is triangulo-parabolic in outline, slightly wider at base than long; the apex is usually rounded, sometimes apparently truncate on account of the tip being slightly and briefly recurved; rarely the apical margin is feebly impressed at middle so as to appéar emarginate; the surface is quite coarsely punctate, the punctures are not usually crowded, each bearing a rather long hair, giving it a bearded appearance.

The prosternum is strongdy arcuate between the coxæ, both being decidedly protuberant ventrally; the ante-coxal surface more or less sinuate and oblique, continuing the surface line of the intercoxal part; behind it bears a small conical mucro. These characters are quite constant in the series before me.

The mesosternum is quite vertical and moderately arcuate, more or less concave.

The abdominal and metasternal salients are about equal in width. The abdominal process is slightly longer than wide, that is, slightly oblong.

The post-coxal portion of the first segment is equal in length to the second, the latter is about, or a little more than twice as long as the fourth; the third is a little less than twice as long as the fourth. 
The metasternum laterally between the coxæ is about as long as the width of a metatibia at middle.

The profemora are very feebly swollen in external half; this condition is very gradually attained from the base; the surface lines are very feebly arcuate when viewed lengthwise; the tibial grooves are moderate in width, with margins rather coarse and slightly arcuate, becoming evanescent a little distance from the base but not contiguous at point of evanescence; floors feebly concave, opaque, and more or less minutely reticulate.

Meso- and metafemora almost subequal in width throughout when taken individually, each having the corresponding sides subparallel. The grooves of the mesofemora are a little narrower than the profemoral, the margins are coarse and subgranulate, evanescent at internal third; floors feebly concave, smooth and opaque, more or less rugulose, sometimes transversely so.

Metafemoral grooves a little narrower than the mesofemoral and very feebly concave; margins coarse, more or less granulate, the posterior frequently finely serrulate, both evanescent a little internal to the middle.

The tibiæ are usually quite stout and usually more or less feebly arcuate. The protibiæ are scarcely compressed and more or less carinate externally; the tarsal grooves are more or less developed and asperate; the articular cavities are more or less closed.

The mesotibiæ are somewhat circular in section, usually not at all carinate externally; grooves more or less developed, rather narrow, opaque and limited by the general muricate sculpturing.

The metatibiæ are quite cylindrical in section, otherwise like the mesotibiæ. The articular cavities are closed in each.

The tarsi are stout and moderate in length.

The protarsi are about a fourth of their length shorter than a mesotarsus. Joints $2-4$ subequal in length and apparently decreasing in width in the order named, a little wider than long and together about equal in length to the fifth; first joint a little longer than wide.

The mesotarsi are about equal to a metatarsus in length. Joints $2-4$, inclusive, subequal in length and very slightly decreasing iu size in the order named, and together subequal in length to the fifth; the first about twice as long as wide.

The metatarsi are about half as long as their respective metatibia. Joints 2 and 3 slightly decreasing in length, width, and size in the order named, each distinctly a little longer than wide, together scarcely as long as the fourth and quite as long as the first.

\section{ELEODES GIGANTEA var. GENTILIS LeConte.}

Elongate fusiform, more or less shining and smooth.

Head about twice as wide as long, feebly convex, lateral impressions very feeble, frontal suture evident and usually marked by a line 
of punctures, very feebly impressed; punctures somewhat coarse, sparsely and irregularly placed, more closely so at the periphery. Antenna moderately slender and moderate in length, scarcely attaining the prothoracic base, feebly compressed and very slightly dilated in outer four joints; the third joint equal in length to the next two taken together, fourth apparently very slightly longer than the fifth, $5-8$, inclusive, subequal in length, eighth feebly triangular and about as wide as long, ninth and tenth orbicular or feebly transversely oval, eleventh short-ovate.

Pronotum subquadrate, widest at about the middle, about oneseventh wider than long; disc moderately convex, more arcuately and strongly so at the sides, finely and rather sparsely punctulate, punctures scarcely at all denser laterally; apex subtruncate in circular arc, and finely beaded; sides rather evenly but not strongly arcuate when viewed from above, slightly narrowed posteriorly and finely beaded; base feebly rounded and less finely beaded, about one-sixth wider than the apex; apical angles not in the least prominent anteriorly, scarcely at all rounded and not acute; basal angles obtuse and not rounded.

Propleurce smooth and more or less sparsely and obsoletely punctulate, rugulose.

Elytra elongate oval, widest at the middle; base very feebly emarginate, scarcely wider than the contiguous prothoracic base; humeri obtuse, not prominent nor rounded; sides evenly arcuate, apex rather narrowly rounded and not produced; disc convex and quite evenly rounded at the sides, arcuately declivous and rather obliquely attenuate posteriorly; surface finely, sparsely, and irregularly punctulate, sometimes scarcely serially arranged, the punctures slightly denser at the sides and on apex, never asperate, scarcely subgranulate at times.

Epipleurce moderately narrow beneath the humeri, very gradually and evenly narrowing to apex; surface finely, sparsely, and obsoletely punctate, sometimes feebly rugulose.

Sterna not coarsely rugose and more or less punctate.

Parapleurce rather sparsely but distinctly and not coarsely punctate.

Abdomen horizontal, sparsely punctulate and more or less rugulose, smooth, and shining.

Legs moderate in stoutness and length, not densely sculptured, most so on the tibiæ; anterior femora mutic in the sexes; tibial spurs subequal; tarsi as in gigantea.

Male.-Elongate and quite fusiform. Elytra gradually narrowed in apical third, evenly, gradually arcuately declivous posteriorly; abdomen moderately convex, more or less broadly and not strongly

$$
59780-\text { Bull. } 63-09-27
$$


impressed at middle on the first three segments; posterior tibiæ more or less feebly arcuate.

Measurements.-Males: Length, 20-27 mm.; width, 7-10 $\mathrm{mm}$. Females: Unknown.

Genital characters, male.-Edeagophore comparatively large, oblong-ovate, very elongate and slightly arched.

Basale elongate oblong, evenly convex from side to side, moderately strongly convex antero-posteriorly, with a moderate longitudinal impression at middle in apical moiety; sides subparallel; surface glabrous and shining, sparsely punctate apically at the sides; apex with a rounded emargination at middle.

A picale triangular. Surface convex laterally, with a depressed oval chitino-membranous area at the middle, thence to apex broadly and not deeply grooved; apex recurved and quite broadly rounded; sides quite straight, although feebly but broadly sinuate at apex; base with a well-marked, rounded lobe at middle and quite strongly sinuate laterally.

Sternite subparabolic in outline and slightly transverse. Each lobe with the external border quite evenly and broadly arcuate from base to apex, the latter narrowly rounded; internal border short and arcuate; surface quite convex, glabrous in basal half, thence to apex strongly punctate, the punctures increasing in density, each with a rather long seta, the latter dense in apical third. Sinus broad and more or less oblong-oval, the inner and contiguous surface of the lobes inwardly and gradually declivous. Membrane not setose and irregularly rugose.

Habitat.-California. The exact locality is not indicated on the specimens at hand. LeConte's cotype before me bears a green "Calif." label, but in his description of the species he gives San Diego, California.

All the specimens that I have seen and which were referred to gentilis by Doctor Horn have thus far turned out to be something else, and I am not sure that he had typical specimens in any of these instances.

Gentilis, no doubt, occurs in Central and Lower California, as well as in the southern part of the State.

Lower California specimens ${ }^{a}$ referred to gentilis by Horn were insularis or some variation of omissa. Colonel Casey failed completely to recognize gentilis, and considered the race described in this paper as pygmae as that species, saying that it is abundant at San Diego. ${ }^{b}$ I have a specimen which he identified as gentilis. It is simply a pygmae with a very quadrate prothorax.

Pygmae is abundant at San Diego, but gentilis seems to be very rare, for I have not seen any recently collected specimens. During

${ }^{a}$ See Proc. California Acad. Sci., 2nd ser., IV, Pt. 1, pp. 306 and 349.

${ }^{b}$ Ann. N. Y. Acad. Sci., V, Nor., 1990, p. 395. 
many years' residence in San Diego County and after collecting over the entire western half of the county I had not a single specimen.

Number of specimens studied, 3 ; one a LeContian cotype.

Type in the LeConte collection in Cambridge, Massachusetts.

Type-locality.-San Diego, California.

Salient type-characters.-Elongate. Thorax convex with the sides rounded and slightly narrowed behind, finely and sparsely punctulate. Elytra elongate oval, declivous and obliquely attenuate behind, finely, sparsely, and scarcely seriately punctulate (LeConfe).

Diagnostic characters.-Closely allied to gigantea but very much smaller, with thorax less rounded on the sides and less narrowed toward base.

In gentitis the elytral punctulation is a little coarser than in gigantea.

One specimen before me measures $27 \mathrm{~mm}$. and is as large as an ordinary gigantea.

There is something strange about the manner in which gentilis has been misunderstood, and it has given me more trouble to study it out than any other species; it was with a feeling of deep satisfaction when, through the kindness of Mr. Samuel Henshaw, I was permitted to receive one of LeConte's cotypes through transmission from the museum in Cambridge, Massachusetts. Two of the specimens already in the material at hand had been referred to gigantea. Mr. Blanchard truly defined gentilis when he wrote me that it looked to him like a small fusiform gigantea.

A specimen in Mr. Ralph Hopping's collection was wrongly identified when received by him and bears the number 7337, and was evidently received from Reinecke, for this name is on the label. This shows how the earlier collectors obtained these specimens, while all recently collected material yields no examples of this race.

Estriata is a modified gentilis. It is more glabrous, the elytra of the male is more inflated and with a tendency to become widest behind the middle.

The male in its genital characters shows some approach to innocens in the oval chitino-membranous area of the apicale of the edeagophore, while the same characters in estriata are intermediate between gentilis and gigantea. But these characters are no doubt subject to considerable individual variation.

Gentilis therefore appears to be nothing more than a race of gigantea, LeConte's types being simply an extreme nanoid form, while Hopping's specimen has the normal size of gigantea. The females probably do not differ from the general form of the female gigantea, the males being dimorphic.

General observations.-The mentum is trapezoido-parabolic in outline and comparatively small, setose, the setæ being moderately long 
and somewhat transversely arranged on the anterior half so as to give a distinctly bearded appearance. Otherwise as in gigantea.

The prosternum is moderately prominent ventrally with the coxæ, convex antero-posteriorly and grooved; there is a small mucro behind.

The mesosternum is arcuately declivous and more or less vertical, concave to a varying degree.

The metasternum laterally between the coxæ is about as long as the width of a mesotibia at middle.

Comparative measurements gave the same relative proportions between the abdominal segments, metasternal and abdominal salients of the two extreme specimens of gentilis before me. LeContian cotype, male, $20 \mathrm{~mm}$; Hopping's large example, male, $27 \mathrm{~mm}$.

The abdominal salient is about a third of its width broader than the metasternal process; the abdominal salient is subquadrate, a little longer than wide; the post-coxal portion of the first segment is equal to the third in length, and the second is twice as long as the fourth.

The profemora are feebly swollen in outer half, but very gradually so; the grooves are moderate in width with margins feebly subcariniform, feebly arcuate, converging to become contiguous and evanescent at basal fourth; the floors of the grooves are smooth and scarcely concave.

The mesofemora are very feebly and just noticeably widened in middle third, narrowing slightly and gradually each way; the grooves are a little narrower, margins scarcely subcariniform and more or less granulate, scarcely at all arcuate, converging slightly to become evanescent at basal third without becoming contiguous; floors of grooves nearly plane.

Metafemora are not swollen, but with the opposed surfaces subparallel; grooves narrower and otherwise as those of the mesofemora.

The tibiæ are very slightly arcuate in the three males at hand.

The protibiæ are obsoletely subcarinate externally, tarsal grooves more or less obsolete; the articular cavities are closed.

The mesotibiæ are obsoletely subcarinate externally at basal third, otherwise as in the protibiæ.

The metatibiæ are more or less rounded, not carinate and obsoletely grooved.

The tarsi vary in stoutness according to the size of the example.

The protarsi are about a fifth of their length shorter than a mesotarsus. Joints $2-4$, inclusive, are subequal in size, apparently very feebly wider than long and together about equal to the fifth; joint one distinctly longer than wide.

The mesotarsi are about equal in length to a metatarsus. Joints 2-4, inclusive, are subequal in size, very feebly longer than wide, 
together about equal to the first; the fifth scarcely as long as the three preceding joints taken together.

The metatarsi are a little longer than half the length of their respective metatibia. Joins 2 and 3 subequal in size, distinctly longer than wide, and together equal in length to the first or fourth taken individually.

\section{ELEODES GIGANTEA var. ESTRIATA Casey.}

Elongate, ovato-fusiform, moderately robust, strongly convex, smooth and polished.

Head rather variable in size, moderately convex, impressions obsolete, rather coarsely punctate, the punctures sparse toward the middle, denser and setose laterally.

Antenna somewhat variable in stoutness, short, reaching to about the prothoracic base, slightly compressed and scarcely, dilated in the outer five joints; third joint scarcely longer than the next two together; fourth to the seventh, inclusive, subequal in length; fourth sometimes slightly longer; eighth triangular; ninth orbicular; tenth feebly transverse; eleventh subovate and more or less obliquely truncate at tip.

Pronotum subquadrate, widest at about the middle, slightly wider than long; disc moderately convex, very finely and sparsely punctate throughout; apex truncate in circular arc, more or less obsoletely beaded; sides broadly arcuate anteriorly, more or less straight and convergent in basal half, at times somewhat arcuate throughout, very finely beaded; base subtruncate, rather finely beaded, and a little wider than the apex; apical angles obtuse, not rounded nor anteriorly prominent; basal angles obtuse and not prominent.

Propleura finely punctulate anteriorly and more or less obsoletely rugulose.

Elytra elongate oval, widest at or behind the middle; base subtruncate and about equal in width to the contiguous prothoracic base; humeri not rounded nor prominent; sides arcuate, apex subacute and not at all produced; disc moderately convex, more strongly rounded laterally and arcuately declivous posteriorly; surface finely or rather coarsely punctate, punctures sparsely placed and not asperate, not denser laterally and arranged without trace of order throughout, at times with evident closely placed series.

Epipleurce moderate in width, gradually narrowing from base to apex, superior margin quite straight when viewed longitudinally; surface smooth, sparsely and obsoletely punctulate.

Sterna quite strongly punctate and rugose throughout.

Parapleura moderately closely punctate.

Abdomen shining, sparsely and irregularly punctulate, rather obsoletely and reticulately rugulose. 
Legs moderate in length and variable in stoutness. Femora rather sparsely punctate, the anterior mutic in the sexes; anterior tibial spurs almost equal. Tarsi slightly dissimilar in the sexes.

Male.-Rather narrow, not distinctly ovate, more fusiform. Elytra quite evenly arcuately declivous and somewhat gradually narrowed posteriorly. Abdomen feebly oblique, moderately convex, and more or less broadly and feebly impressed at middle of first two segments. Legs somewhat slender, especially the tibiæ. Anterior tarsi with a small transverse tuft of modified spinules at tip of first joint beneath, the tuft closing the plantar groove.

Female.-Rather robust. Elytra widest behind the middle, arcuately and somewhat obliquely declivous and somewhat rapidly narrowing posteriorly. Abdomen horizontal, rather strongly and evenly convex. Legs rather stout, the tibiæ moderately so. First joint of the protarsi not modified at tip beneath, plantar groove wide.

Measurements.-Male: Length, $20 \mathrm{~mm}$; width, $7.2 \mathrm{~mm}$. Females: Length, 22.5-26 mm; width, 9-10 $\mathrm{mm}$.

Genital characters, male.-Edeagophore as in gigantea. Sternite rather short and transversely parabolic in outline. Each lobe rather small and subtriangular; external border subangulate at middle, thence to base feebly arcuate, to apex obliquely truncate, apex narrowly rounded; inner border feebly arcuate; surface densely and strongly punctate in apical moiety, each puncture with a long black seta. Membrane not setose, sinus broadly oval.

Female.-Genital segment subparabolic in outline, feebly elongate and finely setose. Superior pudendal membrane broadly exposed, and the dorsal plates widely separated.

Valvula.-Dorsal plate subfalcate, with surface more or less concave, facing upwards and outwards, coarsely punctate, each puncture with a short, rather stout semirecumbent seta; borders gradually converging to the apical border, which is more or less rounded; internal border quite sharp and broadly sinuate; internal surface of the valve much exposed and inwardly declivous, densely and rather strongly punctate in apical third beneath the apex, each puncture with a short, curved, and semirecumbent seta. Apex chitinous, semioval in outline, flattened, projecting upward and backward, moderately divergent, tip broadly rounded; surface feebly convex and more or less punctate.

Appendage minute, scarcely projecting beyond the fossa, which is situated in an excavation between the external surface of apical base and the apical margin of the dorsal plate; short, semioval in form, with a few short setæ at tip.

Basal prominences not noticeable.

Ventrolateral surfaces as in gigantea. 
Habitât-California (Presidio sand hills, San Francisco, June; San Mateo County, at Holy Cross Cemetery; Alameda County).

Number of specimens studied, 8.

Type in Colonel Casey's collection.

Type-locality.-San Francisco, Cal.

Salient type-characters.-Head transverse and moderate in size; antennæ rather short and robust, third joint very slightly longer than the next two together, fourth less than twice as long as wide.

Prothorax just visibly wider than long, apex truncate and equal in width to the base which is subtruncate; sides broadly arcuate anteriorly, convergent and nearly straight in basal half, basal angles obtuse and not at all prominent; disc moderately convex, very finely and sparsely punctate.

Elytra widest behind the middle, humeri not rounded nor prominent; apex acute but not greatly prolonged; disc finely but distinctly and very sparsely punctate, the punctures not asperate and without trace of order throughout (Casey).

Diagnostic characters.-A local race of gigantea, from which it differs in its "smaller size, less attenuate form, wider epipleuræ, less convex pronotum, less arcuate sides of the prothorax, and shorter elytra" (Casey).

From longicollis it is recognized by having the "prothorax more anteriorly dilated, much shorter and rather more robust antennæ, and coarser punctuation" (Casey).

It is undoubtedly more closely allied to gentilis than to any other form belonging to the present subgenus. It is also very variable as indicated by Casey's two specimens and the small series before me. The male, as directly compared with the LeContian co-type of gentitis, has the same form, but is more polished, has finer punctuation, more slender legs, especially the tibia, and is altogether a more graceful insect.

Unfortunately the female of gentilis has not been recognized. Two females of estriata now before me are the homomorphic companions of the male above compared with gentitis, and are more robust with the elytra widest behind the middle and the tibiæ are distinctly stouter. I judge that Casey's smaller specimen with longer and more slender legs is a male, and the larger example with a more robust habitus, is undoubtedly a female. A specimen which I took in the Holy Cross Cemetery in San Mateo county, is the most robust specimen that I have seen and it is a female, it has exactly the same measurements as Casey's large specimen and agrees with his description, the antennæ are distinctly stout and shorter than in the other specimens before me.

The individuals taken about the sand hills on the peninsula are very graceful insects and at first sight apear quite distinct from 
gigantea; specimens taken more inland gradually approach the typical form of the last named species. Estriata is not common.

General observations. - The mentum is trapezoidal to trapezoidoparabolic, more or less feebly convex, rather coarsely punctate, each puncture with a rather long hair.

The prosternum as in gigantea, except that the small conical mucro is usually obsolete.

Mesosternum as in gigantea.

The abdominal intercoxal salient is quite quadrate and about a fifth of its width broader than the metasternal process.

The post-coxal part of the first abdominal segment is about equal to the second in length; the second segment is about a fourth longer than the third, the latter being about a half longer than the fourth.

The metasterum laterally between the coxæ is about equal in length to the width of a mesotibia at apical fourth.

The profemora are scarcely at all swollen, and the surface lines are evenly and rather feebly arcuate, not distinctly subclavate, although slightly narrowed at base; tibial grooves strongly defined by the rather coarse cariniform margins, which are feebly arcuate and convergent, becoming contiguous at the femoral base and there slightly evanescent. The protibiæ are obsoletely carinate externally and oval in section, the tarsal grooves are obsolescent.

The mesofemora are somewhat variable as to point of greatest width; surface lines subparallel, noticeably convergent in basal fourth; tibial grooves distinctly concave, margins not cariniform; evanescent at basal third before becoming contiguous. The mesotibiæ are oval to cylindrical in transverse section; tarsal grooves not impressed and recognized as a smooth surface between the sparse asperities.

The metafemora have the surface lines subparallel, slightly narrowed in basal fifth; tibial grooves as on the mesofemora and evanescent at or basad to the middle. Metatibiæ variable, but with general characters as in the mesotibiæ.

The articular cavities are quite closed on all the tibiæ.

The tarsi are variable as to stoutness and moderate in length.

The protarsi are about a fifth of their length shorter than a mesotarsus. Joints 2-4, inclusive, short and subequal in size and together about equal to the length of the fifth; first joint one-half longer than the second.

The mesotarsi are just a little longer than a metatarsus. Joints 2-4 are subequal and together just a little longer than the fifth; the first is subequal to the second and third taken together. A metatarsus is a little more than half as long as its metatibia. Joints two and three are subequal in size, a little longer than wide, and together equal to the length of the fourth or first. 


\section{ELEODES LONGICOLLIS LeConte.}

Eleodes longicollis LeConte, Ann. Lyc. Nat. Hist. N. Y., V., 1851, p. 134 ; Proc. Acad. Nat. Sci. Phila., 1858, p. 181.-Honn, Trans. Amer. Phil. Soc., XIV, 1870, p. 311.-Сhampion, Biol. Cent.-Amer., IV, Pt. 1, 1884. p. 84 .

Eleodes haydenii LeConte, Proc. Acad. Nat. Sci. Phila., 1858, p. 186.

Elongate to elongate-fusiform, black, the elytra often more or less reddish, smooth and shining.

Head twice as wide as long, more or less moderately convex, finely and quite evenly punctate, the punctures becoming slightly denser at the sides. Antenna moderately stout, about reaching to the base of the prothorax; outer five joints very feebly compressed and scarcely dilated; third joint about as long as the next two taken together ; 4-7, inclusive, subequal and nearly cylindrical; eighth triangular; ninth and tenth suborbicular; eleventh ovate.

Pronotum widest at the middle and about one-seventh wider than long; disc quite evenly convex, the convexity strongest transversely, slight antero-posteriorly, evenly and rather sparsely punctulate, punctures not denser laterally; apex feebly emarginate or truncate in circular arc, very finely margined; sides quite evenly arcuate throughout when viewed from above, slightly converging to apex, finely margined; base more or less arcuate, feebly and very broadly sinuate at middle, rather finely margined, about one-fourth wider than the apex and equal to the length; apical angles not prominent anteriorly, obtuse but not rounded; basal angles obtuse and more or less feebly rounded.

Propleurce smooth, obsoletely punctate and sometimes slightly rugulose.

Elytra elongate to broadly oval, widest at the middle; base truncate and feebly bisinuate, usually equal in width to the contiguous prothoracic base; humeri obtuse and not prominent; sides evenly arcuate, apex feebly produced and rounded; disc convex, frequently broadly depressed, suture also occasionally impressed, arcuately declivous posteriorly; surface finely, irregularly and evenly punctate, frequently with closely placed series of punctures, the intervals with a more or less irregular series, punctures rarely denser at the sides and apex, never asperate.

Epipleurce moderately wide at the humeri, gradually narrowing to apex; surface sparsely and rather evenly punctate.

Sterna and parapleure more or less irregularly punctate and rugose.

Abdomen horizontal; surface finely, sparsely or obsoletely punctate, punctures denser at the periphery of the fifth segment, more or less rugulose. 
Legs moderate in length. Femora not densely punctate, the anterior mutic in both sexes: protibial spurs subequal; tarsi dissimilar in the sexes.

Male.-Elongate. Elytra twice to a little more than twice as long as wide, arcuately and not suddenly declivous posteriorly. Abdomen moderately convex and broadly impressed on first three segments. Posterior tibiæ more or less arcuate. First joint of the protarsi somewhat produced at tip beneath, bearing a tuft of golden pubescence, which obliterates the plantar groove at that point.

Female.-Robust, often fusiform. Elytra broadly oval, often onehalf longer than wide, very suddenly arcuately or vertically declivous posteriorly. Abdomen rather strongly and evenly convex. Posterior tibiæ not arcuate. Anterior tarsi unmodified.

Measurements.-Males: Length, 27-35 mm.; width, 8.5-9.5 mm. Females: Length, 25-30.5 mm.; width, 10-12 mm.

Genital characters, male.-Edeagophore with the apex of the apicale moderately wide and evenly rounded, slightly recurved in apical fourth and punctulate above; general surface feebly convex although broadly depressed. Otherwise as in gigantea.

Female.-Genital segment with the general characters as in gigantea.

Valvula (Plate 1, fig. 7).-Dorsal plate subfalcate, surface obliquefacing upwards and outwards, quite densely and rather coarsely punctate in apical half, each puncture with a very small decurved, subrecumbent seta; internal margin not strongly defined; the internal or pudendal surface of the valve very densely punctate and setose as above, scarcely excavated below the apex.

Appendage and fossa minute, feebly visible from above. Otherwise as in gigantea.

Habitat.-Arizona (Kearn's District, Navajo Indian Reservation, April, A. W. Barber; Peach Springs, July; Santa Rita Mountains, June, Hubbard and Schwarz; Phoenix, collection E. C. Van Dyke; Fort Grant, July, Hubbard and Schwarz; Tucson, March; Sulphur Springs Valley, May, Hubbard and Schwarz; Oracle, July; Galliuro Mountains, May, Hubbard and Schwarz; Fort Yuma, Prescott, June, Barber and Schwarz); New Mexico (Las Vegas, August, collection H. S. Barber; Coolidge, Luna, Hubbard and Schwarz; Santa Fé, collection C. V. Riley) ; Colorado (Colorado Springs, June, Hubbard and Schwarz; elevation 6,000-7,000 feet, Wickham; La Junta, Southwestern (Strecker) ; Holly, Fort Collins, San Luis Valley, and Trinidad, Wickham's list) ; Texas (Marfia, July, elevation 4,6004,800 feet, H. F. Wickham; Alpine, July, elevation 4,400-6,000 feet) ; Kansas (Western, Hubbard and Schwarz) ; Oregon? (one specimen bearing this state label in the collection of the U. S. National Museum) ; Mexico (Northern Sonora, Morrison; San Luis Potosi; 
Hacienda de Bleados; Parras; San Pedro in Coahuila, Doctor Palmer).

Number of specimens studied, 86.

Type is in the LeConte collection.

Type-locality. - "Flumen Gila" (LeConte).

Salient type-characters.-Elongate, black. Thorax obsoletely punctulate. Elytra finely punctulate, punctures subseriate (LeConte).

Diagnostic characters.-Closely related to gigantea, from which it differs by the frequent elongate fusiform or subcylindrical shape. The females frequently have the elytra more or less flattened on the dorsum.

The prothorax is less arcuate at the sides, chiefly because the disc is quite strongly and transversely convex, with sides more or less strongly and arcuately deflexed and in many instances more or less feebly inflexed as well, so that the margin is completely invisible when the prothorax is viewed vertically from above.

The pronotum is only apparently longer than wide, for by direct measurements and in tracings I do not find much difference between longicollis and gigantea.

There is usually only a very slight antero-posterior convexity and this is a good differential character in separating the species from gigantea, but it can not be relied upon entirely.

Some specimens from the Colorado Desert Region and Orange County, California, are as nearly intermediate between longicollis and gigantea as any forms can be, and these mesotypes approach estriata as well.

I consider the two species as modifications of a single and rather recent ancestral form, one ramus of this dichotomous divergence extending westward and northward, the other eastward and northward.

The sculpturing of longicollis is the same as in gigantea-surface smooth, polished, finely and sparsely punctate, but more coarsely sculptured specimens are frequently found, and some are even substriate.

The specimens described by LeConte as haydenii is a variation along this line; the differential characters given are as follows: "Thorax is more rounded on the sides, more distinctly punctulate, the rows of punctures of the elytra are much more evident, and the curvature from the back to the sides is abrupt, while in longicollis it is regular and uniform; the elytra are also more elongate near the apex, so as to produce at the inflexed margin a very slight concavity." It is only a synonym.

Specimens collected by Doctor Palmer in Mexico had the elytra distinctly but finely punctato-striate; other forms were taken but all referable to the present species. 
General observations.-The mentum appears to be more trapezoidoparabolic, otherwise as in gigantea.

The prosternum is also about the same as in that species, probably not as prominent ventrally, and the ante-coxal portion more gradually and evenly continuing the surface line; frequently more strongly mucronate behind, the mucro may be conical and more or less deflexed, or vertically truncate behind with the angle mucroid and deflexed. In the series before me the prosternum is not even in one instance horizontal between the coxæ, but always more or less convex.

The mesosternum is variable, at times quite flat to vertically arcuate, broadly, and more or less strongly concave.

The abdominal process is wider than long and about a fourth of its own breadth wider than the metasternal salient.

The post-coxal portion of the first abdominal segment is equal in length to that of the second; the latter is about a fifth longer than the third and almost twice as long as the fourth.

The metasternum laterally between the coxæ is about as long as the width of a mesotibia at apex.

The profemora are subclavate and not noticeably swollen, greatest dorso-ventral diameter is at the junction of the middle and apical thirds, the surface lines are feebly arcuate; the tibial grooves are well developed, their margins converging and becoming contiguous some distance from the base.

In the series at hand all of the tibix are more or less arcuate. The protibiæ are slightly compressed, obsoletely carinate externally, and the tarsal grooves are not evident.

The mesofemora narrow but slightly toward base and not at all swollen; the grooves are rather short, their rather coarse margins converging and becoming contiguous near the middle, the floors are slightly concave.

The mesotibiæ are quite cylindrical in section; their tarsal grooves are more or less evident as glabrous, opaque grooves limited by asperities.

The metafemora are almost subequal in width throughout, the grooves are rather short, the margins converging to become almost evanescent before uniting at the distal side of the middle.

The metatibiæ are subcylindrical in section, slightly flattened externally and asperate.

The articular cavities are quite closed.

The tarsi are variable in thickness, usually moderately long and somewhat stout. In one specimen collected at Tucson, Arizona, the tarsi are distinctly slender.

The protarsi are about a fourth of their length shorter than a mesotarsus. Joints 2-4, inclusive, subequal in length and very 
slightly wider than long and together quite equal to the fifth; the first joint is short, about a half longer than the second.

A mesotarsus is about a tenth of its length shorter than a metatarsus. Joints 2-4 subequal in length and scarcely longer than wide, together apparently just a little longer than the fifth; first joint almost as long as the second and third taken together.

The metatarsi are half as long as their respective tibix. Joints 2 and 3 are about subequal in length and distinctly longer than wide, together about equal in length to the fourth or first.

\section{ELEODES INNOCENS LeConte.}

Eleodes innocens LeConte, Smithson. Miscell. Coll., No. 167, 1866, p. 114.Honn, Trans. Amer. Phil. Soc., XIV, 1870, p. 312.

Elongate, suboblong to ovate, subopaque to feebly shining, moderately convex. Elytra striato-punctate.

Head nearly twice as wide as long, feebly convex, more or less feebly impressed laterally and along the frontal suture, finely, rather densely and more or less irregularly punctate, antennæ stout, reaching to the prothoracic base, outer four joints scarcely or very feebly compressed and not noticeably dilated; third joint shorter than the next two taken together; fourth to the seventh, inclusive, subequal and subcylindrical; eighth just noticeably shorter; ninth and tenth suborbicular; eleventh oval.

Pronotum quadrate, widest at or a little in advance of the middle, very little wider than long; disc very moderately and quite evenly convex, at times noticeably declivous at the apical angles, very finely to obsoletely punctulate; apex truncate to feebly emarginate laterally within the angles, obsoletely margined; sides more or less feebly and evenly arcuate from base to apex, often rather straight behind the middle, very finely margined; base truncate to feebly arcuate and finely margined, little wider than the apex and about equal to the length; apical angles obtuse, scarcely rounded and more or less prominent, not dentiform; basal angles obtuse, not rounded nor prominent.

Propleura obsoletely punctulate and more or less rugulose, feebly convex and very feebly defined from the pronotal dise by the fine marginal bead.

Elytra oval, smooth, about twice as long as wide, widest at or a little behind the middle; base feebly emarginate or truncate, frequently slightly wider than the contiguous prothoracic base; humeri obtuse, not rounded; sides evenly arcuate, apex not produced and rather narrowly rounded; dise slightly flattened on the dorsum and quite strongly convex laterally, arcuately, and vertically declivous posteriorly; surface striato-punctate, the strial series moderate in 
size and closely placed, usually more or less eroded, intervals more or less feebly convex, finely, sparsely, and obsoletely punctulate; striæ more or less impressed, the punctures slightly denser and irregular on the apical declivity.

Epipleurce smooth and usually impunctate, moderately wide, with margins parallel in middle two-fourths, thence gradually converging to near the apex.

Sterna more or less punctate and rugulose.

Parapleurce rather coarsely punctate.

Abdomen more or less obsoletely punctulate on the first three segments, fourth and fifth more or less punctate; rather strongly rugulose on the first segments, the others obsoletely so.

Legs moderate in length and stoutness. Profemora more or less feebly sinuate in both sexes; tibial spurs rather short, the anterior similar. Tarsi slightly dissimilar in the sexes.

Male.-Elongate, somewhat narrow and suboblong. Elytra usually widest at about the middle. Abdomen oblique, feebly convex, strongly and broadly impressed on the first three segments. Anterior tarsi with the first two joints rather densely clothed at tips beneath, with yellowish pubescence, that more or less obliterates the plantar groove.

Female.-Somewhat robust and more or less elongately ovate. Elytra usually widest behind the middle. Abdomen horizontal, rather evenly but not strongly convex, scarcely longitudinally convex. Tarsi simple.

Measurements.-Males: Length, 17-17.5 mm.; width, 6-6.8 mm. Females: Length, 19-19.5 mm.; width, 7.5-8 mm.

Genital characters, male.-Edeagophore elongate, oval-fusiform and not strongly arched.

Basale oblong oval, sides feebly arcuate and evenly convex from side to side.

A picale (Plate 4, fig. 20).-Subequilaterally triangular, quite strongly depressed; surface with a rather broad fusiform membranous depression at middle three-fifths, laterally more or less convex, with a few scattered and rather coarse punctures; the general surface is flattened and somewhat declivous at the terminal fifth; sides rather strongly arcuate at middle third, thence to the base rather straight, with small accessory lobes visible laterally at basal third, toward apex rather deeply sinuate; apex somewhat produced and narrowly rounded at tip; base arcuately lobed at middle and sinuate laterally.

Sternite somewhat transversely semicircular in outline. Each lobe triangular with the external border evenly and obliquely arcuate from base to apex; internal border more or less straight and converging to the mid-line of the base; apex narrowly rounded; surface 
diagonally convex, basal half smooth and shining, impunctate, the apical moiety feebly and inwardly declivous, quite densely and coarsely punctate, setose, setæ long and dense at apex. Membrane not setose, sinus triangular.

Female.-Genital segment (Plate 4, fig. 21) subparabolic in outline-exclusive of the apices, not setose and strongly chitinized. Superior pudendal membrane broadly exposed.

Valvula.-Dorsal plate suboval to oval-oblong; surface more or less concave, with sides very slightly reflexed, shining and very sparsely punctate; external border rather evenly arcuate; internal margin more or less arcuate, apical margin rounded with angle obsolete; there are a few coarse punctures about the basal margin. Apex strongly produced, excurved, divergent and slightly decurved, convex above, broadly rounded at tip and chitinous, more or less excavated externally at base by the fossa, which has its margins very finely and inconspicuously setose.

Appendage punctiform. The valvular membrane is exposed on the internal surface of the valve, and is more or less chitinous and impunctate.

Superior pudendal membrane is triangularly exposed, longitudinally and reticulately rugulose.

Ventrolateral surfaces convex and not inflated, more or less impressed laterally, sparsely and irregularly punctate, glabrous; submarginal groove well developed beneath the external border of the dorsal plate. Apex more or less coneave beneath. Internal margins of the valves contiguous to near the apex, genital fissure small, narrow, and subapical.

Habitat.-Lower California (Cape St. Lucas, LeConte and Horn; El Taste, Gustav Beyer; Sierra El Chinche, collection of Charles Fuchs).

Number of specimens studied, 8.

Type in the LeConte collection.

Type-locality.-Cape St. Lucas.

Salient type-characters.-Elongate, somewhat shining; thorax quadrate, apex emarginate, apical angles acute and not acuminate, sides broadly rounded, also the base, basal angles obtuse; elytra elongate oval, strongly declivous behind, apex not prolonged, striæ strongly punctate, slightly impressed, interstices with a few sparsely placed punctures. Anterior femora mutic (LeConte).

Diagnostic characters.-Innocens is the only species of the subgenus with striate elytra at present known to our fauna; it is much smaller than gigantea and duller in luster. Horn writes that the anterior femora are feebly sinuate, but I can not see that this character is any more marked here than in the other members of the group. By the nearly mutic femora it is recognized from the members of the 
subgenus Eleodes, except sponsa, caudifera, and longipilosa which have the profemora more or less obtusely armed or sinuate, and besides have a rougher sculpturing, with differently formed elytral apices, which render the diagnosis easy; in innocens the elytra are quite suddenly and arcuately declivous and never in the least produced.

Care must be taken not to confound specimens of the peninsular form of insularis with the present species. This mistake has already been observed in collections.

There is at hand a female insularis, collected at Sierra San Lazaro, Lower California, which has a subopaque luster and the elytra striatopunctate, very similar to the sculpturing observed in innocens; the apical angles are more acute and anteriorly prominent than in the latter species. I had to resort to the examination of the genital segment to feel satisfied as to its true relationship.

In innocens the antennæ are proportionally stouter than in most species.

In insularis (peninsular form) the profemora are more distinctly sinuate or obtusely dentate.

General observations.-The mentum is variable, triangular, triangulo-parabolic, sometimes triangulo-trapezoidal in outline; the surface may be feebly convex to foveate laterally with a median convex ridge, rather finely and obsoletely to rather coarsely punctate, each puncture with a short seta. Very variable considering the small series before me.

The prosternum moderately convex antero-posteriorly in the median line, rather more gibbous and moderately wide between the coxæ, more or less grooved, scarcely widened behind and irregularly sculptured; more or less produced posteriorly, the mucro scabrous and more or less appressed to the body.

Mesosternum almost flat to feebly oblique, broadly and moderately concave.

The abdominal intercoxal process is subquadrate and about a third of its own width broader than the mesosternal salient; it is also equal in length to the second abdominal segment. The post-coxal part of the first segment is equal in length to that of the third, the latter just a little longer than the fourth.

The metasternum laterally between the coxæ is about equal in length to the width of a mesofemur at base.

The profemora are gradually and moderately clavate externally; the tibial grooves are well developed, their margins well defined by finely cariniform edges, which gradually converge to become contiguous at the femoral base; their floors are quite flat, scarcely concave. 
The mesofemora are gradually and slightly thickened externally; the grooves are structurally similar to those of the profemora, but the edges become contiguous a short distance from the femoral base.

The metafemora are but slightly narrowed at base, and therefore have the opposed surfaces subparallel; the grooves are as on the other femora, but have the edges evanescent near the basal fourth before becoming contiguous.

The protibiæ are obsoletely carinate externally and the tarsal grooves more or less obsolete.

The mesotibiæ are subcylindrical and very slightly increasing in diameter from base to apex; the grooves are faintly indicated and the surface asperate.

The metatibiæ are subcylindrical, narrowing slightly toward base; the grooves are feeble and exist as narrow linear impressions between the marginal asperities.

The articular cavities of all the tibiæ are quite closed.

The tarsi are moderate in length and rather stout.

The protarsi are about two-sevenths of their length shorter than a mesotarsus. Joints 2, 3, and 4 subequal in length and just slightly wider than long; the first is about one-half longer than the second; the fifth about equal in length to the third and fourth taken together.

The mesotarsi are a little shorter than a metatarsus. Joints 2,3, and 4 subequal in length and slightly decreasing in width in the order named, together subequal to the length of the fifth; the first about one-half longer than wide and a little shorter than the second and third taken together.

A metatarsus is at least half os long as its tibia. Joints 2 and 3 are about equal in length and breadth, together quite equal to the length of the first or fourth.

NoтE.-I sent to Mr. Blanchard an example of the peninsular form, which I refer to insularis for comparison with innocens, with the following result: "It is surely a sicooth innocens!! The types are 1 male, 1 female, Arizona, having the elytra subsulcate, anterior femora of the male angulate at outer three-fourths. In both sexes the same femora markedly fattened and strongly margined beneath."

I had labeled the specimen E. insularis Linell, and Mr. Blanchard still further writes: "I have been looking at the descriptions of innocens and insularis. It seems that the former was described from Cape St. Lucas, but only specimens now in the collection are from Arizona. The male does not have the large dense brush of golden hairs on the first joint of the front tarsi as is said of insularis."

Doctors LeConte and Horn both give Cape St. Lucas as the typelocality for innocens. The specimens which I consider as true representatives of the species are quite like the peninsular form of insu59780-Bull. $63-09-28$ 
laris in general habitus, but more elongate and more opaque, and these specimens are from Cape St. Lucas and El Taste, Lower California. I do not believe true innocens occurs in Arizona. Doctor Horn referred the peninsular form of insularis to gentilis and quadricollis. This form of insularis occurs in the same region with innocens; both were collected at El Taste by Gustav Beyer. If my conclusions should prove incorrect I should be very much surprised.

\section{Subgenus DISCOGENIA LeConte.}

Mentum transverse, trilobed, inflexed lateral lobes rudimentary, invisible without dissection. Thorax transverse. Elytra with the humeri rounded, rarely obtuse.

Profemora armed or sinuate in the male; feebly armed or mutic in the female.

The internal spurs of the meso- and metatibiæ are slightly longer than the external.

Subgeneric genital characters, male.-The characters, although not distinctive of the present subgenus, may be stated as follows: Apicalc of the edeagophore triangular, depressed, with a more or less widened median membranous groove.

Female.-Genital segment triangular in outline, glabrous, not setose, and fully chitinized; valvular apices strongly produced, divergent and excurved.

Superior pudendal membrane reaching at least to the middle of the dorsal plate. Internal ventral margins of the valves contiguous. Genital fissure closed and subapical. Appendages minutely punctiform.

The subgenus as at present defined contains three species that are not strictly homomorphic, and may therefore be divided into two groups as follows:

Thorax widest at the middle, sides evenly arcuate from base to apex; first joint of the protarsi distinctly thickened at apex beneath, more strongly so in the female Group A.

Thorax widest just in advance of the middle, sides slightly convergent behind and briefly sinuate just in front of the basal angles; protarsi with the first one or two joints slightly thickened at apex beneath, more strongly so in the male Group B.

Group A contains marginata and scabricula; group B the somewhat remarkable planipennis.

The taxonomical arrangement of the subgenera constituting the genus Eleodes is that in the order of morphological sequence, primarily based upon the structural modification of the valves of the genital segment in the female.

The subgenera most closely related to Discogenia are Metablapylis and Steneleodes. The approach to the closely related genus 
Embaphion is gradual and complete, apparently constituting a perfect evolutionary series.

In Metablapylis with nigrina as the central form the valvular apices are short, rounded at tip, convex above and somewhat concave beneath, membrano-chitinous, scarcely divergent or produced.

In Steneleodes with gigantea as typical the apex of each valve is broad, flattened, rounded at tip, convex above and concave beneath, strongly chitinized, and distinctly divergent and moderately produced.

Taking marginata as typical of Discogenia, the valvular apex is moderately broad, slightly flattened, rounded at tip, convex above and concave beneath, strongly chitinized, divergent and excurved, strongly produced.

In Embaphion the general characters are similar to the latter, but the strongly produced and excurved apex is more laminate and more strongly defined from the dorsal plate of the valve.

The other segmental characters are distinctive in each subgenus and render the characters just enumerated as valuable differential criteria.

An examination and analysis of the plates which form an important part of this paper, will elucidate what has been stated above and also demonstrate that the species preserve a wonderful community of subgeneric genital structure.

The species constituting Group A may be differentiated as follows:

Smaller species, scarcely robust, more or less shining, subasperately sculptured; elytra distinctly gradually narrowed posteriorly, apex quite acute. Males armed; females mutic marginata.

Larger species, rather robust, more or less opaque, asperately sculptured; elytra moderately narrowed posteriorly, apex obtuse. Both sexes more or less armed scabricula.

The single species constituting Group B can be recognized from the group characters; the most noticeable characteristic of planipennis is the depressed elytra.

The following synopsis is probably the most practical one that can be formulated from the specific genital characters for any subgeneric section of the genus Eleodes, and is constructed from the female characters alone:

Appendages rudimentary and without setæ.

External margin of the dorsal plate continuous with that of the apex, not angulate, not excavated dorsally at base of apex. Appendages punctiform marginata.

External margin interrupted, angulate; apical margin of the dorsal plate de-

fined by a deep excavation at base of apex ; appendages larger__scabricula. Appendages mammilliform, with pencil of setæ at tip planipennis.

The males apparently have no constant specific differences; at least I have not been able to differentiate any. 
Relationships.-There is no doubt but that marginata and scabricula are closely related, and have undoubtedly diverged from a common ancestral form within recent times. The more obscure relationships of planipennis have been referred to elsewhere.

Distribution.-Discogenia is a subgenus peculiar to California and extends eastward into the Sierra Nevada Mountains as far as Lake Tahoe (elevation 6,280 feet), possibly into western Nevada; in Alpine County to an altitude of 7,000 feet (Blood's meadow).

I do not consider planipennis as a normal constituent of the present subgenus; if it should prove to be, then it must be considered as an eastward modification. In the latter case the first statement will have to be altered. When the obscure question of relationships shall have undergone greater solution, then we will be able to speak more intelligently upon this problem.

Thus far I have only seen specimens of marginata from the maritime regions of central and northern California. The nucleus of distribution seems to be about the Bay of San Francisco.

Scabricula is both montane and submaritime, evidently confined chiefly to central California, and undoubtedly extending more or less north and south of this central region.

Planipennis has only come to me from Arizona, New Mexico, and Colorado.

\section{ELEODES MARGINATA Eschscholtz.}

Eleodes marginata Eschscholtz, Zool. Atlas, III, 1833, p. 10.-MANNerHerm, Bull. Soc. Nat. Moscow, XVI, 1843, p. 268.-LeConte, Proc. Acad. Nat. Sci. Phila., 1858, p. 182.

Eleodes fischeri Mannerheim, Revue Zool., III, 1840, p. 137; Bull. Soc. Nat. Moscow, XVI, 1843, p. 269.

Discogenia marginata LeConte, Smithson. Miscell. Coll., No. 167, 1866, p. 117.-Hokn, Trans. Amer. Phil. Soc., XIV, 1870, p. 320.

Black, oval, and more or less elongate.

Head twice as wide as long, equal to one-half the width of the prothorax, plane to feebly convex, shining, more or less impressed laterally near the frontal suture, sparsely punctate, confluently so at the sides. Antennce reaching to the posterior fourth of the prothorax, outer joints gradually and feebly dilated; the third about three times as long as the second; fourth twice as long as the same; fifth, ninth, and tenth subequal; sixth, seventh, and eleventh equal in length and slightly longer than the fifth.

Pronotum feebly shining, widest at the middle, about two-fifths wider than long; disc evenly and not strongly convex, rather coarsely, irregularly, at times confluently punctate, laterally not broadly and very feebly impressed, and there scabrous from minute granules; apex moderately and evenly emarginate, finely margined; sides 
evenly and broadly rounded, narrowly and acutely margined, margin reflexed; base more or less feebly arcuate, about one-eighth of its width greater than the apex; apical angles nearly obtuse; basal angles obtuse and more or less minutely prominent.

Propleurce smooth, shining, sparsely and irregularly granulate; more or less rugulose over the acetabular convexities.

Elytra oval, shining, widest at the middle; humeri obsolete, rounded; base not margined, somewhat declivous, and scarcely wider than the contiguous prothoracic base; scutellum rather large and triangular; sides evenly arcuate, rather gradually converging at apex, the latter gradually and somewhat produced, rather narrowly rounded; disc quite evenly and moderately convex, more strongly and quite evenly rounded laterally, arcuately and more or less obliquely declivous posteriorly; surface rather coarsely and somewhat densely punctate on the dorsum, becoming gradually more coarsely and subasperately muricato-granulate laterally, and without any sign of order.

Epipleurce moderate in width at the humeri, gradually narrowing to apex; surface feebly concave beneath the humeri and subasperately punctured.

Sterna more or less strongly rugulose and punctate; punctures setigerous.

Parapleurce irregularly and rather strongly punctate, interstices glabrous and shining.

Abdomen rather coarsely, thickly punctate and rugulose on segments one and two, less so on the third, very sparsely so on the fourth and fifth.

Legs moderate in length and thickness. Anterior tibial spurs similar in the sexes the anterior spur longer than the posterior, both acute and rather stout. Protarsi nearly similar in the sexes, both with the first joint distinctly thickened at tip beneath.

Male.-Elongate oval and more or less pointed posteriorly. Elytra more or less slightly wider than the thorax, evenly, obliquely, and arcuately declivous posteriorly, with the apex acute and more or less feebly produced. Abdomen moderately oblique and convex, feebly and broadly flattened on first two segments. Anterior femora armed with an obtuse tooth. Protarsi with the first joint feebly and transversely produced at apex beneath, plantar groove obliterated apically, space between the apico-marginal tufts of spinules simulating it.

Female.-Somewhat robust. Elytra rather broadly oval and wider than the prothorax, slightly pointed, arcuately and slightly obliquely declivous posteriorly. Abdomen horizontal, quite strongly and evenly convex. Profemora mutic, scarcely sinuate. Protarsi with the first joint distinctly and transversely produced at tip beneath, plantar groove quite obsolete. 
Measurements.-Males: Length, 18.5-19 mm.; width, 6.5-7 mm. Females: Length, 16-17 mm.; width, 6.5-7 mm.

Genital characters, male.-Edeagophore of the usual oblong-ovate form.

Basale variable, oblong, more or less feebly convex, with sides very slightly arcuate.

A picale triangular, sides nearly straight, slightly swollen toward base; apex more or less acute; base with middle lobe rather small and rounded, sinuate laterally; dorsal median groove moderately wide apically and linear toward base.

Clave stouter than usual, shorter and not so attenuate toward apex.

Sternite (Plate 2, fig. 11) with each lobe rather long, narrowing somewhat toward apex, the latter rounded; external border evenly arcuate, sometimes slightly angulate at middle, thence oblique and straight from angle to apex; internal border arcuate. Strongly chitinized, surface feebly convex and thickly set with long stiff setæ in apical half. Setæ do not extend across membrane at bottom of the sinus.

Female (Plate 2, figs. 12 and 13) genital segment triangular, not setose.

Valvula.-Dorsal plate nearly horizontal, feebly concave or convex, impunctate; extérnal border nearly straight and directly continuous with that of the apex, becoming slightly more prominent at the transitional point on account of the external margin of apex becoming slightly sinuate; internal margin slightly reflexed, feebly arcuate and directly continuous with the internal apical margin which is strongly arcuate on account of the excurvature; apical margin not in the least defined from apex, the dorsal surface of both being directly continuous, the transitional area forming a concave surface.

A pex produced, not strongly chitinized at base externally, excurved, dorsal surface more or less convex from side to side and directed upward and slightly outward; ventral surface concave, directed downward and inward; internal surface more or less membranous and set with very short chitinous setæ; tip narrowly rounded; fossa obsolete with surface not in the least excavated at its usual site.

Appendage minute and punctiform, without setæ and located on the external margin, projecting but slightly beyond the margins of its minute cavity.

Superior pudendal membrane attaining the middle of the dorsal plate.

Ventrolateral surfaces not inflated, not strongly convex and gradually tapering from base to apex; submarginal groove scarcely visible. Internal margins of the valves contiguous. 
Genital fissure closed and very narrow, finely setose within. Inferior pudendal membrane not visible when the valves are in adduction.

Habitat.-California (San Francisco all the year around; Alameda County; Trinity County, Dr. E. C. Van Dyke).

Number of specimens studied, 60.

Type probably in the Eschscholtz collection.

Type-locality.-Near San Francisco, California.

Salient type-characters.-Thorax subopaque, slightly transverse sides rounded, surface densely and more or less confluently punctate, scabrous and feebly impressed laterally along the margins. Elytra densely subscabrous with reclinate muricate granules, declivous and rather strongly acute behind. Anterior femora armed in the male; mutic in the female.

Diagnostic. characters.-Although usually smaller than scabricula, it is at times quite difficult to differentiate; this is best done by direct comparison: It is less strongly sculptured, thorax not so broad, antennæ more slender, shorter, decidedly so in the female, last joint of the labial palpi is narrower and less triangular, legs are more slender. The males have the elytra narrower, more obliquely declivous and acute at apex, and the profemora armed with an acute tooth.

The female has the elytra less broad, less suddenly, more obliquely declivous posteriorly and more produced. The profemora are mutic.

The female genital characters will always decide the diagnosis. In the male the femoral teeth are more acute in marginata than in scabricula. I believe that the genital characters are quite constant, for in the large series examined no mesotypical characters were observed.

Marginata is rather abundant when its habits are known. About San Francisco it is found around the roots of prostrate shrubs.

Mannerheim's fischeri was considered by LeConte as a large and well-developed form of marginata. The inaccessibility of the type precludes any efforts to determine its true relations. It might be a scabricula; if so Mannerheim's name would have priority over that of LeConte's.

General observations.-The mentum (Plate 6, fig. 20) has the middle lobe large and somewhat variable. Usually quite evenly rounded anteriorly, sometimes subtruncate, and again the sides may be somewhat straight; surface feebly convex and at times more or less foveate laterally. Lateral lobes rudimentary.

The anterior margin of the prosternum is more or less strongly deflexed. The prosternum and mesosternum the same as in scabricula.

The metasternum laterally between the coxæ is short, and equal in length to the width of a mesotibia at middle. 
The abdominal process is subquadrate and slightly transverse, its width is equal to the length of the third segment; the post-coxal part of the first segment is subequal in length to the third, the latter is one-third of its length shorter than the second; the fourth is a little more than one-half as long as the second.

The abdominal intercoxal salient is one-fifth of its width greater than that of the metasternal process.

The tibial grooves on all of the femora are quite strongly margined, distinctly concave and glabrous; the margins are subasperate and converge gradually to the femoral bases.

The anterior margins of the profemoral grooves are quite distinctly carinate and not very strongly dentately laminate at about the outer sixth, thence more or less obsolete to apex.

The external borders of the protibiæ are more or less subcarinate, those of the meso- and metatibiæ are rounded, muricately sculptured, and not in the least carinate.

The protibiæ are slightly compressed, the others subcylindrical. The tarsal grooves are more or less indicated on all of the tibiæ, but most marked on the anterior. These grooves are all asperately sculptured. On the protibiæ the more or less developed carinæ pass to the outer margin of the tarsal grooves, while the internal margins are more or less serrulate.

The anterior surfaces of the protibiæ are feebly subasperately sculptured, and the posterior surfaces are strongly asperate.

Tarsi somewhat slender and moderate in length.

The protarsi are about one-third of their length shorter than a mesotarsus. Joints 1 to 4, inclusive, are small, short, and slightly transverse; the first slightly the thickest and longest, the second, third, and fourth subequal in length.

A mesotarsus is equal in length to a metatarsus. Joint one slightly shorter than the third and fourth taken together; the second, third, and fourth subequal, short, and scarcely longer than wide; second slightly the longest.

A metatarsus is about one-third of its length shorter than its metatibia. Joint one equal to the next two taken together; second and third subequal in length.

\section{ELEODES SCABRICULA LeConte.}

Eleodes scabricula LeConte, Proc. Acad. Nat. Sci. Phila., 1858, p. 18т.

Discogenia scabricula LeConte, Smithson. Miscell. Coll., No. 167, 1866, p. 117.-Horn, Trans. Amer. Phil. Soc., XIV, 1870, p. 320.

Black, oblong-oval. Head nearly one-half as wide as the prothorax, plane to slightly convex, opaque, rather coarsely and irregularly punctate, punctures confluent laterally. Antenna not quite 
attaining the prothoracic base, outer four joints feebly compressed, slightly and gradually dilated, third joint scarcely as long as the next two taken together; fourth slightly longer than the fifth; the latter, sixth, and seventh subequal; eighth about as wide as long and subtriangular; ninth suborbicular in outline; tenth feebly transversely oval; eleventh ovate.

Pronotum opaque, widest at the middle and about one-half wider than long; disc evenly and moderately convex, rather coarsely, densely, and more or less confluently punctate, the punctures coalescing more or less transversely; sides broadly and slightly impressed throughout along the margins, and there finely scabrous from minute granules; apex moderately, broadly, and evenly emarginate, finely margined; sides evenly and broadly rounded, with the narrow margin reflexed; base very feebly arcuate, finely margined, and about onefourth wider than the apex; apical angles obtuse and more or less feebly rounded; basal angles obtuse and not in the least prominent.

Propleurce smooth, more or less opaque, very sparsely and irregularly granulate, more or less rugulose and concave beneath the apparently explanate pronotal margins.

Elytra oval, somewhat shining, widest at the middle; base not margined, slightly declivous, slightly wider than the contiguous prothoracic base; humeri very obtuse, scarcely evident; sides evenly arcuate, slightly convergent posteriorly, with apex rather broadly rounded; disc moderately convex and more strongly rounded laterally, arcuately declivous posteriorly; surface coarsely and somewhat densely punctate on the dorsum at center, becoming more and more scabrous laterally and about apex, the sculpturing consisting of densely placed reclinate and more or less muricate granules that are confused throughout. Frequently the dise is more or less flattened, and more strongly, less broadly, and somewhat more suddenly rounded laterally.

Epipleurce moderate in width beneath the humeri, and gradually narrowing to apex; surface rather thickly and submuricately punctate, the interstices glabrous and shining.

Sterna scabrous from irregularly placed setigerous punctures and rugæ.

Parapleurce coarsely punctate, frequently slightly muricate.

Abdomen more or less moderately, and rather densely muricately punctate, less so on the fourth and fifth segments, coarser and most scabrous on the first.

Legs moderate in length and thickness. Anterior femora more or less armed; anterior tibial spurs similar in the sexes, the anterior longer than the posterior, both acute. Anterior tarsi with the first joint more or less thickened at tip beneath and slightly dissimilar in the sexes. 
Male.-Elongate oval. Elytra scarcely wider than the prothorax, moderately convex, arcuately and obliquely declivous posteriorly and noticeably attenuate. Abdomen moderately oblique, not strongly convex, more or less broadly and obsoletely impressed on first two segments. Anterior femora armed with an obtuse tooth or simply sinuate. Anterior tarsi with the first joint slightly thickened at tip beneath, with small acute tufts of modified spinules at the apicomarginal angles; the tufts do not completely obliterate the plantar groove.

Female.-Robust. Elytra broadly oval and noticeably wider than the prothorax, convex, less attenuate at apex, arcuately and quite vertically declivous posteriorly. Abdomen rather strongly convex. Profemora slightly sinuate and with a small obtuse tooth, or entirely mutic. Protarsi with the basal joint distinctly thickened at tip beneath, and bearing a small tuft of modified spinules, plantar groove obliterated.

Measurements.-Males: Length, 16.5-23.5 mm.; width, $7.2-10 \mathrm{~mm}$. Females: Length, 20-23 mm.; width, 9-11 mm.

Genital characters, male.-Edeagophore elongately oblong-ovate and more or less arched.

Basale oblong-oval, moderately convex and variable; surface longitudinally grooved at middle in apical half.

A picale rather elongate, triangular, sides nearly straight, apex not produced; base moderately and distinctly lobed at the middle, sinuate laterally; dorsal surface moderately convex, with a moderately wide median groove extending from apex nearly to the base.

Sternite with lobes rather large, each distinctly longer than wide, rounded at apex, with the external margin nearly straight in basal half, thence arcuate; surface densely punctate and setose apically, setæ moderately long and dense at tip. Membrane not setose across the bottom of the sinus.

Female.-Genital segment subquadrate in outline exclusive of the apices, well chitinized, apex and dorsal plate continuous internally, not setose.

Valvula (Plate 4, fig. 1).-Dorsal plate horizontal and oblong; surface varying from feebly concave to slightly convex, occasionally with a few scattered punctures; external margin arcuate in apical moiety and more or less sinuate to the base in basal half, where the submarginal groove is visible from above, making somewhat of a sigmoid curve upon the basal prominence of the lateral plate; internal-margin slightly or not at all inflexed and feebly sinuous; apical margin feebly defined from the dorsal surface of apex internally, but distinct externally with the angle rectangular or narrowly rounded. 
A pex produced and completely chitinized, divergent and feebly decurved or recurved; dorsal surface convex, directed upwards and inwards; ventral surface concave and directed downwards and outwards; externally and caudad to the apical margin of the dorsal plate, deeply excavated forming a fossa, at margin of which is the minute subpunctiform appendage, that scarcely protrudes beyond the margins of its articular cavity, and frequently it bears a couple of short setæ at tip.

Superior pudendal membrane reaches to the middle of the dorsal plates, the latter being contiguous apically, but divergent basally. Internal valvular membrane set with few fine, short setæ.

Ventrolateral surfaces evenly convex, with surface lines straight when viewed longitudinally, rather deeply excavated beneath the apical half of the external margin of the dorsal plate, the excavation extending along the ventral surface of the apex.

Submarginal groove fine, sigmoid towards base. Internal margins of the valves contiguous; genital fissure a narrow cleft in apical third, the margins finely setose, setæ soft and scattered. Inferior pudendal membrane not visible.

Mabitat.-California (Lake Tahoe, Eldorado County, July, elevation 6,280 feet; Big Trees, Calaveras County, August, elevation 4,702 feet; Blood's Meadow, Alpine County, July, elevation 7,000 feet; Tuolumne County, D. W. Coquillet and E. C. Van Dyke; Colony Mills, Tulare County, elevation 5,415 feet, Charles Fuchs and Ralph Hopping; Fresno, Alameda, Marin, and Sacramento counties).

Number of specimens studied, 50.

Type (female) in the LeConte collection.

Type-locality.-Sacramento, California; collector, Mr. J. Wittick.

Salient type-characters.-Thorax opaque, transverse, sides rounded, densely and confluently scabro-punctate, on each side broadly impressed. Elytra densely scabrous with reclinate granules, declivous and acute behind. Anterior femora with an obtuse tooth (LeConte).

Diagnostic characters.-Scabricula has to be carefully separated from marginata, which it resembles more than any other species, and this can best be done by comparison: It is more roughly sculptured, usually larger, last joint of the labial palpi triangular, antennæ stouter and longer, thorax broader and the legs stouter, there is also less difference between the sexes.

The males have the elytra narrower and obliquely declivous posteriorly and produced apically; the females have broader elytra, which are more suddenly declivous posteriorly and scarcely produced apically, the anterior femora are feebly armed.

This species is undoubtedly characteristic of the western foothills of the Sierra Nevada Mountains and where the more typical form is 
found. Its presence about Sacramento and San Francisco Bay can undoubtedly be explained by carriage by the rivers that drain the western slopes of the mountains. Its area of distribution no doubt naturally overlaps that of marginata, the latter being a more or less maritime form. Specimens of scabricula indigenous to the valley regions are smaller and with greater difficulty separated from marginata.

The female genital characters are distinctive, those of the male are not.

A male example recently loaned to me by Mr. A. Koebele, presents varietal characteristics as follows: Form as usual, distinctly depressed on the elytra and pronotum, the latter distinctly sinuate before the basal angles, where the sides are parallel for a short distance; elytra densely, asperately muricato-tuberculate, base transverse and the humeri rather prominent and obtusely rounded, sides subparallel nearly as in producta. The protibiæ are suddenly and distinctly constricted at base as in Embaphion; this character is also observed in planipennis.

This form may be known as scabricula forma deplanata.

Habitat.-Napa County, California.

This specimen surely forms a connecting link betwen scabricula and planipennis. On the other hand it may be an aberration, and it remains for other examples to settle this question.

General observations.- The mentum has the middle lobe large and variable, usually rounded anteriorly from the middle; frequently subtrapezoidal and subtruncate anteriorly, even slightly emarginate at apex; surface may be feebly convex and simply punctate or more or less foveate laterally. The lateral lobes are very rudimentary.

The anterior margin of the prosternum is usually more or less stoutly deflexed; between the coxæ usually strongly arcuate and more or less vertically declivous posteriorly and not in the least mucronate. The surface may gradually slope downward and backward from the anterior margin to between the coxæ, with which it is quite prominent ventrally, but less suddenly so than in planipennis. The prosternum is frequently strongly grooved between the coxæ.

In a specimen from Plumas County there is a small but well marked mucro present. In some specimens from Tulare County (Colony Mills) the posterior margin is feebly compressed and quite vertical with a feeble attempt at a mucronate angle. The mesosternum is arcuately declivous and more or less concave.

The metasternum laterally between the coxæ is very short, about equal in length to the width of a mesotibia at apex.

The abdominal intercoxal process is subquadrate and slightly transverse; its width is equal to the length of the third abdominal segment; the post-coxal portion of the first segment equal to the 
length of the second, the third about equal to the fourth, the latter one-third of its length shorter than the second.

The abdominal salient is one-fifth of its own width greater than that of the metacoxal process.

The tibial grooves of the femora are distinctly concave, with well defined asperate or subserrulate margins. The margins of the anterior and middle grooves converge gradually to the femoral bases; those of the metafemora become evanescent at about the middle, thence to base the femoral surfaces are simply more or less flattened.

The grooves of the profemora have their anterior margins more or less dentately laminate at about the outer fifth.

The external surfaces of the protibiæ are subcarinate; those of the meso- and metatibiæ are rounded and scabrously sculptured, not in the least carinate. The protibiæ are slightly compressed; the others are subcylindrical in transverse section. The tarsal grooves are rudimentary on all of the tibiæ, but most marked on the protibiæ; all are roughly sculptured. On the protibiæ the more or less evident carina passes to the external margin of the groove, while the internal margin is quite distinctly serrulate.

The anterior surfaces of the protibiæ are much less roughly sculptured than the posterior surfaces.

The articular cavities of the protibiæ are partly closed, those of the mesotibiæ almost closed, and those of the metatibiæ entirely so.

Tarsi apparently variable in stoutness and independent of sex.

The protarsi about one-third of their length shorter than a mesotarsus. Joints 1 to 4, inclusive, are short and subequal in length; the first is apparently slightly longer and slightly produced beneath.

The mesotarsi are about one-fourth of their length shorter than a metatarsus. Joints 2 to 4, inclusive, are subequal in length and slightly longer than wide; the first is slightly longer and stouter.

The metatarsi are about two-fifths of their length longer than a protarsus and scarcely two-thirds as long as the metatibia. Joint one is distinctly shorter than the next two taken together; the second and third joints are subequal in length, and together about equal to the fourth.

\section{ELEODES PLANIPENNIS LeConte.}

Eleodes planipennis LeConte, Smithson. Miscell. Coll. No. 167, April, 1866. p. 116.-Horn, Trans. Amer. Phil. Soc., XIV, 1870, p. 316.

Elongate oval to ovate, more or less shining, elytra strongly depressed.

Head less than twice as wide as long, quite flat between the more or less prominent sides of the frons, finely and sparsely punctate, punctures denser laterally and on the epistoma. Antenne rather long, reaching a little beyond the prothoracic base, moderate in stoutness, 
scarcely compressed or incrassate, third joint slightly shorter than the next two taken together, fourth slightly longer than the fifth, the latter, sixth, and seventh subequal, eighth just a trifle shorter, ninth and tenth suborbicular, eleventh short-ovate.

Pronotum cordately and transversely oval, widest in front of the middle, where it is scarcely one-half wider than long; disc moderately and quite evenly convex, finely and rather sparsely punctate, narrowly impressed along the sides and feebly granulate; apex rather deeply and evenly emarginate, more or less obsoletely margined, and oneeighth wider than the base; sides evenly and strongly arcuate in anterior three-fourths, thence to base obliquely and more or less sinuate, margin feebly but distinctly reflexed to near the base, the latter quite truncate and one-sixth to one-fourth shorter than the length; apical angles quite acute, not rounded, and slightly prominent; basal angles quite rectangular, not prominent nor rounded.

Propleurce smooth and impunctate or sparsely and feebly muricatopunctate and rugulose.

Elytra oval, widest at the middle, less than twice as long as wide; base not emarginate, usually slightly wider than the contiguous prothoracic base; humeri rounded; sides evenly arcuate, apex feebly produced and narrowly rounded; disc quite flat, sometimes very feebly convex on the dorsum, laterally rather narrowly rounded and quite suddenly inflexed, especially near the humeri, inflexed sides quite plane and oblique, evenly and more or less gradually arcuately declivous posteriorly, feebly sinuate at apex; surface finely and scarcely densely muricately punctate on the sides and apex, sometimes quite densely so, punctures quite simple on dorsum along the suture.

Epipleura smooth, obsoletely and very sparsely punctate; moderate in width beneath the humeri, thence gradually narrowing to apex.

Sterna sometimes smooth, obsoletely punctate and rugose, at other times more coarsely sculptured.

Parapleura more or less indistinctly punctate.

Abdomen smooth, more or less dull in luster, very minutely, sparsely and more or less indistinctly punctate, more or less rugulose and horizontal.

Legs moderate in length and stoutness, rather densely sculptured. Profemora more or less sinuate in outer fifth. Protibiæ quite distinctly and rather suddenly constricted at base, the constriction opposed to the femoral sinuation; spurs similar in the sexes, slender and acute, the anterior slightly longer than the posterior. Protarsi nearly similar in the sexes.

Male.-Body somewhat narrow. Elytra rather obliquely to gradually declivous posteriorly. Abdomen very moderately convex and very feebly flattened at middle of the first two segments. Protarsi 
with the first two joints feebly but distinctly thickened at tips beneath, each bearing a small tuft of spinules at the apico-marginal angles, the second joint is less thickened than the first, in each instance obliterating the plantar groove.

Female.-Body quite broadly oval. Elytra rather evenly arcuately declivous posteriorly. Abdomen rather strongly convex from side to side. Protarsi with the first joint slightly thickened at tip beneath, bearing a small tuft of spinules.

Measurements.-Males: Length, 16-20 mm.; width, 6.8-8 mm. Females: Length, 16.2-19.5 mm.; width, 7.5-9 mm.

Genital characters, male.-Edeagophore rather small, narrow, oblong-ovate, slightly arched.

Basale oblong; surface not strongly convex, flattened more or less on the dorsum, sides nearly parallel.

A picale triangular, about one-half longer than wide, apical fourth more or less decurved; surface flattened, with a broad median membranous groove in basal half; sides nearly straight to tip, the latter broad and narrowly rounded; base rather narrowly lobed at middle and sinuate laterally.

Sternite slightly transversely quadrate in outline. Each lobe rather long, with external border straight or slightly sinuate in basal half, thence evenly arcuate to apex; internal border symmetrically curved with the external border, both borders meeting in a rather narrowly rounded apex; surface very feebly convex, smooth, impunctate, and glabrous in basal moiety, apically coarsely and sparsely punctate, not densely setose, setæ quite long. Sinus triangular, slightly closed at bottom by membrane which is not setose.

Female.-Genital segment (Plate 5, fig. 6) triangular in outline, about one-half longer than wide, strongly chitinized, glabrous, valves contiguous.

Valvula.-Dorsal plate elongately triangular, impunctate; surface directed slightly outward as well as upward; external border quite straight, slightly convergent to apex; apical border oblique, -angle rounded, internally continuous with the chitinous apex, the latter produced, moderately excurved, convex from side to side and concave beneath, thin and sublaminate at tip, where it is rather broad and rounded, internal surface moderately and finely setose, dorsally without setæ.

Appendage small and conical, bearing three or four long setæ at tip; fossa an excavation at base of the external surface of apex and contiguous to the apical border of the dorsal plate.

Superior pudendal membrane attaining the apical third of the dorsal plate and more or less longitudinally rugulose.

Basal prominences not developed. 
Ventrolateral surfaces.-Body triangular, with surface lines straight, evenly convex from side to side; surface smooth and impunctate; submarginal groove distinct and moderate beneath the narrowly expanded external margin of the dorsal plate, terminating at the fossa. Apex membranous beneath its chitinous and expanded dorsal surface, finely setose; ventral plate distinctly defined apically. Internal margins of the valves contiguous, fissure short and apical.

Mabitat.-Arizona (Williams, May, Barber and Schwarz; Southern, coll., E. C. Van Dyke; Chiricahua Mountains, June, Hubbard and Schwarz; at base of Humphreys Peak, August, elevation 9,500 feet, F. H. Snow) ; New Mexico (F. H. Snow; Hubbard and Schwarz; Coolidge; Magdalena, August, F. H. Snow, Warren Knaus) ; Colorado (Manitou, Packard).

Number of specimens studied, 25.

Type (female) in the LeConte collection.

Type-locality.-New Mexico.

Salient type-characters.-Head and thorax sparsely and finely punctate, subdepressed, apex broadly emarginate, base truncate, sides strongly rounded, posteriorly briefly sinuate, basal angles rectangular, small and not prominent. Elytra obliquely declivous behind and sinuately attenuate at apex, humeri obtuse, sides suddenly inflexed, along the suture finely punctate, at the sides and apex densely sculptured with small slightly elevated granules, anterior femora subsinuate (LeConte).

Diagnostic characters.-Quickly recognized from marginata and scabricula by the flattened elytral disc. The prothoracic apex is generally slightly wider than the base, the sides are evenly arcuate anteriorly and converge somewhat posteriorly, becoming slightly sinuate in front of the basal angles, which are rectangular; disc widest in front of the middle.

In some specimens the elytra are very feebly flattened-in fact, quite evenly but not strongly convex-and the smaller of such examples greatly resemble the elongate form of snowii found in Arizona. The genital characters must here be relied upon for their separation.

Planipennis has heretofore been considered a Blapylis. It is the nearest approach to Embaphion that we possess; in fact, it could with as much propriety form a section in the latter genus as the one in which it is now retained, and where it also must form a section intermediate between Discogenia and Embaphion. In genital characters it is an Embaphion, in facies an Eleodes.

The constriction of the anterior tibiæ at base is not peculiar to the genus Embaphion. It is observed to a greater or less degree in the different species of Blapylis; it is absent in the genus Eleodes, and 
appears to be a structural modification with a function whose analogy is found in the femoral teeth of that subgenus.

It might have been a wise course to have created a new genus for its reception, but I am opposed to contributing unnecessarily to an increase in the complexity of our terminology when relationships can be understood without it.

General observations.-Mentum variable, the middle lobe is rather large, usually rounded anteriorly; many examples have the anterior margin truncate and often distinctly emarginate, with sides arcuate or obliquely straight; surface may be feebly and evenly convex, to strongly foveate laterally, with a well-marked meridian ridge.

The prosternum is quite evenly rounded antero-posteriorly between the coxæ and very feebly widened behind the equator of the acetabula; it is quite prominent ventrally with the coxæ; posteriorly it is vertically and scarcely arcuately declivous. In the series at hand there is not the least sign of a mucro.

The mesosternum is arcuately declivous and more or less concave.

The abdominal intercoxal process is comparatively small, subquadrate, and equal in width to the length of the post-coxal portion of the same segment, the latter about equal to the length of the third; the second is one-third of its length longer than the third; the fourth is equal to half the length of the second.

The abdominal process is one-fifth of its width greater than that of the metasternal salient.

The metasternum laterally between the coxæ is short and about equal in length to the width of a mesotibia at middle.

The femora have their tibial grooves well defined and glabrous, their margins are rather thin and inwardly converging quite to the femoral bases. Those of the profemora have the anterior margins feebly laminate at the usual site of the femoral tooth.

The external surfaces of the tibiæ are more or less carinate, most marked on the protibiæ, which are also more or less compressed.

The tarsal grooves are more or less indicated on all of the tibiæ, frequently extending two-thirds of their lengths, most strongly developed on the protibia; frequently the meso- and metatibiæ are simply flattened externally.

Tarsi variable in stoutness, noticeably so in the larger specimens and somewhat slender in the smaller ones.

The protarsi are about one-fifth of their length shorter than a mesotarsus. Joint one distinctly longer than the second, the succeeding three about equal in length, just the least longer than wide; the fifth about as long as the preceding three taken together.

The mesotarsi are about one-tenth of their length shorter than a metatarsus. First joint about one and a half times longer than the second, the latter to the fourth inclusive subequal and distinctly 
longer than wide; fifth slightly longer than the preceding two taken. together.

The metatarsi are about three-sevenths of their length shorter than a metatibia. First and fourth joints subequal, each about equal in length to the second and third taken together; the latter two are subequal in length.

\section{UNRECOGNIZED SPECIES.}

ELEODES VICINA LeConte.

Eleodes vicina LeConte, Ann. Lyc. Nat. Hist., New York, V, 1851, p. 133.-Horn, Trans. Amer. Phil. Soc., XIV, 1870, p. 308.-Casey, Ann. New York Acad. Sci., V, Nov. 1890, p. 395.

\section{ELEODES NITIDA Casey.}

Eleodes nitida Caser, Ann. N. Y. Acad. Sci., VI, Nov. 1891, p. 58.

\section{ELEODES REFLEXICOLLIS Mannerheim.}

Eleodes reflexicollis Mannerherm, Bull. Soc. Moscow, XVI, 1843, p. 270. Genus EMBAPHION Say.

Embaphion SAY, Journ. Acad. Nat. Hist. Phila., III, 1824, p. 254.Lacordaire, Genera des Coléopt., V. 1859, p. 152.-LeConte, Classif. Coléopt. North Amer. (Smithson. Miscell. Coll.), 1861, p. 226-Hons, Trans. Amer. Phil. Soc. Phila., XIV, 1870, p. 320.-LeConte and Horn, Smithson. Miscell. Coll. No. 507, 1883, p. 374.

Thorax and elytra always acutely and sometimes broadly margined, margin more or less reflexed.

The epipleuræ always narrow, rarely defined from the inflexed sides of the elytra, except at apex, where they are always well defined, not suddenly widened at base and never attaining the humeral angles of the elytra.

The above characters are distinctive of the genus and are not observed elsewhere in the Eleodiini.

The constriction of the protibiæ at base is not peculiar to Embaphion, for it is also observed in Blapylis, and to a less degree in Discogenia.

The mentum presents no distinctive characters; it is as variable here as elsewhere. The middle lobe is somewhat larger than in the true Eleodes, slightly smaller than in Discogenia; although the lateral lobes are not so strongly evident as in Eleodes, they are larger than in the subgenus Discogenia.

The abdominal and metasternal processes are moderate and quite equal in width in the present genus, and this is also occasionally observed in Eleodes (fusiformis and opaca).

The profemora are always mutic; the tibial spurs are quite similar in the sexes. The anterior spurs of the protibiæ are never noticeably 
thickened, although slightly longer and larger than the posterior. The internal spurs of the meso- and metatibia are always slightly longer than the external. The tarsi are similar in the sexes and simple.

The abdomen is always on the same horizontal plane as the sterna; its segments are on the same plane in muricatum, contusum, contractum and planum; the third segment slightly oblique in glabrum and elongatum, and distinctly so in depressum.

The genital characters are quite characteristic and immediately follow planipennis of the subgenus Discogenia in the evolutionary series; they are very different from those observed in the remaining genera of the tribe, and only phyllogenetically related to Blaps.

The generic genital characters are as follows:

Male.-A picale of the edeagophore triangular; dorsal surface more or less strongly convex, and without median groove; sternite bilobed; lobes united by a membranous interval.

Female.-Genital segment triangular, or without the apices triangulo-trapezoidal, somewhat depressed; dorsal surface quite plane, not setose. Apices of the valves produced, chitinous, more or less everted, convex above and concave beneath. Valves contiguous beneath; inferior pudendal membrane not visible. Genital fissure narrow and subapical.

Superior pudendal membrane reaching to about the middle of the dorsal plates. Appendages short mammilliform, with a pencil of rather long hairs at their tips.

Although the genital characters present slight specific differentiation, they can not at present be tabulated so as to be of any practical use.

The species should be arranged in the following morphological sequence: depressum, elongatum, glabrum, contractum, planum, contusum, and muricatum. This is also an evolutionary series indicating genealogical relationship with Discogenia.

Such an arrangement will present to the notice of the student that there is a gradual increase of the foliaceous margin from depressum to muricatum; as a consequence of this the apical emargination of the prothorax will increase from a simple broad shallow emargination of the apex, so obvious in Eleodes, to the deep notch with almost parallel sides, about equaling in depth the length of the head, as seen in muricatum.

In the narrowly margined species the prothorax is much broader than long (depressum), and with an increase in the width of the margin the pronotum proper becomes narrower, even longer than wide.

The epipleural line follows the same rule; in the very narrowly margined species it is quite distinct, and indicated in the whole 
course either by a faint groove or a distinctly elevated line; it becomes almost entirely absent in the broadly margined species. In the middle of the series the marginal line of the elytra does not attain the apex (glabrum, contractum, and planum); at the extremes of the series it does.

In those species with feeble elytral margin the humeral angles are more distinct and even prominent (depressum), and less so as the margins increase. Note again what has already been said relative to the obliquity of the third abdominal segment (see p. 451 and below).

Genealogy.-The scheme herewith presented illustrates what has already been said above relative to the apparent progressive differentiation of the species.

The two species which form the extremes of the whole series are the most distinct, not only from each other, but from the other members of the same dichotic stem of the ancestral trunk.

Muricatum has the broadest foliaceous margin; the basal angles

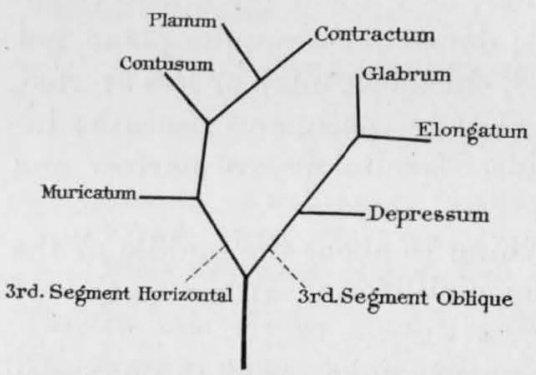

Fig. 8.-Genealogical diagram of the GENUS EMBALPHION. of the pronotal margin project backward over the humeral angles of the elytra; the anterior tibiæ are not carinate externally.

Depressum has the narrowest margin; elytral base more distant from the prothorax, and quite densely seulptured.

In each hemi-series the marginal line decreases - that is, strongest in muricatum, weakest at apex in contractum; strongest in depressum, weakest at apex in glabrum.

It can be assumed that the acquisition of the obliquity of the third segment might determine the lines of divergence from the ancestral trunk.

A careful consideration of the diagram in connection with the characters enumerated under the specific headings should further elucidate the interesting relationships.

Distribution.-Thus far I have studied material from the following States and Territories: California, Arizona, Nevada, New Mexico, Texas, Colorado, Kansas, Nebraska, Wyoming, and South Dakota.

It will be observed that Embaphion has a large area of distribution-approximately two-thirds of the region west of the Mississippi River, not entering the region west of the Sierra Nevada Mountains, nor the extreme northwestern and northern States.

Depressum from eastern central California.

Elongatum from eastern northern California and western Nevada. 
- Glabrum from Arizona and New Mexico.

Contractum from New Mexico.

Planum from Kansas and Wyoming.

Contusum from Arizona, New Mexico, Colorado, Kansas, and Wyoming.

Laminatum from Texas.

Muricatum from Texas, Colorado, Kansas, Nebraska, and South Dakota.

The data here given are suggestive and I shall refrain from making any further comments upon specific distribution until more collecting shall have been done, and it is to be hoped that future collectors will be careful in giving full accounts of locality and elevation.

\section{ANALYTICAL KEY TO SPECIES OF GENUS EMBAPHION.}

Hind angles of prothorax subacute and overlapping the humeral angles of the elytra; body broadly margined. muricatum.

Hind angles obtuse not overlapping the humeral angles; body acutely but not broadly margined.

Thorax sparsely and not coarsely punctured, distinctly margined; not distant from the elytra; legs black.

Elytral margin attaining apex.

Broadly oval; males distinctly caudate

contusum.

Elongate oval; elytra gradually narrowed

elongatum.

Elytral margin not attaining the apex.

Thorax with a moderate foliaceous margin; elytral dise more or less concave, smooth and obsoletely sculptured -glabrum.

Thorax with margin acute, not foliaceous; elytral dise flat or feebly convex.

Acute margin not attaining the apex---------_contractum.

Acute margin attaining the apex

Thorax very coarsely punctured, slightly distant from elytra, the lattel broadly oval, subrugose; legs ferruginous brown ________-_depressum.

\section{EMBAPHION DEPRESSUM LeConte.}

Eleodes depréssa LeConte, Ann, Lyc. Nat. Hist. N. Y., V. 1851, p. 136.

Embaphion depressum LeConte, Smith. Miscell. Collections, No. 140, 1866, p. 60.-Honn, Trans. Amer. Phil. Soc. Phila., XIV, 1870, p. 322.

Rather robust, ovate, black, thin margin of the body almost totally wanting; thorax and elytra slightly distant.

Antenno moderately long and somewhat stout, basal joints moderately pubescent, last three joints slightly thickened.

Prothorax about one-third wider than long, slightly narrowed behind; disc moderately convex, very coarsely punctate; apex rather feebly emarginate; sides moderately rounded, with margin feebly reflexed; base with the middle slightly prominent; basal angles obtuse.

Elytra broadly oval, acutely margined, the marginal line reaching the apex; base emarginate; humeral angles prominent; sides strongly 
rounded, gradually narrowing to apex; disc scarcely convex, acutely inflexed at the sides, sculptured with rows of moderately coarse punctures, bearing short hairs, and more or less distinctly rugose.

Epipleurce with superior marginal line distinctly elevated.

Abdomen with the third segment placed more or less obliquely to the second. Legs ferruginous brown.

Male.-Third abdominal segment distinctly obliquely placed to the second. Anterior tibiæ suddenly and briefly sinuate at base.

Female.-Third abdominal segment slightly oblique to the second. Anterior tibiæ gradually narrowing at base.

Measurements.-Length, .38-.44 inch.

Habitat.-California (Vallecito, LeConte; Maricopa Desert, Horn).

Unknown to me in nature. Extremes of this species should always be carefully compared with those of E. planipennis.

\section{EMBAPHION ELONGATUM Horn.}

Embaphion elongatum Horn, Trans. Amer. Phil. Soc. Phila., XIV, 1870, p. 321.

Elongate, oblong-oval, nearly three times longer than wide, margins of body not foliaceous, surface dull, acute elytral margin reaching to the apex; usually finely sculptured.

Head small, scarcely twice as wide as long, quite flat, impressed laterally within the supra-antennal convexities, the latter quite prominent, impression extending more or less feebly along the frontal suture; surface finely, sparsely, irregularly and muricately punctured, obsoletely so at times. Antennce long, reaching beyond the prothoracic base, outer four joints feebly compressed, scarcely widened, third joint equal to the next two combined, fourth to the seventh, inclusive, subequal; eighth slightly compressed and subtriangular; ninth circular, and at times slightly widened; tenth suborbicular; eleventh oval to ovate.

Pronotum about one-fourth wider than long, evidently narrowed behind; margin acute, moderately explanate, more or less reflexed; disc feebly to moderately convex, finely and sparsely asperately punctate, granular laterally on the margins; apex more or less moderately emarginate - the emargination less than one-third to onefourth wider than deep, obsoletely margined; sides evenly and moderately arcuate from apex to base; base proper truncate to feebly arcuate and about equal to the apex proper, obsoletely margined; apical angles narrowly rounded, subacute, attaining the eyes; basal angles obtusely rounded and projecting slightly beyond the middle of the base.

Propleurce more or less concave beneath the margin at point of reflexion, surface smooth, opaque and very sparsely, finely punctulate. 
Elytra elongate oval, fully twice as long as wide; base subtruncate, feebly sinuate laterally; humeral angles more or less distinct; margin acute, not foliaceous nor suddenly formed, evenly and gradually reflexed and attaining the apex; sides feebly arcuate, gradually narrowing to apex and attenuately converging, apex acute and not produced; disc more or less concave, suture frequently raised posteriorly ; here the disc is more or less biconcave, gradually, evenly areuately declivous behind, acutely inflexed laterally, the inflexed sides moderately oblique and plane; surface sculptured with fine, irregularly, sparsely, and evenly placed, subasperate punctures, the inflexed sides similarly sculptured; each puncture bears a very minute decurved seta.

Epipleurce narrow, scarcely at all differentiated from the inflexed sides of the elytra and similarly punctured; distinctly defined at apex and feebly, minutely dilated beneath the elytral apices.

Stema opaque and finely, irregularly sculptured.

Parapleura opaque and obsoletely punctate.

Abdomen opaque, finely, rather evenly and not densely punctulate; first two segments horizontal, third slightly oblique, last two much less convex.

Legs long and rather slender; posterior femora usually as long as the first four abdominal segments; profemora mutic; tibial spurs quite similar and the protarsi simple.

Male.-Elongate and rather narrow. Abdomen quite strongly convex, median surface of the first three segments more or less broadly and feebly impressed. Anterior tibiæ suddenly and briefly constricted at base.

Measurements.-Males: Length, 15-20 mm.; width, 6-8 $\mathrm{mm}$.

Genital characters, male.-Edeagophore elongately subfusiform, six to eight times longer than wide, more or less arched.

Basale elongate, about five times longer than wide; sides subparallel to slightly arcuate; surface transversely and moderately convex, distinctly membranous centrally at the distal extremity.

A picale rather slender, elongately triangular; dorsal surface moderately convex, with a median linear groove at middle two-thirds, very sparsely and finely punctulate; sides briefly arcuate at base and middle, with intervening edge and side of apex feebly sinuate; apex subacute and slightly produced; base distinctly bisinuate with a median subacute lobe.

Sternite subparabolic in outline, circularly concave at middle like a watch-glass between the bases of the lobes. Each lobe triangular and distinctly longer than wide; external border evenly arcuate, apex subobtusely rounded, and the internal border straight or feebly sinuate; surface more or less convex, concave internally to sinus, basal third smooth and almost impunctate, apical two-thirds densely 
punctured and clothed with quite long setæ. Sinus triangular, twothirds closed by membrane, the latter setose.

Habitat.-Nevada (Horn; Hubbard and Schwarz); California (Lassen County, Charles Fuchs).

Number of specimens studied, 2 (males).

Type in the Horn collection; collected by Mr. William M. Gabb.

Type-locality.-Western Nevada.

Salient type-characters.-The most elongate of our species. Prothoracic margin acute, moderately explanate and reflexed. Elytra with margin simply acute and extending to apex. Epipleuræ indistinctly defined except at apex.

Diagnostic characters.-The elongate form, with elytra gradually and arcuately narrowing to apex give a characteristic facies.

Separated from contusum by its narrower form, besides the body has a greater dorso-ventral thickness, and the males are not caudate. In planum the elytral margins do not reach the apex, in elongatum they do. From depressum by its elongate oval elytra, obsoletely defined epipleuræ and by having the basal joints of the antennæ less pubescent.

General observations.-The mentum is rather small, middle lobe variable, sides converging anteriorly, straight or more or less arcuate, with apex rounded or subacute; surface very slightly convex and more or less feebly foveate laterally.

The prosternum is arcuately prominent ventrally with the coxæ, feebly compressed and sometimes subvertically truncate posteriorly.

Mesosternum arcuately declivous and rather deeply concave.

The abdominal intercoxal salient is small and quite quadrate, onehalf of its width shorter than the post-coxal portion of the same segment, the latter subequal in length to the second; third segment a little shorter than the second; the fourth is one-half the length of the second.

The abdominal and metacoxal salients are quite equal in width.

The metasternum laterally between the coxæ is short and equal in length to the width of a mesotibia at middle.

The tibial grooves of the femora are well developed, more or less concave externally, becoming flat internally, glabrous and impunctate; margins distinct, more or less acute and gradually converging to the femoral base.

The protibiæ are distinctly compressed, and carinate externally; carina quite entire, surface longitudinally grooved behind the same, groove asperately sculptured.

Meso- and metatibiæ subcylindrical in section, flattened or grooved externally, grooves opaque, glabrous and more or less punctate.

The tarsi are moderate in length and stoutness. 
Protarsi about one-fifth of their length shorter than a mesotarsus. First four joints short, subequal in size and length, the first not noticeably longer, each just a little wider than long; the fifth equal to about the preceding three in length.

Mesotarsi about one-fourth of their length shorter than a metatarsus. The first joint just the least shorter than the next two combined; joints two to four inclusive about equal in length and just a little longer than wide; the fifth about equal to the preceding two combined.

The metatarsi are slightly more than one-half as long as a metatibia. The first joint is just a little shorter than the next two combined; the second and third subequal and distinctly longer than wide, both together equal to the fourth.

\section{EMBAPHION GLABRUM, new species.}

Suboblong oval, twice as long as wide, nigro-piceous, surface more or less shining, quite smooth, obsoletely sculptured, margins of the pronotum moderately reflexed.

Head about twice as wide as long, plane or feebly convex, slightly impressed laterally, sometimes along the frontal suture, sides not strongly prominent, obsoletely punctulate. Antenno rather slender and equal in length in the sexes, reaching slightly beyond the prothoracic base, very slightly compressed in outer four joints, which are also feebly dilated, third joint equal to the next two taken together, fourth scarcely longer than the fifth, sixth and seventh very slightly shorter and subequal, eighth subtriangular, ninth and tenth suborbicular, eleventh ovate.

Pronotum proper slightly wider than long and about as wide as one elytron, margins thin and moderately foliaceous, reflexed and concave; disc moderately convex, smooth and obsoletely punctulate, laterally obsoletely granulate and rugulose; apex moderately deeply emarginate, the emargination about four times wider than deep, obsoletely margined; sides evenly rounded from base to apex, not noticeably widening at base; base truncate and about equal to the apex proper, finely margined; apical angles moderately rounded, reaching to the eyes; basal angles rounded and slightly more prominent posteriorly than the base.

Propleurce smooth and impunctate.

Elytra oval, width equal to about two-thirds of the length, margins acute, slightly reflexed and not quite attaining the apex; base subtruncate; humeri proper obtuse and rounded, not anteriorly prominent; sides quite evenly but not strongly arcuate, apex simply subacute; disc smooth, more or less transversely concave or feebly biconcave, sometimes plane between the reflexed margins; frequently 
slightly and briefly arcuately declivous at base, and arcuately declivous posteriorly as usual; inflexed sides not strongly oblique, quite plane at the middle, feebly concave beneath the humeri and distinctly so where it passes into the apex; surface smooth and obsoletely punctate, inflexed sides smooth and impunctate.

Epipleurce smooth, impunctate and obsoletely defined, except at apex; surface on the same plane as the inflexed sides of elytra.

Sterna and parapleurce smooth and more or less obsoletely sculptured.

Abdomen obsoletely sculptured and smooth; third segment more or less oblique to the fourth and fitth segments which have a feeble transverse convexity.

Legs moderate in length and thickness. Anterior femora mutic, tibial spurs quite similar and the tarsi are alike in the sexes, and simple.

Male.-Elytral disc rather obliquely arcuately declivous posteriorly, apex acute and just noticeably produced. Abdomen moderately convex and broadly impressed on first two segments. Protibiæ briefly and moderately constricted at base.

Female.-Elytral dise areuately and more or less vertically declivous behind, apex simply subacute, abdomen rather strongly convex. Protibiæ gradually and feebly narrowed at base.

Measurements.-Male: Length, $17 \mathrm{~mm}$; width, $8.2 \mathrm{~mm}$. Females: Length, $15-17 \mathrm{~mm}$.; width, $7.5-8.5 \mathrm{~mm}$.

Genital characters, Male.-Edeagophore elongate subfusiform, six to eight times longer than wide and more or less arched.

Basale elongate and about five times longer than wide, sides more or less feebly arcuate, surface moderately convex.

A picale elongately triangular; dorsal surface moderately convex, without median groove (in the few specimens examined), impunctate; sides broadly and feebly sinuate; apex subacute and rather slender; base bisinuate with a median triangular lobe.

Sternite as in elongatum.

Female.-Genital segment triangular in outline, rather elongate, surface quite plane and not setose.

Valvula (Plate 5, fig. 14).-Dorsal plate oblong-triangular; surface very slightly concave, smooth, obsoletely and sparsely punctate; external border more or less sinuate; internal border very feebly areuate; apical margin short and more or less feebly rounded or truncate, directly continuous with the dorsal surface of the apex in the internal third, angle rounded, not setose. Apex chitinous, produced and arcuately everted, convex above and concave beneath, tip rounded, excavated externally at base for the appendage, the latter rather short mammilliform, with a few moderately long setæ at tip. Basal prominences obsolete. 
Superior pudendal membrane attaining the middle of the dorsal plate, finely and longitudinally rugulose.

Ventrolateral surfaces.-Body somewhat depressed, surface lines straight when viewed longitudinally, moderately convex transversely, smooth and shining; submarginal groove distinet beneath the not explanate external margin of the dorsal plate. Internal margins of the valves contiguous in basal four-fifths. Fissure very narrowly fusiform in apical fifth, membrane not visible.

Habitat.-Arizona (Winslow, Barber and Schwarz; Holbrook, H. F. Wickham); New Mexico (Coolidge, Wickham).

Number of specimens studied, 7.

Sexitypes (Cat. No. 12235) in the U. S. National Museum collection. Type-locality.-Winslow, Arizona.

Salient type-characters.- Surface smooth, more or less shining and obsoletely seulptured. Pronotum with the lateral margins thin and moderately foliaceous, reflexed and concave. Elytral margins acute, slightly reflexed and not quite attaining the apex; disc more or less slightly concave.

Diagnostic characters.-Conspicuous on account of its smooth integuments and entire absence of the short setæ that are so noticeable in all of the other species. The body has a much greater dorsoventral thickness than any of the species before me. The sexes are also less differentiated than in any other. It differs from contusum, elongatum, and depressum in not having the marginal lines of the elytra attain the apex. From planum by its moderately foliaceous prothoracic margins, more or less concave elytral disc and in the smooth and obsolete sculpturing.

Glabmum appears more robust than any other form on account of the unusual dorso-ventral thickness.

General observations.-Mentum with the middle lobe slightly smaller than usual, subtruncate anteriorly and feebly straightened laterally, the sides oblique and converging to apex, the outline is more semicircular than otherwise; surface smooth and somewhat punctate laterally.

The prosternum is quite prominent ventrally with the coxæ, arcuate antero-posteriorly and rather vertical posteriorly, not in the least mucronate.

Mesosternum arcuate and more or less vertically declivous, longitudinally concave.

The abdominal process is slightly transverse, in width scarcely as long as the third abdominal segment; the post-coxal portion of the first about equal to the second, the latter is twice as long as the fourth; the third is about one-half of its length shorter than the second segment.

The abdominal and metasternal salients are equal in width. 
The metasternum laterally between the coxæ is short, in length about equal to the width of a mesotibia at middle.

The tibial grooves of the femora are entire, glabrous, flat to more or less concave, their margins moderate to feeble and acute, converging to the femoral base in each, where they are scarcely contiguous.

The external surfaces of the tibiæ are as in planum.

The tarsi moderate as usual.

The protarsi are about one-fourth of their length shorter than a mesotarsus. First four joints small and subequal, the first distinctly longer than wide, second, third, and fourth as wide as long; the fifth about equal in length to the preceding three combined.

The mesotarsi are about one-fifth of their length shorter than a metatarsus. The first joint is about one and a half times longer than the second; joints two to four inclusive are subequal in length and a little longer than wide; the fifth about equal in length to the preceding three taken together.

The metatarsi are about two-thirds as long as their respective metatibia. The first joint is about equal to the second and third combined; the fourth equal to the first; the second and third are subequal in length and about one and a half times longer than wide.

EMBAPHION CONTRACTUM, new species.

Oblong-oval, piceous black, feebly shining to subopaque, sides of the body not foliaceous, acute elytral margin not attaining the apex; pronotum constricted in basal eighth; each puncture with a very short, semierect seta.

Head moderately large, more or less plane to feebly convex between the eyes, rather broadly and distinctly impressed within the supraantennal convexities, frontal suture more or less feebly evident; surface sparsely, irregularly, and somewhat finely punctate, punctures slightly denser at the periphery.

Antennce long and moderately slender, outer four joints feebly compressed and scarcely dilated; third joint equal to the next two taken together; fourth scarcely longer than the fifth; the latter to the seventh, inclusive, subequal in length; eighth subtriangular and longer than wide; ninth and tenth very feebly transversely oval; eleventh pointed ovate and scarcely longer than wide.

Pronotum with the total width about one-half greater than the length, margin acute and not foliaceous; disc proper about as wide as long, moderately, broadly, and evenly convex, sparsely, irregularly, and not strongly punctate, with a more or less feeble transverse antibasal impression, laterally rather broadly impressed or feebly concave within the slightly reflexed acute margins, surface here more opaque and obsoletely sculptured; apex broadly, evenly, and moder- 
ately emarginate, evidently not beaded; sides evenly and moderately arcuate to the basal seventh or eighth, there quite abruptly constricted with sides parallel or slightly convergent to base, the latter slightly arcuate and rather coarsely but not strongly beaded, equal in width to the apex; apical angles very narrowly rounded; basal angles subrectangular.

Propleurce smooth, opaque, and obsoletely sculptured.

Elytra oblong-oval, widest at the middle, a third of the length longer than wide; base feebly emarginate between the rather broadly rounded and slightly more anteriorly prominent humeri; sides evenly and moderately arcuate, more strongly convergent in apical fourth where they are feebly and broadly sinuate, the apex appearing somewhat produced and subparabolically rounded; disc flat to feebly convex, limited laterally from the obliquely inflexed sides by an acute margin, that does not attain the apex, arcuately declivous posteriorly in apical third; surface irregularly and not densely subasperately punctate, at times there is a distinct tendency to a serial arrangement, the punctures are slightly denser and a little more muricate at the periphery, the acute margin is subserrulate; inflexed sides more or less obsoletely punctate.

Epipleurce narrow and not dilated at the base, gradually narrowing to apex; surface smooth and impunctate; superior margin not defined in basal half, thence to apex well developed.

Sterna quite smooth and more or less obsoletely sculptured.

Parapleurce rather coarsely and more or less obscurely punctate.

Abdomen smooth, very sparsely and finely punctulate, more or less obsoletely rugulose; punctules more distinct and denser on the fifth segment.

Legs slender and moderate in length, femora mutic, anterior tibial spurs subequal and the tarsi similar in the sexes.

Male.-Unknown to me, the secondary sexual characters are probably as in planum.

Female.-Moderately broad. Abdomen not very strongly but evenly convex. Anterior tibiæ quite gradually and slightly sinuate at base.

Measurements.-Males: Not studied. Females: Length, 18-21.5 $\mathrm{mm}$; width, 9-10 $\mathrm{mm}$.

Genital characters, male.-Not studied.

Female.-Genital segment elongate and triangular in outline, dorsal surface more or less transversely ogival in section, impunctate and not setose.

Valvula (Plate 5, fig. 20).--Dorsal plate oblong-triangular, about four times longer than wide; surface feebly convex basally and concave apically; external border more or less sinuous; internal border nearly straight and somewhat beaded; apical margin arcuate in 
external two-thirds, becoming continuous internally with the inner margin of the fossa. Apex produced and not everted, sides subparallel, externally continuing the line of the dorsal plate, tip rather broadly rounded, dorsal surface concave; internally the valvular membrane is finely setose and semi-chitinous caudad to the pudendal membrane.

Appendage short and nearly hemispherical, projecting very little beyond the fossa, setose at tip, setre long forming a loose pencil. Fossa rather broad and not sharply defined.

Superior pudendal membrane reaching to the apical fourth of the dorsal plate and longitudinally rugulose.

Basal prominences scarcely at all prominent.

Ventrolateral surfaces transversely convex, surface lines straight when viewed longitudinally, concave apically before the apices. Submarginal groove distinct beneath the feebly explanate external margin of the dorsal plate. Internal margins of the valves contiguous in basal two-thirds; genital fissure very narrow in apical third. Inferior membrane not visible.

Habitat.-New Mexico (Cloudcroft, elevation 9,000 feet).

Number of specimens studied, 7 (females).

Types in my own collection.

Type-locality.-Clouderoft, New Mexico; collector, Warren Knaus.

Diagnostic characters.-The seven specimens studied are homomorphic and distinct from their congeners. The shortening of the expanded pronotal margin is quite remarkable, and the basal constriction causes the prothorax to appear more distant from the elytra than in depressum.

In fact, the form of the prothorax is an approach to that observed in Eleodes planipennis. Contractum appears as a step toward the bridging over of the gap between Eleodes planipennis and Embaphion. It is also significant that both should inhabit the same geographical region. Some specimens of planipennis exhibit a tendency to a thinning and reflexion of the pronotal margins, but never to an acuteness of the elytral margins. When such examples are found planipennis must be referred to Embaphion.

In depressum the acute elytral margin attains the apex, in contractum it does not.

In planum the acute and expanded pronotal margins reach to and slightly beyond the base, while in contractum they are abbreviated posteriorly and not extending beyond the basal seventh or eighth, the true basal angles being exposed.

Contractum is without doubt an extreme and perpetuated modification of planum. In the series of contractum examined the abdominal segments are not oblique. 
I am indebted to Mr. Warren Knaus for this interesting addition to our list.

General observations.-The mentum is rather small, feebly transverse, more or less arcuate anteriorly, although at times apparently subtruncate, sometimes feebly impressed at apex so as to appear somewhat emarginate; surface feebly convex, glabrous, and obsoletely punctate at center, narrowly impressed peripherally within the margin, there opaque and distinctly punctate.

Prosternum less suddenly protuberant ventrally than in planum, otherwise the same.

The mesosternum is quite vertical and arcuately declivous, more or less concave as usual.

The metasternum laterally between the coxæ is as long as the width of a mesotibia at apex.

The metasternal and abdominal salients are quite equal in width. The abdominal process is a little longer than wide. The post-coxal portion of the first abdominal segment is about equal to the third in length; the second is about twice as long as the fourth segment.

The tibial grooves of the femora are well developed, more or less concave, but not strongly so. The margins are subcariniform externally, becoming more or less evanescent internally. On the profemora the grooves have the margins slightly arcuate and about attaining the femoral base; those of the meso- and metafemora have the margins quite straight, scarcely attaining the base on the former and evanescent at basal fifth on the latter.

The protibiæ are feebly compressed and distinctly carinate externally; tarsal grooves more or less obsolete, articular cavities closed. On the meso- and metatibiæ the grooves are more or less developed and narrow on apical two-thirds, slightly glabrous, margins asperate, and the articular cavities are closed.

The tarsi are the same as in planum.

The protarsi are about two to three-fifths of their length shorter than a mesotarsus, joints two to four subequal in length and scarcely as long as wide; the first joint is a little longer than wide; the fifth is just the least longer than the three preceding joints taken together.

The mesotarsi are about two-fifths of their length shorter than a metatarsus. Joints two to four, inclusive, are subequal in length and slightly longer than wide; the first joint is about one-half longer than wide; the fifth is slightly shorter than the preceding three joints taken together.

The metatarsi are distinctly more than a half longer than their respective tibia. Joints two and three are subequal in length and distinctly more than one-half longer than wide, and together as long as the fourth; the first is scarcely as long as the next two taken together. 
EMBAPHION PLANUM Horn.

Embaphion planum Horn, Trans. Amer. Phil. Soc. Phila., XIV, 1870, p. 321.

Oblong-oval, about twice as long as wide; margins of body not foliaceous, acute elytral margins not attaining the apex; surface more or less dull.

Head moderate, about twice as wide as long, quite plane between the eyes, feebly impressed laterally; sides of the frons slightly prominent, finely, rather sparsely punctate, each puncture with a minute curved seta, frontal suture at times distinct, sometimes slightly impressed. Antenna quite long; outer four joints scarcely compressed or widened; third joint about equal to the next two taken together; fourth to the seventh, inclusive, subequal; eighth triangular; ninth and tenth suborbicular; eleventh ovate.

Pronotum one-sixth to one-half wider than long and slightly narrowed behind; margin acute, not foliaceous nor suddenly formed; disc feebly convex, finely and rather sparsely punctate, punctures becoming slightly denser laterally, each with a small curved seta; apex evenly but not deeply emarginate, the emargination four or five times wider than deep, usually very finely margined; sides evenly and moderately arcuate from base to apex; margin slightly explanate, widening a little posteriorly, feebly reflexed; base distinctly shorter than apex, transverse, and obsoletely margined; apical angles obtusely rounded, attaining the eyes; basal angles obtuse, rounded, and projecting slightly beyond the middle of the base.

Propleurce smooth, impunctate, and obsoletely rugulose, defined from the inferior surface of the pronotal margin by a shallow groove.

Elytra elongate oval, base at middle slightly prolonged and feebly sinuate laterally; humeral angles distinct and rounded; margin acute, feebly reflexed and not attaining the apex; sides evenly arcuate, gradually converging apically; apex acute and not caudate; disc flattened, at times feebly convex, never concave, evenly and rather gradually arcuately declivous posteriorly; acutely inflexed laterally, the inflexed sides feebly convex; surface sculptured with subasperate punctures, that may be serially arranged or irregular and somewhat denser laterally; the inflexed sides are irregularly and rather sparsely punctate. Each puncture bears a short curved seta.

Epipleurce narrow and not dilated at base, gradually narrowing to apex; superior margin distinctly defined; surface glabrous and impunctate.

Sterna more or less feebly punctate and rugulose, feebly shining.

Parapleurce quite glabrous, feebly and obsoletely punctate.

Abdomen horizontal, more or less shining, sparsely or not very densely punctulate, obsoletely rugulose.

Legs moderate and rather slender, anterior femora mutic, tibial spurs similar and the protarsi simple in the sexes. 
Male.-Somewhat narrow. Antennæ reaching considerably beyond the prothoracic base. Abdomen moderately convex, first three segments rather broadly impressed along the middle. Protibiæ suddenly and briefly sinuate at base.

Female.-More robust. Antennæ reaching slightly beyond base of the prothorax. Abdomen rather strongly corvex. Protibiæ gradually narrowing at base.

Measurements.-Males: Length, 14-19.5 mm.; width, 6-9 mm. Females: Length, 13.2-17 mm.; width, 7-8.5 mm.

Genital characters, male.-Edeagophore very slender, elongate, and moderately arched.

Basale about five times longer than wide, rather strongly convex from side to side, the latter feebly arcuate.

A picale small, triangular, slightly elongate; surface rather strongly convex and without groove; sides feebly and broadly sinuate; apex gradually attenuated and acute; base with a rather short, subacute lobe at middle and feebly sinuate laterally.

Sternite transversely triangulo-parabolic in outline. Each lobe triangular, with external border more or less arcuate to apex, the latter subacute and rather gradually narrowed; internal margin nearly straight and oblique; surface more strongly convex along the external border, thence sloping inward, rather densely punctate in apical two-thirds, setose, setæ long and rather dense, especially in apical third. Sinus more or less semicircular, membrane more or less setose across the same.

Female.-Genital segment (Plate 5, fig. 9) triangular, surface quite plane, impunctate and not setose.

Valvula.-Dorsal plate elongately subtriangular, moderately narrowed from base to apex; surface plane and glabrous; external border more or less feebly sinuate; apical margin truncate at middle, internally continuous with surface of the apex, angle evenly rounded; internal margin very feebly arcuate. Apex produced and chitinous, more or less everted; convex above and concave beneath, tip rounded. Fossa at base of the external surface of apex and beneath apical margin of dorsal plate.

Appendage short mammilliform, with a pencil of four or five rather long setæe at tip.

Basal prominences moderately developed.

Superior pudendal membrane attaining the apical fourth of the dorsal plate, and longitudinally rugulose.

Ventrolateral surfaces.-Body slightly protuberant laterally in basal half, feebly concave laterally before the apices; surface lines straight. Submarginal groove shallow beneath the feebly expanded external border of the dorsal plate. Internal margins of the valves contiguous in basal three-fourths; genital fissure in apical fourth 
and nearly closed, margins fringed with very small setæ. Inferior membrane not visible.

Habitat.-Kansas (George Horn); Colorado (Denver, April, H. Soltau); Wyoming (Cheyenne, June and July, Hubbard and Schwarz).

Number of specimens studied, 34 .

Type in the Horn collection.

Type-locality.-Kansas.

Salient type-characters.-Thoracic margin acute, not foliaceous nor suddenly formed, not deeply emarginate at apex. Elytral margin acute, feebly reflexed, and not attaining the apex; disc flattened, and never concave. Epipleural limits distinctly defined (Horn).

Diagnostic characters.-The thorax is distinctly wider than long, the apical emargination is shallower and broader, the elytral disc is flat or feebly convex, and the apices never caudate; the margin does not reach the apex. The epipleuræ are usually well defined and even feebly convex.

From contusum it differs in the shallower apical emargination of the prothorax, and by the elytral margin not reaching the apex. The prothoracic margin is distinctly narrower.

It is recognized from elongatum by the shorter and broader form and by the elytral margin not attaining the apex.

From depressum by the wider thoracic and elytral margins, and in not having the marginal line reaching the apex.

Planum is undoubtedly very closely related to contusum and a very large series might show it to be simply a subspecies. I deem it best at present not to unite the two until further collecting has been done. The explanate thoracic margin varies in width and the marginal line is often indicated to apex by a line of asperities.

General observations.-The mentum is moderate, middle lobe more or less semicircularly arcuate anteriorly from the subangulate sides. The apex may be subtruncate and the sides straight and oblique; surface feebly convex and more or less obsoletely foveate laterally.

Prosternum and mesosternum as in contusum. In a few specimens there is a very slight tendency for the prosternum to become feebly prominent posteriorly.

The abdominal process is rather small and nearly quadrate, its width is slightly less than the length of the post-coxal portion of the same segment, the latter is about equal to the third in length; the second is one-fifth of its length longer than the third, the latter scarcely twice as long as the fourth.

The abdominal and metasternal salients are equal in width.

The metasternum laterally between the coxæ is short, in length about equal to the width of a mesotibia at middle. 
The tibial grooves of the femora are well developed and defined; surface of each plane to concave, glabrous and at times feebly rugulose; margins well defined and more or less acute, gradually converging to the femoral base in each instance, those of the profemora are slightly arcuate.

The protibiæ are slightly compressed and distinctly carinate externally, carina more or less entire, surface behind it rather narrowly and longitudinally grooved, groove more or less asperate.

Tarsal grooves of the mesotibiæ rather more or less evident externally in apical two-thirds, grooves more or less narrow, subglabrous or subasperate. External surfaces of the metatibiæ are more or less flattened, scarcely grooved and asperate.

The tarsi are moderate in length and stoutness.

The protarsi are about one-fourth of their length shorter than a mesotarsus. The first four joints are subequal in length, the first is slightly longer than wide, the succeeding three feebly wider than long.

The mesotarsi are about one-fifth of their length shorter than a metatarsus. First joint scarcely as long as the next two combined; the second, third, and fourth subequal in length and distinctly longer than wide; fifth a little shorter than the preceding three taken together.

The metatarsi about three-fifths as long as their tibiæ. First joint quite equal to the succeeding two taken together, the fourth just a little longer than the second and third combined, the latter two are equal to each other.

\section{EMBAPHION CONTUSUM LeConte.}

Embaphion contusum LeConte, Journ. Acad. Nat. Sci. Phila., 2d ser., IV, 1858 , p. 20 ; Smithson. Contrib. to Knowledge (Coleopt. Kans. and eastern N. Mex.), 1859, p. 15, pl. I, fig. 8.-Honn, Trans. Amer. Phil. Soc. Phila., XIV, 1870, p. 321.

Var. laminatum Casey, Ann. N. Y. Acad. Sci., V, Nov. 1890, p. 403.

Elongate oblong, piceous black, more or less opaque, sides of the prothorax rather broadly foliaceous, elytral margins less strongly so, margins distinctly attaining the apex.

Head small, less than twice as wide as long, nearly plane, broadly and feebly impressed laterally, sides of the frons rather prominent; surface very finely, sparsely, and quite indistinctly punctate, each puncture bearing a small, short, and curved seta.

Antenno long and rather slender, very feebly compressed in outer four joints, which are feebly widened; third joint a little shorter than the next two taken together; fourth slightly longer than the fifth; the latter, sixth, and seventh subequal; eighth slightly shorter and subtriangular; ninth and tenth suborbicular; eleventh ovate. 
Pronotum proper about as wide as long, lateral margins thin and moderately foliaceous, more or less reflexed and concave; disc rather moderately convex, finely and rather sparsely punctate, laterally more densely so, each puncture with a short curved seta; apex rather deeply and somewhat semicircularly emarginate, the emargination about three times wider than deep, not noticeably margined; sides evenly rounded, margin not widening at base; base quite truncate, and about equal to the apex, with a distinct marginal bead; apical angles obtuse, formed by the moderately advanced foliaceous margins, and are about half as long as the head; basal angles broadly rounded, slightly more prominent posteriorly than the middle of the base.

Propleurce smooth and quite impunctate.

Elytra elongate oval, nearly twice as long as wide, margins acute, slightly reflexed and always attaining the apex; base quite truncate, much wider than the contiguous prothoracic base proper; humeral margins rather broadly rounded, not anteriorly prominent, humeri proper obtuse; sides feebly arcuate or subparallel in basal half, thence to apex quite evenly and broadly arcuate, apex more or less acute and produced; disc quite plane or feebly concave, sometimes biconcave by elevation of suture in posterior half, more or less arcuately declivous posteriorly, acutely inflexed laterally, inflexed sides quite straight and oblique; surface sculptured with subasperate punctures which may be rather densely placed and more or less irregularly arranged, at times somewhat serially so, occasionally the punctures are not asperate and rather coarse; inflexed sides irregularly and more or less densely punctate.

Epipleurce narrow, not in the least dilated at base, very gradually narrowed to apex, smooth and impunctate; superior margin well defined in apical fourth, thence to base by a series of punctures, surface on the same plane as the inflexed sides of the elytra; widening at apex to become the inferior surface of the more or less produced apex.

Sterna quite smooth and more or less impunctate.

Parapleurce rather sparsely and more or less indistinctly punctate.

Abdomen smooth, very sparsely and more or less indistinctly punctulate, obsoletely rugulose; third segment scarcely oblique, others horizontal.

Legs moderate in length, rather slender. Profemora mutic as usual, tibial spurs similar and protarsi simple in the sexes.

Male.-Somewhat narrow. Antennæ reaching considerably beyond base of the prothorax. Elytral dise more or less gradually declivous behind, apex produced into a short cauda, which may be angulate at the sides where the inflexed sides terminate; cauda more or less abruptly produced, rather oblique, and more or less asperate, with 
tips separated. Abdomen moderately convex and more or less impressed on first two segments. Protibiæ suddenly and briefly sinuate at base.

Female.-Rather broad. Antennæ reaching beyond the prothoracic base, but shorter than in the male. Elytral disc arcuately declivous posteriorly, not produced at apex, but more or less acute. Abdomen quite strongly convex. Protibiæ gradually narrowing at base.

Measurements.-Males: Length, $15-20.5 \mathrm{~mm}$; width, $7.2-8 \mathrm{~mm}$. Females: Length, 14-19.5 mm.; width, 7-10 mm.

Genital characters, male.-Edeagophore slender, elongate oblongovate.

Basale elongate oval, surface moderately convex, sides moderately arcuate, apex deeply and triangularly emarginate to receive the base of the apicale.

Apicale slender and elongately triangular; surface evenly and rather strongly convex, without groove; sides nearly straight, gradually converging to apex, the latter acute; base strongly and acutely lobed at middle, oblique and broadly sinuate laterally.

Sternite subparabolic in outline. Each lobe subtriangular, external border quite evenly arcuate to apex, the latter subacute, prominent and slightly produced; internal border sinuate; surface more strongly convex along the external border, thence sloping inward, densely punctured in apical two-thirds, especially internally, setose, setre quite long and dense, more so on apex. Sinus semicircular, membrane not setose across the same.

Female.-Genital segment (Plate 5, fig. 8) elongately triangular with the apices, or triangular-trapezoidal without the same, superior surface plane, not setose.

Valvula.-Dorsal plate suboblong to feebly and elongately triangular, slightly narrowing from base to apex; surface plane, smooth, and not noticeably punctate; external border angulate at basal fourth, thence more or less sinuate and arcuate to apical margin, the latter subtruncate at middle two-fourths, angle rounded, in inner fourth continuous with the surface of apex; internal margin quite straight or more or less feebly arcuate. Apex chitinous, produced, and everted, convex above and concave beneath, rounded at tip; fossa at base of the external apical surface, beneath apical margin of dorsal plate.

Appendage mammilliform, glabrous, with a pencil of few quite long setæ at tip.

Basal prominences feebly evident, lateral surfaces of valves slightly visible from above.

Superior pudendal membrane attaining the apical fourth of the dorsal plate, finely and longitudinally rugulose. 
Ventrolateral surfaces.-Body with surface lines straight when viewed longitudinally, quite evenly convex from side to side, smooth and shining. Submarginal groove rather small beneath the external border of dorsal plate, which is feebly explanate in apical half, terminating at the apical margin. Internal margins of the valves contiguous in basal four-fifths; fissure quite short, nearly closed, margins finely setose. Inferior membrane not visible.

Habitat.-Wyoming (Cheyenne, June, Hubbard and Schwarz; April, H. Soltau); Colorado (Salida, Fort Collins, Clear Creek, South Park Region, San Luis Valley, H. F. Wickham); New Mexico (Deming, July and August, Hubbard and Schwarz; Las Vegas, August, Barber and Schwarz; Coolidge, Wickham); Arizona (George Horn; Winslow, Hubbard and Schwarz; Santa Rita Mountains, July, Hubbard and Schwarz; Tucson, Charles Fuchs) ; Kansas (F. H. Snow; George Horn).

Number of specimens studied, 48 .

Type in the LeConte collection.

Type-locality.-Fort Laramie and Santa Fé, New Mexico.

Salient type-characters.-Opaque. Thorax with deeply emarginate apex, margin broadly explanate, moderately reflexed, apical angles subacute, basal angles broadly obtuse. Elytra with the dorsum plane, acutely margined at apex, margin reflexed, strongly so, seriately, finely and rather densely muricato-punctate. Male with elytral apices briefly prolonged (LeConte).

Diagnostic characters.-In this species the thorax proper is broader, the prothoracic margins are moderately foliaceous and reflexed, the integuments are more or less opaque, finely and subasperately sculptured, the elytral margins attain the apex. The males are briefly caudate.

From muricatum it differs by not having the basal angles of the prothorax prolonged backward over the humeri. The elytral margin is thinner, narrower, and usually scarcely reflexed unless it be near the humeri. The sides of the pronotum are rounded from apex to base and not broader behind, the basal angles are broadly rounded and slightly more prominent posteriorly than the middle of the base.

In contusum the males have the inferior surface of the elytral cauda form by the dilated apices of the epipleural surface.

From glabrum it is recognized by the dull luster and finely subasperate sculpturing, also by the acute elytral margins attaining the apex.

In the U. S. National Museum collection there are two males and two females which were collected in New Mexico. They are the largest and most strongly developed specimens that I have seen. The elytral apices are distinctly caudate, and the elytral disc quite evenly concave transversely in the males and the suture is feebly raised 
posteriorly, indicating an approach to laminatum Casey. The females have the elytral disc broadly oval and quite flat. The epipleuræ are not at all defined from the inflexed sides except at apex, they are glabrous. In these specimens the sexes have the prothoracic margin slightly broader and more decidedly reflexed than the average number of specimens of the typical form (forma typica); in fact, some specimens have the margins scarcely at all reflexed.

These large specimens may be placed as an extreme form in the cabinet, and labeled forma grandis.

General observations.-Mentum more or less variable and moderate in size. Middle lobe arcuate anteriorly, or subtruncate with the sides straight and converging to apex; surface very feebly concave, rather longitudinally prominent at middle and broadly, feebly concave laterally and more or less punctate.

The prosternum between the coxæ is quite suddenly prominent ventrally, antero-posteriorly arcuate, frequently more or less grooved. Feebly widened behind the equator of the coxæ.

The mesosternum is more or less obliquely and arcuately declivous, more or less broadly and feebly concave.

The abdominal salient subquadrate and scarcely as wide as the third segment is long; post-coxal part of first about equal in length to the second segment, the latter twice as long as the fourth; third about one-third of its length shorter than the second.

The abdominal and metasternal processes are subequal in width.

The metasternum laterally between the coxæ is very short and about equal to a mesotibia at base.

The tibial grooves of the femora are entire, well defined and glabrous; their margins are subacute and smooth. The profemoral grooves are more or less strongly concave; the margins converge to become contiguous at the femoral base.

The mesofemora have the grooves scarcely concave; the margins converge to become feebly distant at femoral base.

The grooves on the metafemora are not concave, quite flat, with margins gradually converging and slightly distant at base.

The protibiæ are slightly compressed and carinate externally, the carina is entire, the tarsal groove is immediately behind it and is frequently obsolete, the surface always asperate.

The mesotibiæ are more or less distinctly grooved externally in apical two-thirds; the surface of the groove is glabrous, with sparsely placed asperate punctures.

The metatibiæ are simply flattened externally and asperate.

Tarsi moderate as usual.

The protarsi are scarcely one-fourth of their length shorter than a mesotarsus; joints two, three, and four subequal in size and very slightly wider than long and together about equal to the fifth; the 
first is a little longer than the second; mesotarsi about two-sevenths of their length shorter than a metatarsus; joints two, three, and four subequal, a little longer than wide, and together just a little longer than the fifth; the first about one and a half times longer than wide.

The metatarsi are about one-half of their length shorter than their metatibia; first and fourth joints equal in length and either one is equal to the second and third taken together; the latter two are subequal in length, each about twice as long as wide.

EMBAPHION CONTUSUM var. LAMINATUM Casey.

Moderately robust, black and dull throughout.

Head small, very finely, sparsely, and subasperately punctate. Antennce slender, third joint from four to nearly five times as long as wide, eighth one-half longer than wide.

Pronotum about one-half wider than long; dise proper very feebly convex, fully as long as wide, and having two feeble, subparallel, and sinuous impressions near the middle; surface throughout finely, extremely sparsely, and subasperately punctate; apex strongly emarginate, the emargination not quite three times as wide as deep; side margins very widely and strongly reflexed, the outer edges parallel, strongly and evenly arcuate throughout; base transverse; basal angles broadly rounded and projecting beyond the median portion of the base.

Elytra from one-half to four-fifths longer than wide; base transversely truncate; humeri rounded; sides very thin and broadly but not abruptly reflexed, the acute lateral edges parallel and feebly arcuate in basal two-thirds, then rounded to apex and slightly prolonged, uniting in a prolongation of the suture; disc distinctly wider than the prothorax, each elytron broadly concave, the suture elevated; inflexed sides nearly flat, somewhat coarsely and sparsely but unevenly punctate; surface of disc with approximate, imperfectly defined and feebly impressed rows of rather coarse, impressed punctures, also finely and sparsely asperate.

Epipleura very imperfectly defined except near the apex.

Legs very slender.

Male.-Somewhat slender.

Female.-Moderately robust.

Measurements.-Length, 14-15 mm.; width, 6.8-7.5 mm.

Genital characters not studied.

Habitat.-Texas (El Paso, G. W. Dunn).

Unknown to me in nature.

Type in Colonel Casey's collection.

Type-locality.-El Paso, Texas. 
Casey writes that this form is related only to contusum, and I can not help deciding that it is only one of the extreme forms of that species. I do not consider that the peculiar form of the upper surface of the elytra can give specific standing in this instance. It is true that in the typical contusum the elytral dise is plane, but in the series before me are examples with flat elytral dises; others have them slightly concave, with margins more strongly reflexed, until finally the extreme forms approach the one here described under contusum as forma grandis, for example; the latter is much larger than laminatum, the male having a length of $20.5 \mathrm{~mm}$., width $10.5 \mathrm{~mm}$.; the female, length $19 \mathrm{~mm}$., width $10.5 \mathrm{~mm}$., and is distinctly a much larger form.

The elevation of the elytral suture is observed in some examples of all of the species known to me.

The sculpturing is quite variable and in the extremes of a series quite in contrast. Furthermore, the elytral punctures referred to in the description are merely impressed foveæ, and according to the original remarks do not appear to be in the least setigerous: " the finer, but strong and sparse, asperities are distributed over the surface without regard to the punctures, and each bears a strong, thick, semi-erect seta."

After a careful examination of the sculpturing under high power, I consider that the asperities represent the true punctures, whose margins have been produced into the minute eminences, each bearing a seta.

The minute fovex or dents are not the true punctures. The sculpturing is quite similar in all of the species before me; even the minute foveæ are scattered here and there. The sculpturing of taminatum is peculiar only in the apparent abundance of foveæ.

A comparative study of the elytral setæ shows that in glabrum the setæ are the most minute and the stoutest in contusum, the longest and most slender in planum.

Not having seen the types nor an authentically identified specimen, my views are, of course, founded upon the series at hand and the laws governing homology and analogy.

\section{EMBAPHION MURICATUM Say.}

Akis'? muricata SAY, Journ. Acad. Nat. Sci. Phila., III, 1824, p. 251.

Embaphion muricatum LeConte, Complete Writings of Thomas Say, II, 1859, p. 149; in Thomson's Arcana Nat., I, 1859, pl. xI, fig. 10.Horn, Traus. Phil. Soc. Phila., XIV, 1870, p. 320.

Embaphion concavum LeConte, Proc. Acad. Nat. Sci. Phila., VI, 1853, p. 446.

Oval to oblong-oval, brownish to piceous black, thoracic and elytral margins very broad and foliaceous, strongly reflexed. 
Head small, less than twice as wide as long, plane, sides of the frons slightly prominent, punctate, punctures very feebly subasperate, fine, not dense, each with a small curved and short seta, frontal suture usually not visible. Antenna rather long, quite slender, outer four joints very slightly compressed and scarcely widened, third joint shorter than the next two taken together, fourth scarcely longer than the fifth, the latter and sixth subequal, seventh shorter, eighth feebly shorter than the seventh and slightly triangular, ninth and tenth suborbicular, eleventh subovate.

Pronotum with margins very broadly foliaceous, the margin more than one-half wider than the $d i s c$, the latter comparatively narrow, longer than wide at middle, very feebly convex, usually with irregular depressed areas; finely, more or less subasperately and sparsely punctate; reflexed margins wider posteriorly and more or less concave, a little more distinctly punctate, punctures less sparse, each with a short curved seta; apex deeply and feebly subquadrately emarginate, the emargination about one-half wider than deep, sides almost parallel, and scarcely margined; sides evenly but not strongly arcuate, moderately converging from base to apex; base proper feebly arcuate, not margined and about equal to the length, laterally sinuate; apical angles rather narrowly rounded and formed by the advanced foliaceous margins and nearly as long as the head; basal angles are posteriorly prominent, subacute, and projecting backward over the basal angles of the elytra.

Propleurce smooth and impunctate; inferior surface of the foliaceous margins obsoletely punctate.

Elytra oval to elongate oval; margins broad and reflexed, angles at humeri nearly rectangular and more or less truncate at base, posteriorly extending beyond the apex, the two meeting on a line with the suture above the true elytral apex, and defined from the same by a slight groove, borders evenly arcuate from base to apex or more or less parallel basally; base evenly but not strongly emarginate; humeri proper broadly rounded and not prominent; sides proper more or less evenly arcuate; apex proper not produced and narrowly rounded; disc plane, feebly convex, at times slightly concave, the inflexed sides nearly straight and oblique, gradually and not strongly arcuately declivous behind; surface sculptured with approximate series of fine asperate punctures, which become more irregular and slightly denser laterally. Each puncture bears a short and rather robust curved seta.

Epipleurce narrow, not attaining the humeral margin and not dilated, but gradually narrowing to apex, not defined from the inflexed sides of the elytra and on the same plane; superior margin obsolete, except near apex; elsewhere represented by a line of punctures or a faint groove. 
Sterna more or less dull, finely and not distinctly sculptured.

Parapleura smooth, rather sparsely but not very distinctly punctate. Abdomen horizontal, very finely and sparsely punctulate, obsoletely rugulose and quite evenly convex.

Legs rather slender, moderate in length. Anterior femora mutic, protibial spurs similar in the sexes, the anterior slightly longer than the posterior. Protarsi simple.

Male.-Abdomen moderately convex and not noticeably impressed; anterior tibiæ quite suddenly and briefly constricted at base.

Female.-Abdomen rather strongly convex and the protibiæ gradually narrowed at base.

Measurements.-Males: Length, 16-18 mm.; width, 9.5-10 mm. Females: Length, 15-18 mm.; width, 9-10.5 mm.

Genital characters, male.-Edeagophore elongate oblong-ovate, rather slender, feebly arched and slightly depressed.

Basale oblong, very moderately convex, sides feebly arcuate.

A picale triangular, slightly depressed; surface rather feebly convex and without groove; sides nearly straight or feebly and broadly sinuate to apex, the latter acute and not attenuated; base distinctly subacutely lobed at middle, feebly and broadly sinuate laterally.

Sternite quite parabolic in outline. Each lobe rather long, with external border more or less evenly areuate or straight in basal half, thence feebly arcuate to subtruncate to apex, the latter narrowly rounded and rather prominent; internal border oblique and short; surface scarcely convex, rather densely punctate in apical two-thirds, setose, setæ rather long and not dense.

Female.-Genital segment (Plate 5, fig. 7) triangular, rather elongate, including apices, or subtrapezoidal without the same, surface quite plane and not noticeably setose.

Valvula.-Dorsal plate rather elongate-oblong or oblong-oval; surface scarcely concave, smooth, very sparsely and somewhat coarsely punctate; external border more or less feebly arcuate and slightly explanate; internal border arcuate; apical margin more or less truncate, angle rather broadly rounded, internally continuous with the surface of apex, not setose. Apex chitinous, produced, slightly longer than the width of dorsal plate at basal third, everted, convex above and concave beneath, tip rounded, external border feebly excavated at base and slightly beneath the apical margin of dorsal plate, forming the fossa.

Appendage somewhat spherically mammilliform, glabrous, with a pencil of quite long setæ at tip.

Basal prominences obsolete.

Superior pudendal membrane attaining the middle of the dorsal plate, finely and longitudinally rugulose. 
Ventrolateral surfaces.-Body somewhat elongately triangular, obliquely truncate laterally at base, quite acute at the internal margins of valves in the median line at base; surface lines straight when viewed longitudinally, evenly convex from side to side, smooth and shining. Submarginal groove well defined beneath the feebly explanate external border of the dorsal plate, terminating at the apical margin. Internal margins of the valves contiguous in basal fourfifths; fissure narrowly fusiform in apical fifth, margins finely setose, inferior membrane not visible.

Habitat.-Texas (Mobeetee, July, H. S. Barber) ; Colorado (Pueblo, October 27, H. Soltau; Colorado Springs, Greeley, June, elevation 6,000-7,000 feet, Wickham; Fort Collins, Bellevue, West Las Animas, Wickham); Kansas (Wallace County, elevation 3,000 feet, F. H. Snow ; Rice County, Clark County, June, elevation 1,962 feet, F. H. Snow); Nebraska; South Dakota (Alexandria).

Number of specimens studied, 40.

Type destroyed.

Type-locality.- "Arkansas at the Rocky Mountains," (Say.)

Salient type-characters.-Margins of the thorax and elytra broadly foliaceous and strongly reflexed; basal angles of the prothoracic margins projecting strongly backward over the basal angles of the elytra.

Diagnostic characters.-Distinct from all other species as indicated by the salient type-characters.

The concavum of LeConte is simply a larger, longer, and narrower form, with the broad elytral margins more suddenly and almost perpendicularly reflexed.

General observations.-The mentum is moderate in size and variable. The middle lobe may be more or less arcuate anteriorly, or truncate, evenly slightly emarginate at apex; sides more or less straightened, and converging anteriorly. The form anterior to the lateral and subbasal angles is subparabolic or subtriangular.

Prosternum arcuate antero-posteriorly and somewhat prominent ventrally with the coxæ; sometimes more or less oblique and feebly compressed posteriorly.

Mesosternum variable as to the degree of obliquity; usually subvertically arcuate and broadly, feebly concave.

The abdominal process is subquadrate and just the least transverse, and equal in width to the length of the third segment; the post-coxal part of the first segment about equal in length to that of the third; the second is twice as long as the fourth; the third is about one-third of its length shorter than the second.

The abdominal and metasternal salients are quite equal.

The metasternum laterally between the coxæ is about equal in length to the width of a mesotibia at apex. 
The tibial grooves of the femora are entire and well defined, glabrous, concave on the profemora, less so on the meso- and metafemora; the margins are acute and smooth, gradually converging to the femoral base, where they meet.

The protibix are scarcely at all compressed nor carinate externally, simply flattened or feebly concave in apical half, forming a slight tarsal groove, which is moderately asperate.

The meso- and metatibix are very feebly flattened externally in apical half.

The tibiæ appear to be quite variable as to length. In some examples the protibir are scarcely more than one-half the length of the metatibiæ; while in others they are at least three-fifths as long. This seems to be an individual variation observed more or less throughout the tribe Eleodiini.

The protarsi are about one-fourth of their length shorter than a mesotarsus. The four basal joints are small, the second, third, and fourth subequal in size and length and about as wide as long; the first is about one-half longer than wide; the fifth about equal to the three preceding joints taken together.

The mesotarsi are about one-fifth of their length shorter than a metatarsus. Joints two, three, and four are subequal in length and slightly longer than wide; the first is distinctly more than one and a half times longer than wide; the fifth about equal in length to the preceding three combined.

The metatarsi are about half as long as a metatibia. The first joint is about equal to the fourth; the second and third are subequal, the second apparently just a little longer than the third, and both taken together about equal to the fourth.

\section{Genus ELEODIMORPHA, nev.}

Body rather robust and blapyliform.

Head not deeply inserted, epistoma distinctly emarginate, sides of the front straight and converging anteriorly and not in the least dilated, frontal suture scarcely evident; eyes narrow, transverse, and subreniform; antennæ 11-jointed, outer three joints feebly compressed. Mentum moderate, trilobed, lateral lobes rather small and inflexed, middle lobe trapezoidal, narrowing at base as usual and attached to a short gular peduncle, surface concave.

Maxillary palpi moderate in length, last joint triangular and moderately broad; third subtriangularly obconical, a little longer than wide and about two-thirds as long as the second, the latter elongate and obconical.

Labial palpi small, last joint more pyriform than triangular, constricted at base on internal and lateral surfaces. 
Buccal processes of the genæ strongly and subacutely produced anteriorly over the base of the maxillæ. Mandibles emarginate at tip, cusps apparently equal.

Prothorax moderately transverse and margined; pronotal apex deeply and broadly emarginate (Plate 12, fig. 39), base truncate; prosternum longitudinally impressed before the coxæ, prominent in the median line and continuously so with the intercoxal portion, which is mucronate posteriorly; anterior margin of the prosternum arcuate at middle and broadly sinuate laterally.

Elytra with the disc not strongly deflexed laterally, distinctly margined by the superior border of the wide epipleuræ which occupy the whole of the inflexed side, the superior epipleural margin visible from above throughout its entire length.

Mesosternum and metasternum short and not prominent ventrally. Anteriorly the mesosternum is concave, posteriorly meeting the metasternal intercoxal salient at middle of the coxæ, suture slightly arcuate. Metasternal epimera very distinct. Intercoxal process of the first abdominal segment rectangular and broad, as usual.

Legs rather short, femora moderately compressed and widest near the middle; tibiæ slightly but distinctly dilated apically, feebly but characteristically arcuate, spurs small and normal; tarsi moderate in length and thickness, joints proportioned as in the other members of the tribe, spinous beneath with the plantar grooves distinct.

The tribal characters are distinct and the species has a very Blapylis-like form and the general structure is the same. The types were for years associated with Eleodes parvicollis, scabrosa, and cordata in my collection.

The produced buccal processes of the genæ are as marked as in Nyctoporis. Eleodes blanchardi presents the same condition, but to a much less degree.

The maxillary galea is evidently quite different from that observed in Eleodes and apparently two-jointed. I could not determine positively without dissection.

Salient generic characters.-Epistoma emarginate, sides of front not dilated, buccal processes of the genæ produced (Plate 8, fig. 24 $4^{a}$, mentum concave; impressed sides and prominent middle of the prosternum, the latter with the anterior margin arcuate at middle and sinuate laterally (Plate 8, fig. $24^{b}$ ); wide epipleuræ, elytral disc not inflexed at the sides; femora compressed and widest at middle, tibiæ arcuate and evidently dilated apically.

These characters define a very distinct genus, very unlike anything else found in the United States.

From its southern habitat I suspect that it may be related to some Mexican form and have carefully searched all the literature to determine that fact, but without avail. At present $I$ have no way of 
verifying the results of my previous search and consider it a new and very remarkable addition to our fauna.

Type of the genus.-Eleodimorpha bolcan.

ELEODIMORPHA BOLCAN, new species.

Feebly ovate, somewhat robust; a little more than twice as long as wide; black, somewhat opaque; feebly setigerous beneath; dorsally the very minute setæ scarcely project out of the punctures.

Head somewhat wide, almost plane, punctate, punctures coarse, confluent on the epistoma and laterally, irregular and sparse centrally, scattered on the vertex; sides of the frons scarcely prominent and feebly impressed within; frontal suture slightly evident laterally.

Antenno moderate in length and stoutness, outer three joints feebly compressed and slightly dilated, third joint not five times as long as the second, scarcely as long as the fourth and fifth taken together; joints 4 to 8 rather short, somewhat obconical, the fourth just the least longer than the fifth, the latter, sixth, seventh, and eighth subequal; ninth and tenth slightly transverse and oval; eleventh short, ovate.

Pronotum widest just in advance of the middle, transverse, about one-half wider than long; disc evenly and moderately convex, rather coarsely punctate, punctures simple, irregular, and sparse centrally, becoming denser and submuricate laterally; apex broadly and deeply emarginate, bottom of the emargination rather straight at middle three-fifths, about equal to the length, marginal bead not very coarse; sides evenly and broadly arcuate, moderately sinuate in basal fifth, very briefly and feebly so just behind the apical angles, marginal bead fine; base truncate, rather coarsely beaded, and about one-fifth wider than the apex; apical angles anteriorly prominent and subacute; basal angles rectangular.

Propleurce sparsely and submuricately punctate, and more or less rugulose, moderately convex, not in the least concave beneath the pronotal margins, except at the apical angles.

Elytra oblong oval, widest at the middle, a little more than one-half longer than wide; base truncatc, scarcely to a little wider than the contiguous prothoracic base; humeri not in the least prominent, obtuse, angle almost distinct; sides evenly, moderately, and broadly arcuate; apex obtuse; disc evenly convex from side to side, less strongly so toward the base, more strongly so toward apex, where it is arcuately declivous, not inflexed laterally; surface evenly and not very densely muricately punctate, punctures evenly arranged in evident series, each puncture distinctly defined from the others; the strial are smaller and less muricate, the interstitial are larger and more evident as small shining muricate tubercles, both series less strongly 
developed centrally, at the periphery both stronger and subequal in size, becoming irregular about the apical declivity.

Epipleurce quite broad, occupying the whole of the inflexed sides of the elytra; surface smooth and opaque, sparsely and finely subasperately punctate; scarcely narrowing in basal two-thirds, thence gradually to apex; superior margin visible from above throughout its entire length, forming a distinct and subacute bead for the elytra.

Sterna.-Prosternum impressed before the coxæ, prominent at middle and continuously so with the intercoxal portion, continuing forward to the apical arcuation and posteriorly ending in a conical mucro; surface sparsely and subasperately punctate and feebly rugulose laterally, on the central prominent portion coarsely muricatotuberculately punctate, and with erect brownish hairs.

Meso- and metasterna irregularly and sparsely punctate and more or less rugose. Mesosternum with brownish hairs.

Parapleura coarsely but not densely punctate.

Abdomen somewhat shining, first three segments rather densely punctate and more or less rugose, the small asperities are shining and larger centrally; last two segments more finely and densely punctate in their apical moieties, quite impunctate basally.

Legs moderate in length and thickness. Femora moderately compressed, widest near the middle, mutic in both sexes; tibiæ moderately arcuate in both sexes; spurs small and similar. Tarsi with the plantar grooves entire, marginal and apico-marginal spinules as usual and ferrugineous in color.

Male.-Slightly narrower. Elytra arcuately and just the least obliquely declivous posteriorly. Abdomen subhorizontal, moderately convex, rather strongly, broadly and longitudinally impressed at middle of the first three segments; intercoxal process concave; punctuation finely muricato-tuberculate. Legs stouter, and the protarsi moderately stout.

Female.-Slightly broader and a little more robust. Elytra arcuately and vertically declivous posteriorly. Abdomen evenly convex, intercoxal process feebly impressed, segments rather sparsely and finely subasperately punctate. Legs less stout, anterior tarsi slender.

Measurements.-Male: Length, $13 \mathrm{~mm}$; width, $5 \mathrm{~mm}$. Female: Length, $13 \mathrm{~mm}$; width, $5.8 \mathrm{~mm}$.

Genital characters, male.-Edeagophore (Plate 6, fig. 11) obtusely oblong-ovate in form, well chitinized, moderately elongate.

Basale oblong, about two and a half times longer than wide, rather evenly convex, slightly depressed along the middle, with a faint indication of a median longitudinal linear impression.

Apicale rather broadly subpyriform; apical third strongly and quite suddenly deflexed, becoming immediately horizontal and laminate, broadly rounded at apex; dorsal surface glabrous with basal 
two-thirds somewhat depressed, laterally more arcuate and declivous, circularly membranous at center; sides arcuate at basal third, thence sinuate to apical third, where it is arcuate and continuously so with the broadly rounded apex; base feebly lobed at middle, broadly and feebly sinuate laterally.

Clava (Plate 7, fig. 8) comparatively broad, flattened, and of nearly equal width throughout, obtuse and rounded at apex, slightly arcuate, with convexity outward, not contiguous in the median line, except at base, ventrad to the edeagus; alæ of the apicale evidently differentiated as separate elongate sclerites (subalas), but united by a suture to the apicale.

Sternite transversely parabolic in outline, bilobed. Each lobe subtriangular; surface not strongly but slightly unevenly convex, glabrous, rather sparsely punctate and pubescent in posterior two-thirds, pubescence denser in the apical area, hairs yellowish; external border straight and oblique in basal three-fifths, thence straight and obliquely subtruncate to apex, the latter narrowly rounded; internal border quite straight; interlobar membrane not pubescent. Sinus triangular.

Female.-Genital segment (Plate 6, fig. 12) triangular, about as long as wide at base, superior surface quite plane, chitinized throughout, apically very finely pubescent.

Valvula.-Dorsal plate not defined from the apex; surface glabrous, plane, very sparsely and finely pubescent apically; external border rather straight, rounded at the angle and directly continuous with the feebly and broadly sinuate superior margin of the fossa; internal border broadly sinuate in apical half, thence feebly arcuate to the base.

A pex short, rounded at tip, chitinous, fossa on its external surface, finely pubescent, hairs short but noticeable.

Appendage mammilliform, short, penicillate, hairs quite long.

Superior pudendal membrane long, reaching to the base of the apex, very minutely longitudinally rugulose. Basal prominences noticeable.

Ventrolateral surfaces quite evenly convex in basal two-thirds, glabrous, here and there a minute hair, very feebly impressed before the apex. Submarginal groove distinct beneath the feebly explanate external border of the dorsal plate, subobsolete in basal fourth. Apex feebly convex beneath. Appendage and fossa distinctly visible from below. Internal margins of the valves contiguous, genital fissure apical, small, and fusiform.

Habitat.-Bolcan Mountain, between Warner's Ranch and Julian, San Diego County, California. Taken from beneath a $\log$.

Number of specimens studied, 2 (male and female).

59780-Bull. $63-09-31$ 
Sexitypes in my own collection.

Type-locality.-Bolcan Mountain.

Salient type-characters.-Body blapyliform, surface dull, buccal processes of the genæ produced; prothorax deeply emarginate at apex, angles anteriorly prominent and subacute, base truncate; prosternum impressed before the coxæ, prominent at middle and pubescent. Elytra truncate and more or less coarsely margined at base, adapted to the prothorax; sculpturing of evident series of small shining muricate tubercles; epipleuræ wide, forming the inflexed sides of the elytra. Legs short, femora compressed, tibiæ arcuate, tarsi simple.

Diagnostic characters.-Distinct as defined by the salient type characters, and can not be confused with any other species in our fauna.

General observations.-The mentum is trapezoidal, coarsely punctate and setigerous, surface concave.

Prosternum between the coxæ feebly grooved, not prominent ventrally and with the anterior median prominence forming a continuous and feeble arcuation from the apical margin to the tip of the conical mucro.

Mesosternum deeply concave to receive the prosternal mucro, sides prominent around the acetabula, pubescent.

The intercoxal process of the first abdominal segment is rectangular, slightly transverse, equal in length to the post-coxal portion, its width scarcely equal to the combined lengths of the third and fourth segments.

In the male the post-coxal part of the first segment is about equal in length to that of the third, the second is a little longer than the third.

In the female the post-coxal part is about equal in length to the third, the second scarcely twice as long as the fourth.

The metasternal salient is about a fourth (male) to a third (female) narrower than the abdominal salient.

The metasternum laterally between the coxæ is about as long as the width of a mesotibia at middle.

The superior and inferior surface lines of the femora are distinctly arcuate, most noticeable in the inferior at middle; the tibial grooves are well defined and subentire, the floor of each is flat, smooth, and abruptly limited by cariniform margins, they are longitudinally convex, the convexity is adapted to the tibial arcuation.

In the male the lateral surfaces are longitudinally impressed along the inferior margins, not so in the female where the femora are a little less stout and the grooves limited by thinner margins. 
The tibiæ are arcuate and each is somewhat rounded in basal half and thence to apex somewhat compressed and distinctly but not strongly dilated.

The protibiæ are the most compressed and scarcely carinate externally, the tarsal grooves are evident but feeble and the posterior border of each more prominent than the anterior.

The tarsal grooves of the mesotibiæ are the best developed, their margins are equal.

The external surface of the metatibiæ are flattened and more or less grooved.

The articular cavities of the protibix are nearly open, on the other tibiæ they are shut off from the grooves by well marked but somewhat atrophic edges.

The relative lengths of the tarsi and also of their joints are quite similar in the sexes.

In the protarsi joints two to four inclusive are quite equal and short, the first is longer than wide, the fifth about equal in length to the preceding three taken together.

In the mesotarsi joints two to four inclusive are subequal and short, the first is scarcely as long as the second and third taken together, the fifth is not as long as the combined lengths of the preceding three.

In the metatarsi joints two and three are equal and together about equal to the fourth; the first is a little longer than the fourth.

Tarsal formula:

$\begin{array}{cccc}\text { Pro. } & \text { Meso. } & \text { Meta. } & \text { Metatibiæ. } \\ \text { Male. }-2 & 2 \frac{1}{3} & 2 \frac{2}{3} & 4 \frac{1}{3} \\ \text { Female. }-1 \frac{5}{6} & 2 \frac{1}{2} & 2 \frac{3}{5} & -4 \frac{1}{3} \\ \text { Genus TROGLODERUS LeConte. }\end{array}$

Trogloderus LeConte, N. Amer. Entomologist, I, no. 1, July, 1879, p. 2.

Body elongate, rough, opaque, eyes slightly oblique; sides of the frons moderately dilated, distinctly more prominent laterally than the eyes; epistoma moderately dilated laterally, scarcely in the least reflexed, margin arcuate laterally and emarginate anteriorly; labrum moderately small, transverse, somewhat short, sinuate, strongly retractile beneath the epistoma ; mandibles not at all visible from above; antennæ with the third joint as long as the two following combined, eighth, ninth, and tenth distinctly transverse, somewhat perfoliate, eleventh narrower than the tenth; mentum rounded in front, trapezoido-triangular to parabolic in outline, surface more or less impressed laterally; prothorax deeply emarginate in front, rounded at the sides, then briefly and strongly constricted or simply sinuate, apical angles stout and anteriorly prominent, basal angles small and more or less prominent and acute, disc more or less foveate in the 
median line; scutellum very feebly entering between the elytra, the latter not margined at base nor adapted to the prothoracic base, suture and four costæ each side acutely elevated; epipleuræ narrow, entirely overlapped by the metasternal side pieces and first three abdominal segments, exposed and horizontal opposite the last two segments; prosternum quite strongly protuberant ventrally before the coxæ and produced behind; mesosternum deeply concave; metasternum and first two abdominal segments at middle, broadly and shallowly concave; intercoxal process of first abdominal segment broader than long; profemora more or less armed with a tooth at outer fourth; anterior tibiæ more or less compressed and arcuate.

The above diagnosis differs in several important points from that given by LeConte or Horn.

The laterally dilated epistoma with sides arcuate is in contrast to the condition in the other genera of the present tribe, where the sides of the epistoma are sinuate or straight and convergent anteriorly.

The epistoma in the present genus appears longer on account of the dilatation and less broadly sinuate anterior margin. In most of the specimens before me the labrum is not visible, but in others it is entirely uncovered as in Eleodes, and in all probability it is capable of greater retraction than in the other genera of the tribe, where it is retractile to a less degree.

The mandibles are not visible from above-except slightly in the sinuation of the labrum - as in Eleodes, Embaphion, and Eleodimorpha, and this is no doubt due in part to the fact that the mouth parts are not so strongly developed or prognathic as in the above genera.

In the Scaurini (Cerenopus and Argoporis) the labrum is entirely invisible from above and apparently deeply concealed beneath the produced epistoma, at least I have never seen it protruded.

The scutellum does not enter between the elytra to any extent in costatus, but more so in tuberculatus.

The epipleuræ while narrow, are nearly entirely inflexed above and overlapped by the metasternal side pieces and first three abdominal segments, but they are visible beneath the humeri opposite the mesosterum, horizontal and exposed near the apex opposite the last two abdominal segments. I have not observed such an extreme condition elsewhere in the Eleodiini, although it is more or less indicated in sporadic instances.

All specimens that I have examined are identical in this respect.

The habitus of the insect might be considered somewhat discordant in the present tribe, but no more so than in the cases of Eleodes granosa and veterator in that genus. 
I do not consider it in harmony with the Scaurini as defined by Casey. $^{a}$ On account of the short, transverse head, with eyes near the prothorax, it is more closely related to the Eulabini.

In many respects it is more closely in harmony with Eleodimorpha than any other heretofore mentioned.

The genital characters appear to show greater affinity with the Eleodiini.

Genital characters, male.-Edeagophore oblong-ovate and acutely pointed. Apicale triangular, evenly convex above and acute at apex. Sternite bilobed, lobes separate and united by membrane.

Female.-Genital segment moderately depressed, subequilaterally triangular, valves more or less reflexed and fully chitinized. The dorsal plate is not at all defined from the apex, surface more or less concave, with scattered setæ in apical moiety. The appendage is very small, semi-oval in outline, subapical and feebly penicillate. Superior pudendal membrane moderately exposed and reaching at least to the apical third of the dorsal plate.

Ventrolaterally the submarginal groove is very feebly defined, the surface lines are straight longitudinally. Internal margins of the valves contiguous in basal half, fissure narrow in apical half; inferior membrane not visible.

It can be seen by comparing figs. $4,7,8,13$, and 14 of Plate 6 with those of the different species of Eleodes, and then with figs. 5 and 6 of the same plate, that Trogloderus is more Eleodiinine than Scaurinine. Eulabis agrees with Cerenopus in having the two lobes of the sternite coalescent into one piece, emarginate at apex, and this is distinctly in accord with what appears as true Scaurinine characters. This investigation is in its infancy and not mature for discussion at the present time.

For the present, at least, I agree with Dr. George Horn in retaining Trogloderus in the Eleodiini. Future studies might indicate the advisability of separating it, possibly with Eleodimorpha, as a distinct tribe, and it will indeed be interesting to discover some other closely related species that might indicate its genealogical history.

General characters.-The profemora are stout and subclavate, oval in transverse section; the tibial grooves are shallow and feebly defined by asperate margins, best defined in the males, but in either sex more or less evanescent toward the base, narrower in costatus, especially in the males.

The meso- and metafemora are comparatively slender, slightly and very gradually increasing in width from base to apex, but almost parallel, quite straight, except for the normal curve by which they are adapted to the sides of the body, oval in transverse section; tibial

${ }^{a}$ Annals N. Y. Acad. Sei., V, Nov., 1890, p. 391. 
grooves more or less evanescent in basal half and feebly defined apically, very shallow but rather smooth.

Protibiæ distinctly compressed, especially along the inner side; external border arcuate in basal half, thence straight and with a tarsal groove, that evenly and gradually widens to the articular cavity with which it is continuous; the anterior margin of the groove is rather smooth, the posterior more or less denticulate; the anterior and posterior sides of the articular cavities are feebly dilated. LeConte says that the apical angle is produced, but I do not see that it is in the least so. In the male of costatus the protibiæ are briefly and very abruptly constricted at base so that a right angle is formed; the tibiæ thence to apex quite even in width, as a whole slightly arcuate, each internal edge very broadly and feebly sinuate.

The meso- and metatibiæ are slender, straight, gradually and feebly increasing in size to apex, where they are somewhat dilated, circular in transverse section, and more or less grooved or flattened externally for the tarsi; articular cavities closed.

The protuberant prosternum is very obvious in costatus, less so in tuberculatus, in each it is deeply grooved around the anterior border of the acetabula; in tuberculatus the anterior margin is distinctly deflexed.

Distribution.-Confined as far as known to the arid regions of eastern California and western Nevada, northward into Idaho.

The two known species may be separated as follows:

Pronotum cribrately punctate

costatus.

Pronotum tuberculate. tuberculatus.

The synopsis of genital characters may be formulated as follows:

Superior pudendal membrane long, reaching to the apical fourth

of the dorsal plate.

costatus.

Superior pudendal membrane shorter, reaching to apical third_-_-_tuberculatus.

\section{TROGLODERUS COSTATUS LeConte.}

Trogloderus costatus, LeConte, N. Amer. Entomologist, I, No. 1, July, 1879 , p. 3 , pl. I, fig. 3.

Elongate, oblong-oval, opaque, dirty black, integuments dense; thorax cribrately punctate; elytral costæ acutely elevated.

Head less than twice as wide as long, feebly convex, more or less irregularly impressed, frontal suture not evident, but indicated by the abrupt termination of the frontal impression, at times slightly elevated; coarsely and confluently cribrate, the punctures at times more or less corroded.

Antennce short, scarcely reaching beyond the middle of the prothorax, somewhat clavate, feebly compressed, second joint nearly onehalf as long as the third and not quite as long as wide, third joint about equal to the next two taken together, fourth the least longer 
than the fifth, the latter, sixth and seventh subequal and each about as long as wide, eighth, ninth, and tenth transverse and gradually increasing in width, eleventh narrower than the tenth, trianguloovate and about as long as wide.

Pronotum one-third to one-half wider than long, widest at the middle; disc rather strongly convex and moderately declivous at the apical angles, coarsely, more or less confluently and cribrately punctate, with two deep oval fover occupying nearly the whole of the median line, sometimes forming a deep median groove, or frequently entirely absent; apex deeply and broadly emarginate, beaded laterally, obsoletely so at middle three-fifths; sides moderately strongly arcuate to basal ninth, thence briefly and strongly sinuate to base, here the sides are divergent or subparallel, scarcely at all sinuate behind the apical angles, marginal bead distinctly serrulate anteriorly, posteriorly obsoletely so; base transverse, scarcely beaded; apical angles large, prominent anteriorly, subacute; basal angles minute, acute, and prominent externally or rectangular.

Propleurce more or less convex, but not prominently so, smooth, more or less granulate on the acetabular convexities and posteriorly, sometimes rugulose.

Elytra elongate oval, less than twice as long as wide, widest at the middle; base not margined nor adapted to the contiguous prothoracic base, which is slightly wider; humeri obsolete; sides evenly arcuate and quite evenly and gradually narrowing from the middle to apex, the latter slightly produced and rather narrowly rounded; disc quite evenly and rather strongly convex from side to side, somewhat quickly and arcuately declivous posteriorly, but slightly and broadly sinuate before the moderately oblique apex (viewed from the side), the suture and four smooth costæ each side acutely elevated, sutural costa feeble and evanescent on apical declivity, the humeral and subhumeral meeting anteriorly on humeral region, the subhumeral free and obsolete before the apex, first discal free at both extremities being evanescent on apical declivity, second discal uniting with the humeral before the apex, point of union not tuberculate nor prominent; each interval broad and apparently biseriately subfoveolate, the foveolæ more or less indistinctly marked, more or less feebly transversely coalescent, irregular in the outer two intervals, the minute subsquamiform setæ scattered independently of the pits.

Epipleurce narrow, overlapped at middle by the metasternal pieces and first abdominal segment, horizontal in apical two-thirds; surface smooth, obsoletely punctate.

Sterna sparsely, coarsely, and more or less moderately punctate; mesosternum deeply and broadly concave, sides prominent; metasternum more or less feebly and broadly concave.

Parapleurce coarsely and more or less obsoletely punctate. 
Abdomen horizontal, moderately convex, coarsely and more or less obsoletely punctate; intercoxal process and first two segments at middle third, distinctly and broadly concave, the concavity extending more or less upon the third segment, where it is rather semilunar in outline, the concavity is limited laterally by a convex ridge, well marked on first segment and there continuing the internal line of the acetabula, less evident on the second segment.

Legs rather short and scabrous; femora punctate, tibiæ muricate; anterior tibiæ more or less curved and slightly compressed; tibial spurs similar in the sexes. Tarsi rather short; first joint of the anterior with a distinct process beneath, plantar groove not well defined; apical margin of each joint somewhat prominent beneath; spinules flavate, short and stout.

Male.-Somewhat narrow. Elytra arcuately and slightly obliquely declivous behind, abdomen strongly concave. Profemora with a small and broad tooth at outer fourth. Protibiæ distinetly and briefly constricted at base, distinctly angulate at point of constriction. First joint of the protarsi with a distinct and more or less rounded process beneath, which is about a third longer than wide, truncate at tip, where it is very inconspicuously spinulose.

Female.-Slightly broadened. Elytra arcuately and rather vertically declivous, thence feebly and broadly sinuate before the moderately oblique apex. Abdomen less strongly concave. Profemora obsoletely dentate, tooth sometimes minute. Protibiæ feebly and briefly but not suddenly constricted at base. First joint of the protarsi with a distinct process beneath which is about a fifth longer than wide.

Measurements.-Males: Length, 11-12 mm.; width, 4-4.5 mm. Female: Length, $12.8 \mathrm{~mm}$.; width, $5 \mathrm{~mm}$.

Genital characters, male.-Edeagophore (Plate 6, fig. 7) oblongovate, acutely pointed, not arched.

Basale oblong-oval, twice as long as wide, evenly convex; sides feebly arcuate.

A picale triangular, slightly elongate; disc evenly convex, without a groove; sides feebly arcuate at basal third, thence slightly and broadly sinuate at tip, the latter acute: base arcuately lobed at middle, laterally feebly sinuate.

Sternite transversely trapezoidal. Each lobe triangular and rather long; sides rather gradually and mutually converging to apex, the latter subacute although narrowly rounded; surface more or less evenly convex, glabrous at base and impunctate, apical two-thirds more or less densely punctate and setose, setæ quite long, denser and longer about apical margin. Sinus broad, membrane not setose.

Female.-Genital segment (Plate 6, fig. 13) subequilaterally triangular, valves reflexed and fully chitinized, moderately depressed. 
Valvula.-Dorsal plate triangulo-oblong and not at all defined from the apex, external margin moderately convergent apically; surface more or less concave and with scattered punctures externally and apically, each puncture with a moderately short seta; external margin straight to feebly and broadly sinuate, continuous with the subacute margin of the apex, the latter slightly emarginate externally for the minute fossa; internal margin quite straight; apical margin not in the least evident, apex not at all defined from the rest of the valve, obliquely conforming to the plane of the dorsal plate, more or less rounded at tip, which is subacute and finely setose within.

Appendage minute and punctiform, apparently slightly compressed, calvous.

Superior pudendal membrane long, attaining the base of the apex, finely longitudinally rugulose, narrowly exposed.

Basal prominences not evident.

Ventrolateral surfaces not longitudinally convex, moderately so laterally; surface very glabrous and not defined from apex; submarginal groove very feebly defined for a short distance cephalad to the appendage; apex with few scattered setæ. Internal margins of the valves contiguous in basal moiety, fissure narrow in apical half, membrane not visible.

Habitat.-Western Nevada and the contiguous eastern California ; Idaho (Rock Creek).

Number of specimens studied, 3.

Type in the LeConte collection.

Type-locality.-Rock Creek, Owyhee County, Idaho.

Salient type-characters.-Elongate, dirty black, opaque. Head and thorax coarsely and confluently cribrate, the latter with two deep oval foveæ occupying nearly the whole of the median line. Elytra elongate oval, with suture and four discoidal costæ acutely elevated, intermediate furrows deep and broad, subreticulate (LeConte).

Diagnostic characters.-The distinctly cribrately punctate pronotum distinguishes costatus from tuberculatus; in the latter species the elytral costr are asperate and not smooth as in the former.

The mentum is somewhat small and more or less trapezoido-triangular, foveate laterally, not noticeably strongly sculptured.

The prosternum is strongly protuberant ventrally before the coxæ, arcuately declivous anteriorly and quite horizontal between the acetabula, feebly longitudinally grooved at middle from anterior margin; surface asperately punctate and sparsely setose, setæ short; produced and acute posteriorly.

Mesosternum deeply and broadly concave, sides prominent.

Metasternum laterally between the coxæ as long as the width of a mesotibia at middle. 
The abdominal intercoxal process is slightly transverse, about a third of its width broader than the metasternal salient and equal in length to the post-coxal part of the first ventral segment; second segment is as long as the third and fourth taken together, and nearly three times as long as the fourth.

The tarsi are rather short and slender.

Tarsal formula :

$\begin{array}{rccc}\text { Pro. } & \text { Meso. } & \text { Meta. } & \text { Metatibiæ. } \\ \text { Male. }-1 \frac{1}{5} & 1 \frac{2}{5} & 1 \frac{1}{2} & 3 \frac{1}{2} \\ \text { Female. }-1 \frac{1}{5} & 1 \frac{1}{2} & 1 \frac{3}{5} & 3 \frac{2}{3}\end{array}$

TROGLODERUS TUBERCULATUS, new species.

Elongate, oblong-oval in outline, twice as long as wide, integuments dense and opaque, pronotum tuberculate; elytral costæ acutely elevated and subserrulate, apex bituberculate.

Head less than twice as wide as long, plane, interocular region with three impressions, two lateral and one median, intervening surface convex; epistoma moderately prominent and feebly convex, continuously so with the supra-antennal convexities, frontal suture not evident, but indicated by the rather suddenly convex epistoma; surface punctato-tuberculate. Antenne short, evidently not reaching beyond the prothorax, feebly compressed and somewhat clavate, third joint about equal to the next two taken together, fourth and fifth about as wide as long, sixth and seventh evidently just the least wider than long, eighth feebly transverse, ninth and tenth distinctly so, eleventh small, narrower, and about as long as wide, orbiculo-ovate.

Pronotum widest at the middle, somewhat explanate at the sides, one-half wider than long; dise moderately convex, distinctly arcuately declivous at the apical angles, rather densely tuberculate, tubercles small and rounded, with two deep oval foveæ occupying the whole of the median line and about a third of the width, the fover limited laterally by raised and rounded sides and separated by a similar transverse convexity, the concavity of each reaching the apical and basal margins, respectively; apex deeply emarginate in circular arc (viewed from the front), the emargination appearing angulate laterally when viewed from above, without a bead; sides evenly, broadly, and rather strongly arcuate, quite suddenly sinuate at basal tenth, thence briefly straight and almost parallel to base, margin subserrulate; base, transverse, without bead; apical angles subacute, triangular, stout, and anteriorly prominent; basal angles minute, subacute and feebly prominent posteriorly.

Propleurce moderately convex antero-posteriorly and more or less concave between the somewhat explanate sides of the pronotum and the acetabular convexities, irregularly granulate and more or less rugulose. 
Elytra oval, about a third longer than wide, widest at the middle; base not margined nor adapted to the contiguous prothoracic base, not narrower; humeri rounded or feebly subangulate at the meeting of the humeral and subhumeral costæ; sides evenly and moderately arcuate, apex not noticeably produced when viewed from above, rather broadly rounded; dise rather strongly convex from side to side, slightly depressed on the dorsum, arcuately declivous posteriorly, but sinuate before the slightly oblique apex; surface sculptured with a sutural and four costæ on each side, each acutely elevated, sutural costa feeble and evidently distinct to the apex, subhumeral, humeral and outer discal costæ unite on each elytron near apex in a distinct tubercle, the internal discal costa becoming evanescent on the declivity; each costa is distinctly subserrulate on crest from a series of impressed and rather distantly spaced punctures, each puncture with a minute seta; intervals broad and apparently biseriately subfoveolate, the foveolæ rather distinctly marked and more or less transversely coalescent, giving a subreticulate appearance; each interval with sparsely placed minute elevated granules, which bear a minute seta projecting from their base behind; sculpturing irregular in the outer intervals.

Epipleurce narrow and entirely overlapped by the sternal side pieces and first three abdominal segments, exposed apical portion horizontal, also briefly exposed beneath the humeri.

Sterna and parapleura more or less scabrous and somewhat tuberculate. Sterna feebly concave.

Abdomen horizontal, moderately convex, first segment distinctly flattened and slightly concave between the coxæ, second segment very feebly flattened at middle third; surface more or less scabrotuberculate.

Legs short and scabrous. Femora tuberculately punctate, with a minute tooth at outer fourth on the profemora. Tibiæ muricatotuberculate, protibiæ somewhat constricted at base. Tarsi short and feebly grooved, first joint of the protarsi moderately produced at tip beneath.

Measurements.-Male: Unknown. Female: Length, $12 \mathrm{~mm}$; width, $6 \mathrm{~mm}$.

Genital characters, male.-Not studied.

Female-Genital segment (Plate 6, fig. 14) triangular, a little longer than wide, fully chitinized, valves slightly reflexed.

Valvula.-Dorsal plate elongate, oblong-triangular; surface glabrous and slightly longitudinally concave, very sparsely punctate and setose apically, setæ short; external border more or less feebly sinuate, somewhat prominent toward base; internal margin straight. Apex not defined from the dorsal plate, briefly sinuate externally, forming a fossa, tip rounded, but. not broadly so; internally finely setose on the valvular membrane. 
A ppendage small, flattened, and semi-elliptical, with two or three short setæ at tip.

Superior pudendal membrane attaining the apical third of the dorsal plate and not rugulose.

Basal prominences not evident.

Ventrolateral surfaces with surface lines straight when viewed longitudinally, moderately convex transversely; surface glabrous, sparsely punctate apically and feebly concave laterally before the apices, the latter concave beneath. Submarginal groove scarcely evident. Internal margins of the valves contiguous in basal two-thirds, fissure subapical, with margins feebly setose. Membrane not visible.

Mabitat.-California (Los Angeles County).

Number of specimens studied, 1.

Monotype a female (Cat. No. 12236) in the U. S. National Museum. Type-locality.-Los Angeles County, California; collector, D. W. Coquillett.

Diagnostic characters.-The tuberculate pronotum, which is somewhat dilated at the sides, subserrulate costæ of the elytra, outer three costæ meeting in a tubercle upon the apex, sufficiently characterize this species as distinct.

The female genital characters, if constant in a series, will also prove of value, as the superior pudendal membrane is much shorter and not longitudinally rugulose in tuberculatus.

General observations. - The mentum is moderate in size and subparabolic in outline, obsoletely foveate laterally, and not noticeably scabrous.

The anterior margin of the prosternum is quite strongly deflexed, the surface is gradually and not strongly arcuate between the coxæ, grooved only between the same and mucronate behind. The surface is transversely flattened in front of the coxæ at middle and very decidedly in contrast to the protuberant condition observed in costatus.

The mesosternum is rather narrowly and deeply concave and moderately prominent laterally.

The metasternum laterally between the coxæ is about as long as the width of a mesotibia at middle.

The abdominal intercoxal process is subquadrate and about as wide as the metasternal salient, and as long as the post-coxal part of the first ventral segment, quite equal to the length of the second, which is subequal to the third and fourth segments taken together; the fourth is about one-half as long as the third.

The tarsi are rather short and somewhat stout, at least stouter than in the female of costatus before me.

Tarsal formula:

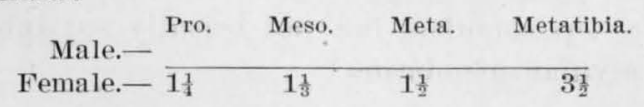




\section{SPECIES NOT RECOGNIZED.}

I have not been able to recognize nor to correlate the following species in the ample material at hand:

\section{ELEODES VICINA LeConte.}

Nigra, nitida, thorace subtiliter punctulato, latitudine haud longiore, lateribus modice rotundatis, postice subangustato, elytris discrete minus subtiliter seriatum punctatis punctis paucis interjectis, femoribus muticis. Long. .7.

Habitat ad flumen Gila.

E. quadricollis aftinis, at elytris punctis majoribus magis discretis distinctius seriatis differt. Mas, subcylindricus, elytris dorso convexis, postice attenuatis. Femina, elytris latioribus, dorso minus convexis, postice vix attenuatis.

The type is from Sonora, which is the same as that of Arizona. $\mathrm{Mr}$. Blanchard writes me that the two males in the LeConte collection are more like carbonaria than quadricollis, the side margins of the elytra being stronger and the punctures at the sides more substriate.

Colonel Casey, who has no doubt seen the types, writes: ${ }^{a}$

Vicina is distinct from quadricollis in having much finer punctures, which are sparser and much less asperate towards the sides, and also in several other characters, among which may be mentioned the form of the prothorax, widest at anterior third in quadricollis and just before the middle in vicinus, the much longer posterior tarsi in the male of vicinus. Vicinus is peculiar to the Gila Valley of Arizona.

A male from M. L. Linell's collection, bearing a label with vicinus written upon it, evidently in his handwriting, corresponds to LeConte's description, and very closely to two males in my own collection from Arizona and without definite locality.

Linell was considered a careful student and his label bears some weight. His specimen is quite different from one which Fall questionably refers to vicina.

I do not believe vicina to be distinct, and it must be a race or form of carbonaria, or quadricollis near the varieties anthracina and lustrans: the form of the protibial spurs in the female must decide which.

\section{ELEODES NITIDUS Casey.}

The following is Colonel Casey's description :

Rather slender, convex and subcylindrical, black throughout and strorigly shining, glabrous.

Head rather sparsely punctate, moderately coarsely so toward apex; antennæ robust, nearly as long as the head and prothorax, the third joint four

${ }^{a}$ Ann. New York Acad. Sci., V, Nov. 1890, p. 395. 
times as long as wide and fully as long as the next two together, last three joints distinctly dilated, forming a club, the ninth and tenth strongly transverse.

Prothorax quadrate, very nearly as long as wide; disc just visibly wider at apical third than at base, evenly convex, externally, minutely, and sparsely punctate; apex transverse, broadly and feebly bisinuate, equal in width to the base; sides parallel, very feebly arcuate; base broadly and rather strongly arcuate; apical angles right, narrowly rounded; basal angles broadly obtuse and not prominent nor at all rounded.

Elytra two and three-fourths times as long as the prothorax, and in the middle nearly one-half wider, about twice as long as wide; base broadly emarginate; humeri right, not noticeably exposed; sides broadly arcuate; apex acutely rounded; disc obliquely declivous behind, having feebly marked, distant, completely unimpressed series of extremely minute punctures; intervals minutely, sparsely, and more or less confusedly punctate, the punctures not distinctly larger or denser laterally.

Femora all slender and completely unarmed; spurs of the anterior tibiæ very unequal, the anterior slender, acutely pointed, and moderate in size; posterior tarsi slightly compressed, nearly three-fourths as long as the tibiæ.

Prosternum slightly prolonged but not at all reflexed, the apex vertical.

Length, $18 \mathrm{~mm}$; width, $6.7 \mathrm{~mm}$.

Habitat.-Arizona.

Casey's specimen was a unique and he compares it with longicollis. He writes that it differs from that species in its flatter, rather shorter prothorax, which is less rounded on the sides, and in its shorter, broader elytra, broadly and rather strongly emarginate at the base and having widely distant rows of punctures, and in having a shorter, stouter, and much more clavate antennæ.

It is possible that the species described by me as dissimilis may be nitidus. Dissimilis is very variable. (See p. 398.)

ELEODES REFLEXICOLLIS Mannerheim.

I have failed to satisfactorily place this species of Mannerheim's, the type of which was taken at Ross, California. This locality is undoubtedly Fort Ross, near the mouth of the Russian River on the coast.

Mannerheim says that it is close to Eleodes planata Eschscholtz, and that the sides of the thorax are unusually reflexed, and the base abruptly narrowed. Peculiar and aberrant forms are occasionally met with. (See scabricula for remarks upon a unique specimen taken in Napa County, California, and in the collection of A. Koebele.)

\section{EARLY STAGES OF THE ELEODIINI.}

Comparatively little has been written upon the early stages of the Tenebrionidæ of the United States, and also little upon the tribe, 
treated in this paper. The only articles accessible are those of Carl F. Gissler ${ }^{a}$. Some of the figures are so very poor in these papers before me that they are of little use.

Mr. Gissler writes that in studying the larval states of the Tenebrionidæ we find that there is scarcely a coleopterous family whose members are homologically so closely allied and correlatively alike, and are all referable to three typical larval forms:

1. Those having homogeneous corneous segments, cylindrical in longitudinal series, the stigmata situated in the pleurites. Example, that of Tenebrio.

2. Form more compact, with only the prothoracic segments corneous and abdominal segments slightly arcuate. The dorsal segments do not overlap, forming a marginal bead, above which (on the tergal part of the segment) the abdominal stigmata are situated. Example, that of Bolitophagus and Bolitotherus.

3. Clypeus not entirely separated, mandibles more strongly dentate, terminal joint of labial palpi large and truncate, pygidium without articulated spines.

The larvæ of the Eleodiini belong to the first form. They are elongately cylindrical, resembling those of the Elateridæ, which are commonly called wireworms.

The former differ in having the cardo of the maxillæ connate and a transverse impression immediately behind the clypeus, thus apparently separating the same from the front, and also by the better developed labrum (Gissler).

Very young larvæ have their antennal joints more globular than the older ones. In full-grown larvæ of the Eleodiini the first joint of the antennæ is much shorter than the second, its substance soft, nonchitinized and retractile; its position is in a minute cavity, which is surrounded by a semi-circular ridge (Gissler).

William R. Erichson has described this as the first joint in the larva of Tenebrio. ${ }^{b}$

From my dissections I regard this simply as the basal articulation with its membrane. Compare figs. 9 and 10, Plate 13. It is quite evident that the antennæ are retractile, but when dissected out it is composed of only three joints.

Mr. Gissler obtained eggs of Eleodes gigantea from specimens kept in captivity. These were discovered in October, and measured in length $0.8 \mathrm{~mm}$; width, $0.85 \mathrm{~mm}$.; elongate oval and milk white in

${ }^{a}$ Bull. Brooklyn Ent. Soc. for $1878-1879$, I, No. 1, p. 11 ; No. 3, p. 18; No. 11, p. 85 .

${ }^{b}$ See Archiv für Naturgeschichte, 1841, p. 365. 
color. In November (20th, 1877) he noticed the first larvæ; none appeared after December.

$\mathrm{Mr}$. Gissler describes the larva of Eleodes gigantea and dentipes as follows :

Larva (Eleodes gigantea).--Head convex above, gular region concave; all the mouth parts like Tenebrio; antennæ differing by the stouter second and third joints. Pygidium with 18 lateral spines, terminal obtuse tip, sparsely frimbriate. Color of small specimens (6 mm.) entirely white.

No trace of ocelli or even dark spots on the ophthalmic region. The small larvæ have the abdominal segments nearly all flat and gradually after several exuviations acquiring the typical wire-shape and darker color. The legs, thoracic and abdominal segments as in Tenebrio.

Larva (Eleodes dentipes).-Pygidium with but ten spines, the two terminal are slightly longer and run parallel over the tip. The front legs also differ from those in the larva of gigantea; the head, mouth parts, antennæ, middle and posterior legs are as in the latter species. A larva but a few hours old (Plate 13, fig. 15) has two small blunt terminal spines, at the sides of which are two stout, long bristles; there are no lateral spines. The latter appear after the first moult. Length, 2-5 mm. Mr. Gissler also writes that a number of Eleodes dentipes began to deposit their eggs in April, and the larvæ grew to 30 and $35 \mathrm{~mm}$.

The above descriptions are very unsatisfactory and give no clear nor complete idea of the structural characters of these larvæ.

Mr. Gissler kept his larvæ in a breeding jar with earth and decayed wood.

I have kept in captivity the several species of Eleodes found about San Francisco and succeeded in obtaining the eggs of several species. In general form and color they were all alike, milky white and oval in form, differing only in size and this in a few fractions of a millimeter; the majority were about a millimeter in length. I examined them carefully under high magnifying power, but the enveloping tunic was alike in all, no sculpturing. The following were examined: Eggs of dentipes, quadricollis, cordata, parvicollis, and scabrosa.

I succeeded in obtaining larve from only one species and that was dentipes; they perished during the excitement following the San Francisco disaster. The larve had reached the length of 9.5 and 10 $\mathrm{mm}$. I discovered them in July and I did not know how long they had been dead. I had not discovered them before April 18.

Between these larvæ and those mentioned by Mr. Gissler I find very little resemblance. This probably depends upon a different age of the larvæ. My study and dissections were made upon two 
larva $10 \mathrm{~mm}$. in length (Plate 13, figs. 4-14), supplemented by eight others. The illustrations give the characters better than a labored description.

\section{LARVA OF ELEODES DENTIPES.}

Length, $10 \mathrm{~mm}$; color, castaneo-testaceous, at times fuscous. Surface glabrous. Form elongately cylindrical, flattened ventrally.

The ultimate and posterior border of the penultimate segments, both above and beneath, sparsely clothed with long flying hairs; the under surface of the thoracic segments are similarly clothed, the hairs being a little longer and rather denser; the sides of the head beneath are rather more conspicuously pubescent. Similar but shorter hairs are scattered here and there over the dorsal surface of the tergites, apparently without a definite orderly arrangement, except laterally just a little in advance of the posterior border on each segment there is a longer hair, and these are observed on all the segments, forming a series on each side; on the prothorax there is a hair at each angle. There is also an evident series on the sternites just within the lateral border on each side; four or five hairs were counted; the number varied, possibly from being broken off; the series are definite and continuous on the abdominal sterna.

Head (Plate 13, fig. 9) somewhat circular in outline, but truncate at base, transverse without the clypeus and labrum, slightly depressed; just behind each antenna are two ophthalmic spots; all are small and transverse, the anterior a little more external than the posterior, separated by about five times their own length; immediately in front of the anterior are three or four setigerous punctures.

Antenno three-jointed, situated immediately behind the mandibles in articular cavities with rather prominent borders; joints one and two about equal in length and about twice as long as wide, terminal joint very small and bearing a seta at tip; retractile. (See figs. 10 and 9, Plate 13.)

Mandibles short, somewhat irregularly triangular in outline, apex emarginate, superior cusp longer than the inferior; superior surface feebly convex, slightly irregular; external surface arcuate as viewed from above, more strongly so just apicad to the middle when viewed from below; external margin of superior surface with a cluster of some three or four setæ at middle, a couple of setæ more basad; internal margin with a small triangular and acute dentiform process slightly basad to the mid-point between apex and molar.

Inferior surface irregularly convex, excavated within the cuspidate apex, distinctly evident as viewed from below. Internal surface with a prominent molar (figs. 13 and 14, Plate 13). Membranous lobes so evident in the adult, obsolete.

59780-Bull. $63-09-32$ 
Maxille rather stout. Cardo and stipes rather distantly separated from the mentum by a membranous structure. Palpi threejointed, second joint slightly broader than the first, third distinctly smaller.

Mentum subquadrate, sides slightly converging to base, apex sinuato-truncate, the articulating membrane attaching it to the palpiger more or less distinct; ligula a delicate median process between the palpi, bearing two setæ at tip.

Labial palpi short and two-jointed; first joint about as wide as long, possibly a little longer if fully extended; second joint much narrower and smaller.

Submentum (figs. $8 s$ and $11 s$, Plate 13 ) trapezoidal, base moderately arcuate, apex truncate, sides feebly, broadly but distinctly sinuate. Both the mentum and submentum are sparsely clothed with rather long flying hairs.

Gula subquadrate, sides somewhat arcuate basally and feebly sinuate apically. Suture distinct.

Labrum transverse, a little more than twice as wide as long, anterior margin slightly arcuate, more strongly rounded laterally. There is an apical series of about eight setæ, and a basal series apparently the same in number.

Clypeus with a feebly transverse impression which shows at the sides as an emargination, just back of which is a setigerous puncture, another more internal, the setæo of the two sides being in line; separated from the frons by a distinct transverse groove which terminates at the anterior border of the antennal socket.

Prothorax nearly quadrate on the dorsum, slightly transverse, in some specimens transversely and feebly concave. Meso- and metathorax much shorter and together scarcely as long as the prothorax.

Abdominal segments subequal in length.

Spiracles.-There are nine pairs. The anterior is situated under the margin of the prothorax in a depression external to the coxa, larger than the others and with the margins more prominent and chitinous. The abdominal are in segments 1-8 inclusive and situated at the anterior margin of the pleurites; they are circular and flat, margins not prominent.

Pygidium (Plate 13, fig. 5) triangular, sides moderately arcuate, apex rather broadly rounded. The marginal series of spines consists of eight on each side, the terminal two are just noticeably a little stouter and longer than the others.

The specimen from which fig. 5 was drawn shows three spines displaced inward from the proximal extremity of the marginal series; another specimen had them present only on one side and in others they were entirely absent. I was unable to determine if this was the result of wear. 
Mr. Gissler notes that in one specimen studied by him there were two spines articulated in one cavity, while in another specimen they were asymmetrically placed, nine on one side and eight on the other. In the sculpturing of the pygidia a few smooth spots were observed in Eleodes.

Legs similar in form, the anterior larger and stouter, claws of the middle and posterior are distinctly more slender; the anterior are more strongly chitinized. The coxæ are quite conical and transverse, also prominent.

The anterior has spines arranged as follows: At inner side of base of claw a spine points inward, tibiæ with three spines on inner surface, femur with three, trochanter with two, each podomere with seattered flying hairs of varying lengths.

The middle and posterior legs also have spines somewhat differently arranged and more difficult of description.

Mr. Gissler writes that in Tenebrio and Eleodes (Plate 13, fig. 15) the first post-embryonic stages are alike in the form of the pygidium. The integumentary appendages of larval pygidia may be regarded as the homologues of the dorsal parapodia of their ancestors-the Annelides.

Two very minute tubercles ean be seen under strong microscopic power at the middle of the base of the pygidial tips in Eleodes. Whether they are orifices or not I can not decide. The larvæ of Eleodes when disturbed and handled violently jerk their abdomen and spurt a turbid, odorless, watery fluid out of two lateral orifices situated under the tergal fold near the posterior margin of the seventh abdominal segment. These structures are a peculiar adaption to the larval body, since the excretion of the repugnatorial glands of the imago is spurted out through the anal opening. The higher development of this gland is certainly attained during the pupal period (Gissler).

Mr. Gissler found that in Blaps mortisaga the pygidium had usually twelve lateral and two latero-terminal spines (Plate 13, fig. 18). Out of ten specimens two had sixteen in all, the rest only fourteen. In Eleodes gigantea and $E$. dentipes he gives as the usual number of spines sixteen lateral and two latero-terminal. A number of either species had only sixteen in all. (See Plate 13, fig. 17.)

The larvæ of Eleodes are abundant, but I have never had time to successfully rear them, to determine the species to which they belonged. From the sand dunes along the coast the larvæ of E. clavicornis and scabrosa have been taken. Two pupæ were obtained; one developed a clavicornis, the other being identical was studied, figured, and preserved in spirits. 
PUPA OF ELEODES CLAVICORNIS.

(Plate 13, figs. 1, 2, and 3.)

Length, $10.5 \mathrm{~mm}$; width of body, $4.5 \mathrm{~mm}$; greatest width from knee to knee, $7 \mathrm{~mm}$. Oblong-oval, moderately arcuate, head flexed against the prosternum; abdomen moderately depressed; color yellowish white, appendages semitranslucent.

Head exposed, vertex visible from above, clypeal region convex, frons somewhat transversely impressed, vertex rather more prominent; antennæ curving backward against the sides of the prothorax, over the profemora, at which point they are not visible when viewed from below.

Pronotum evenly convex; base almost truncate, basal angles rather broadly rounded, sides arcuate, apex feebly and broadly emarginate, with angles somewhat narrowly rounded.

Mesonotum short, transverse, and moderately convex; elytral pads passing obliquely backward and ventrally above the pro- and mesocrura, apical fourth between the meso- and metacrura, visible ventrally only at this point. Epipleural margins apically contiguous to basal half of the mesotarsi.

Metanotum a little longer than the mesonotum, moderately convex, and broadly sinuate behind.

Legs prominent laterally, not appressed against body, distinctly compressed and comparatively broad; tarsi distant from each other in median line, except the metatarsi, which are in contact in apical half; coxæ and sterna visible in the median line.

Abdominal segments convex dorsally, less so ventrally; pleural region of segments one to seven produced laterally into subquadrate laminiform processes; last two segments without lateral processes and more evenly convex from side to side. Fourth ventral segment deeply and broadly emarginate at apex; fifth smaller, rather arcuate at apex and within the emargination of the fourth; third segment broadly and less deeply emarginate.

Abdomen at apex terminating in two elongate processes, each gradually tapering from base to apex, the latter chitinous; beneath the bases of these cerci there is a small segment which is deeply emarginate, with angles prominent posteriorly.

The lateral processes of segments one to seven are limited at base dorsally by a longitudinal impression on either side of the dorsum; the impression begins on segment one and ends on base of the seventh; ventrally the impressions are less strongly marked.

In the specimen at hand the processes of segments two to six are deeply and semicircularly emarginate at middle third, each anterior and posterior third is squarely truncate at apex, with angles subacute, those at the emargination are chitinous and denticulate, each 
dentate angle has a small seta at middle of its side toward the emargination; contiguous sides of the processes of each adjoining segment narrowly chitinous, very minutely and irregularly denticulate; posterior third of the process of first segment not developed; processes of seventh segment imperfectly developed. Anal cerci with a few scattered setæ.

Pronotum with a lateral marginal row of comparatively closely and evenly spaced chitinous setr, internal to which is a submarginal series of distantly spaced setæ, often broken off and appearing as minute chitinous tubercles; there is also a post-apical series of very distantly spaced and similar setæe, as well as an antebasal series similarly spaced.

In Plate 13, fig. 2, it will be seen that the post-apical series appear as marginal when viewed from above.

On the dorsal surface of the head there are four to six setx; dorsal surface of abdominal segments three, four, five, and six with a seta each side near basal and external angle. Legs with a short seta on outer anterior femoral region near the knee; fourth ventral abdominal segment with a subapical row of setæ.

Tribe BI,APTINI.

In (Blaps) the globular outer antennal joints, wide epipleuræ which terminate upon the external surface of the cauda when present, the intercoxal tubercle of the first abdominal segment and the pubescent pit at base of the second abdominal segment the present tribe stands in marked contrast to anything observed in the genus Eleodes, and in fact all of the genera of the Eleodiini, except in the wide epipleuræ which forms the whole inflexed sides of the elytra in Eleodimorphá.

The genital characters are certainly very distinct and more primitive than is to be seen anywhere in the Eleodiini.

Genital characters, male.-Lobes of the sternite strongly connate, clavæ connate, lying dorsad to and forming a pallium for the edeagus, more obsolete alæ, more embryonic condition of the edeagophore, there being a complete solution of continuity in the chitinization along the median line of both the basale and apicale, these segments being longitudinally subdivided by an evident membranous line into lateral sclerites.

Female.-Valves of the genital segment (Plate 5, figs. 16 and 17) completely chitinized, apex of each undifferentiated, appendage absent. The facies of the segment is quite different from that observed in the Eleodìini, but a phylogenetic relationship is evident.

I am not desirous to repeat what may already be known in Europe, but simply to indicate my reasons for not retaining the genus Blaps in the same tribe with the others dealt with in this paper. 
It is only by the assiduous working of data and in the making of deductions in accordance with the laws governing ontogenesis and variation that our knowledge will be complete or as full as scientific progress will permit.

The student must bear in mind that the characters of Blaps given have been drawn up from a very limited number of species, and that it is to be expected that a genus so rich in species will present variations analogous to those observed in Eleodes. I wish to point out that the genus is undoubtedly a divergent stem from the ancestral phylogenetic trunk from which Eleodes also had its origin. A detailed study along the lines which I have laid down might be the means of greatly modifying our view of relationships as at present accepted.

\section{Genus BLAPS Fabricius.}

This well-known genus of the Old World needs no treatment at my hands and is given a place here on account of two species having been introduced into the United States and therefore are to be considered as a part of our fauna.

In many characters it resembles Eleodes and also presents several very distinct and divergent characters.

Mentum transverse, plane and more or less variable in form, sometimes trapeziform, sometimes rounded at the sides and in front, at times subtruncate, rarely sinuate, always narrowing at base for a short distance. The lateral lobes are small and invisible.

Maxillary palpi elongate, last joint securiform, longer than wide.

Labrum prominent, transverse, rectangular or subcordiform, angles rounded and more or less sinuate at middle of the anterior border.

Head prominent, not deeply inserted, frontal suture distinct or obsolete; epistoma with sides more or less straight and convergent anteriorly, apex truncate or feebly sinuate.

Eyes transverse, narrow, subreniform or sublunate.

Antennce moderate, 11-jointed, third joint long, 4 to 7 of variable length, obconical, 8 to 10 globular, 11th oval, pointed at tip.

Prothorax variable; sometimes almost plane and rectangular, at others more or less convex and rounded at the sides, the latter always margined.

Scutellum of variable size, sometimes not visible.

Elytra at base not as wide or wider than the contiguous prothoracic base; form and length variable, frequently attenuated posteriorly and caudate at apex.

Epipleurce attaining the humeral angle where the superior margins are visible from above, gradually narrowing to elytral apex. Legs generally long, especially the posterior; anterior femora more or less thickened; tarsi moderate, spinous beneath, plantar grooves distinct.

Prosternum mucronate or not. 
Male characters.-Narrower, finer punctuation, greater length of elytral cauda when present. Abdomen more or less moderately convex, first abdominal suture more or less impressed with base of second segment and apical moiety of the first, giving the abdomen the appearance of being oblique and the sterna somewhat prominent; first suture with a fossa at middle, densely clothed with golden pubescence on the segmental margins; sometimes a truncated tubercle on the intercoxal process of the first abdominal segment.

Female characters.-Broader form, somewhat coarser punctuation. Abdomen rather strongly convex.

Genital characters.-The characters observed in the specimens at hand are as follows:

Male.-Edeagophore, length $5.5 \mathrm{~mm}$; edeagus $1.5 \mathrm{~mm}$. Very elongate, somewhat flattened, strongly arched, somewhat oblongovate and well chitinized.

Basale, elongate oblong, about four times as long as wide, moderately convex from side to side, divided by a median membranous groove which extends from base to apex, apically continuous with the groove of the apicale.

A picale elongately triangular, at least twice as long as wide, somewhat depressed, disc feebly convex, narrowly and more strongly so laterally, a long median groove extending from base to apex; base quite broadly and strongly lobed at middle three-fifths, laterally broadly and feebly sinuate; sides slightly and evenly arcuate, regularly converging to the subacute apex, the latter rendered minutely emarginate by the median groove.

Sternite transversely suboblong, lobes strongly connate and continuously chitinized, transversely prominent at middle, the surface sloping apically and basally; apical moiety broadly concave; basal half less broadly concave at about middle third, laterally the surface is convex and gradually diminishes toward the lateral angles of the apex; apical margin broadly and evenly emarginate; external borders moderately arcuate; apical angles somewhat prominent and rather narrowly rounded.

Apical moiety densely pubescent, hairs of moderate length and rather coarse, basal portion glabrous.

Clave absolutely not evident as distinct structures. They are present but connate forming a dorsal pallium for the edeagus. The margins of the pallium gradually attain the midline ventrad to the base of the edeagus, becoming contiguous but not connate; beyond the middle of the edeagus the pallium is entirely dorsal, with sides distinctly chitinous and semimembranous at middle. The apex of the pallium projects just a little beyond the caput edeagi. Alæ strongly inflex and somewhat obsolete. 
Female.-Genital segment (Plate 5, figs. 16 and 17) triangular, elongate, general dorsal surface plane and glabrous, appendages absent.

Valvula fully chitinized, apex not differentiated from the dorsal plate, surface slightly irregular, at middle minutely and ocellately punctured, a minute seta arising from each puncture, apex slightly deflexed and subacute, very feebly convex above; external border broadly and feebly sinuate at middle, arcuate basally and apically; internal margins rather straight in apical two-thirds, arcuate and converging from base where they are moderately distant to become contiguous at middle third.

Superior pudendal membrane long, reaching to the base of the apical region, very finely longitudinally rugulose.

Ventrolateral surfaces convex basally, less so towards apex, moderately concave beneath the slightly deflexed apices; internal margins of the valves contiguous basally and apically, genital fissure fusiform and just basad to the middle; submarginal groove obsolete, somewhat evident beneath the apical margin. Dorsal plate not at all explanate. Apical two-thirds very sparsely and finely pubescent.

The following two species can be credited to our fauna:

Blaps simitis Latreille.

Blaps mucronata Latreille.

I shall not attempt a specific diagnosis. Doctor George Horn compared native specimens with the European and dispelled any previous doubts about their correct identification. ${ }^{a}$

Habitat.-A few specimens of mucronata occurred near Baltimore, Maryland. Simitis occurs abundantly at Alexandria, Virginia.

I have had the privilege of studying a series in the collection of the U. S. National Museum, said to have come from West Virginia (Riley Coll.) ; figs. 16 and 17, Plate 5, were taken from a broad female from that series. A small series was kindly loaned me by $\mathrm{Mr}$. Charles Waterhouse, of the British Museum, including what is supposedly correctly identified specimens of similis, mortisaga, and mucronata. Besides these, I examined a series rather recently obtained from London (British Museum), England, by Miss Julia Wright.

The specimens in our American collections do not seem to be definitely labeled. Mr. Liebeck, of Philadelphia, writes me that in his collection is a specimen from Alexandria, Virginia, labeled as gibba; one from Boston, Massachusetts, taken in a warehouse, identical with a specimen (European) in the Horn collection of simitis; two labeled mucronata, supposedly from Canada.

In the Horn collection (Academy of Natural Science, in Philadelphia) there are three forms - one a broad form taken by Doctor Castle at Alexandria, Virginia, and labeled gibba; two forms have 
the label simitis - one a broad form, single specimen from Europe, and the other an elongate slender form, of which some are labeled "Md."

A study of the genitalia of Blaps and their careful comparison with typical forms of the genitalia of Eleodes, Embaphion, and Eleodimorpha leaves no doubt in my mind that they are not in any way directly related and that it is absolutely necessary to erect a new tribe (Eleodiini) to receive our species. No species of the Blaptini (Blaptido), except Blaps, has yet been discovered in the United States fauna.

With Blaps eliminated from the Eleodiini the tribe becomes composed of homogeneous elements, with possibly the exception of Trogloderus, as I conld not study the genitalia in all points of detail for scarcity of material.

\section{APPENDIX.}

In May, 1908, there appeared in the Bulletin of the Department of Geology, Vol. 5, No. 12, of the California University in Berkeley, a paper on the Quaternary Myriopods and Insects of California, by Fordyce Grinnell, jr.

In this paper the author recorded seven species of Eleodes, three being described as new, all having been taken from asphalt beds at Rosemary, near Los Angeles, California. They are supposedly the fossil remains of recent or older species. These are the fossils referred to on page 29 of this monograph.

I had the pleasure of identifying the species for Mr. Grinnell. The following is a list of the species:

Eleodes acuticauda LeConte, also the punctate form; Eleodes acuticauda var. laticollis, Eleodes consobrina LeConte.

The following were described as new : Eleodes (subgenus Eleodes) elongata Grinnell; Eleodes behrii Grinnell and intermedia Grinnell. The last two belong to the subgenus Blapylis.

In order to more fully correlate these new forms with the more recent forms considered in the present monograph, I carefully reexamined the types and record the following facts:

All of the specimens are very brittle, deep black in color, and shining; they appear as if the asphalt had exerted some chemical effect upon them that to a certain extent had modified the structural details.

These specimens are interesting and present some points of structure and sculpturing which can not be correctly described until a larger or more perfect series shall have been collected.

The heads, pronota, and appendages are missing from all the specimens, and the elytra alone can not tell the whole story. 
ELEODES ELONGATA Grinnell.

The type is a right elytron, fully exposed except the epipleural margin, which is sunken into the asphalt. The humerus and epipleura immediately beneath are free. The specimen is too poor and fragile to give a clear idea of the sculpturing.

The elytron is in form like that of Eleodes grandicollis; the punctuation is similar, very sparse and small, scarcely at all subasperate, and quite sharply defined; general surface glabrous and shining. Humerus rounded, and the superior epipleural margin is thin and sharp.

Length, $21.5 \mathrm{~mm}$; width, $9 \mathrm{~mm}$.

Type-specimen.-Number 10025, University California Collection of Invertebrate Palæontology.

This species really appears to be a form of grandicollis; it differs but slightly from some of those of to-day. Grandicollis is so distinct that an elytron or thorax ought to be readily recognized.

\section{ELEODES BEHRII Grinnell.}

One elytron (left), apical sixth buried in the asphalt, dorsal surface and epipleura exposed, and in a fairly good state of preservation.

The elytral base is truncate, humerus rounded and not in the least prominent; side evenly arcuate; disk moderately convex, broadly and evenly arcuately declivous laterally, not striate, punctuation diffuse, rather dense, subasperate, and with a tendency to coalesce in twos and threes, the intervals more or less convex and forming slight transverse rugulæ.

Epipleura rather broad and concave, superior margin moderately prominent and rather sharp, gently curving upward anteriorly to the humerus, thence caudad more broadly and arcuately curving downward to apex; surface smooth, sparsely and distinctly punctate, punctures moderately small; there is also a trace of transverse rugulæ.

This species is without a doubt closely related to consobrina or parvicollis; the elytral sculpturing is more like that observed in the latter.

The epipleural characters are unlike anything known to me; the marked concavity is rarely observed in sporadic instances in individuals of to-day; the curve of the superior margin is more strongly downward to apex than in any species. It is possible that these wellmarked characters are the result of warping in the asphalt.

This species is the only one of the three under consideration that probably deserves a name. It is surely a true Eleodes (Blapylis) and not at all worthy of a generic standing, as the author suggestively wrote. 
Length, $10 \mathrm{~mm}$; width, $4.5 \mathrm{~mm}$; greatest width of epipleura, $1.5 \mathrm{~mm}$.

Type-specimen.-Number 10023, University California Collection of Invertebrate Palæontology.

The type, an elytron which is "narrowly oval" with its fellow of the opposite side would give a more broadly oval figure, like that observed in a small parvicollis, the dorsal surface being somewhat flattened.

\section{ELEODES INTERMEDIA Grinnell.}

A complete abdomen, meso- and metathorax, with elytra, constitutes the type; the specimen is quite strongly flattened.

The form of the body is broadly oval and truncate anteriorly.

Elytra truncate at base; humeri rounded and not prominent; sides evenly arcuate; apex not narrowly rounded; disk evidently flattened on the dorsum, and moderately convex, more strongly and arcuately rounded laterally; surface quite densely and submuricately punctate, punctures coalescing more or less, the interstices convex, forming slight transverse rugulæ; sculpturing denser and coarser laterally and on apex, not in the least striate; surface evidently evenly and moderately arcuately declivous posteriorly.

Epipleurce rather broad at base, gradually narrowing to apex; surface distinctly concave throughout, finely, subasperately, and sparsely punctate; superior margin strong, quite sharp and prominent, not sinuate beneath the humeri, but straight in the anterior moiety, and thence quite evenly and gradually arcuately descending to apex as viewed longitudinally.

Mesosternum evidently feebly arcuately declivous, deeply concave at middle between the prominent and rounded acetabular borders; very densely, rather finely and confluently punctate.

Metasternum and episterna densely and rather finely punctate. The metasternum laterally between the coxæ apparently about two-thirds as long as the post-coxal part of the first abdominal segment.

Abdomen densely and moderately coarsely punctate. First segment at middle evidently as long as the second and third segments combined; intercoxal salient quadrate and distinctly transverse, surface concave and evidently with glabrous areas, equal in length to the postcoxal part of the same segment; second and third segments evidently equal in length and each subequal to the length of the post-coxal part of the first.

Length, $12 \mathrm{~mm}$; width of elytra, $8.5 \mathrm{~mm}$.

Type-specimen.-Number 10026, University California collection of Invertebrate Palæontology.

This specimen is related to parvicollis, and I believe specifically identical with behrii, the latter is smaller and probably a male, while intermedia is the female. 
There is scarcely any difference at all except in size and the epipleural curve.

The age of the asphalt beds at Rosemary, near Los Angeles, is Quaternary. The remains of the saber-toothed tiger were also taken from this deposit. The remains of the Coleoptera were found in the neighborhood of the bones.

My colleague, Dr. E. C. Van Dyke, who has devoted time to the study of the origin of the Californian entomological fauna, considers that the above data substantiate the statements that have been made from time to time that a great deal of the so-called Upper Sonoran or Californian fauna found its way into this State, from the south, at a very early period, probably during early Tertiary times. In this list are to be included most of the typical genera and subgenera of the most southern parts of the State. Already at the time at which these deposits were made, most of the species had assumed the appearance that we see in their descendants, the forms living at the present day. 


\section{EXPLANATION OF PLATES.}

\section{Plate 1.}

Fig. 1. Dorsal view of the right valve of the genital segment of Eleodes nigrina; showing the chitinous, moderately produced apex, evenly and broadly rounded at tip, with the valvular membrane rather largely exposed within and caudad to the superior pudendal membrane.

2. Ventral view of the left valve of Eleodes nigrina; showing submarginal groove, concave ventral surface of apex and part of the genital fissure.

3. Dorsal view of the apicale of the edeagophore of Eleodes nigrina; showing the depressed and broadly membrano-chitinous area at middle.

4. Dorsal view of the genital segment of Eleodes gigantea; showing the fully exposed superior pudendal membrane, falciform dorsal plates, chitinous and everted apices, and minute appendages.

5. Ventral view of the left valve of the genital segment of Eleodes gigantea; showing the broad submarginal groove continuous with the concavity of apex, straight internal margin of the valve, and absence of the genital fissure.

6. Dorsal view of the apicale of the edeagophore of Eleodes gigantea; showing the broadly and strongly depressed membranous surface and slightly recurved apex.

7. Dorsal view of the left valve of the genital segment of Eleodes longicollis; showing its resemblance to that of gigantea, but more strongly punctate.

8. Dorsal view of the right valve of the genital segment of Eleodes grandi. collis; note the truncate apical margin of the dorsal plate, rectangular angle, truncate appendage, and short pudendal membrane.

9. Dorsal view of the right valve of the genital segment of Eleodes tenebrosa; note the plane dorsal plate, long, slender, subacute, and membranous apex; compare with figs. 1 and 2 .

10. Ventral view of the left valve of the genital segment of Eleodes tenebrosa; showing evenly convex surface and subapical fissure.

11. Dorsal view of the right valve of the genital segment of Eleodes pedinoides, typical form; note the explanate and plane dorsal plate which is evanescent apically into the well-developed external apical lobe, also the small rudimentary internal lobe and long pudendal membrane.

12. Dorsal view of the right valve of the genital segment of Eleodes extricata, typical form; note the oval-oblong dorsal plate, acute and small apex, large and flattened appendage.

13. Dorsal view of the right valve of the genital segment of Eleodes obscura, typical variety; note the dorsal position of the submarginal groove, dorsal plate apparently contracted with sides arcuately reflexed, surface deeply concave, basal prominences strongly developed.

14. Dorsal view of the right valve of the genital segment of Eleodes suturalis; compare with figs. $23,13,15,16$, and 17 . 
Fig. 15. Dorsal view of the right valve of Eleodes dispersa; compare with figs. $13,16,14$, and 23 .

16. Dorsal view of the right valve of Eleodes sulcipennis; compare with figs. $13,15,14$, and 23 .

17. Dorsal view of the right valve of Eleodes acuta; compare with figs. 14 and 23.

18. Dorsal view of the right valve of Eleodes armata; note the nearly plane dorsal plate, reflexed internally, the flattened subconical appendage, and that the basal prominence is not well developed.

19. Lateral view of the apicale of the edeagophore of Eleodes texana; note the moderately protruded edeagus between the apex above and the abducted clava beneath.

20. Dorsal view of the right valve of the genital segment of Elcodes militaris; note that the dorsal plate is concave with sides reflexed, submarginal groove somewhat visible from above, appendage large and flattened, the basal prominences evident.

21. Dorsal view of the right valve of Eleodes lucw; compare with figs. 18, 20 , and 22 .

22. Dorsal view of the right valve of Eleodes luca, forma inflata; compare with figs. $20,21,14,17$, and 23.

23. Dorsal view of the right valve of Eleodes texana; note the resemblance between figs. 22 , and 21 as compared with $13,14,15,16$, and 17 .

\section{Plate 2.}

Fig. 1. Dorsal view of the edeagophore of Eleodes omissa; note the membranous groove of the apicale, the fully abducted clave and the extruded edeagus.

2. Sternite (male) of Eleodes omissa, forma communis, exhibiting variation from the typical form; note the sparsely setose interlobar membrane; $a$, the produced internal basal angle of the triangular chitinous plate of the sternite (see p. 18).

3. Dorsal view of the genital segment of Eleodes omissa, common form; compare with figs. 6 and 9 of this plate and fig. 11, Plate 1.

4. Ventral view of the genital segment of Eleodes omissa, common form; note the surface contour, the direction of the appendages and the broad fusiform genital fissure, the visible inferior pudendal membrane.

5. Sternite (male) of Eleodes quadricollis, forma tarsalis; compare with fig. 2.

6. Dorsal view of the genital segment of Eleodes quadricollis, forma tarsalis; note the differences about apices of the valves.

7. Ventral view of the genital segment of Eleodes quadricollis, forma tarsalis; compare with figs. 4 and 10.

8. Dorsal view of the edeagophore of Eleodes quadricollis; compare with fig. 1 .

9. Dorsal view of the genital segment of Eleodes pygmaa; valves slightly abducted; note the resemblance to fig. 3 .

10. Ventral view of the genital segment of Eleodes pygmaa; valves moderately abducted.

11. Sternite (male) of Eleodes marginata; note the rather rounded lobes and long setæ; compare with fig. 2; Plate 3, fig. 2, and Plate 4, fig. 15.

12. Dorsal view of the genital segment of Eleodes marginata; note the nearly fully chitinized valves, the produced and everted apices, and punctiform appendages. Compare with fig. 16, Plate 5. 
Fig. 13. Ventral view of the genital segment of Eleodes marginata; note the contiguous internal margins of the valves and compare with fig. 16, Plate 5.

\section{Plate 3.}

Fig. 1. Dorsal view of the edeagophore of Eleodes obsoleta; see explanation of fig. 1, Plate 2 .

2. Sternite (male) of Eleodes obsoleta; compare with figs. 2 and 5 of Plate 2.

3. Dorsal view of the genital segment of Eleodes obsoleta; note the very explanate dorsal plates, especially at apex; compare with figs. 3, 9, and 6 of Plate 2.

4. Ventral view of the genital segment of Eleodes obsoleta; compare with figs. 4, 10, and 7, Plate 2: $a$, paranal plate (see p. 19).

5. Dorsal view of the right valve of Eleodes letcheri; note resemblance to fig. 12, Plate 1.

6. Ventral view of the left valve of Eleodes letcheri.

7. Dorsal view of the right valve of Eleodes acuticauda; compare with figs. 12,13 , and 9 of this plate, and figs. 8 and 18 of Plate 1.

8. Ventral view of the left valve of Eleodes acuticauda; note the large appendage and the concave surface before the apex.

9. Dorsal view of the right valve of Eleodes dentipes; compare with figs. 11 and 13 (type); note the variability of the apical margin of the dorsal plate and form of the appendage.

10. Ventral view of the left valve of Eleodes dentipes.

11. Dorsal view of the right valve of Eleodes dentipes, showing variation.

12. Dorsal view of the valve of Eleodes laticollis; compare with fig. 7 .

13. Dorsal view of the right valve of Eleodes dentipes, forma confinis (type); compare with figs. 7, 9, and 12.

14. Dorsal view of the right valve of Eleodes porcata; note the broadly rounded external apical lobe; compare with fig. 3 ; the explanate margin of the dorsal plate is less diaphanous, so that the body of valve does not show through it.

15. Dorsal view of the right valve of Eleodes obsoleta; variety showing the obsolete explanate margin toward base.

16. Dorsal view of the right valve of Eleodes carbonaria; compare with figs. $3,14,17,18$, and 20 ; also figs. 3,6 , and 9 , Plate 2.

17. Dorsal view of the right valve of Eleodes humeralis; see for comparison fig. 16.

18. Dorsal view of the right valve of Eleodes cuncaticollis; see for comparison fig. 16 ; note the more membranous external apical lobe.

19. Dorsal view of the right valve of Eleodes hispilabris; compare with figs. $7,8,19$, and 23 of Plate 4 .

20. Dorsal view of the right valve of Eleodes tricostata; note the distinctly oblong dorsal plate and compare with fig. 11, Plate 1.

\section{Plate 4.}

Fig. 1. Dorsal view of the right valve of Eleodes scabricula; compare with fig. 12, Plate 2; the notch defining the apex from the dorsal plate appears to be constant.

2. Dorsal view of the right valve of Eleodes neotoma; note the subapical position of the appendage and compare figs, 9,10 , and 16 . 
Fig. 3. Dorsal view of the right valve of Eleodes (Promus) fusiformis; note the broad and setose dorsal plate as compared to the species of the other subgenera ; compare figs. 4,5 , and 22 ; also figs. 2 and 3 , Plate 5.

4. Dorsal view of the right valve of Eleodes opaca; note the less setose condition. See for comparison fig. 3 .

5. Dorsal view of the right valve of Eleodes goryi. See for comparison figs. 3 and 4 .

6. Dorsal view of the right valve of the genital segment of Eleodes cordata; note the oblong dorsal plate with apical angle evident; compare with figs. $9,10,11,12$, and 16 , also observe the shortness of the superior pudendal membrane as compared to figs. 9, 10, 11, 12, and 16.

7. Dorsal view of the right valve of Eleodes caudifera; compare with figs. 8 and 23 .

8. Dorsal view of the right valve of Eleodes sponsa.

9. Dorsal view of the right valve of Eleodes consobrina; compare with fig. 10 , which is a little less swollen at apex, but the same.

10. Dorsal view of the right valve of Eleodes consobrina; compare with fig. 9, which is more swollen at apex, but the same.

11. Dorsal view of the right valve of Eleodes clavicornis; note the elongate form and narrow dorsal plate and small membranous apex; compare with fig. 22, Plate 5 .

12. Dorsal view of the right valve of Eleodes snowii; compare with fig. 9, Plate 1, and fig. 21, Plate 5.

13. Dorsal view of the right valve of Eleodes granosa; compare with figs. 14 and 28 , noting the short superior pudendal membrane.

14. Dorsal. view of the right valve of Elcodes pilosa; compare with figs. 25 and 28 ; also with fig. 12 , Plate 1 ; fig. 5 , Plate 3.

15. Sternite (male) of Elcodes sulcipennis; compare with fig. 5, Plate 2; also fig. 2, Plate 3, and fig. 11, Plate 2. Note the circular membranous area at base between the lobes, the latter densely pubescent.

16. Dorsal view of the right valves of Eleodes tibialis; note the elongate form, short appendage, and apex ; compare with figs. 2, 10, and 11.

17. Dorsal view of the right valve of Eleodes veterator; note the undifferentiated apex from dorsal plate, and absence of the appendage.

18. Dorsal view of the right valve of Eleodes femorata; compare with figs. 17 and 20, Plate 1.

19. Dorsal view of the right valve of Eleodes gracilis; compare with fig. 23 ; also figs. 9 and 11, Plate 3 .

20. Eleodes innocens.-Dorsal view of the apicale of the edeagophore; note resemblance to fig. 6, Plate 1 .

21. Eleodes innocens (female).-Dorsal view of the genital segment; compare with figs. 4 and 7 , Plate 1.

22. Eleodes insularis (female).-Dorsal view of the right valve; compare with figs. 3,4 , and 5 , Plate 4.

23. Eleodes longipilosa (female).-Dorsal view of the right valve; compare with figs. 7 and 8 , Plate 4 .

24. Eleodes knausii (female).-Dorsal view of the right valve; compare with figs. 16 and 3, Plate 3.

25. Eleodes arcuata (female).-Dorsal view of the right valve; compare with fig. 12 , Plate 1.

26. Eleodes debitis (female).-Dorsal view of the right valve; note the less rounded and more strongly chitinized dorsal plate and short membrane; compare with fig. 16, Plate 3 . These characters were present in all specimens examined. 
Fig. 27. Eleodes ampla (female).-Dorsal view of the right valve; compare with fig. 16, Plate 3.

28. Eleodes granulata (female).-Dorsal view of the right valve; compare with fig. 12, Plate 1 , and fig. 5, Plate 3.

\section{Plate 5.}

Fig. 1. Eleodes ventricosa (female).-Dorsal view of the right valve; note the oblique apical margin and prominent angle; compare with figs. 8, 21, and 22 of Plate 1 ; figs. 12 and 13 of Plate 3.

2. Eleodes striolata (female).-Dorsal view of the right valve; compare with fig. 3 ; also, figs. $3,4,5$, and 22 of Plate 4 .

3. Eleodes subnitens (female).-Dorsal view of the right valve; comparisons the same as for fig. 2.

4. Eleodes parvicollis (female; typical).-Dorsal view of the right valve; compare with fig. 22 ; also, figs. 2,6 , and 10 , Plate 4.

5. Eleodes pimelioides (female).-Dorsal view of the right valve; compare with fig. 6, Plate 4.

6. Eleodes planipennis (female).-Dorsal view of the genital segment; note resemblance to figs. $7,8,9,14$, and 20 ; also, compare with figs. 6 and 10, Plate 4.

7. Embaphion muricatum (female).-Dorsal view of the genital segment; comparisons are to be made with figs. $6,8,9,14$, and 20.

8. Embaphion contusum (female).-Dorsal view and comparisons the same as for fig. 7 .

9. Embaphion planum (female),-Dorsal view and comparisons the same as for fig. 7 .

10. Eleodes schwarzii (female).-Dorsal view of the genital segment; compare with figs. 11 and 12, noting that the valvular apices are quite different, but fully chitinized; compare also with fig. 1, Plate 1.

11. Eleodes nevadensis (female).-Dorsal view of the right valve; compare with fig. 12 ; and also fig. 1 , Plate 1 ; note the produced parallel apices with tips broadly rounded, convex above and concave beneath.

12. Eleodes dissimilis (female).-Dorsal view of the right valve.

13. Eleodes inculta (female).-Dorsal view of the genital segment; compare with figs. 9 and 10 , Plate 4.

14. Embaphion glabrum (female).-Dorsal view of the right valve; compare with figs. $6,7,8,9$, and 20 .

15. Eleodes hornii (female).-Dorsal view of the genital segment; note the tumid apices and smooth membrane; compare with fig. 9, Plate 4.

16. Blaps similis (female; West Virginia).-Dorsal view of the genital segment; note the fully chitinized and coalesced condition of the parts; compare with fig. 12, Plate 2.

17. Blaps similis (female; West Virginia).-Ventral view of the genital segment; note the position of the genital fissure and compare with fig. 13, Plate 2.

18. Eleodes subpinguis (female).-Dorsal view of the right valve; compare with fig. 19, Plate 4 , and fig. 9, Plate 3.

19. Eleodes distans (female).-Dorsal view of the right valve; compare with fig. 19, Plate 4.

20. Embaphion contractum (female).-Dorsal view of the apical moiety of the right valve; compare with figs. $6,7,8,9$, and 14 .

$59780-$ Bull. $63-09-33$ 
Fig. 21. Eleodes lecontei (typical; female).-Dorsal view of the right valve; compare with figs. 10 and 12, Plate 4.

22. Eleodes scabrosa (female).-Dorsal view of the right valve; compare with fig. 11, Plate 4 ; also fig. 4 of this Plate.

\section{Plate 6.}

Fig. 1. Elcodes blanchardii, female.-Dorsal view of the right valve; compare with fig. 10, Plate 4.

2. Eleodes hoppingii, female.-Dorsal view of the genital segment; compare with fig. 4, Plate 5.

3. Eleodes caseyi, female.-Dorsal view of the genital segment; compare with fig. 14, Plate 4, and fig. 5, Plate 5.

4. Dorsal view of the genital segment of Cerenopus concolor.

5. Edeagophore of Cerenopus concolor, dorsal view.

6. Sternite of Cerenopus concolor.

7. Dorsal view of the edeagophore of Trogloderus costatus.

8. Sternite of Trogloderus costatus.

9. Dorsal view of the edeagophore of Nyctoporus aquicollis.

10. Dorsal view of the genital segment of Nyctoporus rquicollis.

11. Edeagophore of Eleodimorpha bolcan, dorsal view.

12. Dorsal view of the genital segment of Eleodimorpha bolcan.

13. Dorsal view of the genital segment of Trogloderus costatus, female.

14. Dorsal view of the genital segment of Trogloderus tuberculatus, female.

15. Last two joints of the maxillary palpi of Trogloderus tuberculatus.

16. Mentum of Eleodes nigrina, female.

17. Labrum of Eleodes nigrina, female.

18. Inferior interungual process of a metatarsus in Eleodes dentipes, male.

19. Unguis from metatarsus in E. dentipes, male.

20. Mentum of Discogenia marginata, male.

Plate 7.

Fig. 1. Ventral view of the male genitalia of Eleodes cordata, edeagophore partly extruded.

2. Dorsal view of the same, edeagophore completely extruded.

3. Ventral view of the genital segments of Eleodes cordata, female, valves abducted.

4. Dorsal view of the same.

5. Ventral view of the sternite of Eleodes parvicollis, apicale slightly visible.

6. Ventral view of the apicale of the edeagophore of Eleodes cordata, showing clavæ partly abducted and edeagus nearly protruded.

7. Ventral view of the apical half of the edeagophore of Embaphion contusum, showing parts in place.

8. Ventral view of the apical half of the edeagophore of Eleodimorpha bolcan, showing relative position of edeagus, clavæ, and subalæ; compare with figs. 7 and 1 .

Explanation of figures.- $a$, apicale; $b$, edeagus ; $c$, clava ; $d$, basale; $e$, sternite ; $f$, apex of right lobe of sternite; $g$, membranous interlobar region of sternite; $h$, membranous apex of the valve; $i$, appendage; $j$, apical angle of the dorsal plate; $k$, submarginal groove; $l$, explanate external border of the dorsal plate; $m$, ventro-lateral surface; $n$, membranous 8 th segment, with sclerites of the paranal region and their articulation with base of the ventro- 
lateral lamina showing through; $o$, sternite of the 7 th segment; $o^{\prime}$, median basal process of the same; $p$, sternite of the 6 th segment, figs. 1 and 3 ; tergite of the 6 th segment, figs. 2 and $4 ; q$, supra-anal plate; $r$, tergite of the 7 th segment; $s$, fossa for the appendage; $t$, superior pudendal membrane; $u$, dorsal plate; $v$, valvular membrane; $v$, inferior pudendal membrane; $x$, genital orifice; $y$, inflexed alæe of the apicale; $z$, inflexed sides of the basale.

\section{Plate 8.}

Fig. 1. Head of Eleodes dentipes, showing lines of measurements: $a$, median line; $b$, post-marginal ocular line; $c$, post-ocular line.

2. Left mandible of Eleodes quadricollis (female), internal surface showing: molar $(c)$, lacinia $(b)$, and post-molar membranous lobe $(d)$.

3. Labium of Eleodes dentipes: $a$, the chitinous paraglossa which is connate with the body.

4. Diagram showing the relative lengths of the different segments of the legs and abdomen in Eleodes sulcipennis:

$A$, femora : $a$, metafemora ; $b$, mesofemora ; $c$, profemora.

$B$, tibiæ: $d$, metatibia ; $e$, mesotibia ; $f$, protibia.

$C$, tarsi : $g$, metatarsus; $h$, mesotarsus; $i$, protarsus.

$D$, abdominal segments: $j$, first visible; $k$, second; $l$, third; $m$, fourth; $n$, fifth.

5. Mentum and labium of Eleodes scabrosa.

6. Mentum and labium of E. clavicornis, slightly extended to show relation between labium and lateral lobes of the mentum, the middle lobe free at apex.

7. Protibial spurs of Eleodes quadricollis, female: $a$, posterior; $b$, anterior.

8. Side view of the first two joints of the protarsus of Eleodes sulcipennis, female: $a$, tuft of modified spinules at apex beneath, the latter thickened and produced; $b$, apico-marginal tuft of spinules bounding groove at apical margin of second joint; $c$, apical spines.

9. Outline of side view of first two joints of the protarsus of $E$. sulcipennis, male, showing the greatly thickened $(a)$ and produced apices beneath, spines not shown, groove obliterated.

10. Inferior surface of right mandible of $E$. dentipes, female, $\times 28$.

11. Maxilla of $E$. dentipes, female: $a$, palpus; $b$, galea; $c$, lacinia.

12. Superior surface of right mandible of $E$. dentipes, female, $\times 28$.

13. Hypopharynx of $E$. dentipes, female, $\times 28$.

14. Protibial spurs of E. sulcipennis, female: $a$, anterior ; posterior without letter.

15. Inferior view of the mouth parts of E. dentipes, female, showing mentum, submentum, gular sutures, labium partly exposed, maxilla, and mandibles.

16. Ventral view of the first two joints of a protarsus of $E$. dentipes, male, showing entire plantar groove.

17. Ventral view of first two protarsal joints of E. dentipes, female, showing plantar groove entire.

18. Lateral view of first two protarsal joints of E. scabricula, male, showing first joint moderately produced at tip beneath, groove entire on the second.

19. Lateral view of first two protarsal joints of E. scabricula, female, showing tip of first joint more produced with tuft of moderately fine modified spinules. 
Fig. 20. Outline of side view of first two protarsal joints of E. quadricollis, male; tip of first joint scarcely at all produced, with apico-marginal tufts.

21. Outline of side view of first two protarsal joints of E. quadricollis, female; first joint distinctly produced at apex beneath, with tuft of modified spines, groove interrupted.

22. Outline of side view of first two protarsal joints of E. longicollis, male; $a$, tuft of golden and rather soft pubescence, groove interrupted; $b$, second joint with pointed apico-marginal tufts, groove entire between the same.

23. Outline of side view of first two protarsal joints of E. longicollis, female; joints partly tipped to one side showing the entire plantar groove.

24. Eleodimorpha bolcan.- $a$, mentum, buceal fissures and produced buccal processes; the submentum is subobsolete, gular sutures distinct as in Eleodes; $b$, outline of the ventral apical margin of the prothorax, arcuate at middle, sinuate laterally.

Plate 9.

Fig. 1. Dorsal view of the edeagophore of Hydrophilus triangularis; $a$, and $d$, the inner and outer lobes of Packard.

2. Ventral view of the same.

3. Dorsal view of the edeagophore of Blaps similis, showing the apicale as formed by the uniting of the inner lobes of Packard.

4. Tentral view of the same, showing the pallium $(a)$ and edeagus $(d)$.

5. Dorsal view of the edeagophore of Eleodes dentipes.

6. Ventral view of the same.

7. Ventral view of edeagophore Eleodes planipennis.

8. Dorsal view of the edeagophore of Eleodes scabricula.

9. Ventral view of the same.

10. Dorsal view of the genital segment of Hydrophilus triangularis, female.

11. Ventral view of the edeagus $(a)$, basal chitinous processes $(c)$ and clave abducted $(d)$ of Eleodes dentipes.

12. Dorsal view of the same.

Plate 10.

Notw.-The bilateral asymmetry is intentional to illustrate variations which are constantly observed, when the pronota are viewed from above.

Fig. 1. Pronotum of Eleodes debilis, female.

2. Pronotum of Eleodes omissa, male.

3. Pronotum of Eleodes omissa, female; variations $a$ and $b$.

4. Pronotum of Eleodes omissa, female; variations $a$ and $b$.

5. Pronotum of Eleodes pygmar, female type.

6. Pronotum of Eleodes pygmaa, female, variation.

7. Pronotum of Eleodes ampla, male.

8. Pronotum of Eleodes ampla, female; $a$, marginal curve as viewed obliquely from the side and from above; $b$, as viewed vertically from above.

9. Pronotum of Eleodes carbonaria, forma glabra, female.

10. Pronotum of Eleodes carbonaria, forma typica, female.

11. Pronotum of Eleodes carbonaria, var. soror, female.

12. Pronotum of Eleodes obsoleta, var. poreata, male.

13. Pronotum of Eleodes obsoleta, male; $a$ and $b$, showing variations in form. 
Fig. 14. Pronotum of Eleudes obsoleta, female; $a$, as seen vertically from above; $b$, as seen obliquely from above and to the side.

15. Pronotum of Eleodes knausii, male; illustrating two variations in form.

16. Pronotum of Eleodes knausii, female; illustrating two variations in form.

17. Pronotum of Eleodes quadricollis, male; illustrating two variations in form.

18. Pronotum of Eleodes quadricollis, female; illustrating two variations in form: $a$, viewed vertically from above; $b$, as seen obliquely trom above and to the side.

19. Pronotum of Eleodes humeralis, female.

20. Pronotum of Eleodes humeralis forma granulata-muricata.

21. Pronotum of Eleodes cuneaticollis, male; illustrating two variations in form.

22. Pronotum of Eleades tricostata, female.

23. Pronotum of Eleodes neomexicana, female.

24. Pronotum of Eleodes pedinoides, male.

25. Pronotum of Eleodes obscura, female.

26. Pronotum of Eleodes hispilabris, female.

27. Pronotum of Eleodes sponsa, female.

28. Pronotum of Lleodes sponsa, female; a variation.

29. Pronotum of Eleodes caudifera, female.

30. Pronotum of Elendes caudifera, male; a variation.

31. Pronotum of Eleodes longipilosa, female.

32. Pronotum of Eleodes gracilis, female.

33. Pronotum of Eleodes dentipes, female; illustrating two variations in form.

34. Pronotum of Eleudes dentipes, female; taken from an aberration.

35. Pronotum of Eleodes dentipes, female; drawn from an aberration in my own collection; the right side is that of confinis, and probably a reversion to the ancestral armata.

36. Pronotum of Eleodes dentipes forma confinis, female; drawn from the type in my own collection; probably a reversional form.

37. Pronotum of Eleodes armata var. impotens, female; drawn from the type.

38. Pronotum of Eleodes armata, female; a variation.

39. Pronotum of Eleodes armata, male.

40. Pronotum of Eleodes militaris, female.

\section{Plate 11.}

Fig. 1. Pronotum of Eleodes femorata, male.

2. Pronotum of Eleodes laticollis, male.

3. Pronotum of Eleodes acuticara, male; typical.

4. Pronotum of Eleodes luco, caudate form.

5. Pronotum of Eleodes eschscholtzi, female.

6. Pronotum of Eleodes tenuipes, male.

7. Pronotum of Eleodes wickhami, male.

8. Pronotum of Eleodes ventricosa, male.

9. Pronotum of Eleodes ventricosa, female; variation.

10. Pronotum of Eleodes falli, male; drawn from type.

11. Pronotum of Eleodes grandicollis, male.

12. Pronotum of Eleodes insularis, female.

13. Pronotum of Eleodes subnitens, female. 
Fig. 14. Pronotum of Eleodes fusiformis, female.

15. Pronotum of Eleodes striolata, male.

16. Pronotum of Eleodes goryi, female.

17. Pronotum of Eleodes opaca, female.

18. Pronotum of Eleodes veterator, female.

19. Pronotum of Eleodes arcuata, female.

20. Pronotum of Eleodes extricata, male; variation.

21. Pronotum of Eleodes extricata, female.

22. Pronotum of Eleodes granulata, male, forma tuberculata.

23. Pronotum of Eleodes vandykei, male.

24. Pronotum of Eleodes vandykei, female.

25. Pronotum of Eleodes letcheri, male.

26. Pronotum of Eleodes Tetcheri, female.

27. Pronotum of Eleodes pilosa, male.

28. Pronotum of Eleodes pilosa, female, variation.

29. Pronotum of Eleodes pilosa, female.

30. Pronotum of Eleodes hirsuta, female.

31. Pronotum of Eleodes granosa, male.

32. Pronotum of Eleodes granosa, female.

33. Pronotum of Eleodes tibialis, male.

34. Pronotum of Eleodes inculta, female.

35. Pronotum of Eleodes snowii, female, New Mexico.

36. Pronotum of Eleodes snovii, female, Arizona.

37. Pronotum of Eleodes tenebrosa, female.

38. Pronotum of Eleodes clavicornis, female.

Plate 12.

Fig. 1. Pronotum of Eleodes hornii, female.

2. Pronotum of Eleodes neotoma, female.

3. Pronotum of Eleodes consobrina, female, typical form.

4. Pronotum of Eleodes scabrosa, male.

5. Pronotum of Eleodes rotundipennis, male.

6. Pronotum of Eleodes rotundipennis, female.

7. Pronotum of Eleodes parvicollis, male, typical form.

8. Pronotum of Eleodes producta, male.

9. Pronotum of Eleodes fuchsii, female.

10. Pronotum of Eleodes cordata, female.

11. Pronotum of Eleodes pimelioides, male, two variations.

12. Pronotum of Eleodes caseyi, female.

13. Pronotum of Eleodes nigrina, male, showing two slight variations.

14. Pronotum of Eleodes nigrina, female, drawn from an aberration simulating humeralis.

15. Pronotum of Eleodes perlonga, male.

16. Pronotum of Eleodes nevadensis, male.

17. Pronotum of Eleodes dissimilis, male.

18. Pronotum of Eleodes schwarzii, female.

19. Pronotum of Eleodes gigantea, male.

20. Pronotum of Eleodes gigantea, female.

21. Pronotum of Eleodes estriata, female.

22. Pronotum of Eleodes longicollis, male.

23. Pronotum of Eleodes longicollis, male, elongate cylindrical form.

24. Pronotum of Eleodes innocens, female.

25. Pronotum of Eleodes marginata, male. 
Fig. 26. Pronotum of Eleades scabricula, male.

27. Pronotum of Elendes planipennis, female.

28. Pronotum of Embaplion muricatum, male.

29. Pronotum of Embaphion contusum, female.

30. Pronotum of Embaphion planum, male.

31. Pronotum of Embaphion glabrum, female.

32. Pronotum of Embaphion elongatum, male.

33. Pronotum of Eleodes hornii, male.

34. Pronotum of Eleodes distans, male.

35. Pronotum of Eleodes subpinguis, female.

36. Pronotum of Eleodes gentilis, male, drawn from a LeConte type.

37. Pronotum of Embaphion contractum.

38. Pronotum of Trogloderus tuberculatus, female.

39. Pronotum of Eleodimorpha bolcan, male.

Plate 13.

Fig. 1. Pupa of Eleodes clavicornis, ventral view.

2. Pupa of Eleodes clavicornis, dorsal view.

3. Pupa of Eleodes clavicornis, lateral view.

4. Larra of Eleodes dentipes, dorsal view, $10 \mathrm{~mm}$; $\mathrm{x} 10$.

5. Dorsal view of the pygidium of Eleodes dentipes.

6. Ventral view of the last five abdominal segments of the larva of Eleodes dentipes, showing position of stigmata on the pleurites.

7. Ventral surface of the right prothoracic leg of the larra of Eleodes dentipes.

8. Ventral view of the maxilla of the larva of Eleodes dentipes; lettering same as on fig. 11.

9. Dorsal view of the head of the larva of $E$. dentipes.

10. Antennæ of the same, $\times 28$.

11. Gula $(g)$, mentum $(m)$, submentum $(s)$, a membranous lobe $(a)$, and labium of larva of $E$. dentipes.

12. Dorsal surface of the left mandible of the larva of Eleodes dentipes.

13. Ventral surface of the right mandible of the larva of Eleodes dentipes.

14. Internal or oral surface of the left mandible of the larva of Eleodes dentipes, showiug molar.

15. Pygidium of Eleodes larva shortly after hatching, x 60. After Gissler.

16. Antenna of Blaps larva. After Gissler.

17. Pygidium of Eleodes larva. After Gissler.

18. Pygidium of Blups larva. After Gissler. 



\section{IN DEX.}

The black-faced numbers indicate generic or specific descriptions.

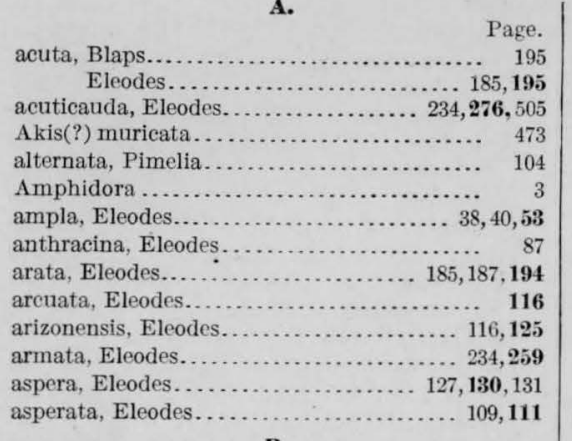

\section{B.}

behrii, Eleodes.

blanchardii, Eleodes

Blaps. carbonaria

extricata............................... 121

hispilabris........................... 217

mucronata............................ 504

obscura.............................. 187

obsoleta.................................. 58

opaca................................. 175

similis........................... 504

suturalis............................... 199

tricostata..... 104

Blaptidæ .............................. 505

Blaptini........................ 501

Blapylis...................... 34, 35, 306, 505 bolcan, Eleodimorpha .................... 479 brunnipes, Eleodes................ 313,384,386

\section{c.}

carbonaria, Blaps.

$$
\text { Eleodes }
$$

45

caseyi, Eleodes ................... 311,313, 388

caudifera, Eleodes. . . . ................... 212,225

clavicornis, Eleodes.......... 310,311,312,371,500 cognata, Eleodes....................... 121,123 compositus, Eleodes

concavum, Embaphion.

217

confinis, Eleodes.

connexa, Eleodes.

consobrina, Eleodes.

constricta, Eleodes. contractum, Embaphion

Page.

contusum, Embaphion.

convexa, Eleodes $=$ connexa...........217,220,222 cordata, Eleodes............ 19,310,311,313,379

costatus, Trogloderus...................... $\quad 486$ cuneaticollis, Eleodes................. 38,40,91

\section{D.}

debilis, Eleodes..................... 38,40,41 deleta, Eleodes......................... 185, 187 dentipes, Eleodes............. 8, 234,251,496,497 depressa, Eleodes.......................... 453 depressum, Embaphion.................... 45 Discogenia........................... 33,35,434

Group A ........................... 434

Group B........................... 434 dispersa, Eleodes............... 185, 187,190,191 dissimilis, Eleodes.................... 393, 398 distans, Eleodes...................... 235, 242 dolosa, Eleodes...................... $38,40,57$

\section{E.}

Early stages, Eleodiini ................... 495 Eggs, Eleodes........................ 495,496 elegans, Eleodes...................... 251,255 Eleodes.................. 3, 29, 30,31,34,35, 183 acuta............................. 185, 195 acuticauda...................... 234,276,505 var. laticollis................. 234,276, 280,505 ampla............................ $38,40,53$

var. dolosa ..................... $38,40,57$ anthracina........................... $38,40,87$ arata .......................... 185, 187, 194 arcuata............................... 116 arizonensis......................... 116,125 armata............................. 234,259 var. impotens................... 234,259,263 aspera................................ 127, 130 asperata............................. 109,111 behrii............................... 505, 506 blanchardii................. 310,311,312,339 carbonaria........................ $38,40,45$ var. soror ........................ $38,40,50$ caseyi.............................. 3,13,388 caudifera........................... 212,225 clavicornis................ 310,311,312,371,500 cognata............................ 121 composita......................... 217,221 confinis.............................. 251,255 
Page

Eleodes connexa................ 217 consobrina ............... 310,311,312,333, 505

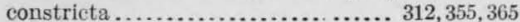
cordata.................. 19,310,311,313,379 var. rotundipennis.................... 379,884 cuneaticollis..................... $38,4 \mathrm{C}, 91$ debilis.......................... $28,40,41$

deleta..................... 185, 187, 194 dentipes................ 8,234, 251,496,497 depressa.......................... 453 dispersa.................... 185, 187, 190,191 dissimilis.................................. var. nevadensis...................... 393, 402

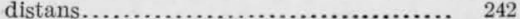
dolosa............................ $38,40,47$ elegans........................... 251,255

elongata........................... 505, 506

eschscholtzi 235,285

var. lucs. . . ................. 235,285, 289 estriata . . . . . . . . . . . . . . . . . . . 412,421

extricata......................... 116,121

var. arizonensis ......................... 125

falli ........................... 235, 305 femorata................................

fischeri. . . . . . . . . . . . . . . . . . . . 436

fuchsii.................. 310,311, 312,343

fusiformis........................ $156, \mathbf{1 7 2}$

gentilis............................. 412,416

gigantea................... $411,412,496$

var. estriata....................... 412,421 gentilis...................... 412,416

goryi ......................... 156, 164

gracilis......................... 235,237

var. distans..................... 235,242

grandicollis......................... 207

granosa............................ 147

granulata......................... 116, 127

haydeni.......................... 425

hirsuta........................ 138, 139

hispilabris.................... 212,217

hoppingii................. 310,311,312,368

hornii............... $310,311,312,350$

humeralis.......................... $38,41,95$

immunis............................. 45

impotens. ......................... 259, 263

impressicollis......................... 371

inculta...................... 310,311, 329

innocens........................ 412,429

insularis.......................... 156

intermedia...................... 505,507

interrupta......................... 72

intricata .............................. 379

knausii...................... 38, 40,67

larva................................ 496

lecontei.......................... 217

lecontei......................... 310,311,321

letcheri........................... 116, 133

var. vandykei ....................... 136

longicollis......................... 411, 425

longipilosa . . . . . . . . . . . . . . . . . 212, 230

lustrans ....................... 38,40,89

marginata. . . . . . . . . . . . . . . . 435,436

militaris.......................... 234, $26 \mathbf{6 7}$

var. femorata.................. 234,272

neomexicana..................... 38, 41,113

neotomæ................. 310,311,312,347
Page.

Eleodes nevadensis................... 393,402

nigrina........................... $89 . \ldots$

var, perlonga..................... 393,898

nitida........................... 450,493

nupta.......................... 217,220

obscura ........................ 185, 187, 193

var. dispersa.............. 185, 187, 190, 191

var. sulcipennis.............. 185, 187,190,194

var. typica....................... 190,193

obsoleta...................... $38,40,58$

var. porcata.................. 38, 40,58,63

obtusa......................... 127, 130

omissa....................... $38,40,72$

var. peninsularis . . . . . . . . . . . $38,40,79$

var. pygmæa.................... 38,40,77

opaca........................... 156, 175

parvicollis.................. $310,311,312,354$

var. constricta ................. 312,355,365

planata.................. $312,355,359$

producta................. $312,355, \mathbf{3 6 2}$

pedinoides. .................... 38, 41, 109

var. neomexicana................ 38,41,113

peninsularis................... $38,40,79$

perlonga. . . . . . . . . . . . . . . . . . . 393,398

pilosa........................... 138, 142

pimelioides.................. 310,311,313,384

var. brunnipes ................ 313,384,386

planata.......................... 104

planipennis ...................... 435,445

poreata......................... 38,40,68

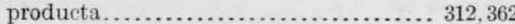

prominens..................... 251,254

pygmæa.................... 38,40,77,418

quadricollis . . . . . . . . . . . . . . . . . $38,40,81$

var. anthracina................ $38,40,87$

lustrans................... $38,40,89$

reflexicollis......................... 450,494

rileyi.......................... $38,41,100$

robusta........................ 104,106

scabricula...................... 435,440

scabripennis . . . . . . . . . . . . . . . 312,338

scabrosa .................. 310,311,312,375

var. rotundipennis ................... 312,384

schwarzii.......................... 393,406

seriata............................. 164

sinuata............................... 266

snowil ....................... 310,311,317

soror....................... $38,40,45,0$

sponsa........................ 212, 21:

stricta............................. 379

striolata............................ 168

subaspera........................... 127

subaspera......................... 321

subcylindrica................... 235, 246

subligata........................ 384

subnitens. . . . . . . . . . . . . . . . . . . 156, 161

subpinguis ....................... 234,247

sulcata........................ 217

sulcipennis................. 195, 187,190,194

suturalis..................... 185, 199, 203

var. texana................. 185, 199,202, 203 typica..................... 202

tarsalis

tenebrosa......................... 310,311, 325

var. nana ....................... 311,328

tenuipes.......................... 235, 294 


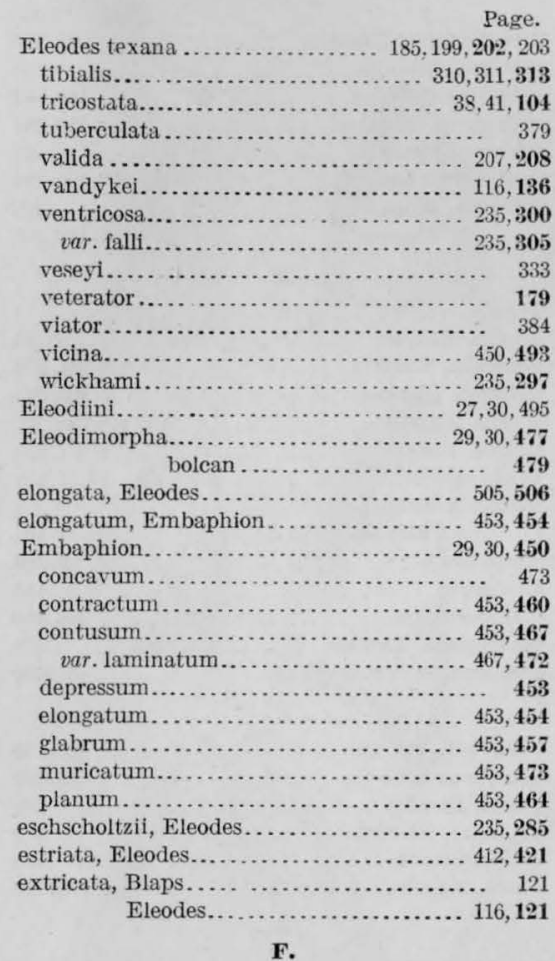

falli, Eleodes..... .................. 235,305 femorata, Eleodes. ................... 272 fischeri, Eleodes.......................... 436 fuchsii, Eleodes................. $310,311,312,343$ fusiformis, Eleodes....................156, 172

G.

gentilis, Eleodes. 412,416 gigantea, Eleodes $411,412,496$ glabrum, Embaphion. 453,457 goryi, Eleodes. ...................... 156, 164 gracilis, Eleodes......................... 235, 237 grandicollis, Eleodes.................... 207 granosa, Eleodes.......................... 147 granulata, Eleodes................... 116, 127 Group A, Discogenia ................... 434

B, Discogenia .................. 434

I, Melaneleodes ................... 41

II, Melaneleodes................... 104 Group Dentipes ...................... 184,211 Grandicollis .................... 184,205 Obseura ........................ 184

H.

haydeni, Eleodes.

Heteropromus. 425 hirsuta, Eleodes. $33,35,179$ hispilabris, Eleodes. hoppingii, Eleodes

138,139 212,217 horr . Eleodes. $310,311,312, \mathbf{3 6 8}$ $310,311,312,350$ humeralis, Eleodes. Hydrophilus.
Page.

immunis, Eleodes....................... 45

impotens, Eleodes................. 234,259, 263 impressicollis, Eleodes................... 371

inculta, Eleodes................. 310,311, 329 innocens, Eleodes . .................. 412,429

insularis, Eleodes...................... 156

intermedia, Eleodes................... 505, 507

interrupta, Eleodes ..................... 72

intricata, Eleodes..................... $\quad 379$

$\mathbf{K}$.

knausii, Eleodes................... 38,40,67

L.

laminatum, Embaphion............ 467,472

Larva, Eleodes .................. 496 dentipes . . . . . . . . . . . . . . 496, 497 gigantea ..................... 496

laticollis, Eleodes................ 234,276, 280, 505 lecontei. Eleodes......................... 217

lecontei, Eleodes.................. 310,311,321

letcheri, Eleodes. . ......................116, 133

Litheleodes........................ $34,35,114$

Iongicollis, Eleodes..................... 411.425

longipilosa, Eleodes.................. 212, 230

lucæ, Eleodes..................... 235, 285, 289

Iustrans, Eleodes.................... 89

\section{M.}

marginata, Discogenia................ 436 Eleodes.................. 435,436

Melaneleodes..................... 33, 34, 35.36

Metablapylis...................... 34,35,391

militaris, Eleodes..................... 234, 267

mucronata, Blaps...................... 504

muricata (?) Akis..................... 473

muricatum, Embaphion............. 453,478

N.

nana, Eleodes........................ 311, 328

neomexicana Eleodes................. 38, 41, 113

neotomæ, Eleodes.............. 310, 311, 312, $\mathbf{3 4 7}$

nevadensis, Eleodes.................... 393,402

nigrina, Eleodes..................... 393

nitida, Eleodes.............. 450,493

nupta, Eleodes.................. 217, 220, 221

Nycterinus

o.

obscura, Blaps ................. 187 Eleodes............... 185, 187, 190, 193 Group ........................ 184

obsoleta, Blaps......................... $\quad 58$ Eleodes..................... 38, 40,58

obtusa, Eleodes.................. 127, 130,131

omissa, Eleodes..................... 38, 40, 72

opaca, Blaps......................... 156,175

Eleodes..................... 156, 175

P.

parvicollis, Eleodes ............. 310,311,312,354 pedinoides, Eleodes................. 38,41, 109 peninsularis, Eleodes.................. 38, 40, 79 perlonga, Eleodes..................... 393,398

Pimelia............................... 3

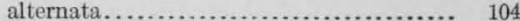




\section{INDEX.}

pimelioides, Eleodes

pilosa, Eleodes.

planata, Eleodes.

planipennis, Eleodes.

planum, Embaphion.

porcata, Eleodes.

producta, Eleodes

prominens, Eleodes

Promus.

Pseudeleodes..

Pupa, Eleodes clavicornis

pygmæa, Eleodes.

quadricollis, Eleodes.

$38,40,81$

R.

reflexicollis, Eleodes.

rileyi, Eleodes.

450,49

robusta, Eleode

$38,41,100$

rotundipennis, Eleodes

s.

scabricula, Discogenia

$$
\text { Eleodes... }
$$

$312,379,384$

scabripennis, Eleodes

scabrosa, Eleodes.

schwarzii, Eleodes.

.. $312,313,338$

seriata, Eleodes

393,406

similis, Blaps.

snowii, Eleodes

504

soror, Eleodes.

$310,311,317$

sponsa, Eleodes.

$38,40,45,50$

Steneleodes.

... 212,213

stricta, Eleodes.

$33,34,35,409$

striolata, Eleodes

379

subaspera, (?) Eleodes.

56,168

subaspera, Eleodes. subcylindrica, Eloge.

s.................. 235, 246

subligata, Eleodes........................ 384

subnitens, Eleodes.................... 156, 161

subpinguis, Eleodes.................... 234,247

sulcata, Eleodes........................ 217

sulcipennis, Eleodes................ 185, 187, 190, 194

suturalis, Blaps........................ 199

Eleodes.................... 185, 199, 202

T.

Tagona................................... 3

tarsalis, Eleodes........................ 81,85

tenebrosa, Eleodes................... 310,311,325

tenuipes, Eleodes....................... 235, 294

texana, Eleodes................. 185, 199, 202,203

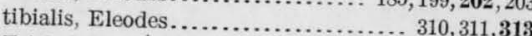

Tricheleodes.......................... 34,35,138

tricostata, Blaps............................ 10

Eleodes..................... $38,41, \mathbf{1 0 4}$

Trogloderus.............................. 29,483

costatus ............................ 486

tubereulatus........................ 486, 480

tuberculata, Eleodes..................... 379

tubereulatus, Trogloderus................ 486,490

v.

vandykei, Eleodes..................... 116,136

ventricosa, Eleodes..................... 235,300

veseyi, Eleodes............................

veterator, Eleodes......................... $\quad \mathbf{1 7 9}$

viator, Eleodes...............................

vicina, Eleodes......................... 450,493

W.

wickhami, Eleodes

235,297

$\mathbf{X}$.

Xysta 


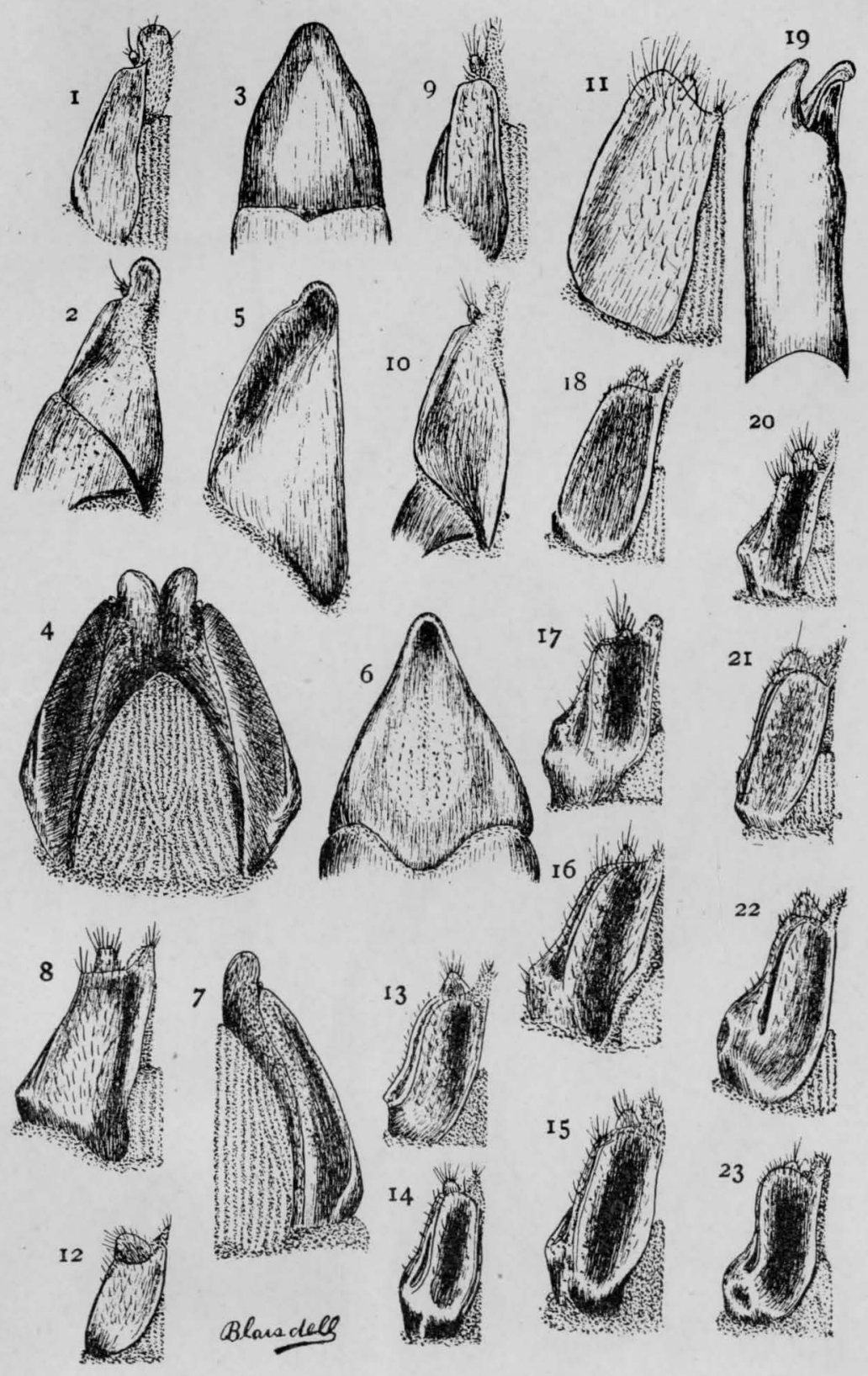

GENITAL CHARACTERS OF THE ELEODIINI.

For explanation of PLATE SEe Pages 509, 510. 

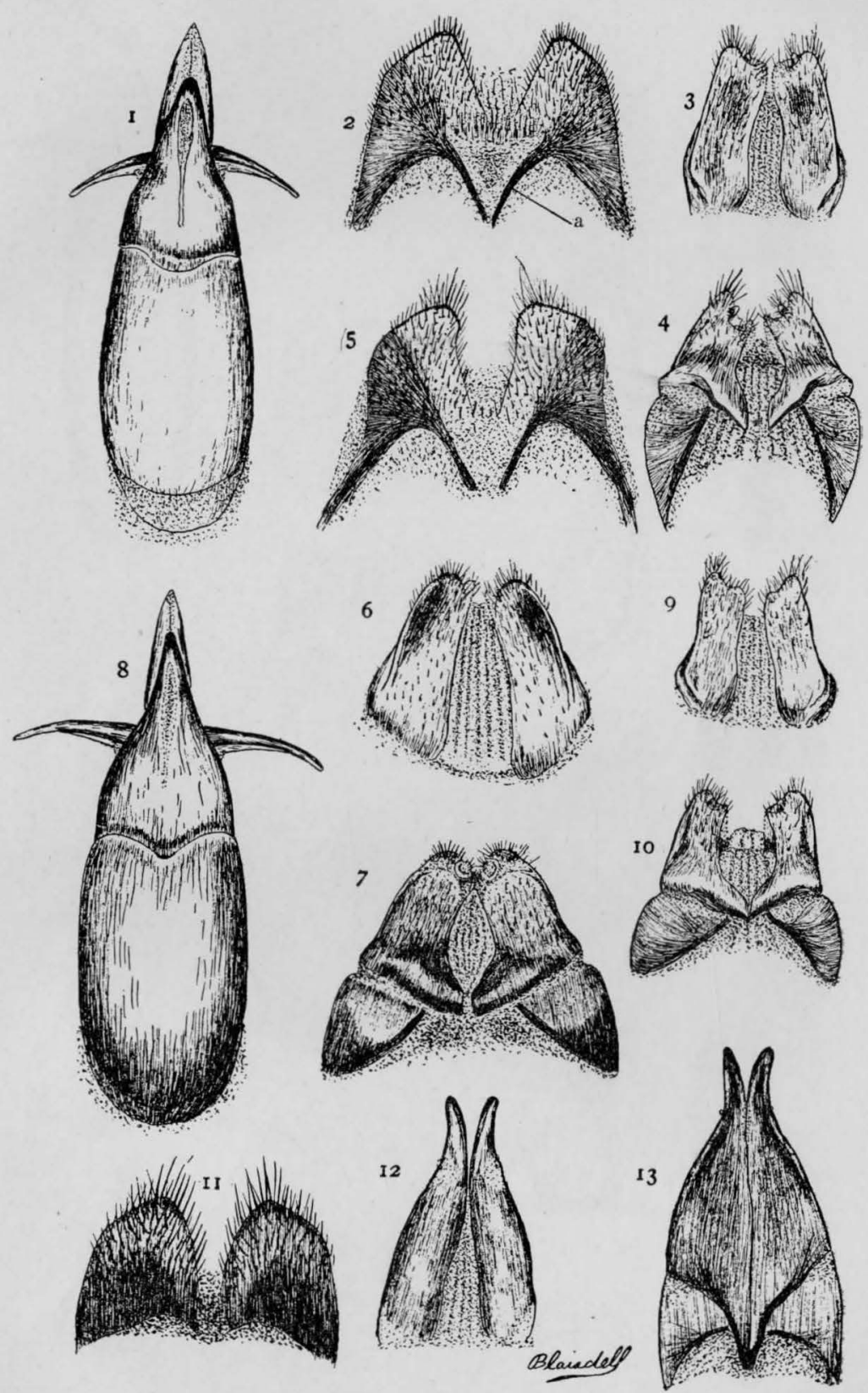

Genital Characters of the Eleodini.

For EXPLANATION OF PLATE SEE PAges 510, 511. 


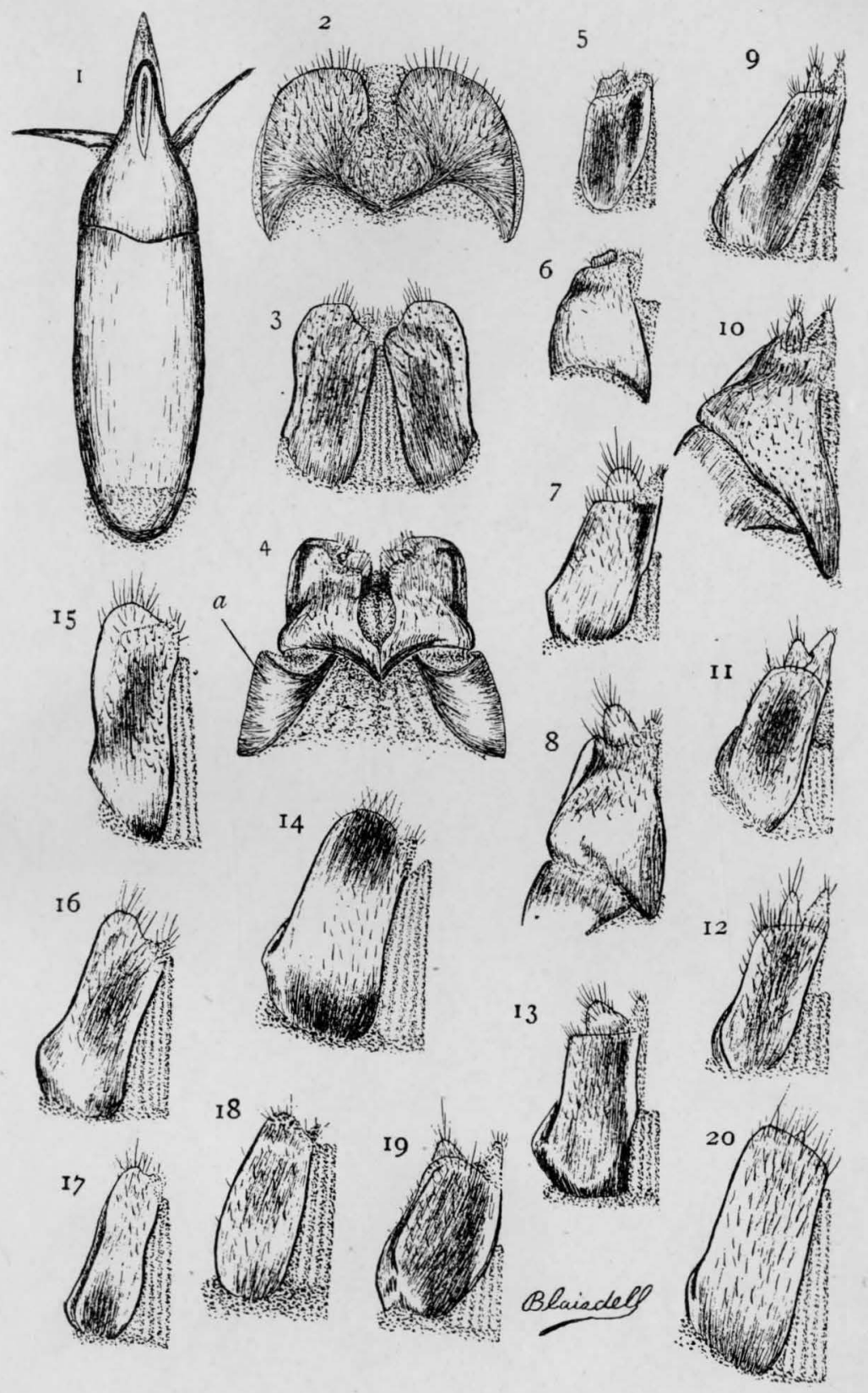

Genital Characters of THE ElEodini.

For EXPLANATION OF PLATE SEe PAGE 511. 


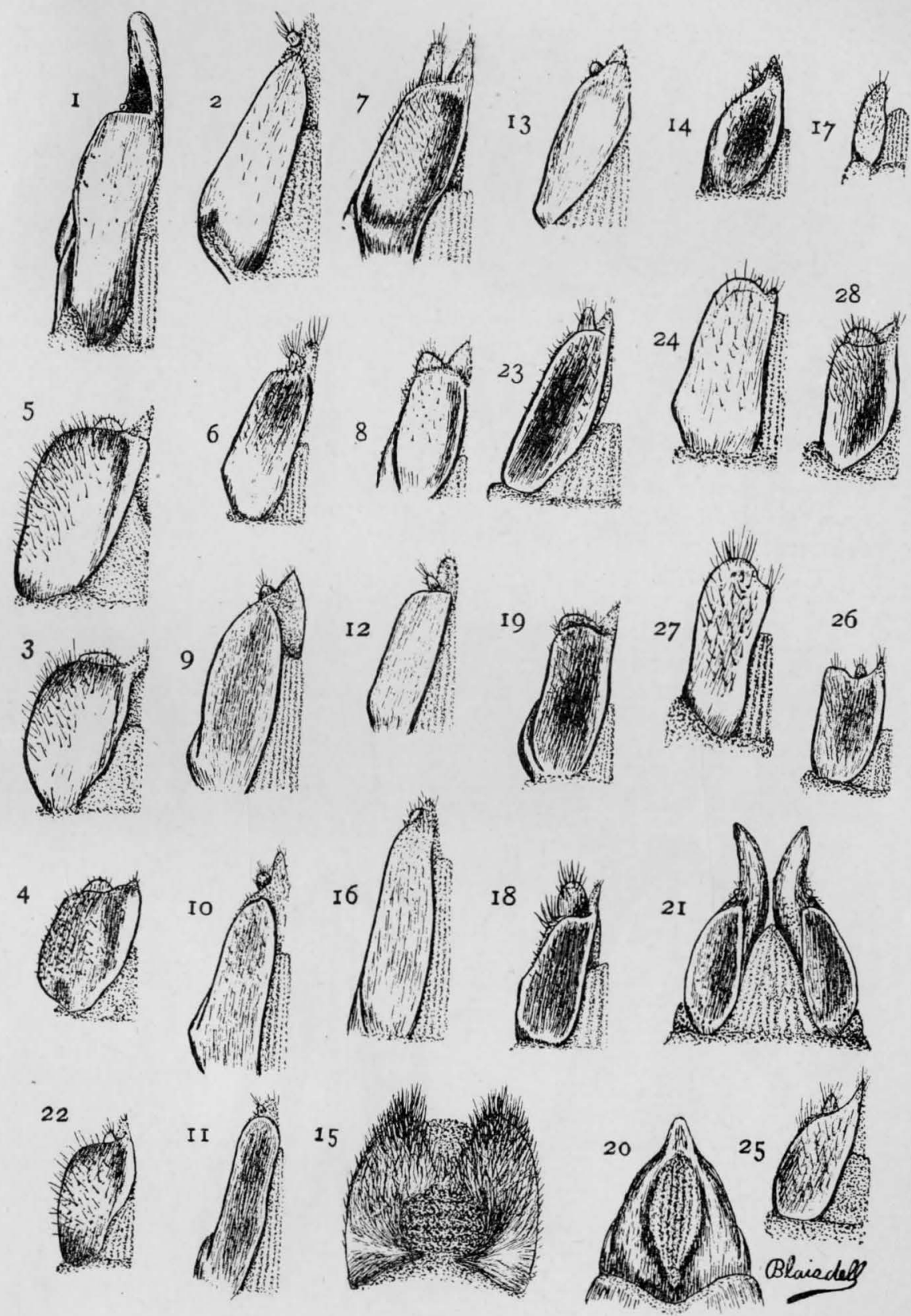

Genital Characters of the EleodinI

For EXPLANATION OF PLATE SEE PAGES $511,512,513$. 

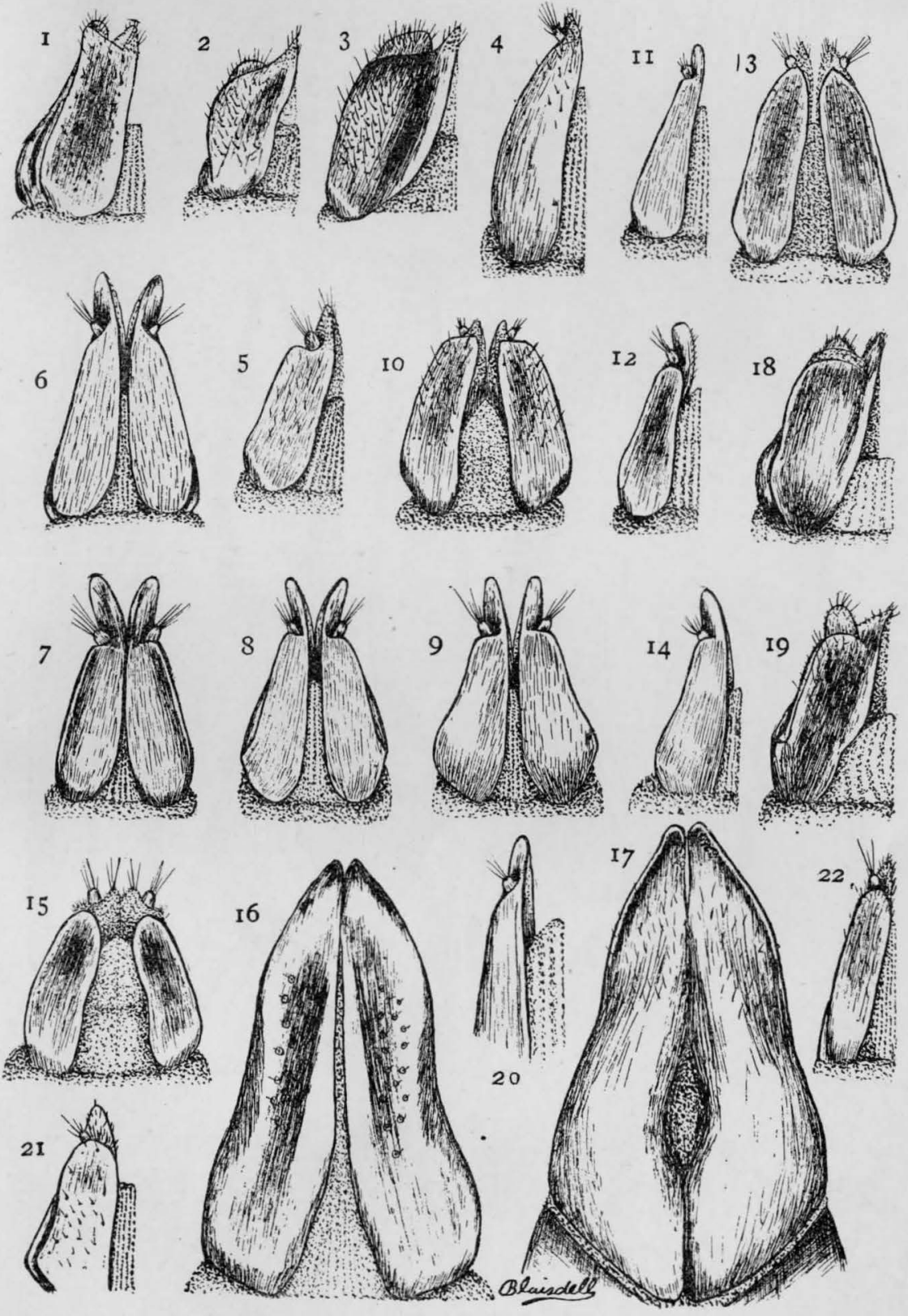

Genital Characters of THE ELEODIINI.

FOR EXPLANATION OF PLATE SEE PAGES $513,514$. 

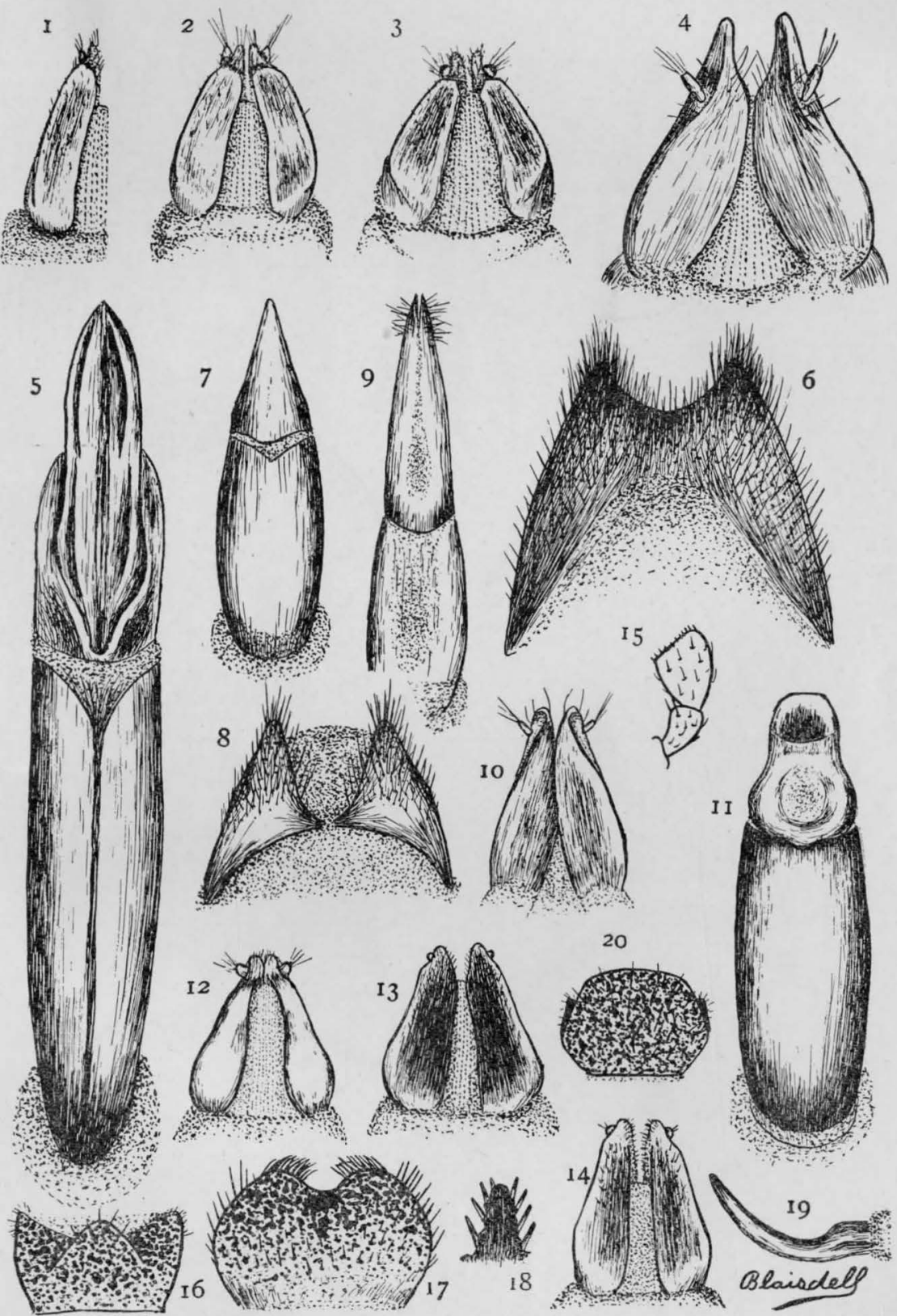

Comparative and Genital Characters of the Eleodini and Related Tribes. 

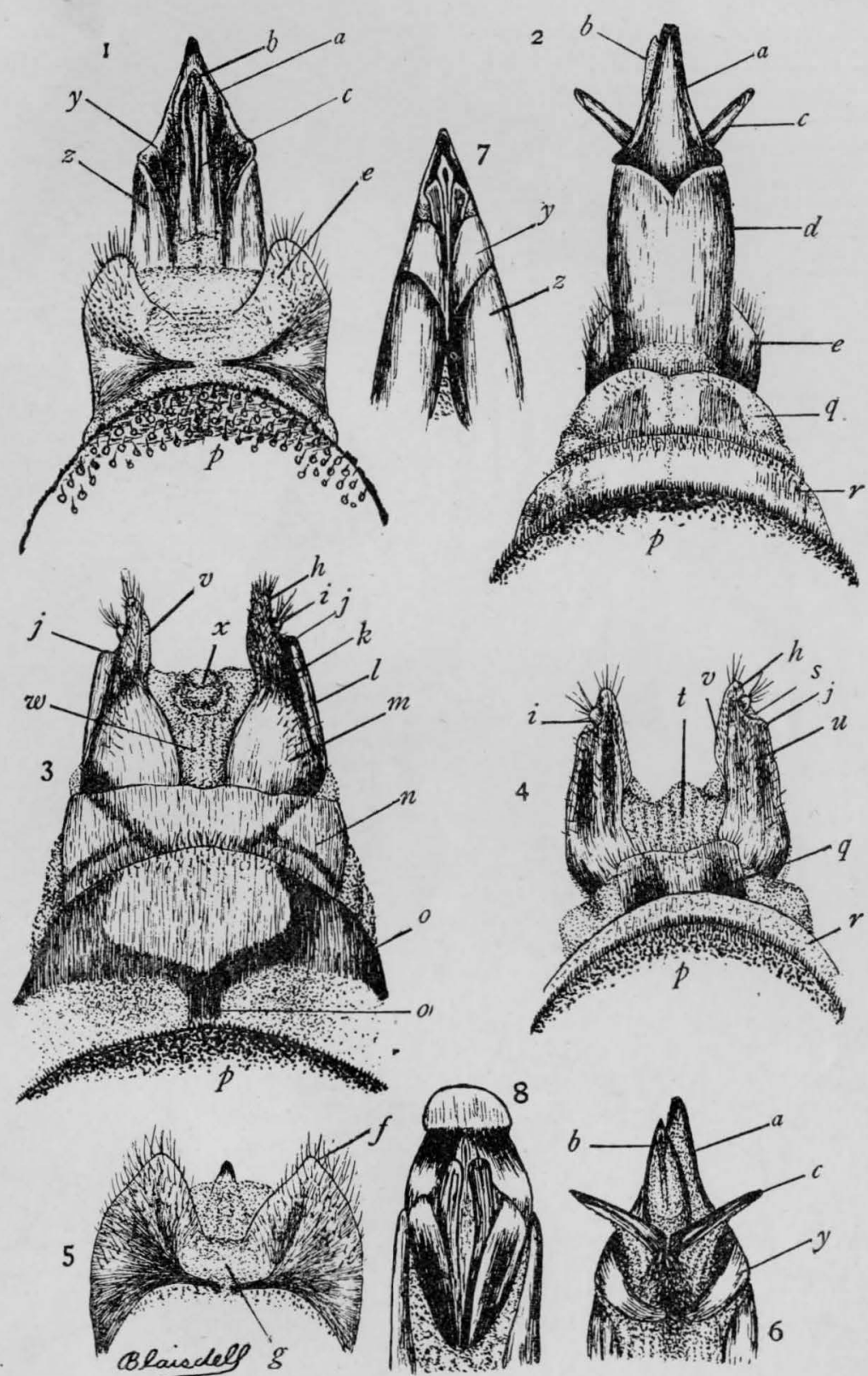

Topography of the Genital Segments of the Eleodini.

For EXPLANATION OF PLATE SEE PAGES 514, 515. 


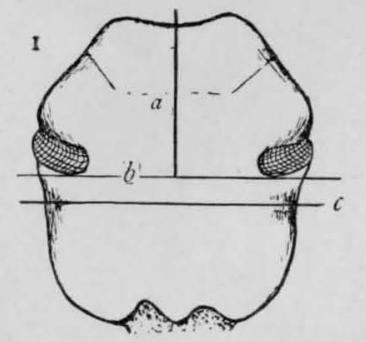

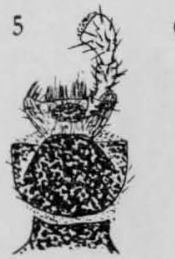
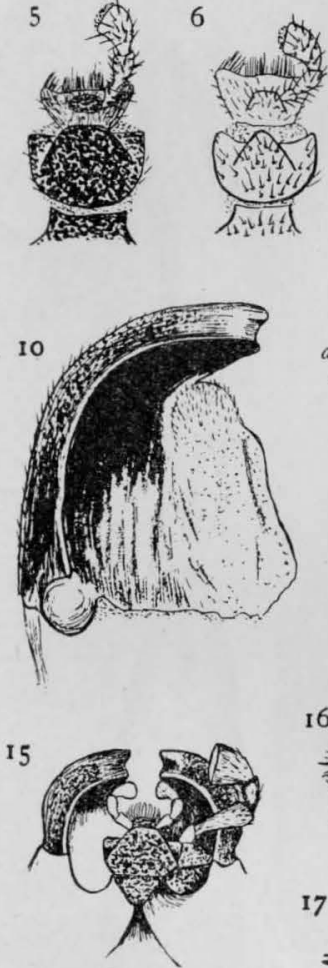

${ }^{16}$
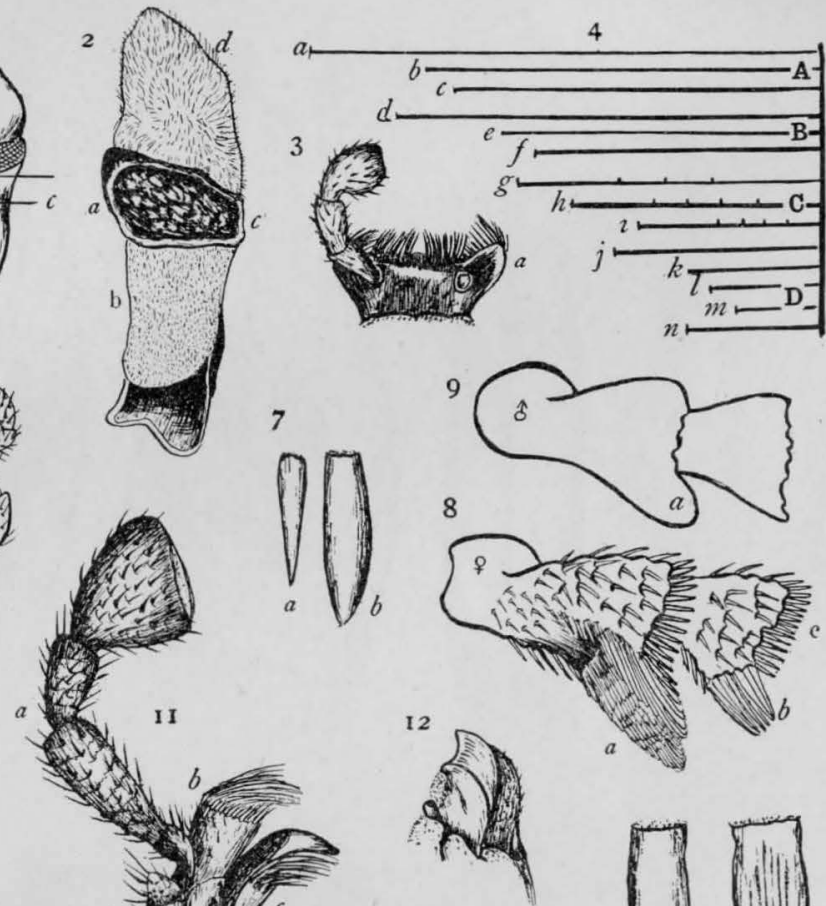

13
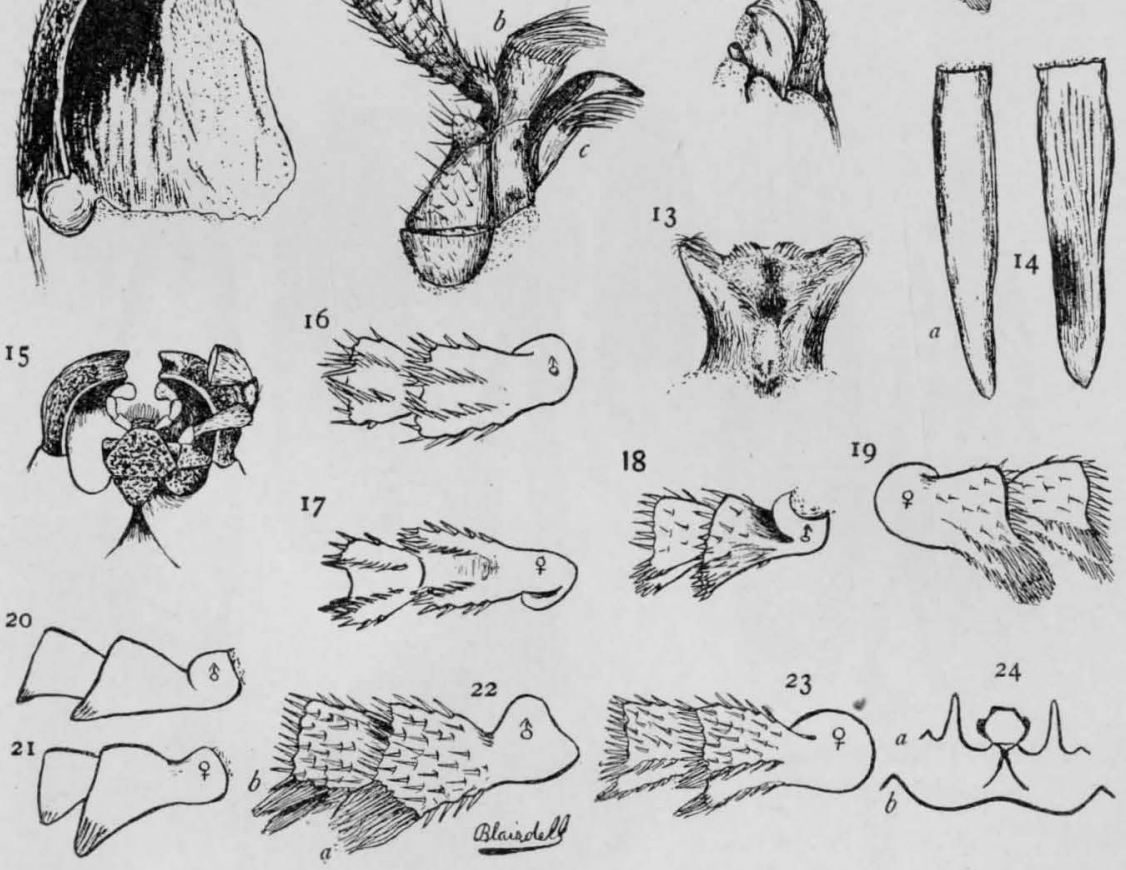

ANATOMY OF THE ELEODIINI.

FOR EXPLANATION OF PLATE SEE PAGES $515,516$. 

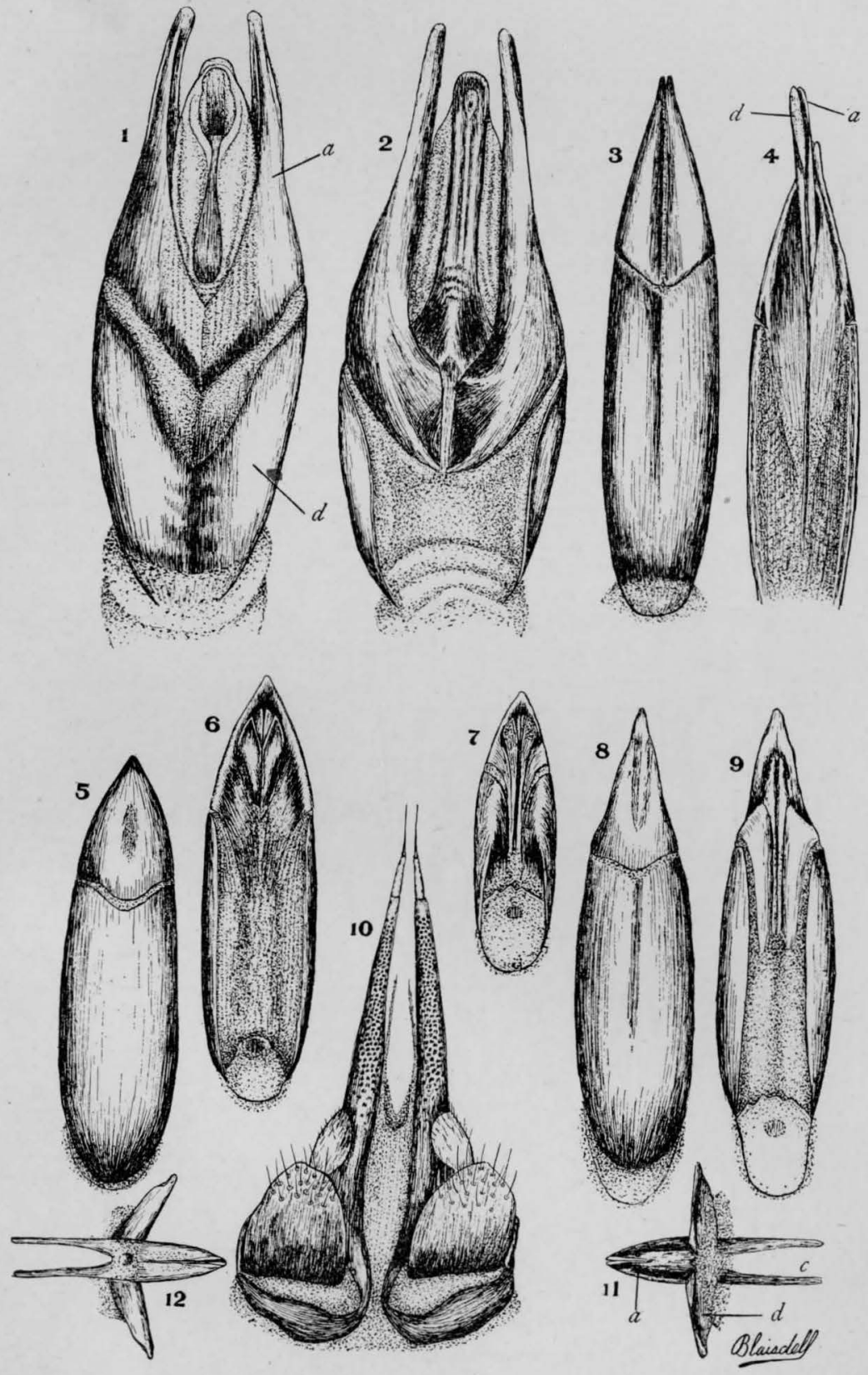

Homology of the Genital Segments of the Eleodini. 
U. S. NATIONAL MUSEUM

BULLETIN NO. 63 PL. 10
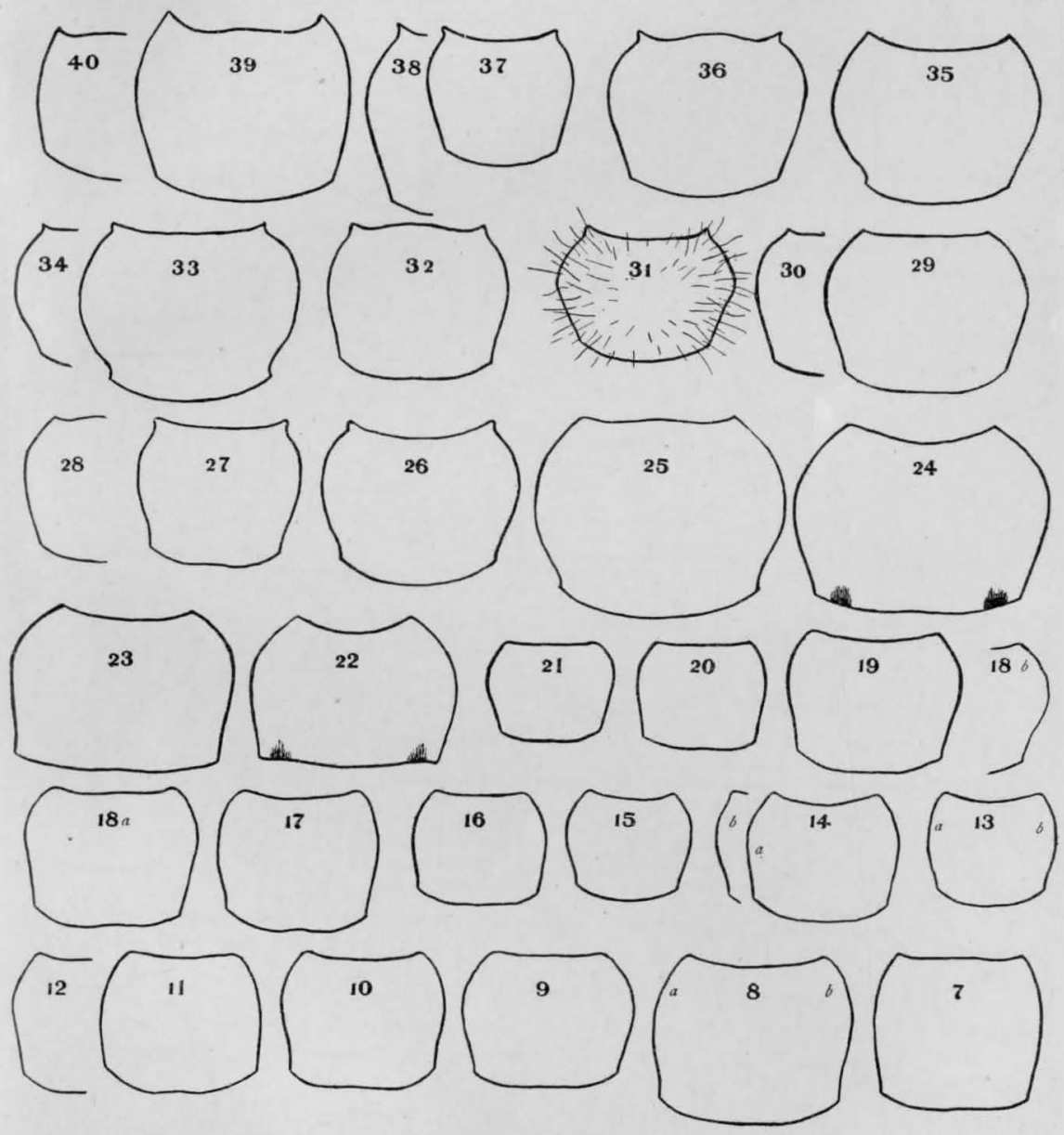

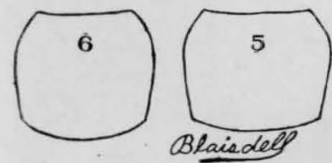

Blair del
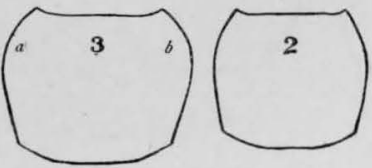

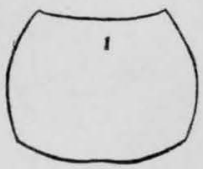

PRONOTA OF THE ELEODIINI.

For EXPLANATION OF PLATE SEE PAgES $516,517$. 


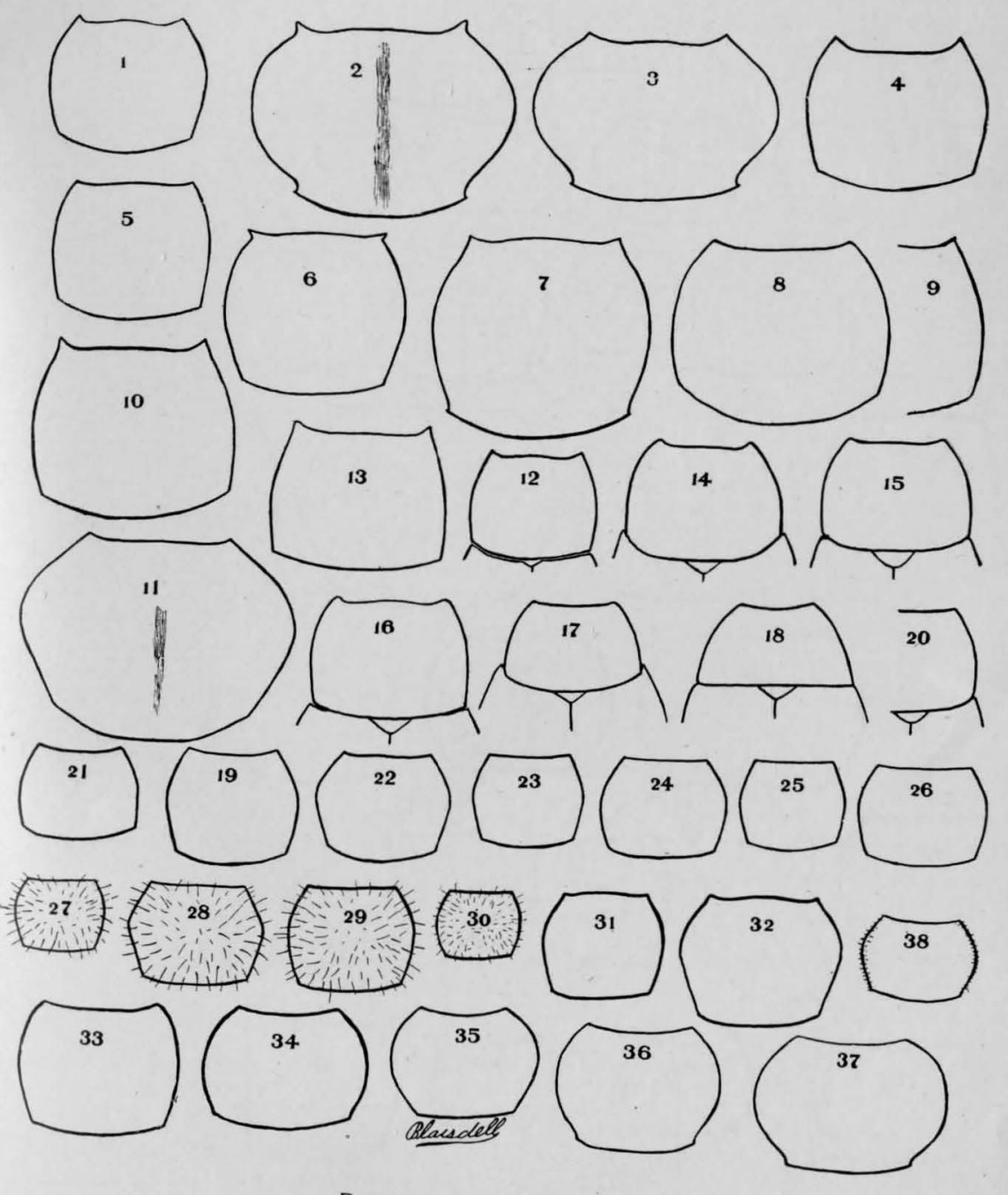

PRONOTA OF THE ELEODIINI.

For EXPLANATION OF PLATE SEE PAGES $517,518$. 


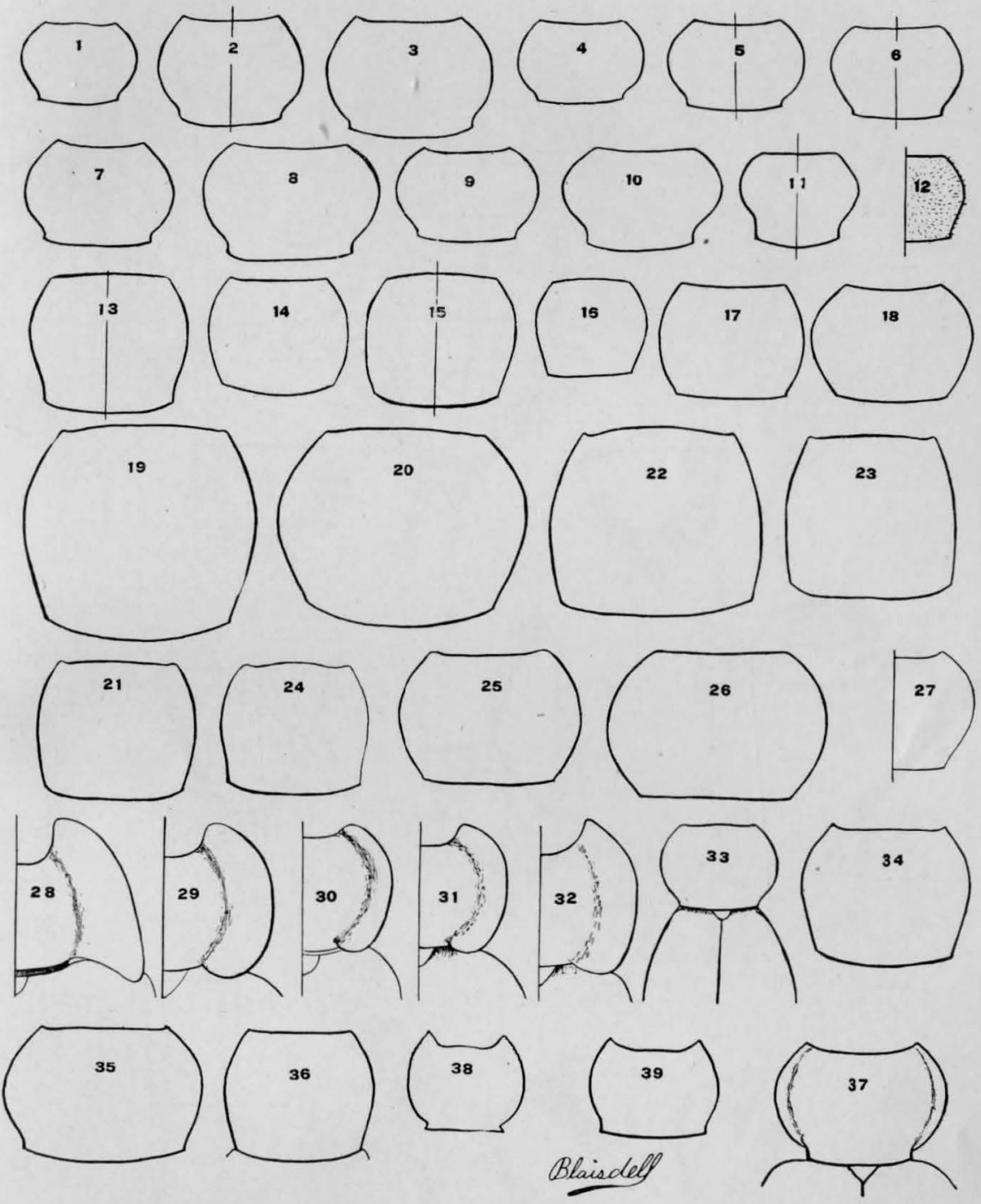

PRONOTA OF THE ELEODIINI.

For EXPLANation OF PLATE SEe PAges $518,519$. 

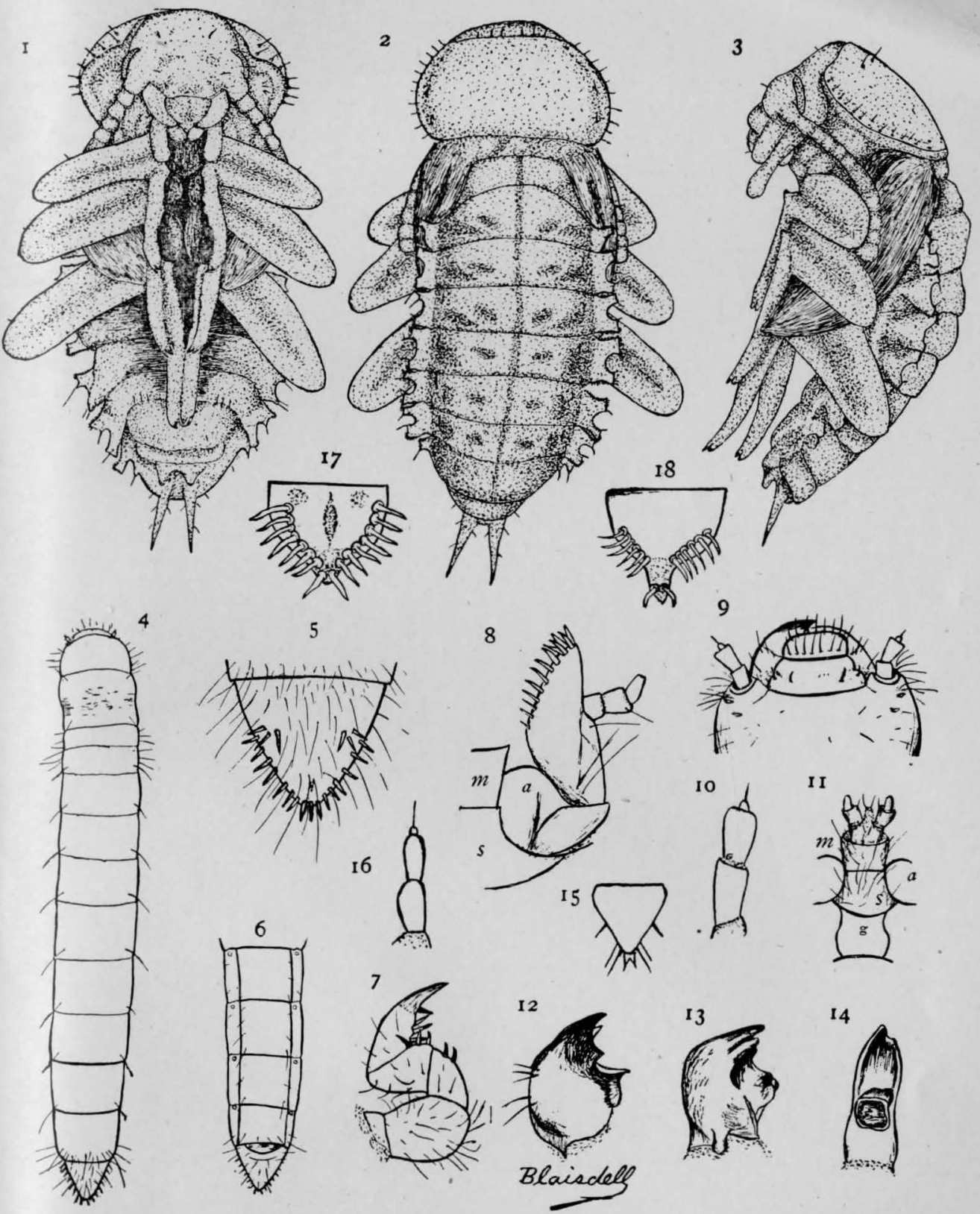
